

\section{ALBERT R MAMIIIBRART}

AT

CORMELL VNAMERSITTT

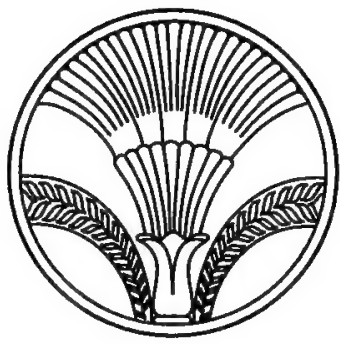


CORNELL UNIVERSITY LIBRARY

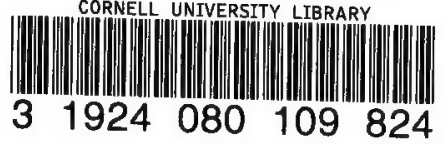




\section{Cornell University Library}

The original of this book is in the Cornell University Library.

There are no known copyright restrictions in the United States on the use of the text.

http://www.archive.org/details/cu31924080109824 




THE

\section{AMERICAN SHEPHERD}

BEING A

HISTORY OF THE SHEEP,

WITH THEIR

BREEDS, MANAGEMENT, AND DISEASES.

IILUGTRATED WITH

PORTRAITS OF DIFFERENT BREEDS.

SHEEP BARNS, SHEDS, \&C.

WITH AN APPENDIX,

EMBAACING UPWARDA OF TWENTY LETTERA FROM EMINENT WOOLGROWERS AND GHEEP-FATTENERS $O F$ DIFFERENT BTATE, DETAILING THEIR REGPECTIVE MODES OF MANAGEMENT.

B Y L. A. MORRELL.

N E W Y O R :

HARPER BROTHERS, PUBLISHERS

1863. 
Emrened, according to the Act of Congress, in the year 1845, BY HARPER \& BROTHERS,

In the Clerk's Office of the District Court of the United States for the Southern District of New York. 


\section{State Agricultural Hall,}

Albany, April 16th, 1845.

AT a meeting of the Executive Committee of the New York State Agricultural Society, a work entitled "The American Shepherd," by L. A. Morrell, of Lake Ridge, Tompkins county, New York, was'presented, and the manuscript examined. The Committes have great pleasure in recommending the work to the attention of wool-growers and others interested in the Breeding and Management of Sheep, as one containing a large amount of Practical and Scientific information on the most important branch of American Agriculture.

Mr. Morrell has a high reputation as a skilful and successful farmer in everything appertaining to the breeding and improvement of Sheep. The work before us embodies the results of long experience, aided by a thorough research into the practice of the best breeders of Sheep and Wool-growers in Great Britain and the Continent. The work contains letters from some of the most distinguished Wool-growers and Breeders in America, which add much to the value of the work.

B. P. JOHNSON, President.

IUTHER TUCKER, Rec. Secretary. 



\section{PREFACE.}

That a work embracing perhaps all the topics of the present treatise, has long been demanded by American Wool-growers, cannot be denied. The English, and other foreign works on the important subject of Sheep Husbandry, notwithstanding the ability with which they are written, are unadapted to our wants, chiefly because the breeds of sheep and modes of management are, in the main, so essentially different in our own country and Great Britain. Something AmerrcaN, therefore, is needed-a work which would tend to correct the many errors and abuses of management, and enter into such minute details connected therewith, as would teach the merest novice his duties.

With many others, I have long been waiting with the hope that some one having the necessary practical knowledge, and in other respects eminently qualified, would undertake the difficult task of supplying us with such a treatise; but no one having come forward, after due consultation with some friends, on whose judgment I could safely rely, I determined to attempt what, under other circumstances, I could not have summoned the resolution, and I may add, temerity, to do. It is, therefore, with no ordinary degree of apprehension that $I$ appear before the public in the character of an author, and the more especially of a work of this kind, having been obliged, in a measure, to carve out my own way, and act the "lone pioneer."

It was my original intention to have limited the historical part to the prominent and most profitable breeds, but so little is generally known of those peculiar to Asia and Africa, as well as remote portions of Europe, it appeared 
to me that a brief notice of these would be acceptable; and, in addition, $I$ have introduced all that the Scriptures afford us concerning the sheep, thereby bringing forward everything of consequence to know from the most remote antiquiry to the present period. I have availed myself, principally, of Mr. Youatt's standard and able work to aid me in this department; and also to him and Mr. Bläklock, both distinguished Veterinary Surgeons, for much of what is offered on the Diseases of Sheep; and to Mr. Spooner, the author of a recent English work, and likewise a Veterinary Surgeon, for the interesting chapter on the Structure, or Anatomy of the sheep. All this necessity compelled me to do, owing to the paucity of works in American libraries relative to the history of the species, and the very little progress as yet made among us in scientific classification and treatment of diseases. Mr. Youatt is probably the first veterinary surgeon of the age, and is at present the editor of a London periodical devoted to that science; therefore, that part of this work concerning Diseases is, undoubtedly, entitled to much confidence ; in addition, my own observations and experience, together with all that I could gather from others, have been added.

It is many years that $I$ have been a practical manager, of sheep, a vocation to which I am enthusiastically attached. I acknowledge an affection for the sheep, paramount to that for any other domestic animal, and have studied its instincts and habits at all seasons, and under all circumstances; and now and always have shared with my laborers in every department connected with management. What, therefore, is offered on this subject, is the result almost solely of what my own eyes have seen, and hands handled-indeed, is nearly a transcript of my system of practice. Being aware, however, of the tenacity with which farmers cling to their particular modes of management, right or wrong, I entered into an extensive correspondence with distinguished wool-growers, to aid me in perfecting this department of the work, with a view to confirm positions which are set forth, and strike a more effectual blow at errors. To my brother wool-growers, as well as all others, who have so kindly aided me in my 
undertaking, I acknowledge myself under deep obliga. tions, and doubtless this will be the response of every reader. The Appendix cannot be otherwise regarded than as a valuable portion of this work.

The portraits of the several breeds of sheep were submitted to a number of competent judges, and pronounced faithful representations. In reference to that of the Spanish Merino, it, with one other, was forwarded to the Hon. Wm. Jarvis, of Vermont, who pronounced it " a fair likeness of a Merino in high order, and with a long fleece." It will be apparent to every one, that an American Merino portrait would be inappropriate in treating of Spanish Merinos. All the cuts were drawn from life, and mostly by the celebrated animal painter, Harvey, of London.

In conclusion, I have chosen very frequently to give the very language of my authorities, rather than my own, except when condensation became necessary. For any one individual to write an original work of this character, embracing such a variety of topics, of course is impracticable ; therefore the course adopted I believed to be best, because it would be likely to have more weight with the reader. My object has been to bring before the public a strong work-authentic, if possible, in every particular, and worthy to be trusted and appealed to upon any question and point of importance; and lastly, I have endeavored to convey everything in language simple and unadorned, to suit the capacity of the humblest of my brother wool-growers, for whose benefit chiefly this was written. To these, and all others engaged in this honorable vocation, I appeal for a decision upon its merits, which, if favorable, will afford me a degree of pleasure not easily conceived, and terminating only with life. 



\section{ONTENTS.}

\section{INTRODUCTION.}

THE zoological character of the sheep-domesticated at a very early period of the world-Abel the first recorded shepherd-the flesh of the sheep not used for food before the flood-vegetables the only means of sustenance permitted by the Divine law-after the flood this command was abrogated-vegetable food only eaten by some of the pagan sects of the East at the present day - the milk of the sheep used as an article of sustenance-converted into cheese and butter-Homer's description of milking the ewes-Mr. Burckhardt's description also-custom of the ancients of removing their flocks from one locality to anotherJabal lived 500 years before the flood, and was the first Nomadic shepherd-Arabian and Tartarian shepherds at the present day conform to that primitive custom-D'Arviex description of the sameParson's description of the peregrinations of the Arabs-flocks in ancient Palestine very numerous-number which Job possessed, \&c.these numerous flocks accounted for-the ewes supposed to have lambed twice in the year-flocks very numerous at the present day in Palestine-Dr. Shaw's statement of this-first recorded improvement was in the color of the fleece-originally tawny or dingy-blucktendency of the sheep in modern times to return to the original hueinstance the South Down, Norfolk, Black-faced sheep of Scotland, and Asiatic and African breeds-Jacob the original improver of the color-his scheme for accomplishing it-in process of time the fleece became wholly white-the Scriptures silent as to the form of the aneient sheep, except that the ram was horned-the fat-rumped breed abounding so numerously at the East induced Mr. Youatt to suppose these to be the primitive breed instead of the Argali-his remarks and those of Mr. Price on the subject-the question will always remain unsettled-the horned ram more particularly mentioned-the polled sheep an accidental variety-reasons for cultivating them-humanity a prominent characteristic of the primitive shepherdo-Arab shepherds the same-Buckingham's remarks-quotation from Dyer's Fleecemusic of the ancient shepherds a means to control their flocks-remarks -Goldsmith's description of the Alpine shepherds-evidence from the Bible that the primitive shepherds washed their flocks before they were shorn-Solomon's comparison of the teeth of his mistress to a flock just come up from the washing-in early times the fleece was detached from the pelt by pulling-humanity dictated another course, and accordingly the shears, in process of time, were invented and extensively used-the shearing time an occasion for feasting and rejoicing-quotations in corroboration of this-remarks of Burder on the subject-the system of cotting practised by the Israelites-remarks of 
a writer on this point-custom also in Greece and Tarentum-art of weaving understood in the primitive ages-Scripture testimony-dyeing also-quotation from Virgil-the Egyptians the probable iuventors of the weaving of flax-discussion of the subject by a writer-description of the rude mode of weaving of the Arabs-conclusion . . . 13

\section{CHAPTER I.}

\section{PROPERTIES OF WOOL.}

Introductory remarks- structure of the skin of the sheep-used for bookbinding, and for the inscription of valuable documents-anatomy of woolly fibre-the weight of testimony in favor of the theory that it is tubular in conformation-its vascularity-remarks of Dr. Good on the vascularity of the hair-its structure by small filaments ranged side by side-remarks of Bakewell-chemical composition of wool, horns, hoofs, \&c.-yolk or gum-its chemical properties-its value-promotes the growth of the wool-mats it as a defence against cold and wetabounds much in the Merino fleece-temperature and condition of the sheep influence its production-not found so much in the Saxon breed -considerable quantity in some of the English sheep-its substitute in Scotland by smearing the sheep in autumn-additional value imparted to cloth by yolk-description of the form of the fibre of wool by Youatt-its semi-transparency, \&c. - the wool of half-starved sheep breachy, \&c.-importance of good condition to counteract it-elasticity of the fibre-pliability also-dependent on the spiral curvescauses the beautiful pile or nap of cloths-spiral curve-conspicuous in the Saxon and Merino varieties-not so much in the Leicester and other breeds- the number of spiral curves in a given space in proportion to the fineness of the fibre-German experiment to determine this point-this principle should govern much in breeding-softness-importance of this quality in wool-much dependent on the proper supply of yolk-experiment in cloth manufacture from harsh and soft wool of the same fineness - superiority of that from the latter-fipeness a comparative term when applied to wool-varies much in different individuals of the same breed-difference in the diameter of the fibre between its extremes-diameter of the fibre-the Merino has four qualities in its fleece-grade sheep many more-cut representing where the different qualities of wool grow on the Merino-length of the staple-preference given by the manufacturer to a long stapleless dead end than short-long staple fine wool needed for fine worsted fabrico-the question stated, whether a compact fleece with a long staple can be produced on the same sheep-compact fleeces necessary in a northern climale-color-first recorded improvement in sheepmanufacturers prefer fleeces entirely white-reasons-flock-masters should never breed from black or smutty sheep-trueness-constituted by equality of the fibre from root to point-inequalities caused by unequal feeding and exposure of sheep-common in some degree to every breed-Saxon and Merino ewes should be turned off when eight or nine years old-influence of temperature-inequalities of temperature cause an unequal growth of the fibre-necessity of sheltering sheep during winter to counteract it-remarks of Mr. Hunter on the influ- 
ence of climate on hair and wool-Mr. Youatt's remarks-M. Lasteyrie's statement-the cultivation of the Merino and Saxon breeds in the Southern States alluded to-causes of the degeneracy of the Me. rinos in South America-felting-this long remained a mysteryspeculations in former times on the subject-the cause of felting of wool surmised by M. Monge-the true theory, but did not demonstrate it-the first successful effort to demonstrate Monge's thecry by Mr. Youatt-his description of the scene and results-the number of serrations within an inch of Merino wool-cuts representing microscopic views of Merino and South Down fibres-conclusion of the chapter with remarks by Mr. Youatt . . . . . . . 27

\section{CHAPTER II.}

\section{HISTORY OF SHEEP.}

ARGALI, MUSMON, ASIATIC, AND AFRICAN SHEEP.

History of the Argali-its comparative size and horns-color and texture of its coat-inhabits the mountains and elevated plains of Asiafind in small flocks-rams-fight furiously in the rutting seasonkilled in autumn for their flesh and skins-difficult to domesticate unless taken young. American Argali.-Supposed to be a variety of the Asiatic-remarks of Abbe Lambert-W ashington Irving's description of the animal on the Rocky Mountains-called ahsata or big horn-is found nowhere else in America-dimensions of a maleremarks of Major Smith. The Mouscon or Musmon-considered as identical with the Argali by Buffon and Wilson-inhabits the mountains of Sardinia and Corsica-described by Wilson-from fifty to an hundred herd together-difficult to domesticate.

Anjatic Breeds. Fat-rumped breed-abounds where the primitive shepherds roamed-Dr. Anderson's description of the animal-often weigh $200 \mathrm{lbs}$. - fat on the rump weighs from 20 to $40 \mathrm{lbs}$. FAT-TAILeD breed-more numerous than the fat-rumped-is found extensively in Africa-Dr. Russel's aecount of the breed-tails often weigh $15 \mathrm{lbs}$. -whole live weight about $150 \mathrm{Jbs}$ - - supposed to be a variety only of the fat-rumped.

Persian Sheer. Fat-tailed predominate-Fraser's account of a Persian caravan-a variety of sheep in the province of Kerman produce very fine wool-much of it manufactured into shawls.

Tibet Shefr. Are very numerous-a small variety of the fat-rumped with black heads and necks-wool soft and long-converted into long shawls.

East India Sheer. Consist of the fat-rumped and fat-tailed varieties.

Chinese Sheer. Breeds differ much from each other-a breed with extraordinary long legs-a breed resembling some of the European varieties-antiquity of Chinese manufactures alluded to.

A rrican Breeds. Egyptian, Ethiopian, and Abyssinian-both varieties of the fat-tailed found in Egypt-fat-tailed and fat-rumped prevail in Ethiopia-also in Abyssinia - the many-horned sheep.

Madagascar Sheep. Dr. Anderson's description of the same.

Fape of Good Hope Sheer. Native sheep of the broad-tailed breedovery variety of color-experiment with the Merinos by the Dutch- 
its failure, and causes-renewed attempt by the English-is successful-wool exported from the colony-number of its sheep.

Angola Sheep. Description of a very singular variety.

Guinea Sheer. Two varieties found on the slave coast-one resembling some of the European breeds-sheep very hairy, and men very woolly

Morocco Sherp. Breeds superior to other African-distinguished for excellence in the time of Columella-ewe of this breed owned by Chancellor Livingston-description of it . . . . . . 48

\section{CHAPTER III.}

\section{EUROPEAN SHEEP.}

Italian Sheep. Were very superior in the time of the Romang-fleece cultivated with extraordinary care-reasons for the same-celebrity of the sheep of Apulia and Tarentum-generally supposed to be the progenitors of the famed Meriuos-description of the management of the Tarentine sheep.

Spanigh Shezp-Marinos, \&c. Spain possessed of valuable breed at an early period--superiority of the fleece of Botica-of the Tarentine variety-introduced by Columella-also African rams to improve the Chunah breed-origin of the name of Merino-the Tarentine sheep amalgamated to some extent with the black sheep of Spain-evidence of this-portion of Spain conquered by the Moors-they established extensively woollen manufactures-Seville contained 16,000 loomsMoors expelled by the Spaniards-manufactures ceased-fruitless attempts of the Spanish to revive them-the excellence of the Merino continued through centuries of political strife-Chunah sheep-abounds thronghout the kingdom - owned by the peasants - supposed to have been improved by the English Costswold breed-Spanish Merinos classed in two grand divisions-Estantes and Transhumantes-the latter composed of the Leonese and Sorians-their location in winter -places where summered-cause of their peregrinations-the Transhumantes fell into the hands of the king, courtiers, and clergy-tribunal of Consejo de la Mesta-its tyrannical laws-incidents of these journeys - under a Mayoral-numerous under-shepherds with dogsday's travel length of the journey-injury to the crops by the sheep on the way-vigilance necessary on their arrival at their place of destination-construction of pens for folding at night-large quantities of salt given to the sheep-half the lambs destroyed after yeaning-Spanish notion on this point-exportation of the skins of the slaughtered lambs-few male lambs castrated-marking of the lambs-number of men employed as shepherds-a singular race of men-buildinge for shearing, called esquilos-sweating and shearing-number shorn in a day - number of shearers employed-remarks of a writer concerning the management of the Tarentum sheep-corresponded with Spanish management-Arthur Young's account of the Catalonian and Pyrenean Merinos-his description of their fleeces, \&c.-number of the estantes or stationary Merinos-ditto of the transhumantes or travelling-number of the Chunah breed-superiority of the transhumantes-Mr. Youatt' description of the qualities of the Merino-weight of fleeces, \&c. 
First ram imported by M. Delessert from the Rambouillet flock-Seth Adams's importation-his account of the same-Hon. William Jarvis's importatious-his account of the same-also Chancellor Livingston's-also Gen. Humphreys' - number of Merinos purchased by Mr. Jarvis-the kinds-what ports of the United States they were landed, and the number at each port-his description of the qualities of the Paular variety of Merinos-the Nigrettis-the Aqueirree-the Escurials-the Montarcos- the Gaudaloupes-number of each he put on his farm in Weathersfield, Vermont-manner of breeding thernallusion to an importation of Rambouillet Merinos by a citizen of Connecticut-weight of American Merino fleeces-enterprising feeling for wool improvement-public attention directed to the Merinos-commended.

French Sheer. The breeds varied as the face of the country-remarks -the most valuable wooled sheep in the south part of the kingdomsheep of Arles-number-migratory-summered on the Alps-sheep led by goats-singular sagacity of these animals-M. Daubenton's experiments with Merinos-his success induced the French government to import nearly 300 from Spain-were placed at Rambouillet, near Paris-not prosperous at first-the prices ewes and rams sold at from time to time-also their fleeces-experiments in erossing with native sheep--publication on their management by $\mathbf{M}$. Gilbert-school established for the education of shepherds-slow increase of Merinos in France-reasons assigned-prices of Rambouillet Merinos in 1834Mr. Trimmer's description of the flock-extract from M. Gilbert's Report concerning them-importation from the flock by D. C. Collins - number imported-his motives for so doing - description of his sheep from the American Agriculturist.

Swise Shemp. Consist of two kinds-valley and mountain-the former conform to the English long-wooled breeds-the mountain the most valuable-have been improved by the Merino cross . . . . 59

\section{CHAPTER IV.}

Saxon Sheep. Introduction of Merinos into. Saxony in 1765-the late Mr. H. D. Grove's account of the same-cause of the high prices of Saxon sheep-prices of rams-breeding in and in a cause of the fineness of their fleeces-remarks of $\mathrm{Mr}$. Grove on German management -remarks of Mr. Carr-also Dr. Bright-sheep. driven into the yards daily in winter-great care in selecting breeders-mode of examination-description of the native breeds of Saxony-remarks on the Infantado Merinos of Germany-mode of washing them-description of the form of the Saxon Merino-average weight of their fleeces-great care in washing and shearing-wool carried to Leipsic for a marketmanner of packing wool-large amount exported to England and France-superiority of German woollen fabrics-history of the introduction of the Saxons into the United States by H. D. Grove-many miserable specimens of the breed imported-many American flocks which rival the best German in fineness-American Saxons more 
hardy than the German Saxons-obstacles in the way of American breeders-will be cultivated with equal profit with Merinos-averago weight of American Saxon fleeces.

Prussian Sheer. Exertions of M. Fink to improve the fieece of Prussia-his experiments with Merinos crowned with success-importation of Merinos by the government in 1786-failure to do well-second attempt through M. Fink-resulted in success-agricultural school established to teach the best modes of managing Merinos-M. Fink's system in winter-Prussian fleeces now rival the best Saxon.

Silesian Sheep. Native sheep better than those of Prussia and Hungary-the introduction of the Merinos effented great improvementSilesian wools now equal to Saxon.

Hungarian Sheep. Native sheep of Hungary very inferior-Merinos introduced by the Empress Maria Theresa-agricultural school established to instruct in their management-rapid progress of wool improvement in Hungary-fleeces compete successfully with Saxonnumber of sheep in the Territory-fiock of Prince Esterhazy.

Swedish Sheer. The first Merinos carried from Spain taken to Sweden in 1723-introduced by Mr. Alstroemer-he triumphed over all difficulties-agricultural school established-premiums awarded for the best wool-mode of management in Sweden-the native sheep very inferior.

Danish Srieep. Native sheep conform to those of Sweden-Merinos imported in 1797 under government patronage-crossed with native breed-good effects-wool exported.

IcEland SheEr. The native breed very hardy-carry from two to six horns-wool worthless for manufacturing.

Russian Sheep. More attention to breeding of sheep than cattlewandering tribes possess many-great variety of breeds-cloth manufacture-extensive flocks owned by the rich Tartars-Merinos introduced-great improvement followed-wool exported from Odessadescription of the character of Russian Merino wool.

Australian Sheep. Character of the climate and herbage of Australia-subject to severe drought-no sheep indigenous to the countryBengal sheep introduced-their inferiority-South Downs and Leicesters exported from England-favorable cross with the Bengal sheep - Merinos taken there-afterwards the Saxous by Captain McArthur -description of Australian wool-its microscopic scrutiny by $\mathbf{M r}$. Youati-used much for the better combing purposes-quantity of wool exported in 1843 - mode of management of sheep in the colony $\rightarrow$ theep subject to foot-rot--manner of washing-average weight of the Australian fleeces . . . . . . . . . . . . 81

\section{CHAPTER V.}

\section{BRITISH BREEDS.}

South Down. Classification of the British breeds-middle-wooled breeds-superiority of the South Down-their location-Mr. John Ellman-deseription of the old South Down-means of Mr. Eliman to improve them-description of improved South Downs-a perfect South Down described-endure short keep-their mutton-adapted 
for a low country-former weight of fleece-present weight of the same - weight of quarters-serrations of the fibre-its diameter-wool harsh-changed character-South Downs healthy-prices of $\mathrm{Mr}$. Ellman's flock.

Rreland Shemp. Origin of name-their locality-weight of quarters -fine fleeces-weight of the same-diameter of fibre-form of the Ryeland.

Dorser Sherp. Description of pure breed-fecundity of Dorset ewes -failure of cross with Leicester-successful with South Downstheir value near cities.

Black-Faced SheEp. Their locality-origin in dispute-description of the old, and improved-quality of mutton-weight of quarters-their hardiness of constitution.

Cueviot Shegr. Remarks-locality of Cheviot breed-description of purs breed-hardihood-when fit for the butcher-weight of quarters -qualities of wool-its adaptation-Sir John Sinclair's description of the ancient Cheviot-crossed with Leicester-result-extension of the breed-Highland snow-storms.

Shetland Isínand Shemp. Their situation-origin of the breedweight of quarters-weight of fleece-quality of the wool-price formerly-remarks by Youatt.

IRIBH SheEp. Adaptation of Ireland for sheep-soil, climate, and herbage-character of native breeds-description of the same by Cully - successful cross with New Leicesters-weight and character of fleece-its uses . . . . . . . . . . 102

\section{CHAPTER VI.}

\section{BRITISH BREEDS.}

New. Leicester or Bakewerd. Origin of the long-wooled sheep in doubt-remarks-Old Leicester sheep-description of an improved Leicester-time when Bakewell commenced their improvementmeans employed-his selections-extensive spread of improved Leicesters-propensity to fatten-early maturity-weight of quartersquality of mutton-not a favorite with the butcher-faults of the New Leicester-quality and weight of the fleece-extensive cross with other breeds-cross with the Cheviot-Sir John Sinclair's opinion-introduction of the breed into America.

Teeswater Sheep. Origin of the name-description of the Old Teeswater-very prolific-instance by $\mathrm{Mr}$. Cully-weight of the fleecegreat success in crossing with the improved Leicester.

Romney Marsh Sheep. Locality of Romney Marsh-characteristics of the old breed-weight of the fleece-the breed improved by cross with Leicesters.

Lincoln Shezp. Character of the pure Lincolns-were bred for the fleece-general remarks-contest between the Leicesters and Linicolns-cross with the Leicester-the result-weight of the quarters - weight of the fleece-character of the wool, and uses-diameter of the fibre.

Baypton Shenp. Where found and origin of name-description of the 
breed-weight of quarters-weight of fleece of a ram-cross with Leicester-result.

Cotsword Sheer. Antiquity of the breed-origin of the name-dispute among writers of the ancient Cotswolds-characteristics of the Cotswold breed-cross with Leicester-result-weight of quarterscross with Hampshire Downs-its success-quality of mutton.

Welsh Sheer. Primitive breeds-their character by Ellis-weight of the quarters-quality of the mutton-cross of the valley sheep with Leicester and Cotswold-result.

Merino She ep in Enguand. Introduced by George III-a second importation by that monarch-success which attended it-experiments in crossing with English breeds-that of Mr. Coke and its resultSir Joseph Banks and Lord Somerville-prices of Merinos in England-Merino Society instituted-the result thereof-downfall of the Merinos-reasons by several therefor-remarks on the climate.

Table of Prices for Wools. Spanish Merino-Portuguese-German, Saxon, and Silesian-Austrian, Bohemian, and Hungarian-Australian-Van Dieman's Land-British wools : : . . . . . 115

\section{CHAPTER VII.}

\section{SHEEP OF THE UNITED STATES.}

Woolcy Shegr of Rocry Mounrauss. Captain Bonneville's deseription of them-general character of the native sheep.

Otrer Breed. Their origin-description of the breed.

Arlington Long-wooled Sheep. Cultivated by Mr. Custis-description of the breed by Chancellor Livingston.

Smith's Island She e P. Their locality and characteristics-general remarks on the progress of wool improvement in the United Statescharacter of the wool in several States-Prairie management by George Flowex-remarks on the same-sheep culture in the Southern States... . . . . . . . . . . . . 131

\section{CHAPTER VIII.}

\section{SUMMER MANAGEMENT OF SHEEP.}

Sudden Change from Dry to Green Food improper. Reasons therefor-course recommended-separation of the weak from the strongmanner of doing it. Tagging or sheEP-slovenly mode of performing it by many farmers-reasons for doing it well-when it should be done-mode of doing it with male and female-humanity recommended-where the tag wool should be placed-its manufacture. CutTING horns aND hoofs-how it should be done-reasons for doing it. Drafting shegr for sale-should be turned to good keep. ParTURITION OR ILAMBNG-period of gestation-proper period for lambing - care of the ewes before the event-reasons for the sime-smooth fields recommended-danger of ewes being cast-consequences-necessity for watehfulness - duties of the shepherd during parturitionmeans he should employ-ewes should not be interfered with too soon after their labors cummence-influence of the weather-mode of assisting the ewe to lamb-fright of the ewe after mechanical aid 
is employed-means to induce her to suckle-lambs of fine-wooled oheep sensitive to cold and wet when they drop-storms should be anticipated-ewes should be got under cover-course when the lambs are brought to the fire to overcome numbness-means adopted with twins-death of the lamb causing sometimes garget-pasture of the ewes before and after parturition-number should herd together-affection of the ewe for her offspring-an instance related by the Ettrick Shepherd, James Hogg. SALting-no longer a mooted question -philosophy of salting-an instance in France-care to be observed in the spring-quantity necessary at a salting-salting in troughs not recommended-time of day when the writer salts his flocks-benefit of salting late in the fall-very essential in winter-salting of hay recommended.

Washrng. Careless mode of doing it by many-the most suitable time depending on the weather-water and weather should always be comparatively warm-consequences of violating it-the day should be one of sunshine-flock-master should be present-should be done on temperance principles-running stream of pure water recommended -use of vats-process described-the "clean thing" should be aimed at and not missed-quotation from Samuel Lawrence on the subject - soap for buck fleeces-neceesity for turning the sheep on a green sward after washing-driving the sheep along a dusty road should be avoided-Spanish custom of washing-English and German alsoloss by scouring Spanish, German, Australian, and American Merino and Saxon wools-also South American-reform called for in American mode of washing wool.

Cagtration and Docking. Time when it should be done-cool weather recommended-reasons therefor-lambs should be brought from the field without bustle and confined in a small pound-mode of castration-docking the tail-should be cut short-reasons assignedconsequences of a long dock-ointment used-the ingredients and preparation-application of it-means to employ after the process is through with ................ .... 159

\section{CHAPTER IX.}

\section{SUMMER MANAGEMENT CONTINUED.}

Shearivg. Harvest of the shepherd-remarks of censure on American shearing-fault lies more at the door of the flock-master than shearer -bad policy of hiring men to shear by the job-consequences-the practice should cease-number a good shearer can perform in a day $\sim$-what constitutes a good shearer-instructions for a novice in shearing - whole process described-bad policy of fretting at a new beginner-kinduess recommended-good effects of so doing-mode of taking off the fleece in England-recommended.

INTERIM between Washing and Shearine, \&cc. Length of time should depend on the state of the weather-time stated-bad consequences of shearing in cold weather-effects of storms on sheep just shorn-their suffering very great if exposed-duty of the flock-mas. ter under such circumstances-horns and hoofs should be cut if not alroady done-indications of scab. 
Sonring, \&c. Duty of the master-quality of the fleece better judged of than at any other time-nood or bad points of form readily seenretaining the best for breeders-bad consequences of neglecting to sort sheep at this time-classification of the flock-ewes and lambs only should run together-those selected for sale should be turned to good keep.

Marring, \&c. Painting the initial letters of the owner's name on the sides of the sheep-the ludierous style it is usually done-an iron formed to represent a triangle or diamond recommended-where the mark should be put-materials for marking.

Rolling the Flegces. Fleeces should be carefully taken from the floor-indifferent locks put in a basket-the process of rolling and tying described-consequences of slovenly rolling.

Arrangement of Wool for Sale. The flock-master should keep before him the motto of shopmen-applicable to everything the farmer selle-rough and tumble style of arranging wool for sale-a good light important-a bad light aggravates the appearance of wool if indifferently washed-best mode of arranging wool described-good consequences-cheating practices of wool-growers exposed-reprobated - size of twine stated.

Shanaing-house and Appendagess. Inconveniences without themthe expense reimbursed in a few years-construction of pounds-wool loft should be well lighted-a north light preferable-trap door.

Baleing Wool. Burlap used for sacks--the proper width, and quantity required for each sack-truss hoop necessary-its adjustment-process of packing described-too much haste generally in packing wool.

Snefp-Tick. The class of sheep they most infest-consequences of permitting them to live-modus operandi of eradicating them-quantity of tobacco for 100 lambs-time when necessary to go through the operation-good condition an immunity against ticks-tobacco decoction good for cutaneous irruptions.

Magaot Fly. Several varieties-named and described-their habitsmeans employed for destroying maggots on the sheep, and warding off flies-great vigilance necessary on the part of the flock-master during the summer.

Noxjous WeEds. Laurel, burdoc, and-tory-weed-burs injurious tc wnol-lessens its value-method of destroying burdocks . . 177

\section{CHAPTER $\mathbf{X}$.}

\section{SUMMER MANAGEMENT CONTINUED.}

Localitres for Sheep. Fit localities of British breeds-commended.

Soll. The sheep an upland animal-loves the short herbage of mountain-sides, if the soil is not pozchy from an excess of moisture-its repugnance to water-seeks dry situations for rest-its instincts in this regard-chalky soil of England-its effect on the fleece of the Down sheep-effects of hard water-calcareous soil-a sandy soil objectionable-reasons for the same-a soil should have a due admixture of clay-uniform supply of pasture very necessary.

Herbage. Important to the flock-master-influence of herbage on the 
carcase and fleece-remarks by Youatt-changed character of English wools since the introduction of the turnip system-Dr. Parry's remarks-deductions from the premises-variety of herbage necessary to the welfare of sheep-experiments by Linnæus in offering plants to the horse, ox, and sheep-instinct of sheep on this point--philosophy of variety of herbage-remarks in review-change from old to new pastures recommended-reasons for changing the pasture often - small fields recommended-incidental duties-remarks growing out of localities of British sheep.

Grasses. Degree of nutriment they possess-Vernal-Meadow Foxtail -Blue Meadow-Rough-stalked-Sheep's Fescue-Round-headed Cock's Foot-Welsh Fescue-Narrow-leaved Meadow-Meadow Fescue-Rye-grass-Fertile Meadow-Cat's-tail or Timothy-Trofoil Clover-White Clover-remarks.

Shade Trees. Not appreciated by the American husbandman as they should be-grateful to sheep during the summer-will thrive better if provided for them-kinds of trees for shade mentioned.

W ATER. Not so necessary for sheep as other animals-they need it in August-breeding ewes should have access to it at all times.

Weaning Lambs. The time dependent on the breed and other circumstances-the usual time of suckling four months-when the ewes and lambs are separated; they should be put far apart-reasons-lambs should not be put on too high keep immediately-consequences of so doing-salting them to avoid the danger from gorging themselvestame sheep put with the lambs-ewes for a week or more should be put on low keep-danger of doing otherwise-after which their feed must be good-reasons.

Ear-marking. Lambs should be marked when they are weanedcropping the ears should be avoided.

Whear Stubbres. Danger of turning sheep upon them-reasons therefor-swine should always precede sheep-other grain stubbles not dangerous to sheep-young sheep should be turned on them.

Overstocking. Opinions of a foreigner-overtitócking too common with American farmers-consequences of overstocking-35 acres required for supporting 100 sheep of the Merino and Saxon varieties-example cited of a New York flock-master.

Fall Pafturing. Sheep should not be kept on pasture exclusively, late in the fall-reasons assigned.

Sorting ror Winter. Necessity for classifying sheep-particulars mentioned-early preparation for winter important-reasons . . 192

\section{CHAPTER XI.}

\section{WINTER MANAGEMENT.}

Introductory Remarkg-Obgervations on Chimate. Sheep dispersed over a large portion of the world-accounted for-the sheep, if long accustomed to a temperate climate, it is difficult to model at willcircumstances which influence-geographical positions where the sheep does not attain perfection-extremes of temperature unfavorable-if left to its instincts will avoid extremes-remarks of Blacklock-favorable climate of Australia for sheep-the sheep does best in the coun. 
tries of the vine-southern hemisphere better suited to its habits than the northern-western parts of continents also more congenial than the eastern-southern and northern temperature of the Alps-de. ductions.

Protection. Its importance-large losses accrue from its neglectpractised in Germany and elsewhere-Mr. Youatt recommends protection, and every other sheep historian-quotation from the Mountain Shepherd's Manual-false notions of many on the subject--the author's experience detailed-lost many sheep before he sheltered his sheep-per centage of loss since they were protected-a prevention of disease-improves the properties of wool and increases the weight of the fleece-particulars stated on this point-protection a means of increasing the number of lambs-accounted for-also a saving of prov: ender - the cause why - also a means of making additional manuremanure the farmer's mine or capital stock-protection urged by humanity.

Pronuction of Animal Heat. Principle of caloric-its free or sensible form, and latent or uncombined form-evolved by the union of sulphuric acid and water-how carbonic acid is produced-combustion produced by the union of carbon and oxygen-the former the fuel and the latter the fire-carbon furnished by the food-in cold climates fatty substances necessary, abounding more with carbon-reversed in warm climates, the inhabitants preferring a vegetable diet-application of these principles to the several positions under the head of protection..................... 210

\section{CHAPTER XII.}

\section{WINTER MANAGEMENT CONTINUED.}

Feeding. A knowledge of fundamental principles necessary to correct practice-it is a law of nature that nothing is lost or annihilated-the tree derives its nourishment from the atmosphere and the soil-animals from the food taken into the body-food a two-fold purpose to perform, one to nourish the body, and the other to support animal heat by means of respiration-in carnivorous animals the whole of their food is converted to flesh-in the herbivorous species only a partanalyses of flesh and fat-proportions of constituents nearly the same -no food destitute of nitrogen can nourish the body-analysis, of mutton fat-sugar, starch, gum, oil, or butter, produce fat, but not flesh-analysis of hay-nutritious portions of the blood are fibrine and albumen-in proportion as albumen abounds in food is its nutrient properties - analysis of albumen-young animals not disposed to take on fat like adults - cause stated-analyses of cow and asses' milkcassein the only nitrogenized substance in milk-various tables showing the relative proportions of nutriment of the different kinds of food consumed by sheep-items connected therewith-Petri's table of variations of fodder for sheep-relative proportions of a slaughtered sheep -Thaer's remarks on food--Veit's table showing that sheep consume of food in proportion to their live weight-Mr. Spooner's estimateVeit's remarks on the different kinds of straw.

Fatrening. Introductory remarks by Spooner-quietude and warmth 
contribute greatly to the fattening procese-cold robs the system of animal heat-warmth a substitute for food-experiment of Lord Ducio to prove this-experiment by the same to prove that quietude is necessafy-regularity in measure of food and time of feeding importantthe stables should be well supplied with litter-water-times of day for feeding-sheep when fattening should have a variety of food-the shorter the process of fattening the more profit will result-kinds of food best adapted for fattening-caution against waste . . . 220

\section{CHAPTER XIII.}

\section{WINTER MANAGEMENT CONTINUED.}

Recapitulation of analyeses of flesh, fat, \&c.-what food will produce the most wool-the question briefly considered-De Raumer's table of experiments-conclusions.

Obgervations on German Management. Their practical and scientific knowledge relative to agriculture-their economy in feeding-variations of fodder-effect of variety of food on the fleece-natural wool -bad policy to over-feed for the sake of making heavy fleeces-practice of the Germans-fodder should be proportioned to the live weight of the sheep-Petri, Thaer, and Veit on this point-the result of their experiments-quantity of hay alone necessary for 100 sheep for 150 dayo-the quantity required according to English estimate-quality of the hay should be considered-old meadows furnish the" best hay for sheep-top dressing them-an equal amount of food necessary to produce a pound of flesh or a pound of wool without regard to the breed -example of the South Down and Leicester-quantity of food required by each-example of Saxon and Merino-quantity of food they respectively consume-heavy fleeces produced at a proportional cost -remarks.

Importance of Green Food. Feeding of green food an essential point of good management-dry food produces the stretches-remarksgreen food improves the properties of wool.

WATER. Should have water during the winter season-reasons fully assigned.

Management of Lamis. Remarks on the importance of providing well for young stock of all kinds-early graining very important-modus operandi-quantity to begin with, \&c.-meal should be sprinkled on potatoes-quality of their hay-treatment of two-year olds-treatment of breeding ewes-treatment of wethers-treatment of bucks-treatment of hospital shesp-modes of foddering-racks-description of several-troughs-their construction-fodder pens-regularity of foddering-its necessity - barns and shelters-plans of sheep-barns, 238

\section{CHAPTER XIV. BREEDING AND CROSSING.}

Introductory remarks-qualities of a good mutton sheep-qualities of pure British breeds-the Leicester-South Down-Cheviot-Lincoln -Cotswold-remarks urging a more extensive cultivation of these breeds-reasons assigned. 
IN-Any-In Breeding. Quotations from Blacklock, Spooner, and other writers for and against the system-the author's conclusions on the question.

Crossing. Recommended-observations as to the course it is best to practice.

BREEDING REGISTER. Mode of marking the ears in Germany-form of a Breeding Register kept by the late H. D. Grove-interesting remarks of his own breeding.

infuence or Sex. Examples-good points of a Merino and Saxontupping season, and the duties devolving on the flock-master, , 262

\section{CHAP'TER XV.}

\section{STRUCTURE OF THE SHEEP.}

General view of the structure of the sheep-skeleton-bones of the head-bones of the body-bones of the fore extremitieg- the footbiflex canal-the hind extremities - muscles or flesh-brain and nerves - organs of digestion-the urinary and generative organs-contents of the chest-circulation of the blood-respiration and its effects. 292

\section{CHAPTER XVI.}

Introductory observations. Diseases of the brain are sturdy or dizzyhydrocephalus-trembling-apoplexy. Diseases of the air-passagesworms in the head, cansed by the ostris ovis or gad-fly-coryza or colds. Diseases of the stomach and intestines, are hoove-braxystretches-diarrhcea or scours-acute dropsy, or red water-dysentery -poison. The lungs-anatomy of the liver-rot-inflammation of the lungs-dropsy. Diseases of parturition, are abortion-inversion of the uterus-garget. Integument or skin. Diseases of the skin, are scab or itch - erysipelas-Johnswort-scab. Pelt-rot-fore mouth. Maggots. Foot-rot-fouls . . . . . . . . . . . . 349

\section{CHAPTER XVII. \\ SURGICAL OBSERVATIONS.}

Wounds-to stop bleeding-removal of extraneous matter-closure of the wound-bandaging-clean cuts-punctured wounds-bruises and sprains-wounds of joints-fractures-blood-letting . . . . . 382 


\section{INTRODUCTION.}

The sheep, according to Cuvier, belongs to the ORDER Ruminantia; having teeth in the lower jaw only, opposed to a callous substance in the upper jaw ; six molar teeth on either side, and the joint of the lower jaw adapted for a grinding motion; four stomachs, and these, with the csophagus, so constructed that the food is returned for the purpose of rumination; long intestines not cellated :-the TRIBE $\mathrm{C}_{\mathrm{A}-}$ PRIDE ; the horns, where they are found, being permanent; placed on a vascular bony basis or process ; the horny sherth receiving its increase by annual ringlets at the base, forming deep sulci around the horn, with others as deep running longitudinally, and dividing the surface of the horn into a succession of irregularities or knots. The general structure light, and adapted for springing or swiftness: the ears usually erect and funnel-shaped; the pupils of the eye oblong, and there not being any canine teeth in the mouth:- the GENUs Ovis; with or without horns, and these, where present, taking more or less a spiral direction; the forehead or outline of the face convex; no lachrymal or respiratory opening under the eye; the nostrils lengthened, and terminating without a muzzle; no beard; the body covered with short, close hair, with a downy wool beneath, and, in a domestic state, the wool prevailing over the hair, or quite superseding it ; the legs slender, yet firm.

Of these there are three varieties: the Ovis AMnon, or Argali; the Ovis Musmon; and the Ovis Aries, or Domestic Sheep. The first two will be described in a future chapter, and the last will form the subject of this work.*

From the earliest period of the world the sheep has been domesticated by man, and appropriated to his wants. "Cain

- Animal Kingdom-Synopsic. 
brought of the first fruit of the ground an offering to the Lord ; and Abel. he also brought of the firstlings of his flock, and of the fat thereof."

After the expulsion of the progenitors of the human race from the garden of Eden, a division of labor was assigned to Cain and Abel, the latter as a "keeper of sheep, and Cain a tiller of the ground."

During the antediluvian age there is no authority for supposing that the flesh of the sheep was used for food, vegetables and bread being the only materials of human sustenance. The sentence of Adam is- "Cursed is the ground for thy sake. In sorrow shalt thou eat of it all the days of thy life, and thou shalt eat of the herb of the field; in the sweat of thy face shalt thou eat bread."

The language to Noah after the deluge is very different: - "The fear of you and the dread of you shall be upon every beast of the earth and upon every fowl of the air, upon all that moveth upon the earth, and upon all the fishes; into your hand are they delivered; every moving thing that liveth shall be meat for you. Even as the green herb (which was formerly appointed to be your food) have I now given you all things."

But many centuries elapsed, notwithstanding this Divine permission, before the flesh of animals generally was used. It was first partaken at the periodical sacrifices offered to the Most High, subsequently as a luxury, and an indulgence not to be justified except on some particular occasions. The primitive custom of subsisting on vegetables alone is retained by fragments of the population of the East, and is enjoined in their code of religious obligations. This usage, however, prevails only in a limited degree with some of the pagan sects.

Although the flesh of the sheep wàs so long excluded as an article of sustenance, the milk of the ewe was appropriated to that purpose by the antediluvians, as it has since been in various parts of the world, and especially even to the present day by the wandering tribes of the East. A learned author thus remarks on this subject:-" Ewe's milk was used in the manufacture of cheese many. centuries before there is any record of this article of human sustenance being derived from the milk of the cow. Ewe-mill cheese was often made in the early times on a large scale, and was a very material and valued article of food. Butter is frequently 
spoken of in the sacred Scriptures, but it is the opinion of the best commentators that, during the first period of the Jewish history, the word so translated means the caseous and not the oleaginous product of milk. In one passage, where the mechanism described is too plain to be mistaken, the proper translation is given, and that in the most ancient book in the world:- Hast thou not poured me out like milk, and curdled me like cheese ?"* There is much reason to believe that this was the product of the sheep, for such was the cheese spoken of by other writers of a remote age; and the 'butter of kine,' mentioned in a later period of Jewish record, would seem to be a delicacy of rare occurrence, promised as the "reward of obedience."

Homer flourished about 900 years before the Christian era, and in his Odyssey alludes to the subject under consideration:

"He next betakes him to his evening cares, And, sitting down, to milk his ewes prepares: Of half their udders eases first the dams, Then to the mother's teats submits the lambs. Half the white stream to hardening cheese he pressed; And high in wicker baskets heaped : the rest, Reserved in bowIs, supplied the mighty feast." $\dagger$

Mr. Burckhardt gives the following account of the manu facture of butter from ewes' and goats' milk by the Syrian Arabs:- "The sheep and goats are milked during the three spring months, morning and evening. They are sent out to pasture before sunrise, while the lambs or kids remain in or near the camp. About ten o'clock the herd returns, and the lambs are allowed to satiate themselves, after which the ewes belonging to each tent are tied to a long cord, and milked one after another. When a ewe is feeble in health her milk is left wholly for the lamb. The same process occurs at sunset. From a hundred ewes or goats (the milk of which is always mixed together) the Arabs expect, in common years, about eight lbs. of butter per day, or about seven cwt. in the three spring months."

In the prifitive ages, after the flocks became too numerous to be supported permanently in one locality, it was the custom to remove them to a contiguous one, which originated the race of men called wandering shepherds. Jabal was "the father of such as dwell in tents and have cattle." He 
lived about 500 years before the flood, and was the first nomadic shepherd. The example of the original shepherds affords a correct picture of the present mode of life of the Arabian and Tartarian shepherds. Abraham and Lot lived in tents. "These Arabs," says D'Arvieux, "have no other lodging but their tents, which they call their houses; they are all black, of goat's-hair canvass, and are stretched out in such a manner that the rain easily runs off without ever going through them. Their whole families, and all that they have in the world, even to the stables, are there, particularly in the winter. The tent of the Emir is of the same stuff, and differs only from those of his subjects in bigness."

Abram pitched his tent on a mountain. The same author says that " the Arabs commonly encamp on the top of some little hills, where there are no trees to hinder them from discovering a great way off all that come and go, that they may not be surprised, having nothing else to fear."

Abram, it is recorded, often changed his place of residence. D'Arvieux continues, "The Arabs set themselves down wherever they find springs of water, or rivulets in the valleys, and pasture for the subsistence of their cattle, and then decamp, as soon as that is gone, and go and post themselves in another place every fortnight, or at most every month. They live all the summer upon these hills, always advancing towards the north: and when winter begins to come in, they go by degrees towards the south, as far as Cæsarea of Palestine, and on the outside of the mountains of Carmel."

Parsons, the traveller, refers to the peregrinations of the Arabs. "It was entertaining enough to see the horde of Arabs decamp. First went the sheep and goats in regular divisions, then followed the camels and asses, loaded with the tents, furniture, and kitchen utensils. These were followed by the old men and the women, and the boys and girls on foot. The children that could not walk were carried on the backs of the young women, and the boys and girls : and the smallest of the lambs and kids were carried under the arms of the children. The procession was closed by the chief of the tribe mounted on the very best horse." The foregoing manifests the tenacity with which the Arabs adhere to the customs of their forefathers established thousands of years ago.

On the authority of the Scriptures, the flocks which abound- 
ed in Palestine were very numerous. Job had 14,000 sheep, besides oxen and camels. When the 12,000 Israelites made an incursion into Midian, they brought away 675,000 sheep. When the tribes of Reuben and Gad made war with the Hagarites, their spoils amounted to 250,000 sheep. The King of Moab rendered a yearly tribute of 200,000 sheep; and Solomon offered 120,000 at the derication of the Temple.

There are several circumstances which will readily account for these numerous flocks. They constituted almost the only riches of the people; comparatively few were slaughtered, for, as has already been observed, their flesh was rarely eaten; except on solemn sacrifices or occasions of peculiar rejoicing, and there is reason for helieving that the ewes had lambs twice in the year. An author remarks - "The Jewish writers frequently speak of the first and second yeanings, referring the former to the month Nisan, corresponding to the March of the modern calendar; and the other to the month Tissi, answering to September." It appears, from the concurrent testimony of several travellers, that these numerous flocks were not confined to ancient times. Sir John Chardin saw flocks in the neighborhood of Aleppo of immense numbers. Dr. Shaw states that "several Arabian tribes who can bring no more than 300 or 400 horses into the field, are possessed of more than as many thousand camels and oxen, and treble the number of sheep and goats."

The first, and, indeed, only improvement in sheep breeding which the Sacred Book informs us, is relative to the fleece, the color of which, it is generally believed, was originally tawny, or dingy-black. Although the fleece is now so generally white, yet instances are not uncommon in some of the best-bred flocks, which indicates the tendency to return to the original color. This is perceptible in the legs and faces of the distinguished South Down (but from no intermixture of blood has become a permanent characteristic of that breed), nwre so in the Norfolks and black-faced sheep of the Scottish Highlands, and especially so in the African and Asiatic breeds.

The motive which prompted Jacob to attempt a change of the color, originated in a bargain between himself and Laban, that the former should have in future the speckled or ringstreaked sheep and goats, as a compensation for his services 
These could hitherto have been very few-and were of course accidentals - or the selfish and avaricious father-inlaw would not have consented to the proposal. It was clearly Jacob's wish to increase the number which would fall to his share, by art, and the principle upon which he acted was drawn from the experience of the female of the human species as exhibited in instances where the imagination of the mother caused deformities, or peculiar external marks on her offspring, before its birth. The ingenious device he adopted is set forth in Genesis, 30th chapter, and 37 and 38 verses. Jacob's scheme was crowned with success, which probably induced others to follow his shrewd example; and subsequently, by selections in breeding from male and female of such as possessed the largest proportion of white in the fleece, in process of time, it became wholly so. In David's time, he likens it to snow; and Solomon speaks of the teeth of his mistress, as resembling a flock of sheep just come up from the washing.

Jacob's policy inculcates a lesson to breeders of all kinds of domestic animals which should not be neglected. It establishes the supremacy of art, and the ease with which both the form and coat can be moulded to the will of man.

The Scriptures are silent relative to any peculiarities of the form of the ancient sheep-saving that the ram was horned-and se have no information of any attempts having been undertaken for its improvement. From the fact-as will more fully appear from the following pages-the fat-rumped and fat-tailed sheep abounding in those countries which were occupied by the primitive shepherds, Mr. Yonatt arrived at the conclusion, that the peculiar adipose substance collected on the rumps and tails, was common to the sheep both before and after the deluge, and sustains his opinion on the following passage of Sacred writ: And Moses "took the fat, and the rump, and all the fat that was upon the inwards," and "burnt them on the altar upon the burnt-offering." Accordingly he rejerts the commonly received opinion that the Argali is the original breed; and the following observations of $\mathrm{Mr}$. Price, an English writer of distinction on sheep, will throw a doubt over the subject, and leaves the question unsettled, where, with man at least, it will probably forever remain.

The question whether the different varieties of the same species of animal have been produced by accidental devia tions from one original parent breed, or whether there may 
not have been, from the beginning, several varieties of the same species, endowed with different qualities, and instincts, and propensities, adapting them to the situation in which they are found, is one of considerable interest to the zoologist, but with which the breeder of any species of animal has little to do. It is also a question difficult to solveit is one that does not admit of demonstrative proof either the one way or the other, and on which it does not become the candid inquirer to speak positively and with arrogance.

These observations are induced by the careless and presumptuous way in which almost every natural historian at once settles the matter. He does not seem to admit of any doubt respecting the affair, but at once assumes it as a certainty that every species of animal was derived from one original parent, and sets himself to work to inquire which was the parent breed, and, worse than all, derives many fanciful, nay, even some practical conclusions from that which rests at best only on probability. Thus there is scarcely a writer on sheep who does not take the question at once for granted, and describe the Argali, or the Musmon, or some creature of his own imagination, as the common origin of all.

There is no doubt that one variety of domesticated ani: mals, if prevented from mixing with any other, will in general propagate the same kind without any material change. It is also acknowledged that if, from some unknown or accidental cause, an individual is produced, possessing some unusual peculiarities, his progeny, to a certain degree, will probably possess the same peculiarities; and if a male and a female are selected with these peculiarities, and care is afterwards taken to exclude all who have them not, a new and permanent breed may be established. It is likewise sufficiently clear, that climate, soil, and pasture will gradually effect a considerable change in the form and the quality both of the wool and the flesh of every breed. These changes, however, have their limits ; they go no farther than producing modifications of the former breed : the essential and distinguishing character may yet be recognised, or, if it should be rendered somewhat obscure, it will burst forth again when the animal regains his native soil and climate.

The question is, when there are varieties of a species essentially and altogether different from each other; when the act of man has and could have little to do in effecting such a difference; when there was nothing to prevent that inter 
course which would soon wear down and efface every accidental variety, and restore the primitive character-the question then is, whether these variations are not best explained on the supposition of an original adaptation of each to the situation in which it was placed, and the functions it was to perform.--See Price on Sheep, p. 14.

The fact has been incidentally stated that the rams, at least, of the primitive sheep-were horned. When Abraham, in obedience to the Divine command, was about to sacrifice his son Isaac, his arm was arrested by a voice from heaven, "and he lifted up his eyes and looked, and behold, behind him a ram caught in a thicket by his horns." The trumpets used in war were made of rams' horns.

The polled sheep were probably an accidental variety; and when first occurring, cultivated partly for their singular ity, and more for their utility, whether with reference to the additional closeness of folding of which they were capable, or the fewer accidents that were likely to occur, or, most of all, from the superior docility and quietness of those to whom nature had not given these weapons of offence, and of the use of which all animals soon become too conscious.

- A prominent characteristic of the ancient shepherds, was their humanity and extreme watchfulness of their flocks. This was proverbial, which induced the prophet thus to speak of the Messiah : "He shall feed his flock like a shepherd; he shall gather the lambs with his arm, and shall care ry them in his bosom, and shall gently lead those that are with young." So true are the Arabs to the customs of their ancestors, that they evince a cimilar care and humanity, which should put to the blush very many modern shepherds. "Some beasts of burden, guided by the young men, bear little ones just dropped, and not able to travel. The little children, just able to toddle along themselves, are employed in driving, at their own slow pace, the lambs a little older."*

\footnotetext{
"In flowery spring-time, when the new.dropped lamb, Tottering with weakness by its mother's side, . Feels the fresh world about him, and each thorn, Hillock, or furrow, trips his feeble feet,Oh, guard him carefully."-Dyer's Fleecen
}

Music, in olden times, was one of the means adopted to control sheep. So universal was the practice, that the an-

- Buckingham's Paleatine. 
cient poets associated the music of the shepherds with their chief amusement and pleassure. The pastures on which the sheep fed, consisted of immense plains, or occasionally of abrupt alternations of hill and vale, with many a tangled copse and forest, so that the sheep, or a portion of them, were often out of the sight of the keeper, and occasionally beyond the reach of his voice; he therefore had a horn, or pipe, by means of which he could be heard at a greater distance, and the well-known sounds of which the leaders of the flock would immediately obey. To while away the time, he would, perhaps, occasionally endeavor to draw other and more pleasing sounds from this instrument necessary to his vocation, and thus he would naturally, or almost necessarily, become, to a greater or less degree, a musician ; therefore the interesting stories of the poets are not all fictions; and it can easily be imagined that the shepherd would often be found playing on his pipe in the midst of his flock, and they apparently attentive to, and pleased with, the strain, for they would have sufficient intelligence to associate with it a sense of the kindness and protection they experienced from the player.

Goldsmith, in his 'Animated Nature,' alludes to the subject:- "Before I had seen them trained in this manner, I had no conception of those descriptions in the old pastoral poets, of the shepherd leading his flock from one country to another. As I had been used to see these harmless creatures driven before their keepers, I supposed that all the rest was pure invention; but in many parts of the Alps, and even some provinces of France, the shepherd and his pipe are still continued with true antique simplicity. The flock is regularly penned every evening, to preserve them from the wolf, and the shepherd returns homeward at sunset with his sheep following him, and seemingly pleased with the sound of his pipe, which is blown with a reed, and resembles the chanter of a bagpipe." ,

The Bible affords undoubted evidence of the fact that it was customary with the ancient shepherds to cleanse or. wash their sheep before they were shorn.

Solomon, as has been already observed, compared the teeth of his mistress to a flock of sheep just come up from the washing. These early records, however, do not speak of the manner in which the operation was performed; but the inference is, that inasmuch as sheep constituted the chief riches of the people, and were objects of so much 
care, suitable and convenient places were erected, by many, for this purpose. Jehu "slew the brethren of Ahaziah at the pit of the shearing-house." The "pit' here spoken of, it is rational to suppose, was the pool in which the sheep were washed previous to the shearing. From the scarcity of water in parts of the land which the patriarchal shepherds occupied, it is doubtful whether the practice of cleansing the wool upon the back was very general.

In what particular period of the world the periodical separation of the wool from the pelt, by means of shearing, took place, we have no accurate information. In earlier times it was the practice to detach the fleece by pulling, which was probably not a very difficult task, as the wool, when matured, at each revolving year dropped from the sheep, as is the case with the coarser-wooled varieties at the present day. But the fleece would not separate over the whole animal alike easy, and portions would not yield without inflicting pain. Therefore, prompted by that humanity which so distinguished the management of the primitive shepherds, the shears, in process of time, were invented, and intro- duced into general use.

In olden time, as now in many parts, the sheep-shearing was the season for feasting and rejoicing. It was the harvest of the shepherd, and when he had gathered it, a generous feeling prompted him to make glad the hearts, for a few hours at least, of those who had participated in the work. Nabal asks of the servants of David, "Shall I take my bread and my water, and my flesh that I have killed for my shearers, and give it unto men whom I know not whence they be?" At a later period another, but not pleasing, account is given of the festivities of that season: "And it came to pass that Absalom had sheep-shearers in Baalhazor, and Absalom invited all the king's sons, and Absalom commanded all his servants, saying, When Amnon's heart is merry with wine, then kill him." Burder, in his work on Oriental. Literature, says-"The close of harvest was a season of rejoicing in most of the ancient nations, and sheepshearing was the harvest of the nomadic shepherd. This periodical festival was even enacted by law. Cecrops, the founder of the kingdom of Athens, about the time of Moses, ordained that "the master of every family should after harvest make a feast for his servants, and eat with those who had taken pains together with him in tilling his ground " 
The system of cotting was known and adopted by the Israelites. After repelling the invasion of Sennacherib, Hezekiah applied a portion of the spoil to works of public utility ; he built "storehouses, for the increase of corn, and wine, and oil, and stalls for all manner of beasts, and cotes for flocks." But, a commentator remarks, - "This has refer ence more to the inhabitants of-considerable towns or cities than to the wandering shepherds:"

An intelligent writer in the English Annals of Agriculture says, that " the ancients were so perfectly satisfied that a variety of climate was absolutely necessary to the production of fine wool, that those people whose situation admitted not of any change, had recourse to art,- -housing them from the day to defend them from the too powerful rays of the sun, and exposing them to the cold of night. This was practised by Hezekiah; Columella informs us that the same conveniences were adopted in Greece and Tarentum, and there is a line in Milton's Lycidas confirming the custom of their nocturnal exposure :-

'Battening our flocks with the fresh dews of night." "

For a long period it has been customary to cott or shelter sheep during the night, instead of the day, to protect them from the ravages of wild beasts, from cold, and to preserve their dung for manure.

The Scriptures abound with passages which demonstrate the art of, weaving to have been well understood in the primitive ages. Job says, "My days are swifter than the weaver's shuttle." Moses alludes to those whom "God had filled with wisdom of art to work all manner of work of the engraver, and of the cunning workman, and of the embroiderer in blue and purple, in scarlet and in fine linen, and of the weaver, even of those that devise cunning work."

Some three hundred years before the escape of the Israelites from Egypt, in the history of Joseph it is recorded that he was decorated with a coat of many colors, being not only proof that weaving was practised to a considerable degree of perfection, but dyeing also. Solomon thus describes the good wife:- "She seeketh wool and flax, and worketh willingly with her händs. Her household are clothed with scarlet." The foregoing, as well as following passage, indicate also, that in every country where the simplicity of manners and virtuas of the female are uncon 
taminated, spinning and weaving are the ordinary and chosen employments. "She maketh herself coverings of tapestry; her candle goeth not out by night. She layeth her hands to the spindle, and her hands hold the distaff."

"Night was now sliding in her middle course:

The first repose was finished; when the dame

Who, by her distaff's slender art subsists,

Wakes the spread embers and the sleeping fire.

Night adding to her work, and calls her maids

To their long tasks by lighted tapers urged."**

A writer on ancient manufactures says-_" Modern historians have united in tracing the invention of weaving to the Egyptians,- the weaving not of wool, however, but of flax; and the fabric of the linen cloths in which some of the Egyptian mummies were wrapped has scarcely been excelled at the present day. Yet it may be questioned whether the claims of the nomadic shepherds have been fairly considered. The cultivation of the sheep was coeval with the expulsion from Paradise; the cultivation of flax must have been an improvement in husbandry of far later date. When the descendants of Noah were scattered, they pursued their old avocation; their flocks and their herds accompanied them until they chanced to find some peculiarly fertile and convenient tract, which they gradually made their permanent abode; and then, building cities for themselves, they by degrees changed their way of life, and applied the arts, which they already possessed, to other and more extensive purposes.

'ithe children of Mizraim, the offspring of Ham, found in Egypt a soil not well fitted for the prosperous management. of the sheep. The Nile overflowed its banks twice in the year; and when its waters receded, a surface was left that was soon covered with luxuriant vegetation, but which infected and destroyed the sheep that fed upon it. Accident or experiment, however, soon proved that it was favorable to the cultivation of flax, and that from the fibres of the flax fine linen might be woven. Did the discovery of the flax lead to the invention of weaving, or was an art, known and practised for many a century before, directed to the manufacture of this new material ? The latter is the more probable supposition, especially if it is recollected, that during 
the early period of the history of the Patriarchs, some as. sociated tribes, that had previously inhabited the country to the east of Egypt, invaded and conquered the districts bordering on the Nile, and established a dynasty there under the appellation of the Shepherd Kings. The Abimelech, with whom Abraham had controversy, and who presented to him sheep, oxen, and slaves, was one of those shepherd kings.

To Egypt, then, let the honor still be yielded of having first woven the fibres of the flax into linen; but the invention of weaving, the conversion into cloth of the animal fibres that grow on the back of the sheep, is a claim of yet more ancient date, and belongs either to those who wandered with their flocks far from the plains of Ararat, or who carried the customs and arts of their forefathers into the country which they subjugated."*

Burckhardt thus describes, the loom at present found among the Arab shepherds :-

"The Arab women use a very simple loom; it is called nulon, and consists of two short sticks, which are stuck into the ground at a certain distance according to the desired breadth of the shauke, or piece to be worked. A third stick is placed across over them, and over the two horizontal cross sticks, the woof. To keep the upper and under woof at a proper distance from each other, a flat stick is placed between them. A piece of wood serves as the weaver's shuttle, and a short gazelle's horn is used in beating back the thread of the shuttle. The loom is placed before the maharrem, or women's apartment, and worked by the mother and her daughters. The distaff is in general use among them. At Palmyra I saw several men using the distaff: and among the Kilby Arabs all the shepherds manufacture wool."

The foregoing details are important as aiding to confirm, by collateral testimony, the authenticity of the Scriptures as shown in the customs of the wandering hordes of the East at the present day, which are the identical customs of the primitive shepherds : also, the humanity and watchfulness of their flocks which characterized the latter, examples, which should have their due weight with every shepherd now, and in all time to come.

* Farmer's Series. 



\section{THE AMERICAN SHEPHERD.}

\section{CHAPTER I.}

\section{PROPERTIES OF WOOL.}

As frequent allusions will be made in various parts of this work to the structure of the fibre, the distinctive peculiarities of the various kinds of wool, and the uses to which these wools are respectively applied, it is apparent that here will be the proper place for a discussion of the subject; and the reader is invited, for reasons which will appear obvious, to give it his careful attention.

\section{STRUCTURE OF THE SKIN.}

The skin of the sheep, and of animals generally, is composed of three coats, or layers. The external one is called the cuticle or scarf skin, which is exceedingly to gh, deroid of feeling, and pierced by innumerable small holes, for the passage of the wool and insensible perspiration.

The next layer is termed the mucus coat, a soft structure, its fibres having scarceiy more consistence than mucilage, and consequently separated with much difficulty from the coat below it. From the fact that the pulpy substance of this layer uniformly approximates the color of the hair, or wool, it is supposed that here resides the coloring matter. This is the seat also of sensation; the nerves, or rathor their terminations, ramifying minutely in its substance.

The third or lowermost layer is the cutis or true skin, dense, firm, elastic substance, in order to fit closely to the parts beneath, to yield to the various motions of the body, and the resistance of external injury. The true skin is 
composed almost entirely of gelatine, so that although it may be dissolved by much boiling, it is insoluble in water at the common temperature.

It is well known the skin of the sheep is seldom fully tanned, but is prepared in a peculiar way, and used for the common sort of binding for books, or is converted into parchment, which, from its durable nature, is used for the inscription of documents of more than ordinary value. Other uses made of the pelts of lambs in foreign countries, mention will be made hereafter.

\section{ANATOMY OF WOOL.}

Although the fibre of wool has been submitted to severe examinations of powerful microscopes, its internal structure is not yet definitely settled-whether solid, or conisting of a hard exterior tube with a pith within. The weight of testimony, however, is much in favor of the supposition of the latter. The fact may be adduced in support of this conclusion, that the wool of the sheep, when in high condition, is coarser than when in low flesh, the fibre being distended apparently from no other cause than the superabundance of the secretive matter designed for its growth. Could it be otherwise were it not tubular in its conformation? It may, however, proceed from another cause, for it has been satisfactorily ascertained that the fibre is vascular, being supplied with ressels which convey nourishment from the pulp, which seem to accompany it to a considerable distance from the root, if not through its whole extent.

The learned Dr. Good says:- "The Plica polonica, a disease whose existence is doubted by some, but of the occasional occurrence of which there is abundant testimony, completely establishes the vascularity of the hair; -for it is an enlargement of the individual hairs, so much so as, in some cases, to permit the passage of red blood, for the hair will bleed when divided by the scissors." Admitting it to be true that the hair is vascular, it follows that the fibre of wool is also ; and hence if a sheep is in more than ordinary condition, the consequent repletion of the fluids would cause an increased bulk of the fibre, without the necessity of a tubular conformation. But leave is taken of the question, with the repetition that the preponderance of testimony is in favor of the theory that the fibre is hollow.

Each fibre of wool is composed of a number of filaments 
or sinaller hairs, ranged side by side, which can be perceived without difficulty, from the tendency it sometimes has to unravel at the point. Mr. Bukewell has remarked on this as follows: "Hair is frequently observed to split at its points into distinct fibres-a division has also been seen in the hair of wool. This seems to prove that they are formed of distinct long filaments uniting in one thread or hair. In large hairs I have discovered a number of divisions from the root to the point. In one hair I distinctly perceived fifteen of these divisions of fibres lying parallel to each other, and in some of the fibres a further subdivision was distinguishable. Probably these subdivisions were each composed of others still smaller, which the limited power of our instruments may prevent us from discovering. If such be the structure of the hair of some animals, it is at least probable that the hair of all others may have a similar conformation, although the fibres of which they are composed may be too minite, or adhere too firmly together to permit us to separate or distinguish them."

\section{ITS CHEMICAL COMPOSITION.}

'The fact has long since been established that the chemical composition of nails, hoofs, horns, hair, wool, and even feathers, is substantially the same. According to Henry, they are made up of an animal substance resembling coagulated albumen; and sulphur, silica, carbonate and phosphate of lime, and oxides of iron and manganese. The similarity of the odor of hoofs, horns and hair, perceptible when burned, is within the experience of all. It is also well known that the horns of cattle are made up of elongated fibres or hair, which will be obvious to any one who will take the trouble to examine with the aid of a microscope. Indeed, without this instrument, the fact can be established as exemplified in the horns of the deer, at certain stages of the growth, and also those of the giraffe, on the surface of which hairs can be distinctly traced. Other testimony may be found in the circumstance, uniformly the same, that the horns conform in the degree of their twist or curve to the hair or wool of the animals on which they respectively grow. Thus, in the Angora goat and wild sheep of the Rocky Mountains, the horns are, like the hair and wool they produce, comparatively straight; while the horns of the Saxon and Merino resemble the beautiful spiral curve of their wool. 
YOLK.

This peculiar substance is so called abroad, from its adhesiveness and color; but with us it is termed gum, an appellation derived from its glutinous properties, quite as appropriate. It is apparent in the fleeces of fine-wool sheep, especially the Merino, at all seasons of the year, but very much so in the winter and spring; and.although diffused through the whole fleece, yet such is its profusion in the Merino, that it is observable in detached concrete particles, resembling ear wax. According to the chemical analysis of Vauquelin, it consists principally of a soapy matter, with a basis of potash; a small quantity of carbonate of potash; a small quantity of acetate of potash; lime in an unknown state of combination; and an atom of muriate of potash. Its peculiar odor, well known to those familiar with the fleeces of Saxon and Merino, is derived from the infusion of a small quantity of animal oil, and is in every respect a true soap, which would permit of the fleece being thoroughly cleansed by the ordinary mode of washing, were it not for the existence of this uncombined fatty or oily matter, which remains attached to the wool, and rendering it glutinous, until subjected to the process of scouring by the manufacturer.

There are some, from ignorance, who imagine the yolk or gum to be, if not absolutely a detriment to wool, at least a useless concomitant. This, however, is a decided mistake. It is a peculiar secretion from the glands of the skin, acting as one of the agents in promoting the growth of the wool, and by its adhesiveness, matting it, and thereby forming a defence from the inclemency of the weather. From accurate observation, it has been ascertained, that a deficiency of yolk will cause the fibre to. be dry, harsh and weak, and the whole fleece becomes thin and hairy; on the contrary, when there is a natural supply, the wool is soft, plentiful and strong. The quantity is depending on equability of temperature, the health of the sheep, and the proportion of nutritive food it receives.

Although it is found in greater or less quantities in the fleeces of almost every variety of sheep, such is its excess in the Merino breed, that it causes dirt to collect on the surface to such a degree as to form an indurated crust, with a hue resembling the thunder cloud. This excess, although, as already remarked, no way injurious to the fibre, yet in 
one sense it is so to the manufacturer, from the uncertainty as to the amount of loss sustained by cleansing. Hence it is that the European manufacturer refuses to purchase Spanish Merino wool, without being thoroughly washed with soap, which is always performed after the fleece is shorn, and even then the wool shrinks, by the manufacturer's mode of cleansing, generally about 10 per cent.

It has been observed that temperature has an influence in determining the quantity of yolk; hence, the equable and mild climate of Spain is favorable to its production; and although the Escurial Merino is for the most part the parent stock of the Saxony sheep, yet, from the opposite character of the climate to that of Germany, it is found in a greatly diminished quantity in Saxon fleeces. The Saxon Merino, however, when kept in fair condition, has the requisite supply to give additional softness, pliability, and strength ti) the fibre.

On the authority of an English writer, the wools of se veral breeds of sheep in the more southern part of the kingdom abound in yolk in great abundance, so that a fleece, unwashed on the back, will lose one-half of its weight by thorough scouring. A deficiency of this substance is perceptible as progress is made horthward; and in Northumberland and Scotland, it is common for the farmers to supply its loss by means of smearing the sheep, in autumn, with a mixture of tar and oil, or butter, which will be more particularly noticed hereafter. To confirm the propriety of this, as well as afford additional testimony of the virtues of yolk, the following fact is quoted, recorded by Mr. Bakewell, the eminent sheep breeder :-

"An intelligent manufacturer in my neighborhood, who kept a small flock of good wooled sheep, informed me he had adopted the practice of rubbing the sheep with a mixture of butter and tar. He could speak decidedly to the improvement the wool had received by it, having superintended the whole process of the manufacture. The cloth was superior to what ungreased wool could have made, if equally fine; it was remarkably soft to the touch, and had a 'good hand and feel,' the appearance of the threads being nearly. Iost in a firm, even texture, covered with a soft, full nap."

The additional value, then, the yolk imparts to the wool, affords a useful lesson to the wool-grower, to take such care of his sheen as will best supply the needful quantity. Equa 
bility of temperature being one requisite, he should protect his flocks during the winter season; and good condition being another, wholesome and nutritious food should not be spared.

\section{FORM OF THE FIBRE.}

The fibre of wool is circular, differing materially in diam. eter in the various breeds, and also in different parts, of the same fleece. It is generally larger towards the point and also near the root, and in some instances very considerably so. Mr. Youatt's description cannot be simplified-or improved. "The fibres of white wool, when cleansed from grease, are semi-transparent; their surface in some places is beautifully polished, in others curiously encrusted, and they reflect the rays of light in a very pleasing manner. When viewed by the aid of a powerful achromatic microscope, the central part of the fibre has a singularly glittering appearance. Very irregularly placed minuter filaments are oometimes seen branching from the main trunk like boughs from the principal stem. This exterior polish varies much in different wools, and in wools from the same breed of sheep at different times. When the animal is in good condition and the fleece healthy, the appearance of the fibre is really brilliant; but when the sheep has been half starved, the wool seems to have sympathized with the state of the constitution, and either a wan, pale light, or sometimes scarcely any, is reflected."

His closing paragraph is especially true. The wool of half-starved sheep can be detected without any difficulty by the wool stapler and experienced buyer, and its consequent deterioration affects the price. The fibre of such wool is finer, it is true; but the numberless breaches injure every manufacture for which it is used. This is another illustration of the bad policy of farmers in neglecting to keep their sheep in uniform good condition. Healthy sheep will produce healthy wool, both being always the most valuable, and consequently paying the largest dividends.

\section{ELASTICITY.}

A writer observes-" There are two antagonistic principles continually at work in every part of the frame of every animal : and it is on the delicate adjustment and balance of power between them, that all healthy and useful action de. 
pends ; the disposition to give way, or submit to some alter. ation of form when pressed upon, and an energy by means of which the original form is resumed, as soon as the external force is removed." These two principles are beautifully exemplified in the fibres of wool, obviously much dependant on the numerous and minute spiral curves, so manifest in the Saxon and Merino. Take; for instance, a single fibre of wool of these varieties of sheep, if it be stretched to its full length, and then suddenly set free at one extremity, it will resume its ringlet form; and hence upoI the union of pliability with the elastic principle chiefly de pends the usefulness, and consequently value of wool.

The play of these powers is differently adjusted in different wools. In the Saxon, calculated for our finest fabrics, the action of these opposing principles is beautifully balanced. Hence it is the fabric is so easily shorn of its superfluous nap, the facility with which it yields to pressure, and covers the threads of the cloth with a dense, soft pile. Notwithstanding the injury the elastic powers may receive by the process of manufacture, yet by the aid of a microscope, the nap presents innumerable minute curves closely hugging the texture; and to this much of the beauty of our finest cloth is owing. To these opposing powers of the fibre, the felting principle is not a little indebted, as will be explained hereafter.

\section{SPIRAL CURVE.}

The spiral curve, or ringlet form of wool, has been referred to. This is one of the distinguishing qualities between wool and hair, the latter being comparatively straight. It is remarkable in all short-wooled sheep, but in no other varieties is it so conspicuous as the Saxon and Merino. It is observable in the Leicester and other long-wooled varieties, but in a far less degree; and with some species of the goat, under the hair of which is found a perfect wool, having the true felting property, and the fibre considerably curved.

There is an intimate connexion between the fineness of the wool, and the number of the curves, or otherwise, in pro. portion to the number of curves in a given span, is the diameter of the fibre. It should be stated, however, that this is more generally true of pure Saxon and Merino. It can be easily demonstrated, if the experiment is fairly made with the micrometer, care being taken not to destroy the curves 
by extension, but the fibre placed in the instrument as it naturally grows upon the sheep. From M. Lafoun's work on German management of sheep, the following is extracted, bearing on this point:

"Those breeding pure Saxons, inspect their flocks three times in the year; before winter, when the selection of lambs is made, in the spring, and at shearing time. Each sheep is placed in its turn on a kind of table, and examined carefully as to the growth, the elasticity, the pliability, the brilliancy, and the fineness of the wool. The latter is ascertained by means of a micrometer. It being found that there was an evident connection between the fineness of the fibre and the number of curves, this was more accurately noted, and the following table was constructed. The fleece was sorted in the manner usual in France. The fineness of the Superelecta, or picklock, is represented by a span corresponding with the number 7 on the instrument."

\begin{tabular}{lllll} 
Bort. Name. & $\begin{array}{c}\text { Carves in } \\
\text { an inch. }\end{array}$ & & \multicolumn{1}{c}{ Dlameter of fbre. } \\
1. Superelecta, & 27 to 29 & 7 & or $1-840$ th of an inch. \\
2. Electa, & 24 to 28 & 8 & or $1-735$ th & "s \\
3. Prima, & 20 to 23 & 9 & or $1-660$ th & " \\
4. Secunda Prima; & 19 to 19 & 10 & or $1-588$ th & " \\
5. Secunda, & 16 to 17 & 11 & or $1-534$ th & " \\
6. Tertia, & 14 to 15 & $11 \frac{1}{2}$ or $1-510$ th & "
\end{tabular}

The above will show the necessity of more care with wool-growers in breeding from such sheep only whose wool - approximates nearest to the principle laid down, as it is to this curled form of wool its most valuable uses depend. It is one agent, though not the principal, in producing the phe. nomena of felting. "It materially contributes to that disposition of the fibres which enables them to attach and entwine themselves together; it multiplies the opportunities for this interlacing, and it increases the difficulty of unravelling the felt."

The numerous and minute curves being, as observed, eminently characteristic of the pure Saxon and Merino, will serve as a sure test, in all cases, of the purity of blood, and therefore affords a certain and unerring guide in the selection of breeding sheep. If it is rightly adhered to, the every day attempts to dispose of grades for high-bred sheep will be frustrated. 


\section{SOFTNESS-FINENESS.}

It is not as generally known as it should be, that softness is a quality of wool of much consequence. When the wool buyer and stapler proceed to an examination of a parcel, their judgment will be materially affected as to its value, whether "soft in handle," or otherwise. This, however, generally speaking, is the result of comparative fineness; but by no means always so, for wool of the same quality of fineness has not the same degree of softness. There are several causes to account for it, and amnng them is soil; as, for instance, the chalky districts of England affect the wool to such an extent as to make it invariably brittle and harsh. This, however, is only local. The general cause of a deficiency of softness in wools of the same breed, may be referred directly to the condition of the sheep. It has already been stated that when the animal was kept in uniform good condition, the necessary quantity of yolk was supplied. Now if there is but little of this substance, which will follow an abuse in management, the wool will be less pliable and "kind to feel." Therefore it may be set down as a universal rule, that wool owes much of its softness to the presence of a sufficiency of yolk.

As a testimony how much this quality of wool is appreciated by the manufacturer, jt is affirmed on the authority of an English author, "that two parcels of sorted wool being taken, possessing the same degree of fineness, but the one having the soft quality in an eminent degree, and the other being harsh, the cloth prepared from the first, at the same expense, will be worth more to the manufacturer than the other, by full 20 per cent."

\section{FINENESS.}

This term, when applied to wool, is wholly comparative ; various breeds of sheep producing wool essentially different in quality, the same breeds varying much, and all breeds exhibiting qualities of wool of mequal fineness in the same fleece. It is also sometimes the fact that the extremity of the fibre, as ascertained by the micrometer, is five times greater in bulk than the centre and roo $^{3}$.

The fibre may be considered coarse when it is more than the five hundredth part of an inch in diameter, and very fine when it does not exceed the nine hundredth part of an inch, 
as exhibited occasionally in choice samples of Saxon Merino. wool. It is said there are animals which have a wool underneath a covering of hair, the fibre of which is less than the twelve hundredth part of an inch.*

The following cut will show the points in the pure Merino and Saxon where the different qualities of wool are to be found. The divisions do not always accurately correspond, but Lasteyrie and Chancellor Livingston, who were both familiar with pure Spanish Merinos, agree as to their general truth, and the observations of the writer confirm their decision.

It is, then, a matter to be studied by the wool-grower who is desirous of propagating sheep of the fire-wooled varieties ; for grades will often exhibit seven and eight qualities in the same fleece, whereas it will be seen that unalloyed breeds show but four qualities. Individuals have occasionally been found in original Saxon flocks whose fleeces would divide into only two sorts; but this is very rare.

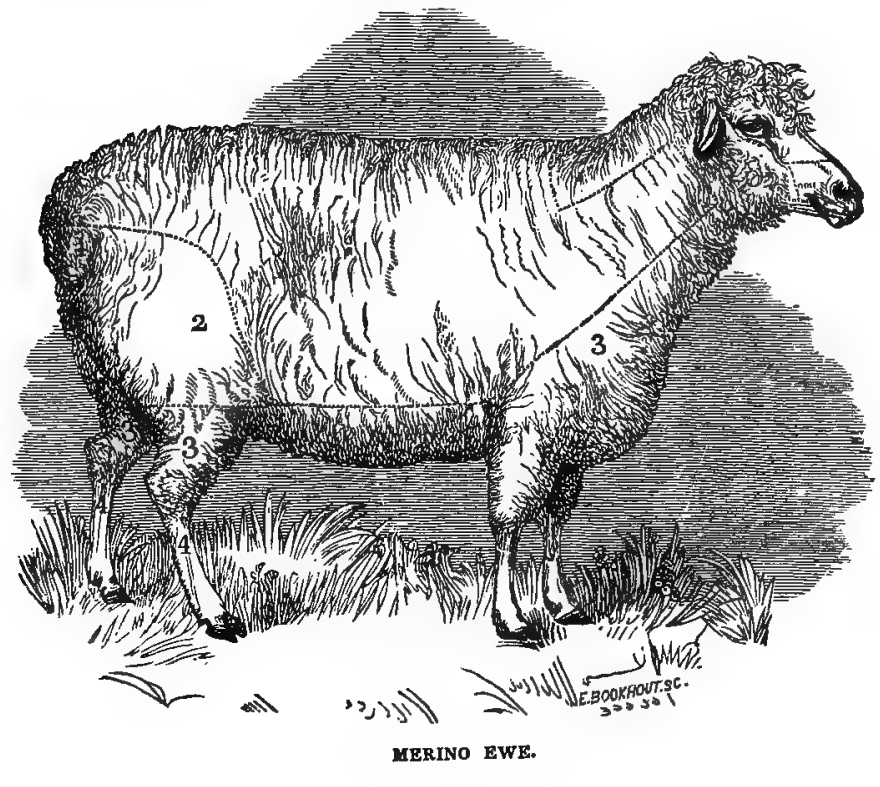

- Luccock. 
The refina (fig. 1), or the picklock wool, begins at the withers, and extends along the back to the setting on of the tail. It reaches only a little way down at the quarters, but, dipping down at the flanks, takes in all the superior part of the chest, and the middle of the side of the neck to the angle of the lower jaw. The fina (fig. 2), a valuable wool, - but not so deeply serrated, or possessing so many curves as the refina, occupies the belly, and the quarters and thighs down to the stifle joint. No. 3 , or third quality, is found on the head, the throat, the lower part of the neck, and the shoulders, terminating at the elbow; the wool yielded by the legs, and reaching from the stifle to a little below the hock, is procured from the tuft that grows on the forehead and cheeks, from the tail, and from the legs below the hock.*

\section{LENGTH OF THE STAPLE.}

Formerly, wool of short staple only was thought by the manufacturer indispensable to make a fine cloth with a close pile or nap, but the improvements made in machinery within a few years have superseded this consideration, and now long-staple wool is most valued. This in part proceeds from the fact that short wools have more "dead end," proportionally, than long; again, the new American enterprise for manufacturing muslin de laines, calls for a long, tough, fine staple. The Australian wools, which are of Merino and Saxon-blood, from the mildness of the climate of New South Wales, are very much longer in staple than formerly, and are much used for the above object. It is a query, however, whether a fine and very compact fleece, possessing a long fibre, can be produced on the same sheep. Very close, fine fleeces, are always comparatively short in staple; and close fleeces are indispensable in our rigorous climate, to protect the sheep from the effects of cold and wet; on the contrary, open fleeces are usually long in staple, but a poor defence zgainst a low temperature. It is, therefore, a question for the wool-grower of the North to consider whether, in obliging the manufacturer, he will not adopt a policy injurious to the constitution of his sheep. In a more southern latitude, this consideration is not so important.

COLOR.

The alteration of the color was the first recorded im- 
provement of the sheep, and its purity, its perfect whiteness, should never be lost sight of by the sheep-master of the present day. It is, however, not so much considered as it should be. Manufacturers desire none other fine wools than those of the purest whiteness, for the reason that those of a black or dun-colored hue, do not receive a perfect fancy dye, and therefore can be converted only into black cloths; hence, they are valued accordingly. Flock-masters should never breed from individuals that are otherwise than purely white ; for, independent of the above consideration, black or smutty sheep mar the appearance of a flock.

TRUENESS.

The quality of trueness of the staple especially enhances the value of every grade of wool in which it is found. It comprises an equality of the diameter of the fibre from the root to the point, and uniformity of the fleece generally. When the filament greatly lacks in this particular, it may be ascribed to an irregular and unhealthy action of the secretion of wool, which, in turn, must be attributed, in general, to abuses in management of the sheep. For instance, if the animal has fared kindly till the winter season, and then exposed to storm, and cold, and withal ill fed, the growth of that part of the fibre during this period will be considerably diminished in diameter, proportionally weak, and when examined by the microscope, presents a withered appearance. On being turned to pasture, the fare being better, and the secretions again becoming healthy and abundant, an enlargement of the fibre follows; but it is greatly destitute, from the causes stated, of the quality of trueness, and therefore debases the value of the whole fleece. The weak and withered parts of the fibre are termed breaches, and injure materially every manufacture in which it is employed, the felting property being deteriorated, and the cloth having less strength and softness. The skilful stapler and wool-buyer will, on critical examination, easily detect this serious fault, and prize the -wool accordingly. By pulling asunder a single fibre, the break will uniformly be confined to the breachy or withered point. This is termed unsound wool.

Although this description of wool is generally, as remarked, the result of bad management of the flock, yet it is common to all good sheep. With the Saxon and Merino, after the ewes, particularly, pass the age of eight or nine years, the 
yolk lessens in quantity, which is followed by comparatively a hard, inelastic, unyielding character of the wool, with the strength and weight greatly diminished. Therefore, notwithstanding the singular longevity of these breeds, it is better to pass them over to the butcher, when arrived at the age mentioned.

Intimately connected with producing a sound and true sta ple, is the

\section{INFLUENCE OF TEMPERATURE.}

It cannot be doubted that equability of temperature is an important agent in perfecting the several properties of wool. The Spanish custom, continued for centuries, of driving the sheep in the spring to the northern and mountainous parts of the kingdom, which are there kept until the approach of winter, originated in part from the conviction that this theory was sound. Indeed, it is founded in the natural instinct of the sheep. Every one knows it is impatient of heat. In the midst of summer, in all latitudes where it is found, it will seek the most elevated points for the sake of the cooling breeze, and retire to shades to guard itself against the burning rays of the sun. In winter it will flee to a place of refuge from storms and cold. All this testifies strongly in favor of the correctness of the premises. But the question may be asked; what has the bodily comfort of the animal to do with perfecting the several properties of the fleece? The answer is, every thing. If health and thrift are promoted by equability of temperature, the cutaneous glands are alike healthy, and a regular and even growth of the fibre naturally follows.

But strictly speaking, equability of temperature is nowhere to be found; therefore, in our rigorous and changeable climate, the fibre of wool must ever present a greater or less inequality of diameter between its extremes. It is remarkable that the point has always the, largest bulk. 'This is the product of summer, after shearing time, when there is a repletion of he secretions which produce the wool, and when the pores of the skin are relaxed and open, and permit a larger fibre to protrude. The portion near the root is the growth of the spring, when the weather is getting warm; and the intermediate part is the offspring of winter, when, under the influence of the cold, the pores of the skin comtract, and permit only a finer fibe to escape. 
An author remarks, "The variations in the diameter of the wool in the different parts of the fibre will also curiously correspond with the degree of heat at the time the respective portions were produced. The fibre of the wool, and the record of the meteorologist, will singularly agree, if the variations in temperature are sufficiently distant from each other for any appreciable part of the fibre to grow."

In confirmation of the general fact as to the influence of climate on wool and hair, the remarks of Mr. Hunter, an English author of high authority, are quoted: "Sheep carried from a cold to a warm climate soon undergo a remarkable change in the appearance of their fleece. From being very firm and thick, it becomes thin and coarse; until at length it degenerates into hair. Even if this change should not take place to its full extent in the individual, it will infallibly do so in the course of a greater or less number of generations. 'The effect of heat is nearly the same on the hairs of other animals. The same species that in Russia, Siberia, and North America, produce the most beautiful and valuable furs, have nothing in the warmer climates but a coarse and thin covering of hair."

The above must be received with some limitation. $\mathrm{Mr}$. Youatt makes the following remarks: "Temperature and pasture have an influence on the fineness of the fibre, and one which the farmer should never disregard; but he may in a great measure, counteract this influence by carefu managament and selection in breeding. The original tendency to the production of a fleece of mixed materials existing, and the longer coarse hair covering and defending the shorter and softer wool, nature may be gradually adapting the animal to his new locality; the hair may increase and the wool may diminish, if man is idle all the while; but a little attention to breeding and management will limit the extent of the evil, or prevent it altogether. A better illustration of this cannot be found, than in the fact that the Merino has been transplanted to every latitude on the temperate zone, and to some beyond it-to Sweden in the north, and Australia in the south, and has retained its tendency to produce wool exclusively, and wool of nearly equal fineness and value."

M. Lasteyrie, the unwearied advocate of the Merinos, uses this remarkable language:- "The preservation of the Merino race in its purity at the Cape of Good Hope, and 
under the rigorous climate of Sweden, furnish an additional support of this, my unalterable opinion, fine-wooled sheep may be kept wherever industrious men and intelligent breeders exist."

Notwithstanding the above is so consolatory, and withal so very encouraging to our brethren of the Southern States to embark in sheep husbandry, yet it is undeniable that in northern latitudes the finest wools are produced; but this has arisen much from superior skill in breeding, and great assiduity in management in every regard. If sheep are properly selected from high-bred Merino and Saxon flocks, and taken to a latitude not south of $28 \mathrm{deg}$., if rightly managed, will suffer little deterioration for many years, and will produce wools of a like description of the Australian, soft, of even and long filament, fit for felting, and also admirably adapted for the finest and most beautiful of worsted fabrics. An instance is known by the writer, ${ }^{*}$ of an imported flock of Saxons having been taken to Tennessee some twenty years since, and judging from the samples of wool from it now in his possession, the conclusion is inevitable, that little or no deterioration has been produced by the climate. If sheep are provided with suitable retreats for shade during the heat of the summer months, there are many districts in the Southern States unsurpassed for wool cultivation. If there is a tendency to coarseness, it will be retarded or wholly prevented by an occasional recurrence to northern stock getters.

Many imagine that the climate of the Southern States is wholly unsuitable for the production of a fine fleece, because of the inferiority of the wools of South America. The degeneracy of the Merinos taken there, has not arisen so much from the climate, as because "industrious men and intelligent breeders" were not present to manage them ; furthermore, very many of the sheep transported there from Spain, were of the Chunah breed, producing very coarse wool, and these were promiscuously bred with the Merinos. The conservative power over the fleece lies in good management far more than climate.

FELTING.

The phenomena of felting long remained enshroulded in

* Mr. Mark H. Cockrill-see his letter in Appendix 
mystery. This gave rise to numerous speculations as to the primary cause or causes, many of which, although plausible at the time of their publicity, now that the true cause has been discovered, appear sufficiently ridiculous. But the keen sagacity of man at length mastered the subject by surmising the correct theory, without the means, however, to demonstrate it, for want of microscopes of adequate power. To M. Monge, the distinguished French chemist, are we indebted for the first correct view of the structure of the fibre, which, from its peculiarity, mainly depends the felting principle. He asserted "that the surface of each fibre of wool is formed of lamellæ, or little plates which cover each other from the root to the point, pretty much in the same manner as the scales of a fish cover that animal from the head to the tail, or like rows placed over one another, as is observed in the structure of horns ;" and he accounts for the felting process in the following way :

"In making a felt which is to constitute the body of a hat, the workman presses the mass with his hands, moving them backwards and forwards in various directions. This pressure brings the hairs or fibres against each other, and multiplies their points of contact. The agitation gives to each hair a progressive motion towards the root; but the roots are disposed in different directions-in every direction; and the lamellæ of one hair will fix themselves on those of another hair, which happens to be directed a contrary way, and the hairs become twisted together, and the mass assumes the compact form which it was the aim of the workman to produce. If the wool is in cloth and subjected to the process of fulling, the fibres which compose one of the threads, whether of the warp or woof, assume a progressive movement; they introduce themselves among those of the threads nearest to them, and thus by degrees all the threads become felted together, the cloth is shortened in all its dimensions, and partakes both of the nature of cloth and of felt." No language can be employed which will convey a more correct and vivid impression of the process of felting, than the foregoing.

Through the indomitable perseverance of Mr. Youatt, the author of a valuable, though too diffuse, treatise on British sheep-husbandry, Monge's theory was finally demonstrated, although he was often frustrated, and almost yielded to de- r.air, from the imperfections of his instruments. The con- 
Btruction at last of a superior achromatic microscope by $\mathrm{Mr}$. Powell, of London, enabled him to realize his ardent wishes; and his own description of the scene, and the conclusions to which he arrived, are of too much interest to admit of any abbreviation.

"On the evening of the 7th of Feb. 1835, Mr. Thomas Plint, woollen manufacturer, resident at Leeds; Mr. Symonds, clothing agent, of London, Mr. F. Millington, surgeon, of London, Mr. Edward Brady, veterinary surgeon, Mr. Powell, the maker of the microscope, and the author himself, were assembled in his parlor. The instrument was, in Mr. Powell's opinion, the best he had constructed. A fibre was taken from a Merino fleece of three years' growth; the animal was bred by, and belonged to Lord Western. It was taker without selection, and placed on the frame to be examined as a transparent object. A power of 300 (linear) was used, and the lamp was of the common flat-wicked kind. The focus was readily found; there was no trouble in the adjustment of the microscope; and after Mr. Powell, Mr. Plint had the first perfect occular demonstration of the irregularities in the surface of the wool, the palpable proof of the cause of the most valuable of its properties-its disposition to felt.

"The fibre thus looked at, assumed a flattened ribandlike form. It was of a pearly grey color, darker towards the centre, and with faint lines across it. The edges were evidently hooked, or more properly serrated-they resembled the teeth of a fine saw. These were somewhat irregular in different parts of the field of view, both as to size and number. The area of the field was now ascertained; it was one-fortieth of an inch in diameter. By means of the micrometer we divided this into four, and we then counted the number of serrations in each division. Three of us counted all four divisions, for there was a difference in some of them. The number was set down privately, and it was found that we had all estimated it at fifteen in each division. Having multiplied this by four, to obtain the whole field, and that by forty, the proportionate part of an inch of which the field consisted, we obtained a result which could not be disputed, that there were 2,400 serrations ir. the space of an inch, and all of which projected in the same direction, viz. from the root to the point. Then, before we quitted the examination of the fibre as a transparent object, we endeavored to ascar- 
tain its actual character, and proved it to 1-750th of an inch.

"We next endeavored to explore the cause of this serrated appearance, and the nature of the irregularities on the surface, which might possibly account for the production of these tooth-like projections; we therefore took another fibre, and mounted it as an opaque object. There was considerable difficulty in throwing the light advantageously on the fibre, so small a space only as 1-30th of an inch intervening between the lens and the object. At length Mr. Powell perfectly succeeded; and we were presented with a beautiful glittering column, with lines of division across it, in number and distance seemingly corresponding with the serrations that we had observed in the other fibre that had been viewed as a transparent object. It was not at once that the eye could adapt itself to the brilliancy of the object; but by degrees these divisions developed themselves, and could be accurately traced. These were not so marked as the inverted cones which the bat's wool presented, but they were distinct enough; and the apex of the superior one, yet comparatively little diminished in bulk, was received into the ${ }^{-}$ excavated base of the one immediately beneath, while the edge of this base formed into a cup-like shape, projected, and had a serrated, or indented edge, bearing no indistinct resemblance to the ancient crown. All these projecting indented edges pointed in a direction from root to point.

"Whether these, like the cones of the bat, are joints, or at least points of comparative weakness, and thus accounting for the pliancy and softness of the fibre, or regulating the degree in which these qualities exist, may perhaps be better determined by and by; one thing, however, is sufficiently plain, that these serrated edges in the transparent object produced (when the fibre was resolved into its true form as an opaque one) by the projecting edges of the cups or hollowed bases of the inverted cones, afford the most satisfactory solution of the felting principle that can be given or desired. The fibres can move readily in a direction from root to point, the projections of the cups offering little or no impediment, but when they have been once involved in a mass, and a mass that has been pressed powerfully together, as in some part of the manufactory of all felting wool, the retraction of the fibre must be difficult, and in most cases impossible." 
The annexed cuts exhibit microscopic views of the fibres of wool from picklock samples of Merino and South Down fleeces. The relative difference of serrations cannot be conveniently delineated in a plate : a marked. difference, however, will be observed in the construction of the lamella.

No. 1, a fibre of Merino wool as a transparent object; No. 2, the same, as opaque. No. 3, a fibre of South Down wool, transparent: No. 4, the same, opaque.

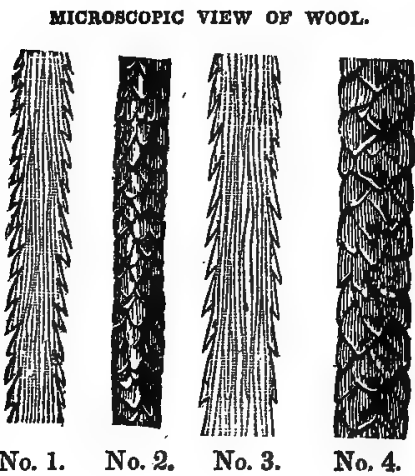

The following observations by Mr. Youatt, whose indefatigable zeal and diligence in the investigation of many particulars embraced in the present chapter, entitles him to much honor, will conclude the subject :-

"There can no longer be a doubt with regard to the general outline of the woolly fibre. It consists of a central stem or stalk, probably hollow, or at least porous, and possessing a semitransparency not found in the tibre of hair. From this central stalk there springs at different distances, in different breeds of sheep, a circlet of leave-shaped projec- 
tions. In the finer species of wool these circles seemed at first to be composed of one indented, or serrated ring; but when the eye was accustomed to them, this ring was resolvable into leaves, or scales. In the larger kinds the ring was at once resolvable into these scales, or leaves, varying in number, shape, and size, and projecting at different angles from the stalk, in the direction of the leaves of vegetables, from the root to the point, or farther extremity. In the bat there seemed to be a diminution in the bulk of the stalk, immediately above the commencement of the sprouting of the leaves, and presenting the appearance of the apex of an inverted cone received in the hollowed cup-like base of another immediately beneath. The diminution in the fibre of the wool at these points could be only indistinctly perceived; but the projection of the leaves gave a somewhat similar cone-like appearance. The extremities of the leaves in the long Merino and the Saxon wool were evidently pointed, with acute indentations or angles between them. They were pointed likewise in the South Down, but not so much, and the interposed vacuities were less deep and angular. In the Leicester the leaves are round, with a diminutive point or space. Of the actual substance and strength of these leafy or scaly circles nothing can yet be affirmed; but they appear to be capable of different degrees of resistance, or of entanglement with other fibres, in proportion as their form is sharpened, and they project from the stalk, and in proportion likewise as these circlets are multiplied. So far as the examination has hitherto proceeded, they are sharper and more numerous in the felting wools than in others, and in proportion as the felting property exists. The conclusion seems to be legitimate, and indeed inevitable, that they are connected with, or, in fact, that they give to the wool the power of felting, and regulate the degree in which that power is possessed.

"If to this is added the curved form which the fibre of the wool naturally assumes, and the well-known fact, that these curves differ in the most striking degree in different breeds, according to the fineness of the fibre, and, when multiplying in a given space, increase both the means of entanglement and the difficulty of disengagement, the whole mystery of felting is unravelled. A cursory glance will discover the proportionate number of curves, and the microscope has now established a connexion between the closeness of the curves 
and the number of the serrations. The Saxon wool is re. markable for the close packing of its little curves ; the number of serrations are 2720 in an inch. The South Down wool has numerous curves, but evidently more distant than in the former sample; the serrations are 2080 . In the Leicester the wavy curls are so far removed from each other, that a great part of the fibre would be dissipated under the operation of the card, and the serrations are 1860 ; and in some of the wools which warm the animal, but were not intended to clothe the human body, the curves are more distant, and the serrations are not more than 480 . The woolgrower, the stapler, and the manufacturer, can scarcely wish for better guides.

"Yet there is no organic connexion between the curve and the serration; the serrations are not the cause of the curve, nor do the curves produce the serrations; the connexion is founded on the grand principle that the works of nature are perfect; that no beneficial power is bestowed without full scope for its exercise. The curves of the smooth fibre might entangle to a considerable degree, but some of the points would be continually unravelling and threatening the dissolution of the whole felt. The straight fibre, however deeply serrated, its root being introduced into the mass, would often pass on, and pass through the felt and be lost It is by the curved form of the jagged fibre that the object can be accomplished certainly and perfectly.

"Future observers may possibly detect in wool the apparent coned and jointed structure of the hair of the bat, and then a third and powerful principle would be called into action, the pliability of the fibre, the ease with which it is bent in every different direction, and in each becomes more inexplicably entangled. A great point, however, is gained by the knowledge that in proportion as the auxiliaries in the felting process are multiplied, the direct agents are also increased." 


\section{CHAPTER II.}

\section{HIS TOR Y OF SHEEP.}

ARGALI, MUSMON, ASIATIC, AND AFRICAN פHEEP.

\section{ASIATIC ARGALI.}

THE following description of the Asiatic Argali is from the pen of Professor Low :-

"The Argali possessing the generic characters of the sheep, is somewhat less than the size of a stag. He bas enormous horns, measuring more than a foot in circumference at the base, and from three to four feet in length, triangularly rising from the summit of the head so as nearly to touch at the root, ascending, stretching out laterally, and bending forward at the point. He has a fur of short hair, covering a coat of soft white wool. The color of the fur externally is brown, becoming brownish grey in the winter; there is a buff-colored streak along the back, and a large spot of a lighter buff-color on the haunch, surrounding and including the tail. The female differs from the male in being smaller, in having the horns more slender and straight, and in the absence of the disc on the haunch. In both sexes the tail is very short, the eyelashes are whitish, and the hair beneath the throat is longer than on any other parts of the body.

"These creatures inhabit the mountains and elevated plains of Asia, from the Caucasus northward and eastward, to Kamschatka and the Ocean. They are agile and strong, but very timid, shunning the least appearance of danger; their motion is zigzag, and they stop in their course to gaze upon their pursuer, after the manner of the domestic sheep. They are usually found in very small flocks, and at rutting season the males fight desperately, using their homs and forehead in the manner of the common ram. They are hunted by 
the people of the country for their flesh, which is esteemed to be savory, and for their skins, which are made into clothing. In autumn, after having pastured during the summer on the mountains and in the secluded valleys, they are fat, and in high request; but as winter advances, they are forced to descend from the mountains in search of food; they then lose their plumpness, and are sought after only for their skins. When taken young they are easily tamed, but the old ones never resign their natural wildness."

\section{THE AMERICAN ARGALI.}

This supposed variety of the Asiatic Argali is well known as the "big-horn of the Rocky Mountains."

The Abbé Lambert gives the following account of it:"Besides several sorts of animals known among us, there are two sorts of fallow beasts unknown in Europe. They call them sheep, because they have the figure of our sheep. The first species is as large as a calf one or two years old. Their head has a great resemblance to that of a stag, and their horns to those of a ram. Their tail and hair, which are speckled, are shorter than those of a stag; their flesh is very good and delicate."

The following account was rendered-by Capt. Bonneville, and published by Washington Irving in his work entitled the "Rocky Mountains."

"Amidst this wild and striking scenery, Captain Bonneville, for the first time, beheld flocks of ahsata, or big-horn, an animal which frequents these cliffs in great numbers. They accord with the nature of such scenery, and add much to its romantic effect; bounding like goats from crag to crag, often trooping along the lofty shelves of the mountains, under the guidance of some venerable patriarch, with horns twisted lower than his muzzle, and sometimes peering over the edge of the precipice, so high that they appear scarce bigger than crows; indeed, it seems a pleasure tc them to seek the most rugged and frightful situations, doubtless from a feeling of security. It has short hair like a deer, and resembles it in shape, but it has the head and horns of a sheep, and. its flesh is said to be delicious mutton. It abounds in the Rocky Mountains, from the fiftieth degree of north latitude, quite down to California; generally in the highest regions capable of vegetation; sometimes it ventures nto'the valleys, but on the least alarm, regains its favorite 
cliffs and precipices, where it is perilous, if not impossible for the hunter to follow. The dimensions of a male of this species is, from the nose to the base of the tail, five feet; length of the tail, four inches; girth of the body, four feet; height, three feet eight inches; the horn, three feet six inches long ; one foot three inches in circumference at the base."

In that valuable work entitled the "Animal Kingdom," Major Hamilton Smith remarks :-"If the American species be the same as the Asiatic, which appears very probable, it can have reached the New World only over the ice by Behring's Straits; and the passage may be conjectured as comparatively of a recent date, since the Argali has not spread eastward beyond the Rocky Mountains, nor to the south farther than California."

\section{THE MOUFLON OR MUSMON.}

Buffon and Wilson have considered this sheep as identical with the Argali; others regard it as a variety only. It inhabits the mountains of Corsica and Sardinia, and has been found in some of the islands of the Grecian Archipelago. It is asserted by Pliny as having abounded, at an early period, in Spain.

Wilson, the distinguished naturalist, describes it thus :"It is usually about two and a half feet in height, and three feet and a half from the nose to the commencement of the tail. The horns never exceed two feet in length; they are curved backwards, and the points turn inwards; the roots of the horns are very thick and wrinkled; the ears are of a middle size, straight and pointed; the neck is thick; the body round; the limbs muscular; and the tail short. The color is generally of a dull, or brownish-grey, with some white on the "fore part of the face and on the legs; a tuft of long hair beneath the throat; a dark streak along the back; and the upper part of the face black, with black streaks along the cheeks. The forehead of this sheep is particularly arched. The females are generally without horns, and where they do appear, they are considerably Jess than those of the male."

The Musmons, like the Argali, love to roam on the highest mountain-tops, where they are seen congregated in herds of from fifty to an hundred. . It is covered by a fine hair of no great length, having beneath it a thick, grey-colored wool, 
short, out full of spirals, and the edges thickly serrated. Cuvier says the Musmon is difficult to domesticate, rarely axhibiting intelligence, confidence, affection, or docility.

\section{ASIATIC BREEDS.}

\section{FA1-RUMPED-FAT-TAILED-PERSIAN-TIBET-EAST INDIA-CHINESE.}

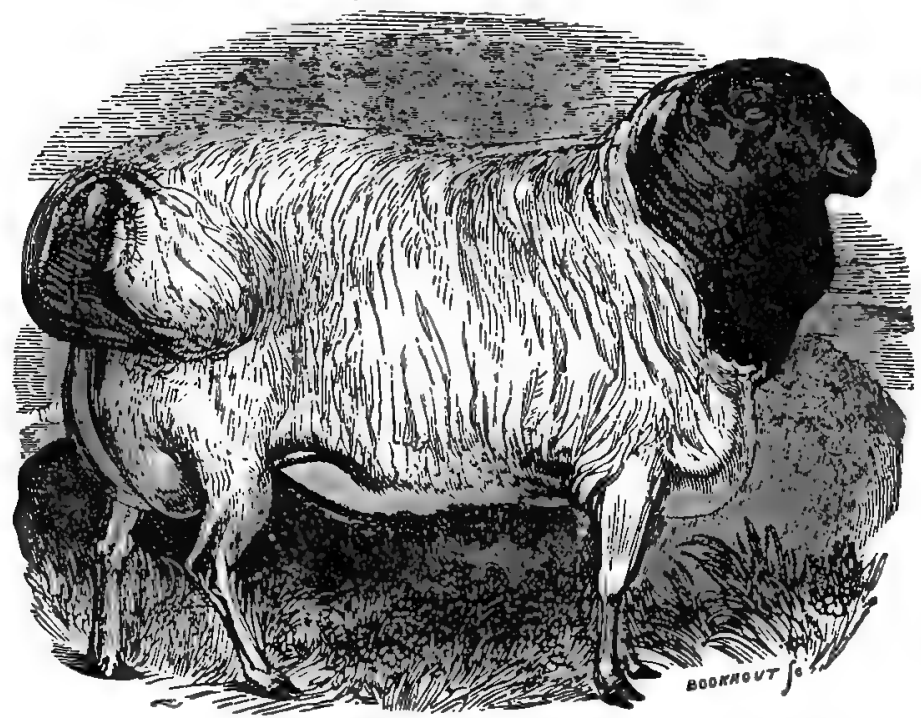

FAT-ROMPED BHEEP.

From the earliest times of which we have any authentic accounts, the Fat-rumped sheep has inhabited the countries over which the patriarchal shepherds roamed. It is but little known in Africa, but prevails extensively in the north and south of Asia; is found in Palestine in greater numbers than any other breed, and reaches far into the interior and northern parts of Russia. It is purest in the deserts of Great Tartary, no other variety being near to contaminatp its blood. 
Dr. Anderson, the traveller, gives the following account of this singularly-formed breed: "The flocks of all the Tartar hordes resemble one another, by having a large yellowish muzzle, the under jaw often projecting beyond the upper; by long hanging ears, and by the horns of the adult ram being large, spiral, wrinkled, angular, or bent in a lunar form. They have slender legs in proportion to their bodies, a high chest, large hanging testicles, and tolerably fine wool mixed with hair. The body of the ram, and sometimes of the ewe, swells gradually with fat towards the posteriors, where a solid mass of fat is formed on the rump, and falls over the anus in place of a tail, divided into two hemispheres, which take the form of the hips, with a little button of a tail in the middle to be felt with the finger."

This breed often weigh $200 \mathrm{lbs}$., and may be considered the largest of the unimproved sheep; of which weight the soft oily fat alone that forms on the rump amounts to from 20 to $40 \mathrm{lbs}$. In the neighborhood of Caucasus and Tauri$\mathrm{da}$, the hind-quarters of the -sheep are salted as hams, and sent in great quantities to the northern provinces of Turkey. In parts of Russia the fat-rumped sheep bears a somewhat fine fleece, but generally speaking it is coarse, and is adapted only for the purposes of inferior manufactures.

\section{FAT-TAILED SHEEP.}

This race of sheep is more extensively diffused than the fat rumped, since it is found throughout Asia, a great part of Africa, as well as through the north-eastern parts of Europe.

Dr. Russell, in his history of Aleppo, gives the following account of it, as it appears in Syria :- "The dead weight of one of these sheep will amount to 50 or $60 \mathrm{lbs}$., of which the tail makes up 15 or $16 \mathrm{lbs}$.; but some of the largest that have been fattened with care weigh $150 \mathrm{lbs}$., theatail alone composing one third of the whole weight. This broad, flattish tail is mostly covered with. long wool, and, becoming very small at the extremity, turns up. It is entirely composed of a substance between marrow and fat, serving very often in the kitchen instead of butter, and cut into small pieces, makes an ingredient in various dishes."

Dr. Russell further remarks-" Animals of this extraordinary size (150 lbs.) are, however, very rare, and kept up 
in yards, so as to be in little danger of hurting their tails from the bushes. The shepherds in several places in Syria fix a thin piece of board to the under part, which is not, like the rest, covered with wool, and to this board are some. times added small wheels; whence, with a little exaggeration, we have the story of the Oriental sheep being under the necessity of carts to carry their tails. But the necessity of carriages for the tails of the African sheep, mentioned by Herodotus, Rudolphus, and others, is real. 'The tail of that animal when fat actually trails, not being tucked up like those of the Syrian sheep."

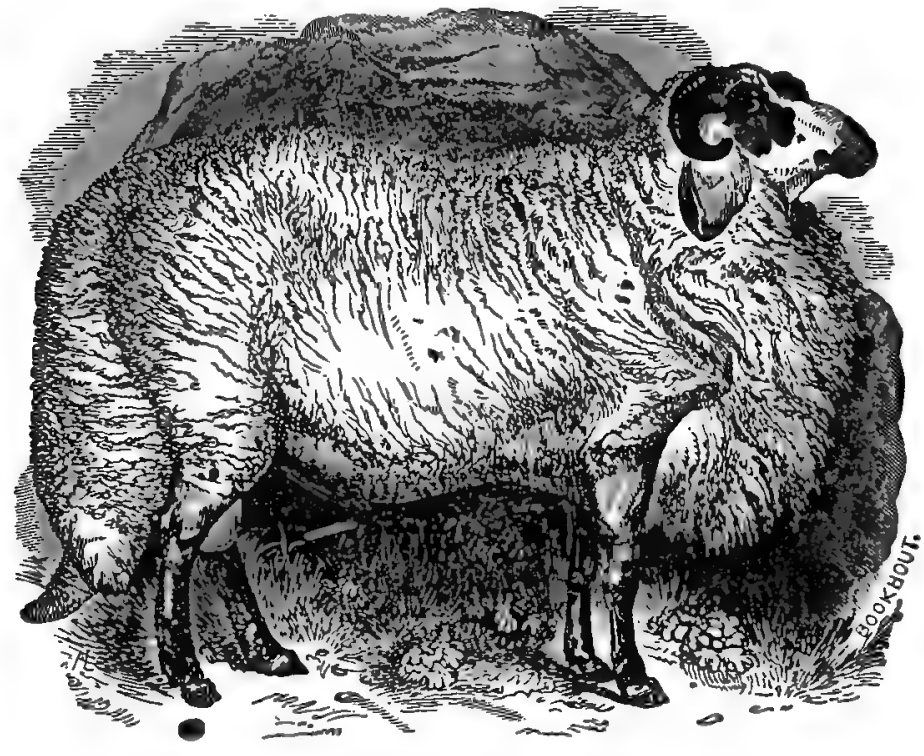

THE FAT-TAILED BHEEP.

A distinguished writer on sheep supposes the broad or fat-tailed sheep merely a variety of the fat-rumped; "the strange collection of adipose matter having only shifted its situation from the posterior part of the haunch-the very rump-to the superior part of the tail. This may have been at first accidental, and perpetuated by accident or design." 


\section{PERSIAN SHEEP.}

In Persia the fat-tailed sheep predominate greatly over the fat-rumped; and although the chief sources of wealth to a large class, no efforts are bestowed upon their improvement. The shepherds still follow the wandering life of their ancestors. In Fraser's account of Persia, they are thus described :

"When the pastures are bare, they shift to some other spot. 'The march of one of these parties is a striking spectacle. The main body is generally preceded by an advanced guard of stout young men, well armed, as if to clear the way; then follow large flocks of all kinds of domestic animals, covering the country far and wide, and driven by the lads of the community. The asses, which are numerous: and the rough, stout yaboos (small horses), are loaded with goods, tents, clothes, pots and boilers, and every sort of utensil, bound confusedly together. On the top of some of the burdens may be seen mounted the elder children, who act the part of drivers, and the lesser urchins holding on manfully with feet and hands. A third class of animals bear the superannuated of the tribe, bent double with age, and hardly distinguishable from the mass of rags that forms their seats. The young men and women bustle about, preventing, with the assistance of their huge dogs, the cattle from straying too far. The mothers, carrying the younger infants, patiently trudge on foot, watching the progress of their domestic equipage. The men, with sober, thoughtful démeanor, armed to the teeth, walk steadily on the flanks and rear of the grotesque column, guarding and controlling its slow and regular movement."

Much wool is grown in those districts of Persia, where the majority of the inhabitants lead a pastoral life ; the most valuable is found in the province of Kerman. This is a very mountainous country, hot and dry in summer, and intensely cold in winter. The wool of the sheep is fine quality, and that which grows at the roats of the hair of the goat is nearly as fine. 'The latter is manufactured into various fabrics, which almost equal the beautiful shawls of Cashmere. The fine felt carpets, for which Persia is so celebrated, are manufactured from the wool of the sheep, either in Kerman or Koprasan. Although these districts are remotely situated from each other, the wool of the sheep nearly corresponds, and " is remarkable for being spirally-curled, 
and of a grey, or mixed black and white color. The sheep are below the ordinary size, the horns of the ram curved back and spiral at the tip, the ears pendulous, and the tail not very broad. The fine furs are from the lambs slaughtered with their dams a few days before yeaning."*

\section{TIBET SHEEP.}

The sheep of 'Tibet, which are very numerous, are chiefly a small variety of the fat-rumped Persian and Abyssinian, with black heads and necks. Some are hairy, with short wool underneath, while others bear a long, soft, and fine wool. It is from the latter that many of the costly Indian shawls are made. Not a little of this peculiar wool finds its way to British India, and is there manufactured. The mutton of Tibet sheep is said to be peculiarly well flavored.

\section{EAST INDIA SHEEP.}

The sheep which abound in the provinces of British India, consist for the most part of the fat-rumped and fat-tailed varieties, and therefore no farther notice will be requisite.

\section{CHINESE SHEEP.}

In the immense Empire of China, as might naturally be expected, breeds of sheep are found differing essentially from each other. One of the most singular is the Long-legged sheep, distinguished, as their name would imply, for the exträordinary length of the legs. This breed have horns which are of middle size, and curved; the forehead is arched, the neck short, with a collar of hair reaching from the nape of it to the shoulders; the head, legs, and mane are of a redbrown color; the tail is long, and the wool short and coarse.

The fat-rumped and fat-tailed extensively abound in the more southern parts of China; and in certain districts a small breed is found resembling the form of the European breeds, which produces a fine and very useful long wool.

The antiquity of Chinese manufactures is proverbial. An old traveller says, that "when the Dutch presented the Emperor of China with some scarlet and other cloths made in Europe, he asked how, and what they were made of ? Being told, he replied that his súbjects could make them, and therefore, there was no need to bring them so far." 


\title{
AFRICAN BREEDS.
}

\author{
EGYPTIAN-ETHIOPIAN-ABYSSINIAN-MADAGASCAR-CAPE OF \\ GOOD HOPE-ANGOLA-GULNEA-MOROCCO.
}

EGXPTIAN, ETHIOPIAN, AND ABXSSINIAN SHEEP.

According to Dr. Anderson, the fat-tailed sheep prevail in Egypt, and both varieties of them are found; but those with long tails, nearly or quite reaching to the ground, are more numerous than the broad-tailed kind. They are of a large size, mostly with black heads and necks, an external coat of hair, and their flesh well flavored.

In Nether Ethiopia the sheep begin to be more numerous; they are large-some of them with tails from 18 to 25 lbs. in weight-with black heads and necks, and the remainder of their bodies white; others are quite white, with tails reaching nearly to the ground, and curved at the extremity.* Here also appear the fat-rumped sheep, with black heads and necks, but of smaller size than the Persian breed.

Proceeding farther south, says Bruce, they are taller and all black; their heads large, and with ears remarkably short and small. 'They also, like all the native sheep within the tropics, have an external covering of hair. It is in this region (Abyssinia) that the many-horned sheep is found, many bearing four, and some writers have asserted that individuals have been seen with six horns.

\section{MADAGASCAR SHEEP.}

The island of Madagascar is situated on the eastern coast of Africa, and mostly within the tropic of Capricorn.

The sheep have broad tails like those of Africa. Dr. Anderson states the following: "A Danish East Indiaman put into Leith roads on her return home. I went on board to see what curiosities she had, and I there found a sheep, which was closely covered with a close coat of thick, short hair, very smooth and sleek, like the coat of a well-dressed horse, but the hairs rather stiffer, and thicker set on the skin, and the color a fine nut-brown. This sheep, I was 
told, was brought from the island of Madagascar, and that all the sheep found on the island were of the same sort."

CAPE OF GOOD HOPE SHEEP.

The British colony of the Cape of Good Hope occupies the extreme verge of Southern Africa, between the 30th and 35 th degrees of south latitude.

The native sheep are of the broad-tailed breed. 'Barrow * says " they are of every variety of color, black', brown, bay, but mostly spotted; their necks are small, their ears long and pendulous. They are covered with strong frizzled hair, of which little use is made, except for cushions and mattrasses."

When the. Cape was in possession of the Dutch, an experiment was made with the Merinos, which, from the unfavorable climate, prejudice and bad management, resulted in utter failure. After its cession to the English, a more extensive and fairer trial was made with Merinos, which was attended with better success. Much good wool is now sent over to the mother country, which amounted in 1833 to nearly $100,000 \mathrm{lbs}$. The number of sheep, of all kinds, in the colony, exceeds two millions.

ANGOLA SHEEP.

Angola is situated on the south-western coast of Africa. Here is to be found a very singular sheep, which is thus described in the "Animal Kingdom." "It is called the Zenu. Its legs are long and slender, but the arms and shanks are muscular and strong. There is a slight elevation at the withers, the chest is narrow and flat, and falling in between the arms; the false ribs project, and give to the carcass a strong resemblance to that of the $Z e b u$. The fat is most singularly disposed. It is taken from the tail or rump, and is distributed over three parts of the animal. A small portion of it is spread over the posterior part of the loin and the commencement of the haunch. A more decided accumulation is found on the poll, and precisely of the semi-fluid character which the fat assumes in the tail, or the rump of other Eastern sheep. 'This mass commences from the base of the ears, and extends backwards, in the form of a rounded projection, half way down the neck. Under the jaw, ex-

- Barrow's Southern Africa. 
tending downwards and covering the larynx, is a third collection of soft fatty matter." This is certainly a very curious variety of sheep, and is found in no other part of the world.

\section{GUINEA SHEEP.}

There are two kinds of sheep on the slave coast. One is small, their forms resembling, in some particulars, the European sheep. Says a Dutch traveller,- "They have no wool, but the want is supplied with hair, so that here the world seems inverted, for the sheep are hairy and the men are woolly. The hair is like that of the goat, with a sort of mane like a lion on the neck, and so on the rump, and a bunch at the end of the tail."

The most numerous breed in Guinea is of a different character. 'The male is horned, the horns generally forming a semicircle, with the points forward; the females are hornless ; the ears are pendulous, and black spots are distributed on the sides of the head and neck, as well as body." A writer remarks, "The sheep in Guinea have so little resemblance, in general, to those in Europe, that a stranger, unless he heard them bleat, could hardly tell what animals they were, being covered with white and brown hairs like a dog."

\section{MOROCCO SHEEP.}

Morocco is situated in the northern latitudes of Africa. Its sheep are far superior to any other breeds of that region, and the only ones worth cultivating. 'The form and fleece were highly appreciated in the days of Columella, as was proved by his selection of a ram to improve his Spanish ewes, at the time of his residence near Cadiz. Chancellor Livingston, in his "Essay on Sheep," says-"I have in my flock a ewe that is descended from a Barbary ram. Her fleece is long, straight, and fine." She was tupped by one of his Merino rams, and the produce from the cross exhibited a wool equal to seven-eighths Merino!

* Asimal Kingdom. 


\section{CHAPTER III.}

\section{EUROPEAN SHEEP}

ITALIAN-SPANISH, MERINOS, \&C.FRENCH-\$WISS

ITALIAN SHEEP.

WhEN the Roman Empire was at its height of power, the sheep of Italy surpassed all others in the fineness of their fleeces. "The best wool, of all others," says Pliny, "is that of Apulia, which is of a very short staple, and especially in request for cloaks and mantles."

Ancient authors represent the Italian sheep and wool as being cultivated with a degree of care, which, if true, outstrips every thing in modern times. The reason of this is obvious. The sumptuous Roman was clothed at one period in woollen fabrics, and ambitious to appear in none other than the finest, induced the extreme assiduity in perfecting the material for its manufacture. At length the silk and cotton fabrics of the East were introduced, which, on being found better adapted to the climate, caused the excessive care of the sheep to relax $_{2}$ which were soon after cultivated more for the carcass than the fleece. The celebrated breeds of Apulia and Tarentum ultimately disappeared, and were succeeded by a larger, coarser, but, under the altered circumstances, more profitable race.

The remarks of $\mathrm{Mr}$. Youatt concerning the old Tarentine or Tarentum breed, the admitted probable PROGENITORS OF The FaMED MERINo, will be read with interest.

"Although the old Tarentine sheep produced a wool unequalled in early times, they were not without their defects, and very serious ones too. They were called by the agriculturists of those days pellite, from the skins and other clothing with which they were covered; and also molles, not only from the softness of their fleece, but from the delicacy of their constitution, apd the constant care that was re. 
quired to preserve them from anjurious vicissitudes of heat and cold. The care bestowed upon the fleece was a work of great labor. It was frequently uncovered, not only to ascertain its condition, but for the refreshment of the animal; it was drawn out, and parted and combed, if it was beginning to mat; it was frequently moistened with the finest oil, and even with wine; it was well washed three or four times in the year; the sheep-houses were daily, and almost hourly, washed, and cleaned, and fumigated."

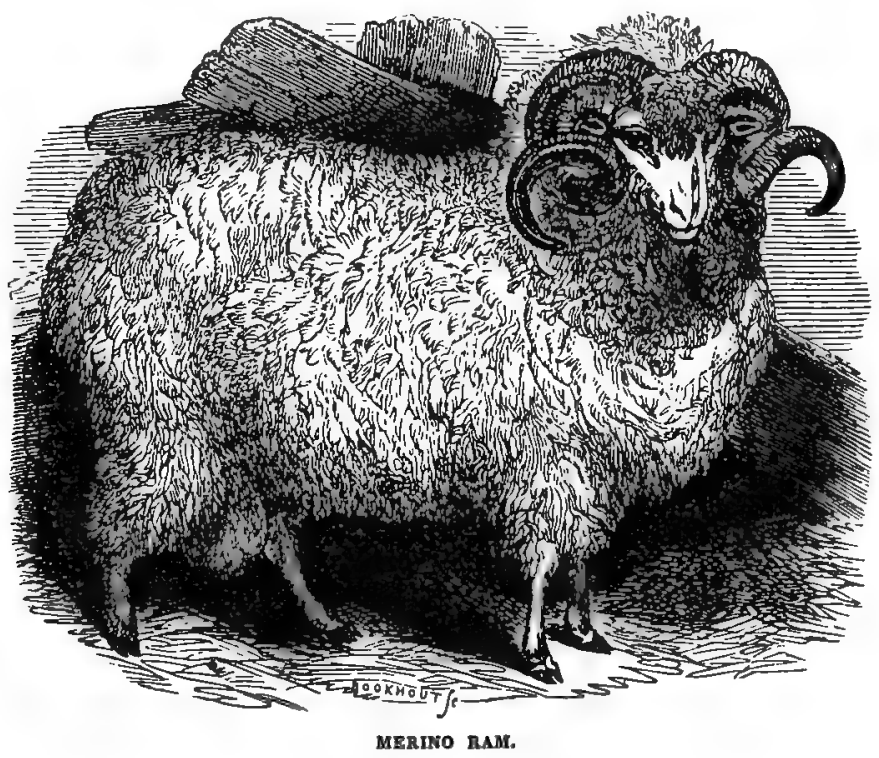

SPANISH SHEEP, MERINO8, ETC.

The history of the Spanish Merino sheep, the spread of which in different countries has effected so complete a revolution in the character of the fleece, cannot but be a matter of much interest to the American wool-grower; therefore the compiler has no apology to render for the extended notice of this renowned breed, which is here presented.

At a very early period, it appears from the accounts of several writers, Spain was possessed of several breeds, the 
fleeces of which varied in color and quality. One of these was black, and noted for its fire texture; but the "red. fleece," as it was called, of Bøtica, Granada, and Andalusia, was superior in fineness to all others. The breed which bore the latter, it is now generally believed, were originally from Italy, and of the Tarentine variety, already described. They were crossed with the more inferior kinds, while others of the race were kept distinct; and from the congeniality of the climate and herbage, retained their original superiority of fleece.*

In the reign of the Emperor Claudius (A. D. 41), Columella, a distinguished lover of agriculture, introduced many of the Tarentine breed into Spain, of which he was then a resident; and also improved the inferior breeds, by conveying into the colony some African rams of singular beauty, which had been exhibited at Rome, and which will account for the probable origin of the Chunah brèed, to be presently noticed.

Although the Tarentine sheep undoubtedly laid the foundation of the excellence of the Merino race, yet the breed betray an amalgamation to have taken place to some extent -with the black sheep, referred to, as individuals occasionally, at the present day, have a dun-colored ear, and also spots of that hue on one or more of the legs.

In the eighth century the Saracens or Moors conquered a portion of Spain, and which, in the language of a writer, "they found fruitful in corn and pleasant fruit, and glutted with herds and flocks." This warlike and enterprising race were distinguished for their luxurious customs, and a fine and expensive wardrobe was regarded an object of essential importance. Hence, in the 13th century, Spain became renowned for her woollen manufactures, then scarcely known in the rest of Europe, and Seville alone contained no less than 16,000 looms. The manufacture therefore of the finest fabrics was the source of much national wealth, as large quantities were exported to every part of Europe, as well as Africa.

But after the expulsion of the Moors, manufactures became almost extinct. Nearly a million of these enterprising

* The evidence of the foreign origin of the Merino is implied in the name, of which "the Spanish orthography is Mareno; which signifies from or beyond sea." -William Jarvis. 
ertisans were driven from the kingdom during the reigns of Ferdinand V. and Philip III.; and the consequence was that "the 16,000 looms of Seville dwindled down to 60 , and the woollen manufacture almost ceased to have existence throughout Spain."

The Spanish government saw too late its fatal error, as the many fruitless attempts to restore the manufacture of the beautiful fabrics of the Moors have fully proved. But during all this while, however, the Merino, notwithstanding its neglect, continued to produce its invaluable fleece, which, instead of meeting with adequate skill at home for its manufacture, was sent abroad to be worked by other more ingenious and industrious nations. "The perpetuation of the Merino sheep in all its purity, amidst the convulsions which changed the whole political existence of Spain, and destroyed every other national improvement, is a fact which the philosopher may not be able fully to explain; but which he will contemplate with deep interest. In the mind of the agriculturist, it will beautifully illustrate the primary determining power of blood or breeding, and also the agency of soil and climate, a little too much underrated, perhaps, in modern times."

Independent of the Merinos, there is another race, in Spain, called Chunahs, which are larger and heavier than the Merinos, and carry a fleece the staple of which is from five to eight inches long, and coarse. This breed extends throughout all Spain, and is the favorite of the peasant and small proprietor. The Chunahs are supposed to have been much improved by the English Cotswold breed, of which there exists a record of the 15 th century of a number having been exported to Spain with a view to lengthen the staple of the coarser and more inferior breeds of that country. The sheep under consideration are stationary, or never move from their homes for pasture; and hence compose, in part, one of the grand divisions of Spanish sheep denominated Estantes or stationary.

The Merinos are of two classes, one of which, like the Chunahs, are of the Estantes or stationary character, which, as the name implies, are never moved beyond the districts in which they are owned, for pasture; the other class or

* Wansey. 
division is termed transhumantes," or migratory, which are annually driven to the north of the kingdom for pasturage during the summer months.

The latter are composed of the Leonese, and the Sorians. The former pass the winter on the north bank of the Gaudiana, in Estremadura, and begin their march about the 15th of April, in divisions of from two to three thousands. They pass the Tagus at Almares, and direct their course towards Trecasas, Alfaro, and L'Epinar, where, they are shorn. 'This operation having been performed, they recommence their travel towards the kingdom of Leon. Some halt on the Sierra (ridge of mountains) which separates Old from New Castile, but others pursue their route to the pastures of Cevera, near Aquilar del Campo. Here they graze until the latter part of September, or early in the following month, when they commence their return to Estremadura.

The Sorian sheep having passed the winter on the confines of Estremadura, Andalusia, and New Castile, begin their route about the same time. They pass the Tagus at Talavera, and approach Madrid ; thence they proceed to Soria, where a portion of them are distributed over the neighboring mountains, while the others cross the Ebro in order to proceed to Navarre and the Pyrenees.

These periodical journeys are made necessary by the severity of the drouth in Spanish Estremadura, from the close of April till near the ]st of October, which parches the plains to such a degree as to destroy almost entirely the growth of the pasture. The rains commence falling about the autumnal equinox, and continue, with intermissions of a few days only, until the latter part of March. In a few weeks from their beginning the plains assume a beautiful verdure, and so continue till the approach of the dry season; and during this time the thermometer rarely falls below 40 deg. $\dagger$ The rains are of frequent occurrence in the summer season on the sierras or mountains; and thus these numerous migratory flocks are supported the entire year on grass, which the Spaniard at one time supposed was the cause of some of the valuable properties of the Merino fleece. The fallacy, however, of this has been fully proved.

* From trans and humus, expresaive of their change of climate and pasture.

+ William Jarvis. 
"The greater part of these travelling sheep, says Chancellor Livingston, in process of time got into the hands of the king, or into those of the principal courtiers and clergy; and from thence we must probably date the oppressive code by which their march is regulated, and the origin of the great Council of the Royal Troop (Consejo de la Mesta) by whom those laws are administered." This tyrannical tribunal was established as early as the 14th century. It established a right to graze on all open and common land that lay in the way; it claimed also a path ninety yards wide through all the enclosed and cultivated country; and it prohibited all persons, even foot passengers, from travelling on these roads while the sheep were in motion!

The following interesting narrative of incidents connected with the annual peregrinations of these sheep is from $\mathrm{Mr}$. Youatt's work, by whom it was compiled chiefly from the writings of $\mathrm{M}$. Lasteyrie.

"They are divided into flocks, each of which is placed under the care of a mayoral, or chief shepherd, who has a sufficient number of others under his command, with their dogs. He uniformly precedes the flock, and directs the length and speed of the journey; the others with the dogs follow, and flank the cavalcade, collect the stragglers, and keep off the wolves, who regularly follow at a distance and migrate with the flock. A few asses or mules accompany the procession, in order to carry the little clothing and other necessaries of the shepherds, and the materials for the fold at night. Several of the sheep, principally wethers, are perfectly tamed, and taught to obey the signals of the shepherds. These follow the leading shepherd, having been accustomed to be fed from his hand; they lead the flockthere is no driving-and the rest quietly follow.

"When passing through the enclosures, they sometimes travel eighteen or twenty miles a day ; but when they reach an open country, with good pasture, they proceed more leisurely. Their whole journey is usually more than four hundred miles, which they usually accomplish in six weeks, and thus spend, in going and returning, nearly one quarter of the year in this injurious manner.

"I: may be-readily supposed that much damages is done, carelessly, or unintentionally, or wilfully, to the country over $\mathbf{x h i c h}$ these immense flocks are passing; and particularly. as the migrations take place at the times of the year when 
the property of the agriculturist is most liable to injury. In addition to this, the servants of the Mesta, like the servants of Government elsewhere, have little common feeling with the inhabitants of the country which they are traversing; they commit much serious and wanton injury, and they refuse all redress.

"The shepherds and the sheep equally know when the procession has arrived at the point of its destination. It is necessary to exert great vigilance over the flock during the last three or four days, for the animals are eager to start away, and often great numbers of them make their escape. If they are not destroyed by the wolves, there is no great danger of losing them; for they are found on their old pasture, quietly waiting the arrival-of their companions, and it would be difficult to make any of them proceed a great way beyond this spot. The shepherds are immediately employed in constructing pens for the protection of the sheep during the night, and which are composed of ropes made by twisting certain rushes together, which grow plentifully there, and attaching them to stakes driven into the ground. They next build, with the branches of trees roughly hewn, rude huts for themselves.

"When the sheep arrive at their summer pasture, which at first is very luxuriant, the mayoral endeavors to guard against the possible ill effects of the change from the uncertain and scanty pasturage found on the journey, by giving the flocks a considerable quantity of salt. He places a great many flat stones five or six feet from each other, and strews salt upon them, which is eagerly devoured. This is repeated on several successive days; and a case of general inflammation, or hoove, seldom occurs.

"During the summer pasturage the labor is light of the shepherd. The ewes are put to the rams early in August. After their return at the close of autumn, and when yeaning time approaches, the barren ewes are separated from the others and placed on the poorest pasture. The Merinos are not $^{\prime}$ good nurses, and nearly half of the lambs-or in bad seasons, and when the pasture fails, full three-fourths-are destroyed as soon as they are yeaned. The males are always sacrificed first; the others are usually suckled by two ewes-for it is a common opinion in Spain that the mother that fully suckles her lamb would yield less wool; they are afterwards placed on the best pasture, in order that they 
may acquire sufficient strength for their approaching journey. The skins of the slaughtered lambs are sent into Portugal, and thence find their way to England, where they are used for the manufacture of gloves. The wool is soft and silky, and is formed into little rings or curls.

"Few of the male lambs are castrated, because it is believed that the weight of the fleece is much increased on the ram, without acquiring proportional coarseness. 'The shepherd, however, early in March, has four operations to perform on the lambs: he cuts off their tails five inches below the rump, for the sake of cleanliness: he marks them on the nose with a hot iron: he cuts off the tips of their horns that they may not hurt each other in their frolicks, and he castrates those which, from their superior strength, and superior size, he has selected to become bell-wethers, and lead the flock in their peregrinations.

"It is supposed that forty or fifty thousand men are employed in these peregrinations of the sheep. They are a singular race of men, enthusiastically attached to their profession, rarely quitting it, even for a more lucrative one, and rarely marrying. 'The number 'of dogs kept for the purpose of guarding the sheep exceeds thirty thousand.

"The shearing does not delay the flock more than a day. Buildings are erected at various places in the early portion of their journey ; they are very simply constructed, and consist only of two large rooms, each of which will contain more than a thousand sheep: there is also a narrow, low, long hut adjoining, termed the sweating house. The sheep are all driven into one of these apartments, and in the evening those intended to be shorn on the following day are transferred into the low, long hut. As many are forced into it as it will possibly hold, and there they are left during the night. As some are liberated in the morning, the others are urged towards the end of the hut, while more from the apartment occupy their situation. In consequence of this close confinement they are thrown into a state of great perspiration; the yolk, which formed a somewhat hard crust on *he fleece, is melted, and thus the whole is rendered softer, and is more easily cut. There is no previous washing, nor any other preparation for the shearing. From 150 to 200 shearers are generally collected, and a flock of a thousand sheep is disposed of in a day, although five rams or eight ewes are reckoned a good day's work for a Spanish shearer! 
The sheep are turned back as they are shorn into the second apartment, and on the following day continue their journey: thus in the space of six days, as many flocks, each consisting of a thousand sheep, pass through the esquilo (shearing hut), and leave their fleeces behind them. The wool is then cleansed with water and soap and sorted in the esquilo, and is ready for sale."

A writer in the Encyclopedia Londonensis states the following: "The management of the Spanish flocks is peculiarly Roman, and shows the Italian origin of these sheep. The Merino mayoral corresponds exactly with the magister pecoris of Varro and Columella. . The practice of destroy ing half the sheep at their birth, and of suckling each of the survivors on two ewes; of sweating the sheep before they were shorn, in order to increase the softness of the fleece, and of conducting them from their high winter to their summer stations, by long journeys through public sheep walks, have been derived from Roman institutions."

Mr. Youatt condensed Arthur Young's account of the Catalonian or Pyrenean breed, as here presented :-

"The journeys of these sheep are smaller, and performed in a different manner. On the northern side of the Spanish portion of the Pyrenees are two mountains, the sides of which. are covered with short, but plentiful herbage, and from one to the other of which the sheep are continually travelling during the summer. In the winter they are sent into the lower part of Catalonia, a journey of twelve or thirteen days, and when the snow begins to melt in the spring they are conducted back again to the mountains; thus they are kept the whole year in motion: they are never housed or under cover, and never taste of any food but what they find for themselves.

"Mr. Young had the opportunity of examining a flock of these Catalonian sheep, consisting of about 2000. They were generally polled, but a few, both of the rams and ewes, had horns. The legs were white or reddish-the faces some white, some red, and some speckled, and-some with a tuft of wool on their faces : the carcase was round, the back straight : they were in good condition : would weigh, when fat, from 15 to 18 pounds per quarter, and resembled, on the whole, the South Down breeds.

"Mr. Young wished to examine them more closely, and intim ed this to the shepherd, who immediately walked into 
the flock, and singled out a ram, and bid it to follow him. holding out his hand as if to give him something. The animal immediately came with the shepherd, and submitted itself to Mr. Young's inspection. He found that mellowness of the skin which is the surest proof of a good fleece, and of a good breed. The wool was beautifully soft and fine, and weighed, as he imagined, about eight pounds: the average weight of the fleece before washing was usually about four or five pounds. Four shepherds, provided with fire-arms, and four or five large Spanish dogs, had the care of the flock. The sheep were collected together every night on a particular spot,- - the shepherd slept in a little hut close.by, and the dogs gave certain notice of the approach of danger. During the day the head shepherd sat on the mountain top, or on an elevated spot, whence he could see everything around him, while the flock browsed on the declivities,"

The Estantes or stationary Merinos amounted at one time to two millions, and the transhumantes to ten millions; but it is difficult to estimate correctly the number of each at the present time. The Chunah breed, Chancellor Livingston states in his essay, numbered about six millions.

The Leouesa, which compose a very large proportion of the travelling sheep, are superior in fleece to all others in the kingdom, and which will always sell for considerably more per pound than that of any other Spanish sheep. But on the other hand, says Mr. Youatt, on the authority of Burgoyne, "there are stationary flocks both in Leon and Estremadura, which produce wool as good as that of the transhumantes." It will appear, therefore, that these migrations are not the exclusive cause of the superior fleeces of the transhumantes, as the Spaniards are wont to suppose.

For reasons not necessary for the compiler to assign, he quotes from $\mathrm{Mr}$. Youatt the following accurate description of the prominent characteristics of the true Spanish Merinos, in which, it will be seen, he justly extols their excellencies, and notes impartially their defects, which, however, are trifling compared with the returns which their invaluable fleeces afford.

"The first impression made by the Merino sheep on one unacquainted with its value would be unfavorable. The wool lying closer and thicker over the body than in most other breeds of sheep, and being abundant in yolk, is corered 
with a dirty. crust, often full of crocks. The legs are rather long, yet sinall in the bone; the breast and the back are narrow, and the sides somewhat flat; the shoulders and bosoms are heavy, and too much of their weight is carried on the coarser parts. The horns of the male are comparatively large, curved, and with more or less of the spiral form: the head is large, but the forehead rather bw. A few of the females are horned, but generally speaking they are without horns. Both male and female have a peculiar coarse and unsightly growth of hair on the forehead and cheeks, which the careful sheep-master cuts away before the shearing time: the other part of the face has a pleasing and characteristic velvet appearance. Under the throat there is a singular looseness of skin, which gives them a remarkable appearance of throatiness, or hollowness in the neck.* The pile, when pressed upon, is hard and unyielding; it is so from the thickness with which it grows on the pelt, and the abundance of yolk, detaining all the dirt and gravel which falls upon it; but- when examined, the fibre exceeds in fineness, and in the number of serrations and curves, that which any other sheep in the world produces. The average weight of the fleece (unwashed) in Spain is eight pounds from the ram, and five from the ewe. The staple differs in length in different provinces. When fatted, these sheep will weigh from 12 to 16 pounds per quarter.

"The excellency of the Merinos consists in the unexampled fineness and felting property of their wool, and in the weight of it yielded by each individual sheep: the closeness of that wool, and the luxuriance of the yolk, which enables them to support extremes of cold and wet as well as any other breed; the easiness with which they adapt themselves to every change of climate, and yet thrive and retain, with common care, their fineness of wool: an appetite which renders them apparently satisfied with the coarsest food; a quietness and patience into whatever pasture they are turned, and a gentleness and tractableness not excelled by any other breed.

* Lord Somerville has some observations on this point :- "The second property to be noted in this sheep is a tendency to throatiness, a pendulous skin under the throat, which is generally deemed a bad property in this country, and the very reverse in Spain, where it is much esteemed, because it is supposed to denote a tendency both to wool and a heavy fleece." - Somerville on Sheep. 
"Their defects, partly attributable to the breed, but more to the improper mode of treatment to which they are occasionally subjected, are, their unthrifty and unprofitable form; a voraciousness of appetite* which yields no adequate return of condition; a tendency to abortion and to barrenness; a difficulty in yeaning; a paucity of milk, and a too frequent neglec o? their young. $\dagger$ They are likewise said, notwithstanding the fineness of their wool and the beautiful red color of the skin when the fleece is parted, to be more subject to cutaneous affections than most other breeds. Man, however, has more to do with this than Nature."

\section{HISTORY OF THE INTRODUCTION OF MERINOS INTO THE UNITED STATES.}

The first individual of the breed introduced into this country, was by Mr. Delessert, a French banker. He purchased two pairs, in 1801, selected from the celebrated Rambouillet flock, near Paris, which were shipped early of the same year to the United States, but three of them perished on the passage, and the survivor, a ram, was placed on his farm near Kingston, New York.

It had become a matter of history, that the next importation of Merinos was by Gen. David Humphreys, of Connecticut; but very recently a competitor for that honor has appeared. It is now of little moment, further than as a chronological fact, although the individual in question, Mr. Seth Adams, of Zanesville, Ohio, is worthy of praise as one of the 'pioneers to improve the fleece of his native country. $\mathrm{Mr}$ Adams' statement $\ddagger$ was addressed to the editor of the Alba-

* This is unmerited, because it is not true. A fat sheep is the glory of an Englishman, and in forming an estimate of the Merino, he is apt to lose sight of a great physiological point, namely, no sheep can be the bearer both of a superior fine fleece and much fat, because the assimilation of food cannot act for both objects in an equal degree. We must be content with one great excellence, and not expect more from one animal. - Compiler.

+ Not so, after arriving at maturity, and properly provided for.-Compiler.

$\ddagger$ "I imported in the brig Reward, Capt. Hooper, which left Diepe in August, 1801, and arrived in Boston in October following, a Merino ram and ewe. These, I believe, were the first pair of Merinos imported to the United Spates. The Agricultural Society of Massachusetts having offered a premium of $\$ 50$ for the importation of a pair of sheep of superior breed, General D. Humphreys imported a flock of Merinos, and sent some of them to Massachusetts, and he, or some one for him, applied to 
ny Cultivator (which is appended to the present page), in which the priority of his importation to Gen. Humphreys' is clearly shown, and a reference to the archives of the Massachusetts Agricultural Society will confirm it.

For particulars relative to further importations of the Merinos, the compiler is indebted to the Hon. WILlmam JARvIs, of Vermont, whose name, with that of DAvid Humphreys, will ever be associated, in the minds of Americans, with the Merino, and cherished with gratitude as the great founders of wool improvement in the United States. The account was originally addressed to L. D. Gregory, of Vermont, and which is invaluable from its authenticity, and graphic details; and the compiler thus publicly expresses his grateful obligations to $\mathrm{Mr}$. Jarvis for his kind permission to insert it in the present work, and its readers will doubtless feel likewise.

After many interesting details concerning the management of Merino sheep in Spain, Mr. Jarvis proceeds thus :

"I shall now call your attention to the first introduction of them into the United States. Soon after the accession of Mr. Jefferson to the Presidency, Chancellor Livingston was appointed Minister to France, and in 1802, he obtained from hat government three or four Merinos of the Rambouillet flock, which he sent to New York and put on one of his sarms. This flock was obtained by the King of France rom the King of Spain, and were undoubtedly pure-blooded sheep. A little before Gen. Humphreys left Spain, ${ }^{*}$ he was enabled to get two hundred sheep from Spain into Portugal, and they were sent to Figueira, at the mouth of the Mondego, and thence shipped to the United States. From what flock he obtained them, I never could learn, though I inquired a number of times; but as Spanish Estremadura and Leon border on Portugal, from $38 \mathrm{deg}$. of latitude to the northern boundary of Portugal, and as no other than the

the society for the premium. Knowing from report, that his sheep did not arrive before the spring season after mine, I applied at the same time for the premium, and after having examined the sheep and wool, and comparing with those of General $\mathbf{H}$., the society awarded to me the premium, and awarded to General $H$. a gold medal for having imported a larger number. My sheep were from the flock imported by Bonaparte, and distributed through France to improve the flocke of that kingdom."

* For further particulars concerning General Humphreys' importation, 000 Mr. Jarvis' letter in Appendix. 
Leonesa Transhumantes are found in that part of Spain, there can be but little doubt that they belonged to that race.

"I attempted in 1806, also in 1807, to obtain some from the most celebrated flocks, but the laws were so strict against their exportation without royal license, that I failed of success. After the French invasion in 1808 , the law became more relaxed, and in 1809 , by special favor, I obtained two hundred Escurials. At the second invasion of the French under Joseph Bonaparte, the rapidity of the march of the French troops hurried the Supreme Junta from Madrid, and they retired to Badajos. Being without money, and being afraid of disgusting the Estremadurans, by levying a tax upon them, they were compelled to sell four of the first flocks in Spain, which had been confiscated in consequence of the proprietors joining the French. These were the Paular, previously owned by the Prince of Peace; the Negretti, previously owned by the Conde Del Campo de Alange; the Aqueirres, which had been owned by the Conde of the same name, and the Montarco, owned by the Conde de Montarco, and were such sheep as could not have been got out of Spain, had it not been for the invasion of the French and the distracted state of the country growing out of that invasion. When the Junta sold, it was upon the express condition of their granting licenses to carry them out of the kingdom. Four thousand of the Paular flock were sent to England for the king; and Col. Downie, a Scotch officer in the British service, but who then held the rank of General in the Spanish service, and I, purchased the remainder of the flock, between three and four thousand more; and of this purchase, I took fourteen hundred, and he sent the rest to Scotland with the exception of two or three hundred, which he sold to come to this country. Sir Charles Stewart purchased the Negretti flock and sent them to England, with the exception of about a hundred I got out of his flock after they reached Lisbon.

"I purchased about seventeen hundred of the Aqueirres flock of the Junta, and the remainder was sold and sent to England. The Montarco flock was bought by a Spaniard and a Portuguese, and about two thousand seven hundred were shipped to this country. I shipped to the United States the fourteen hundred Paulars, one thousand seven hundred Aqueirres, two hundred Escurial, one hundred Negrettis, and about two hundred Montarcos. Of this number, about one 
hundred were sent to Wiscasset and Portland, one thousand one hundred to Boston and Newburyport, one thousand five hundred to New York, three hundred and fifty to Philadelphia, two hundred and fifty to Baltimore, one hundred to Alexandria, and two hundred to Norfolk and Richmond. Besides those which I shipped to the United States on my own account there were about three hundred Gaudaloupes purchased by others, and two to three hundred of the Paular flock sold by Gen. Downie, shipped to Boston; and of the Montarco flock, shipped by others, about two thousand five hundred were sent to Boston, Providence, New York, Philadelphia, Baltimore, and Savannah. The Gaudaloupes, Paulars, and Montarcos, which were shipped to Boston by others, were for the account of Gorham Parsons, Esq., Gen. Sumner, D. Tichenor, and E. H. Derby, Esq. All these sheep were shipped in the latter part of 1809 , during 1810 , and the early part of 1811 , and were the only Leonesa Transhumantes, if we include Gen. Humphreys' and Chancellor Livingston's, (which I have no doubt were of the same stock) that were ever shipped to the United States. Badajos is but little over one hundred miles from Lisbon, and all the sheep purchased there and in that vicinity, were shipped from Lisbon. I was then Consul there, and from my office was actually acquainted with all the shipments, as certificates of property from me always accompanied them.

"I shall now, in compliance with your wishes, give you a description of the sheep of the different flocks sent to this country. The Paulars were undoubtedly one of the handsomest flocks in Spain. They were of middling height, round-bodied, well spread, straight on the back, the neck of the bucks rising in a moderate curve from the withers to the setting on of the head, their head handsome, with aquiline curve of the nose, with short, fine, glossy hair orr the face, and generally hair on the legs, the skin pretty smooth, that is, not rolling up or doubling about the neck and body, as in some other flocks, the crimp in the wool was not so short as in many other flocks, the wool was somewhat longer, but it was close and compact, and was soft and silky to the touch, and the surface was not so much covered with gum. This flock was originally owned by the Carthusian friars of Paular, who were the best agriculturists in Spain, and was sold by that order to the Prince of Peace when he came into power. The Negretti flock were the tallest Merinos in 
Spain, but were not handsomely formed, being rather flatsided, roach back, and the neck inclining to sink down from the withers; the wool was somewhat shorter that the Paular and more crimped, the skin was more loose and inclined to double, and many of them were wooled on their faces and legs down to their hoofs. All the loose-skinned sheep had large dewlaps. The Aqueirres were short-legged, round, broad-bodied, with loose skins, and were more wooled about their faces and legs than any other flock I ever saw, the wool was more crimped than the Paular, and less than the Negretti, but was thick and soft. This flock formerly belonged to the Moors of Spain, and at their expulsion, was bought by the family of Aqueirres. The wool in England was known as the Muros flock, and was highly esteemed. All the bucks of these three flocks had large horns. The Escurials were about as tall as the Paulars, but not quite so round and broad, being in general rather more slight in their make; their wool was crimped, but not quite so thick as the Paular or Negretti, nor were their skins so loose as the Negretti and Aqueirres, nor had they so much wool on the face and legs. The Montarco bore a considerable resemblance to the Escurials. The Escurial flock had formerly belonged to the crown, but when Philip the II. built the Escurial palace, he gave them to the friars, whom he placed in a convent that was attached to the palace, as a source of revenue. These four flocks were moderately gummed. The Gaudaloupe flock was rather larger in the bone than the two preceding, about the same height, but not quite so handsomely formed, their wool was thick and crimped, their skins loose and doubling, their faces and legs not materially different from the two latter flocks, but in general they were more gummed than either of the other flocks. In point of fineness there was very little difference between these six flocks, and as I have been told by well-informed persons, there is very little difference in this respect among the Leonesa Transhumantes in general. 'The Escurials, the Montarcos, and the Gaudaloupes were not in general so heavy horned as the other three flocks, and about one in six of the bucks were without horns, or what is commonly called a polled buck.

"I had selected by the Paular shepherds, who came with that flock, three hundred sheep which I shipped to Newburyport. The half of these were Paulars, a fourth Aqueirres 
an eighth Escurials, and the other eighth Montarcos and Negrettis. These I put on the farm in Weathersfield, Vt., that I bought after my return to the United States, and also drove up about a hundred, the remainder of those I had shipped to Boston. In compliance with the invariable practice in Spain, -I bred the respective flocks separately, or what in farmer's ranguage is called in and in; the custom in Spain having existed from time immemorial, of breeding the bucks and ewes of the same cabanna or flock together, or in and in; but in about 1816 or 1817 , I mixed the different flocks together, and have so bred my Merinos ever since."

An importation of Rambouillet Merinos was made by an enterprising citizen of Connecticut several years since, which is properly noticed under the head of French Sheep.

The average weight of the Spanish Merino fleece has already been given; that of the American Merino may be safely, under good management, stated at $3 \frac{1}{2} \mathrm{lbs}$.; small flocks, however, which are apt to receive better attentions than large, will yield about 4 lbs. ; but recently, instances have been recorded, where the flocks have been unusually well selected, and fed, an average of $4 \frac{1}{2}$ to $5 \mathrm{lbs}$. has been obtained. High feeding has much to do in increasing the weight of the fleece, as will appear hereafter.

An enterprising feeling is abroad over large portions of our country for wool improvement, and public attention has latterly been directed to the Merinos to forward this important branch of agriculture. This is right. There exists no hardier breed than the Merinos; and for the small flock proprietor, whose locality is cold and exposed, they are especially well adapted. 'To the Merinos we must look for the greatest general improvement of the fleece throughout our widely-extended country.

\section{FRENCH SHEEP.}

With the exception of the celebrated Rambouille Merino flock, near Paris, there is little to interest the American wool-grower relative to the sheep and sheep husbandry of France.

The breeds are varied as the face of the country, and none, except towards the more southern parts of the kingdom, that yield a fleece possessing much intrinsic excellence either for the purposes of combing or cloth. This appears some. what singular, considering the aptitude of the French nation 
for the art of manufacture, the general excellence of the agriculture of the country, the adaptation of the climate for perfecting the several properties of wool, and the superabundance and variety of the herbage. The conclusion is natural, from the proximity to Spain, that France would have availed herself of the superiority of the Merino wool, and long since have become second to no country in the extent of its culture. The prize, however, which she conld so easily have possessed, through culpable neglect, has passed to Germany and Austria, and now to these countries is she indebted, like England, for the finest wool employed in her manufactures. Justice, however, requires the statement, that, before her bloody and exterminating Revolution, measures were in progress to ameliorate the character of the native sheep, by the introduction of the Merino as rapidly 2s the government of Spain would sanction their exportation; but that terrible event overthrew this contemplated good to the agriculture of the nation. The first, and only marked successful effort, was the flock of Merinos, known since as the Rambouillet's, which will presently be referred to.

As has already been remarked, the most valuable wooled sheep are found in the southern parts of the kingdom; and none probably surpass, form and fleece combined, those of Arles, which embraces the Districts of Crau, Camarque, and Le Plain du Bourg. About 250,000 are kept in these districts. All these sheep are migratory, being driven from the plains of Arles in the pring of the year towards the Alps which divide Provence and Dauphine from Italy, and are driven back in November. These migrations have continued from time immemorial; and laws have been enacted limiting the road for their passage to 36 feet in breadth. The flocks vary in number from 10 to 40,000 ; and to every 1000 sheep three shepherds are allowed, each of whom has his dog. The sheep are led by goats which are trained for the purpose, and have bells around their necks. The discipline in which these animals are kept, and the intelligence which they display, is very great. They halt or proceed at the direction of the shepherd; they come to the centre at the close of each day's march, and there wait in the morning for the proper order, when they repair to their station at the head of the troop with the greatest regularity. If they come to a stream they halt, until the word of command is given. and then they plunge immediately into the water, and are 
followed by the rest of the flock. The journey usually lasts from twenty to thirty days. "When they arrive at the mountains each shepherd has his appointed boundary marked out; and the proprietors of the land are usually paid about twenty sous per sheep for their pasture during the summer. The shepherds.sleep with their flock in the open air, and live almost entirely on bread and goats' milk.*

The question of the influence of these peregrinations on the fleece has been already considered under the head of Spanish Sheep.

M. Daubenton having experimented a sufficient length of time to test the effect of change of climate and habits of the Merino, which resulted in their retaining every valuable quality for which they are so celebrated, the French government resolved in 1786 to make a trial, under its immediate patronage, on a larger scale than any previously made. "Accordingly 376 ewes and lambs were purchased in Spain, and sent to Rambouillet, in the neighborhood of Paris, where was an agricultural establishment expressly devoted to the improvement of the domesticated animals. Sixty of them died on their passage.

"The Rambouillet flock gradually increased, and a few were given to those agriculturists who appeared, to be disposed to bestow sufficient care on their cultivation. This was an illadvised measure. 'That which could be had as a gift was deemed to possess little value ; and the new breed had not justice done to it. It was then determined that an annual sale of a portion of the flock should take place. The first sale was made -in 1796, ten years after their establishment at Rambouillet. The average weight of the fleece in the yolk was then $6 \mathrm{lbs} .9 \mathrm{oz}$; the average price of the fleece 5 francs!-the average price of the sheep, 107 francs for a ram, and 71 francs for a ewe, and the highest price at which a single sheep sold was 200 francs. Five years afterwards the flock had so much improved in public estimation, and in real value, that the average weight of the fleece was $9 \mathrm{lbs}$.- its price 28 francs; the average price of the ram 412 francs, that of the ewes 236 francs, and the highest price of any of the sheep 630 francs. $†$

"The most rigorous examination was instituted; and the

* Anuales de l'Agric. France.

+ A franc is about one fifth of a dollar. 
superfine wools obtained in France from the pure breed, were worked into cloths in every respect as good as those from the refina or prima wool of the best breeds in Spain. The wool produced from the mixed breed, after the fourth or fifth cross, when made into cloth, was equal to that manufactured from superfine wool.

"In order to perfect the undertaking, a publication on the treatment of sheep was drawn up by $M$. Gilbert, under the patronage of government; a practical school for shepherds was instituted at Rambouillet, and two other depôts for Merino sheep were established, one at Pompadour, and another at Perpignan, at the foot of the Pyrenees.

"These statements would seem to be highly encouray" ing; but so systematically had the sheep been neglected in France, and so inveterate were the prejudices of agriculturists generally, that when an account was taken of the number of sheep in France, in 1811, 25 years after the establishment of the flock at Rambouillet, there were thirty millions of the native breeds, and only two hundred thousand pure Merinos.

"At the sale of Merinos at Rambouillet in 1834, the average price of the ram was 328 francs, and the greatest sum given for the best 510 francs. The average price of the ewe had sunk to 108 francs, and the highest price of the best was only 210 francs."*

Mr. Trimmer, an English writer, has stated the following concerning the Rambouillet flock, which he visited in 1827:

"The sheep in size are certainly the largest pure Merinos I have ever seen. The wool is of various qualities, many sheep carrying very fine fleeces, others middling, and some rather indifferent; but the whole is much improved from the quality of the original Spanish Merinos. ***** Individuals are found in this flock with dewlaps down to the knees, and folds of skin on the neck, like frills, covering nearly the head. Several of these animals seem to possess pelts of such looseness and size, that one skin would nearly hold the carcases of two such sheep. The rams' fleeces were stated at 14, and the ewes' $10 \mathrm{lbs}$. in the grease. By thorough cleansing they would be reduced half, thus giving 7 and 5 lbs. each."

From the fact that an importation from this celebrated 
flock into the United States has recently taken place, and others not unlikely to follow, it is proper that the public should be fully enlightened as to the degree of its merit.

The following is a portion of a report concerning them, drawn up by M. Gilbert, of the French National Institute, and will be found inserted in Chancellor Livingston's "Essay on Sheep." The eminent moral character of $\mathrm{Mr}$. Livingston forbids the suspicion that the account is exaggerated, as he had the opportunity personally to attest its truth.

M. Gilbert says-"The stock from which the flock of Rambouillet was derived, was composed of individuals beautiful beyond any that had ever before been brought from Spain : but having been chosen from a great number of flocks, in different parts of the kingdom, they were distinguished by very striking local differences, which formed a medley dis agreeable to the eye, but immaterial as it affected their quality; these characteristic differences have been melted into each other, by their successive alliances, and from them have resulted a race which perhaps resembles none of those which compose the primitive stock, but which certainly does not yield in any circumstance to the most beautiful in point of size, form, and strength; or in the fineness, length, softness, strength, and abundance of the fleece. The manufacturers and dealers in wool, who came in numbers to Rambouillet this year (1796) to purchase, unanimously agreed to this fact, at the very time that they were combining to keep down the price. All the wool of Spain that I have examined, not excepting the prime Leonese, the most esteemed of any, appeared to me to contain much more of jar (hair) than that of Rambouillet."

An importation transpired, in 1840, of twenty ewes and two rams, selected from this celebrated flock, by Mr. D. C. Collins of Hartford, Conn., who is still their proprietor. The motives which prompted this laudable enterprise, together with a minute description of these valuable sheep, appear in the American Agriculturist, of July, 1843. The following account was prepared by its editor, who had expended much time in examining them :-

"While Mr. Collins was travelling in Europe in the year 1839 , having his eye occasionally upon its agriculture and improved stocks, among other things, this gentleman wa struck with the marked superiority of the Spanish Merinos composing the celebrated royal flocks kept at. Rambouille 
in France, about 40 miles from Paris. He accordingly de termined to procure a small breeding flock, with a view of raising bucks to restore the fine-wooled sheep of our country to their original character for strength of constitution and weight of fleece, together with excellence of quality.

"The result of our observations, and the information we obtained, with respect to these Spanish Merinos from the Royal flocks of Rambouillet, and the produce bred from them in this country, is :-

"1. They possess as good constitutions, and are as thrifty and as hardy as any native or imported sheep whatever.

" 2 . They attain a great age, having been known to reach 20 years, and may be depended on as good breeders till 12 or 14 years old.

" 3 . They have large, loose skins, full of folds, especially around the neck and below it, on the shoulders, and not unfrequently over the whole body; the wool thickly covering its surface, the forehead, cheeks, and the legs, clear down to the hoofs, giving the fleece, when shorn and spread out in its ample dimensions, the appearance of having been taken from the carcase of a huge buffalo, rather than so small an animal as the domestic sheep.

"4. The fibre of the wool is very fine, quite equal to the best Merino in Spain, and is the very antipodes of that of which so much complaint is made by the manufacturer, of being harsh, dry, crispy, and wiry. 'The fleece opens of a brilliant creamy color within, on a skin of rich pink, and is soft, glossy, wavy, and very even over the whole body; is exceedingly close and compact, and has a yolk free from gum, and easily liberated when it comes to be washed, but which protects the wool from the weather, and keeps it free of the dead ends that are so objectionable. It becomes of the purest white when scoured by the manufacturer, and still retains its mellow, oily touch, so grateful to the handling of good judges. Its felting properties are beyond dispute, making it a choice material for the manufacture of fine cloths."

SWISS SHEEP.

There are several breeds of sheep in the several Cantons of Switzerland. The valley sheep are not dissimilar to the 
ong-wooled English breeds, and approximate more nearly .o the Lincoln variety.

The mountain breed are esteemed the most valuable, having fine, shert wool, which, latterly, has been much improved in quality and weight by the Merino.

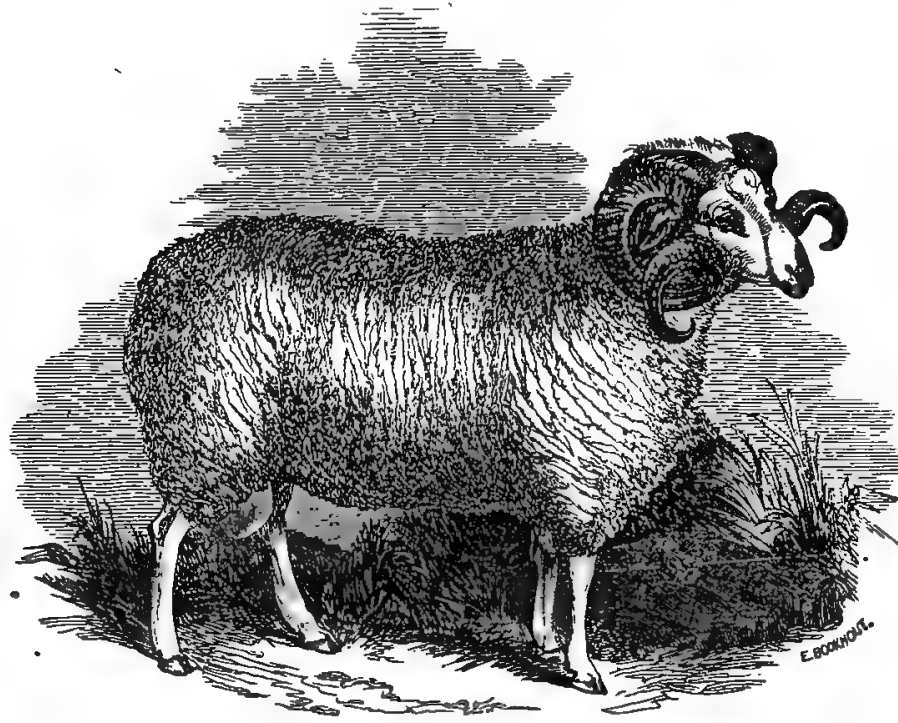

EAXON RAM.

BAXON SHREP.

The following history of the introduction of the Merinos into Saxony was written by the late Mr. Henry D. Grove, of Hoosic, N. Y., whose decease will long be lamented by those who knew his many private virtues, and by American agriculturists, who will not cease to pay the homage of gratitude to his memory, for the enthusiastic enterprise and zeal he continued to manifest to his latest moments to improve the fleece of his adopted country:

The following was addressed to Messrs. Benton \& Barry, at whose request it was written, and affixed to their useful work on the Statistics of Sheep and Manufactures of tho United States, and published in 1837. 
"In the year 1764, the Elector of Saxony obtained, by special negotiation through his ambassador, a grant from the King of Spain, for the purchase of one hundred ewes and one hundred rams, and a few surplus ones to keep that number good in case any should die during the passage. Accordingly one hundred and nineteen ewes and one hundred and ten rams were selected, principally from the Escurial flocks, then the king's private property, under the care and management of the monks belonging to the monastery of that name, and which were considered the finest sheep in the kingdom. They were shipped at Cadiz, in the month of May, 1765, accompanied by two Spaniards to take care of them. Five rams and three ewes died on the. passage; the remainder arrived safely at the Elector's private domain at Stolpen. The Spanish shepherds remained with, and took care of the flock till the middle of the following year, when they took their departure for Spain. During the time, however, they remained in Saxony, they instructed Saxon shepherds in the care and managernent of sheep.

"In order the better to make this valuable acquisition benefit the country as much as possible, the Elector appointed a commission, to superintend and direct the general concerns of the sheep establishment, whose particular duty it was made, to spread all the information they could obtain on the care and management of sheep before the public, and who were especially instructed to dispose of the young rams at low prices, in order to induce the sheep-owners to improve their flocks. The tenants of the government domains were particularly favored, by giving them the preference in the purchase (which is kept up till this day), while every possible care was taken to induce farmers generally to improve their breed of sheep throughout the Electorate. It was further required of the said commission to make a detailed report to the government, annually, on the condition of the sheep establishment, and at the same time to submit a list of the persons who had received sheep from the national flock.

"During the first years these valuable animals found many opponents, and the improvement of the Spanish crop was very slow, mainly on account of the common prejudice of the farmers, which was heightened when the scab broke out among them, but afterwards they became convinced of their value, and the improvement was more rapid. But as most 
of the flocks in Spain are more or less affected by the scab, those transported to Saxony had to undergo the same ordeal. This, of course, heightened the prejudice of many against them, who pronounced them as entirely unfit for the country, their meat not eatable, or at best, of a miserable description; a notion, however, which soon exploded. The scab, however, caused great ravages among them before they were entirely cured of this disease.

"When the commissioners had exercised their functions ten years, the call for young rams was so great, -and in order the more rapidly to improve the breed of the country,that they resolved to petition the government to make another importation of ewes and rams from Spain, for which purpose the Elector obtained another grant from the King of Spain for three hundred rams and ewes. At the end of the year 1777, a gentleman by the name of Vaigt, manager of Count Eiorsidel's farms, who was considered one of the best judges of sheep at that day in Saxony, was provided with the necessary credentials and sent on that mission. But, for some cause unknown, he selected only one hundred and ten two year old rams and ewes, and returned home with them. These were, however, of a very superior quality, selected from the best flocks of Leon, Escurial, Cavagnon, Negretti, Montarco, and Sorian, and exceeded greatly in beauty of form and quality of wool, the first importation. The cost of them was about forty rix dollars per head.

"With this acquisition, the commissioners then planted the Merino Tree on the fruitful soil of Lohmen and Rennersdorf, from whence, in conjunction with Stolpen, many pure blood flocks derive their origin. And I owe it to truth to remark, that I have examined private flocks equal, if not superior, to the national flocks.

"It would lead me too far here, to detail the introduction of the Spanish and Saxony Merino into other parts of Germany, Prussia, Austria, \&c. Suffice it to say, that many districts rival Saxony ; Prussia, especially, fosters her flocks, not only by premiums, bestowed through her agricultural societies, but by that enlightened protection to domestic industry, which so truly characterizes that government."

The invaluable properties of pure Saxon wool, and the demand consequent for its manufacture into fabrics, the fineness of which the world has never before produced, is the cause of the high value of Saxon sheep, and their spread 
over so large a portion of Eurepe, and remote parts of the world. No other breeds are so highly prized on the Continent, and none which command such enormous prices. Mr. Grove has stated, that, while grade Saxons sell for 3 to 15 dollars per head, individual rams of uncontaminated blood often bring from 100 to 250 rix dollars; a flock was purchased, destined for Russia, a few years since, for which the average price paid exceeded 500 dollars ; and Mr. Spooner states that, latterly, rams have been sold at the almost incredible prices of 100 to near 300 guineas per head. The cause of these extravagant prices has been stated; and so long as there exist grades in society, and the highest of these covet a wardrobe of the finest texture, the breed will continue to be appreciated, and sedulously cultivated.

The means adopted to improve the wool of the Saxon breed so much beyond the Melinos of Spain consisted for the most part, originally, in the system of breeding in-and-in, and a great degree of care in management, which is briefly, but imperfectly, detailed by several writers, as follows :- - the first remarks are by Mr. Grove :- "The Germans keep their sheep under comfortable shelter during the winter. By this means they do not require, in the first place, so much provender; secondly, the tip ends of the wool do not get weather-beaten, which is an injury; thirdly, a great quantity of manure is saved. They hurdle their sheep during summer for the purpose of manuring the land, which makes it more productive. They raise large quantities of roots, such as ruta baga, potatoes, mangel wurtzel, carrots, round turnips, \&c., to feed out during winter. Combined with straw, it is considered an economical mode of wintering sheep. They enrich their land, moreover, by this course of management, which enables them to keep still more sheep and cattle, and zaise more grain. Many farmers in that country keep their sheep from nine to ten months of the year in the yard; some only part of their flock, and others their whole flock. For this purpose they sow red and white clover, lucerne, and esparrette, which is mowed and fed to them in racks, three times a day, and in wet weather a foddering of straw. It follows, as a matter of course, that the stables and yards are well littered with straw every day. It is considered that an acre, thus managed, will maintain double the number of sheep, or cattle, than it would to turn them out to pick for themselves. By this course of management they are ena- 
bled to keep large numbers of sheep, without infringing much on their grain growing, and enabled to come in competition with the wool-growers of other countries. As there are no fences in that country, the sheep are attended by dogs: One shepherd with his dog will manage from five hundred to eight hundred in the summer, all in one flock."

Mr. Carr, an English gentleman farmer, but now a resldent of Germany, states the following in the Journal of the Royal Agricultural Society. of Enigland. "These sheep (Saxons) cannot thrive in a damp climate, and it is quite necessary that they should have a wide range of dry and hilly pasture, of short and not over-nutritious herbage. If allowed to feed on swampy or marshy ground, even once or twice, in autumn, they are sure to die of liver-complaint (rot) in the following spring. They are always housed at night, even in summer, except in the finest weather, when they are sometimes folded in the distant fallows, but never taken to pasture till the dew is off the grass. In the winter they are kept within doors altogether, and are fed with a small quantity of sound hay, and every variety of straw, and which is varied at each feed. Abundance of good water to drink, and rock salt in their cribs, are indispensables."

Baron Geisler has been many years one of the most successful breeders of Saxon Merinos, and for a long time (on the authority of Dr. Bright) "he has exercised unwearied assiduity by crossing and recrossing, so that by ${ }^{n}$ keeping the most accurate registers of the pedigree of each sheep, he has been enabled to proceed with a mathematical precision in the regular and progressive improvement of the whole stock. Out of seventeen thousand sheep, comprising his flock, there is not one whose whole family he cannot trace by reference to his books; and he regulates his yearly sales by these registers. He considers the purity of blood the first requisite towards perfection of the fleece." Dr. Bright makes a few remarks on management.

"For fourteen days before the coupling-season the rams should be daily fed with oats, and this food should be continued not only' during that particular period, but for fourteen days after; and one ram will thus be in a condition to serve 60 ewes, if other proper attentions have been paid to him previously.

"During the lambing period a shepherd should be constantly day and night in the cote, in order that he may place 
the lamb, as soon as it is cleaned, together with its mother in a separate pen, which has been before prepared. The ewes which have lambed should, during a week, be driven neither to water nor to pasture; but low troughs of water for this purpose are to be introduced into each partition, in order that they may easily and at all times quench their thirst.

"It is also very useful to put a small quantity of barleymeal into the water, for by this means the quantity of ewes' milk is much increased. When the lambs are so strong that they can eat, they are to be separated by degrees from their mothers, and fed with the best and finest oats, being suffered at first to go to them only three times a day, early in the morning, at mid-day, and in the evening, and so to continue till they can travel to pasture, and fully satisfy themselves."

Although rigid attention is bestowed on these sheep during winter, yet they are not quite the hot-house objects which, from the remarks of $\mathrm{Mr}$. Carr, the reader would infer. On the authority of $\mathrm{Mr}$ Youat, although the sheep in Saxony and Silesia are housed at the beginning of winter, yet they are turned out and compelled to se ek, perhaps under the snow, a portion of their food whenever the weather will permit; and the season must be unusually inclement in which they are not driven into the yards at least two or three hours during the middle of the day. The doors and windows also are frequently opened, that the sheep-houses may be sufficiently ventilated. This is the practice as far north as Sweden.

Very great care is taken by the Saxon flock-master in the selection of the lambs which are destined to be saved in order to keep up the flock. "When the lambs are weaned, each in his turn is placed upon a table, that his wool and form may be minutely observed. The finest are selected for breeding, and receive a first mark. When they are one year old, and prior to shearing them, another close examination of those previously marked takes place; those in which no defect can be found receive a second mark, and the rest are condemned. A few months afterwards a third and last scrutiny is made; the prime rams and ewes receive a third and final mark, but the slightest blemish is sufficien to cause the rejection of the animal. Each breeder of note has a seal or mark secured to the neck of the sheep, to de 
tach or forge which is considered a high crime, and punished severely."*

Before the introduction of the Merinos into Saxony the indigenous sheep consisted of two distinct varieties, one bearing a wool of some value, and the other yielding a fleece applicable only to the coarsest manufactures. Both of these breeds have been most extensively crossed with the Saxon Merinos, and very many mixed flocks now exhibit fleeces litte inferior to the best and purest Escurial sheep.

According to Mr. Carr, the Infantado Merinos are also cultivated in their purity, and are described by him as having shorter legs, and heavier and rounder bodies than the Escurial Saxons, with heads and necks comparatively short and broad. The wool is often matted upon the neck, back, and thighs, and grows upon the head to the eyes, and upon the legs to the very feet. The grease in their fleeces is almost pitchy, so as to render the washing very difficult. $\mathrm{He}$ describes the mode of washing as follows :- "A warm, mild day, without harsh or drying wind, is indispensable. A marl-pit with a depth of from 8 to 10 feet of clear water is a favorite washing place. The sheep are thrown in from a stage in the evening, and made to swim the whole length of the pond (20 or 30 yards), between rails, with boards on one side, from which women or boys assist them through their bath, by placing wooden rakes or crooks under their chins, and so passing them onwards. When the water has dripped from the fleeces for an hour or two, the sheep are put into a house for the night, as close together as possible, in order to cause the greater evaporation, and the next day they are swum three or four times through the pond, and they are kept in the house (well supplied with clean straw) on dry food, for three or four days, until the wool, by sweating as it is termed, has recovered its characteristic softness. The fleece of this species is generally thick, closely grown, and abundant. Ewes average 2 1-4 to 3 l-4 lbs. by careful feeding (which, however, must never approach to feeding to be fat, else the wool becomes wiry and hard), and rams and wedders vary from 4 lbs. to even 6 lbs."

The Escurial Saxon breed have long, tapering -necks, small heads, with little wool upon them, round carcases with rather narrow yet deep chests, and when in good flesh.

* C. Howard. 
generally well proportioned. Indeed, specimens may be selected from the best flocks which rival in symmetry of form any sheep in the world. Compared with other breeds, they are small, and consequently their fleeces are proportionally light; but being comparatively free from gum, is one of the prominent causes. The average weight of the ewe fleeces is from 1 1-2 to 2 1-2 lbs., and full-grown wethers and rams from $21-2$ to $4 \mathrm{lbs}$. The finest and purest flocks yield heavier fleeces than those engrafted on common stock.

Extraordinary care is observed in washing the sheep before shearing (another cause of the fleeces weighing light), which is manifested by the little waste when subjected to the manufacturer's process of cleansing."

The shearing is conducted in the most skilful manner, each shearer, generally, being limited as to the number of fleeces he is to clip per day, in order to ensure a greater degree of care in his work. Thus, the skins of the sheep are not mangled as in our country, and otherwise presenting a slovenly appearance, from unevenness of the clippings.

After the shearing season is past, the wool is bought of the small proprietors by agents of wool merchants, and transported to Hamburg, Breslau, and Leipsic, where it is orted, and resold for exportation and home manufacture. The annual wool Fairs of Leipsic are wonders in their way, millions of pounds often exchanging hands in a single day. The large proprietors of pure, flocks effect their sales by samples, subject to sorting, which is an art nowhere better understood than in Germany. The fleeces of the same quality are opened and spread flat against each other, when packing, and each bale is made to contain from 400 to 500 lbs. The amount of German wools (which includes Prussian, Saxon, and Austrian) annually exported is enormous, England receiving annually from 20 to $30,000,000 \mathrm{lbs}$.; the amount taken by France is also many millions of pounds.

Few Americans are aware of the superiority of German woollen fabrics, as, from the great pains, and therefore expense involved, in their manufacture, few specimens comparatively reach our shores. The Germans make no haste in doing anything, but all their performances are conducted with skill, and with an eye to durability; and thus German

* See Summer Management_article Washing. 
cloths are unrivalled in strength, the brilliancy and permanency of their dyes.

The following Report relative to the introduction of the Saxon Merinos into the United States, was drawn by Mr. Grove, and read before the annual meeting of the New York State Agricultural Society, in 1838, and which will be found in the 1st volume of Transactions of the Society :-

"The first importation of Saxony sheep into the United States was made by Mr. Samuel Henshaw, ${ }^{*}$ a merchant of Boston, at the instance of Col. James Shepherd, of Northhampton. They were but six or seven in number. In 1824, Messrs. G. and T. Searle, of Boston, imported 77 Saxon sheep. They were selected and purchased by a Mr. Kretchman, a correspondent of the above firm, residing in Leipsic, and shipped at Bremen on board the American schooner Velocity. I was engaged to take charge of the sheep on the passage, and I also shipped six on my own account. I am sorry to say, that as many as one-third of the sheep purchased by Kretchman (who shared profit and loss in the undertaking) were not pure-blooded sheep. The cargo were sold at auction at Brookline, as 'pure-blooded Electoral Saxons,' and thus unfortunately in the very outset the pure and impure became irrevocably mixed. But I feel the greatest certainty that the Messrs. Searle intended to import none but the pure stock; the fault lay with Kretchman. In the fall of 1824, I entered into an arrangement with the Messrs. Searle to return to Saxony, and purchase, in connection with Kretchman, from 160 to 200 Electoral sheep. I was detained at sea seven weeks, which gave rise to the belief that I was shipwrecked and lost. When I finally arrived, the sheep had been already bought by Kretchman. On being informed of what the purchase consisted, I protested against taking them to America, and insisted on a better selection, but to no purpose.

" The number shipped was 167,15 of which perished on the passage. They were sold at Brighton, some of them going as high as from 400 to 450 dollars. A portion of this importation consisted of grade sheep, which sold as high as the pure bloods, for the American purchaser could not know the difference. It may be readily imagined what an inducement the Brighton sale held out to speculation, both in this

* American Agriculturist ; the name was left blank in the Report. 
country and Saxony. The German newspapers teemed with advertisements of sheep for sale, headed 'Good for the American market ;' and these sheep in many instances were actually bought up for the American market at five, eight, and ten dollars a head, when the pure bloods could not be purchased at from less than 30 to 40 dollars each. In 1826, Messrs. Searle imported three cargoes, amounting in the aggregate to 513 sheep. They were of about the same character with their prior importations, in the main good, but mixed with some grade sheep. On the same year, a cargo of 221 arrived, on German account, Emil Bach, of Leipsic, supercargo. A. few more good sheep, and of pure blood; but taken as a lot they were miserable. The owners sunk about 3000 dollars. Next came a cargo of 210 on German account; Wasmuss \& Multer owners. The whole cost of these was about $\$ 1,125$, in Germany. With the exception of a small number, procured to make a flourish on, in their advertisement of sale, they were sheep having no pretensions to purity of blood. In 1827, the same individuals brought out another cargo. These were selected exclusively from grade flocks of low character. On the same year the Messrs. Searle made their last importation, consisting of 182 sheep. Of these I know little. My friends in Germany wrote me that they were, like their other importations, a mixture of pure and impure blooded sheep. It is due, however, to the Messrs. Searle to say, that as a whole, their importations were much better than any other made into Boston.

"I will now turn your attention to the importations made into other ports. In 1825, 13 Saxons arrived in Portsmouth. They were miserable creatures. In 1826, 191 sheep arrived in New York, on German account. A portion of these were well descended and valuable animals, the rest were grade sheep. In June, the same year, the brig Louisa brought out 173 on German account. Not more than onethird of them had the least pretensions to purity of blood. Next we find 158, shipped at Bremen, on German account. Some were diseased before they left Bremen, and I am happy to state that twenty-two died before their arrival in New York. All I intend to say of them is, that they were a most curious and motley mess of wretched animals. The next cargo imported arrived in the brig Maria Elezabeth, under my uwn care. Thev were 165 in number, belonging 
to myself and F. Gebhard, of New York. These sheep cost me 65 dollars per head, when landed in New York. They sold at an average of 50 dollars a head, thus sinking aboul $\$ 2,400$ ! I need not say that they were exclusively of pure blood. A cargo of 81 arrived soon after, but I know nothing of their quality. The next importation consisted of 184, on German account, per brig Warren. With a few exceptions they were pure-blooded and good sheep. We next have an importation of 200 by the Bremen ship Louisa. They were commonly called the 'stop sale sheep.' They were of the most miserable character, some of them being hardly half grade sheep. 'The ship Phebe Ann brought 120 sheep, of which I know little, and 60 were landed at Philadelphia, with the character of which I am unacquainted. Having determined to settle in America, I returned to Saxony, and spent the winter of 1826-7 in visiting and examining many flocks. I selected 115 from the celebrated flock of Macherns;-embarked on board the ship Albion, and landed in New York June 27th, 1827. In 1828, I received 80 more from the same flock, selected by a friend of mine, an excellent judge of sheep. On their-arrival they stood me in 70 dollars a head, and the lambs half that sum."

Notwithstanding so many imperfect specimens of the Sax. ons, as appears from the above, reached our shores, and which have laid the foundation of much prejudice towards the breed, yet there are many flocks in the states which rival some of the best German in fineness, and superior to the latter in average weight of the fleece. The delicacy of constitution which characterizes the German Saxons does not appearr nearly to the same degree in the American, and the reader-will learn by reference to the Appendix many particulars from different sources to corroborate this statement.

The American breeders of this noted race have struggled against a discouraging obstacle, from the injustice of manufacturers, by not paying the true difference of value between their fleeces and more inferior grades. This, however, latterly, has been somewhat rectified, and eventually, with increase of competition, will be wholly so ; and therefore this breed, with their meritorious progenitors, the Merinos, will continue to be more and more extensively bred, and, by proper management, with equal degrees of profit.

The average weight of American Saxon fleeces is from 2 1-4 to 3 lbs. 


\section{PRUSSIAN SHEEP.}

Until the middle of the 18th century, no attempts had been made either by individuals or the Prussian government to ameliorate the quality of the native sheep, which are represented to have been of a very inferior character. The first move towards their reformation was made by Mr. Fink, distinguished as an enterprising agriculturist, and his enthusiasm in sheep-husbandry. His first effort was to obtain the Silesian native breed, which had long been celebrated for the comparative fineness of their wool. Some improvement was effected, but he was not satisfied, and became seized with the mania-then common in Germany-for Merinos, and accordingly imported a number of superior animals of this breed, direct from Spain. His success in naturalizing them to the climate, and wonderful improvement accomplished by them to his native flocks, attracted the attention of the Prussian government. Frederick II., in 1786, imported one hundred rams and two hundred ewes from Spain; but, says Mr. Youatt, "illustrative of the difference in result when an organized plan is conducted by one acquainted with all its details, and whose heart is in the affair, and when it is committed to those who know and care little about it, the greater part of the sheep that were distributed in the neighborhood of Berlin perished by various diseases ; those that were sent to distant farms in the country degenerated, and the advantage was far from commensurate with the expense."

The monarch, however, did not despair. Mr. Fink was commissioned by the government to purchase a flock of one thousand of the choicest Merinos ; and a school was established to instruct in their management, at the head of which he was wisely placed. As a proof of the extent to which he improved his own flocks, it is stated on the authority of Lasteyrie, who had an opportunity of examining them, "that the sheep are less than the Merinos of Spain, hut are by no means inferior to them in perfections of fleece. Before the improvements had taken place the native breeds produced wool that sold from $5 d$. to $8 d$. per lb., but now, improved by the use of Spanish rams, it sells from $2 s$. to more than $3 s$. sterling per $\mathrm{lb} . "$

A brief sketch of his system of management may not be unacceptable to the reader; valuable, principally, as it illus 
trates his knowledge of the fondness of sheep for variety of food, which all experience confirms as contributing so much to their welfare.

"He properly maintains, that occasional exposure to the air is favorable to the quality of the wool, and therefore, although the sheep are housed at the beginning of November, yet whenever it freezes, and the ground is hard, even although it may be covered with snow, the sheep are driven to the wheat and rye fields, where they meet with a kind of pasturage exceedingly wholesome; and while they feed there they are likewise benefiting the crop. - When the weather will not permit their being taken out, they are fed on hay, aftermath, and chopped straw of various kinds. The kind of straw is changed as often as possible, and wheat, barley, and oat-straw, and pease-haulm follow each other in rapid succession. The oat-straw is sparingly given, and the pease-haulm is preferred to the wheat and barley-straw. Oil-cake, at the rate of six or seven pounds per hundred, and dissolved in water, is also allowed when the flock cannot be turned on the young wheat.

"Three or four weeks before lambing, an additional allowance of hay and straw is given to the ewes; and while they are suckling, a little oat-meal is mixed with the solution of oil-cake. When the weather will permit the turning out the ews, the lambs are still kept in the houses, and the mothers brought back to them at noon and at night; after that the lambs are not permitted to graze with the ewes, but are turned on the fallows or the clover of the preceding year; for it is supposed that they unnecessarily fatigue themselves by running with their mothers, and almost incessantly trying to suck, and that on this account they refuse the herbage on which they are placed and take less nourishment than when quietly kept on separate pastures. A few barren ewes, however, are placed with the lambs for the purpose of guiding them, and perhaps teaching them to select the best and most wholesome food."*

Many of the Prussian flocks, at the present day, rival in fineness the purest Saxon, and command an equal price for their fleeces. 
SILESIAN SHEEP.

As has already been said, a portion of the native sheep of Silesia were comparatively fir.er than those of Prussia and Hungary. Nevertheless, the breed was infinitely below the Merino in the value of their worl, and it was not until the introduction of the latter that Silrsian fleeces took high rank. At present the wools of that province, for the purposes of the best manufactures, are almost equally valued with the purest and finest Saxony.

HUNGARIAN SHEEP.

Hungary, a large territory within the Austrian dominions, abounded with native sheep corresponding in inferiority with other northern countries of Europe, which, with bad management, rendered them comparatively worthless for all purposes.

The celebrated Empress Maria Theresa, after witnessing the success of the Merinos in Saxony, through that enterprise which shone so conspicuously in her character, to engage in everything which would tend to promote the welfare of her people, was induced to import in 1775 sevaral hundred of that breed. They were placed at Mereopsi] where an agricultural school was established; but it was long before her laudable exertions were attended with the desired success. In process of time other importations of Merinos were made; and within the last thirty years no sheep districts have surpassed Hungary in the rapid progress of wool improvement. The Hungarian fleeces now compete successfully with the best Saxon, as will be seen on reference to the wool table of prices, in the London market. in the following pages.

The number of sheep in the Territory of Hungary is probably about eight millions, three milliens of which are the property of Prince Esterhazy!

\section{SWEDISH SHEEP.}

For many centuries the Merinos were confined to Spain and preserved with jealous care. Sweden appears to have. been the first country which succeeded in procuring them. and there are now about seven hundred thousand in this country.*

* Spooner. 
They were introduced into that high latitude as early as 1723 by $\mathrm{Mr}$. Alstroemer, an enterprising agrieulturist, and was deemed at the time a presumptuous, indeed, an almost insane attempt. He triumphed over all difficulties, which induced the Swedish government to yield its patronage, by the formation of an agricultural school, which offered premiums for the best Spanish Merinos, and on the sale of the best wool.

A brief notice of the mode of management in this extreme northern latitude may be acceptable.

"The system of migration is completely abandoned. Both the native and imported sheep, after having been pasvured during the day, are usually housed at night at all seasons, on account of the great number of wolves. The peasantry and small farmers have these houses too confined and crowded; the better sheep-master has them large and well ventilated. The native Swedish flocks are kept in these buildings when the weather is unusually severe; the Merinos are housed during the six winter months; but scarcely any inclemency of weather will prevent the whole flock being driven out daily, at least for a few minutes, in order to breathe the fresh air while the sheep-house is cleaned. The Merino sheep are seldom used for breeding until they are two and a half years old, and are fattened for the butcher at seven."**

The native sheep of Sweden are an inferior race in all respects, but the wool of which is strong, and valuable for the elothing of the peasantry.

\section{DANISH SHEEP.}

The native sheep of Denmark correspond with those of Sweden, Norway, and the more northern parts of Russia. The head is long and thin, the neck arched, the eye small, the countenance mild, the legs and tail without wool.

In 1797 the government was influenced, by the example of Sweden, to patronize the Merinos. Accordingly 300 I eoonese Transhumantes were procured and located in the vicinity of Copenhagen. By careful and skilful management the success in propagating them equalled expectation; and by crossing them with native sheep, a fair wool was procured. 
Denmark now exports nearly a million of pounds of wool, one half of which is represented to be of the finest quality of Merino.

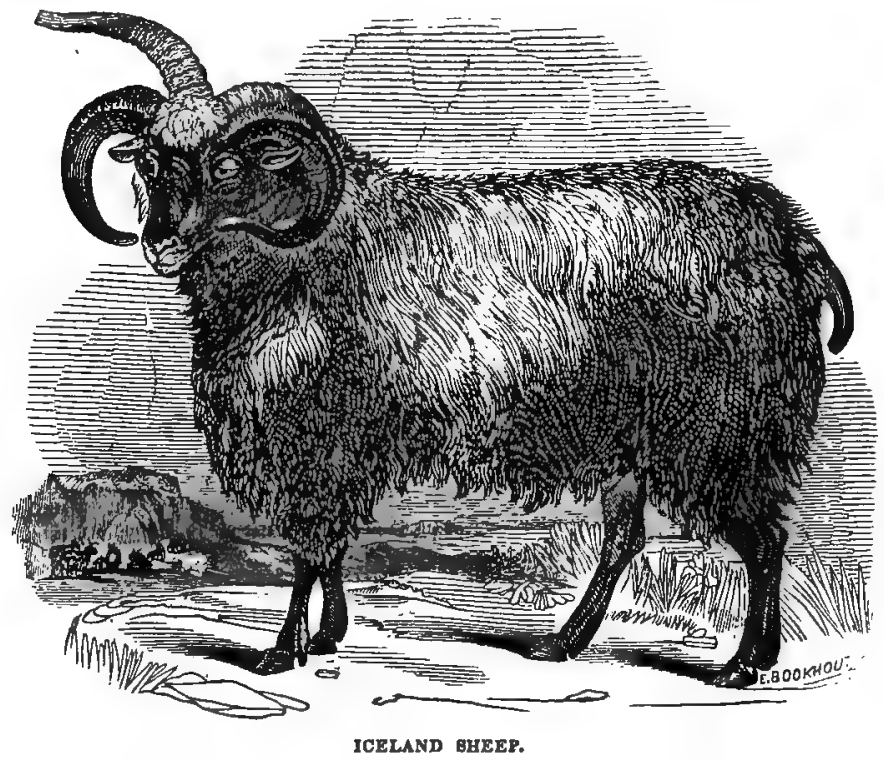

\section{ICELAND SHEEP.}

The sheep of Iceland are of two kinds : the first, termed the native breed, is small, in color from dun to almost black; the second is larger, the fleecewhite, and supposed to have originated from more southern regions. The fleece of these breeds consists of hair externally, with a thick, close layer of wool within, impervious to cold and wet; it is worthless for manufacturing, and is used for horse collars, and more or less is exported and appropriated to this purpose.

The principal peculiarity about the native sheep is the number of their horns, many individuals having four and five, and instances have been known of eight. These hardy animals propagate without the care of man, and seek refuge 
from storms among the caverns of the coast during the winter season.

\section{RUSSIAN SHEEP.}

From the certainty that a large portion of the waste places of the immense Empire of Russia is destined to be filled with countless hordes of sheep, a brief notice of the progress already made will doublless be of some interest to the American wool-grower.

The following account is supplied by Youatt:

"Far more attention continues to be made to the breeding of sheep than that of cattle, through almost the whole of this immense Empire. All the wandering tribes possess a great number of sheep. Many of the inferior Boors and Cossacks in Southern Russia have flocks consisting of many hundreds.

"The characters of the sheep differ materially in the various districts. Towards the north they are small, shorttailed, and bear a coarse and harsh wool. About the river Don, and still more towards the centre, and on the banks of the Dneiper, and in some districts of the Ukraine, they yield a better wool; and thence the greater part of the material for the inland cloth manufactories is supplied. In the neighborhood of the Baltic a still superior breed is found, and the Dago and Oesel islands, near the Gulf of Finland, are celebrated for their wool. The half-cloths that are manufactured from it have often as fine and close a substance as that which is imported from Great Britain. The finest of the Russian wools are exported from Odessa, on the Black Sea.. It is the produce of all the neighboring provinces, but rincipally of the Crimea. There is no district in the em.ire so fitted by nature for the pasturage of sheep.

"There are three kinds of sheep in the Crimea and in Taurida. The common breed is white, or black, or grey, with very coarse wool, and a long tail covered with fat. They are kept in exceedingly large flocks. A rich Tartar will frequently possess 50,000 sheep. The grey sheep produce the grey lamb-skins, 30,000 of which are exported every year. Fifty or sixty thousand black lamb-skins, which are also much valued, are exported from the Crimea. "The mountain sheep are smaller than those on the plains. Their wool is beautifully fine, and, even before the improvement which many of the flocks have undergone 
used to find its way to the French manufactories. The Crimea was scarcely in the possession of Russia ere many attempts were made to improve the sheep, naturally so valuable. 'The Merinos were in process of time introduced here, as into every part of Europe. A few have been cultivated as a pure flock; more have been employed in improving the native breeds, and the consequence is that the wool exported from Odessa is increasing in -quantity and value every year. In $1828,184,000 \mathrm{lbs}$. of wool were shipped from this port; in 1831 that quantity had increased to more than $1,260,000$ lbs.*

"The staple from a sample of Odessa wool is from four to six inches in length. The diameter of a fibre is the 1-750th part of an inch, and 2080 serrations to an inch. The wool is very soft, and possesses good felting properties : but it is inferior to Merino, and most decidedly so to Saxony"

\section{NEW SOUTH WALES, OR AUSTRALIAN SHEEP.}

The island of New Holland, now better known as Australasia, or Australia, is situated in the Indian Ocean, between (including the southernmost point of Van Dieman's Land) the 11 th and 41 st degrees of south latitude. The climate is temperate of that portion of the country devoted to sheep husbandry, compared with the same latitude of the United States, which may, in part, be ascribed to the proximity of the settlement to the salubrious influence of the ocean. The country is subject to severe droughts, though not of frequent occurrence. "The great drought which commenced in 1826, did not terminate until 1829. Very little rain fell during the whole of this period, and for more than six months there was not a single shower." $f$ The soil in general, though exceedingly variable, being in many parts almost wholly barren, is highly productiue of herbage well adapted to the sheep.

There were no sheep indigenous to the country, therefore the early colonists were compelled to provide themselves with mutton and wool from the native Bengal sheep, which, it is hardly necessary to say, were of the most inferior character. According to Mr. Atkinson, these sheep resembled goats more than anything else; but the change of climate, as well as of herbage, contributed in a short time to work a

- MeCulloch's Dietionary + McCulloch's Com. Dictionary 
singular modification of the fleece, losing its hairiness, and tolerable wool supplying its place.

Soon after importations were made to a considerable extent of South Down and Leicester sheep, which, being crossed with the Bengalee variety, was productive of much improvement over the latter, not only in the quality of the mutton, but a similar benefit to the fleece.

At this period (1800) there were about six thousand sheep, of all kinds, in the colony; and comparing this insignificant number with that of the present time, shows how remarkably the animal is disposed, in temperate latitudes, to increase. The number thirteen years afterwards was 65,000, in 1828 563,000 .* The export of wool, of all kinds, in 1843, amounted to $16,226,400 \mathrm{lbs}$. $\dagger$

The colonists, from the kind nature of the climate, were induced to experimemt with the Merino. Accordingly a few were sent over from England, and it was observed that the fifth and sixth cross produced a quality of wool little inferior to the pure Merinos of Spain. This is stated by Mr. Youatt, on the authority of Mr. Collins, and must be received with some doubt, considering the decided inferiority of the sheep previously in the colony.

The success of the Merinos paved the way for still greater improvement, by the introduction of the Saxons, which have since stamped the high character and value of Australian wools. The original importation was made by Captain McArthur, then in government employ, and distinguished as an enterprising and zealous agriculturist. Mr. Youatt says, "It would not perhaps be truly said, that the quality of the Saxon fleece was improved by the change of climate-perhaps it was somewhat deteriorated-but it soon became evident that its properties were superior to any that the colony had hitherto possessed."

The present prominent characteristics of Australian wool, of the improved breeds, are, great length of staple, softness in an unusual degree compared with other wools of the same fineness, and "working kindly" in every manufacture in which it is employed. But the climate unquestionably, although comparatively so temperate, together with imperfect management, have wrought deteriorating effects, compared with the wool of the original Saxon stock on its first introduc- 
tion into the colony. 'The testimony is conclusive of a decidence in fineness, and also in the felting property. The diameter of a fibre from a sample of picklock taken from a fleece belonging to Captain McArthur, whose flock is esteemed the purest and best in the colony, was the 1-780th of an inch, about the same as pure Merino, and the serrations 2400 in the span of an inch less by 150 than Merino, and 320 less than a fibre of picklock Saxon. This is the result of a microscopic view made by Mr. Youatt, and he remarks as follows:"The serrations of this sample were very sharp, and in appearance almost barbed. But there is a marked difference, not only in the length but in the structure of the Saxon wool, as obtained direct from Germany and imported from Australia. The fibre of the Australian is considerably longer, but it is not so fine-the serrations are not so numerous-they are of a different character, seemingly giving pliability and softness to the one, and feltiness to the other. In truth, the manufacturer has properly classed them, although he knew nothing of their microscopic appearance. He has appropriated the true Saxon wool to the making of the finest cloth, owing to its superior felting quality; and he is using the Australian wool for the better combing purposes, in which a strong tough wool, soft and long in the staple, is useful."

Before proceeding to give an account of the mode of managing sheep in Australia, taken from Cunningham's "Two Years in South Wales," it is proper to state the fact, not perhaps known to every reader, that it is to the colonies of New South Wales and Van Dieman's Land England banishes her criminals, to expiate their crimes in menial servitude, not a few of which are employed in the capacity of shepherds.

"When the country is destitute of timber, the sheep are very easily managed, and so many as a thousand may be trusted to a single shepherd; but in general they are divided into flocks of about three hundred breeding ewes, or four hundred wethers. Every flock has a shepherd, who takes his sheep out to graze before sunrise, and brings them in at evening. He keeps always before the flock, to check the forward among them from running onwards, and wearing out the old, sick, and lame; making all thus feed quietly, so as to keep them in good condition. In summer he sees, too, that they have water during the heat of the day; and in drawing up conder a tree for shade, when it is too hot for 
feeding, he passes occasionally gently among them, spreads them out, and makes them take a fresh position in as small groups as possible, under another tree, because, when they remain too long together in one place, they are apt to become 'broken-winded. It is a rule that sheep should never remain in one spot so long as to paddle the ground much with their feet; and hence, in riding round your sheep stations, you have something whereby to judge whether or not your instructions are attended to. The shepherd takes out his victuals with him, and is required to be on the alert all day long, to prevent the sheep from being lost in the woods, or wild dogs from pouncing in among them.

"Three flocks are always penned together under the charge of a watchman, who counts each regularly in at night, and the shepherds again count them out in the morning; so that they form a regular check upon each other, and prevent losses from carelessness or depredation. The watchman has a small weather-proof watch-box to sleep in, and is assisted by a watch-dog; he keeps up a good fire, which generally deters all native or wild dogs from approaching the fold. The hurdles are made of light swamp oak, iron bark, or gum, measuring seven feet long, with five bars, so close together that a young lamb cannot creep through. They are shifted to fresh ground daily, being sloped outward, and propped together by means of forked sticks, driving a stake through between the bars here and there to keep the hurdles firm, and prevent the wind from blowing them over. ${ }^{* * * * *}$ Bells are attached to the necks of the stoutest leaders, to keep the flock together, and give warning of anything going wrong within the fold."

Notwithstanding the equability and dryness of the climate, the sheep are subject to the same maladies, though less frequent, of those in Europe, and especially that lamentable scourge, foot rot. This ọiginates from the poachy nature of the soil.

The manner of cleansing the fleece, is by conveying water through spouts, where practicable; and otherwise, by swimming repeatedly the sheep across narrow streams, and afterwards squeezing the wool with the hands. It is not unusual for many of the fleeces to lose three fifths by thorough washing.

The average weight of the fleeces of the improved breeds is from two to two and a half pounds. 


\title{
CHAPTER V.
}

\author{
BRITISH BREEDS.
}

SOUTH DOWN-RYELAND-DORSET-BLACK-FACED-CHEVIOT-SHET-

LAND ISLAND-IRISH SHEEP.

SOTTH DOWN.

THE sheep of Great Britain for a long time have been classed into middle-wooled, and long-wooled. The short wools, properly speaking, now employed in English cloth manufactures, are of foreign growth.

The middle-wooled breeds comprise the South Down, Norfolk, Dorset, Cheviot, and some others, which are inferior, however, to these.

Confessedly, on all hands, at the head of the middlewooled varieties, stands the South Down, and are destined, doubtless, to occupy a large share of the attention of American breeders.

The original as well as present location of a large proportion of this breed is on the South Downs (from whence the name of the breed is derived), a long range of chalky hills, diverging from the great chalky stratum which intersects the king dom from Norfolk to Dorchester. "They nay be considered as occupying a space of more than sixty miles in length, and about five or six in breadth, consisting of a succession of open downs, with very few enclosures. On these downs a certain breed of sheep has been cultivated for many centuries, in greater perfection than elsewhere; and hence have sprung those successive colonies, which have found their way to every part of the kingdom, and materially benefited the breed of short-wooled sheep wherever they have gone."*

The perfection of carcase which the South Down at present exhibits, is owing to the skill of that distinguished sheep. 
breeder, Mr. John Ellman. He says, "This breed was formerly of a small size, and far from possessing a good shape, being long and thin in the neck, high on the shoulders, low behind. high on the loins, down on the rumps, the tail set on very low, perpendicular from the hip bones, sharp on the back, the ribs fiat, not bowing, narrow in the fore-quarters but good in the leg, although having big bone."

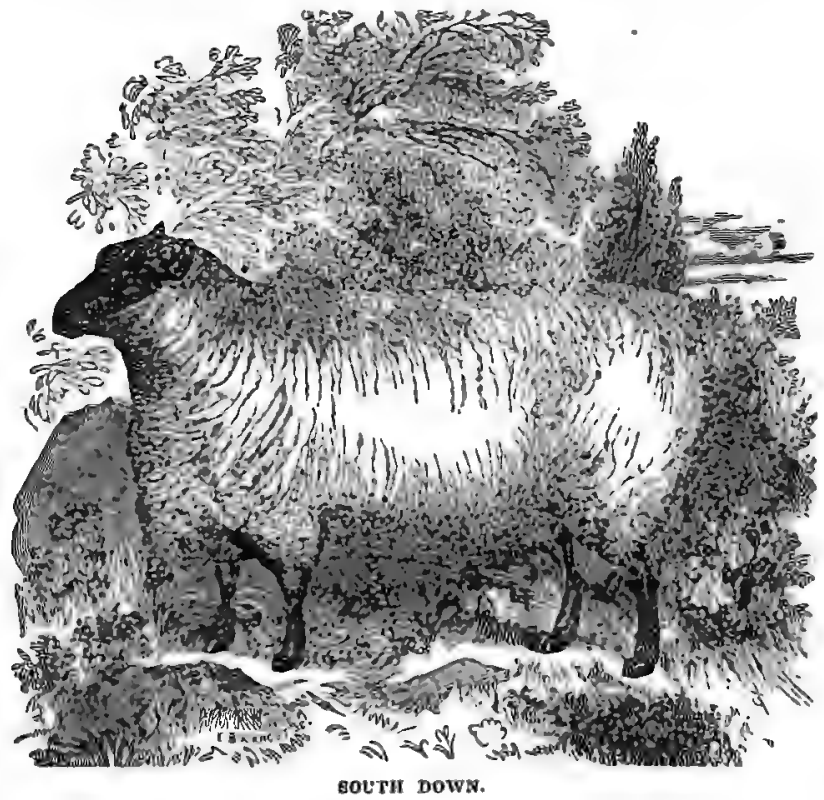

The improvement effected by Mr. Ellman, was nur from any admixture of foreign blood, "for even the cross with the Leicester was a failure, and the promised advantages to be derived from the Merinos were delusive." It resulted, mainly, from the practice of the true principles of breeding; a system of choice selection from male and female. The introduction of turnip husbandry was another very important agent, which essentially promoted thrift and size, and an early development of form. "They are now," 
says Mr. Ellman," much improved both in shape and constitution. They are smaller in bone, equally hardy, with a greater disposition to fatten, and much heavier in carcase when fat. They used seldom to fatten until they were four years old; but it would now be a rare sight to see a pen of South Down wethers at market more than two years old, and many are killed before they reach that age."

The following description of a perfect South Down, from the pen of Mr. Ellman, will be valuable to the American breeder, as well as guard the ignorant from imposition :-

"The head small and hornless; the face speckled or grey, and neither too long nor too short. The lips thin, and the space between the nose and the eyes narrow. The underjaw, or chap, fine and thin; the ears tolerably wide, and the forehead well cotered with wool, and the whole space between the ears also.

"The eye full and bright, but not prominent. The orbits of the eye, the eye-cap, or bone, not too projecting.

"The neck of a medium length, thin towards the head, but enlarging towards the shoulders where it should be broad and high, and straight in its whole course above and below. The breast should be wide, deep, and projecting forwards between the fore-legs, indicating a good constitution, and a disposition to thrive. Corresponding with this, the shoulders should be on a level with the back, and not too wide above; they should bow outward from the top to the breast, indicating a springing rib beneath, and leaving room for it.

"The ribs coming out horizontally from the spine, and extending far backward, and the last rib projecting more than the others; the back flat from the shoulders to the setting on of the tail; the loin broad and flat; the rump long and broad, and the tail set on high and nearly on a level with the spine. The hips wide; the space between them and the last rib on either side as narrow as possible, and the ribs, generally, presenting a circular form like a barrel.

"The belly as straight as the back.

"The legs neither too long nor too short. The fore-legs straight from the breast to the foot; not bending inward at the knee, and standing far apart both before and behind; the hocks having a direction rather outward, and the twist, or the meeting of the thighs behind, being particslarly full; the 
bones fine, yet having no appearance of weakness, and of a speckled or dark color.

"The belly well defended with wool, and the wool coming down before and behind to the knee, and to the hock; the wool short, close; curled, and fine, and free from spiry projecting fibres."

This breed will sustain themselves with occasional short keep, and endure hard stocking equal to any other; and their early maturity is but liltle inferior to the new Leicesters, the flesh finely grained, and of peculiarly good flavor." Blacklock says "it is unadapted for bleak situations, but sufficiently hardy and active for a low country."

The average weight is from 15 to $18 \mathrm{lbs}$. a quarter ; $\dagger$ but on the authority of Mr. Youatt, Mr. Grantham exhibited a pen of three sheep at Smithfield in 1835, one of them weighing $283 \mathrm{lbs}$; the second $286 \mathrm{lbs}$; ; and the third $294 \mathrm{lbs}$.

The average weight of the fleece was, in 1800, $2 \mathrm{lbs}$, and the staple at that time very short: it has now increased to 3 lbs.; and the lowland South Down, from better keep, shears from $3 \frac{\mathrm{l}}{2}$ to $4 \mathrm{lbs}$.' The staple has increased from $1 \frac{1}{2}$ to 2 inches in length to from 3 to 4 inches. A picklock fibre is the 1-600th part of an inch in diameter, and the serrations 2080 to an inch: For a microscopic view of the fibre, the reader is referred to the proper place.

A serious objection has always existed against English South Down wools, from the brittleness of the fibre, originating in the chalky nature of the soil, on which a large proportion of this breed are kept. Formerly much of this wool was employed in the manufacture of army cloths; but its changed character, within a few years, has also changed its uses, and it is now converted into flannels, baizes, and worsted goods of almost all descriptions. The paucity of serrations will prevent its uses beyond combing purposes, for which it is now highly prized.

There are no sheep more healthy than the South Downs They seldom suffer from the hydatid on the brain, nor are they as much exposed to rot as the sheep in many other dis tricts. Their general health is supposed to be much connected with frequent change of food, and their daily journeys to and from the fold.f

The South Downs have borne witness to a mania for their

* Baxter. † Blacklock. $\quad \ddagger$ Library of Ag. Knowledgศ. 
possession, like the Merinos and Saxons of our own country. In 1800, two of Mr. Ellman's rams were sold to the Emperor of Russia, in order to try the effect of a cross on the Northern sheep, for one hundred and fifty guineas each. When Mr. Ellman retired from public life, in 1829, his flock was sold by auction at the following rates: 770 ewes $\$ 1364$ each; 320 lambs \$7 92 each; 36 rams $\$ 11250$ each; and his best ram for $\$ 29250$. This valuable breed continue to sustain the high character they acquired through Mr. Ellman's efforts, and amongst the purest and best flocks, very high prices are demanded and obtained for breeders.

For a further notice of the qualities of the South Down, the reader is referred to the chapter on Breeding and Crossing.

\section{RYELAND SHEEP.}

In point of number, the most distinguished breed of sheep in Herefordshire, is the Ryeland, so called from a district in the southern part of the county, on which a large quantity of rye used to be grown, and where many of these sheep were bred. This breed are rather small, seldom exceeding $16 \mathrm{lbs}$. to the quarter; and the weight of the fleece about 2 lbs., but surpassing in fineness any other British breed. The diameter of the fibre was formerly the same as pu a Merino, and the number of serrations 2420 to an inch.

'The pe. 'liar form of the Ryeland, in some respects resembling the Merino, led to the suspicion that the breed was of foreign extraction. The lightness of the fleece, and its comparative inferiority as a mutton sheep, will cause it eventually to be merged into other more profitable breeds and then the variety will become extinct.

\section{DORSET SHEEP.}

Dorsetshire possesses a valuable breed of sheep, peculiar to itself. The pure breed are entirely white, the face long and broad, with a tuft of wool on the forehead; the shoulders are low but broad, the back straight, the chest deep, the loins broad, the legs rather beyond a moderate length, and the bone small. They are a hardy and useful breed, and the mutton is well flavored, averaging, when three year's old, from 16 to $20 \mathrm{lbs}$. a quarter.* 
A principal characteristic of this breed is the almost singular fecundity of the ewe, often bearing lambs twice in the vear. "When on luxuriant food, they will often admit the male ten or twelve days after yeaning, and continue to suckle the first lamb after they are pregnant with a second."

Crosses with the new Leicester have been attempted, but failed of success. The cross with the South Down has been otherwise, and the breed resulting from it are esteemed so valuable that it threatens to supersede both the Dorset and South Down.

In the neighborhood of cities, where early lambs are in request, the pure Dorset will always be properly appreciated.

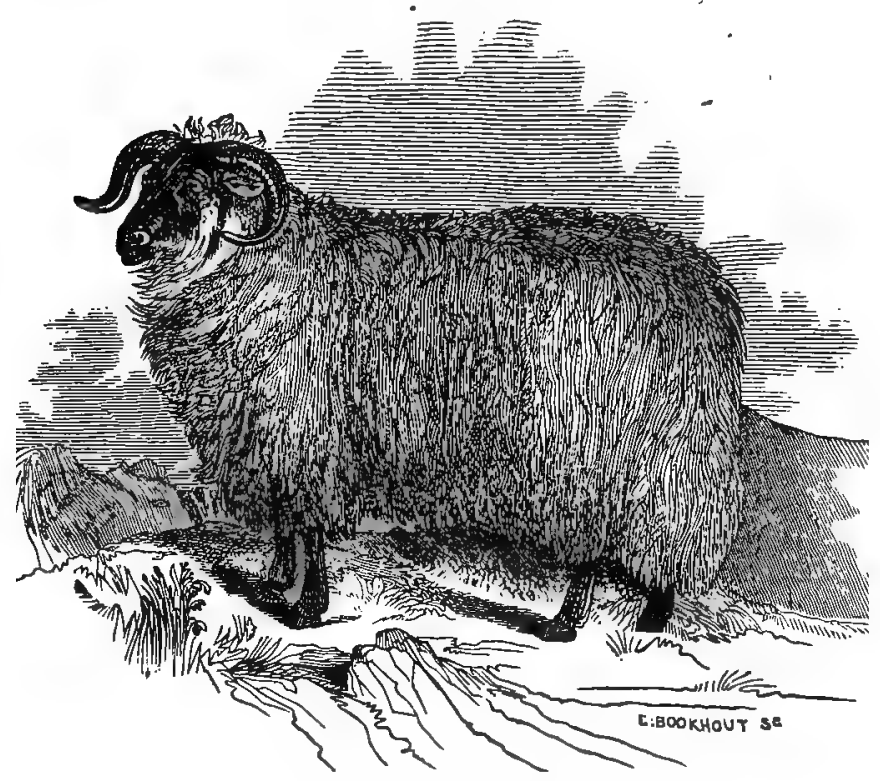

THI BLACK-FACED HEATH GHEEP.

BLACK-FACED SHEEP.

This noted breed abound in the mountainous parts of Jancashire, Westmoreland, Cumberland, Northumberland, and over the whole of Scotland. 
By many it is supposed to be the aboriginal sheep of Scotland; but Mr. Cully, who is high authority, thinks the dun-faced sheep, which is smaller and slower in arriving at maturity, to be the true original Scottish sheep.

The belief is common in Scotland, that the black-faced sheep are of foreign origin, and the forest of Ettrick was their original locality."

"They have mostly horns, more or less spirally formed, but the females are frequently without horns. The faces and legs are black, or at least mottled; the eyes are wild and fierce. They are covered with wool about the forehead and lower jaw, and the wool generally is somewhat open and long, coarse, and shaggy; not so long, however, but that the sheep may be properly "classed among the middlewooled breeds." $\dagger$

In consequence of greater attention to choice selections of individuals for breeding, the form has changed, within a few years, for the better; the carcase has become so short, round, firm, and handsome, as to acquire the name of short sheep, in contradistinction to the Cheviot, or long sheep.

The mutton, especially since this improvement of form was effected, is highly esteemed in the London market, resembling, more than any other English breeds, the South Down in the fineness of its grain and the delicacy of its flavor. This is attributed in a measure to the nature and variety of the herbage on which they are fed during summer. The weight of this breed, when fattened, is from 16 to $20 \mathrm{lbs}$. per quarter, and the weight of the fleece unwashed is about 5 lbs.

No other breeds equal the black-faced sheep in hardiness of constitution, and endurance of cold.

\section{CHEVIOT SHEEP.}

One of the most distinguished British breeds of sheep is the Cheviot; and from their comparative early maturity, valuable mutton qualities, and, especially, hardiness of constitution, which would adaptate then to the rigorous climate of the northern portions of our own country, it can scarcely be doubted that a trial, at least, ere long, will be made by some of our enterprising countrymen, and their general merits tested. 
"The Cheviot Hills ase a part of that extensive and elerated range which extends from Galloway through Northumberland into Cumberland and Westmoreland, occupying a space of from 150 to 200 square miles. The majority of them are pointed like cones; their sides are smooth and steep, and their bases are nearly in contact with each other The soil, except on the very top, is fertile; and from the base to the summit of most of them there is an unbroken ind rich greensward.

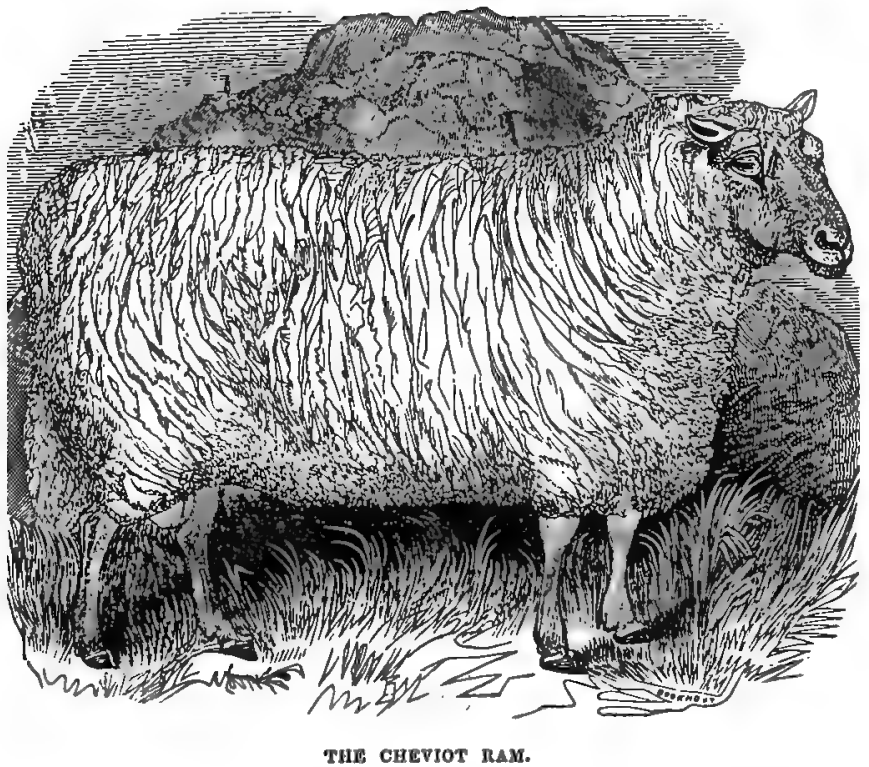

"On the upper part of that hill in Northumberland, which is properly termed the Cheviot, a peculiar and most valuable breed of sheep is found. They have been there almost from time immemorial. Tradition says that they came from the border districts of Scotland; but they are totally different from the black-faced sheep, and bear no resemblance to the original dun-faced Scottish sheep. How two breeds, so otally different from each other, came to inhabit the neigh- 
boring districts of Ettrick forest and the Cheviot Hills, neither history nor tradition has attempted to explain."*

They are described by Youatt, as hornless ; the face and legs generally white; the eye lively and prominent; the countenance open and pleasing; the ear large; the body long, and hence they are called "long sheep," in distinction from the black-faced breed. They are full behind the shoulder, a long, straight back, round in the rib, and well proportioned in the quarters; the legs are clean and small-boned, and the pelt thin, but thickly covered with a fine, short wool, which extends over the whole of the body.

All authorities concur in stating that the Cheviot breed possess considerable fattening properties, and can endure much hardship both from starvation and cold. It is fit for the butcher when three years old, and at two years when crossed with the Leicester. The wethers average from 12 to $18 \mathrm{lbs}$. per quarter, but some have been exhibited at the Highland cattle shows, weighing 30 and $32 \mathrm{lbs}$. per quarter.

The wool is not quite so fine as the South Down, and since the improvement of the carcase commenced, the wool has been used mostly for combing purposes.

The following is Sir John Sinclair's description of the original Cheviot, "ss it was in 1792 ; since which time it has been extensively crossed with the new Leicester, with decided success, so far as earlier maturity and fattening are concerned, but with a corresponding reduction of hardiness.

"Perhaps there is no part of the whole island where, at first sight, a fine-wooled breed of sheep is less to be expected than among the Cheviot Hills. Many parts of the sheep-walks consist of nothing but peat bogs and deep morasses. During winter the hills are covered with snow for two, three, and sometimes four months, and they have an ample proportion of bad weather during the other seasons of the year, and yet a sheep is to be found that will thrive even in the wildest part of it. Their shape is excellent, and their fore-quarter, in particular, is distinguished by such justness of proportion, as to be equal in weight to the hind one. Their limbs are of a length to fit them for travelling, and enable them to pass over bogs and snows, through which a shorter-legged animal could not penetrate. They have a closer fleece than the Tweeddale and Leicester breeds, which

- Farmer's Magazine. 
keeps them warmer in cold weather, and prevents either snow or rain from incommoding them. They have never any other food, except when they are fattened, thian the grass and natural hay produced on their own hills."

The Cheviot has pushed itself over nearly all Scotland, and is everywhere contesting the ground inch by inch with the black-faced sheep. With every improvement in agriculture it advances. The fleece being more compact, it is found to be a better endurer of cold, though not so patient of hunger. On scanty pasture it does quite as well, and where there is great abundance, it leaves its black-faced competitor far behind; and it is supposed that it will soon be the only breed worthy of the Highlands of Scotland.

This may be considered a proper place to describe those terrible storms in the Scottish Highlands, to which these and the black-faced sheep are so often exposed. The subjoined accounts are from the "Shepherd's Calendar," by the Ettrick shepherd, James Hogg. "The first account is termed the "thirteen drifty days."

"For thirteen days and nights the snowdrift never once abated; the ground was covered with frozen snow when it commenced, and during all the time of its continuance, the sheep never broke fast. The cold was intense to a degree never before remembered, and about the fifth and sixth days of the storm, the young sheep began to fall into a sleepy and torpid state, and all that were so affected in the evening, died in the night. About the ninth and tenth days the shepherds began to build up huge semicircular walls of their dead, in order to afford some shelter to the remainder; but shelter availed little, for the want of food began to be felt so severely, that they were frequently seen tearing one another's wool.

"When the storm abated on the fourteenth day, there was on many a high-lying farm not a living sheep to be seen. Large misshapen walls of dead, surrounding a small prostrate flock, likewise all dead and frozen stiff in their layers; were all that remained to the forlorn shepherd and his master. In the extensive pastoral district of Eskdale-muir, which previously contained more than 20,000 sheep, only forty young wethers were left on one farm, and five old ewes on another."

The sheep seem possessed of an instinctive foresight of the approach of these storms, and will hurry to a place for 
protection, when the shepherd himself sees not a cloud, and " dreams not of the wind." "I had left," says one of these mountain shepherds, "my sheep under their accustomed shelter, and where I had never failed to find them safe and comfortable in the morning, and I was plodding my weary way homeward; but before distance and darkness closed them from my sight for the night, I looked back to see if they had given over work (digging for their food from under the snow), when I was surprised to see them on their march down hill towards a plantation which would afford securer shelter, and to which I had been accustomed to drive them when I feared the coming tempest. They had fallen into rows, pacing one after another until they reached the plantation, and there was nothing to suggest to my mind the return of a drift, but their movement and their bleating. They passed through the plantation, and took that side of it which would afford them a safe shelter from the southwest hurricanes. It, however, happened that, although their instinct had admonished them that a tempest was impending, it had not taught them from what quarter that tempest would come, and it soon began to blow from the northeast, from which they had no defence. When I came to them in the morning, the wreath was higher than the dyke, and was leaning over upon the trees. Some of the strongest sheep had kept treading down the snow as it gathered around them, and were on the top of the wreath; but many of them further back were quite immersed in the snow. However, by means of probing and digging, I got them all out, except two that had been crushed by the weight of the snow."

Instances are recorded showing an-almost incredible tenacity of life, when covered with snowdrift. A sheep near Kendal was, in the winter of 1800 , buried in the snow thirtythree days and nights, without the possibility of moving, and yet survived. In the same winter, a sheep near Caldbeck, in Cumberland, was buried thirty-eight days; when found it had completely eaten the wool off both its sides, and was rcduced to a skeleton.*

Within the last twenty years much attention has been paid to smearing the sheep of the Highland districts with a composition of tar and whale oil, which mats the wool, and shields the animal alike from cold and wet.

* Annual Register. 


\section{SHETLAND ISLAND SHEEP.}

The Shetland Islands are situated far to the north of Scotland. The sheep which inhabit them have long been selebrated for the remarkable fineness of their wool. They are not, however, aboriginal, but derived many centuries since from Denmark. They are small, seldom weighing more than ten pounds to the quarter, and yield about two pounds of wool, which has commanded as high as from three to four shillings sterling per pound.

Mr. Youatt says - "There is, perhaps, no part of the world in which the breed, or the few of it that are at present found, have remained, century after century, precisely in the same state. This admits of a ready explanation. The pure Shetland sheep deserves not the name of a domestic animal. $\mathrm{He}$ is scarcely seen more than once in the year, when he is hunted home in order to be shorn. Often he is scarcely seen at that period, for he left his coat among the bushes, and is suffered to escape disregarded."

\section{IRISH SHEEP.}

The sheep has been an inhabitant of Ireland from time immemorial, but history and tradition afford no accounts from whence the animal sprung.

Few countries are better adapted than Ireland for breeding and perfecting the sheep. The climate is removed from extremes of heat and cold, and the soil, even to the summits of its highest mountains, prolific of pasture.

The primitive sheep were of two kinds, short and long wooled; the former are confined to the mountains. In the county of Wicklow the short-wooled breed abounds, perhaps, at the present time, in the largest number. The fleece is represented as wavy, weighing from 2 to $3 \mathrm{lbs}$., and the fibre about two inches in length. The breed is valuable from the fineness of its wool, hardiness, and endurance of hard stocking. The cross of the South Down was attended with evident advantage, yet, from the prejudice and jealousy of the Irish farmers, it was not carried to the extent its success deserved. A cross was also attempted with the Merino, but it failed principally besause the Merino was not suited to the humid and cold pastures of the mountains.

The native long-wooled breed, until about the beginning of the present century, had been sadly neglected. They 
are described by Mr. Cully, thus : "I am sorry to say I never saw such ugly sheep as these-the worst breeds we have in England are by much superior. One would suppose that the sheep-breeders in Ireland have taken as much pains to breed awkward sheep, as many of the people in Fingland have to breed handsome ones. I know nothing to recommend them except their size, which might please some oldfashioned breeders who can get no kind of stock large enough. These sheep are supported by very long, thick, crooked, grey legs, their heads long and ugly, with large flagging ears, grey faces, and eyes sunk; necks long, and set on behind the shoulders; breast narrow and short; hollow both before and behind the shoulders; flat-sided, with high, narrow, herring backs; hind quarters drooping and tail set low."*

Mr. Youatt follows up this description with the remark, "that much must be set down to the score of prejudice." $\mathrm{Mr}$. Cully himself was at that time a successful breeder of the New Leicester, and no doubt was anxious to extend his favorite breed into Ireland. This by others was soon effected, and the cross established a sheep admirably adapted to the rich pastures characteristic of the country, and resulted in large increase of profits to those who embarked earliest in the enterprise. So much as 150 guineas were paid for the hire of a single ram of the improved breed of Leicesters.

Mr. Youatt says - "The new breed struggled for a while against prejudices and difficulties of every description, and at length completely triumphed. They gradually spread over the whole of Ireland; and the Irish sheep that are now brought so plentifully to the English market will scarcely yield to the best improved Leicesters that any part of Great Britain can produce." The improved fleece woighs from 5 to $7 \mathrm{lbs}$; ; the fibre is the 560th part of an inch in diameter, and the serrations 1920 in the space of an inch. Irish wool is used for stuffs, bombazines, and bombazetts.

* Cully on Live Stock. 


\section{CHAPTER VI.}

\section{BRITISH BREDS.}

NEW LEICESTER, OR BAKEWELL-TEESWATER-ROMNEY MARSHLINCOLN-BAMPTON-COTSWOLD-WELSH SHEEP-MERINO SHEEP IN ENGLAND.

NEW LEICESTER, OR BAKEWELL.

Some writers have contended that the valuable family of long-wooled sheep, now so extensively spread over Great Britain, was of foreign origin; but thorough investigation proves their assertions groundless."

With the short-wooled variety, from time immemorial, each was assigned a locality admirably adapted, from soil, herbage, and climate, to itself; and thus their respective peculiarities both of form and fleece, through many centuries, remained distinct. Both varieties have been essentially improved by the art of man, as has already been shown in reference to the South Down; and, if possible, a still greater improvement has been effected of the long-wooled breeds, especially as to profitableness of carcase, through the indefatigable efforts of Mr. Bakewell, of Dishby, Leicestershire, and Mr. Cully, his able coadjutor.

The compiler will offer no apology for introducing to the reader nearly the whole of Mr. Youatt's faithful and interesting history of this renowned breed, valuable to all as showing the means adopted by Mr. Bakewell by which the New Leicester was brought to its present perfection of carcase, and extraordinary early.maturity.

\section{THE OLD LEICESTER SHEEP.}

"This was a large, heavy, coarse-wooled breed, common to most of the midland counties, and reaching from the south of Yorkshire, and as far as Oxfordshire and Gloucestershire.

* Luccock. 
It had a white face, no horns-it was long and thin in the carcase, flat-sided, with large bones-thick, rough, and white legs-and weighing, the ewe from 15 to $20 \mathrm{lbs}$., and the wether from 20 to $30 \mathrm{lbs}$. the quarter. It was covered with wool from 10 to 14 inches in length, coarse in quality, and weighing from 8 to $13 \mathrm{lbs}$. The pelt and offal were thick and coarse; the animal was a slow feeder, and the flesh was coarse-grained, and with little flavor."

NEW LEICESTER BHEEP.

The following description of the New Leicester will show the reader in what respects $\mathrm{Mr}$. Bakewell effected his improvement over the old breed.

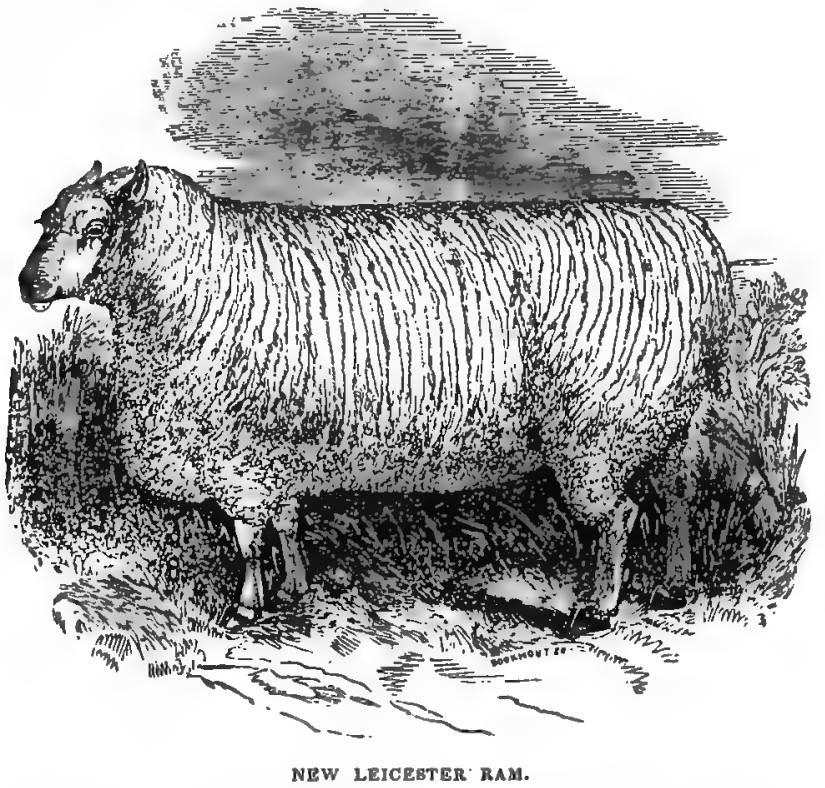

The head should be hornless, long, small, tapering towards the muzzle, and projecting horizontally forwards. The eyes prominent, but with a quiet expression. The ears thin, rather long, and directed backwards. The neck full and broad at its base where it zroceeds from the chest, but gradually ts 
pering towards the head, and being particularly fine at the junction of the head and neck ; the neck seeming to project straight from the chest, so that there is, with the slightest possible deviation, one continued horizontal line from the rump to the poll. The breast broad and full; the shoulders also broad and round, and no uneven or angular formation where the shoulders join either the neck or the back, particularly no rising of the withers, or hollow behind the situation of thése bones. The arm fleshy through its whole extent, and even down to the knee. The bones of the leg small, standing wide apart, no looseness of skin about them, and comparatively bare of wool. The chest and barrel at once deep and round the ribs forming a considerable arch from the spine, so as in some cases, and especially when the animal is in good condition, to make the apparent width of the chest even greater than the depth. The barrel ribbed well home, no irregularity of line on the back or the belly, but, on the sides, the carcase very gradually diminishing in width towards the rump. The quarters long and full, and, as with the fore legs, the muscles extending down to the hock; the thighs also wide and full. The legs of moderate length, the pelt also moderately full, but soft and elastic, and covered with a good quantity of white wool, not so long as in some breeds, but considerably finer.

"It was about the middle of the last century that Mr. Bakewell first applied himself to the endeavor to improve the then existing breed in Leicestershire. Up to this period very little care had been bestowed upon the breeding of sheep.

"Two objects alone appear to have engrossed the attention of the breeders : first, to breed animals of the largest possible size; and, secondly, such as should produce the heaviest fleeces. Aptitude to fatten, and symmetry of shape, that is, such shape as should increase as much as possible the most valuable parts of the animal, and diminish in the same proportion the offal, were entirely disregarded.

"Mr. Bakewell perceived that smaller animals increased in weight more rapidly than very large ones; and that they consumed so much less food, that the same quantity of herbage applied to feeding a larger number of small sheep would produce more meat than when applied to feeding the smaller number of large sheep which alone it would support. $\mathrm{He}_{\mathrm{e}}$ also perceived that sheep carrying a heavy fleece of wool 
possessed less propensity to fatten than those which carried one of a more moderate weight.

"Acting upon these observations, he selected from the different flocks in his neighborhood, without regard to size, the sheep which appeared to him to have the greatest propensity to fatten, and whose shape possessed the peculiarities which he considered would produce the largest proportion of valuable meat, and the smallest.quantity of bone and offal.

"In doing this, it is probable that he was led to prefer the smaller sheep, still more than he had been by the consideration above stated, because it is found that perfection of shape more frequently accompanies a moderate-sized animal than a very large one.

"He was also of the opinion that the first object to be attended to in breeding sheep was the valure of the carcase, and that the fleece ought always to be a secondary consideration. The reason of this is obvious: the addition of two or three pounds of wool to the weight of a sheep's fleece is a difference of great amount; but if to procure this increase a sacrifice is made of the propensity to fatten, the farmer may lose by it ten or twelve pounds of mutton.

"The sort of sheep, therefore, which Mr. Bakewell selected were those possessed of the most perfect symmetry, with the greatest aptitude to fatten, and rather smaller in size than the sheep then generally bred. Having formed his stock from sheep so selected, he carefully attended to the peculiarities of the individuals from which be bred, and, it appears, did not object to breeding from near relations, when by so doing he put together animals likely to produce a progeny possessing the characteristics that he wished to obtain.

"Mr. Bakewell has been supposed by some persons to have formed the New Leicester variety by crossing different sorts of sheep; but there does not appear to be any reason for believing this; and the circumstance of their varying in their appearance and qualities so much as they do from the other varieties of the long-wooled sheep, can by no means be considered as proving that such was the system which he adopted. Every one, who has attended to the breeding of domestic animals must have experienced that, by careful selection of those from which he breeds, and with a clear and defined conception of the object he intends to effect, he may procure a progeny in which that object will be accomplished 
"Such is the origin 'of the New Leicester breed of sheep, which have within little more than half a century spread themselves from their native county over every part of the United Kingdom, and are now exported to the continents of Europe and America. Such, indeed, have proved to be their merits, that at the present day there are very few flocks of long-wooled sheep existing in England, Scotland, or Ireland, which are not in some degree descended from the flock of Mr. Bakewell. A pure Lincoln or Teeswater flock is very rarely to be found; and although some flocks of the pure Cotswold breed remain, in the greatest number of instances it is probable that they have been crossed with the New Leicester.

"No other sort of sheep possesses so great a propensity to fatten-no other sort is fit for the butcher at so early an age-and although they are not calculated for the poorest soils, where the herbage is so scanty that the sheep must walk over, a great deal of ground for the purpose of procuring its food, no other sort of sheep, in soils of a moderate or superior quality, is so profitable to the breeder.

"They vary much in size, weighing at a year and a half old, with ordinary keep, from 24 to 36 lbs. per quarter.* In this respect, therefore, they are inferior to the Lincoln, the Cotswold, and the Teeswater sheep. By crossing them with either of these breeds, the size of the sheep may be considerably increased; and it is said that this may be done without diminishing perceptibly either their inclination to become fat, or the early maturity for which they have always been remarkable.

"The kind of meat which they yield is of a peculiar character. When the sheep are not over fattened, it is iender and juicy, but, in the opinion of many persons, somen hat insipid.

"The Leicester sheep were never favorites with the butcher, because they had little loose inside fat. It ought, nevertheless, to have been recollected that the smallness of the head, and the thinness of the pelt, would in some measure counterbalance the loss of tallow; and that the diminution of offal is advantageous to the grazier, for it shows a

* The heaviest pure Leicester, of which there is any authentic account, belonged to Mr. Morgan, of Loughton; its live weight; was $368 \mathrm{lbs}$, and the weight of the carcase, $248 \mathrm{lbs}$ 
disposition to form fat outwardly, and is uniformly accom panied by a tendency to quickness of improvement.

"The New Leicesters, however, are not without their faults. They are not, even at the present day, so prolific as most other breeds. This was too much overlooked in the time of Bakewell and his immediate followers. Their object was to produce a lamb that could be forced on so as to be ready, at the earliest possible period, for the purposes of breeding or of slaughter, and therefore the production of twins was not only unsought after, but was regarded as an
evil.

"It was likewise, and not without reason, objected to them that their lambs were tender and weakly, and unable to bear the occasional inclemency of the weather at the lambing season. This also was a necessary consequence of that delicacy of form, and delicacy of constitution too, which were so sedulously cultivated in the Leicester sheep.

"The last objection to the New Leicester sheep was the neglect and deficiency of the fleece. There is little cause, however, for complaint at the present period. The wool has considerably increased in length, and has improved both in fineness and strength of fibre; it averages from 6 to $7 \mathrm{lbs}$. the fleece, and the fibre varies from five to more than twelve inches in length. It is mostly used in the manufacture of serges and carpets.

"The principal value of this breed consists in the improvement which it has effected in almost every variety of sheep that it has crossed; but it has met with, especially in Wales, a powerful antagonist in the Cotswold."

The introduction of additional evidence showing the necessity of providing luxuriant pasturage for the Leicester breed, will be proper.

"I occupied a farm," says a Lammermine shepherd, "that had been rented by our family for nearly half a century. On entering it, the Cheviot stock was the object of our choice, and so long as we continued in possession of this breed, everything proceeded with considerable success; but the New Leicesters came into fashion, and we, influenced by the general mania, cleared our farm of the Cheviots and procured the favorite stock. Our coarse bean pastures, however, were unequal to the task of supporting such heary-bodied sheep; and they gradually dwindled away into less and less bulk; each generation was inferior to the preceding one: 
und, when the spring was severe, seldom more than two thirds of the lambs could survive the ravages of the storm."

Sir John Sinclair has also recorded his opinion on this point "The Leicester breed is perhaps the best ever reared for a rich arable district; but the least tincture of this blood is destructive of the mountain sheep, as it makes them incapable of withstanding the least scarcity of food."

The New Leicester breed have been extensively introduced into the North American British Provinces, and the United States; and when suitable localities have been chosen, their cultivation has been attended with success.

\section{TEESWATER SHEEP.}

This breed derives its name from the river which separates Durham from Yorkshire. It is supposed, from its similarity of conformation to the old Lincolnshires, to have orig. inated from that stock. "It was a tall, clumsy animal, polled, and with white face and legs; the bones small compared with those of other large breeds, yet supporting a thicker, firmer, and heavier body than their size would indicate; wide upon the back, somewhat round in the barrel, and yet yielding a heavier carcase than any other sheep, but proportionably longer in growing to perfection; the meat, how ever, was finer-grained than could be expected from such an animal."

The old Teeswater was exceedingly prolific. Mr. Cully records a singular instance of a ewe belonging to a Mr. Eddison, which, at two years old, brought him four lambs, three in the following year, two in the succeeding one, and the extraordinary number of five, the next year. The fleece weighed about nine pounds previous to any improvement of the carcase by the cross of the New Leicester; and the wool was remarkably long, coarse, and thinly set on the skin.

The improvement which followed the cross alluded to, at length superseded entirely the old breed; and the improved Teeswater sheep now rivals the Leicester, in disposition to fatten, early maturity, as well as quality of fleece.

ROMNEY MARSH SHEEP, OF KENT.

Romney Marsh is an extensive tract of land recovered trom the sea in a very early period of English history: 
A portion of the soil is poor and sandy, but very much of the marsh affords a superabundance of rich and valuable pasture for sheep. A long-wooled and highly profitable breed of sheep has been kept on these reclaimed lands from time immemorial, and which has undergone but partia] change, until within a few years.

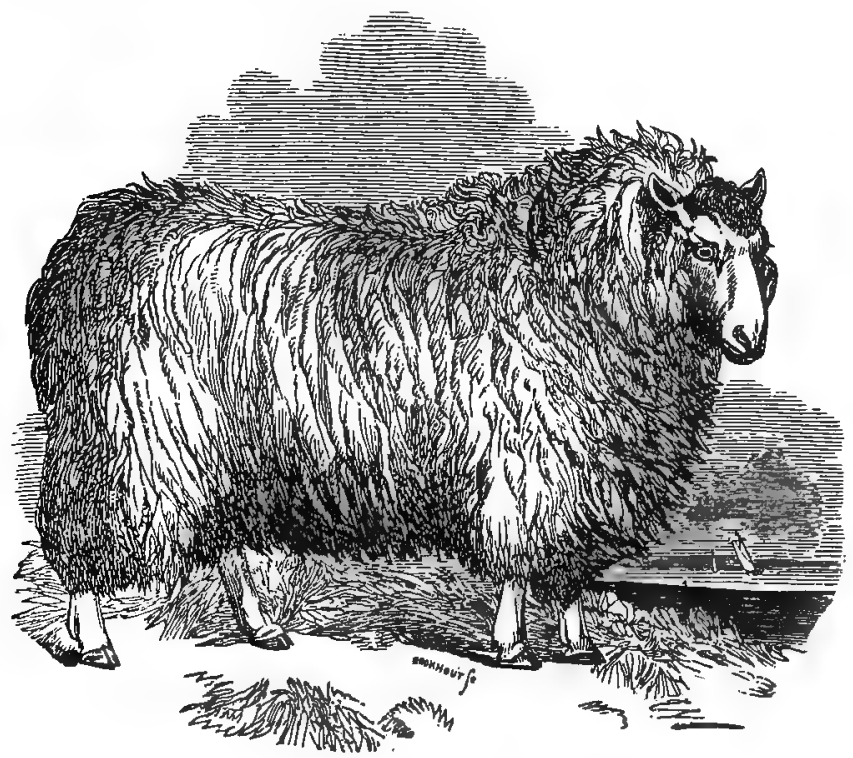

ROMNEY MAREH RAS.

"The pure Romney Marsh breed of sheep are distinguished by thickness and length of head, a broad forehead with a tuft of wool upon it, a long, thick neck and carcase. They are flat-sided, have a sharp chine, and tolerably wide on the loin, have the breast narrow and not deep, and forequarter not heavy nor full. The thigh full and broad, the belly large and tabby, the tail thick, long, and coarse; the legs thick, with large feet; the wool long, and not fine ; they have much internal fat, and are great favorites with the butcher They have much hardihood; they bear their cold 
and exposed situation well, and they require no artificial food during the hardest winter, except a little hay." "."

The average weight of the fleece is from 6 to 7 lbs. The breed has been successfully crossed with the Leicester, and many of the bad points of the original stock rectified.

\section{LINCOLN SHEEP.}

From the fact that the Lincoln sheep have been introduced into this and other states, and are deservedly formidable rivals of the Leicester and Cotswold, the author, from mutives of delicacy towards the respective breeders, prefers to render the account of the Lincoln breed in the language of Mr. Youat, which, on perusal, will appear an impartial one.

After contradicting, on good grounds, the assertions that the breed was originally foreign, he says- "The Lincoln sheep, according to Ellis, who is the oldest agricultural writer in whom any description of them is given, were the "longest legged and largest carcassed sheep of all others, and carried more wool on them than any sheep whatsoever."

"It is true that a larger quantity of wool was clipped from the Lincolnshire sheep than any other in the kingdom; and thence arose the error into which the Lincolnshire breeders fell; they bred for the fleece, and for the fleece alone. Bakewell neglected the fleece-ithe Lincolnshire farmer the carcase ; hence the opposite errors of each, and the reasonableness and advantage of the plan by which both the carcase and fleece were at length brought to the highest degree of perfection.

"If the Lincolnshire farmer too much neglected the carcase, there were times when the sheep, or when nature, would vindicate its claims. It is true that the form was gaunt and somewhat unsightly, but the excellence of the breed, as a grazing sheep, would occasionally appear. If the Lincoln would consume more food than the Leicester, it would increase in weight proportionably to the extra quantity of food which it ate; and this, together with the additional weight of wool, rendered it nearly or quite as profitable to the farmer.

"There was a long and acrimonious contest between the 
Leicesters and the Lincolns for the point of supremacy. The continuance, however, of the contest, and the doubt which even now exists in the minds of some, with regard to the relative value of the respective breeds, show that the old Lincolnshire should not have been spoken of in a disparaging way. Before they were allied to the Leicesters, and ill-formed and rough as they were, they had attained no small degree of excellence both in the carcase and the wool.

"At length a union was established between them. The Lincoln ewe was put to the Leicester ram, and the progeny certainly displayed, and to a very great and profitable extent, the excellencies of the male parent; the wether attained its maturity a full year sooner than it was accustomed to do, and with less comparative expense of food even in that time; and when the ewe was drafted, she too was sooner ready to be sent to the market, and weighed considerably more than she was wont to do, and was in higher repute and more readily sold.

"Mr. Clark, of Canwick, in 1827; exhibited two wether sheep in Lincoln Market, the fleeces of which had yielded, each, 12 lbs. of wool. They were slaughtered-the carcase of the larger one weighed $261 \mathrm{lbs}$.: the fore-quarters were, each of them, 73 lbs., and the hind quarters 57 1-2 lbs.! On the top of the rib the solid fat measured nine inches in thickness!

"The average weight of the fleeces of the Lincoln breed is from 8 to 10 lbs. It has since become finer and the color is improved, but it is shorter, a material objection in some fabrics, and it has lost some of that toughness which is an indispensable quality in the best combing wool. The light and tender kind of wool is valuable in the manufacture of the rougher woollen articles, but it is not suited to the finer worsted fabrics.

"The fibre is the 480th part of an inch in diameter, and the serrations 1280 in the space of an inch."

\section{BAMPTON SHEEP.}

This breed is found extensively spread over the north of Devonshire, and also in Somersetshire. The name is derived from a village on the borders of the two counties, where they are supposed to have been first bred.

In the Annals of Agriculture, a writer thus describes them : "They are the best breed in Devonshire, and have "existed 
in the neighborhood of Bampton for centuries. A fat ewo of that breed rises to $20 \mathrm{lbs}$. a quarter on an uverage, and wethers to $30 \mathrm{lbs}$. or $35 \mathrm{lbs}$. a quarter at two years old. 'They are white-faced; the best breed living, more like the Leicesters than any other, but larger boned,-longer in the legs and body, though not so broad-backed. Eighteen lbs. of wool have been shorn from a ram of this breed that was supposed to be 40 lbs. the quarter.

They have been crossed with the Leicester with evident advantage it is considered by some, while others contend to the contrary, the wool being lessened in weight, length, and toughness, and the lambs more tender and difficult to rear

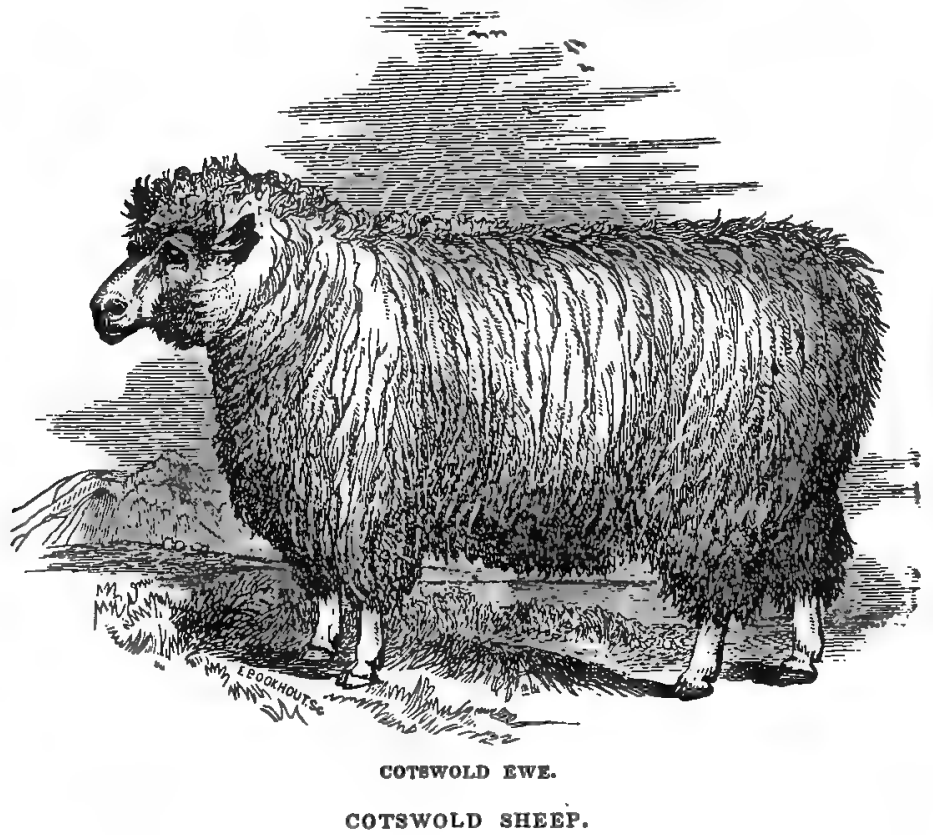

The following account of this breed is by Mr. Spooner :"This is an ancient and celebrated breed, its wool being spoken of very favorably by many old writers, Cotswold signifies a sheep-fold and a naked hill. The Cotswold hills, the native tract of the breed, are of moderate elevation, pos- 
sess a sweet herbage, and though formerly consisting mostly of bleak wastes, have been latterly much improved. Camden speaks of the breed as having fine and soft wool. Dray. ton writes of its fleeces as more abundant than those of Sarum and Leominster. Speed, writing 200 years ago, speaks of the wool as similar to the Ryeland, and rivalling that of Spain. Indeed, some imagine it was the origin of the Merino sheep, as in 1464 Edward IV. permitted a number to be exported to Spain, where they greatly increased and spread. Spain, however, before this, was celebrated for the fineness of its wool. Markham, in the time of Queen Elizabeth, speaks of the Cotswold as having long wool, and Mr. Marshall and other writers consider that they have always been a long-wooled breed. It is difficult to reconcile these differences of opinion; for my own part, I am disposed to think that the present are the descendants of the old race; be this as it may, we have no evidence, either oral, written, or traditional, of the change having been made.

The Cotswold is a large breed of sheep, with a long and abundant fleece, and the ewes are very prolific and good nurses. Formerly these bred only on the hills, and fatted in the valleys of the Severn and the Thames; but with the enclosure of the Cotswold hills, and the improvement of their cultivation, they have been reared and fattened in the same district. They have been extensively crossed with the Leicester sheep, by which their size and fleece have been somewhat diminished, but their carcases considerably improved, and their maturity rendered earlier. The wethers are now somelimes fattened at fourteen months, when they weigh from $15 \mathrm{lbs}$. to $24 \mathrm{lbs}$. per quarter, and at two years old increase to $20 \mathrm{lbs}$. or $30 \mathrm{lbs}$. The wool is strong, mellow, and of good color, though rather coarse, six to eight inches in length, and from 7 to $8 \mathrm{lbs}$. the fleece. The superior hardihood of the improved Cotswold over the Leicester, and their adaptation to common treatment, together with the prolific nature of the ewes and their abundance of milk, have rendered them in many places rivals of the new Leicester, and have obtained for them of late years more attention to their selection and general treatment, under which management still further improvement appears very probable. They have also been used in crossing other breeds, and have been mixed with the Hampshire Downs. It is, indeed, the improved Cotswold that, under the term New or Improved 
Oxfordshire Sheep, are so frequently the successful candidates for prizes offered for the best long-wooled sheep at some of the principal agricultural meetings or shows in the kingdom. The quality of the mutton is considered superior to that of the Leicester, the tallow being less abundant, with a larger development of muscle or flesh. We may, therefore, regard this breed as one of established reputation, and extending itself throughout every district of the kingdom."

WELSH SHEEP.

Little can be said of the welsh sheep to interest the American wool-grower. The primitive breeds are of two kinds-mountain and valley sheep; the former producing. a short fine wool, and the latter a coarse fleece with medium length of staple.

Ellis, the ancient author of the "Shepherd's Sure Guide," says-" I am now come to write on the hardiest sheep there are for living in a cold country, and any where else, on that short bite of grass where a large sheep would pine and starve; but they are not the choice of many, because they are apt to straggle and run away. They are a small, short, knotty sheep, that come from the poorest living, and thrive and fatten quickly for the butcher, and become the sweetest of mutton, particularly for a private family's uses, who delight to eat the best and finest sorts." The ewes of this breed average about $8 . \mathrm{lbs}$. to the quarter, and the wethers $10 \mathrm{lbs}$, when at three years old. The mutton is particularly well-flavored, and in the months of October and November, commands a much higher price than that of other breeds of. larger size. A considerable quantity of Welsh mutton finds its way to the London market.

Since the introduction of turnip husbandry, the cross of the Leicester has been tested, and in many parts of the valley regions more productive of herbage than others, it has succeeded; but the Cotswold, from greater natural hardihood, has contested the ground with the Leicester, and with marked superiority over its formidable competitor.

\section{MERINO SHEEP IN ENGLAND.}

George the III. was distinguished as an ardent promoter of agriculture, and determined in 1787, to make a fair trial of this renowned breed; and accordingly a few were ordered and placed on his farm at Kew. They were selected in Es 
tremadura, on the borders of Portugal; and this, at that time, was a sort of smuggling transaction, as no Merinos could be sent from any Spanish port without a license from the king; therefore they were obliged to be shipped from Lisbon. The sheep were hastily - chosen from different flocks and various districts, and consequently exhibited but little uniformity, and not fully the true character of the breed; the king, therefore, soon disposed of them to others.

Subsequently, it was determined to make a direct application to the Spanish monarch for permission to make a selection from some of the best flocks. This was promptly granted; and a small number was taken from the Negrette variety, then deemed the most valuable of the migratory sheep. This flock arrived in 1791, and was immediately placed on the king's farm.

From ignorance, they were at first badly managed. Having been placed on a moist and luxuriant soil, many soon became affected with foot rot, and others died from attacks of liver rot. This calamity was a triumph to the prejudiced, but a change to dryer pasture proved a remedy, which soon led to a change of opinion in their favor. In a short time it appeared that they were no more subject to diseases than British sheep.

Crosses took place with several varieties of the native breeds, with various success. Doctor Parry crossed with the Ryeland, the most superior short-wooled sheep in England, and the fourth cross produced a wool equal to pure Merino.

- Mr. Coke, the renowned English agriculturist, also experimented on both the Ryelands and South Downs, and affirmed that the cross with the latter was superior to that of the former. It was but a few years afterwards, that he expressed the following opinion, in an address before the Merino Society, at Holkham:- "I feel it my duty," said he, to state my latest opinion of the effects of the cross of a part of my South Down flock with Merino tups, and I wish it could be more favorable. From the further trial which I have made, (this, the fourth year), I must candidly confess that I have reason to believe that, however one cross may answer, a farther progress will not prove advantageous to the breeder." This opinion of Mr. Cokse should be duly considered by every American breeder.

But, sometime antecedent to this decision of $\mathrm{Mr}$. Coke 
very many who had entertained apparently insurmountable prejudices were bold to acknowledge the merits of the Merinos, and became fully satisfied that neither the climate or herbage of their new home were incompatible with perfect success. Sir Joseph Banks and Lord Somerville were amongst their staunchest and zealous advocates, and the latter duly tested the sincerity of his opinions, by importing a considerable flock of them.

Thirteen years after the king's importation of the Negrette flock, a public sale by auction was made of Merinos. The rams averaged about fifty dollars per head, and the ewes thirty. In 1808, four years after, the prices averaged 130 dollars for rams, and 100 dollars for ewes. In 1810 the $\mathrm{Me}-$ rinos arrived at the climax of public favor. In this year, at another public auction sale, rams commanded nearly 300 dollars per head. "One full-mouthed Negrette was sold for over 800 dollars, and another for nearly 700."

A Merino Society was instituted in the following year, at the head of which was placed Sir Joseph Banks, with fiftyfour Vice Presidents, and local committees were established in every county in England, Scotland, Ireland, and Wales.

Mr. Youatt observes-" No more striking instance can be produced of the fallacy of human expectations and judgment, than the establishment of this society. From this period is to be dated the rapid decay of the Merinos in public estimation." After a passing tribute of just praise to the breed, he proceeds to say, "In Great Britain, nevertheless, where the system of artificial feeding is carried to so great a degree of perfection-where the sheep is so early and so pro fitably brought to the market-that breed, however it may ulti mately increase the value of the wool, can never be adopted, which is deficient, as the Merinos undeniably are, in the principle of early maturity, and general propersity to fatten."

Other reasons for the abandonment of the Merinos are given by Mr. Plint, a distinguished agricuiturist. He says - I I always thought the speculation of cultivating the $\mathrm{Me}$ rinos a decidedly foolish and unprofitable one. We can consume all the coarse wool we grow, and more if we conld get it ; and taking carcase and weight of wool together, the longwooled sheep is more profitable by far than the Merino. Besides, if the English breeds were to any considerable extent superseded by the Merinos, the price of that wool would fall, and long wools would rise; and ise advantage of grow- 
ing fine wool, on account of its high price, would slip through the fingers of the agriculturist. If we could grow more of both kinds, well and good; but in present circumstances, a profit by foreign wool is as good as a profit by fine wool, and we can only have one; and it is the part of wisdom to take that which is easiest got."

The above are the substantial reasons for the downfall of the Merinos in Great Britain, and not altogether, as many have supposed, from the humidity of the climate. Long after their introduction, the wool of the Merinos was carefully compared with the best samples of pure Spanish, and no deterioration was perceptible. A dry climate is best suited to the Merino, but many years would elapse before a humid one, without other causes, would produce any essential change in the properties of its fleece. High feeding is altogether a more potent cause of deterioration.

The Table will indicate to the reader the comparative va lue of the wools imported into Great Britain. 'The prices were current in 1834, in London.

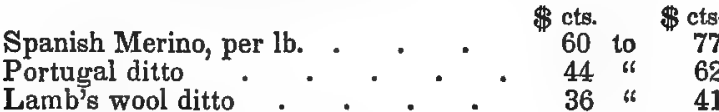

Grerman, Saxon, and Silesian:-

1st and 2d Electoral . . . . 105 " 115

Prima . . . . . . . 88 " 110

Secunda . . . . . . . 66 " 677

Tertia . . . . . . 48 " 55

Austrian, Bohemian, and Hongarian :-
1st Electoral
• • •

$\begin{array}{llllllll}1 \text { st Electoral . . . . . } & & 88 & 4 & 1 & 20 \\ \text { Prima } & . & 77 & 6 & 1 & 00\end{array}$

Secunda . . . . . . . 55 \& 78

Tertia * . . . . . . 44 " 67

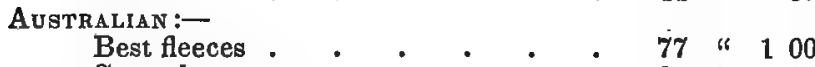

Seconds . . . . . . . 61 " 68

Inferior flocks . . . . . 50 " 62

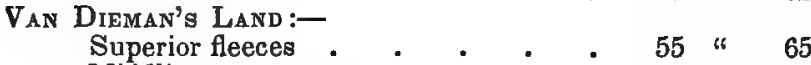

Middling . . . . . . .

Inferior . . . . . . . . 22 " 24

British Fleeces:-

North and South Down . . . . $\quad$. 44 " 48

Leicester fleeces . . 33 " 44

Romney Marsh, Lincoln, and Cotswold $\quad 40$ " $\quad 44$

Anglo Merino in yolk . . . $\quad 22$ " 30 


\title{
CHAPTER VII.
}

\author{
SHEEP OF THE UNITED STATES AND \\ SOUTH AMERICA.
}

WOOLLY SHEEP OF ROCKY MOUNTAINS-OTTER SHEEP-ARLINGTON LONG WOOLED SHEEP-SMITH'S ISLAND SHEEP-REMARKS ON MERINOS AND BAXONS-PRAIRIE MANAGEMENT OF SHEEPOBSERVATIONS ON WOOL CULTURE IN THE SOUTH, AND SOUTHWESTERN STATES-CENSUS STATISTICS-SOUTH AMERICAN SHEEP -ALPACA, OR PERUVIAN SHEEP-WOOL CULTURE ON THE PAMPAS.

\section{SHEEP OF THE UNITED STATES.}

NeIther North or South America can boast of any aboriginal or primitive domestic breeds of sheep: those which have received the name of "native" having been brought over at various periods from Europe by the colonists.

Before proceeding to notice several of these breeds, it will be proper to refer to an animal found among the Rocky Mountains, which is confounded with the Argali, and known as the "woolly sheep." Captain Bonneville says, "This animal is found about the country of the Flathead Indians. It inhabits cliffs in summer, but descends into the valleys in the winter. It has white wool, like a sheep, mingled with a thin growth of long hair; but it has short legs, a deep belly, and a beard like a goat. Its horns are about five inches long, slightly curved backwards, black as jet, and beautifully polished. Its hoofs are of the same colour. This animal is by no means so active as the big horn; it does not bound much, but sits a good deal upon its haunches. It is not so plentiful either; rarely more than two or three are seen at a time. Its wool alone gives it a resemblance to the sheep; it is more properly of the goat genus. The fleece is said to have a musty flavor; some have thought the flesh might be valuable, as it is said to be as fine as that of the goat of Cashmere but it is not to be procured in sufficient quantities." 
The colonists, coming as they did from various districts of their native countries, it is presumed brought with them breeds of sheep peculiar to those districts; and having been promiscuously bred, at the period of the introduction of the Merinos, few of them conformed to any of the varieties of the more distinguished British breeds.

They were long legged, narrow chested, comparatively slow in arriving at maturity, yielding a coarse white wool of medium length of staple, and the fleeces averaged from. 3 to 4 lbs. The principal recommendation consisted in being prolific breeders and good nurses; but their defects greatly predominated, being untractable, impatient of restraint, scaling high fences, and committing often serious depredations on the crops of the farmer. Happily this ungainly and unpiofitable tribe has disappeared, except in portions of the southern States, and their place has been supplied with more profitable sheep, effected by crossing them with Merinos, Saxons, and the improved English breeds.

For the gratification of the curious, rather than for utility, the compiler will notice a singular breed of sheep known as

\section{THE OTTER SHEEP.}

This unique breed have derived no little fame, not so much however, from their peculiarity of conformation, as from their fortuitous origin; this being the fact, as the sire and dame of the first individual of the breed were distinguished by the usual characteristics of the natives, long legs, \&c. This accidental origin, therefore, is valuable to the philosopher as accounting in part for the numerous varieties of the genus Ovis, now spread over almost every inhabitable part of the globe. Climate and herbage are also prominent causes of differences in conformation, but accident has undoubtedly had more to do in producing these differences, than is generally conceded.

The precise point where the Otter breed originated seems unsettled; Chancellor Livingston states that it was on an island opposite the New England coast; another writer says it was in Massachusetts, and in a flock which belonged to Seth Wright, and occurred in 1791. It is however, of little moment, as the breed have been abandoned, and become extinct.

A ewe gave birth to twins, one of which was a male, with legs so short, and being turned outward, that, as Chancellor 
Livingston observes, "they appeared as if they had been broken and set by an awkward surgeon." When running, its gait was of a hobbling or rickety character, and painful to the beho:der. The body was long and round, and the animal presented no other evidence of mal-formation. Curiosity induced, at first, breeding from it, and the progeny presented a striking resemblance to the sire. They were prized for no other reason than because nature had deprived them of the power to scale fences and commit depredations on the farmers' crops, which was so characteristic of their progenitors. This is probably the only instance where man has availed himself of a defect in the animal kingdom, and turned it to his advantage.

\section{ARLINGTON LONG WOOLED SHEEP.}

Chancellor Livingston thus notices this breed: "From the Qtter breed I turn with pleasure to the Arlington long wooled sheep. These, Mr. Custis, who was the original breeder of them, informs me were derived from the stock of that distinguished farmer, soldier, statesman, and patriot, Washington; who had collected at Mount Vernon whatever he believed useful to the agriculture of his country; and, among other animals a Persian ram, which Mr. Custis describes as being very large and well formed, carrying wool of great length, but of a coarse staple. This stock, intermixed with the Bakewell, are the source from which the fine Arlington sheep are derived; some of which, he says. carry wool fourteen inches in length, and are formed upon the Bakewell model. * * * * The sample of wool which Mr. Custis sent me from this stock possessed every ingredient which is esteemed in combing wool. It was fine for the sort, soft, silky, and beautifully white."

This breed is still held in high estimation among some farmers in Virginia and Maryland, but are now very much inferior to their ancestors, and the improved long wooled British breeds, both for mutton and value of fleece.

There is yet another breed of sheep to notice, which have been somewhat famous, and were doubtless abundantly superior to the average of other sheep of the day. They were called the

SMITH'S ISLAND SHEEP.

The island is on the coast of Virginia, and it, together 
with the sheep, were the property of Mr. Custis, who stated the breed to be peculiar to that part of the country..

The climate being temperate, and the soil producing a succulent and varied herbage, all being so well suited to sheep, the carcase and wool in ppocess of time became greatly improved; and hence the deservedly high estimation of the breed by Mr. Custis and others. The wool was very white, and comparatively fine; the staple from 8 to 10 inches in length, and the fleeces averaged about $8 \mathrm{lbs}$. The descendants of the flocks, though greatly degenerated, are diffused over a wide section of country in Virginia, and further south.

From the foregoing brief description of the qualities of the native sheep, it will readily be conceived that they were susceptible of great improvement. Their amelioration commenced on the arrival of the Merinos introduced by Chancellor Livingston and Gen. Humphrey, but until the embargo of 1807, there was little stimulus to aid this laudable enterprise. After that event and during the war with Great Britain, which soon after followed, the nation was thrown upon its industrial means for the supplies of the staple necessaries of life ; and wool culture received such an impetus, and such consequently was the competition for the possession of the Merinos, that individuals of the breed sold for the enormous prices of from 500 to 1400 dollars per head. Manufactures had been commenced, and notwithstanding the little skill employed in them at that early day, they prospered; but on the declaration of Peace in 1815, commerce brought to our shores the cheaper fabrics of Europe, and the Merinos and our infant manufactories were prostrated together. Remunerating prices could no longer be cotained for wool of any description, and this unfortunate state of things continued without intermission for many years. Notwithstanding this, however, the wool growers of the north were too sagacious not to appreciate the Merino fleece, and to see in the vista of the future a period when its culture would again be a source of prof: Hence the Merinos spread gradually over all the northern States; and in all instances where the principles of breeding were properly understood and practiced, their fleeces suffered no deterioration.

The policy of our National Government in 1824 being more in unison with the agricultural interests of the country, revived the spirit for extending the culture and improvement 
- of the fleece, which had been so many years prostrate and dormant. Accordingly the Saxons were soon after introduced; and notwithstanding the gross frauds which were practised by bringing with them so many worthless specimens of the race, and the untoward circumstances which since then wool-growers have been obliged to contend against, the exertions to perfect the fleece have been crowned with much success, though by no means commensurate with its importance.

The New England States, from the unkindness of the soil peculiar to large portions of them for the cultivation of crops, at an early day became distinguished for the growing of wool, and yet maintain their high rank, not only for the extent of its production, but the fineness of its texture. There are Saxon flocks in Connecticut and New Hampshire which rival some of the best German; and Merinos also in nearly all of these States, whose fleeces surpass in weight and fineness those of Spain at the present day, and equal the farfamed Rambouillets of France.

The State of New York has within her borders more than one quarter of all the sheep in the Union; and in the aggregate, the wool of her flocks is unsurpassed in quality by that of any other State.

The State of Pennsylvania, although she has fewer sheep by far than her soil is capable of supporting, yet on her western borders, especially in the county of Washington, she has flocks that are rarely equalled.

Ohio too is far advanced in wool culture, and the flocks descended from the celebrated sheep of Messrs. Wells and Dickinson, formerly of Steubenville, are of very superior quality, the wool of which is distinguished for length and silkiness of staple.

From Pennsylvania and Ohio have sprung, principally, the colonies of sheep which are now present on the western prairies, and which leads to the subject of wool culture on those immense plains.

The following extracts are from a pamphlet on the subject of Prairie Management, written by Mr. George Flower, and published in 1841. Mr. Flower has been a resident of Edwards County, Illinois, since 1817, and during the whole of this period, a manager and proprietor of fine-wooled sheep.

"A glance must now be taken at the difficulties and risks to which flocks are exposed in new countries, and which 
have hitherto prevented their rapid increase upon any large scale.

"The wolf is a great drawback on the pleasure and profit of sheep-keeping. It is not only what the beast destroys, but the expense incurred in watching against his'attacks. But the greatest loss sustained is being obliged to pen the sheep every night, for safe keeping. *** * Deaths, from unknown causes, have swept away whole flocks, newly bronght into the State, which tends to dampen similar enterprises. Many sheep are often purchased from drovers, which have been over-driven, and which has laid the foundation of disease. From whatever cause it may arise, if the sheep are poor in the fall of the year, great loss will accrue to the owner. 'The dry, mild weather in autumn is often accompanied with scanty herbage, and sheep rapidly decline unobserved, the growth of wool concealing their poverty from an unpractised eye, and a mortal stroke is inflicted before the owner suspects it. It is a great point to procure sheep from healthy floeks, if possible. When they are brought from a distance, care should be taken that they are not over-driven. $\Gamma$ weive or fifteen miles a day is far enough, and should never be urged beyond their naturally slow pace. It behooves the farmer to see that he has an abundance of nutritious food on their arrival at their journey's end. Keeping sheep of all ages in a flock, in a pasture barely sufficient for them, destroys the young and the old. The strong, robust sheep eat up all the food. In winter feeding, not allowing sufficient trough and rack room for all the sheep to feed at once, without crowding each other, starves the weakest. These are some of the known causes of failure of success, and lest there should be others of a local nature, I would advise every new beginner to be moderate in the number of his flock the first year; two or three hundred is enough for the ewe flock.

"The Prairie grass is green, succulent, and nourishing, until the first part of July ; from that time onward it becomes less and less acceptable. If a flock is kept upon it, in the latter part of summer it requires a large range and fresh pasturage. But a method is known to the frontier settlers, of retaining spring herbage, until the approach of winter. Select a patch of prairie (some five or ten thousand acres) that

" has not been burned the preceding year. The mass of old dry grass, in the middle of June, is sufficiently combustible to 
allow fire to consume it with the growing crop of green grass. Burn a patch in June, and the young grass will immediately spring up, which, in July, will afford a rich pasture of young, tender, juicy grass, about eight inches high. Burn another patch in July, which will afford another pasture in August; and a third on the first day of August; which will remain green and tender till killed by winter frosts. In this way juicy pasture may be secured from early spring until the succeeding winter. But some forecast is necessary to secure this. In the previous autumn these spots should be selected and made secure by burning round, as the hunters know how ; otherwise they might be consumed in the general conflagration, which often sweeps hundreds of miles of prarrie grass in the fall of the year. Supposing no cultivated grasses are prepared, sheaf oats, or hay and corn, should be given at night; the flock going out to pick what they can through all the fine days of autumn and winter:

"In the summer the shepherd must have a cabin near his pasture ground, and a sheep-yard with a wolf-proof fence. The flock must be out at the first dawn of day, and graze late in the evening. During all the heat of the day they will shade in some neighboring grove. The shepherd must have his horn and rifle, and a pair of good hunting dogs, to chase away the wolf and fox. The size of the flock may be limited only to the size of the pasture. For a summer establishment I should select an eminence on some of our extensive prairies, and build four cabins, for the families of four shepherds-all under the eye of an experienced man. These four shepherds should each diverge with their respective flocks to the four points of the compass, and all return at night.

"Where there are no cultivated grasses, there should be large fields of early sown rye, for winter and early spring food. Also oats, sown, perhaps, in the same field where oats grew before, by ploughing the field immediately after the crop is off, and sowing about a bushel to the acre. If no cultivated grasses are provided for sheep to feed on in autumn, it is difficult to keep up their condition in the latter part of the year. But the greatest advantage is to be derived from blue grass, which, if shut up in June, will keep green all winter; and, if a succession of pastures is provided, the sheep will do well upon them all the winter, and will only need feeding when the snow is frozen on the ground." 
Mr: Flower states, that the diseases to which sheep are subjected on the prairies of Southern Illinois, are liver-rot and foot-rot; the former caused by " suffering sheep to pasture on land that is overflowed with water; even a crop of green oats, early in the fall before a frost comes, has been known to rot young sheep." He observes, that sheep fed exclusively on pasture are more liable to foot-rot than others.

The following communication, writen at the request of the writer, by $J$. Ambrose Wight, associate editor of the Prairie Farmer, sets forth the extent to which Northern Illinois is adapted to sheep culture ; and, in the main, his remarks are doubtless applicable to the prairies of all the Northwestern States and Territories. There is manifestly so much ignorance prevalent on this subject, no apology is necessary for the minuteness with which Mr. Wight has treated it.

"It is but a little while since wool-growing was commenced in Northern Illipois. Small flocks, of from ten to a hundred, have been kept here since the first settlement of the country, consisting generally of hardy, coarse-wooled animals; and though the success of the business, when conducted in this manner, might be proof of the adaptation of the country to the keeping of sheep, to a certain extent, it would not be entirely satisfactory to one who should ask the question, whether the country were adapted to growing fine wool on a large scale. It is now about four years since a commencement was made of driving in large flocks for this latter purpose; since which time the incrcase has been about one hundred per cent. yearly, until last season, when the increase was so much larger, that no accurate estimate can yet be made of it.

"In order to answer your inquiries the more satisfactorily, I will take them up in their order.

"First- I would be glad to know whether the pasture of the prairies dries so much in summer as to compel the removal of sheep from them to other localities?'

"If the question relates, as I suppose it does, to summer drought, I answer no; the upland prairies-a term which I suppose embraces nineteen twentieths, if not more, of the prairie lands of Northern Illinois-sustain drought better by far than any lands I have ever known. A large component of all these lands-and the remark applies as well to what are here called 'barrens'-is black sand; though the color varies much in different localities. The ashes made by the 
annual fires are also no inconsiderable component, and aid in giving character to the soil. Most of the subsoil is a sort of hard-pan, made of clay or loam cementing together pebbles and gravel, and is found from one to three or four feet below the surface, and is so tenacious as to require a pick to break through it.

"In the lowlands, both of prairies and barrens, the subsoil is sometimes clay, and the soil more or less argillaceous. The timber growing on the barrens will yery nearly determine the character of the soil and subsoil. If the Burr Oak is plenty, the former will be sandy, and the latter hard-pan; if black or white oak abounds, clay will be more likely to be found. Besides the resistance to drought, offered in the character of the soil, the roots of the wild grass run to an extraordinary depth; many of them reaching entirely through the soil, however deep it may be. The grass grows in stools, at distances of from three to twelve inches apart, there being, in fact, where the wild grasses only are found, no such thing as a surface turf, such as is formed by red-top and kindred grasses. It will be seen that it requires a very dry summer indeed to affect such pasture, on such a soil. In the autumn of 1837 , there was, in this latitude, for the five months succeeding the 5th of August, not rain enough to wet the ground perhaps an inch in depth; and yet potatoes and corn turned out well, and the prairies continued in verdure about as well as usual.

"If, however, the question is asked,-Does not the pasture on the prairies fail early in autumn, so as to compel the removal of sheep to other pasture before it is time to go into winter quarters? I answer, yes-long before. In many sections the prairies afford no adequate pasture for 'dairy purposes after the first of September. In other localities such pasture will continue in some vigor till as late as the first or even middle of October; this is the case with lands lying within thirty miles of Chicago; but such lands will be proportionably late in the spring. The wild grasses are extremely vigorous while they last, but are all, without an exception, short-lived. This may be a habit or condition, induced by the annual fires, which kill out all but those with long roots; and a prevention of fires and cultivation might, after a time, change the character of some of them in this respect; but it never will. They are disappearing, a little 
more slowly, but as surely as the Indians, before the ploughshare and march of cultivation.

" Does the Prairie grass conform in habit to any of the Finglish grasses?"

"This question has been already pretty well answered. There are a large number of wild grasses here. The different plants which go to make up the foliage of the prairies, in any township of land, are very numerous. I have heard them estimated by those who had paid attention to the subject, at two or three hundred. Of these, though but an infe. rior proportion are, strictly speaking, grasses ; yet they all, or nearly all, afford herbage fit to be eaten by animals. An individual has but to cross any prairie, which has not been fed or mown, in a tolerably wet season, and note the endless prospect of blossoms, mingled with green, which wave under the wind like the surges of a sea of flowers; observe the ever-changing colors of the swells, as they come and go, to be sensible that there is variety enough. These flowers change throughout the season, a dozen or two varieties being in bloom at once, and continue in the fall long after the prairies are fit for pasture, the rear being brought up by blue and yellow weeds. These flowering plants diminish in number at once from feeding or mowing, and soon almost entirely, with the exception of the coarser ones, disappear

" "What length of time is foddering necessary in Norther" Illinois?'

"The seasons have been extremely variable since my resi dence here-now nearly nine years. The winter of 1842 and ' 43 was the severest one since the settlement of the State, and the foddering season lasted from the middle of October to the middle of April. The winter of 1843 and '44 and the present one would require foddering for a less time, by full two months. This is on the supposition, however, that good artificial pasturage is provided. If the wild prairies alone are relied on for pasture and hay, full two months must be added to the foddering season; and stock would barely get through at that; and I think that sheep, in multitudes of instances, would perish. In this latitude, with timothy, red-top, and clover pastures, the average time would be from four and a half to five months. If a good blue grass pasture were provided, in such winters as the last and the present, it might be reduced to two months; and I am told, that some so provided for, one hundred miles 
south of here, have, the present winter, scarcely foddered at all. I apprehend, however, that our winters here will always be variable, and that it will be far more difficult to predict their length and intensity than in New England. In relation to the value of blue grass for fall and spring pasture, Thomas N. Welles, of Peoria, in a communication to the Prairie Farmer, remarks as follows :- My sheep have had no feed of any kind, since the first day of April, except pasturage, (blue grass,) and they are now (May 10th) fat. They were put upon it as soon as the snow would let their noses to the ground. Last fall my stock were kept upon the grass till the 12th of November, when the herbage, was covered with snow. Had the climate been open, the sheep would have required little else than the grass. The tame grasses, and especially blue grass, even if fed through the summer and fall, will afford good feed about six weeks later in autumn, and six weeks earlier in spring, than the prairie grass. If shut up all the summer and fall, the blue grass affords the best feed all winter, when the snow does not cover it.' 'The winter adverted to was the severe one already mentioned.

- "What are sheep" chiefly fed on ?"

"It is.doubtful if any fixed mode of feeding has been adopted except in particular instances. Every sort of feeding, according to circumstances, is practised. Some feed almost entirely on the wild grass and hay of the prairies, which, when cut on uplands and well cured, is believed by sheep-keepers to be as good as any other, though more of it in weight will be required than of good English hay. Some feed this hay with a proportion of oats in sheaf, and roots twice a week, and this is undoubtedly, with salt, good treatment. It is found to be decidedly better to keep sheep up in small flocks, with very little ground to run over, while kept on hay, than to let them run out a part of the time, and get such grass as they can pick, while there is not enough to sustain them. They eat much dirt in such cases, are liable to be poisoned, and lose their appetite for hay. A settled course of feed of one character, embracing proper variety, is found here, as at the East, decidedly preferable. The old rule, to keep them at grass, while they can be with profit, and then to put them to hay and keep them at it, works as well here as anywhere.

"It is reported that sheep removed from the old States be- 
come very fat the first season on the prairies; is this condi. tion kept up many years after?'

"The first part of this question is true of persons, and is undoubtedly true of stock, and in part may be attributed to a change of climate. The change from an atmosphere which is surcharged with oxygen and which stimulates the lungs like that of the East, to one surcharged with carbon, and which stimulates the liver like that of the West, is at first generally attended with obesity. From other causes too, stock turned upon the clear prairies, become fat, and keep so till the feed fails. Some of the reasons are, that the grass, while it is highly nutritious, is somewhat astringent, and does not scour cattle when turned upon it in the spring, like the eastern grusses. Oxen can be put to hard work with no other feed, as soon as it is started in the spring, and will keep in good heart and become fleshy. Again, the air of the prairies is the freshest and purest on earth; and stock are less annoyed by insects while fanned by it, than anywhere else. Sheep or other stock, but more particularly the former, put upon a given piece of wild prairie, and confined to it, unless the range be very large, would not continue to keep fat one season after another, though they would the first; but if allowed a new range each season, they would always keep fat. 'The reason is this :- sheep in such cases will go over their range and select such food as they prefer, and will keep at it till it is gone. Hence the wild bean and pea vine, and a few other kinds of plants, will obtain their constant attentions, and will be kept so short that they will, on a given piece of land, die out the first year. Therefore if turned out upon the same grounds another season, the best food will be gone, and the poorer, with which they must then take up, and which itself gets continually poorer, will not sustain them in their first condition. A small flock of sheep will thus run over a large extent of ground.

"Hence the utter hollowness of a supposition which appears to be common at the East, that large flocks of sheep can be sustained on the wild grass of the prairies alone. There are many places, it is true, where a farmer might keep a large flock on the wild prairies during the summer months with profit, provided he had not two many neighbors in the same business. But such flocks would continually lessen their own range, at the same time that it is lessening 
by immigration, settlement, and extended culture. I have been in the country about nine years, having gone at the first into an entirely unsettled region, and have paid much attention to the matter; and it is my belief, that the wild prairies are desirable for wool growing to a very limited degree ; but that the cultivated prairies are desirable for this purpose to an almost limitless extent. When the cultivated grasses are fully introduced, and people get at the business in a proper manner, the prairies will supply wool of all qualities in inconceivable quantities. Hence I have constantly urged this view of the subject, and maintained the necessity of entering upon the-cultivation of grasses at once.

" 'Is there any deterioration of the wool of fine flocks?"

"In a letter from George Flower, of Edwards Co., in this State, published in the Prairie Farmer, I find the following: - When I emigrated to this country in $1817 \mathrm{I}$ brought with me six of the finest animals of the wool-growing species ever imported into this country. This is the origin of my flock. They have been kept on the same farm where I now reside ever since. No deterioration in wool has taken place; on the contrary, the wool fibre of them is somewhat finer:' If the above is true of Southern Illinois, it is doubtless equally so of the northern part of the State; since that is nearly 400 miles south of this, and consequently much warmer. Very gross keep is supposed to render wool somewhat coarse. Even, healthy keep, not too high, is generally considered best for a good staple of fine wool.

"Are shepherds and dogs indispensable when sheep are not enclosed.'

"On the open prairie, it would undoubtedly be unsafe to trust large flocks, without oversight. Many have kept small flocks, for years, without, by merely folding them at night. In small flocks, where feed is plenty, there is little disposition to ramble. Sheep soon get accustomed to their homes; but in large flocks the temptation is increased with the dangers of it. If the pasture is near the house, and a good dog is kept, any further care is generally dispensed with. The prairie wolf is a term beneath which animals of considerable difference in size and fleetness are ranged. Now and then a black or brown one is found, and some of the grey ones equal them in ferocity. They are very sly. animals; and I have known one, protected by a hazel bush, to enter a flock, while the keeper was with it, and kill quite 


\section{SHEEP OF THE UNITED STATES AND SOUTH AMERICA.}

a number of sheep before he could be got out. The flock frequently does not seem to apprehend the wolf, or flee from him; and he will do his work without causing any commotion among them. Still the destruction by wolves is very limited, and they are easily exterminated. Settlement, and the common modes of war, would soon drive them out; but there is a fal more potent means of being rid of them. Strychnine, an extract of nux vomica, introduced into small pieces of meat, is a most insidious and deadly mode of extermination. A correspondent of the Prairie Farmer thus describes his mode of using it:- Take a carcase of any kind, or in want of that, the offals of beef or pork, and lay them in a place likely to be frequented by wolves, as a bait or decoy. Then take a piece of fresh lean meat or liver, about the size of a small cracker, and cut, with a penknife, into the edge of it, to the centre, or a little beyond; then put in the strychnine, in bulk about the size of a kernel of wheat, or the 1-8th part of a grain. Be careful that none gets on the outside, and lay it within a few feet of the bait." The strychnine in crystals is best; and a wolf will frequently fall dead on the spot where he eats it. Thousands have been killed by this means the present season, and if persevered in, the country will soon be rid of them.

"Is foot-rot common, and is not liver-rot a formidable disease to which sheep are subject there?'

"The foot-rot, known as such in New England, has never, as far as I can learn, been discovered here. Sheep have sometimes had a disease of the hoofs, [the fouls], which has in all cases been cured by paring, with perhaps a little washing in water.

"The liver-rot has never, I think, made its appearance in Northern Illinois. I have never known but one instance of it in the West, and that was in another State, and far south of this. Frequent examinations have been made for it, this season, among sheep lately driven in; and though many have been found with diseased lungs, caused by over-driving, no diseased livers have, that I can learn, been found. I presume this question was prompted by the impression that many of our prairie lands are wet; but from the description of our soil already given, it can readily be seen that the liver-rot can never prevail to any extent here. Our lands are too dry and warm for that disease, unless under some new and unexpected development. The most common dis 
eases known among us, are what is called 'the drying of the many-folds,' and a sore face.*

" "What sections of your State are best suited to sheep?"

"It is impossible to say, for though the State extends in length about 400 miles by about half that distance in breadth, there is such a similarity in its general pastures, that the description of any three counties together would be a general description of the whole. There are particular differences, it is true, but these are balanced more or less against each other. Those parts of which I can speak from observation are the Fox, Rock, and Illinois river valleys, though the term valley has no particular applicability to the counties lying near these rivers, unless a valley may consist of high, dry, warm, rolling land. The central counties of Sangamon, Cass, Morgan, Scott, and the adjacent ones, are likewise well adapted to wool growing; nor have I seen any section of the State, unless the region lying within ten miles of this city, (Chicago) which is an exception.

"There are in every county some wet lands, which are not suitable, but these form a yery inconsiderable portion. 'The flocks of sheep which have been driven in, have gone to every part of this, as well as to neighboring States and Territories; and though some losses have been experienced the past winter, from want of care and skill, and from the nature of the season last summer, when they were driven, they will doubtless continue to come in, as long as there is a market for wool.

"It will be seen that the same general rules apply to sheepkeeping here as are applicable elsewhere. We have a good climate, can produce plenty of feed, have warm, dry soils, all of which are necessary for the business. Skill, enterprise, care, and attention will ensure success in it. But any launcleing out into wild experiments, predicated on ideas of the all'-sufficiency of green savannas and South American pampas, will end in disappointment and disgust."

Mr. Wight's concluding paragraph is very significant, and, in connection with his preceding remarks, at once dissipates the notion which has so generally prevailed at the East, that

* The former of these diseases is doubtless caused by the astringent properties of the prairie hay, and the absence perhaps of water. Green food occasionally, and frequent salting, with daily access to drink, will act as a prevention. The sore face can easily be cured by the external application of warm tar mixed with sulphur.-Author Am. Shepherd. 
the prairie grass was at all seasons of the year abundant and consequently, that sheep could be sustained with very little fodder, and generally managed at little cost and trouble. This, however, is fallacious; and those who have embarked largely in the business, without previously having made the provision of cultivated herbage, have learned that that benignant decree of Providence-_ " by the sweat of thy brow shalt thou eat bread"-cannot be evaded; or in other language, that neither wool nor any of the necessaries of life can be procured without labor. The fulness with which Messrs. Flower and Wight have treated the subject, supersedes further remarks.

We will now advert briefty to some of the Southern States where there are large ranges admirably adapted by nature for wool culture.

'The western part of Virginia can already boast of possessing some of the finest wooled sheep in the Union; and from the nature of the climate, soil, and herbage of portions of that section of the State, it cannot be doubted that they are destined to greatly multiply. It is true, the climate does not permit of any considerable reduction of the time for foddering, compared with Pennsylvania and portions of New York, yet the mountain lands are cheap, and productive of herbage of a varied character, so well suited to sheep. If the natural grasses are not abundant enough, the deficiency can be supplied by sowing from time to time the seed of the cultivated kinds. This course may be necessary in all the mountain ranges of the South, when appropriated to sheep husbandry. Sheep pastured on such elevations, and transported to the warmer atmosphere of the valleys during winer, cannot but be a source of profit; and if our Southern riehds do not choose to avail themselves of such natural advantages, they may rest assured, that, ere long, they will be wrested from them by the hardy and enterprising sons of the North.

In large districts of the mountainous portions of North Carolina, sheep can be reared at perhaps as little expense as any section of the United States. The grass peculiar to them, it is stated by some, is not agreeable to sheep; but this can be remedied in a very brief time by adopting the course above recommended.

The following extract of a letter from the Hon. T, L Clingman, of North Carolina, addressed to Mr. J. S. Skin 
ner, designates some of the districts of that State best adapted to wool-growing, which are embraced in the counties of Yancey, Haywood, \&c.

Mr. C. says the elevation of Burnswille, the county seat of Yancey, is about 2900 feet above the level of the ocean, and that the general level of the county is much higher. The climate is represented as being delightfully cool in summer, the mercury seldom rising higher than 70 or $80 \mathrm{deg}$. Very little of the county is said to be too rough for cultivation; a large portion, it is said, is a sort of elevated tableland; undulating, but not too broken; "even," says Mr. C., "as one ascends the higher mountains, he will find occasionally on their sides, flats of level land containing several hundred acres of land in a body. The top of the Roan (the highest mountain in the county except the Black) is covered by a prairie for ten miles, which affords a rich pasture during the greater part of the year. The ascent to it is so gradual that persons ride to the top on horseback from almost any direction. The same may be said of many of the other mountains. The soil of the county generally is uncommonly fertile, producing, with tolerable cultivation, abundant crops. What seems extraordinary to a stranger, is the fact that the soil becomes richer as he ascends the mountains. The sides of the Roan, the Black, the Bald, and others, at an elevation even of five or six thousand feet above the sea, are covered with a deep rich vegetable mould, so soft that a horse in dry weather often sinks to the fetlock. The fact that the soil is frequently more fertile as one ascends is, I presume, attributable to the circumstance that the higher portions are more commonly covered with clouds, and the vegetable matter being thus kept in a cool, moist state while decaying, is incorporated to a greater degree with the surface of the earth, just as it is usually found that the north side of a hill is richer than the portion most exposed to the action of the sun's rays. The sides of the mountains, the timber being generally large, with little undergrowth and brushwood, are peculiarly fitted for pasture grounds, and the vegetation is in many places as luxuriant as it is in the rich savanna of the low country."

The following extract of a letter received from the Hon. John A. Jones, of Paulding County, Georgia, shows the ease with which sheep, in process of time, can be maintained in that portion of the State. The wolf, formerly so destrt ctive 
at the North, will gradually disappear with the increasing settlement of the country.- "I believe the pine forest in the middle and southwestern region of the State best adapted to the raising of sheep. The climate is so mild that they need no shelter during the winter; the wild herbage is varied, lixuriant, and succulent through the summer, and will keep them in high flesh; the hardy plants that stand the winter sustain them in healthy store order. I think, however, there are still wolves in that region, which makes it necessary the sheep should be guarded; indeed, I am convinced of this, from one or two years' experience with a flock of five hundred, kept on the 'Lookout' mountains (in the northwest corner of the State), that it cannot be safely done in a wooded country. If the range of the sheep is limited they become poor and sickly; if permitted to roam at pleasure, they scatter, and are lost and killed. In this region we are obliged to afford them grain pastures, or feed them on corn or hay three months of winter. If we dared to turn them in the forest, one month's foddering would suffice; but this the wolves will not permit us to do."

It is deemed superfluous to particularize further the various sections of the Southern States in which the culture of wool can be profitably carried on. Suffice it to say, that wherever the herbage is varied and suitable for the sheep, in summer and winter, the soil dry, and industrious men to manage, there can wool be grown, and probably with more profit than the great staple, cotton. The influence of climate upon the fleece has already been considered; and the reader will find fully discussed, under the head of "Summer Management," everything appertaining to localities and herbage for sheep, thereby enabling each one to form an opinion as to the suitability of his situation for sheep husbandry.

The following extracts from a communication, recently published in the American Agriculturist, by Judge Beatty, of Kentucky, conveys some valuable information for the benefit of those engaged in wool-growing in the South and Southwestern States, as well as sets forth the great facilities for that branch of husbandry in Kentucky, which, doubtless, is equally applicable to large sections of Tennessee.

"For some years after I- commenced raising sheep (my cleared land and pastures being then very limited), I housed them during the winter months, and fed them with hay sheaf oats, and occasionally with corn. But when my clear 
ed land and pastures became more extensive, I found that I could winter my sheep to better advantage by suffering them to run on blue grass pastures, kept in reserve for them, hauling out and scattering on the turf corn fodder, when the grass became too short, or was covered with snow. This mode of feeding required less labor, and was less expensive, than housing them; and experience soon taught me that my sheep passed through the winter in better condition than when housed, and fed on hay and grain.

"I have now about 300 acres of cleared land; nearly one of half of which is in meadow, clover, and blue grass-poa pralensis; and the other half reserved for cultivation in corn, wheat, hemp, \&c.; and 150 acres in woodland, the greater 'part well cleared up and sown in blue grass. I have been tanght by experience, recently, that sheep will do remarkably well on the rankest clover, which will enable me in future to keep more of my blue grass pastures in reserve for winter feeding. During the last fall (the season being favorable), my clover fields furnished my flock, of somewhat less than 400 , sufficient pasturage till the month of January; and they have been since kept on my blue grass pastures, without the necessity of feeding, except some four or five days when the ground was covered with snow; and there is still grass enough to carry them through the residue of the winter.

"The low price of hemp, and agricultural products generally, has induced me to sow down much of my cleared land in clover, which will enable me to keep double the number of sheep I now have, without interfering with my farming operations; and when I get the whole of my woodland cleared up and set in blue grass, I expect to extend my flock to 1000 sheep. Thus you see we are neither under the necessity of incurring the expense of erecting buildings to shelter our sheep, nor of raising grain or hay for their food; nor even to employ laborers to feed them, except during the short time it may become necessary to haul out fodder for them, when the ground is covered with snow. And in a single day enough may be hauled out on sleds to last them a week or more.

"It is argued by some that our rich lands are too valuable to be appropriated advantageously to sheep husbandry. There would be much force in this objection if they were entirely appropriated to that purpose. But not so when sheep husbandry is combined with large hemp and corn crops. Hemp 
has hitherto been a profitable crop, though now it is too low to justify its extensive culture ; and large corn crops are necessary with a view of raising horses, mules, cattle, and hogs. There is no system of husbandry so well calculated to prepare our lands for large products of corn and hemp, as feeding sheep on our clover lands. I had supposed, till I made the experiment, that sheep would not do well on rank clover. To satisfy myself on this point, I put about 150 wethers on a clover field, when in flower, early in May. The clover was at the time nearly as high as the sheep's backs (Merinos). I kept them on this during the whole summer, and in the fall they were fat enough for the butcher. It is true they trod down much of the clover; but, as I had an abundance of pasture, this was an advantage, as it left a thick mat of grass on the ground, intermingled with the droppings of the sheep, distributed with much regularity. This thick covering prevented a loss of manure by washing rains, and rapidly brought on a second growth of clover, which furnished my whole flock with an abundance of pasture till the early part of January. The season was, however, unusually favorable, and hence the clover pastures lasted two or three weeks later than usual. In future I intend to keep my sheep entirely on my clover fields from the time they are in flower, and thus I shall be able to keep in reserve a greater supply of blue grass for winter feeding.

"But it is not upon our high-priced rich lands alone that we can carry on sheep husbandry to advantage. Kentucky has a belt of hill and mountain country, bordering on the Virginia line, on the east, and on the rich lands of the State on the west, averaging about 75 miles in width, extending from the Ohio river and Big Sandy, latitude 38 degrees, $40 \mathrm{~min}$ utes, to the Tennessee line, 35 degrees 30 minutes north. The whole of this region is admirably adapted to sheep husbandry. The most northern part but a few minutes north of my residence, and extending about two degrees farther south. The lands are very cheap, the State price of those not yet appropriated only five cents per acre, and those purchased second-handed, more or less improved, may be had from 25 to 50 cents per acre, and still less when unimproved. This country, in a state of nature, furnishes, during the spring, summer and fall months, a fine range for sheep, and is susceptible of great improvement by clearing up and sowing the cultivated grasses for winter feeding. This whole country 
s finely adapted to the Spanish mode of sheep husbandry. Very large flocks might be driven to the mountain region, some thirty to sixty miles from the rich lands, immediately after shearing time, grazed till late in the fall, and then brought back to be sustained, during the winter, on the luxuriant blue grass pastures of the rich lands of the interior.

"A very intelligent friend, residing in the southern part of the above district of country, speaks of it in the following terms: "One of the strongest proofs of this region of country being favorable to the growing of sheep stock is, that we are situated in the same degree of north latitude with the sheep-raising parts of Spain-Leon, Estremadura,. Old Càstile, \&c.-only that our mountains are more richly and abundantly clad with luxuriant wild grasses and fern, pea-vine and shrubbery, than the mountain regions of Spain, where they raise sueh abundant stocks of sheep. Wayne county, with a few adjoining counties, affords more fine water power than any country of the same extent that $I$ have ever known; and for health and fine pure drinking water, no country excels it on the face of the globe. Now is the time to commence ise business of sheep husbandry, whilst land can be got almost for nothing. It is worthy of remark that our sheep which are suffered to roam and graze in the mountains altogether, produce about ONE FOURTH more wool at a shearing than the sheep that are raised and grazed altogether on our farms, and of a MUCH BETTER QUALITY!' In another part of his letter he says, "The tops of the mountains of Spain are sterile, without verdure, producing no food for sheep or other animals to graze on; our mountains are quite different; they are thickly clad from bottom to top, and all over the top, with fine rich wild grasses and shrubbery of every variety for stock to graze on. In the midst of our mountains are to be found a great abundance of salt water, and stone coal of the finest quality, together with a great variety of mineral waters and pure springs.'

"Another friend, residing in Knox county, writes to me, 'My sheep upon' my farm, adjoining Barboursville, do not thrive, even with pasture and winter food, like the sheep in the extremities of the county, which have neither pastures nor winter food, except what they get in the woods. Without cultivated grasses of any description, sheep will live and do well all the winter, sibsisting on the spontaneous growth of the country.' 
"Another friend, residing in the northern portion of the above described mountain region, writes that 'the counties of Carter and Lawrence, and the eastern portion of the State, are admirably adapted to sheep husbandry. There are several flocks of sheep in this neighborhood that thrive and increase wonderfully, running at large, at little cost or trouble to the owners. Many flocks have no other reliance, during the winter, but what they get in the woods. The great advantages of this country for sheep husbandry is, the cheapness of the land, its adaptation to grasses, grain, and roots, its healthfulness - sheep delight in mountain or hilly landthe natural evergreens and shrubbery upon which sheep can feed and subsist in winter, though it is not safe to rely altogether upon these." "

The following conclusions of Judge Beatty are sound, and coincide with the views of many others:

" A few remarks as to the probable future market for wool will conclude my letter, already, I fear, too long. The returns of the late census show that the number of sheep in the United States in 1840 was a fraction less than 20,000,000. Twice this number would probably not furnish more wool than would be needed by a population of $17,000,000$, if we were to manufacture all our own blankets, carpets, and every other description of woollen fabrics. The period is not very distant when this will be done, with the exception of some very fine goods. We shall then need about $100,000,000$ pounds of wool for a population of $17,000,000$, and in that proportion for home consumption, even supposing none should be exported. Now as our population increases, as past experience demonstrates, at a compound ratio of three per cent. per annum, we shall have a population of $34,000,000$ in the year 1864; 51,000,000 in 1878; and 60,000,000 in 1888 . We shall need at these respective periods, two, three, and four hundred millions of pounds of wool. If we estimate sheep, upon an average, to produce $2 \frac{\mathrm{I}}{2} \mathrm{lbs}$. of wool per head, we shall require in the year 1888, a little more than forty years hence, $160,000,000$ of sheep. This view of the subject, without looking to a foreign market, holds out a strong inducement to engage in sheep husbandry." 
UNITED STATES CENSUS STATISTICS OF LIVE STOCK AND WOÓL FOR 1839.

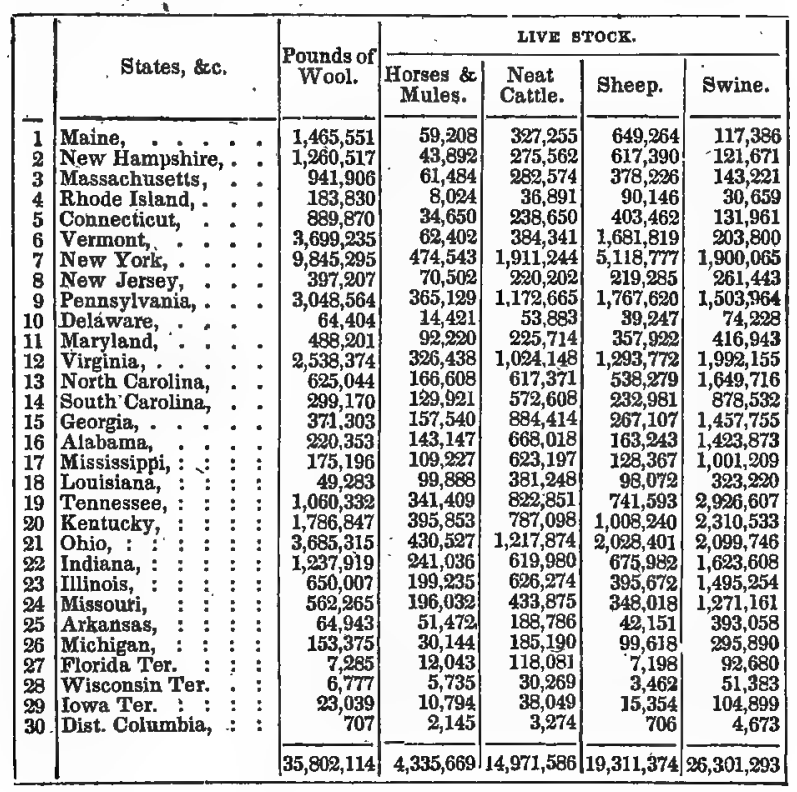

\section{SOUTH AMERICAN SHEEP.}

As has already been observed, no sheep are found in South America of an indigenous character. The Argali is not there, and the only native animal whose covering is appropriated to manufactures, is the Lama of Chili and Peru.

\section{ALPACA OR PERUVIAN SHEEP.}

This animal, which, from its great resemblance to the camel, was classed by Linnæus in the Camelide, is the Lama of Peru and Chili. There are, according to Cuvier, three species of the animal ; the Guanico, the Paco, and the Vicuna. It is the Paco or Alpaca which is under notice, and which, from the peculiar qualities of its long silky hair or wool, has obtained the name of Peruvian sheep. The following authentic description of this animal, and the uses 
to which its fleece is applied, is from a late London Jour. nal :-

"Nine-tenths of the wool of the alpaca is black, the remainder being partly white, red, and grizzled. It is of a very long staple, often reachíng twelve inches, and resembles soft glossy hair-which character is not lost in dying. The Indians in the South American mountains manufacture nearly all their clothing from this wool, and are enabled to appear in black dresses, without the aid of a dyer. Both the lama and alpaca are, perhaps, even of more value to the natives as beasts of burden than wool-bearing animals, and their obstinacy when irritated is well known. The importance of this animal has already been considered by the English; in their hat, woollen, and stuff trade, and an essay on the subject has been publisbed by Dr. Hamilton, of London, from which some of these details are collected.

"The wool is so remarkable, being a jet black, glossy, silk-like hair, that it is fitted for the production of fabrics differing from all others, occupying a medium position between wool and silk.

"It is now mingled with other materials, in such a singular manner, that while a particular dye will affect those, it will leave the alpaca wool with its original black color, thus giving rise to great diversity.

"The alpaca weighs, when full grown, from 160 to 200 lbs. It yields annually a fleece weighing from 10 to 14 lbs., or more. The flesh is said to be wholesome and nutritious-the skin may be used for bookbinding and other purposes.

"The alpaca is found in large herds on the Andessometimes at an elevation of 10,000 or 11,000 feet above the sea, where eternal snow rests on the mountain tops, where frequent and violent storms prevail, and where the scanty herbage is of the coarsest kind. There they prosper, meeting with but slight attention on the part of the shepherds. Disease is unknown among them; they are attached to their keepers, and never stray from their herds. They brave the fiercest snowdrifts; the strongest of the herd advance first, bend down their heads to meet the coming storm, and trample down or leap over the hillocks of snow that obstruct their passage.

"Viewing the peculiar habits of this animal, the idea of the author is, that it might, with but little trouble or expense, 
and with great advantage, be naturalized in those mountainous districts of Scotland and Ireland, and on the bleak and barren hills of England and Wales, which, from their nature, can never be brought into cultivation, and which now yield subsistence to no creatures fit for the use of man. From long and extensive inquiries he is convinced that the alpaca will live and flourish on the coarse mountain grasses, where an English sheep would starve; and he is satisfied that thus a large addition might be made to our national wealth, as the alpaca would produce fleeces doúble the weight of those taken from an English sheep, and of a superior quality, while it would furnish a wholesome meat for general consumption.

"The experiments which have hitherto been made for naturalizing the alpaca in England have not, it must be owned, turned out favorably; but we must be careful not to confound accidental casualties with a natural incapacity of the creature to flourish on our soil. The only trials yet made have been on too limited a scale to furnish any decisive result. They have been kept in pairs, or groups of five or six, and have rarely been judiciously treated. In some instances they have received the seeds of disease during their long voyage, from which they have never recovered, and in others have been injured by being. afforded rich pasturage, instead of the coarse and scanty food to which they are accustomed. Yet, even under these unfavorable circumstances, the whole current of testimony of those who have kept them is in favor of their prospering well on our high lands, if the experiment were fairly tried.

"Mr. R. Bell, of Villa-house, in the county of Kerry, procured a small herd of alpacas, and his account of them is so curious and interesting that we extract a few of his sen. tences :

"The alpacas on his farm are of various colors, some being brown, others black, and one perfectly white. They have not been shorn since the month of June, 1841, and the average length of their wool at this time is eleven inches, and so firm to their bodies that the smallest lock cannot be pulled off without great force; therefore they never lose a bit. It is exceedingly fine and silky; indeed, very much finer than any alpaca wool I have yet seen imported into England; and, during the two years they have been here, there is a visible improvement in the texture of their coat, 
and I think that the wool of the alpaca lamb here is superior in fineness even to that of the vicuna. I have never, everr after a whole day's rain, found them wet to the skin; for their wool, on becoming wet on the outside or surface, mats together, and becomes quite impervious to the heaviest showers. I certainly do not exaggerate when I say that each of the old alpacas here would clip at this time upward of thirty pounds of wool.

"The alpacas are exceedingly playful, and, to see them to full perfection, a dog should be taken into the field beside them; and as they run at play with the dog, their fine and noble positions are displayed to most advantage. From what I have observed of the nature and habits of the alpaca, I do most heartily confirm your statement, " That they would live where a sheep would starve,' and would be most valuable as a breeding stock in the United Kingdom. They are peculiarly well adapted to mountainous districts, however coarse the herbage, if the ground be dry; although, at the same time, I will say that the alpaca is as fond of a bite of good sweet grass as any animal I know of."

There are at present about one hundred of these animals in Great Britain, and efforts are making by an association to introduce more of them. In addition to the foregoing, it has been stated by $\mathrm{Mr}$. Walton, a member of this association, " that the alpaca breed in the third year, the period of gestation is seven months, have one at a birth, attain the height of $3 \frac{1}{2}$ or 4 feet, and usually live ten or twelve years. In Peru, they are generally shorn every third year, about April, when the wool is about eight inches long; it usually grows three inches in a year, but if shorn yearly grows six or eight inches. A make alpaca shorn three years ago had a coat from eighteen to twenty inches long; and instances are known of alpaca wool attaining the extraordinary length of thirty inches."

Considerable quantities of alpaca wool are imported into England, where much of it is spun, taken to France, and made into the finest Cashmere shawls. If the experiment is successful of propagating the alpaca in England, it surely can be done in the United, States, as the climate is doubtless more congenial to it, as well as the herbage. When American enterprise calls for its covering, the trial will unquestionably be made. 
WOOL CULTIVATION ON THE PAMPAS.

Almost the whole of the South American wool is the pro. duction of Spanish sheep that have been taken over there, and that have multiplied to a very great extent. Both the sheep and the fleece have considerably degenerated, proceeding in part from unfavorableness of the climate, but probably more from unskilful management. Large quantities of wool are exported to the United States, and also Great Britain, but so decidedly bad in quality, that very little of it, comparatively, can be used except for the most inferior manufactures. The extraordinary facilities for wool culture from climate and exuberance of herbage adapted to the sheep in parts of South America, have induced many enterprising foreigners to embark extensively in the business, and great improvement in a few.years may be expected to result in the quality of the wool.

The following account of sheep management in Buenos Ayres is by a correspondent of the Albany Cultivator:"The fertile 'Pampas' in the interior of South America' have been long celebrated for the immense herds of cattle and horses reared upon them. So abundant are they, and so easily reared, that they are slaughtered in many places for their skins and tallow alone. Sheep too of native breed, with coarse hairy wool, have been so plentiful that their carcases were used for fuel in burning brick. The expense of transportation and the absence of timber and salt for barreling alone prevents us from the competition of their meat in our own parts. The attention of agriculturists there has been of late years turned to improving their stocks of sheep by large importations of Saxony from this country and from Europe. An English gentleman began the business with a stock of 60 Saxons and 3000 ewes, and in the year 1835 he had increased the number to 45,000 , and the grade was nearly increased to full blood. In the year 1837 he had 90,000, and intended to keep on until he numbered 200,000 , which quantity he has doubtless attained before.this time; others were copying his example, until the business bids fairly to outstrip that of cattle, within a few years. The prices at which grade wools have sold have been from 8 to 12 cents per pound in Buenos Ayres.

"The price of government lands there is ten cents per acre. It is laid off in 'estancias,' a league square, con- 
taining 5,760 acres English; the face of the country almos a dead level, no timber, but a luxuriant coat of grass.

"A cottage is erected in the centre of the farm for the shepherd, and an ample yard enclosed by driving the trunks of the common peach into the earth, and wattling the interstices with the branches. An 'estancia' will support 3,000 sheep, which is about the size of their flocks. The only care they require is to guard them at night and during a storm. They will seldom wander beyond the landmarks during the day; at the approach of a storm they turn their heads to leeward, and feed on until turned by their keeper towards their place of seeurity. An instance has been known where 900 of a fine stock, and the best sheep in it, were destroyed by being in a storm, pressed by the rear ranks into a run of water, until the chasm was filled with dead bodies, and the remainder of the flock passed over. The shepherd does not remain with the flock, but at the cottage, having a horse already saddled and bridled (ready for a sudden call) always at the door in the daytime.

* Thus far very little attention has been paid to cleaning the wool for market. It is generally sold in the dirt " 


\title{
CHAPTER VIII.
}

\author{
MANAGEMENT OF SHEEP.
}

SUMMER MANAGEMENT.

\begin{abstract}
A SUDDEN CHANGE,FROM DRY TO GREEN FOOD IMPROPER-SEPARATION OF THE WEAK FROM THE STRONG-TAGGING OFं SHEEPCUTTING OF HORNS AND HOOFS-DRAFTING-PARTURITION-SALT ING-WASHLNG-CASTRATION AND DOCKING.
\end{abstract}

A SUDDEN CHANGE FROM DRY TO GREEN FOOD IMPROPER.

As a starting point, let us imagine the time to have arrived when the duties of the flock-masier relative to foddering his flocks are about to be suspended, by turning them to pasture. This period, in the Northern States, is from the 1st to the 20th of April. It is a critical time with sheep, owing to the rigor and vicissitudes of the climate, and their long confinement to dry food, especially so with the finer-wooled varieties, and therefore claiming more than ordinary care. But many of the duties involved require to be exercised a month or more antecedent to the time under consideration, and which will be found fully detailed under the head of Winter Management.

If sheep have been confined wholly within yards, and not permitted to taste the young grass until it is sufficiently advanced to satisfy their hunger without the aid of other food, there is great danger in turning them upon it too suddenly. This results from its flashy and stimulating properties, causing scours or purging, and unfortunately with that portion of the flock least able to endure the attack, namely, those in low flesh, and consequently feeble. In nearly all such cases, death will often follow, unless a timely arrest of the disease is made by a return in part to dry food.

But it is better to attend to the prevention, which is, to allow the flock to graze an hour or two each day for at least 
a week previous; and during this time let the best of hay, accompanied with grain, be provided. If sheep, however, have been trained to eat roots, and have partaken of them freely through the month of March, the danger accompanying the too sudden transition from hay or other dry food, will in a measure be avoided.

SEPARATION OF THE WEAK FROM THE STRONG.

Notwitstanding the duty of the shepherd may have been faithfully discharged by taking out from time to time such as are failing in flesh during the winter season, and putting them to better keep, yet not a few in indifferent condition will be found in large flocks at this period, which had better be separated and treated accordingly. The two classes needing this attention perhaps the most, are generally ewes which have already or are about to yean, and yearlings. Whatever they are, let them be put upon the best pasture the farm will furnish, and a few only together.

The separation will be quickest performed, by adopting the following method:

Let the flock be stationed one or two hundred yards distant from a gateway or bars, and then, if called by the shepherd, moving on a run, the weaker sheep will soon fall to the rear, and when these are about to pass the gateway, let them be cut off from the others by some one in the vicinity. 'This mode is sure, and is preferable to pounding the flock, as mistakes are unavoidably committed by so doing, especially with yearlings, owing to the unusual length of wool in individual cases, which frequently hides from the shepherd their impoverished condition.

\section{TAGGING OF SHEEP.*}

At or about this time, is assigned the important and indispensable duty of the flock-master of thoroughly tagging his sheep. It is wholly neglected by many, and with the great majority of wool-growers the slovenly and half-way manner of performing it is extremely censurable. It is thus, because the manufacturer expects from us that the wool from about the dock and below it, as well as that between the thighs, all

* In England termed clatting. 
of which is generally of an inferior character, shculd be separated from the fleece. This being the case, by neglecting it, we commit a direct fraud upon him, which he does not fully detect, until his purchases fall into the hands of his sorters.

Tagging should always be attended to before the sheep are turned off to pasture, for the reason that if any of them only slightly scour, the wool about the dock and thighs is rendered a mass of filth, and therefore is lost. In this situation, too, they are liable to be fly-blown, and without timely discovery, the sheep is also lost. From these considerations alone, it is clearly the interest of all to have this matter seasonably and well performed.

The easiest mode, and that which the writer has adopted for many years, is to place the sheep upon a table, resting on its rump. The table should not be more than twenty inches in height, and about four feet in breadth; the length must be accommodated to the wants of the flock-master, three feet at least being required for each tagger. It should be as capacious as this, with a view to spreading the wool as it is cut off, which facilitates the separation of the good locks from particles of dung and other stuff wholly useless.* A stool should stand upon the floor beside the table, for the tagger to rest one foot upon; this brings his thigh in such a position as easily accommodates the back of the sheep against it, and is thus placed in a posture to perform the task without pain to himself.

If it is a male, the. first operation is, to cut the wool one or two inches from about the extremity of the sheath, for, if it is neglected, the wool being constantly saturated with urine, will cause soreness, and sometimes ulceration. After this, let the wool be shorn from the scrotum or testicle bag. Then the tagger with one hand presses upon the thigh joint, which forces the leg to lay in a horizontal position, he proceeds to shear from the inside of the thighs, and down the leg to the fetlock; the other being served in the same way, he then grasps with one hand both legs near the hoofs and draws them upwards and towards him, which enables him to cut all that is necessary from the dock and immediately below it.

With the ewe the process is the same, with the addition

- The table can also be used for rolling the fleeces when shorn 
of shearing all the wool growing on the udder, as well, if it is long, a little from around it, which permits the lamb, in its first attempts to suck, to find the teats without difficulty. This is very important, for if the lamb drops when the temperature is low, the sooner it receives nourishment the better; but if delayed in finding the teats, from the cause stated, the cold prostrates it, and it soon dies.

Ewes, if tagged at the period recommended, are generally, in the Northern States at least, heavy with lamb, and therefore humanity demands that they should be handled with the utmost care, or abortion may follow.

The tag wool should be placed in a dry situation until ready for use, and if wet, which is very common, it should be spread thinly over the floor, and at intervals of two or three days, stirred with a fork.

There are many household purposes, such as flannels, stockings, and carpeting, to which this description of wool can be converted; and the increased price the fleece wool will command, affords an ample compensation to the farmer for the expense of tagging his sheep as directed. He will find consolation, also, in having performed an honest part towards the manufacturer.

\section{CUTTING HORNS AND HOOFS.}

After the individual has performed his task of tagging, let him place the sheep upon its feet, and if the toes of the hoof require cutting, let another be at hand with a sharp chisel and mallet to do it. This will often be found necessary with the Merino and Saxon breeds; and the ground being usually wet at this season, the hoofs will be softer and more easily cut, than perhaps at any after period. The paring of the feet also, adopted by many in localities where foot-rot prevails, as a prevention of that disease, might now be attended to.*

It is not unfrequently the case, that the horns of sheep are turned inwards, and from this cause likely to grow into the head or eyes, unless prevented. If neglected, a wound in the flesh ensues, causing great irritation; and if in the warm season, life is endangered by attacks from maggots. If the horn is large, a fine saw should be used; if otherwise, the chisel and mallet will perform it soonest, and in.

- See Foot-rot. 
flict the least pain. As to the use of a block on which to rest the horn, or placing it against a post or studd of the building, must be determined by its shape, and proximity to the head where it may be necessary to sever it. If the quick is touched, let it be anointed with tar.

\section{DRAFTING.}

Although drafting sheep for the drover and butcher is not confined to any particular season with farmers of the North, yet no period is preferable to the present, for selecting wethers and such ewes as have been ondemned for breeding, for sale, after shearing. From the increased competition of drovers at the present day, more discrimination is exercised in their purchases than formerly, and consequently it will pay well to have such as are drafted put at once into good pasture. An increased price for the carcase, and some increase of wool, will be the natural consequence of this treatment.

\section{PARTURITION, OR LAMBING.}

'The usual period of gestation with the ewe is five months, or an average of 152 days.

The proper time for parturition must be determined by circumstances, of which climate and locality are the most prominent, and these the flock-master must steadily keep in view. "The month generally selected in the Northern and Middle States is May, the vicissitudes of the climate forbidding an earlier period, unless in instances where buildings are provided for shelter, the expense of which is greater than the majority of farmers are willing to incur.

The ewes during pregnancy should be disturbed as little as possible, and every attention paid to the quantity and quality of their food. Ewes, however, should not be kept $f a t$ at this stage; indeed this state is injurious, as it predisposes them sometimes to abortion; but what is usually termed "good store condition" should be maintained through the whole period of gestation. Neither should ewes be exposed to storms and cold during the winter and early spring months, but thoroughly protected from both. It cannot be expected from any domestic animal a healthy offspring, in our rigorous climate, if the dam has been permit-. ted to suffer the hardships of cold and starvation; therefore it will be wise if the sheep husbandman will always hold 
up to view the apothegm, "so the dam, so the offspring." There must be good condition to sustain the mother in the trying hour of lamb-birth; and like good condition is equally necessary to sustain the lamb subsequently, and impart to it sound constitution, size, and thrift.

The field chosen for the ewes to fold should be dry, free from stumps, open ditches, and possess as level a surface as possible, as in little hollows ewes are liable to be cast, which is caused by lazily stretching themselves in sunny weather, when in a lying posture. In this situation they will often be found flat on their backs, and violently kicking the air, without the power of recovery, until aided; and, if unseen by the shepherd, death will follow sometimes in a few hours.

But perhaps no field affords that smoothness of surface to prevent these too often fatal occurrences, and therefore the duty devolves upon the shepherd of passing leisurely over every part of the field, several times during the day, to guard agajnst them. But this duty must not be delayed until some of the ewes have dropped their lambs; he must commence his career of watchfulness at least ten days before, for it is very common with ewes that are in over good condition to be found in this perilous situation some days before their time.

Other duties obligatory upon the shepherd are lucidly set forth by Mr. Youatt, as follows :

"The lamber should have with him his lamb-crook; a bottle of milk-ewes' milk if possible, and carried in his bosom or in an inside pocket, that it may be kept warm ; some cords to tie the legs of the ewes that he may have occasion to assist or examine; a little pot of grease or oil, to lubricate his hand, if he should have occasion to introduce it into the womb of any of the ewes; a sharp knife, with a round or rather curved extremity, should it be necessary to remove the lamb piece-meal from the mother; a piece of stout polished iron rod, of the size of a goose quill, twelve inches in length, and rounded at one end, somewhat like a button hook, in order to remove from the womb a dead or divided fotus; a small quantity of cordial, consisting of equal parts of brandy and sweet spirit of nitre; and a strong infusion of ergol of rye.

"The period of lambing having commenced, the attention of the lamber should be increased. He should carefully observe every ewe that appears to be in labor. While she walks about and does not exhibit any extraordinary degree of 
suffering, he should not interfere; nor should he do so if she rises when he approaches, and walks away, unless her labor has been protracted iwenty hours or more. He should not be in haste to render his assistance, although she should be continually lying down and getting up again, and showing more impatience or irritability than actual pain ; but if her strength appears to be declining, his immediate aid is required. If he has to drive her to the fold or pound, it should be as gently as possible, or he should drive some others with her, in order that she may not be frightened by being alone selected. The early interference of the lamber is always prejudicial, and very frequently fatal. Nature, in the course of twenty or twenty-four hours, will, in the great majority of cases, accomplish that which cannot be hurried on by art without extreme danger.

"The state of the weather will'cause a very considerable difference in the duration of the labor. When the weather is cold and dry, and especially if the situation is somewhat exposed, the progress of the labour will be slow-the throes will be comparatively weak and ineffectual, and the ewe may and should be left a considerable time before mechanical assistance is rendered. When, however, the weather is warm, and especially if, at the same time, it is moist, the throes will be violent, and the strength of the sufferer will be very rapidly wasted; there will be a dangerous tendency to inflammation, and the aid of the lamber is speedily required. Except under these circumstances, no motive of curiosity, no desire to know how the affair is going on, should induce the lamber to interfere while the throes are natural and the strength continues, unless it is evident, without handling the ewe, that a false presentation, or some mechanical cause, prevents the expulsion of the foetus. When the ewe is nearly exhausted she will often suffer the lamber to kneel beside her and successfully afford the requisite assistance. . If there is a violent struggle between the patient and the lamber, the fotus will often be destroyed; but his help, when she quietly submits to him, will rarely fail to preserve the mother and her offspring. Let it be supposed that, from certain circumstances, she is driven to the pound, or that she is lying quietly by the lamber in the field. He should first endeavor to ascertain the nature of the presentation. Is the lamb coming in the right way with its muzzle first, and a fore-foot on each side of it? If the tongue is not protruding from the mouth and becoming almos 
black, and her strength is not quite wasted, a table spoonful of his cordial, with double this quantity of the infusion, will probably increase or recall the pains; and the lamb will soon be born. If this is not effected in a quarter of an hour, a second dose of the infusion should be given; and, that being followed by no good result, he should try what mechanical assistance will do. He should draw down first one leg and then the other, endeavoring with his finger to solicit or coax the head onward at the same time. If he cannot readily get at the legs, he should push the head of the lamb a little backwards and downwards, when he will probably be able to grasp them. If he does not now succeed, the cause of the obstruction will be sufficiently plain, namely, the too great largeness of the head, which cannot pass the arch of the pubis; and, therefore, either tying the legs of the ewe, or an assistant keeping her down on her right side, the lamber should grasp the two fore-legs in one hand, and with one or two fingers of the other, urge it forward with as much force as is consistent with the safety of the lamb. The young one will rarely fail to be extracted by these means, except the head very much exceeds the common size."

In addition to the above sound observations, when mechanical aid is employed, it is always accompanied with considerable fright to the ewe, and if she is permitted to escape immediately after the birth of her lamb, will often refuse to own it; therefore, should it be alive, let it be placed at once before her, and by its form and scent, she will, in most cases, recognise it as her offspring. On the whole, the surest way is, to secure the ewe in a small pound or shed, and there leave her for the day; for, if she has a supply of milk, rarely further trouble need be apprehended. Should she, however, under these circumstances, or any other, refuse to suckle, she must be held, and a teat placed in the mouth of the lamb. This alternative seldom fails to conquer all difficulty.

The lambs of fine-wooled sheep are extremely sensitive to cold and wet when they drop, and to guard against exposure, the sheep-master must endeavor to anticipate storms, and place his flocks beforehand under shelters. These should be capacious, as the ewe dislikes too much company at the time of parturition, as will be noticed in her retiring often quite distantly, if in a field, from the rest of her companions, when the event is about to transpire. In such instances 
where no sheltering is provided, greater labor and vigilance must be employed, the presence of the flock-tender being constantly needed, with his bottle of warm milk, and putting the more helpless in a large basket, lined with hay or straw, and bringing them before the fire for an hour or more, until animation is restored. When lambs are separated from their dams under such circumstances, care should be observed not to have them wrapped or touched with anything that is offensive, as its scent, when very young, is the principal source of recognition by the mother. A clean blanket or woollen cloth will be best, if swaddling should be found necessary.

It is proverbial that the Merino and Saxon varieties are not as good nurses as the English breeds, and nature therefore rarely overtasks, by supplying them with twins. When this occurs, however, if the ewe is in her prime, condition good, udder large, and her keep good, it will be proper to let both of the lambs run with the mother; but if the reverse of this, let one of them be brought up by hand, or, as is the Spanish custom, be destroyed. A different course will probably cause runts of both, and is one of the means by which many flocks, in process of time, are sadly deteriorated.

When the ewe loses her offspring, it is followed by a distension, and frequently an inflammation, of the udder But such cases will be found by the reader fully treated of in the chapter of diseases, under the head of garget.

During the period of lambing, continuing as it does for a fortnight or more, the pasture for the ewes, if they are in fair flesh, should not be luxuriant; but when it is passed, then they may be removed to better keep; and in all cases the situation should be dry, and free from too great exposure. If the season has been unpropitious for early grass, and consequently the keep during parturition too low, the flock should have the run of two lots, which should adjoin, and the communication between them at all times kept open. The adoption of this course prevents the confusion incident to changing the whole flock at once.

The number of ewes herding together at this important period should not exceed one hundred, and a still less number will result advantageously to both the flock and master. He should at all seasons keep before him the fact, that 
a few sheep kept together will do better than many, which will be more particularly enforced hereafter.

The affection of the ewe for her offspring is often exceedingly strong, as the following example will testify, although rather an extraordinary instance, related by the Fittrick Shepherd.

"One of the two years while I remained on the farm at iV:-lenslee a severe blast of snow came on by night, about the latier end of April, which destroyed several scores of our lambs, and as we had not enough of twins and odd lambs for the mothers that had lost theirs, of course we selected the best ewes and put lambs to them. As we were making the distribution, I requested of the master te spare me a lamb for a ewe which he knew, and which was standing over a dead lamb, about four miles from the house. He would not let me do it, but bid me to let her stand over her lamb for a day or two, and perhaps a twin would be forthcoming. I did so, and faithfully did she stand to her charge. I visited her every morning and evening for the first eight days, and never found her above two or three yards from the lamb; and often as I went my rounds, she eyed me long ere I came near her, and kept stamping with her foot, to frighten away the dog.

"The weather grew fine and warm, and the dead lamb soon decayed; but still this affectionate and desolate creature kept hanging over the poor remains with an attachment that seemed to be nourished by hopelessness. It often drew tears from my eyes to see her hanging with such fondness over a few bones, mixed with a small portion of wool. For the first fortnight she never quitted the spot; and for another week she visited it every morning and evening, uttering a few kindly and heart-piercing bleats; till at length, every remnant of her offspring vanished, mixing with the soil, or wafted away by the winds."*

\section{SALTING.}

An important duty devolves ppon the flock-master to see that his sheep are regularly and plentifully salted from the time they are turned to pasture till the commencement of the foddering season.

Fortunately the question, whether salt contributes to the

* Hogg's Shepherd"s Calendar. 
health and thrift of sheep, is, at the present day, no longer mooted, its salutary effects being universally admitted. It operates to stimulate the appetite, and essentially aids the digestive organs in extracting the nutriment of food; and within a few years it has been ascertained that its free use to sheep has mitigated, if not wholly prevented in some localities that terrible scourge to British flocks, the liver-rot. Its security against the attacks of other dangerous maladies, further time and observation will doubtless demonstrate.

In Mr. Youatt's work will be found the following remarks on the benefits of salting:

"Passing by the beautiful country of Montpelier and the mouths of the Rhone, the traveller can study the fine sheep and the sheep husbandry of Arles. The district of the Crau, in length nearly eighteen miles, and about half as much in breadth, extends from the mountains towards the seacoast. It is one uniform gentle declivity : in no part of it is there the slightest portion of stagnant water, and not a tree or shrub is to be seen. The soil is dry and apparently barren enough, but produces a varied herbage well adapted to the sheep. Not less than one hundred and thirty thousand sheep graze on this declivity."

A writer in the Memoirs of the Royal Academy of Sciences at Paris attributes the thriving of the sheep on such a spot to the free use of salt, thereby enabling the digestive organs to extract every particle of nutriment which the food contains. He says, "On this spot, seemingly so sterile, by the free use of salt, more numerous flocks of sheep are bred and reared than upon any other common of equal extent throughout the whole kingdom; and, what is not less remarkable, the sheep are healthier, hardier, and endure the severity of the winter with less loss, though they have fewer sheep cots for covering, than those fed and bred on more copious pastures, and that have, besides, the advantage of more convenient shelter."

For a short time after sheep have been turned to pasture, precaution must be observed not to salt them too freely, as, in conjunction with the stimulating nature of young grass, scours or purging will follow; and its effects upon ewes shortly before parturition, if allowed access to it without limit, will tend to abortion, as will be found more fully no. iced in another chapter.

If common fine salt (say Salina make) is used, two quarts 
to the hundred, given about once a week, is a prudent quan tity at that time, and may be increased to four quarts after the first of May, for every fourth or fifth day, during the remainder of the pasture season. If coarse salt (St. Ubes) is used, a quarter to one third less than of fine will be proper, it being of a much stronger quality.

Salting in troughs would be well enough, provided the sheep could be stationary in one enclosure; but the necessity of their removal frequently for change of pasture, requires the removal of the troughs also; and the flock-master with several hundred sheep will soon learn that that is quite too troublesome. Again, troughs are thought by many indispensable during the season when the Estris Ovis, or sheep gad-fly, is winging its tormenting career, for the reception of the tar (upon which salt is sprinkled) as a defence against its attacks. But this does not supersede'their removal, and if time and their expense' are considered, it will be found cheaper to pound the flocks several times during the flight of the fly, and with a common paint brush or swab, tarring their noses can very quickly be performed, and far more effectually than it can be done by themselves in the troughs."

The writer salts his sheep upon the ground, before the dew evaporates, selecting a place which is clean, and the grass short, and divides a handful into two or three parts, as a large quantity thrown upon one spot will not scatter sufficiently the quantity used for the flock, and thereby the sheep are afforded a more equal chance. Salt is a fertilizer of the soil, and should any be left uneaten, which is not very likely, of course its effects will not be lost.

Many suppose that sheep, late in the fall, require little or no salt. This is quite a mistake, it being the very period when it will prove most useful to them, by, contributing to extract the little nutriment, left in the decaying herbage, as well as causing its better' relish.

Salt is quite as necessary in the foddering season, if not more so, than at any other time, for the reason that dry food being harder of digestion than green, the stimulating properties of salt is requisite to aid the process. It is not impor. tant that the hay, or whatever else may be fed, is salted, if the sheep have access to it in troughs or mangers. But if the hay is salted when it is secured, none else will be re-

- See chapter on diseases, Estris Ovis, for further remarks. 
quired. This is deemed by a large majority to be the better way, and coincides with the writer's views and practice.

WAS HING.

This is a branch of sheep economy which is wholly indispensable.

The careless and slovenly manner with which it is performed by the great majority of American wool-growers, calls for severe reprehension; the evil consequences resultirg from it, however, are inflicted mostly upon themselves.

The most suitable time depends upon the latitude and season; the latter causing sometimes, in the same locality, a considerable variation. At all events, the flock-master must be sure of one thing, namely, that the water and weather are comparatively warm. The violation of this is very common, which is exceedingly cruel and inhumane, and often exposes sheep to disease.

The day selected should be one of sunshine, if possible; and as this work in the Northern and Middle States is commonly attended to from the 10th to the 25th of May, it will rarely be the case, at that season, that the water will be of the right temperature before nine or ten o'elock in the morning; and when only a few sheep are to be washed, it will be better generally to delay it until the afternoon:

If the washing can be conducted immediately after a warm rain it. will be easier, the effect - of it being to soften and loosen the dirt; in this event, the yearlings should be selected first, as they are generally the filthiest.

* The flock-master should always' be present; and if he does not possess the physical ability or inclination to "bear a hand,": he should at least see that everything goes off properly, and is conducted on "temperance principles," for rum has done its full share of mischief on such occasions. $\mathrm{He}$ should be provided with a pair of shears, and if any dung locks are seen, they should be severed before the sheep are put into the water.

Where there is a running stream of pure water, with a gravelly or stony bottom, no better mode can be adopted for wool cleansing, and none other is so economical.

- For a number of years past the writer has used a vat, made of two inch pine plank, and held together by three inch oal gripes. It is about nine feet long, four and a hals 
wide, and three and a half in depth. It is placed at the bottom of a gentle fall, upon top of which is laid the troughs that conduct the water into the vat, the elevation of them being about eighteen inches above the level of the top of the vat. The dimensions of this are much larger than is necessary for the farmer with a small number of sheep, as it admits of the use of two sets of troughs, and therefore calculated for the washing of two sheep simultaneously. All circumstances being right, five to six huudred can be well washed in it per day.

On one side of the vat is a permanent platform made of stone and floored with plank, the surface having a gentle inclination towards the vat, on which the sheep are held for a minute or more, after being washed, that the water may Irain from the fleece. Beside the vat (not in it) and upon .he platform stands one of the washers, and a temporary staging on the opposite side accommodates another. One man is employed to bring the sheep from a small pound close at hand, and put them into the vat, in which two are held at a time by another at the lower end, for two or three minutes, with a view to soften the dirt. The washers then take them, and each holds one under the troughs or spouts, turning them in every position to receive the full benefit from the fall of the water, which proceeds with such force as to dislodge the dirt rapidly, and in a much briefer time than it can be done by squeezing. When the supply of water is full, no squeezing will be required, except, perhaps, the belly and thigh wool. As soon as the sheep held by the man for soaking pass from his hands to the washers, he is immediately supplied with others; and thus while two are soaking, two others are being washed under the spouts. One end of the vat being set a little below a level, the dirt passes freely off, and consequently the water is comparatively pure, the good effects of which will be seen in the almost cotton whiteness of the inner portion of the fleece. As to eradicating all the dirt from the external surface of wool when upon the sheep, it is not expected, for it is impossible to accomplish it; and therefore it must necessarily be left to the cleansing process of the manufacturer. But that much more can be extracted than is usual, cannot admit of a doubt; and if a general trial will only be made, those who undertake it will be sure to succeed, and rewarded not only with the grateful thanks of manufacturers, but a hand- 
some advance upon the prices of their wool. In confirmation of this, Mr. Samuel Lawrence, of Lowell, Mass., an "eminent woollen manufacturer, states the following: "These cheating practices are short-sighted, inasmuch as the 'clean thing' brings a price proportionate. We always fix the price per lb, by the quantity of scoured wool it will yield. In our purchases we frequently make a difference of five cents per lb. in precisely similar qualities." This advance will amply compensate for the longer time required in washing our sheep well, and if acted upon, with many of us, our characters for honesty will be considerably amended. urgindss, especially of the Merino breed, require an extra lations of dưntherrand if a little soft soap should be used, at tajefol asper. But the anything in value in the estima-

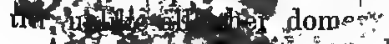

Afer sher should be turned upon a the sord that no dirt may collect on the

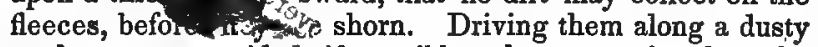
road - ivoided, if possible, when returning from the w̌ashing.

The Spanch custom is to cleanse the fleece with soap, after it is shorn, the grease or yolk abounding to such a degree, with its concomitant dirt, as to preclude the possibility of cleansing it properly in the ordinary way.

In England, the breeds having less of gum than others, washing is comparatively easy, and, where practicable, is done by swimming the sheep to and fro in a pond or stream, and gently squeezing the wool with the hands.

The washing of Saxony sheep in Germany and other parts of the Continent, conforms to the better modes adopted in this country, but is performed with far greater nicety and care.

On the authority of the manufacturer above named, Spanish wools, after being washed with soap, as already mentioned, lose 10 per cent. by the manufacturer's process of cleansing ; German or Saxony wool 24 per cent., but if accommodated, that is, the skirts and head taken off, only 16 per cent:; the Australian or New South Wales wools about 30 per cent.; American Saxony averages 36 per cent., and American pure blood Merino $42 \frac{1}{2}$ per cent.* The waste from South American wools is enormous, being from 70 to 80 per cent. ;

* It is proper to state that all manufacturers do not agree with Mr Lawrence in opinion, many of them estimating the waste of American, Saxon, and Merino wool to be a little less than above stated. 
but it is exported " in the dirt," which will explain it. The above statement proves conclusively the indifferent manner with which wools grown in the United States are washed by the growers, and calls loudly for a reform.

\section{CASTRATION AND DOCKING. -}

This is an important and necessary operation to lambs, but in very many instances is cruelly and unskilfully performed.

The proper time depends much on the weather, the size of the lamb, and varying from five to twenty days from its birth.

As the ewes about washing time are, or should be, thin inparturition, two or three days ans in the the are held for a ed for this purpose, alth

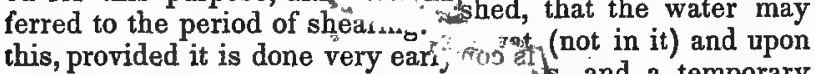
moist temperature is very unpropitiou dan tes"another. One fusion of blood in individual instances, whic "s omall pound sults in the death of the lamb.

h two are

Let the lambs be broutht from ihe field wu" as inive bustle and hurry as possitlo, and immediately cunfined in a small pound, to prevent any exercise or running about when catching them. This, and the observance of the following rules, have been the practice of the writer many years :-

One catches a lamb and seats himself astride of a narrow plank or scantling, which is placed at an inclination of about 30 degrees, pressing the back of the lamb firmly against his belly, and with his hands grasps the hind legs, drawing them upwards and towards him, so that the scrotum is fairly exposed for the operation. The operator with a sharp knife cuts off about one half to two thirds of the testicle bag; ther. drops his knife, and draws out one of the testicles at a time till a portion of the connecting cord is seen, which he divides by friction of his thumb nail. This mode of division lacerates the cord, and less bleeding will follow than if done by a sharp instrument. It may, to some, appear unnecessary, and therefore objectionable, to cut off so much of the scrotum or bag; but if dislodged of its contents it is certainly quite an useless affair, the little wool growing upon it being almost worthleas, and a bother always to the tagger and shearer when utting it off. No danger can arise either, if the ointment which will presently be spoken of, is used. 
After the testicles are removed the operator grasps the tail of the lamb and severe it about one inch from the root. Here the writer may be again condemned for eutting off apparently too much of the tail, it being considered a necessary appendage which the God of nature has provided the animal to brush away annoying insects. But the evil consequences of a moderate length of dock, or indeed any at all, he has seen too often manifested, to induce him to swerve from his practice; humanity, indeed, sanctions it. The sheep which carries a " natural tail," or only half a one, is very certain not to take that care of it, in regard to cleanliness, which it ought; on the contrary, it is often seen with large accumulations of dungutitached to it, and presenting anything but atayful aspen. But the sheep in not to be blamed for this, and domestic animals, it can and does void f lying póstures and a huge tail will not enditing occasions, without an extraordinary

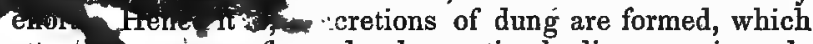
attran, le maggot-fly, and unless a timely discovery is made 1 the ma the sheep dies a horrible death. Thus the 1. E of the an hal is often jeopardized, and therefore is it not Humane to deprive it of so perilous an appendage? Again, if the Qld calculation of the farmer be true, that it takes one Shel of corn to fat a swine's tail, it is a problem to deternine, how much feed is requisite to keep in " store order" the undivided tail of a sheep.

At the conclusion of the castration and docking, use is made of the ointment alluded to. It is composed of the following ingredients : say one quart of tar, two lbs. of lard, and after being warmed to a thin liquid, add a gill, of spirits of turpentine, and apply it by means of a soft swab to the mutilations, and for one or two inches around them. This is very healing in its effects, prevents inflammation from colds, and, what is of most consequence, is an effectual guard against the attacks of the maggot-fly. None will approach it, so abhorrent is the effluvia of tar or turpentine to all winged insects.

The lambs are put out of the pound as fast as each has passed the operation, and are disposed to be very quiet, which is quite right, as it checks the discharge of blood. Let them remain about for an hour or more, if the pasture to which they are to be turned is distant, and then they may be moved off, but very slowly. Be careful, before this is 
done, to look in the corners of fences, behind trees or what$z o t$, in the immediate vicinity, as some may be concealed, and the stiffness consequent of their wounds will make them unwilling to return with the flock, unless discovered and aroused. Some work may be saved by this little piece of vigilance, as they may get mixed with other flocks subse quently brought up. 


\section{CHAPTER IX.}

\section{S UMMER M ANAGEMENT CONTINUED}

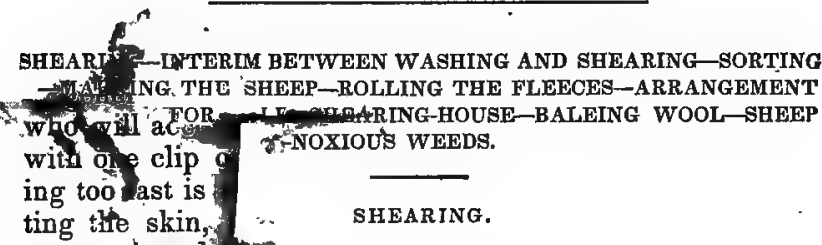

easy to it and

The follewi the novice: -

tharvest of the shepherd, as the reader has in the "olden time" was celebrated at its fupposing leastings and other demonstrations of rejoious - goodly custom has for long been discontinthry, if we except the "ancients" of Nantucket, einaciously adhere annually to its observance.

$n \cdot 1 s$ very properly termed a harvest, for thus it is to the faithful and humane flock-master; but the reverse of this is the case with that unprofitable servant, whose slothfulness and negligence may be seen manifested in the emaciated and partly denuded forms of his flock, at this interesting period. The former reaps a bountiful reward, while the other gathers little else than burs and tag-locks!

The remarks of censure prefixed to the notices on tagging, washing, and castration, in reference to the heedless and unskilful manner with which these matters are usually attended to, by a large majority of wool-growers, will apply with tenfold force to the subject now under consideration. It will be proper to say, without ceremeny or fear of contradiction, that the shearing of sheep, as generally conducted in the United States, is utterly disgraceful. The passing traveller, to be satisfied of the truth of this assertion, need not confine his observation to the "poor man's flock" as seen grazing by the roadside, but in the fields of those: who sustain the reputation of good farmers in their respective neighborhoods, will often behold sheep whose appearance indicate 
that their fleeces were gnawed off rather than shorn. But with a view to repress indignation, the writer will not enter into further description of such slovenly-looking objects, but propose the question, Whose fault is this, and to whose door is it to be laid? Is it the shearer, or is it the master?

In the first place, the mass of wool-growers are themselves ignorant of the details of this important art, very few having ever learned it practically, and consequently are incompetent to teach it. Therefore, when the shearer is proceeding with his work, the master looks on, and, if faults are committed, he is incapable of directing how they shall be avoided. He

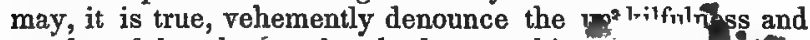
cruelty of the shearer, but he has not himse.. knowledge to take the shears and should be held; and how far they should or the position the sheep should lie in tearing the fleece with its feet. In a a m probable that the shearer, with o vir. tis two, has been hired to perform the $v$.... much per head; and under such circum? "cuts in" and dashes ahead to accol. speedy time, regardless of the scolding or manner of his work, or humatity to the

There are shearers, but they are few, who can work quickly and yet do it well; but these have acmpired the art correctly at the beginning, and have wisely athered to its rules through a long experience. But the great ma- jority have been spoiled when learning the rudiments, by the very class of farmers alluded to. Thus ewen shearers who have had the benefit of some correct teaching, are made reckless performers by parsimonious notions on the part of those who have employed them.

Bad habits are very easily acquired by a shearer, as the writer has had frequent opportunities of observing in those who have served him in this capacity for successive years; but it has been in the employ of these shear-by-the-head or job flock-masters. Here is the root of the evil-urging shearers to do more than they can do weill, and thereby confirming the old but truthful adage, "haste makes waste." The axe must be laid at the root of this evil at once, or good workmen will continue to be, as now, few and far between. The wool-grower must cease to entertain the false notion that by hiring his shearing done by the head or job, he is 
the gainer, for the very reverse is the fact in nine tenths of such instances, owing to the slovenly and half-way execution which follows, the sheep carrying away wool enough to doubly pay the ordinary day wages. The fault, it will have been seen, lies at the door of the master, and not wholly to the shearer.

Of those who can shear a large number in a day, and perform it skilfully, there are very few; but nothing precise can be stated, as it depends entirely on the breed. If they are Saxons or Merinos, or grades of these breeds, it will be very safe to say, from twenty-five to forty, taking the average of a flock; the grown sheep fewer than of yearlings. In-arneral terms, it may be said that he is a good workman whd ill accomplish about the largest number, cuts the wool with o clip of his shears, and not in twain, as one shearing too ast is apt to do, shears even and close without cutting the skin, and holds his sheep in those positions both easy to it nd hiself.

The follow instructions may be followed, intended for the novice: :-

Gupposing that the floor of the shearing-house has previously begin thoronghly cleaned, the pound containing the Hock fittered, with straw-the shearer proceeds to bring his sheep upon the floor. This he must avoid doing after a common method, which resembles, rather than anything. else, the rough-and-tumble efforts of a dog dragging a woodehuck from his burrow-but after catching it, to throw his. IIght arm around the body, grasping the hrisket with his hand, then lift it, and with his left hand remove dirt or straw, if any adhere to the feet. If the sheep is filthy about the tail, or perchance any burs are attached to the wool, at the threshold of the door, let all be cut off by a suitable pair of shears at hand for such purposes only. Then he may place the sheep on that part of the floor assigned to him, resting on its rump, and himself in a posture, with one knee on a cushion, and the back of the animal resting against his left thigh. He grasps the shears about half-way from the point to the bow, resting his thumb along the blade, whlch affords him better command of the points. He may then commence cutting the wool at the brisket, and, proceeding downwards, all upon.the sides of the belly to the extremity of the ribs, the external sides of both thighs to the edges of the flanks; then back to the brisket, and thence upwards, shearing the 
wool from the breast, front, and both sides of the neck-but not yet the back of it-and also the poll or fore part, and top of the head. Now the "jacket is opened" of the sheep, and its position, and that of the shearer, is changed, by being turned flat upon its side, one knee of the shearer resting on the cushion, and his other gently pressing the fore-quarter of the animal, to prevent any struggling. He then resumes cutting upon the flank and rump, and thence onwards to the head. Thus one side is completed. The sheep is then turned on to the other side, in doing which great care is requisite to prevent the fleece from being torn, and the shearer acts as upon the other, which finishes. He must then take his sheep near to the door through which if is to pass out, and neatly trim the legs, and leave not a solitary lock anywhere as a harbor for ticks. It is absolutelymecessary for him to remove from his stand to trim, otherwise the useless stuff from the legs becomes intermingled with the fleece wool.

In the use of the shears, let the blades be laid as flat to the skin as possible, not lower the points too much, nor cut more than from one to two inches at a clip, frequently not so much, depending on the part, and compactness of the wool.

The above instructions being designed for a beginner, we will suppose that this is his frrst and unly" atiempt." Let his employer, when he is about it, and it win." a good while, have an eye on all his movements, kindly and carefully ${ }^{\prime} \mathrm{di}$ recting them. After the pupil is through his maiden effort, you will see him smoothing out the crinkles and aches from his back and hips-for thus the poor fellow will feel-and if the weather is warm-and of course it should be-wiping the dripping sweat from his brow. But be easy; let him blow a while before he catches another sheep, for if you hur ry him, long before night you will hear-murmured from his lips, that "shearing is a back-breaking business-it's not what it is cracked up to be," \&c. \&c., indicating that he is already disgusted with it, and if so, adien to his ever arriving at skilfulness. But if he has time afforded to straighten. himself, and is patted with kind compliments " upon his unexpected well-doing - that he improves with each successive sheep-and that he will be sure to make a first-rate shearer," you will bring him under the yoke without his knowing its hardships. He will probably shear eight or ten the first 
day, and possibly a few more the next; at all events, guard him all the while, and see that he hurries not, or slights his work in any respect.

In this way, and none other, can we properly educate shearers to do their work with tact, and increased profit to the flock-master. This is but a transcript of the writer's course; and to show its good results, he has now in mind an instance, among several, where he instructed a raw one, and the following season his pupil sheared forty per day, and performed his task admirably.

Again: if this plan could be generally adopted, good shearers would be more plentiful, and wool-growers, aside from other evils, would not be compelled to delay shearing often beyond the proper time, for want of them.

There is yet another mode of taking off the fleece, not uncommon in this country, very generally adopted in England, and in nowise objectionable, and which is here laid before the reader. The following description of it is from the Farmer's Series :

"A barn or shed into which plenty of light can be admitted near thenshearers should be selected, and a part of the flofe ove large canvass sheet, on which two shearers oxt The sheet should be nailed down, and a - aced under it to soften it as a cushion. The floor of the ban should be swept out quite clean, and a 4 wht broom be at-hand to sweep the sheet when necessary. iverything being arranged, a shearer seizes a sheep, and sets on its rump, and keeps it in this position by resting the ck against his dwn legs. He removes all straws, th that may have adhered to the wool. $\therefore$ thus held, the wool is removed from the head and neck as far as the shoulders, and also from the belly, the scrotum, and the edge of the thighs. The head of the animal is then bent down sideways, and the shearer, placing a leg on each side of the neck of the sheep, pushes out the opposite ribs by pressing his knees gently against the ribs that are nearest to him. He next shears the wool from the far side with his left hand, from the belly to the middle of the back, and as far down as the loins. The sheep is now turned, and the right hand is employed to shear the wool from the near side. The sheep is then laid flat on its side, and kept down by the shearer with his face towards the rump of the sheep, resting his right knee on the ground in 
front of the neck, and his right toe being brought to the ground a little behind and below the poll; the head and neck of the sheep are thus confined by his. right leg, while he uses his right hand to shear the wool from the hind-quarter. In this way the clips of the shears will appear in concentric rings round the body of the sheep. The dirty portions of wool about the tail are then removed by the shears, and kept by themselves ; ${ }^{*}$ the outside of the fleece is folded inwards, beginning at the sides, and narrowing the whole fleece into a stripe about two feet wide. The stripe is then rolled firmly up from the tail and towards the neck, the wool of which is stretched out and twisted into a rope, and wound round the fleece to give it a cylindrical shape."

\section{INTERIM BETWEEN WASHING AND SHEARING, ETC.}

The interim between washing and shearing should depend on the state of the weather; if cool and cloudy, the yolk or oil will not appear so readily, a substance, as the reader has been informed in a previous part of the work, which is highly necessary to confer softness and brilliancy to the wool. If the weather has been sunny, from a week to ten days from washing will be quite long enough; and wen the work of shearing begins and is proceeding, the "temperature, in the Northern States at least, cannot be too warm. But there are thousands who violate this, and thereby reap sad consequences to themselves, by the death of many of the sheep, which arises from the extreme sensitiveness of the animal to cold immediately after its fleece has been shorn. To guard against this evil as much as possible, it not be safe to begin shearing, in this latitude, before the ist of June, and will be yet safer, generally, to defer it a few days longer. After waiting till the last moment, if a cold rain storm should occur during the process, those which have been shorn should be put under cover without a moment's delay, as death to many of them will infallibly follow, if it is neglected. The extreme suffering of sheep under such circumstances is inconceivable, and no one, unless wholly devoid of humanity, to say nothing of regard for his pockets, will refrain to fly to their immediate relief. Veteran flockmasters will duly appreciate these remarks, as there are few

* This is exceptionable; it should be done before anything else- $-A u$ thor Am. Shepherd. 
of us who have not in times past been losers, by inhumanly neglecting this important duty.

If the cutting of the horns and hoofs has not already, been attended to at tagging time, as has been recommended, it should be no longer delayed, but done now.

Although the indications of scab at any time, are infallible with the experienced flock-master, yet perchance a discovery has not been made, after the fleece is removed it can no longer escape. observation. Should any be found infected, a resort to the proper remelly must not be delayed for a moment.*

\section{SORTING, ETC.}

To the breeders for mutton, and more particularly the cultivators of wool, no other occasion than the present is more favorable to institute thorough examinations of the forms and fleeces of their flocks. It is thus, because the wool will often conceal, when growing upon the sheep, minor imperfections of the carcase; but after the fleece is shorn, they become more obvious. If the sheep are of the mutton variety, those of the same age should be compared' as to size, and the individuals having the greatest, with most approved proportions, should be marked, and retained for breeding purposes. Although the fleece can be pretty accurately judged by the experienced wool culturists for several months antecedent, yet not so well as now; and every one bearing wool distinguished for those properties most desirable, as well as possessing a symmetrical form, with indications of thrift and easy keep, must also receive a lasting mark, for it should not be parted with. Let the fleeces of the most approved be weighed, and every other particular noted.' 'In this way only can the wool culturist advance, whilst its neglect will soon manifest itself in a deterioration both of fleece and carcase.

Although it is quite common, and withal very necessary, to classify sheep, by a division into flocks of the sexes, at the beginning of the foddering season, yet if it has been neglected, it should be now done. Nothing should be permitted to run with the ewes and lambs, and their continuance on the best pasture will be of the highest advantage. The wethers and dry ewes selected for sale should also be turned

* See Chapter on Diseases. 
to good keep; and indeed so of all others of the flock, if possible.

\section{MARKING, ETC.}

There is another incidental duty connected with shearng time-namely, marking the sheep before they are finally disposed of to the fields. It is usually done by the shearer or with his aid. This does not refer to ear-marks, but painting the initial letter of the owner's name upon the body of the sheep, which, however is commonly performed in a very uncouth and ludicrous style. This can be obviated by having the letter cut in pasteboard, and thereby some degree of taste and uniformity will result. If a letter is not indispensable, it will be better to have an iron formed to represent a ring, triangle, or diamond, with a handle attached; then dip the iron in the paint, which should be deposited in a shallow vessel, and immediately apply it to the wethers on the right shoulders, ewes on the left, or vice versa, and the bucks on the rump. This is practicable, if others near by do not adopt the same mark. Such marks of ownership are quite necessary, with a view to distant or more obvious recognition, and more especially so if any of the flock are breachy and disposed to stray The manner in which it is done frequently reflects the character of the flock-master. If it is done neatly, the inference is that his other performances are likewise.

The materials for marking should be lampblack and linseed oil, or, as a substitute for the latter, hog's lard. Let the lampblack be "killed," as painters term it, by usirg a very little of spirits of turpentine, before the oil is mixed. It will not rub off so easily if allowed to stand twenty-four hours before applied. It is common to use tar; but this is objectionable with the manufacturer, it being difficult to separate by the cleansing process.

As soon as the flock is pounded for shearing, the lambs should be separated before anything else is done, lest the wound occasioned by severing the dock should be irritated by the squeezing and jostling of the old ones. An examination of the altered tups may be made to see if all is right. If there are any worms (which is not very likely if the precaution has been observed to anoint thoroughly as recommended), let spirits of turpentine be applied, which the flockmaster should never be without. 


\section{ROLLING THE FLEECES.}

After the shearer has performed his task, the fleeces must be carefully taken from the floor, and put upon the rolling table, the outside of it uppermost. The valuable loose locks about the shearer's stand must all be picked up, and the useless stuff from the legs, \&c., put into a corner, bag, or basket. It should not be swept out of doors, as it possesses valuable properties for manure.

The roller then proceeds to spread out the fleece, which cannot be too carefully done, separates the ragged portions from the skirts and head, and then makes it as compact as possible by pushing from all sides towards the centre. The loose wool is then thrown upon the fleece, which is followed by turning over the sides and ends so as to form an oblong stripe, say about two or three feet long, and one and a half wide, which is moved to the front edge of the täble. He then commences to roll the long side of the stripe, aided by a boy at the other end of it, who lay their arms flat from the elbow to press the wool as the rolling proceeds, till the stripe is reduced to six or nine inches in width, depending on the size of the fleece. The boy then mounts upon the table, and each commences rolling from the ends of the stripe till the parts meet, when the boy rolls his portion on top of his assistant's, firmly pressing it till the twine is passed round both ways and tied, which effectually secures. the fleece, no matter how roughly handled.' After it receives a slight pressure, it pre. sents somewhat the form of a cheese.

There are other modes of putting up fleeces, performed without any aid; but the writer has yet to see that individual who alone can roll a fleece as firm and solid as it should be, at the same time giving it a symmetrical and attractive form. If it is loosely rolled, the quantity of canvass used for packing is necessarily much increased; and this item of extra expense is more than equivalent to the services of a lad as an assistant.

ARRANGEMENT OF WOOL FOR SALE, ETC.

The slovenly manner in which wool is rolled and afterwards prepared for exhibition to the buyer, deserves a passing remark.

The wool-grower should keep before him the motto of 
the shopmen, "goods tidily kept are half sold." This applies with equal propriety to everything saleable by the farmer, and to nothing with greater force than his wool. They are too prone to get along with this matter in a "rough and tumble" style, doing up the fleeces untidily, and then depositing them in dark and uninviting places for exhibition. If wool has been well cleansed, it will not be ashamed of too much light; if only half washed, a dark corner only aggravates its appearance. There is an art in disposing wool for sale, which enables the flock-master to put his best foot out, and yet be guiltless of artifice to deceive the buyer; on the contrary, increases his opportunity to judge accurately of everything appertaining to condition and quality.

The adoption of the following will carry out the writer's views and practice :-

First, against one, or all sides-if necessary-of the woolloft, let four or five tiers of fleeces be placed upon top of each other, as nearly alike as to size as possible; the next pile, one tier of fleeces less, and so on diminishing the succeeding piles one tier, till the last is reduced to a single one. In this way, the fleeces represent piazza steps, or perhaps more properly, the ascending seats of an amphitheatre. It will readily be conceived, that if the fleeces have been neatly rolled and adjusted, the whole is not only attractive, but saves the buyer much tine in overhauling it, which is unavoidable if disposed of in a bin, or piled in any other form. This constitutes one of those "inviting appearances" which the world delight to gaze on, and which the world are sometimes disposed to pay a little beyond the intrinsic value for the sake of possessing. Let the flock-master honestly tag his sheep and cleanse his fleeces, and put nothing within them but the "clean thing," and the inviting scene before the buyer cannot mislead, or deceive him afterwards.

This leads to an exposure of other "cheating practices" of wool-growers, alluded to by Mr. Samuel Lawrence, under the head of "washing." In a communication to the writer he states the following:-" The practice of enclosing in the fleece clippings, \&c., is too common, and should be discouraged by manufacturers. I have known sin ounces of this useless stuff taken from one fleece. There is another practice equally disgraceful-the use of five to twenty times as much twine as is necessary. A short time since I took sixtysix feet of large twine from one fleece" 
No further comment is necessary, than to say, that any fock-master who will put tag.or dung locks, clippings, \&c., in the fleece, with a view to increase the weight, for such is the motive; is committing a gross fraud, and in every instance of discovery, his crime should be exposed to the public for reprobation.

In addition to excessive quantity of twine, it is not unusual for the size to be adapted almost as well for rope-traces, as tying of fleeces. It should be about half the size of a pipe's tail, as smooth as possible, otherwise, the fibres of flax, hemp, or cotton are intermingled with the wool; the carder cannot dislodge them-they receive the dye imperfectly, and con sequently deface the surface of the cloth.

\section{SHEARING-HOUSE AND APPENDAGES.}

Flock-masters are subjected to many incorreniences for want of an appropriate place for shearing, with the necessary appendages of pounds, \&c. The expense of a shearinghouse is not large, and will amply reimburse the expense in a few years, as it can be used for the reception of farm implements, \&c., when the shearing is over, and wool removed.

The fence for the pounds should be constructed of posts and boards; two are required, and the one contiguous to the shearing-house need not be more than twenty feet square; the other may be much larger.

It is very important that the wool-loft should be well lighted. No matter how well the fleeces may have been cleansed, yet if there is a deficiency of light, they present a dingy aspect. One window of good size is all that is necessary at the south end, and two will be required at the opposite or north end, for the reason that from that quarter the light is milder, and gives the wool, if fine, a softer and more silky appearance. Wool sorters always give a "north light" the preference.

The trap door for suspending the sacks when packing, should be in a central part of the floor, which leads to the subject of

\section{BALEING WOOL.}

The article commonly used for baleing is termed by the merchant, burlaps, which varies in width from 35 to 40 inches; the latter is preferable The quantity necessary for a 
sack is 3 yards. A truss hoop is used, around the ril.1 of which the mouth of the sack is twisted, and is then placed on a square frame just large enough to permit the rim of the hoop to rest. The elevation should be sufficient to clear the sack from the lower floor, when suspended. Some half dozen fleeces are then thrown in for a layer, followed by a man who carefully adjusts and treads each successive layer, till full. Generally, there is quite too much haste in this matter, and consequently the wool is too loosely packed, and an extra quantity of canvass is made necessary. It will be well before the packing commences, to stuff the bottom corners of the sacks with wool clippings, and tie them, which afford handles for lifting the bales.

\section{THE SHEEP TICK-(Acarus reduvius.)}

This disgusting insect infests sheep of all ages, but none others so much as yearlings. While they tend to impoverish the animal, if collected in large numbers, they stain the wool in such a manner as to make it difficult to cleanse. But they are so easily and effectually eradicated, it is inhumane in any flock-master to permit their torments to any portion of his sheep. The following is the modus operandi for destroying them:

For 100 lambs, use $5 \mathrm{lbs}$. of inferior plug tobacco, or 10 lbs. of stems; the former should be chopped into small pieces, that its strength by boiling may be more fully extracted. This will require some hours to do, and the most effectual way will be to apply at first two pails of water, which may boil for half an hour, and then take one pail of liquor from the kettle, and at the same time add another of water, and so on till 30 gallons of decoction is made, for which the quantity of tobacco named will be adequate.

A half hogshead will be the best thing for the deposite of the liquor, upon one side of the top of which should be fastened a rack, to rest the lambs after their immersion, in order that the liquor may drain from them. If this is not done, much of it will be unnecessarily wasted. About a week after shearing the ticks will have left the ewes and fastened themselves upon the lambs, which will be the proper time to have them got up for this purpose. The lambs must be held by the head with both hands, and then dipped to the ears, using great care that none of the decoction passes into the eyes or mouth 
There are some flock-masters who immerse all their sheep, but if the lambs are faithfully attended to every year, at the period recommended, few, if any, of the remainder of the flock will ever be infested. Good condition is one of the best preventives for this nuisance.

The tobacco decoction will.also be found excellent for slight wounds of the skin, and cutaneous irritations from johns. wort.

\section{MAGGOT-FLY.}

Sheep during the summer months are subjected to extreme annoyance from flies-principally the Estris Ovis, or gadfly, and the several varieties of worm, or maggot flies. Fine-wooled sheep, from the close texture of their coats, do not suffer from the attacks of the latter, unless dirty from scours or wounds; but the English long-wooled varieties are especially exposed. The following observations are copied from Blacklock:

"The insects passing under the name of "Fly," though most troublesome in August, attack the sheep from May to September, inclusive, depositing their eggs among the wool, in general about the tail, the roots of the horns, or any part which affords, from its filthy appearance, a prospect of suitable provision for the maggot. When these eggs are hatched, a process which"is, in sultry weather, almost instantaneous, the maggot erodes the skin, and speedily brings the adjacent parts into a fit condition for the reception of succeeding members of its species.

The backs of long-wooled sheep are, from their exposure, more liable to be selected by the flies, as a receptacle for their eggs, than the corresponding. parts in such as are covered by a short, thick fleece.

No sooner has the maggot begun its operations, than the sheep becomes uneasy and restless, rubbing itself on stones and trees, and endeavoring, by every means in its power, to free itself from the annoyance. Teased by the constant irritation, fever soon sets in, and, if the sheep. be unrelieved by the shepherd's aid, death will inevitably follow.

It is only lately that attention has been paid to the history of the insect pests which originate the mischief, so little damage do they appear to have occasioned in former periods. In a valuable paper, containing the result of observations made on this subject in the Highlands, and published in the 
second number of the Quarterly Journal of Agriculture, they are thus described:

"The fly which is so troublesome to sheep, as far as my observations could extend, consist of four species, viz.- the Muscar Ceasar, Cadaverina, Vomitoria, and Carnaria, of Linnæus.

"M. Ceasar is of a shining green color.

" $M$. Cadaverina, the thorax shining bluish, the abdomen green, like the Ceasar.

" $M$. Vomitoria, thorax black, or dark-blue grey, abdomen dark glossy blue. This is the common Blue-bottle or Fleshfly.

" $M$. Carnaria, grey; the thorax has three black longitudinal markings on the upper surface; the abdomen is checquered, in some positions shining whitish.

"In all instances in which I observed them, the green flies were the first to attack, and this is the common opinion among the shepherds. After a time, when the larvæ (maggots) commenced gnawing the flesh, the putrid stench, which was thereby occasioned, attracted other species. The Bluebottle was very common, more numerous than both the former species; and perhaps contributed most to accelerate the death of the animal, after the others had commenced. **

"In five days after the larvæ are hatched they arrive at full growth, provided they have plenty of food; they then cease to eat, and seek to assume the pupa state, crawling under ground two or three inches. Here they remain about fourteen days, when the shell cracks, and the imago, or fly, appears."

The correctness of this description of their transformation Blacklock attests, from having watched their habits during his anatomical pursuits in the summer months.

To ward off the attacks of flies, various substances obnoxious to them have been recommended. Tar, with spirits turpentine, may be applied about the ears, horns, and tail ; while others prefer a little melted butter, thickened by flour of sulphur, put also along the sheep's back, which is, on the authority of Blacklock, an effectual preventive.

Flock-masters cannot be too vigilant during the summer months, in watching closely every individual, and if any are seen with scours, they should be got up, and tar and turpentine applied. Rams should be still more closely observed, especially the Saxon and Merino, whose pugnacious tempers 
incline them so frequently to battle, often inflicting wounds around the base of the horns which are certain to call the flies. Many valuable rams have been lost from this cause, which watchfulness might have prevented.

\section{NOXIOUS WEEDS.}

Sheep, from their fondness of variety of herbagè, are often disposed to pluck weeds possessing poisonous qualities; and to guard against this evil entirely, the only remedy is, for the flock-master to eradicate everything of the kind from his sheep-walks. The low Laurel, Kalmia Angustifotia, is always fatal to sheep, and Johnswort also, if partaken of too freely; but the-reader is referred to the chapter on Diseases for further observations relative to these.

The burs of the common Burdock and Tory-plant are both injurious to the appearance of the fleece, and much vigilance is requisite to destroy these weeds, as their most congenial places of growth are in fence corners, and beside old stumps and logs, and therefore not so easily seen. But it is an old observation of wool-growers, "if you want to find a burdock, put a sheep on the track," and the trophies of success will soon be seen carried in its fleece. Burs in wool injure materially its sale, and a reduction in price frequently follows. If a burdock is early severed near the root, and a handful of salt applied, it will never again " rise and report progrešs." The common thistle should also be kept down, for which the washer, shearer, and esperjally the roller of fieeces, will return their grateful thanks 


\title{
CHAPTER X.
}

\author{
SUMMER MANAGEMENT CONTINUED.
}

LOCALITIES FOR SHEEP-SOIL - HERBAGE-DEDUCTIONS-VARIETY OF HERBAGE-REVIEW OF PREMISES-FREQUENT CHANGE OF PAS TURE-INCIDENTAL DUTIES-REMARKS ON THE LOCALITIES OF ENGLISH SHEEP-GRASSES AND THEIR RELATIVE NUTRITIOUS PROPERTIES-SHADE TREES-WATER-WEANING OF LAMBS-EAR MARKING-WHEAT STUBBLE-OVIRSTOCKING-PASTURING IN THE FALL-SORTING SHEEP FOR WINTER QUARTERS.

\section{LOCALITIES FOR SHEEP.}

ON right locality mainly depends the ultimate profits of sheep culture, which, among other prominent circumstances, embraces that of climate, which will be found fully considered in a subsequent chapter.

Until within the last hundred years no extraordinary attention had been paid to sheep husbandry in Great Britain; but when the nation became aroused to its vast importance, it was discovered that the prominent breeds, with their numerous subdivisions, were placed on localities admirably adapted by nature to each. The light-quartered, long-legged, restless Welsh sheep were gambolling upon the mountains, and pick. ing the uncultivated herbage, peculiar to them. The Down sheep were upon the hill slopes feeding upon a soil affording adequate sustenance for a medium-sized breed; the heavy-quartered, long-wooled varieties were consuming the fat pastures of the plains and valleys; and the Cheviot and iron-constitutioned black-faced sheep were sustaining themselves among the heather of the North mountains of England, and Highlands of Scotland, where other breeds would have perished from starvation and cold. The pliancy or constitution of the sheep, unequalled by any other domestic animal, which adaptates it to almost every transition' of climate and soil, will account for the difference of conform= ation of the several breeds, as observsd in these varied lo- 
calities. But centuries were required to accomplish this, for nature, when left to herself, is slow in effecting radical results. But thus the English husbandman found them at the commencement of the era of improvement, and he understoc $d$ quite too well his interest to transfer the sheep, whose accustomed walks for centuries were on the slopes and mountain tops, to the abundant herbage of the valleys, or exchange the rich keep of the larger varieties for poorer and more scanty. He was content to improve the forms, and increase the disposition to fatten and earlier maturity, but to. go no farther; and long experience has attested his practical wisdom. But this commendable example, from various causes, is too. often lost sight of by the American breeder, and will presently be alluded to.

The first point appertaining to locality which will be considered, is

soll.

The soil most suitable for the sheep is a dry one. It is emphatically an upland animal, and loves the short and varied herbage of hill and mountain slopes, provided the soil is not poachy from an excess of moisture. To no other domestic quadruped is water more repugnant, unless when necessary to lave its thirst, as will be seen in its aversion to crossing streams, and always selecting the driest points for feeding and rest. Whether it is thus, because it is endowed with the instinctive knowledge, that the presience of too much moisture in a soil engenders diseases too fatal to it, cannot conclusively be determined. But there is strong presumptive evidence that it is so, from the fact that this intelligent principle abounds in all the brute creation to that degree, when free from the restraints of man, which induces the formation of such habits only as conduce for the most part to their welfare and safety.

The chalky districts of England, on which so large a por tion of the Down sheep are fed, causes a harsh and inelastic feeling of their wool, as has already been remarked in a former part of the work. Blacklock says-" Soil, also, has much influence on the pliability of the wool. Chalky lands, which are so notorious for injuring the fleece, are supposed to act in the manner of a corrosive, but the correct explanation is, not that the chalky particles attack the fibre in a direct way, but that they render it brittle, by absorbing the 
oily moisture with which it is naturally imbued. Moreover, the plants growing in such situations cannot but be injurious to sheep, owing to their impregnation, though a slight one, with calcareous matter; for grooms know well how soon a horse's coat becomes disordered by the frequent use of hard or well water, and prefer, therefore, the river for their-steeds."

His last remark is true, and is worthy of much consideration with the wool-grower. By careful observation and comparison, it will be found that where sheep are fed on limestone soils, and, consequently, the water hard, the wool from them does not possess that peculiar softness, as that from sheep of the same stock kept on lands deprived of cal careous matter, and the water soft. Exceptions, however, to this exist, if the herbage materially differs of the respective localities, as for instance, if in the latter it is very luxuriant, and coarse, and the former short, and abounding in aromatic plants.

The presence of too much moisture in soils being a paramount objection, other than very chalky ones, none are wholly exceptionable for the purposes of sheep culture but those of the opposite extreme, viz.-too dry, from their porosity. This is the case in nearly all sections where sand greatly predominates; and is thus, to a considerable extent, south of the Middle States, in light loams, from exposure to too much heat. That soil, to furnish a uniform supply of pasture, should have a due admixture of clay, to cause such a degree of adhesiveness as will prevent the herbage, during the summer months, from withering, by drought. Too much sand in a soil is a fatal objection to sheep culture wherever it is found, and especially so in the South and Southwestern States, as nothing contributes so much, not only to perfect the several properties of wool, but early maturity and perfection of carcase, as a uniform and plentiful supply of food at all seasons ; and this a soil too porous cannot be expected to furnish during the warm parts of the year, scarcely in any section of the United States. *:

The next essential thing connected with locality, is

HERBAGE.

There is nothing beyond this in importance to the sheepbreeder, as from the quality and quantity of the herbage produced on his lands necessarily, in a measure, influences 
his choice of breeds, and" determines the number he can keep

The question has been conclusively settled, that food exerts a more immediate and radical influence upon the carcase, and especially so upon the fleece, than any other known circumstance, which is confirmed by every sheep historian. Mr. Youatt states the following: "Pasture has a far greater influence than climate on the fineness of the fleece. The staple of the wool, like every other part of the sheep, must increase in length or in bulk when the animal has a superabundance of nutriment; and, on the other hand, the secretion which forms the wool must decrease like every other, when sufficient nourishment is not afforded.

"When little cold has been experienced in the winter, and vegetation has been scarcely checked, the sheep yields an abundant crop of wool, but the fleece is perceptibly coarser, as well as heavier. When the frost has been severe, and the ground long covered with snow-if the flock has been fairly supplied with nutriment, although the fleece may have lost a little in weight, it will have acquired a superior degree of fineness, and a proportional increase of value. Should, however, the sheep have been neglected and starved during this prolongation of cold weather, the fleece as well as carcase is thinner, and although it may have preserved its smallness of filament, it has lost in weight, and strength, and usefulness."

There can be no doubt that in Great Britain wool has materially changed its character since the introduction of artificial food, and the adoption of the forcing system. Mr. Nottage states," of the Western Down sheep, "that he used to get one-eighth part of the finest. English wool from eacb fleece; but that now the quantity is so small he does not throw it out; he does not set a basket for it at all." Mr. Sutcliffe says, that-" Thirty years ago there was, in some South Down flocks, nearly as good wool grown, as the fine German that now comes into the country." Mr. Varley adds, that " he used to throw his wool extremely high to the sort-very good to the sort-but he found that the qualities generally were getting so low, that if he continued that sort of practice, he should have been looking into two of his best bins without finding a bit of wool in them." Mr. Fison

- Testimony before a committee of Parliament. 
states of the Norfolk sheep, the "in 1780, 420 lbs. of clothing wool grown in Norfolk would produce 200 lbs. prime-in 1828, it would produce only 14 lbs." These are certainly convincing proofs of the effect of high keep.

Dr. Parry, an English writer on sheep, and distinguished as a patron of the Merino, says- "The fineness of a sheep's fleece of a given breed is, within certain limits, inversely as its fatness, and perhaps also as the quickness with which it grows fat. A sheep which is fat has usually comparatively coarse wool, and one which is lean, either from the want of food or disease, has the finest wool; and the very same sheep may at different times, according to these circumstances, have fleeces of all the intermediate qualities from extreme fineness to comparative coarseness."*

The facts and deductions set forth in the foregoing ex tracts are applicable wherever sheep are kept, as may be seen manifested in very many flocks which have been removed from the old States, to the prairies of the West. A large, and intelligent wool-growert of Washington, Penn., who with others has kindly favored the writer with his course of management, after alluding to the effect of climate upon the fleece, says, "Much also, in my opinion, depends on the soil ; high, poor lands will produce better wool than rich low lands. I sent a flock a few years since to Warren County, Illinois, of about our latitude, and after three years' experience I scarcely knew my own wool ; the quantity of fleece and size of the sheep have increased, but the wool has not retained its fineness. This no doubt arises from the pasturage; they become very fat in summer, which increases the harshness of the wool and destroys that delicate texture it has in the more eastern and high lands."

But the effect of rich keep is not peculiar to the prairies; and therefore forms no objection to them for wool culture, simply because there is a decidence in fineness, since the carcase is enlarged and with it the quantity of wool, the filament or fibre made stronger, as, also, the fabric from which

- Columella, whose sheep were cultivated principally for their fleece, mentions the hungry lands about Parma and Modena, as feeding the most valuable sheep; and Virgil was perfectly aware of the influence of luxuriant pasture in giving coarseness to the fleece when he warns against the "pabula lata:"

"Nor in too rank a pasture let them live."

+ John H. Ewing, Esq. 
it is made. But it is not now the business of the writer to discuss the policy of removing the finest breeds to the prairies ; sufficient for him is it to make known the result from ordinary to high keep, and that the effect everywhere is precisely the same where experiments have been made: It may, however, be remarked, that the cheap uplands, not easily made arable for general agricultural purposes, will eventually be occupied for the cultivation of the finest wool, simply because they are best suited to the object. It is on these localities the Saxon and Merino can be maintained in healthy store order, and beyond this nothing more is required. On the other hand, the rich valley lands will be in requisition to fill our granaries, and large districts of the prairies, unneeded for this purpose, will graw the medium and coarser wools, of which, owing to the competition of the extreme fine qualities of Germany and other large portions of Europe, no redundancy can be produced, for very many years at least, to over supply the wants of the American manufacturer.*

No other domestic animal is known to manifest that fondness for variety of herbage equal to the sheep.

Blacklock, after properly rebuking the English breeders for not providing a greater allowance of straw or like materials to mix with their turnip feeding, proceeds to say- "We find, from a perusal of the works of travellers, and from the anatomical peculiarities of the sheep, that it is fitted for residence in countries precipitous-in surface, and scantily supplied with herbage; consequently, it -must range over a vast extent of ground for a subsistence, and its food must, owing to the varied features of the country, consist, not of one or a few plants, but of a most extensive mixture of herbage. Experiment also points out that the deductions from these observations are correct. Sheep, in fact, consume a greater number of plants than any other domestic animal. Linnæus, in examining into this subject, found, by offering fresh plants to such animals, in the ordinary mode of feeding, that horses ate 262 species, and refused 212 ; cattle ate 276 species, and refused 218 ; while sheep took 387 species, and only refused 141. We find, too, great difficulty in preventing sheep from springing over the dykes and hedges that we place as boundaries to their rambling habits, yet how seldom

* For further remarks, see Sheep of the United States. 
do we see the true cause of their determination to set them at defiance. We may partly account for it by considering their analogy. to the goat, and their propensity to scale rugged eminences; but I think these movements rather indicate an anxiety to change a pasture already exhausted of variety, for fresh fields, and herbage abounding in that miscellaneous provision which nature apparently reckons essential for them. Shepherds own as much, and will tell you that frequent change of pasture is the soul of sheep husbandry."

In explanation of the philosophy of variety. of food, an English author* briefly remarks,- "It is also well worthy of remark, that various herbaceous plants which spring up among others that are esculent, yet are rejected by cattle when offered alone, give a higher relish and even salubrity to the fodder with which they are intermixed. As man cannot live on tasteless, unmixed flour alone, so neither can cattle in general be so thrifty by mere grass, without the addition of various plants in themselves too acid, bitter, salt, or narcotic to be eaten alone. Spices and a portion of animal food supply us with the requisite stimulus or additional nutriment, as the ranunculus tribes, and many others, season the pasturage and fodder of cattle."

In reviewing the premises set forth appertaining to localities, with a view to further practical conclusions and comments, it is manifest in the first place, that the sheep culturist must beware of soils too wet; and, consequently, poachy. Lands of this character are found quite to as great an extent, indeed more so, on mountain declivities as in valleys; it therefore is clearly to the interest of those in possession of such, if they contemplate embarking in sheep husbandry, to have them made as dry as possible, by drainage, before they are stocked. If the adoption of this course does not succeed (as is often the case from being "springy"), they should be abandoned for sheep culture, and converted to dairy or other purposes. If persisted in, the owner may expect those consequences which are inevitable, namely, foot-rot and other diseases incidental to such localities. $\dagger$

It will also have been seen, that the short and yet nutritious hebrage of uplands is best adapted to the Merino and Saxon varieties, as being most conservative of those peculiar 
properties of their wool which adaptates it to the manufacture of the finest and softest fabrics; but on the other hand, if these breeds are removed to rich pastures, these valuable qualities of the fleece become in a measure deteriorated. This is unquestionably true if the removal is permanent, but will prove in nowise injurious if a change is made from upland to valley herbage at short and frequent intervals. Indeed, this is highly proper, as that variety of food, so conducive to the health and thrift of the animal, is thereby afforded.

From old or natural to the cultivated grasses, alternately once a week or fortnight, the flock-master will learn, from observation, suits well the inclinations of sheep. In keeping with this, they should be allowed occasionally the range of open wood-lands, to brouse upon forest shoots, the slight acidity of which is much to their liking.

A further argument in favor of frequent change of pasture, is the fact that if sheep are confined too long on one enclosure, no matter how good the feed may be, it becomes tainted by their constant wanderings over it; and hence, from their nice habits and extraordinary keenness of smell, will neglect it. When the flock is seen nosing here and there without eating contentedly, lose no time in removing them, even if the pasture to which they are taken is shorter and less abundant. It will be fresh and untainted, which is always reason enough for the change.

Connected with frequent shiftings of their pasture, is the necessity of small enclosures. This is well understood to be the right policy in England, and, where feasible, is rigidly adhered to. "In an enclosed country sheep generally do best when they are separated into small parcels; they feed more quietly, and they waste less. When as many, sheep are put upon a fair-sized pasture as it will properly keep, they will be cleared off for market considerably earlier than if they were put in large numbers on extensive grounds. Grass land, in small divisions, will keep and fatten many more sheep than when they are of a greater extent." ${ }^{\prime *}$ Some of the writer's fields are large, but mostly from ten to fifteen acres-and he has learned the fact that 100 sheep will do better on twenty-five acres if divided, than on thirty acres with no division.

* Farmer's Series. 
There are several incidental duties to notice when chang ing sheep from one pasture to another, or removing them for any purpose, namely - where gates are not provided, to take out three or four of the lower bars. It is quite common to drop only one end of them; and if an hundred or more sheep are to pass through, they lose their good manners and patience, and rush with such impetuosity that the weaker ones are frequently thrown down and injured, as, alsa, liable to have their feet caught in the bars, and legs thereby broken. This is of still more consequence, if the flock consists of ewes and young lambs.

Again: when flocks of this description are changed, the master should go thoroughly around the field to see that all the lambs are aroused, as, when quite young, they sleep much in the daytime, and therefore are liable to be left. The better course is, not to remove them beyond an adjoining lot if possible, and still better, until after shearing to leave the communications open to change themselves at pleasure As has been before observed, this obviates all confusion and trouble.

Before proceeding to enumerate the various grasses, and detail their relative proportion of nutritive properties, it will perhaps be well to recall the introductory observations to the present chapter, respecting the appropriate localities of the different breeds of sheep in Great Britain, intended as hints to the American breeder.

It is always of paramount importance to adaptate the breed to the quantity of feed the particular locality on which they are placed is capable of furnishing. But, in this and other States, this consideration hitherto, in very many instances, has been lost sight of. The American farmer hears of the amazing size, weight of carcase and fleece of some of the English breeds, and makes undue haste to purchase, in some instances without previously knowing whether their wool is suitable for felting or combing purposes, and without duly considering the fact that the relative quantity of food sheep consume is in the ratio of their size. The herbage of his farm is of the upland character, or their situation is too much exposed to cold, or, on the principle that "a "sheep is a sheep," he stints them to the quantity of feed which is capable of supporting a similar number of the smaller breeds; and from one or more of these causes, his expectations āre disappointed, and he abandons them with execrations. Thi 
has arisen from placing them on too low keep-the locality was not adapted to them, because the soil was not capable of furnishing that rich and abundant herbage requisite to support and fatten such large animals. He was not aware that the profits of the English breeds must be looked to from the carcase and not so much from the fleece; and therefore, to bring around quick and remunerating returns, that they required large and continuous supplies of succulent food from the start. One of the grand improvements effected in the English mutton sheep, is an earlier maturity, in order that they may be cleared off to the butcher in the shortest time; but to accomplish this the English breeder takes spe- cial care-not to place the famed Leicester, Cotswold, or Lincoln breeds on the stinted feed of mountain sides, but in such situations where ample provision is found for full feed and quick fattening. In such localities as are near to a market where fine.fatted mutton is appreciated and paid for accordingly, the heavy British breeds will be found profitable; under other circumstances, the Merino, Saxon, and grades of these varieties will bring the largest returns of profit to the American sheep culturist.

Connected with the general observations of the present chapter, is the consideration of the various grasses, with the amount of nutriment they respectively afford. The following summary was compiled by Mr. Youatt from Sir Humphrey Davy's distinguished work on Agricultural Chemistry. Their times of flowering differ not essentially in this country and England, and in this order they will be mentioned.

The Sweet-scentad Vernal Grass (Anthoxanthum odoratum) is found on almost every kind of soil, and is a true, permanent pasture grass for general purposes, and for early appearance; but it is not liked by sheep, who will scarcely touch it if there are any white clover or meadow foxtail.

Meadow Foxtall Grass (Alopecurus pratensis). This flowers about May 20, and the seeds are ripened about June 24. On a clayey, loamy soil, at the time of flowering, will yield about one and a half tons to the acre (in this country), every half pound yielding $1 \quad 1-4$ drachms of nutritive matter. The aftermath affords 2 drachms of nutritive matter from every half pound. Sheep are fond of this grass during May and June.

Short Blue Meadow Grass (Poa Cerulea), common 
in the drier parts of peaty meadows; nutritious, but not sufficiently productive for the purposes of hay. Sheep and cattle are exceedingly fond of it.

Rough-stalked Meadow Grass (Poa trivalis). In rich, moist soils, and sheltered situations, it is a highly valuable grass ; but on high and exposed ground its produce is inconsiderable. It flowers about the middle of June, and seed ripens July 10 . It is highly nutritive, and sheep are exceedingly fond of it. The nutritive matter is, at seed time, 5 1-2 drachms to the pound. Its superior value when fully ripe is very striking, and should not be forgotten.

Kentucky Blue Grass, June Grass, Spear Grass, \&c. (Poa pratense), supposed to be indigenous to this country. It is one of the most nutritive of grasses, either for pasture or hay ; and on rich soils, particularly those of a calcareous nature, is one of the most valuable that can be cultivated. It is this variety which gives name to the far-famed "שlue grass" pastures of Kentucky, and the fertile valleys of Ohio.

Sheer's Fescue (Festuca ovina). Flowers about June 25, and the seeds ripen about July 10 . The produce is comparatively small, and the proportion of nutriment is not more than 3 drachms to the pound; but sheep are exceedingly fond of it. Linnæus affirms that sheep have no relish for hills and heaths that are destitute of this grass. Sheep are so fond of it, they thrive wherever it is found.

Cock's Foot, or OrChard Grass (Dactylis glomerata). This is an exceedingly productive and nutritive grass; affording in the flowering time 5 , and when the seeds are ripe, 7 drachms to the pound of nutritive matter. The leaves of the aftermath are very succulent. It is valuable for permanent pasture, and sheep eat it very readily.

Welsh Fescue (Festuca Cambrica). The sheep are as fond of it as of the common sheep's fescue, while it is more productive and succulent. It is most valuable when the seeds are ripe.

Narrow-leaved Meadow Grass (Poa angustifolia). Flowers at the end of June ; and the seed perfect at the end of July. On account of its early and rapid growth, it is very valuable for permanent pasture, and sheep like it.

Hard Fescue (Festuca duriuscula). This grass is most prevalent on light rich soils, but is always found in the best natural pastures, where the soil is retentive. "It is one of the best of the finer or dwarf-growing grasses; and is most 
valuable for the feeding of sheep. It flowers about the beginning of July, and at this time it affords 7 drachms of nutritive matter to the pound.

Mradow Fescue Grass (Festuca pratensis). It constitutes a very considerable portion of the herbage of all rich natural pastures, and makes excellent hay. It is much liked by cattle, but sheep comparatively neglect it. At flowering time it yields about 3.4 of a ton per acre, and affords 9 drachms to the pound of nutritive matter.

RYE GRAss (Lolium perenne). Mr. Sinclair says of this grass: "Sheep eat it when it is in the earliest stage of its growth, in preference to most others; but after the seed approaches towards perfection, they leave it for almost any other kind. A field in the park at Woburn was laid down in two equal parts, one part with rye grass and white clover, and the other part with cock's foot and red clover. From the, spring until midsummer the sheep kept almost constantly on the rye grass, but after that they left it and adhered with equal constancy to the cock's foot during the remainder of the season." This grass is of almost equal value at the Howering and seed season-the latter at the end of July. It may, however, be objected to, as it exhausts the soil.

Fertile Meadow Grass (Poa fertilis). In early growth, the proportion of nutritive matter, and the nutritive quality of the latter math, this grass will yield to few. It continues to send forth a succession of flowering culms until the frost arrests their growth. It is therefore an excellent meadow grass combined with others.

Meadow Cat's-Tail, or Timothy Grass (Phleum pratense): This is of much value, for permanent pasture, mixed with other grasses, on account of $_{\text {its early herbage, its great }}$ productiveness, and the superior proportion of nutritive matter which it contains. At a little before the seed is ripe, when it should be cut, it affords no less than 11 1-2 drachms of nutritive substance to the pound. It is most useful for sheep in the form of hay.

Mr. Youatt proceeds no farther than the above, except the mention of some of the artificial grasses, such as tares and the several varieties of vetches; but very many years must elapse, before necessity will require their culture in this country.

Of the Clovers, the most valuable variety for general purposes is the common red clover (Trifolium pratense). Sheep 
however, eat it sparingly before the first flowering, if any of the natural grasses abound in the same field. But the aftermath or rowen they eat greedily, and is exceedingly nutritious to all domestic animals. Clover will be alluded to again hereafter, and the comparative quantity of nutriment it affords, mentioned.

White Clover (Trifolium repens). This grows spontaneously on dry uplands, after they have been manured with gypsum or with bog marl. It is a very sweet grass for pasture, but not productive. Sheep eat it readily when mixed with other varieties, and proves salubrious to them.

But, of the various natural grasses common to the United States, none appear to be so much relished by sheep, or afford a greater degree of nutriment, than the blue or poa pretense and timothy grasses. Unlike some of the others, sheep consume these with avidity from the earliest to the latest period of the pasturage season. A tolerably well-conducted experiment, made several years since, satisfied the writer that the sheep-grower must rely much on timothy, as being for pasture and hay combined, unsurpassed by all others.

\section{SHADE TREES.}

For the purposes of adornment and utility, shade trees are not sufficiently appreciated by the American husbandman. To; sheep, particularly just after shearing, they are peculiarly grateful ; and, during the warm season, are indispensably necessary to promote thrift, inasmuch as they contribute to greater quietness. If the axe has been ruthlessly laid to the roots of those which have been natural tenants of the farm, their places should be supplied by others. The common maple, linden, and sycamore will be found valuable for this purpose. A few of the second shoots of forest clearings, which grow with great rapidity, and consequently, in a few years, afford an abundant shade, should be left, and the most thrifty ones selected for this purpose. If the flockmaster is careful in his observations, he will learn that sheep which have had the benefit of woods to retire to during the heat of the day, will be in better condition in the fall, than others deprived of such grateful retreats.

WATER.

Water is not deemed so absolutely necessary for sheep as other domestic animals, since their instincts lead them to 
groze early in the morning, before the dew evaporates, and agam for a while in the evening, when the temperature of the season is warmest. In the hot month of August, however, when the feed is less succulent, they appear eager for it, and should be gratified, if possible. But the lambs, when suckling, will do better if the mothers have access to it at all times. Therefore, since every pasture is not supplied with water, the master should appropiriate those which contain it to his breed ewes. It should be considered, that the milk secretions cannot be so abundant if the ewe suffers too much from thirst, nor in any wise do as well.

\section{WEANING LAMBS.}

This period necessarily varies somewhat with locality, the particular breed, the time of parturition, and the disposition afterwards to be made of the lambs.

The time usually allotted for the lamb to suckle is about four months, and if the weaning takes place about Septem. ber 1st, which is about the common period in the Eastern and Middle States, it supposes the birth to have been in the early part of May. If the lambs are of the mutton breed, a longer or shorter time is taken, depending on the condition they are in for the butcher. But with sheep kept for wool culture, in about this latitude, weaning should not be delnyed beyond August 25th, or at most a few days after. early as this is quite necessary, as the time is full short for the owes to recover their wonted order for renewed gestation, and pass with safety through the rigorous winters incident to our climate.

The first thing to be attended to, is to remove the lambs and the ewes as far as possible from each other. There will be plenty of confusion and unhappiness for a while, and which would be prolonged until it was injurious both to the mother and the offspring, if they were able to hear each other's bleating. The lambs should be placed on better pasture than that to which they had been accustomed, in order to compensate for the loss of the mother's milk. But it must not be too luxuriant, otherwise, they overgorge themselves, and acute diseases in some form will follow. From this cause flock-masters often complain of losing their lambs soon after weaning, which might, however, have been prevented, if they had previously been trained to eat salt, 
which, when given freely, operates much to counteract hoove, and some other diseases of the digestive organs. When lambs are first placed on clover rowen, let them have all the salt they will eat. If this is done, the gases evolved, instead of acting as in cases of hoove, will pass naturally through the intestines. This is applicable to every class of sheep, and the course recommended is founded upon the writer's experience.

When the weaning takes place, let one or two tame sheep be put with them, to subdue their wildness, learn them to eat salt, and aid in conducting them through bars for change of pasture.

A contrary course must be adopted with the ewes, in reference to their pasture, for a week or more after weaning.It can scarcely be too poor; otherwise, it is frequently followed by great distension of their udders, and inflammation or garget. Under any circumstances they should be watched, and if this is likely to occur with any of the flock, they should be separated and milked for a day or two, and during this time fed with hay or other dry food. After the lapse of a week or more, the ewes should be placed on such pasture as will hasten their return in the most speedy time to good condition. Should there be a few, which is often the case, much below the order of the majority of the flock, they shyuld be taken out, and put on better keep than the others. 1. may be traced frequently to a neglect of this. This admonition is applicable also to the lambs.

\section{EAR-MAR KING.}

The duty devolves on the flock-master, at the time of weaning, to mark the ears of his lambs, and putting the initiali of his name on their bodies, if deemed necessary. One, or both, is quite indispensable, as, from their anxiety to get to the mothers immediately after their separation, they will creep through fences, in places, too, where it would not be supposed possible, and stray. This is quite likely to happen, if placed in enclosures adjoining the road in which sheep are permitted to run. It is quite common to crop one of the ears, which is not proper, as it gives the sheep an unnatural and ungainly appearance. It requires no special ingenuity to devise a mark which will leave the length of the ears entire. 
WHEAT STUBBLE.

Permitting sheep to run on ungleaned wheat stubble is exceedingly dangerous, and should be avoided. This arises from the inflammatory nature of wheat, if eaten in too large quantities by herbivorous animals. Swine should always precede sheep, unless the field is small, and the flock a large one. Even under these circumstances it will conduce to greater safety, if the sheep are full salted at the time, and lightly for one or two days following. There is no danger to be apprehended by allowing sheep tó glean other stubble. The lambs and least fleshy portions of the flock should have the run of them.

\section{OVERSTOCKING.}

Said a foreigner to the writer, "There are two important errors committed by American agriculturists-they overdo, and underdo; the former consisting in cultivating too much land, and overstocking,-and the latter in the slovenly per formance of their work, and heedless management of their animals." There is no want of sagacity or truth in these assertions, however unpalatable they may be. If overstocking is an "overdoing," few of us can escape the charge, for it is confessedly quite too common an error; and to this cause, perhaps, more than any other, the passing traveller may attribute the emaciated carcases of sheep during the winter which he sees around the dwellings of numerous farmers. Too many of us imagine that sheep can be supported on little or nothing; while others suppose the larger the number they can assemble on their premises, the greater, consequently, must be the returns of profit, not being sensible of the fact that 100 sheep well fed and well managed are more lucrative than the addition of one quarter more, if ill fed and otherwise indifferently provided. Charity should be extended to the inexperienced under such circumstances, but withheld from those who pertinaciously cling from year to year to this unprofitable, and it may justly be added, inhumane policy. The wellordered husbandman will gather wisdom from seeing his ertirs ; but the " overdoing" and " underdoing" not from his, unWiff gradual reduction to poverty make them too tangible longer to escape his observation.

The number of acres required for the annual support of one hundred sheep of the Merino and Saxon varieties, or 
high grades of these, it is scarcely necessary to say, depends entirely on the quantity of feed the soil is capable of furnishing. If the writer may judge from his own experience and of the many with whom he has corresponded, the average may be stated at thirty-five acres. One flock-master made provision, last season, by the aid of some straw and chaff fed through the winter for the above number, from off twentyfive acres. But his locality is of the fertile region of Western New York, and his example therefore will not be safe generally to follow, without the hazard of incurring the charge of "overdoing." In considering his success, the straw and chaff must be taken into view, which of course grew not on the area of land stated.

BAD POLICY IN KEEPING SHEEP TOO LONG ON PASTURE

\section{ALONE, LATE IN THE FALL.}

It is the practice of a large majority of flock-masters to allow their sheep to run upon the fields in the fall, as long as the ground is uncovered with snow, without the aid of a little hay or grain. This is bad management, and cannot be too strongly condemned. The grass, it is well known, after repeated freezing, loses much of its virtue to nourish, and therefore fails to keep up good condition, unless accompanied with a modicum of hay, or grain. The diminution of flesh $\mathrm{n}$ not be very apparent, yet nothing is more certain than that the sheep are losing their stamina. If some are expostulated with on this subject, they reply, "We do offer hay. but the sheep refuse to eat it ;" but on further investigation it proves to be the tops of their stacks, somethimg not worthy the name of hay, and therefore no wonder the sheep rejected it, preferring the decaying grass to such trash. It would not have been thus, if it had been barn hay; which is an item proving the great utility of barns to the flock-master. Many sheep are sent out of this " breathing world before their time ;" and if their ghosts were permitted to return and unfold the cause, they would shake their woolly locks, and say, "We did it," by starvation late in the fall. Let us reform in this matter altogether.

SORTING, PREPARATORY TO WINTER.

$+2$

This very obvious and essential duty is strangely unheeded, yet nothing scarcely is more important. To put tho 
weak with the strong, spring lambs with adults, or wethers with breeding ewes, should always be avoided.

The writer, about the 10th of November, assembles his lambs, and classifies them as to condition and size, and herds them in flocks of about one hundred each.

The older sheep are already divided with respect to sex, as he never permits wethers and ewes to run together, at least not after their first shearing. Of these, 100 constitute a flock.

The least fleshy are selected, and, from this time onward, receive attentions accordingly.

Wethers, designed to be turned off the following summer, are thrown out, and fed a little grain daily, as these are provided through the winter mostly with oat or wheat straw, with an allowance of grain ; therefore, early graining is somewhat necessary:

The breeding ewes should be sorted with great care; but this duty will be found adverted to in the chapter on Breeding.

An early preparation for winter, in this latitude, is quite indispensable; otherwise, from the vicissitudes of the climate, a premature depth of snow will find the flocks unsorted and many little duties undischarged. After the 1st of November, the master should be speedy in making all repairs necessary about his barns, yards, \&c., for the reception. of the flocks into their respective quarters. It is better to be, a few days too early, rather than even a few hours too late. "Ever ready" is the motto of the thrifty and well-ordered flock-master. 


\title{
CHAPTER XI.
}

WINTER M ANAGEMENT.

\begin{abstract}
INTRODUCTORY REMARKS-OBSERVATIONS ON CLIMATE-PRO
TECTION OF BHEEP-PRODUCTION OF ANIMAL HEAT.
\end{abstract}

\section{INTRODUCTORY REMARKS.}

ON reviewing the subject of Summer Management, it will be perceived that the duties of the flock-master are far from being few, and that nothing short of unremitted care is required to ensure that degree of condition and health with his sheep, to enable them to withstand the hardships of * Northern winters. If it has been thus, it will be well with them, and the truthful adage, "well summered, half wintered," will be verified. On the other hand, if they have not sufficiently occupied his thoughts, and have been permitted to "sherk" for themselves; while the rest of his stock only have eaten of the fat of the pasture,-it will not be so well with them; and consequently, it will be a vain expectation that, at the proper time, they will make grateful returns for attention and humane treatment which they have not received.

But whatever may be the condition of the flock when winter arrives, to carry it through with safety and profit, greater skill and attention will be called in requisition than during any other period of the year, as will be fully demonstrated before the detail of duties involved is concluded.

\section{OBSERVATIONS ON CLIMATE.}

Although the influence of temperature upon the sheep has been partially considered in the early part of the work, yet a few additional remarks are deemed necessary, with a view to establish certain premises, from which useful deductions will be drawn, having an important bearing on the duties interwoven with winter economy. 
The history of the breeds with their distinctive peculiarities, found dispersed over so large a portion of the world, exhibiting such diversified forms and coverings, naturally excites our wonder, and staggers the belief of a common origin. But this perplexity is easily unravelled. In consideration, it would seem, of their great utility to inan, nature has endowed them with a pliancy of constitution, which accommodates them to every variety of climate, becoming impressed at each transition with some peculiarity suited to their welfare. But where the climate is temperate and equable, the sheep, if long accustomed to it, seems almost to defy our efforts to model it at will; but whatever the locality, if a change is wrought in any important particular, nature constantly battles to return to the original point, unless the alteration attempted is in unison or compatible with the temperature and other circumstances which surround it. Thus, if any given breed, distinguished for its compactness of fleece, is transported to a latitude materially warmer than that to which it had been accustomed, nature flies to its aid by relieving it of a portion of its superfluous coat, to prevent the suffering consequent of an oppressive degree of heat. To this may be referred the cause of the annual falling off of the fleece, when unshorn, of the coarser breeds, in nearly all parts of the world, at the approach of -summer. There is an exception to this, in the'Merino variety, but its fleece becomes thinned by removal into regions too warm, and man's efforts are in vain to counteract it. And thus it is, too, if the heavy British breeds are taken to a climate materially colder than its native, the carcase losing its rotundity, unless precautionary measures are adopted to protect them against the cold incident to their new locality; the fleece, also, is shortened in staple, but proportionally thickens, to check the escape of warmth from the body, and thereby guarding against a rapid waste of the system.

It will be deduced from the foregoing, that plants and animals are analogous, and that however pliant may be the constitution of the sheep, there are geographical limits, out of which it does not attain perfection. It is true, the animal propagates in Iceland, and districts within the tropics; although there are certain localities in the last, in which sheep have been taken to from temperate latitudes, and perished from the excessive heat of the climate. This was the case in Batavia, as also on the plains of South America 
near the equator. Extremes of temperature, then, being un suited to the animal, the question arises, How does it happen to have spread over so many parts of the world in spite of such extremes? Simply for the reason, that when under the dominion of its instincts, and free from the restrictions of man, it will not subject itself to the danger of an extreme in anything, for it will not remove to remote points in a single season, and thereby expose itself to sudden changes. A writer happily remarks-"The natural dispersion of all animals is gradual, so that their constitutions are enabled, from the slowness of the transition, to accommodate themselves, by an alteration in covering and habit, to surrounding circumstances, which would, were the variations abrupt, speedily destroy them. The reason why a race of animals occasionally thrives so well in a country to which it may be removed, appears to lie in its being suited, I may say, accidentally, by peculiar conformation, to the temperature to which it is transplanted. There are some happy climates, where, introduce what animals you will, no matter how stunted they are, or how different the degree of warmth may be, the offspring will thrive, proving large and vigorous, and every way worthy of being placed at the head of the species. These are, however, cases where the transition is from an extreme heat or cold to a temperate one." The writer quotes in corroboration of these views the report of Mr. Dawson, of the Australian Agricultural Company, as follows: "Both the climate and the soil appear by nature to produce fine wool, and fine animals too, even from the worst beginnings. The latter seems a paradox. The extensive range afforded to every animal keeps it in good condition, and, perhaps, the natural grasses have more of good in them than their appearance indicates. However this may be, the climate clearly has a wonderfnl effect on the size of all animals, even upon man, who is universally tall here, though born of diminutive parents. From this. I am led tc believe, that the climate governs chiefly, and thus every breeding animal introduced here will attain a size not knowr. in Europe."

Notwithstanding sheep are forced to submit to extremes of temperature, there is a happy medium of climate which it delights in, and which greatly disposes it to yield the largest profits, and this is found in the countries of the vine. The western parts of continents also are more congenial to 
its habits than the eastern; and the Southern hemisphere than the Northern, for the reason, that in the former situations the temperature is milder and more equable. Degrees of latitude, in reference to temperature, correspond in the ratio of elevation or declination on mountains ; and thus it is that at an altitude on the Cordilleras, under the equator, of from 3,500 to 7,000 feet, sheep propagate scarcely without care during the entire year, while at the base, the heat is so excessive they perish. On elevated points, the southern side is very much warmer than the northern, as will be seen on the Alps at identical degrees of height, the north aspect presenting the Glacier, and the southern the vineyard yielding a perfect fruit.

From the foregoing premises, somewhat incoherently stated for the sake of brevity, as also in consideration of the subject having been hetofore partially treated, the reader will readily deduce, that the temperature of the Eastern and Middle States is not so well suited to the nature of the sheep, as in sections where the climate is more temperate. It will therefore appear, in order to counteract the injurious effects of exposure to the rigors of Northern winters, that shelters are indispensably necessary; which leads, without further preliminary remarks, to the subject of

\section{PROTECTION.}

There is nothing appertaining to sheep economy, in the Northern States, more generally neglected than the provision of ample and warm accommodations for shelter, and from no other cause does such large losses annually accrue. It is rigidly practised in all climates corresponding to our own, in Prussia, and throughout all Germany, as well as in Scotland and the northern parts of England; and every sheep historian earnestly recommends it. $\mathrm{Mr}$. Youatt frequently alludes to it as a very necessary point of good management, and the Mountain Shepherd's Manual (a Scotch publication) speaks thus :- "Shelter is the first thing to be attended to in the management of sheep. While every good shepherd is decidedly hostile to their being confined, or to their being forced into shelter, whether they wish it or not, it cannot be too strongly recommended to all sheep farmers, to put the means of avoiding the severity of stormy weather within the reach of their flocks at all times." The remarks of Mr. 
Spooner on the subject, with the examples he adduces, will be quoted hereafter.

The opponents of shelters assert, without, however, ever having made any experiments to decide positively, that they tend to make sheep tender, induce disease, \&c., which is about as reasonable as it would be to contend that man physically degenerates by having a comfortable dwelling to protect him from the cold inseparable from northern climates. But before offering any philosophical reasons to sustain the question of the necessity of shelters, the writer begs to obtrude his own experience touching this matter; and if more space is occupied than many think necessary, his apology must be found in his belief that nothing is more conducive to the health and thrift of sheep, and, consequently, profit to the flock-master, and which he will endeavor to demonstrate.

Until within the last ten years, we writer's flocks, like thousands of others at the present time in this and other States, were denied the benefits of shelters; and the loss, in proportion to the severity of winters, varied from five to ten per cent. The diseases caused by their exposure were scab, pelt-rot, dysentery, and colds, which caused an excessive discharge of mucus from the nostrils, while many died from no other cause, apparently, than sheer poverty of condition. Since, however, his sheep have been protected, the deaths have not exceeded one and a half per cent. in regard to number, and if comparative value were the standard, it would not be considered of any moment, as the loss has been mostly among diminutive spring lambs-so from bad nursing, and old ewes which, from superiority of fleece or carcase, were retained thus long, to breed from. If this is contrasted with the per centage of loss before the resort to protection, it will readily dispel the delusion that shelters enervate the constitution of sheep, or-are in any wise an inducing cause of disease; for, since protected, no epidemic has prevailed among them, and disease of any kind is rare indeed, and only occurring in individual cases.

The next strong argument in favor of protection, is the fact that it materially increases the weight of the fleece, as well as improves its properties, which arises from the better condition which it is the means of producing.

All farmers are aware that in fattening swine, or other animals, mildness of temperature is of paramount importance ato hasten the process-and why? The philosophical reason 
will be duly assigned hereafter; but in common parlance, the answer is, because the comfort of the animal is thereby promoted; and it will not be denied that this is equally applicable to the sheep. Hence, if the animal will better retain its flesh, or be likely to receive accessions from being sheltered, because it conduces to greater comfort, it follows that its fleece will be increased proportionally; for the flesh secretions and the wool fluids are derived from the same source; and any cause which will increase or diminish the one will operate thus on the other. But the following facts will supersede for the present further theorizing :

The clips of the writer's flock, (which is of the Saxon Merino blood) before sheltering, varied from 2 lbs. $5 \mathrm{oz}$. to 2 lbs. $9 \mathrm{oz}$. per head, the latter, under the most favorable circumstances, being the maximum. But since then, notwithstanding material advaryes have been made in fineness, it has averaged $2 \mathrm{lbs} .12 \mathrm{oz}$., and the last season arose to $3 \mathrm{lbs}$. $2 \mathrm{oz}$; and thus the aggregate amount of increase, within about nine years, exceeds 2000 pounds, which has amply reimbursed all expenses incident to the construction of barns: shelters, and their appendages, to say nothing of other profits derived from the same cause.

The additional softness of the fleece, and also evenness and soundness of the fibre, may be traced to the same cause which increases its weight; for if the cutaneous glands are full and healthy, which follows good condition, greater supplies of yolk are imparted to the wool, conferring greatel pliability, elasticity, and brilliancy, and, at the same time, promoting greater equality in the growth of the filament. Hence it is that in Spain, Australia, and other countries corresponding in mildness and equability of climate, the wool of the sheep possesses a degree of softness and uniformity of growth unequalled by any other, which arises, for the most part, from the evenness of the condition of the sheep through the year, and consequently regular supply of yolk, not being checked in its flow at any period by extreme cold. From this cause, the true Spanish, Merino, and Australian, to use the phraseology of manufacturers, "work more kindly" than all other fine wools; and less wastage follows in the process of cloth making, occasioned by their soundness and toughness.

Another material source of profit, induced by better condition from sheltering, is the increased number of lambs. 
ing, and consequently were unable in many instances to fold without assistance. In all such cases, the character of the offspring may easily be conceived; for, if they lived, they were puny and ill constitutioned, from the deficiency of nutriment afforded by the mothers. It is needless to add, that when winter came it made terrible havoc with these.

But an entire change came over the ewes after they had experienced the benefits of protection. Rarely mechanical aid is now needed at parturition, the lambs are alike healthy with their dams, and receive a "good start" from the greater amount of nutriment afforded them; and thus the foundation of all good animals, in all cases, is laid.

Another source of profit originating from protection, is the saving of provender.

Facts, the result of thorough experiments, which will hereafter be adduced, satisfactorily confirm this position, although "the writer regrets that he has none to offer deduced from his own experience. But nevertheless, he is as well persuaded of its truth, as though he. had made hundreds of experiments, for it is founded. in the very nature of things, and made conclusive by only ordinary observation. Every practical farmer is well aware, that every description of stock will consume more food in severe, or moderately cold weather, than when it is otherwise. Now nature is always exerting herself with everything, from man to the reptile, to promote its physical welfare for the preservation of the principle of life. Hence when any animal is exposed, or subjected to extreme hardship, and our climate is the greatest natural one, it is prompted to partake of greater quantities of food in order to combat, or counteract it ; therefore, inasmuch as sheep, from the severities of our winters, are subjected to more hardship, without protection than with it, the inference is legitimate that they will consume a larger amount of food with a view to their welfare. But further reasoning here will not be necessary, as this position will be again adverted to.

Again, shelter for sheep is a means of making additional manure, which is the mine to which the farmer must look as the main source of his wealth. Indeed, this is his capital stock, and whether it is to be increased or diminished, depends wholly on his bad or good management. If the ma- 
nure is protected from the weather, its virtues are not dissipated by the winds; and, being amassed at a single point, can be distributed when and where it best suits the interest of the husbandman. In Germany, England, and elsewhere in Europe, this matter is deemed of such consequence, it is customary to fold the sheep nightly in convenient places, that their manure may be concentrated, and subsequently deposited where it is most needed. Thus the American wool-grower, if he chooses, can make his flocks efficient auxiliaries to increase the productiveness of his lands, and thereby reap greatly additional profits from his labors.

What has been advanced in support of the policy of protection, it is apparent, has been with entire reference to pecuniary gain; but does not humanity urge us to its adoption? If the sheep had not been tamed to man's submission, its instincts would not have led it to regions like ours. No, the God of nature would have protected it from the sufferings inseparable from northern winters, by guiding its wandering steps to warmer climes. Therefore, since man has appropriated it to his use, does not the great Dispenser of good require of us that we should deal kindly towards it? It is, indeed, a religious obligation thus to do, which it would seem none but barbarians would violate. When the storm howls, and bitter cold urges around the "blazing hearth," let us feel happy in the reflection that we have provided the animal, which clothes and warms us, with the means of making its situation alike comfortable with ourselves.

Before entering into further details of a mere mechanical nature connected with management, it will be proper to illustrate the foregoing . results by some familiar reference to the principles of chemistry, and which will serve also as a fit prelude to observations on feeding and fattening.

\section{PRODUCTHON OF ANIMAL HEAT.}

Animal heat is produced by means of respiration, the chemical process being carried on in the lungs.

An extremely subtle fluid pervades all nature denominated caloric, the particles of which have a tendency to repel each other and unite with other substances. This is apparent if we touch a body the temperature of which is lower than that of the hand, caloric passing rapidly from it to the substance and a sensation of cold is experienced; and, on the contrary, 
gree ul heal hom the passage os calunc into the nana. Fire or heat is the derivative of caloric. It is one of those singular phenomena of nature, that caloric exists in two different states, the one in a free or sensible form, the other in a latent or combined form. Thus two bodies may have apparently the same degree of temperature, yet one contains a larger quantity of caloric than the other, but from its peculiar combination with the body, it is not sensible to the touch. For instance, if sulphuric acid and water be mixed, although each fluid may be before cold, a high temperature will suddenly be effected, and caloric will be evolved.

In the process of fermentation of malt liquors, the temper ature is elevated, and carbonic acid is produced, the sub. stance expired by the lungs; indeed, whenever this is formed, heat is evolved.

Now heat is produced and supported by the chemical union of two substancces, oxygen and carbon, which cause combustion of wood, coal, and our candles. Carbon is the fuel, not only in ordinary combination, but also in the animal economy ; while oxygen may be regarded the fire. Carbon is furnished by the food, whether in man or beast, and if a sufficiency is not taken in to counteract the consuming tendency of the oxygen, a gradual waste of the system follows, and life eventually ceases. Now in cold climates the air is dense, and in proportion to this is the amount of oxygen inspired by the lungs, and greater waste of the system would take place were it not counteracted by an increase of appetite, and consequently more food is required, especially that which contains within it the largest proportion of carbon. Thus in the icy regions the inhabitants consume largely of oily or fatty substances which consist chiefly of carbon; while those living in hot climates prefer vegetable diet. So we perceive the functions of the lungs and the stomach singularly agree. In cold weather large fires are necessary to keep up the animal warmth; otherwise the tissues of the body would be rapidly wasted by the consuming properties of the oxygen.

Without proceeding further, the above will afford a ready solution of several of the positions under the head of protection. It will be deduced that, if the equilibrium of the system in reference to animal heat is deranged, unhealthy action surely follows. If the sheep is permitled to breathe too 
dense or cold an atmosphere, the excess of oxygen with which it is surcharged, if the language may be used, becomes proportionally voracious for the carbon of which it preys on; and if it meets not with an adequate supply in the food, it flies to the tissues of the body. In this case the equilibrium is overcome-the carbon of the food is not a match for the oxygen, and the consuming fire-for thus it is aptly termed-gradually wastes the-system, and life sooner or later terminates in the last stages of exhaustion or impoverishment. To this may be ascribed what every farmer has borne witness, namely, when extreme cold occurs for a few days together, during its continuance, but more particularly at its subsidence, his stock, if exposed, present a lank and haggard appearance; and hence the common saying, "Cold impoverishes animals." Here is the reason at hand, furnished by science, why all animals thrive better in temperate latitudes ; as also, why it is proper, if transported to colder ones, the means recommended should be adopted to guard against the waste incident to exposure. If the effects of low temperature can this be avoided, it follows that the equilibrium will be preserved-the general organization unimpaired, and thus disease will be warded off. Here too is the ready explanation, why the sheep yields a heavier fleece -no larger quantity of carbon being abstracted from the food than is needed for respiration, having portions adequate for nourishing the frame; and thus the lacteals or absorbents carry through their fructifying channels ample provision to expand and increase dimensions at every point. And thus too we learn, why protection, by modifying the temperature of the air inhaled, sheep will consume less provender, for the reason that less oxygen is imbibed, and consequently a smaller portion of food will supply the requisite quantity of carbon it unites with to engender animal heat through the act of respiration. 


\title{
CHAPTER XII.
}

\section{WINTER MANAGEMENT CONTINUED}

\author{
FEEDING-SCIENTIFIC PRINCIPLES APPLED-FATTENING.
}

\section{FEEDING.}

$W_{E}$ are now about to enter a department of winter econo my of the highest importance, and will require at the outse a brief development of a few fundamental principles, a know ledge of which is indispensably necessary to correct practice.

It is a law of nature that nothing is lost or annihilated. In the combustion of wood or straw, the elements which compose them only change their form by assuming a gaseous character, and thereby become active agents in reproducing other bodies of like nature. The majestic tree, springing into existence from the tiny acorn or nut, in attaining its huge bulk, does not produce any new elements; its growth is derived from the power it possesses to assimilate that which floats in the atmosphere or exists in the soil. These are the sources of nourishment to plants; on the other hand, animals derive their sustenance from the food taken into the body, and through the process of digestion converting the nutrient part of the food into flesh and blood. The animal mass, with its various organs, is formed of the constituents of the herbage upon which it feeds. The exercise of animals to obtain subsistence, and for other purposes, requires a certain force, to produce which is attended with loss or waste of the system-" the living parts become dead parts, and are at length cast from the system." To counteract this tendency to waste food is required, and when the supply of food and the waste are equal, the weight of the animal is unaltered.

Food has a twofold purpose to effect: one is to nourish the system, the other affords the means by which animal heat is 
supported. The temperature of the body is considerably warmer than the surrounding atmosphere, and varies but little throughout the whole year. The cause of this high temperature has already been explained.

According to the theory of Liebeg, in carnivorous animals the carbon required for the purposes of respiration and warmth, is supplied by the waste of the tissues of the body, which waste is materially greater than in herbivorous animals ; but in the latter the greater proportion is supplied by the food itself. In the carnivora the whole of the food is converted into flesh; but in the herbivorous species a part only is thus assimilated, other portions being required for animal heat, and the formation of fat. But this will be better understood by the following analysis of these several substances. Flesh and blood consist of the following elements, subject to some variations, and to the water being removed. To avoid decimals, we will suppose the substance to consist of 10,000 parts.

\begin{tabular}{|c|c|c|c|c|}
\hline & & Flesh. & & $\begin{array}{l}\text { Blood. } \\
\mathbf{5 1 9 5}\end{array}$ \\
\hline $\begin{array}{l}\text { Carbon } \\
\text { Hydrogen }\end{array}$ & $=-$ & $\begin{array}{r}5182 \\
757\end{array}$ & - & 717 \\
\hline Nitrogen & - - & 1501 & & 1507 \\
\hline Oxygen & - & 2137 & & 213 \\
\hline \multirow[t]{2}{*}{ Ashes. } & - & 423 & - & 442 \\
\hline & & 0,000 & & 000 \\
\hline
\end{tabular}

By comparing the above, it will be perceived that the relative proportions of constituents is very nearly the same, especially those of carbon and nitrogen. These, then, are properly the proportions in which these elements unite in the tissues of the body, and hence nitrogen being a distinguished element of flesh and blood, no food destitute of nitrogen can nourish the body.

By the following analysis of mutton fat, it will be seen that the principal difference between flesh and fat consists in the absence wholly of nitrogen.

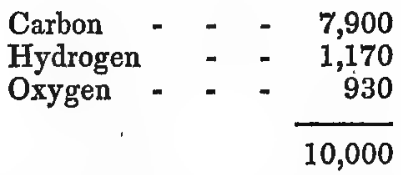

Thus it is that such articles of food as sugar, starch, gum, 19* 
oil, or butter, will increase the development of fat, yet not so the flesh; consequently animals confined wholly to such diet, will certainly die.

The analysis of hay is thus: 1162 parts being dried in the air will contain 162 parts of water, which, being deducted, leaves 1000 parts, which are thus composed:

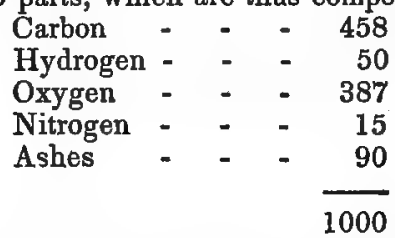

A scientific writer comments on the analysis of blood and hay as follows:- It is evident that an animal, to make 10 lbs. of blood, must eat $100 \mathrm{lbs}$. of hay before he acquires sufficient nitrogen to compose it. By consuming this 100 lbs. of hay, which we will suppose divided into 10,000 parts, he will take 4580 parts of carbon, whilst not more than 520 parts are required by the blood, leaving 4060 portions not required for nutrition; there will also be 424 parts of hydrogen unrequired, and 3656 of oxygen; what then becomes of these superfluous elements? Why, they are required principally for the purpose of sustaining the heat of the body; the hydrogen and oxygen form water, and the carbon unites with the oxygen taken by respiration, producing heat by the combustion, and is given off by the lungs in the form of carbonic gas. The nutritious portions of the blood are fibrine and albumen, whose elements are almost exactly the same, and correspond also with the fibrine and albumen found in vegetables. Although nitrogen forms such an essential part of nutritious food, yet it cannot, in any way, enter the system or afford nourishment in a simple or uncombined form, but only in such combination as we find in albumen. It is evident, therefore, that to form blood food must be taken which contains albumen, or substances analogous to it, in order to be nutritious, and in proportion to the amount of albumen it possesses will be its nutrient properties. Modern chemists designate food which is thus capable of nourishing as nitrogenized or azotized, from its containing nitrogen; whilst other varieties of food, such as starch, gum, sugar, fat, wine, beer, and spirits, which contain no nitrogen, are denominated carbonized or unazotized." 
Albumen is thus composed :

\begin{tabular}{llllll} 
Carbon - & - & - & - & - & 550 \\
Hydrogen & - & - & - & - & 70 \\
Nitrogen & - & - & - & - & 159 \\
Oxygen - & - & - & - & - & 221 \\
\hline 1000
\end{tabular}

Fat, we have seen, contains no nitrogen; it is clearly, therefore, produced from the excess of the carbon of food beyond that which is required for respiration. Starch, gum, sugar, and other similar substances, are converted also into fat by the abstraction of their oxygen.

Young animals are not disposed to take on fat like adults, much of their food being assimilated into blood, for the development of size. Another cause may be assigned, the additional waste from their playful exercise, which is peculiarly so with lambs. This arises from their breathing being increased, thereby consuming a larger amount of oxygen, and more carbon consequently is expended. The milk of sheep contains a much greater proportion of nitrogenized matters, than the food partaken by the lamb after its weaning.

The following shows its analytical composition :

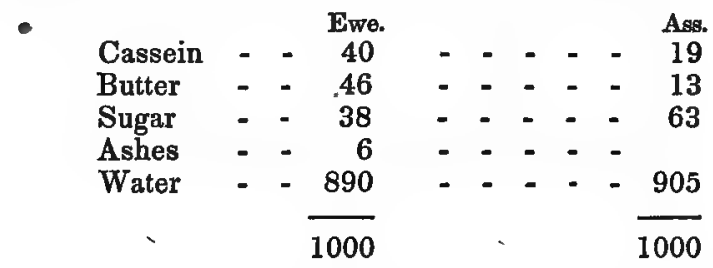

Of the above, Cassein is the only nitrogenized substance, and this with butter form cheese. Cassein resembles albumen, into which it can readily be converted in the system. The butter and the sugar are the carbonized constituents for respiration, and the ashes contain phosphate of lime and common salt, for the formation of bone and the gastric juice.

The writer will now proceed to spread before the reader a series of tables, exhibiting the relative proportions of nutriment of the various kinds of food consumed by sheep, which were prepared by distinguished scientific men. The 
first will show, that the usual food of sheep abounds very considerably with the carbonized constituents.

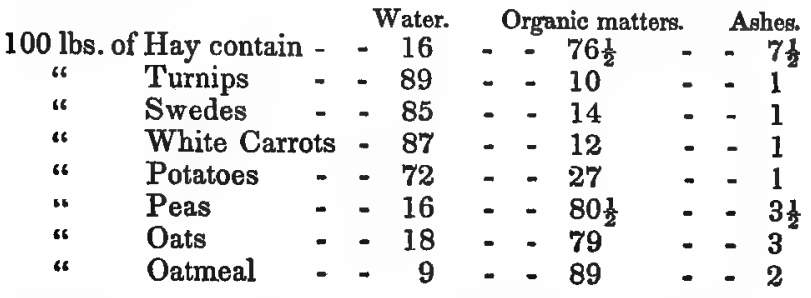

The organic matters thus separated are found to consigt of the following proportions :-

\begin{tabular}{|c|c|c|c|c|}
\hline & & Albumen. & & Unazotized matters \\
\hline Hay & & -8 & - & $-\quad-68 \frac{1}{2}$ \\
\hline Turnips & - & 1 & - & 9 \\
\hline Carrots & - & - & - & -10 \\
\hline Potatoes & - & -2 & - & - $24 \frac{1}{2}$ \\
\hline Oats & - & $-10 \frac{1}{2}$ & - & -68 \\
\hline Peas & - & -29 & - & $51 \frac{1}{3}$ \\
\hline
\end{tabular}

The next table, showing the nutriment of a large number of articles of food, is translated from the French, by W. Rham, of England, and is said to be "the result of the experiments made by some of the most eminent agriculturists of Europe in the actual feeding of cattle." Mr. Rham accompanies it with the following observations :

"Allowance must be made for the different qualities of the same food on different soils and in different seasons. In very dry summers the same weight of any green food will be much more nourishing than in a dripping season. The standard of comparison is the best upland meadow hay, cut as the flower expands, and properly made and stacked, without heating; in short, hay of the best quality. With respect to hay, such is the difference in value that if $100 \mathrm{lbs}$ of the best is used, it will require $120 \mathrm{lbs}$. of a second qual ity to keep the same stock, as well as $140 \mathrm{lbs}$. of the third and so on till very coarse and hard hay, not well made, will only be of half the value, and not so fit for cows or store cattle, even when given in double the quantity. While good hay alone will fatten cattle, inferior hay will not do so with out other food. 
"I shall gire the table as it stands, and add the notes which accompany it.

Good hay - - 100 is equal in nourishment to Lattermath hay $\quad-\quad 102$

Clover hay - - 90 made when the blossom is completely expanded.

Ditto - - - 88 before the blossom expands. Clover, second crop $\quad 98$

Lucerne hay - $\quad 98$

Sainfoin hay - $\quad$ - 89

Tare hay - - 91

Clover hay, after the

seed - - - 146

Green clover - $\quad$ - 410

Vetches or tares, green $\quad 457$

Shelter wheat straw $\quad 374$

Rye straw - - 442

Oat straw - $\quad$ - 195

Pea straw - - 153

Bean straw - $\quad$ - 140

Mangold-wurtzel $\quad$ - $\quad 339$

Turnips - $\quad 504$

Carrots - - 276

Swedish iurnips - 308

Wheat (cleaned) - 45

Barley - - - 54

Oats - - $\quad$ - 59

Vetches - - 50

Peas - - 45

Beans - - - 45

Wheat bran - $\quad$ - 105

Wheat and oat chaff $\quad 167$

"Lattermath hay is good for cows, not for horses. Raw potatoes increase the milk of cows, but they must be given with caution, and only a few at first, till the stomach is accustomed to them; boiled, they fatten every kind of stock; mixed with cut chaff, they are excellent for horses; 14 lbs. of boiled potatoes will allow of a diminution of $8 \mathrm{lbs}$. of hay; hence their value in this way is calculated.

" Every kind of cattle eat turnips except horses. Turnips will feed store pigs, but they will not fatten them. Carrots and parsnips are excellent for horses, and, when boiled, will 
fatten hogs. Ruta-baga is liked by horses; it makes their coats fine, but it must not be given in too great quantity, or it will gripe them."

In the German Farmer's Encyclopedia, Petri, an honorary and corresponding member of many societies for the promotion of agriculture, contributed a valuable paper on "The keeping, care, and breeding of Sheep," in which will be found the following table of the comparative nutriment of various kinds of food.

$100 \mathrm{lbs}$. of aromatic meadow hay contains $50 \mathrm{lbs}$. nutritious

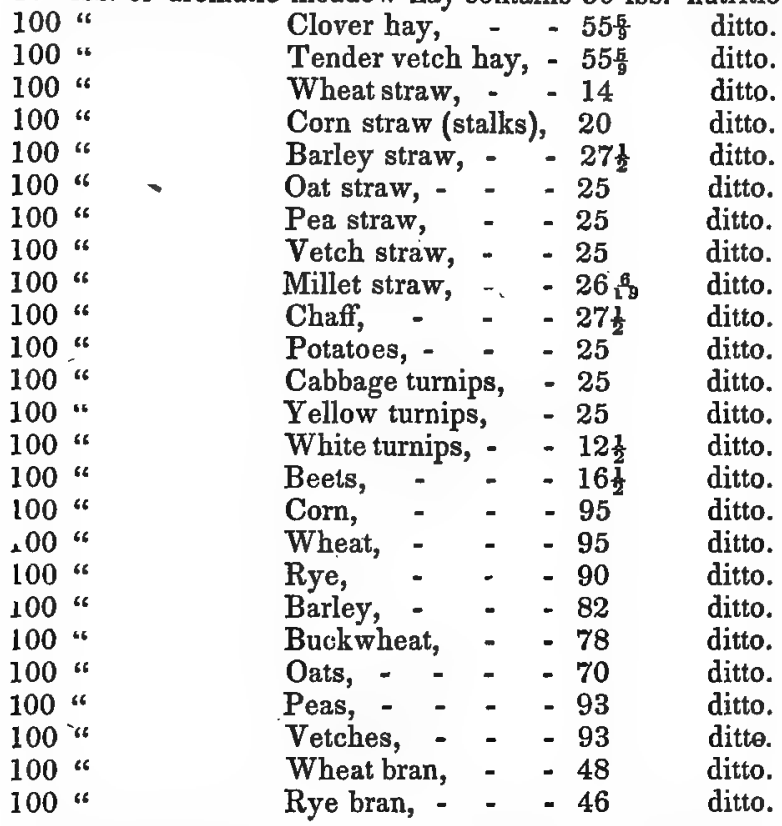

Petri confirms what has already been said in relation to the fondness of sheep for variety of food, by enumerating 252 plants which they eat with salutary effects, and 39 others they partake, of an injurious tendency.

He gives the following as examples of average of fodder for a ewe in the month of January, when the yeaning commences in March: 
Ist day, - In the morning, 章 lb. of good oat straw.

2d day, noon, $\frac{1}{2}$ " of good hay or clover. evening, "3 of good barley straw. morning, $\frac{3}{4}$ " of millet straw. noon, 2 " potatoes with $4 \mathrm{oz}$. chopped straw, and $4 \mathrm{oz}$. of oats.

3d day,

evening, $\frac{3}{4}$ " barley straw. morning, $\frac{3}{4}$ " hay. noon, $\frac{3}{4}$ " hay. evening, 1 " wheat, oat, barley or buckwheat straw.

dth day, morning, $\frac{3}{4}$ " summer straw. noon, $\frac{1}{2}$ " chopped straw, with 3 oz. oats and $3 \mathrm{oz}$. bran, moistened with water.

oth lay.

6th days evening, $\frac{3}{4}$ " winter straw. morning, "3 of hay. noon, 2. " of potatoes with $\frac{\mathrm{I}}{3} \mathrm{lb}$. chopped straw.

evening, "3 winter straw. morning, $\frac{3}{4}$ " of hay. noon, as in 4th day. evening, 1 " of straw.

He has ikewise given the following table of variations of Fodder, wuich may be successfully practised with sheep :

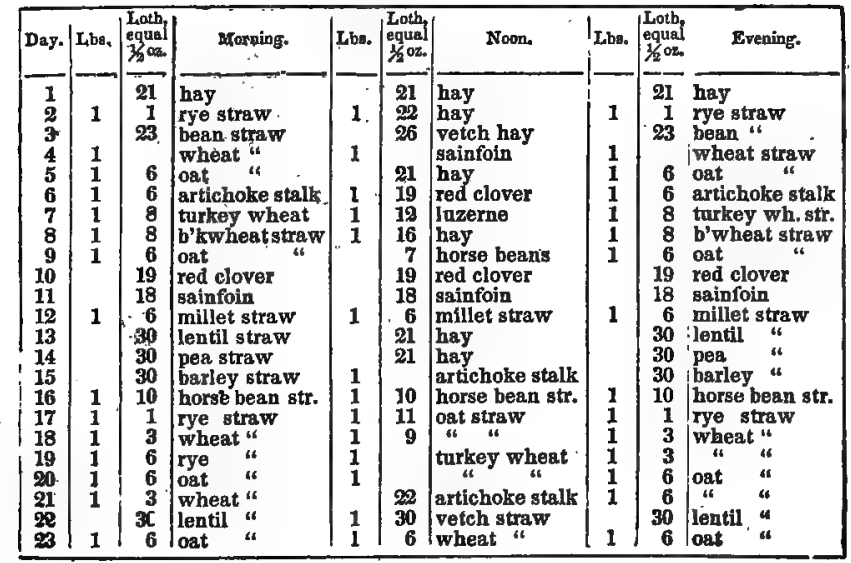


Petri allows on an average to a sheep, of hay, 3 to $3 \frac{1}{2} \mathrm{lbs}$. per head, and says : "In the winter a full-grown sheep of 70 lbs. live weight, eats, in fattening-fodder, $3 \mathrm{lbs}$. of hay, or with some hay 3 to 4 lbs. potatoes, or 14 to $18 \mathrm{lbs}$. of cab bage leaves, by which he weekly gains $1 \frac{1}{2} \mathrm{lbs}$. of flesh and wool." The following example, of a slaughtered sheep weighing $116 \mathrm{lbs}$., gives the proportions of the parts :

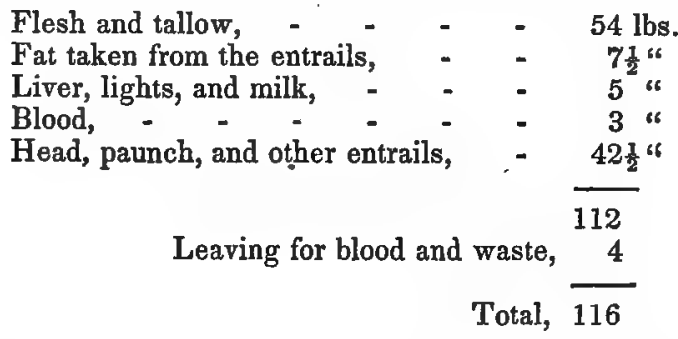

Thater was a long time at the head of the distinguished agricultural school of Mogelin, in Prussia, where many experiments were conducted in sheep management under his own eye. The late Judge Buel, in his Farmer's Companion, speaks of him as one "who has not, perhaps, his superior in the practical and scientific business of farming anywhere."

Thaer says, "The quantity of hay which is given to sheep is very different. In poor sheep-folds it is considered much to allow 3,000 or 4,000 lbs. of hay to 100 sheep for a wintering. In better conducted ones 7,500 lbs. is considered the minimum for 100 sheep : $3 \frac{1}{2} \mathrm{lbs}$. of dry fodder for a sheep daily are necessary, and the greater proportion of this in nutritious hay, compared with dry straw, the better. Where hay is not plenty, it is usual to have recourse to grain-fodder; oats, rye, and barley are equally good; where peas, beans, and vetches are largely cultivated, these may be used. The grains are given them either threshed or unthreshed; more frequently they have the rough grain mixed with chaff somewhat moistened. It is customary also, especially with the kernels of the leguminous fruits (peas, beans, \&c.), to soak them; others prefer to fodder with the pods strewed on chopped straw, \&c. Sheep which have daily $1 \frac{8}{4}$ lbs. of hay, and 1 $\mathrm{lb}$. of potatoes, or $1 \mathrm{lb}$. of hay and $2 \mathrm{lbs}$. of potatoes, and some straw, can be kept in a well-fed, wool and milk-producing state" 
VeIT was Professor of Agriculture in the Royal institution of Bavaria, and his work is full of experiments and calculations at that seat of agricultural science. He makes the following observations:-

"The need of fodder is proportioned to the live weight of the sheep, and two and a half pounds of the value of hay is required daily for every $100 \mathrm{lbs}$. live weight, to keep the animal in a profitable state. Hence the following amount of fodder is required :"-

$\begin{array}{lccccc} & \begin{array}{l}\text { Live wt, of. } \\ \text { lbs. }\end{array} & \begin{array}{c}\text { Daily. } \\ \text { lbs. }\end{array} & \begin{array}{c}\text { Yearly. } \\ \text { lbs. }\end{array} & \begin{array}{c}\text { Summer. } \\ \text { lbs. }\end{array} & \begin{array}{c}\text { Winter. } \\ \text { lbs. }\end{array} \\ \text { For a long-wool German sheep, } & \mathbf{1 0 0} & \mathbf{2 . 5 0} & \mathbf{9 1 2} & \mathbf{5 3 2} & \mathbf{3 8 0} \\ \text { Infantado Merino, } & 88 & \mathbf{2 . 2 0} & 803 & \mathbf{4 7 3} & \mathbf{3 3 0} \\ \text { Electoral species, (grade Saxons, } & \mathbf{7 5} & \mathbf{1 . 8 7} & \mathbf{6 8 2} & 402 & 280 \\ \text { Escturial electoral, (pure Saxon,) } & 62 & \mathbf{1 . 5 5} & \mathbf{5 6 6} & \mathbf{3 3 4} & \mathbf{2 3 2} \\ \text { One-eighth electoral, } & \mathbf{6 6} & \mathbf{1 . 6 5} & \mathbf{6 0 2} & \mathbf{3 5 5} & \mathbf{2 4 7}\end{array}$

In juxtaposition with the above the writer will place the estimate given in Mr. Spooner's work on sheep.

"An ox requires 2 per cent. of his live weight in hay per day; if he works, he requires 2 1-2 per cent.; a milch cow, 3 per cent.; a fatting ox, 5 per cent. at first ; $41-2$ per cent. when half fat; and only 4 per cent. when fat; or $41-2$ on the average. Sheep grown take up $31-3$ per cent. of their weight in hay per day, to keep in store condition." It must be understood by the reader that, in this estimate as well as all others, good hay is the standard of nutriment, and that if any grain or other food is used as an equivalent, allowance must be made for the quantity of hay accordingly.

The following remarks relative to the different kinds of straw, by VEIT, are worthy of attention by the feeders of every kind of stock.

" 1 . The straw of the usual liguminous fruits, and especially of lentils, vetches, and peas, is more nutritious than the straw of seed-clover. The greener the tips are, the less it is lodged the better can it be dried and brought in, the more nourishing it is. The fine stalk vetch straw is also very nutritious, behind which stands somewhat the pea straw, with its thicker stalk. All straw of liguminous fruit is particularly a welcome fodder to sheep, on which account therefore it is greatly prized by many sheep-owners, and considered equal to hay. .

"2. Oat and barley straw is the straw for fodder of the cereal fruits. Oat straw is most agreeable, and also most nutritious, on account of its peculiar taste, for all species of 
cattle, because on the tips of the panicles are usually found unripe grains, and oats are cut before they are fully ripe. Barley straw has, on account of its moisture, and short period of vegetation, a high value as fodder, and other things being equal, is as nutritious as oat straw, if it were not, as is the case, fully ripe before reaping. Yet it is more liable to injure than oat straw, because it imbibes more moisture from the air and soil.

"3. Straw of summer wheat, summer speltz, and summer rye, for fodder, stands after oat and barley straw.

"4. The stalk of maize or Indian corn contains much saccharine matter, and therefore is very nutritious, used fine, and agreeable to all kinds of cattle. The cobs, after the corn has been taken off, ground up, are likewise a very nutritious fodder, and the hard stalks may be chopped up for the purpose. Taking all these things into view, it stands next to the straw of summer rye in value as fodder.

"5. Millet straw has a hard stalk, but contains at least as much nutriment as the winter straws.

"6. Buckwheat, on account of its quantity on a field of less fertility, and if of fine stalk, in which its value as fodder from its straw being rich with leaves, is enhanced, is as good as the straw of winter grain.

" 7. Bean straw, in case its leaves have not fallen off or decayed, and the ends of the stalk are green when it is cut, as many experiments have shown, is more valuable than generally supposed."

Observations naturally suggested by a review of the tables of feeding, as well as some comments on German management of sheep in general will be found in the succeeding chapter.

\section{FATTENING.}

As an introduction to the subject, the following interesting observations by Mr. Spooner will be considered very apposite :-

" Though in many countries the principal value of sheep is to be attributed to their woolly covering, yet in this country (Great Britain), for some years past, the flesh has been the greatest source of profit, and the carcase, therefore, the paramount consideration.

"This has naturally led the attention of breeders to the consideration of what particular breed has the most aptitude 
to make flesh and fat, how these qualities could be improved, and what particular shape or form is connected with this propensity to fatten? But though the above has been perhaps the principal consideration in view, there are other subordinate ones springing out of it of scarcely inferior importance-such as which breed, or individual sheep, will fatten soonest on good pasture ? Which on indifferent or bad pasture? Which has the earliest maturity? Which can bear wet and dirt with the greatest impunity, or can best endure exposure to the weather in a cold and severe locality?

"These several points must all enter into the consideration of the sheep-owner, who must of course pay the utmost attention to the nature and quality of his land and its suitability for particular sheep, being, after all, governed by the ultimate calculation as to which brings in the greatest return of profit.

"The various points in the form of a sheep, connected with the aptitude to fatten, have received the utmost attention from practical and sagacious breeders, although some of these points are still matters of dispute. The superiority of particular improved breeds is now generally acknowledged, and may be considered to be established on certain principles, though in arriving at these principles it must be confessed that we are little indebted to science, but to the long and attentive observation and correct reasoning of sagacious and practical men. It is, indeed, only very lately that anything like a correct explanation could be offered for the various phenomena that attend the fattening of animals, or why one description of food should be more suitable for the purpose than another. It had, indeed, been laid down as a fact, that a large capacious chest and lungs were necessary for the production of fat, and that its secretion depended in a great degree on the quantity of air that could be respired; whilst the researches of modern chemists have shown that nothing could be further from the truth. And now that the fallacy has been exposed by chemistry it can also be readily shown by anatomy, for we find that whilst the horse and the camel have eighteen ribs; the $o x$ and the sheep have only thirteen. The absence of these five pair of ribs must of course materially diminish the cavity of the chest, and its greater breadth (necessary for another purpose) does not by any means compensate for its diminished length. Animals of speed have rarely a propensity to fatten, but in greyhounds, foxes, deer, 
\&c., we find the chest is long and deep, though not wide, whilst in pigs, sheep, and oxen, we notice an opposite conformation. The fact is, in proportion to the activity of the animal is its respiration and demand for oxygen, and in proportion to the consumption of oxygen is the wear and tear of the system and the consumption of the elements of the food. If the exertions are therefore excessive, that portion of the food that would have increased the weight of the body is called for to support respiration.

"In animals having a propensity to fatten, we find the chest of a circular form; the ribs spring from the spine more horizontally than in others, almost at right angles; this is observed in the ox, compared with the horse, and still more so in the sheep. The effect of this conformation is certainly in one respect to increase the width of the chest, but another important effect is to increase very considerably the size of the abdomen; for in order to obtain the greatest possible nutriment from the food, it is essential that the organs of digestion should be capacious, which cannot be the case unless the cavity in which they are situated is large. The abdominal muscles and membrane which support the bowels are attached to the cartilages of the ribs, and the short ribs in some measure cover the abdomen. It must, therefore, be evident that in proportion to the width between the posterior ribs must, in a great measure, be the size of the abdomen; and this width must be in proportion to the horizontal direction in which the ribs are given off. The loins must correspond with the ribs; the transverse processes are long and horizontal in proportion to the horizontal manner in which the ribs spring from the spine; for, in fact, they are but a continuation of the same roof, and must possess the same relative proportions. We must illustrate this point by comparing it with an umbrella, which, when thoroughly open, the whalebone ribs, so to speak, coming off at right angles, may be compared with the broad circular animal, and, when half extended, to the narrow-chested, flat-sided beast. In its former state the umbrella forms the roof of a much larger space of ground than it does in its latter state; and, in the same manner, the long transverse lumbar processes must form the roof of a larger abdominal cavity than the short transverse processes found with narrow loins. The same form that extends the roof of the abdomen, also gives a larger surface for the muscles of the back and loins to rest 
on; and thus we find in sheep of this description a very considerable development of the flesh or muscles of the loins -the primest part of the carcase. It is a common observation with judges of sheep, that one of the best points is a channel between the shoulders and along the back. This is, indeed, a desirable form, for it is connected with those neiessary qualifications for producing flesh and fat. The channel along the back is owing partly to the large development of the muscles of the loins and back arising from the form we have commended, and partly to the shortness of the upright or spinous processes of the vertebræ of the back. Now the use of these processes is to afford leverage to the mus-. cles, and their length, therefore, enhances the activity of the animal. Sheep, however, do not possess nor require these active powers, and they would, in fact, be very detrimental to the principal object of the animal's existence; it is a quiet state and a quiet disposition that disposes an animal to increase in flesh and fat. The shortness of these processes is illustrated in the sheep as compared with the goat, and in the improved breeds of the former as compared with those of the mountain and the forest."

With a view rather to confirm principles already stated, the following remarks by Mr. Spooner, and the examples in illustration, are quoted. It will be proper to add, that in no other country is the system of fattening better understood than in England, established by numerous experiments of her many enlightened and sagacious breeders.

"Quietude and warmth greatly contribute to the fattening process. This is a fact which has not only been developed by science, but proved by actual practice.. The manner in which these agents operate is simple and easily explained: -motion increases respiration, and the excess of oxygen thus taken requires an increased quantity of carbon, which would otherwise be expended in producing fat. So likewise, cold robs the system of animal heat, to supply which more oxygen and more carbon must be employed in producing extra combustion, to restore the diminution of temperature. Nature enforces this restoration of warmth by causing cold to produce both hunger and the disposition for motion, supplying carbon by the gratification of the former, and oxygen by the indulgence of the latter. The above facts are illustrated by Lord Ducie :-

"One hundred sheep were placed in a shed, and ate 20 
lbs. of Swede turnips each per day, whilst another hundred, in the open air, ate $25 \mathrm{lbs}$, and at the end of a certain period the former animals weighed each 3 lbs. more than the latter, plainly showing, that, to a certain extent, warmth is a substitute for food. This was also proved by the same nobleman in other experiments, which also illustrated the effect of exercise :-No. 1. Five sheep were fed-in the open air, between the 21st of November and the 1st of December; they consumed 90 lbs. of food per day, the temperature being about $44^{\circ}$; at the end of this time they weighed 2 lbs. less than when first exposed. No. 2. Five sheep were placed under shelter, and allowed to run at a temperature of $49^{\circ}$; they consumed at first 82 lbs., then 70 lbs. per day, and increased in weight $23 \mathrm{lbs}$. No. 3. Five sheep were placed in the same shed, but not allowed any exercise ; they ate at first 64 lbs., then $58 \mathrm{lbs}$., and increased in weight 30 lbs. No. 4. Five sheep were kept in the dark, quiet and covered; they ate 35 lbs. per day, and increased in weight $8 \mathrm{lbs}$.

"A similar experiment was tried by Mr. Childers, M. P., and is thus related by that gentleman in the Journal of the Royal Agricultural Society of England for that year. $\mathrm{He}$ says, 'I last winter enclosed a small yard with posts and rails, and erected a low thatched shed, just large enough to allow a score of sheep to lie down at once. The floor of this shed was boarded with rough slabs, and was raised eighteen inches above the surface of the ground, the boards being placed three-eighths of an inch apart, in order to allow the free passage of water and keep the boards dry, as my great fear was that the sheep might get the foot-rot.

"s 'I then proceeded, on the 1st of January, to draw forty wethers out of my flock of Leicesters, and divided them into two lots, as equal in quality as I could get them. On weighing each sheep separately, I found the weight of one score to be $2565 \mathrm{lbs}$., and that of the other $2580 \mathrm{lbs}$. I put the first lot into the yard, and placed the other lot on turnips. 'The field was a dry sandy soil, well sheltered, and peculiarly favorable and healthy for sheep. Each lot had exactly the same quantity of food given them, which was as follows:-

" ' Ist. As many cut turnips as they could eat, which was about $378 \mathrm{lbs}$. per day for each lot.

" ' 2 d. Ten pounds of linseed cake, at the rate of half pound per sheep per day. 
“ 3d. Half a pint of barley per sheep per day.

" " 4 th. A little hay, and a constant supply of salt.

" "For the first three weeks both lots consumed equal por-tions of food ; but in the fourth week there was a falling off in the consumption of the wethers in the shed of $52 \mathrm{lbs}$. of turnips per day; and in the ninth week there was also a falling off of 28 lbs. more; of. linseed cake there was also a falling off of 3 lbs. per day. The wethers in the field consumed the same quantity of food from first to last. The result of the experiment was as follows:

\begin{tabular}{|c|c|c|c|c|}
\hline January 1 , & $\begin{array}{l}20 \text { Shed Wethers. } \\
2565 \text { lbs. }\end{array}$ & Increase. & $\begin{array}{l}20 \text { Field Wethers. } \\
2580 \text { lbs. }\end{array}$ & Increase. \\
\hline February 1, & 2870 & $305 \mathrm{lbs}$. & 2794 & $214 \mathrm{lbs}$. \\
\hline March 1, & 3020 & 150 "6 & 2914 & 120 เ \\
\hline April 1, & 3355 & 335 " & 3092 & 178 “ \\
\hline
\end{tabular}

" Consequently the sheep in the shed, though they consumed nearly one fifth less food, made above one third greater progress. The circumstances of the experiment were, if anything, unfavorable to the sheep in the shed. The turnips, by being stored in a house for their use, became drier than those consumed by the sheep in the field; and also in February the shed wethers were salved or rubbed with mercurial ointment, which is generally supposed to give a check to feeding sheep. The floor of the shed was kept clean by fresh straw litter after every rain." "

Mr. Spooner adds the following:- "The result of these important and valuable experiments is precisely what we should expect from theoretical reasoning on the principles of the subject. It shows the pecuniary advantage of attending to the comforts of sheep and other animals, the expediency of providing proper sheds, and affording shelter when the weather is severe, and lessening, as much as possible, their exercise."

Quietness, as has been observed, is indispensable to rapid fattening of sheep, or cattle, and to contribute as much as possible to this object, regularity is requisite not only in the quantity of the food, but the time which it is given. It is not a little surprising how quick animals, especially when fattening, will learn the stated hours when their food is to be supplied; and if it is transgressed, they become restless, which greatly retards the process. The observance of this with full measure of feed, are of paramount importance. 
Again : it is essential that the sheds or buildings in which they are confined should often be supplied with fresh litter, and plenty of it; in short, everything must be done to promote complete rest, ease, and contentment.

Sheep, when fattening, should not be fed oftener than three times a day-namely, when day has fairly dawned, at noon, and an hour before sunset. The interim between feedings will enable them to fill themselves leisurely, and to have time sufficient for that quiet digestion which is interrupted by too frequent feeding. Water should be given without limitation, and that immediately after their meals.

The sheep-fattener must not lose sight of that peculiar habit of the animal exhibited in its fondness for variety of food. Indeed, change is very essential, as otherwise it may become cloyed on one species of diet. In fattening all animals, the shortest time in which it can be accomplished, the most profit will result. To effect this, we will suppose that it will take at first only of one kind of sustenance sufficient to maintain good store order; if it can be induced to eat one quarter more of another sort, then it begins to acquire fat; but if in addition to this, its appetite can be stimulated to eat yet another quarter of something else, it will readily appear -that the animal will fat all the sooner. A great point to gain, is to induce it to eat as largely as possible of the most nutritious food; but we shall fail in this if the appetite of the sheep is not courted and stimulated by variety. An author remarks - "Variety of food, with animals, operates like cookery in the human subject, enabling more sustenance to be taken."

When sheep are put up for fattening, care should be observed at first not to feed in full quantities of grain or meal, as, in so doing, acute diseases of the intestines will be avoided. Again: those of the same age with similarity of condition should be put together, as better calculations may be made of the aggregate quantity of food they will require daily. This is suggested for the reason that animals, when growing, require longer time and additional feed to make them fit for the butcher, as a portion of it nature appropriates for the development of muscle or flesh. Hence the great excellence of some of the improved English breeds, whose early maturity allow of fattening when only eighteen months old.

The following sound observations by Mr. Spooner will 
conclude the subject:- "With respect to the most advantageous food to be given, there is some difference of opinion, some preferring oil-cake, some beans or peas, and others oatmeal or barley-meal. It must, of course, depend, in some measure, on the nature of the farm, as it must, to a certain extent, be preferable to use the product of the farm. Sheep certainly prefer beans to oats; and where the former are grown they can be undoubtedly used to advantage. They abound in that principle in which turnips are most deficient, and thus are adapted to counteract, in a measure, the too weakening effect of the turnips; and the latter, abounding more in the elements of fat, prevent the beans from hardening the flesh too much, which they are otherwise apt to do. Oats and barley are more fattening than beans, both contain less albumen; and oil-cake nourishes but little, but possesses the principle of fat in a concentrated form. Perhaps the best plan would be to begin with beans, gradually mixing oil-cake, and finishing with that and turnips alone; or it may be prudent to mix other grain with the beans; or, if more convenient, substitute peas. Mr. Childers states that sheep fed with the addition of half a pint of barley per sheep. per day, half a pound of linseed-cake, with hay, and a constant supply of salt, become ready for the butcher in ten weeks, and gain of flesh and tallow $33 \mathrm{lbs}$. to $40 \mathrm{lbs}$. per head (one sheep gained 55 lbs. in twelve weeks); and that, with artificial food, 30 tons of turnips will feed 60 sheep; while, on the usual plan of feeding on turnips alone, out of doors, the average of the country is that 20 tons of turnips will feed, in sixteen weeks, 10 sheep, with. a gain of only 20 lbs. of flesh and tallow."

Although the ruta-baga turnip is the essential food for fattening sheep in Great Britain, yet in localities in the United States unadapted for its culture, the American breeders have ample substitutes in potatoes, Indian corn, as .well as all other grains usually appropriated to this purpose abroad. By reference to the tables of comparative nutritiousness. of the different kinds of food, and by weighing a few of the sheep when put up for fattening, a ready calculation will be made of the quantity required for feeding daily, which is highly necessary to know, in order to prevent waste. Profit being the ultimate object in keeping sheep of any kind, small thing's must be kept steadily in view. Handfuls make bushels, and ounces make pounds. 


\section{CHAPTER XIII.}

\section{WINTER MANAGEMENT CONTINUED}

REVIEW OF THE TABLES OF ANALYSES-WHAT FOOD WILL PRODUCE THE MOST WOOL-DE RAUMER'S TABLE OF EXPERIMENTSOBSERVATIONS ON GERMAN MANAGEMENT-VARIATIONS OF FODDER-FODDER PROPORTIONED TO THE LTVE WEIGHT OF THE SHEEP -IMPORTANCE OF GREEN FOOD-WATER NECESSARY-MANAGEMENT OF LAMBS-TWO-YEAR OLDS-BUCKS-HOSPITAL FLOCKMODES OF FODDERING-RACKS-TROUGHS-BARNS AND SHELTERS -PLANS OF SHEEP BARNS.

IF the reader will now pause, and recall that which has been set forth in the two preceding chapters, but more particularly the last, he will perhaps concur with the writer, that there is much matter for reflection, and much to form the basis of correct practice in winter economy. Let us take a brief and familiar retrospect.

From the analyses of fat, flesh and blood, and of the various kinds of food consumed by sheep, although very clear conclusions may be drawn by the better educated, yet perhaps it will be well, for the benefit of those whose information is limited in the rudiments of science, to glance at these things again.

It will have been seen, that there is quite a distinction in different plants in regard to the relative proportions of the nitrogenized and carbonized constituents they respectively contain ; and that food destitute of the former can afford no nutriment to the blood, and consequently none to the body; but those which furnish carbonized properties most abundantly, make much fat. Hence all kinds of food which are highly carbonized, to be which they must possess much of sugar, starch, gum, \&c., in combination, are fitted for fattening purposes. Therefore it will appear plain that wheat, barley, corn, rye, oats, buckwheat, and ruta-baga, are better for fattening, than the leguminous grains-such as peas 
beans, \&c., simply for the reason that their chemical prop erties correspond more nearly with the elements of fat, and the organs of the system therefore readily assimilate them for its formation. The question now presents itself,

WHAT FOOD WILL PRODUCE THE MOST WOOL?

Peas, beans, vetches, \&c., are useful for the purpose of enriching the blood, by furnishing it with large supplies of albumen, which is its principal constituent. It will be remembered that in the analyses of flesh and blood the relative proportions of their constituents are nearly identical; con sequently, whatever food contains nitrogen, and the greatest amount of albumen, is best adapted to the development of flesh or muscle, and is therefore the most nutritious. Wheat, rye, barley, and buckwheat, contain large quantities of albumen, especially the first two ; while oats, it will have been seen, contains $10 \frac{1}{2}$ per cent. of its organic elements of albumen, and peas and beans no less than 29 per cent. What conclusion, then, is to be drawn from this? In Chapter I. it is seen that the chemical composition of horns, hoofs, hair, wool, and even feathers, is substantially the same ; their organic elements are coagulated albumen and gelatin, and their inorganic, silica, carbonate, and phosphate of lime, and the oxides of iron and manganese. Hence it will readily appear that that food given to the sheep which will supply the greatest proportion of albumen, in the same ratio will increase the wool secretions, and consequently be productive of the most wool, provided, however, they also hold in suitable combination the inorganic substances of wool, without which they assimilate mostly for the formation of flesh or fat. This may be exemplified thus-a soil may be highly productive of corn, as well as a few of the cereal grains; yet for the production of wheat it may lack the proper proportion of the phosphate and carbonate of lime, and consequently the berry will not only be deficient in quantity, but quality.

The following table exhibits the results of the experiments of the distinguished agriculturist De Raumer, on the effects produced by an equal quantity of several substances in increasing the flesh, tallow, and wool of sheep : 
1000 lbs. potatoes, raw, with salt,

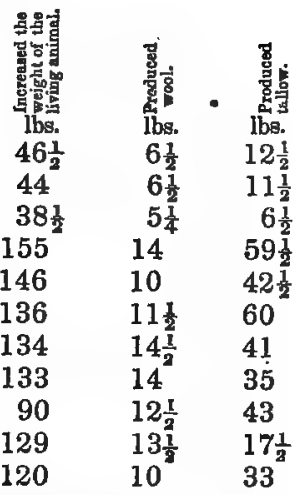

These results are said to agree with those of De Dombale, and with those of a number of other agriculturists.

It will be perceived by the above table, that wheat produces the greatest increase in the flesh of the sheep, though but little greater than oats; that peas, wheat, and rye, produce the greatest increase of wool; and that barley and wheat cause the greatest increase of tallow. That, as an average, grain generally gives about three times the increase in the flesh, that roots do when in equal weight; that grain produces about twice as much wool as is caused by an equal weight of roots, and several times the amount of tallow.

The legitimate conclusion from the foregoing is, that the flock-master, whose object is wool only, must rely on good hay and some straw, whose constituents are admirably adapted for the growth and perfection of wool, with a moderate allowance daily of ground peas and oats, and some potatoes as green food, for the greatest amount of wool; and those gross substances, oil-cake, corn-meal, and ruta-baga, may be turned over to the producers of fat mutton. 'This will presently be adverted to again.

\section{OBSERVATIONS ON GERMAN MANAGEMENT.}

The Germans are unrivalled in their scientific and practical knowledge of every department in agriculture, and in no one superior to that of sheep management. Economy is the grand basis of every species of cultivation, and their profits are rigidly determined by the expense of means employed 
in production. A writer who is familiar with the subject speaks thus: "The great distinction in German agriculture, compared with our own, is economy. The question is not, whether a great crop can be produced, or a fine story can be told, what large animals can be raised, \&c.-but what is the whole cost, the expenditure of labor, of land, of manure, \&c. For this reason computations have been made, and the proportion of all the parts and processes has been fixed. Economy compels them to weigh and measure their fodder. The minutest details have been entered into, the most difficult points examined, and the results brought out."

The variations of fodder, daily, with the quantities of each duly weighed and proportioned to the size of the animals to be fed, as observed in the different tables, is not a solitary experiment to determine a point only; but having become confirmed by thousands of experiments, is the basis of universal practice among her numerous wool-growers. The late Mr. Henry D. Grove, in seasons of scarcity, was accustomed to weigh daily the rations of his flock; and thus permitted nothing to waste, which exhibited the economical practice of his native country. These remarks are deemed essential, in order that the tables may be appreciated by those whose information is limited relative to the perfection to which sheep husbandry has attained in Germany.

The first thing which will strike the reader is the daily

VARIATIONS OF FODDER,

in which we see manifested the principle of economy practically carried out. The grain fields, and not almost wholly meadows, as in this country, are made greatly the means of maintenance of their flocks during winter; thus not a pound of straw nor a pound of anything valuable is permitted to be wasted. Hence the cultivation of sheep and crops in a measure are mutually dependent on each other. The manure of the flock augments the quantity of grain, and thus a larger quantity of straw is provided for it in return. We also observe displayed, their knowledge of that habit of the sheep as seen manifested in its eagerness for varieties of food, and of its love of frequent change. In this habit of the animal we behold, that wise economy of nature-in endowing it with instincts to promote its welfare to the greatest extent in every point of view. One kind of food may develop flesh, 
and another make fat; but it seems to be aware that several kinds are required to enable its digestive organs to effect such chemical combinations as will not only nourish the wool, but assimilate the inorganic substances which compose the external parts of the filament. From thousands of experiments made in Germany, it thas been demonstrated that hay alone will not produce as much wool, as when straw is mixed, which cannot be philosophically explained on any other principle than that which has been laid down. It must be repeated, that variety only will furnish those perfect proportions of organic and inorganic materials of which wool is composed. If we give the animal too much food of a carbonized or fattening character, the fibres of wool, being tubular in their conformation, distend or become coarser, and the weight is certainly increased; but on the contrary, if fed several'kinds, and each abounds as largely as possible with albumen, the fibre is materially increased in length, though not so much in bulk, simply because the variations of food supply to a greater extent the substances requisite to form the filament This may be termed natural wool, the quantity or weight of which will be as great as that produced by feeding grosser food, which has the effect to increase the diameter of the fibre at the expense of the length, and therefore is coarser, as well as harsh and wiry. The Germans abhor feeding large quantities of fattening food ir growing Saxon wool, as it destroys its delicate texture, and its value is lessened accordingly for the manufacture of the finest and softest fabrics.

The American wool-grower need not overfeed simply with a view to make heavy fleeces, as the wool of the sheep, when fat, is comparatively coarse ; and the expense of the food used in placing them in this condition, together with the reduction in the value of their wool, will more than counterbalance the gain from the increased weight. The wool of the Saxon and Merino variety is never so beautiful and perfect in all respects, as when it is natural; and this follows only from keeping the sheep in healthy store order, and nothing beyond that. The feeding of grain by the Germans is simply as equivalents, hay always being the standard, by which the quantity of any kind of food, daily, is determined. Their aim is not to increase the flesh and fat at the expense of the wool or any of its valuable properties; and if we ever expect to rival them in the extensive production of the most beautiful wool in the world, and at the least sacrifice, we must imitate their 
economy in feeding, and unsurpassed mode of management in all things.

The next point which will claim attention, from a review of the tables, is, that the quantity of

FODDER SHOULD BE PROPORTIONED TO THE LIVE WEIGHT OF THE SHEEP.

That animals, after arriving at maturity, consume of food in the ratio of their size, is a fact which admits of no dispute.

Petri, it appears, estimated 3 lbs. of hay, or with some hay 3 to 4 lbs. potatoes, or 14 to $18 \mathrm{lbs}$. of cabbage leaves to be necessary for a sheep of $70 \mathrm{lbs}$. live weight, when fattening-and with this amount daily of food would gain $1 \frac{1}{2} \mathrm{lbs}$. of flesh and wool weekly.

'Thaer's estimate is $3 \frac{1}{2}$ lbs. of dry fodder for a sheep daily, and "the greater proportion of this innutritious hay, compared with dry straw, the better."

Veit, from numerous experiments, determined that $2 \frac{1}{2} \mathrm{lbs}$. of the "value of hay" is required daily for every $100 \mathrm{lbs}$. live weight, to " keep the animal in a profitable state."

Now we will suppose, taking. Veit's estimate as the standard, that the average weight of a flock of sheep to be $80 \mathrm{lbs}$. per head, and the foddering time 150 days; this will give 2 lbs. daily to each, and for 150 days $300 \mathrm{lbs}$, and consequently for that period 100 will eat $30,000 \mathrm{lbs}$., or 15 tons.

This certainly seems a low estimate as to the quantity a sheep requires daily, it being $\frac{66}{10}$ ths less than the English standard, as rendered by Mr. Spooner. But different breeds and their subdivisions vary so materially in weight, that to form a proper estimate, the sheep-master should weigh some of each of different ages of his flock $k_{j}$ and by classifying them according to their relative size, he may feed with greater accuracy. He must remember, however, that sheep when growing, of any breed, require nearly as much food as when ihey have arrived at maturity; and sheep growing should never be stinted.

Another very important consideration must not be lost sight of, namely, the quality of the hay. If it is coarse, much of it sheep will reject; and consequently an allowance of from 10 to 25 per cent. must be made-accordingly. It is for this reason, old meadows produce a better quality of hay for sheep, than new ; that of the former being finer, and more miscella. 
neous. Sheep love clover hay, and will increase more rapidly in flesh if it is provided for them, than by any other description; but the quantity in bulk, comparatively, they require of it, is enormous. If farmers will top-dress their meadows with sheep manure, and occasionally harrow them, and early in the fall sow a little of timothy and other grass seed, the herbage will maintain a vigorous growth, and full crops for successive years may be expected. The manure, however, from the sheep-folds will, if hay has been used for fodder, afford generally the requred quantity of seed.

From the above premises we are enabled to deduce an exceedingly important fact, which, if always duly considered, will be the means of avoiding the serious blunders hitberto so frequently committed by American breeders, namely, that it requires an equal amount of food to produce a pound of flesh, or a pound of wool, without regard to the size of the sheep, or the breed. This is indeed a truism, and therefore self-evident. But by way of illustrating the point, let us select one of each of the rival breeds of England-the South Down and Leicester; we will suppose the live weight of the former, when in store condition, to be $100 \mathrm{lbs}$., and that of the Leicester 150 lbs., which is probably, in general, the relative disproportion. Now it is clear, taking the estimate of Mr. Spooner, which is the standard of England, the Down sheep will consume 3 1-3 lbs, of hay daily, while the Leicester will need 5 lbs. Is the latter, however, more or less profitable than the Down? Clearly there is no difference, for the offal is relatively the same, and so is the proportion of the valuable parts-the flesh and the wool. The expenditure of food for the Leicester is greatly the largest, but only in proportion to the difference of value derived from the additional size of its carcase. Thus it is seen, the pound of everything in both animals costs alike, and all circumstances being equal, the profits are the same.*

But we will go farther, and instance the Merino and Saxon, alike distinguished for wool-growing purposes. The Saxon, it will be remembered, is of the same race, being only a sub-variety of the former. Let a selection be made of one of each, which combines to the greatest extent their

* Let it be understood by the reader that the point is wool and flesh, and not fat, which it will readily be conceded several breeds of animals will gather more rapidly than others, arising either from improved conformation or more quietness of habit. 
perfections respectively. By taking the standard of Veit, as shown in his table, of the live weight of a pure Merino, say $88 \mathrm{lbs}$., and that of a pure Saxon, say $62 \mathrm{lbs}$ : (which is perhaps the comoarative weights of the breeds when pure), the Merino, if fed at the rate of $21-2 \mathrm{lbs}$. of hay per $100 \mathrm{lbs}$. of live weight, consumes $2 \frac{20}{10}$ ths lbs. daily, and the Saxon $1 \frac{55}{100}$ ths lbs., a difference, it will be noticed, of nearly 40 per cent. less than the Merino. Now, both being supplied with this pro rata of ration daily, the Merino will produce 40 per cent. more of wool and flesh, at an expenditure, however, of 40 per cent. more of feed. Thus it is clear that the pound of wool and flesh, in both cases, costs precisely the same. Hence it may be laid down as a rule by which the unwary may learn, that, after knowing the usual average weight of carcase and fleece of a given breed, if he hears of any very extraordinary individual instances of either, generally it may be ascribed to extra feeding, and at a cost accordingly.

Let not the reader, however, misapprehend the point in question. The breeds of sheep vary much in the quantities of wool they respectively produce, and individuals of a given breed will often outstrip their fellows, although fed in the same fold, in the amount of wool they will yield. But. if two are selected of the same breed and of equal weight, and fed precisely alike, and all other circumstances equal, if one- shears a heavier fleece than the other, it will be found, on weighing, to lack an equal amount of flesh, which his comrade has acquired at the expense of his covering. This has arisen from the difference in the assimilation of the food -in the one case, more for the formation of wool than the other.

\section{IMPORTANCE OF GREEN FOOD.}

The feeding of green food, such as potatoes, apples, hemlock or pine bows, \&c., is strangely disregarded by a large majority of American sheep-growers. This is a prominent point of attention in German management; indeed, it is thus in every section of the Continent where fine-wooled sheep are cultivated. The sheep, if placed in localities suitable to its general habits, at no period of the year is it so perfectly

- healthy and thrifty as during the season of pasturage; and from this the inference should be deduced, that succulent food is the prominent inducing cause. Confinement wholly to dry 
food does not comport with that variety of condiment, which has so frequently been urged; and consequently, if a provision is not made of something else, it will be followed by disorganized action of the digestive functions producing costiveness and constipation. The disease so frequent and fatal in American flocks, called the " stretches," results from costiveness; but this is scarcely known. in England, which arises from the large quantities of succulent food the sheep are supplied with during the winter months. In addition to this, further proof may be found in the fact that it is never known to attack the animal during the grass season. The writer speaks from personal observation, in stating that a supply of green food is indispensably necessary as a preventive of this disease.

In addition to green food operating thus, it has a tendency to increase the wool and yolk secretions, and thereby those valuable properties of wool, such as elasticity, softness, and soundness, are increased and perfected; and withal, being conducive to health, the condition is improved, and consequently an augmented quantity of wool is a certain result.

WATER NECESSARY.

That water during the foddering season is of paramount importance to the health and general well-doing of sheep, is no longer a mooted point. It is true that the animal will quench its thirst, as far as it is possible, by eating snow ; but if tested by experiment, it will readily be seen which it prefers. Some object to provide water, for the reason, that when the weather is very cold, it drinks too much, and thereby is robbed of much animal heat. 'This is somewhat true, but if warm shelters are provided, as they should be, it is counteracted. If the experiment is made with a given number, a portion being permitted access daily to water, and the others only the poor privilege of eating frozen snow to be dissolved in the stomach, it will be discovered that the first are more healthy, and will yield a greater crop of wool, which will be distinguished for those properties named under the preceding head. It cannot be expected that the wool fluids will be abundant if the sheep is denied water, unlese roots form. a good proportion daily of its consumption. In this case they will rarely drink, provided they are not salted too profusely. If the reader will refer to the chapter on the 
"Structure of Sheep," he will discover that a large supply of saliva is needed in the process of rumination, which must be afforded, mostly, either by green food or water. In conclusion, humanity demands our practical attention to this subject.

Having introduced sufficient to answer as a basis for what the writer deems a correct system of practice in winter, he will now proceed briefly to set forth some general instructions for the management of the different classes of a flock -and first-

\section{MANAGEMENT OF LAMBS.}

The necessity for making ample provision of pasture for lambs from their weaning until the approach of winter, has already been urged. This, however, is not properly attended to by many, and when winter is at hand, their condition is by no means what it should be. It may be set down as a rule never to be transgressed with impunity, that all animals when growing should be bountifully fed, as well as receive all other proper attentions conducive to their welfare; otherwise, it will be in vain to expect, when at maturity, they will exhibit the perfection of their species. The general qualities of any domestic animal, however perfect nature may have done her work, can always be further improved by art, or otherwise, by judicious feeding, and strict attentions in every other regard. It is very much from this cause, that celebrated breeders have gained their renown for improvements effected in breeds of cattle, as well as sheep. If we would have perfect animals, we cannot commence too early to lay the foundation of their excellence.

It is a custom with quite a large majority of sheep farmers to delay graining their lambs until the approach of spring, when they are sometimes far gone-in poverty. Is this wise? Would it have been thus if they had been grain-fed at the beginning and through the early part of winter? Is it not better to begin as soon as this, in order to furnish them with the necessary stamina to withstand the severities of northern winters, which is always greatest in the months of January and February? Put them early in a condition to pass through those terrible months, and subsequently all will be well. Truly the course of flock-masters, in this regard, is like giving the patient his medicine when he is on the confines of death! Therefore, viewing the matter in this light, 
the writer has no hesitation in-saying that a single peck of grain fed in December is worth the bushel fed in March.

As was remarked at the conclusion of Summer Management, the grass at the beginning of November loses much of its nutrition from repeated freezing; therefore at this period the lambs should be assembled, and classed relative to size and condition, divided into flocks of about 100 each, and feeding them grain should forthwith commence. As it is sometimes impracticable to call them into the sheep-folds without considerable trouble, the feeding-troughs should be removed to the field in which they are confined; then the flock-master may begin feeding them about four quarts of oats, daily, which he should be careful to distribute the entire length of the troughs. They will be very shy for a day or two, but the example of approaching them by the tame sheep which were placed among them at weaning time, will be the means of soon overcoming it. After the lapse of a week, the quantity of grain may be gradually increased to a half a bushel, which should be the minimum quantity for the residue of the season. When the major portion have partaken of the oats, the troughs may be removed back to the sheep-yards, and the time fixed for feeding should be about sundown, after which they can retire to the shelters, should the weather require it. At this time, a little hay should also be given early in the morning, which may be pursued until circumstances demand a change wholly to fodder.

About the middle of December, or before, let the feed be somewhat changed, by mixing with the oats a portion of pea-meal or wheat shorts; at all events, let it be meal of some kind which they may fancy, for in order to induce them to eat potatoes it will be necessary to cut them into delicate pieces and sprinkle the meal well over them. If sheep are wholly unaccustomed to potatoes their aversion to them will not be overcome without the adoption of this course. Beets and ruta-baga may be substituted,for the potatoes; but the reader has been informed that they are better adapted to the purpose of the sheep-fattener. If it is our wish to grow wool and not fat mutton, it will be wise in us to use those means which will afford the largest returns. Half a bushel of potatoes given at intervals of twice a week will be the right quantity, which it will be well to continue to sprinkle with meal, as well as with a small quantity of salt. On other days the peameal and oats may. be fed. 
The hay given them should be of fine stalk, and of the choicest quality; but in its place may be substituted once or twice a week, for a single foddering, oat or barley straw. If the lambs are thus provided through the winter, and have the benefit of warm shelters, their size at shearing time will equal the majority of "two-year olds, whose treatment has been only ordinary.

\section{TWO-YEAR OLDS.}

The class of sheep thus designated refers to those passing into their second year; therefore they require extra atteitions, on account of not having yet attained their maturity. 'The quantity of food they need is quite as much as will suffice for mature sheep, which proceeds from that law of nature, when the animal is growing, the dead parts of the system thrown off are not in the ratio of increase of the living parts, demanded for the development of size; and to effect this, additional food is necessary. Here is the reason why animals are stunted-the food given them was only equal to the natural waste, whereas, an extra quantity was needed not only for this, but an extension of the system and its various organs. When animals become matured, this extension or growth ceases, and the waste parts and the new formations are equal, when adequately provided with food.

It will be proper, therefore, to make provision for this class, and especially the ewes, approximating that of lambs. The measure of grain, however, must be determined by circumstances; if they have attained good size, and the season has been favorable for the accumulation of flesh, a less quantity will be required. Let them have pine or hemlock brouse, which has a very salubrious tendency with sheep, cut apples, or potatoes, and also pea, oat, barley, or wheat straw once or twice a week. They should have a variety, at all events.

\section{BREEDING EWES.}

This portion of the flock demand no especial attention beyond a full measure of food, until the approach of spring. The course of management then will depend on the time of. yeaning, which, if fixed for the month of April, they will require a large measure daily through March of potatoes, for the assimilation of milk. In addition, nothing better can be supplied them than a half pint each of wheat shorts, mixed with a 
little barley or oat-meal. Oil-cake and corn-meal are not so suitable, as they do not afford as much cassein, the only nitrogenized element, as the reader has been informed, of milk. Their fodder through the winter should be of a miscellaneous character. Pea and buckwheat straw are highly agreeable to them, especially the former, which, from its succulency, is well suited to their situation.

The reader is referred to the correspondence in the Appendix for many valuable hints on the management of breeding ewes, when the yeaning takes place in April. In conclusion, comfort, quietness, and generous feeding are cardinal points of attention with breeding ewes, through the whole period of gestation.

\section{WETHERS.}

The proper treatment for wethers must be determined by their ages; when growing, however, they should receive better attention than is usually bestowed. If turned off after their third year, which is usually done if of the Saxon or Merino variety, during the previous winter some graining will be necessary for profit's sake. At this age the writer confines his wethers mostly to oat and wheat straw, feeding, in addition, to each hundred half a bushel of corn-cob and oatmeal mixed, or that quantity of unground oats and corn, daily, with half a bushel of cut apples, thrice a week. Apples are much relished by sheep, and withal are very nutritious. After partaking of a mess they manifest greater eagerness for other food, which is quite conclusive of their being stimulating to the appetite. 'They are an excellent substitute for roots and brouse. Half a bushel (quartered before fed) to the hundred, thrice a week, will be proper.

\section{BUCKS.}

After the tupping season is over, the bucks should be separated from the ewes, and fed a generous allowance of good hay, with some grain. The latter is especially necessary, if they have performed extra service; and whether thus or not, those which have not yet attained maturity, should receive the best of attention. For development of the greatest size and the fairest proportions, which are certainly objects of the nighest importance, no other policy will accomplish. It will be wise, thefefore, in the flock-master not to spare 
his attentions, at no period of the year, to his stock's rams. For some other observations on this subject, the reader is referred to the chapter on Breeding and Crossing.

\section{HOSPITAL FLOCK.}

This is the general appellation of such sheep as are in low condition, proceeding either from poor keep, or temporary illness.

The attentive and well-ordered sheep husbandman will not be troubled with many of this class, for he will not overstock, neither will he permit any to remain on his hands till they have become too old; thus few will enter the "poor house" to reflect unskilful management. It is scarcely necessary to say, however, that every good flock-master will provide a place for the reception of sheep under consideration, as often, in spite of his humane care, disease will make its way to some individuals, which, in that event, require removal from their strong and healthy comrades, and treated accordingly. After the disease is subdued, their diet should depend much on the character of the malady. As a general rule, their food at first should not be of an exciting nature, especially if the disease was seated in the stomach, or intestines. But all suitable advice in this regard will be found in the history of diseases. When a sheep is seen declining in flesh, let it be removed forthwith to the hospital, and after a few weeks perhaps it may resume its place in the flock from whence it was taken; this is often so, if the removal is instant in the early stages of decline. Variations of the food will greatly contribute to restore invalids, as well as those in poverty of flesh.

\section{MODES OF FODDERING-RACKS.}

The custom so general among sheep-farmers of strewing fodder on the ground, is attended with a vast waste in the aggregate, and a corresponding ill-doing of the flock. No animal is more nice in its habits, or more keen in its sense of smell, than the sheep; consequently, if their fodder is thrown upon the ground, in moist weather, two or three passing over it, will cause the whole flock to reject the greater proportion, and thus from day to day their appetites are unsatiated. The waste from this slovenly practice during one season only, will more than counterbalance the cost of suitable racks. 
FIC. 1 .

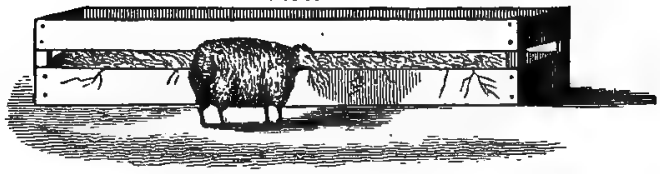

FIG.3.

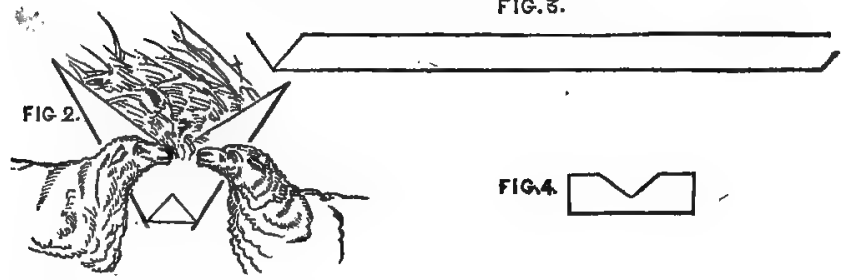

The kinds of rack most generally approved conforms to those represented in the cuts, or are very similar.

Figure 1 is a model of those used by the writer for many years. They cost but little, and little waste can result from their use ; and are also light, and therefore easily removed, which is sometimes necessary whether feeding is done under cover or not. Where, however, the severity of the climate compels, feeding wholly under shelter, the kind designated by figure 2 , appears admirably adapted for the purpose. The writer, however, never having used any of this description, cannot speak confidently whether their superiority is greatly over the other kind, and must therefore refer the reader to the remarks concerning them of several of his correspondents.

The upright pieces or posts of figure 1 should be of pine or hemlock scantling, 2 by 3 inches, and at least 2 feet 9 inches in length. The lower boards 12 inches in width, and the upper 10 inches; the spaces between them 9 inches; the width of the rack 2 I-2 feet. The most convenient length is about 12 feet, and if thus, 6 will be required for 100 sheep of the Saxon and Merino varieties, or grades of these, when full grown.

For lambs, the width of the lower boards may be reduced two inches, the top board not any, and the space between, less about two inches, the width of the rack four inches less. and the posts shortened three inches. 
From the length of the posts, an allowance, it will be seen, is made for nailing the lower boards two or three inches above the bottoms of them, which is proper. Five racks, if each is 12 feet long, will be required for 100 lambs of ordinary size. There should be no crowding when eating.

The front and upper edges of the lower boards should be planed slightly, to prevent the wool from the breasts and necks of the sheep from being rubbed off. To secure, the boards permanently to the posts, spikes should be used of sufficient length to clinch. Four spikes to each side and end board are necessary.

Figure 2. The most correct idea of the cunstruction of this is given by the cut, which represents one sawed in two crosswise. Six pieces of 3 by 4 inch scantling and 33 inches each in length are required for a rack. The shelving boards, as seen above the heads of the sheep, are of $\frac{3}{4}$ inch stuff, and 14 inches in width, and are very necessary to prevent hay seed and chaff from falling into the necks; and further, the hay, if pulled down faster than eaten, cannot waste, as it is saved by the troughs. The front board of the troughs should be 9 inches in width; the space for the heads of the sheep 10 inches; and from the top of the space to the end of the support, 14 inches. The triangles A A represent the troughs. This is a double rack, but on this principle they can be made single, and placed against the sides of the shelter. . They are more expensive than the kind first described, but have decided advantages for feeding within doors, as troughs are connected:

\section{TROUGHS.}

The boards of the trough (Fig. 3) may be of hemlock, or pine; the former, however, are not only cheapest, but hold nails more firmly. They should be 10 inches in width, one inch thick, and nailed at right angles; or, simply the edges of two nailed together. A notch must then be sawed precisely to correspond with the flare of the trough-into a twoinch pine plank, a piece of which 12 inches wide and 15 inches long constitutes the proper dimensions for the end pieces, or legs of the trough. (See end piece, Fig. 4.)

FODDER PENS.

In connection with the subject in hand, pens for the reception of the fodder when thrown from a stack or barn, are 
very necessary. Let four pieces of 3 by 4 inch scantling be used for posts, to which slats or boards 4 or 5 inches in width should be nailed, and sufficiently close to prevent the sheep from putting their heads between them. On each side of the pen should be fastened a slat diagonally, which adds to its strength. The posts may be $3 \frac{x}{2}$ feet high, and the pen about five feet square. 'Thus the hay is not run over by the sheep when thrown down, and injured; and if the quantity should exceed a foddering, it can remain in the pen, and the trouble of pitching it back is saved.

\section{REGULARITY OF FODDERING.}

The remarks as to regularity of feeding when fattening are equally applicable to store sheep. At a given hour nature calls for the allowance of food, and the careful shepherd will see that it is not transgressed. But it is not more a fixed time, than regular quantity, which needs observance. Quantity, however, varies with temperature, as well as the quality of the fodder, of which the reader has already been made acquainted.

There are not a few who think it necessary that sheep should be fed four times per day; but this is wholly unnecessary-three is quite often enough. If fed early in the morning, at noon, and, in the heart of winter, an hour and a half before sunset, it affords them ample time between feedings for quiet rumination and rest, which is interrupted by more frequent attentions. Let the roots, grain, or whatnot always be fed at" noon; after which the sheep will work at the stubbs or coarser parts of the hay or straw left of the morning foddering; and thus all is consumed. If, however, the temperature is severe, let a little fresh fodder be given in addition to their grain.

\section{BARNS AND SHELTERS.}

Of the utility of barns for the protection of fodder no one will question, and that a well-constructed barn is conducive to economy, is susceptible of demonstration. Hay is often essentially damaged when stacking, by a sudden and violent rain; whereas, whatever is secured in a barn is freed thereafter from harm. Again, a skilful stacker is rare, and therefore much hay is subjected to damage from this cause; and when unthatched, of course much is injured on the surface. Taking only these into view, the inducement is ample for 
every sheep-farmer to build commodious barns for the reception of his provender. That they will reimburse their expense in a few years, by the saving "of hay, and the better order of the flock can be sustained from the improved quality of the hay, all who have had the opportunity to judge, will at once testify.

The construction of barns, as with dwellings, will always vary, depending on the taste and means of the proprietor. Where the climate is severe, and subject to considerable depth of snow, making it difficult at times to travel a distance to the sheep-folds, a large barn capable of sheltering all the sheep, as well as their provender, is certainly desirable, and would be preferred to several, especially if placed remotely from each other. But it is a question, however, whether the extra time consumed in carting the hay to fill one of these mammoth barns will not more than overbalance this inconvenience. Again, in case of conflagration by lightning, which, if ever, is almost always after being filled with hay, the loss is very considerable. The prudent flock-master, therefore, will duly consider everything before he makes his decision.

The locality of the writer being favorable with regard to climate, and the snow rarely of much depth, he gives the preference to single barns, which are situated on the borders of his meadows, and therefore very convenient for the reception of hay. These barns are 32 by 24 feet, with 16 feet posts. The sheds are placed at the east end of the barns, and front the south. The latter, however, is objectionable; they should be on the west side, and front the east. By this plan the barn affords ample protection from the cutting winds of the north while the flock is feeding. The writer would recommend, in reference to the sheds, the north gable ends to be placed in a line with the south sides of the barns, with single roofs, the peaks of which may ascend to the eaves of the barns, and the lower ends elevated ten feet from the ground. The space for the sheep to occupy should be six feet in height, with a view to easy removal of the manure by carts; and above, there will be abundance of room for the stowage of straw and pea vines, for the variations of fodder, and for the deposite of "litterings. For 100 sheep the shed should be 20 by 30 feet at least. By this plan, it will be seen that the feeding racks must be placed in the yards.

To those whose circumstances forbid the expense of the 
erection of barns and framed sheds, the writer would recom mend the following:-For the consumption of 100 sheep, during the foddering season, two large stacks of hay are necessary; let those be placed in a north-east and southwest-line; and when they are about to be built, place two poles 35 feet each in length on the top of the stack pens, the centre of the poles to be supported by strong crotches. Before winter the hovel may be completed by putting rails crosswise of the poles to support the straw necessary for the roof; the back can be made of common boards, or by placing rails or poles parallel, and about one foot apart, and stuffed with old or partly rotted straw. This description of hovels are warm, and made in a very brief time. Wind-breakers may be built at right angles of the hovels, of the materials and manner as the back of the hovel, which afford much protection from winds when the sheep are feeding.

The following plans of sheep-barns are submitted, and which were selected from a large number forwarded to the writer, nearly all of them possessing considerable merit.

Fig. 1 represents a side-hill barn with underground apartments, which are unquestionably warmer for sheep than any other, and probably can be erected at as little expense. Where, however, it is not feasible to build after this model, the kinds represented by Fig. 2 and 3 may be substituted. In regard to Fig. 2, the carriage-house and horse stable may be dispensed with, and a shearing and wool house substituted.

\section{DESCRIPTION OF FIGURE 1.}

BY M. Y. TILDEN, OF NEW LEBANON, COLUMBIA CO., N. Y.

A. Well with pump.

B. Wator tubs.

C. Boxes for hay 4 by 6 ft. directly under a trap-door, through which hay is thrown from the mow; this prevents the sheep running into it before feeding, and also keeps the dust and seed ont of the wool.

D. In this section is a shearing floor, 13 by $40 \mathrm{ft}$, and wool room 14 by $18 \mathrm{ft}$ plastered.

Racks are placed around the sides of each apartment. 
WINTER MANAGEMENT.
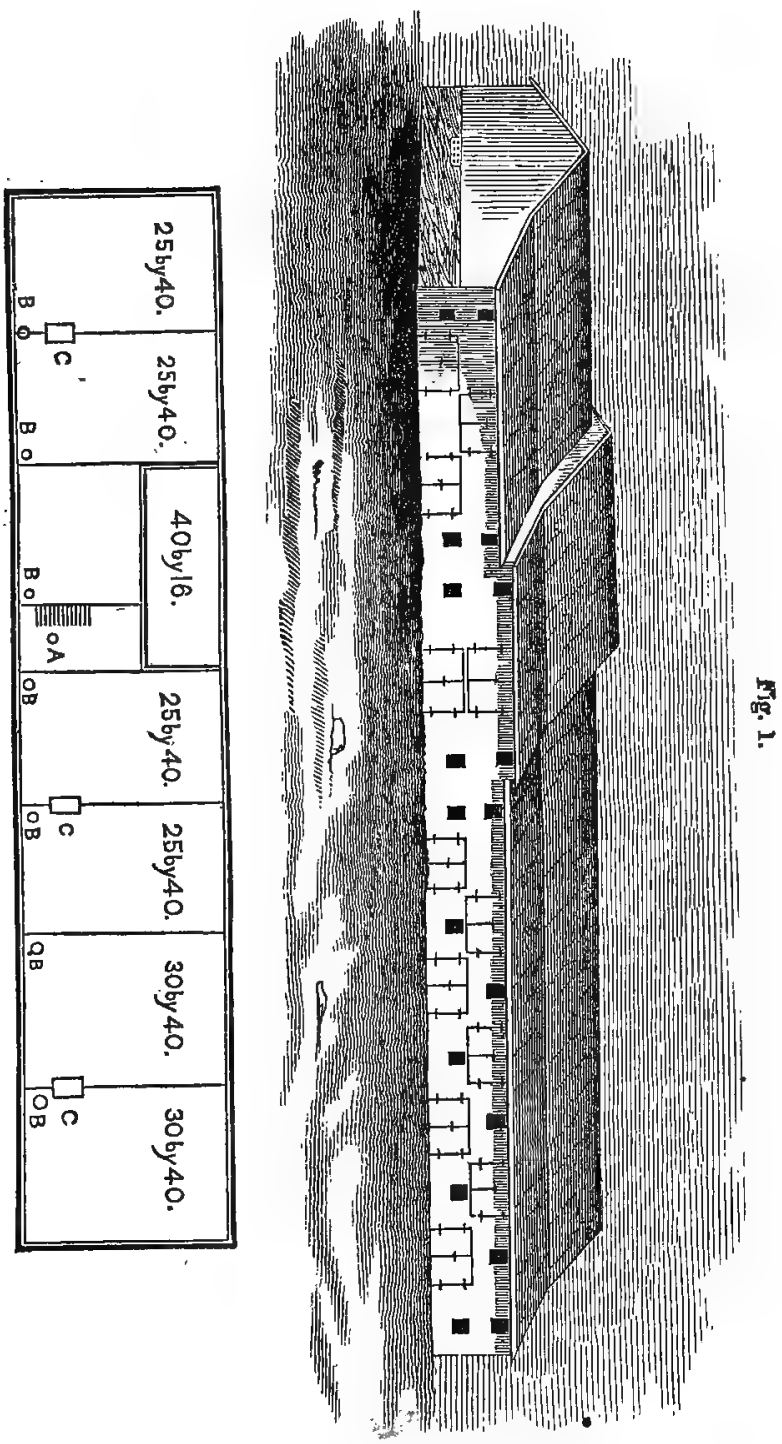


\title{
DESCRIPTION OF FIGURE $\%$
}

\author{
BY RICHARD MORGAN, OF ATtRORA, CAYUGA CO, N. Y.
}

I have adopted the plan of bringing all of the baildings nuon the farm Into one compact body instead of being seattered promiscuously over the farm. You will discover that I have drawn fonr sheep-barns in connection with each other, a description of one of which will answer for all. Sheep barn No. 1 is a building $f f f^{\prime}$ feet in length by twenty in width, with fifteen feet posts, the first room or sheep room to be six feet and $\mathrm{a}$ half in height from the bottom of the gill to the floor. A tight floor overheed to keep out all dust and seed. The sheep are to be on the ground, it being better than a floor of wood. A pen three feet high, and to contain a space equal to five or sir feet square, to be placed as shown by the letter $\mathbf{P}$ on ground plan, for receiving the hay when pitched from the mow, that the sheep may not trample apon it, and for holding the surplus hay that may be pitched from the mow. A rack for hay, grain, and roots, to extend entirely around the barn, exceptIng at the doors; one door opening into the interior yard and one into the outer yard. The outer yard, in which the sheep are to go into, for their daily exercise, extends around the barnstapon three sides, to be subdivided Into small yards for the accommodation of each flock; to be enclosed by a fence five or sir feet high, close boarded; the division fences are each to have a gate near the barn for passing with a team, as the barns are to be filled with hay from that side; yards No. 1 and 4 are thirty-five feet by fifty; Nos. 2 and 3 are thirty-five by elghty-five feet. The mow is sufficient for twelve or fourteen tons of hay each. The sheds, if built all at a time, may be divided by a fence between flocks, and the mow be left all in one.

Each sheep barn gives room for one handred sheep; fifteen inches of rack for each sheep; sufficient room for all to lio down in, without being too much crowded; the room should be well ventilated by funnels running up through the roof, or by windows near the upper fioor, with blinds, or slats. The barn I believe to be a good size for one hundred sheep, but to thase who are willing to add two or three feet more in width, in order to give an alley between the sides of the barn and racks, would find it convenient and profitable;-but with the size given there would not be sufficient room. I will give you a description of the barn and carriage room attached. The barn, carriage-house, and stable, occapies thirty-five by one hundred feet; $\mathbf{K}$, is a granary for oats; $J$, is a bay for oats in the sheaf; a cellar under both for rooks, with stairs at $S$, to enter the cellar, to be closed by a trap door, to be hung with hinges; $I$, is threshing floor; $G$, is bay for hay; $H$, is a stable for four cows or oxen; a passage way leads from the stable into the barn floor; a small door opens out of the stable into the yard; a small door also, from the threshing floor, with large door in front for driving In with hay and grain: the whole occupies forty-four feet of the building; $F$, is a covered road-way into the yard, twelve feet in width, $-D$, is a grain room for the horses; $C$, is the horse stable with five stalls, racks for hay and grain, \&c.; B, is an alley, for mixing feed, enclosed tight to keep dust and dirt out of the wagon-room; $O$, is stairs leading into the hay mow ; $A$, is carriage room, a deposit for farm implements, sc. A tight floor-covers the carriage room and stable, leaving the room nime feet in the clear. At $N$, stairs lead into a room for storing wool. Let a room of sufficient size be partitioned off in the loft, and be made tight against rats, mice, and dust, lighted by a window in the end of the barn. Let there be a window or door at each end of the mow for filling the same with hay. When the sheep ere to bo shorn let them be housed in sheep barn No. 1 ; let the wagon and tool room be cleared out for the purpose, and be used for a shearing room; V, V, V, are tables, or leaves made smooth, and to be hung with hinges to the side of the room near the floor, to be used for shearing upon, eight and a half feet wide; when not in use to be fastened back against the side of the roon, taking up but two inches of the room; the roller to place his table in such a place near the stairs, that he may throw the fleece, when tied up, directly into the wool loft; let there be a trap door in the wool loft for sacking the wool. The sheep, when "fleeced," may be turned into the interior yard. If the barns canoot be supplied with water by pipes, let the well be dug as shown in the yard. Yard No. 5 would answer a good purpose for fowls, and yard No. 6 for the hogpen, or if needed, erect a shelter, and keep the bucks gafe from tho other sheep, or such other purpose as may be most convenient. The interior yard is fifty by sixty feet and may be used for young cattle. I should have given the height of the barn and carriage house, which is eighteen feet posts. The expense of erecting one sheep barn would be about 150. The expense of erecting all of the bulldings: would be about eight or ten hundred dollars, depending entirely upon the prlce of jumber, and of labor. 
WINTER MaNaGEMENT.

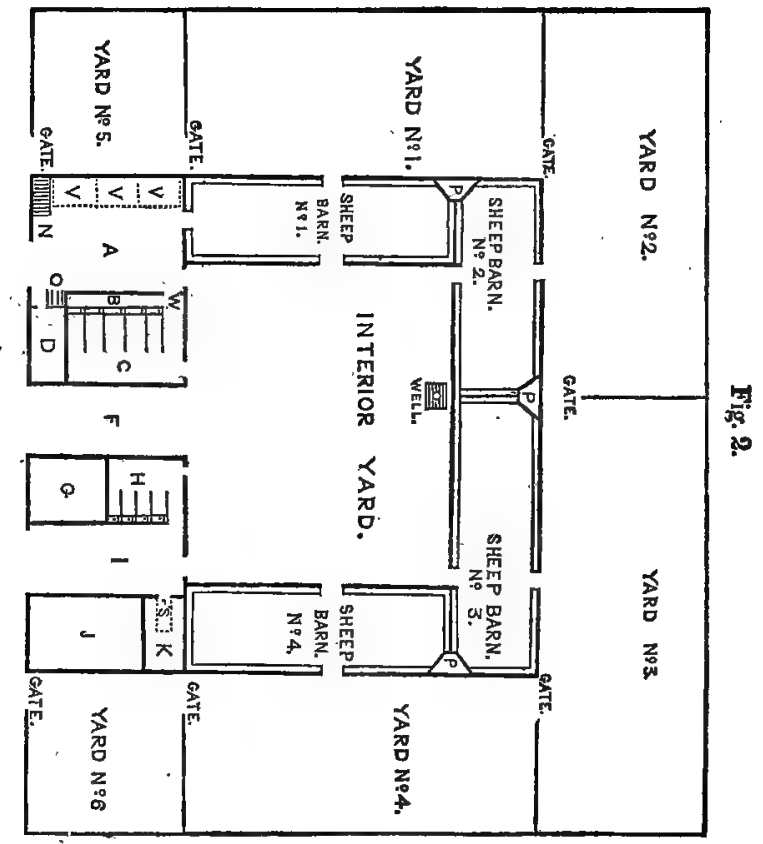




\section{DESCRIPTION OF FIGLRE 3.}

\section{BY JOSHUA BICKNELL CHAPLN, PROVIDENCE, R. ISLAND}

Na 1-A, represents the main building or store-house-of the following dimen sions : length $45 \mathrm{ft}$., width $34 \mathrm{ft}$., height to the eaves $16 \mathrm{ft}$.

The front internal arrangement is shown by supposing this end open.

B, B, are grain bins for convenience of daily distribution. They are 3 1-2 ft. wide $12 \mathrm{ft}$. long, $3 \mathrm{ft}$. deep in front, and $3 \mathrm{ft} .8 \mathrm{in}$. at the back, with one or more divi sions. The bins are placed in lobbies - that lead, from either side, to the sheep-folds At the farther end of the main building on the left is a granary (not shown in the drawing) 12 by $15 \mathrm{ft}$. and $8 \mathrm{ft}$. high. Adjoining this may be constructed a wool room, of like dimensions; and over these two rooms, as well as over the lobbies, are spaces for depositing the straw of the different grains.

The space at the right, $\mathrm{C}, \mathrm{C}$, beyond the lobby, and occupying the entire re mainder of that side of the barn, forms a capacious bay for the deposit of clover hay, \&ec.

The width of the lobbies, including the bins, is 7 1-2 ft. The width of the main floor is $10 \mathrm{ft}$. Under this, and descended to by a trap-door, is the cellar, capable of containing 2500 bushels of roots.

It is intended that the main fioor be used for the operations of eutting or otherwise preparing the food, shearing, \&c. The entrance at each end is the sanie. The barm will contain from 60 to 80 tons of hay, and 2000 bushels of grain.

On the right and left of the main building are two wings, $\mathrm{E}, \mathrm{E}$, which are the sheep barns. These are $75 \mathrm{ft}$. long (they may be longer or shorter according to the number of sheep desired to feed), $25 \mathrm{ft}$. wide, and $6 \mathrm{ft}$. high at the eaves, and will amply accommodate 400 or 500 sheep.

$F, F^{7}$, are the racks, which pass all around the folds, with the exception of an entrance at either ends : the one for the ingress and egress of the sheep to the yards, the others for the convenience of the shepherd. Between the racks and the outer walls of the fold is a passage way, of $21-2 \mathrm{ft}$. width, passing all around, the floor of which extends under the racks, and four feet beyond them, into the fold proper. This is designed for the sheep to stand upon while feeding--by this plan they eat better and waste less. The platform is elevated about $8 \mathrm{in}$. above the ground-(represented in the drawin gby the shaded.part).

The windows, hinged shntters, and doors, are sufficiently well shown in the drawing. The shutters should be kept open, except during storms, and severe cold weather. No animal suffers sooner or more seriously from imperfect ventilation than the sheep. Allowing a fold on either side of the main barn, admits of a division of the flock, which is of much consequence.

The disposition of the yards is alsn shown by the drawing. Racks and open sheds may be arranged around these if desirable.

A small house may be attached, and a division yard made at the outward end of either fold, say at $G$, for diseased sheop. At $H$ is a pump.

No. 2 is an enlarged view of the rack, $f, \& c . ; a$ is the platform spoken of above, $b$ is the back of the rack, $c$ the feeding trough in front, $d$ the feeding hopper to the trough. 
WIN'T́ER MANAGEMENT.

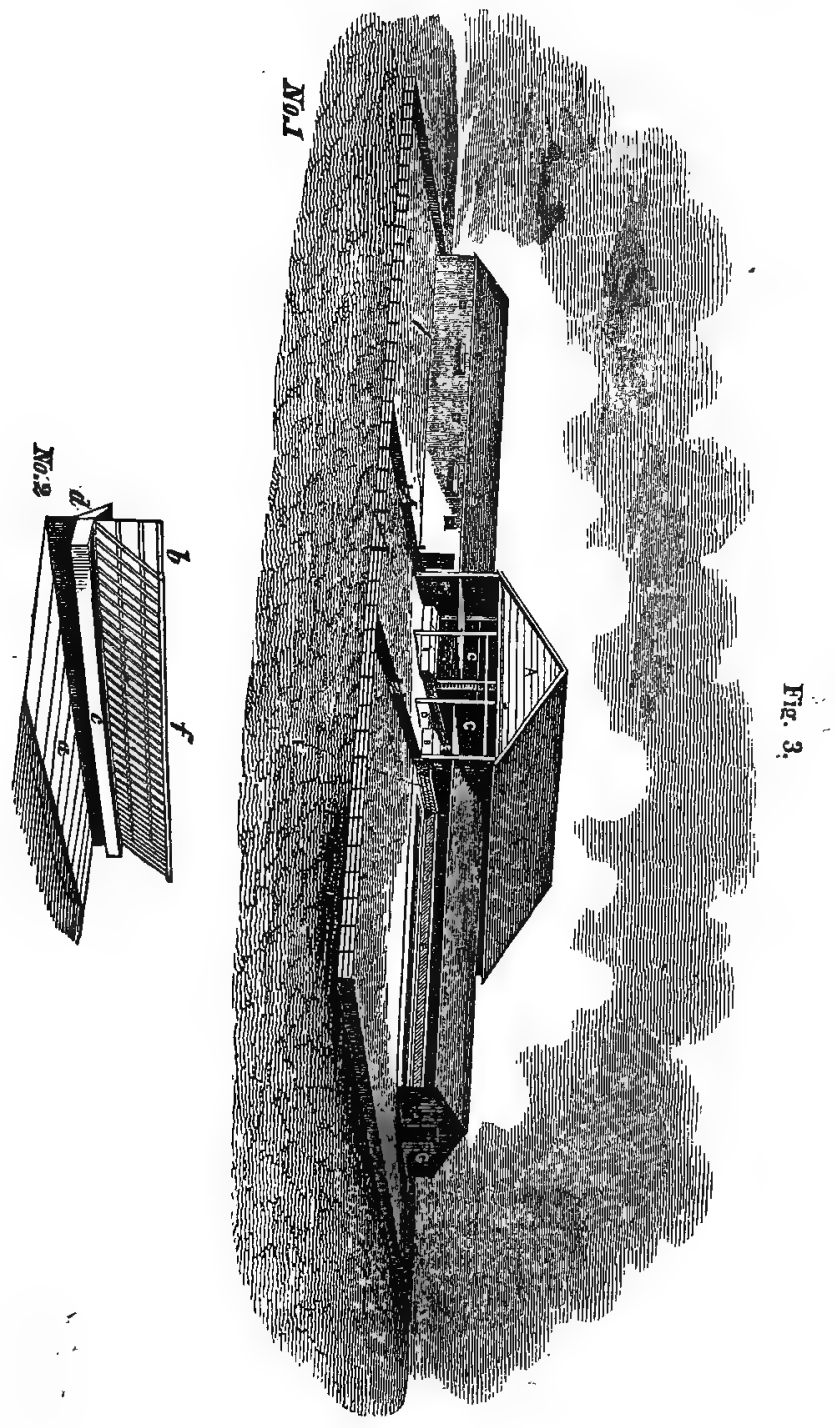




\section{CHAPTER XIV.}

\section{BREEDING AND CROSSING.}

INTRODUCTORY OBSERVATIONS-QUALITIES OF A GOOD MUTTON SHEEP-QUALITLES OF PURE BRITISH BREEDS-LFICESTER-SOUTH DOWN-CHEVIOT, \&C.-REMARKS ON THEIR CULTIVATION-IN-AND. IN BREEDING-CROSSING-BREEDING REGISTER-INFLUENCE OF SEX-GOOD POINTS OF A MERINO AND SAXON-TUPPING BEASON.

INTRODUCTORY OBSERVATIONS.

THERE is no department connected with the management of every description of stock of such paramount importance ass the one we are about to consider; and comparative success or failure must depend in a measure on the degree of knowledge of physiological principles the breeder may possess, together with that information acquired by perseverance, and close and discriminating observation. Those principles which form the basis of successful stock breeding are not wholly the results of scientific investigation, but in part by having the particular points to be added or changed in the form and fleece well defined in the mind, a ready perception of minute blemishes as well as good points, and indefatigable attentions in management in every regard. The breeder acts on that general law of nature, that "like produces like," a knowledge of the anatomical structure of the animal, with a thorough acquaintance of its habits ; but art or skill is equally necessary to make everything available to his purpose. So it is an union of art and science which forms the perfectly successful breeder.

The jostling incident to a redundant population necessarily begets excessive competition in every department of industry, which sets invention at work, and wit accordingly is sharpened to aid in every enterprise. Hence, in England, to support her numerous subjects, everything is brought into requi 
sition-every rood of ground is made subservient to grazing or tillage-the form of every animal is studied, and if susceptible of improvement, with a view to additional profit, is persevered in till accomplished. Perfection, therefore, in tillage and stock can only become very general where competition is excessive at all points, in order to secure individual competency, and the support of an overgrown population. Thus we have only to refer to countries sparsely settled, and the means of support consequently ample and attainable with little effort, to find indifferent agriculture, as well as indifferent animals, and therefore little knowledge possessed, or attention paid, to correct principles of breeding. Our own widely-extended country unfortunately affords incontrovertible evidence of the truth of this position; hence it is apprehended that we shall not practically avail ourselves of all the light which has been afforded on breeding, to a very general extent, for many years to come, because stern necessity is not at our backs, as in overgrown Europe, to require it. This is the fact at present, and it is feared the cause stated will long operate to retard the progress of general improvement in stock, commensurate with its importance.

England is indebted to Bakewell and Ellman for extraordinary reformations in her breeds of sheep; but it is hazarding little to say that she numbers hundreds among her breeders at the present day quite as enlightened as their illustrious predecessors. Bakewell and Ellman acted as pioneers in a new and unexplored enterprise, and are worthy of the renown they have so justly acquired; but their efforts were bent to improve the form and hasten its maturity, while the American Bakewells and Ellmans have a twofold and far more important object to accomplish-improvement of form and fleece. Both are within the reach of American enterprise and skill, and in process of time will be attained.

As hitherto remarked, the carcase engrosses almost exclusively the attention of British breeders, mutton being the great object, and the fleece therefore takes secondary rank, while in the United States it is the reverse. The subject of breeding consequently will be divided, and that which will claim attention first, is the consideration of the English breeds of which the writer has no personal experience in their cultivation, and therefore is necessarily compelled to rely on such authorities as his best judgment approves. The following sound observations of Mr. Spooner will open the discussion: 


\section{QUALITIES OF A GOOD MUTTON SHEEP.}

“' There are various points that are sought after by breeders, not because of the particular value of those points, but because they are evidence of other valuable qualities, such as aptitude to fatten and early maturity. Thus, in the South Down breed, small heads and legs, and small bones, are esteemed, as they are qualities which are found connected with fattening properties. Black muzzles and legs are also valued, probably because they denote the good constitution and hardihood of the animal. We must, however, take care lest, in carrying these points to an extreme, we neglect other valuable qualities. Straightness of the back, breadth of loins, and rotundity of frame, are points which cannot be disputed, and are not merely signs of good qualities, but good qualities themselves. 'The straightness of the back, so perfect in the Leicester, is by no means natural to the South Down, in an unimproved state, but rather the contrary. In the improved breeds, however, it is present, and is justly regarded as an excellent point, giving a better surface for the laying on of flesh, and affording larger scope for the abdominal organs. Its converse, too, a round or convex back, is produced or increased by the effects of poverty and cold, and is almost sure to follow if the breed is neglected and exposed.

"The development of bone, of course, requires nutriment as well as any other part, though not, perhaps, in the same degree. Large bone, therefore, abstracts nutriment which would otherwise be more profitably employed, and thus is anything but a desirable point in sheep. Horns, for the same reason, are much better dispensed with. One point in sheep, which is justly regarded as extremely favorable, is a soft, mellow feeling of the skin and parts beneat $k$. These parts are the cellular, or rather adipose membranes, which in fat sheep are full of fat, and in lean sheep, when possessing this mellow feeling, denote the plentiful existence of these membra nous cells ready for the reception of fat, which is deposited in them almost in the form of oil.

"Breadth of loin and rotundity of frame are qualities that require no observation, having been before alluded to. The former denotes the presence of a large quantity of flesh in the spot where it is most valuable, and it also bespeaks a large and roomy abdomen. A round frame is also the sure attendant of a large abdomen, and an extended surface for the 
muscles of the back and loins: A general squareness of frame bespeaks large muscleş; particularly of the quarters.

"What, indeed, is wanted in a good-formed animal, is as much flesh and as little bone and gristle as possible, and this flesh is required where it is most valuable; for instance, it is much more valuable on the loins and quarters than about the head and upper or scrag-end of the neck. A large development of flesh is pretty sure to be accompanied by a disposition to fatten; but for profitable feeding it is essential that these qualities should be developed early-constituting early maturity.",

\section{QUALITIES OF PURE BRITISH BREEDS.}

The three pure breeds which claim so large a share of atterition in Great Britain, are the New Leicester, South Down, and Cheviot. It is universally conceded that, so far as propensity to fatten and early maturity are considered, the Leicester outstrips all competition. These qualities may be regarded as a model, and other breeds are proportionally valuable as they approximate these-prominent points of the Leicester. Placed on a fertile pasture, and free from exposure, its quick and large returns of profit will ever make it the favorite of a large majority of English sheep-farmers. Its drawbacks, originating from the extreme refinement of its breeding by $\mathrm{Mr}$. Bakewell and his successors, are, comparatively, a weak constitution, incapacity to endure travel and exposure to bleak situations, and great liability to inflammatory disorders. Again, the assimilation of its food tends so greatly to the production of flesh and fat, the milk secretions are proportionally injured, and its qualities therefore for nursing are decidedly inferior to the South Down, Cotswold, Lincoln, Cheviot, as well as some other varieties. Its prominent good qualities, as mentioned, have been turned to the improvement of othere breeds deficient in these qualities, and to such an extent that an original Lincoln or Cotswold is quite rare in all England; indeed it is thus with all other of the ancient long-wooled varieties. Mr. Spooner observes, "That the Leicester have been extensively employed in improving the breed of other sheep, and so successfully has this practice been in many instances that the result of the cross has produced.a breed more profitable than the Leicester itself, retaining the fattening qualities of the sire with the greater hardihood and adaptation to the soil possessed by the 
native breed." This is applicable to the Lincoln, Cotswold, and Romney-marsh breeds. The mutton of the Leicester (on the authority of Mr. Spooner) is by no means so good as the South Down, which, however, is partly, not wholly, owing to the early period (twenty months) at which they are fit for the butcher, and partly to the very large proportion of tallow compared to the lean. Thus it is not a favorite in the London markets, and accordingly, of late years, the first cross between the Leicester and the Down has been produced instead of the Leicester; and it is contended that this cross is the most profitable sheep that can be fattened, making greater and more rapid progress than the Down, and better meat than the Leicester.

In the history of the South Down the reader is made aware that between the original Down and the Improved there is a wide difference, the latter possessing most of the important requisites which constitute the perfect mutton sheep. With a propensity to fatten inferior only to the Leicester, but with later maturity, this breed are good travellers, hardy compared with the Leicester, and "capable of thriving on short pasture. Their mutton is second only to the mountain breeds in fineness of flavor, and instead of their fat being concentrated as in the Leicester, it is dispersed through the flesh, or "well mattled," according to the butcher's phraseology. Mr. Spooner says, "Nothing can afford a better proof of the sterling qualities of this breed than the fact that some twenty years since, the price of South Down wool rendered the fleece a matter of great importance; and now, although the price is reduced to one third, and it can never expect to realize much advance, yet, notwithstanding this, the valuable qualities of the animal, and the improvements that have been made, have enabled the breed still to retain a foremost rank in public favor."

The South Down ram is extensively imployed at the present day in Great Britain for perfecting the more inferior breeds, and with the long-wooled sheep to produce a first cross, the mutton of which is so highly esteemed. A distinguished breeder in Hampshire some years since crossed the improved Cotswold ewe with the Down ram, and to such perfection has he brought the product, that he now challenges all England to produce a breed that will yield larger returns. The Down is evidently making rapid progress in the estimation of American breeders, and thus far, the crosa 
with low grade sheep has been attended with much success, which, however, considering its marked superiority, is by no means a cause of wonder. Wherever the pasture is not over-abundant, this breed is likely to take precedence over all others for mutton.

The third pure breed is the Cheviot, which are inferior to the South Down in fattening powers and early maturity, but greatly superior in hardihood and endurance of cold. Their excellence as nurses is pre-eminent, and consequently in instances where it was desirable to push forward lambs for market, the cross with the Leicester has been resorted to with complete success. In the northern parts of this State, as well as through the New England States, the Cheviot is admirably adapted to the climate, and ordinary modes of management.

The next breeds of the long-wooled varieties which will be very briefly noticed, are the Lincoln and Cotswold. These, however, have lost some of their original characteristics by extensive crossing with the Leicester ram, and by it have been made as greatly superior to their ancestors, as the modern Leicester is over the old breed. In many respects the Lincoln and Cotswold are better suited for American breeders than the Ieicester, being hardier, carrying heavier fleeces, and withal, are better nurses; and; as observed of the Leicester, where ample provision can be made for quick fattening, and placed in localities which afford facilities for easy access to a good mutton market, they are worthy of much consideration with those who cultivate sheep for the carcase.

The above brief summary of the qualities of the prominent English breeds, which is but a recapitulation of what the reader has remarked in their history, is for the purpose, in part, of calling the attention of American breeders to their great and undisputed merits. It will at once be conceded, that they are not as profitable as the fine-wooled breeds, if placed in situations unadapted to them, and such localities have already been pointed out. But it is scarcely necessary to say, that it would be unwise for all to turn their attention to raising fine wool, and wholly neglect the production of an article which is beginning to be so highly appreciated, and paid for accordingly, in our city markets. Fine mutton must always be in requisition as well as fine wool ; and with a considerate choice of breeds which produce the former, and of such as are partic ularly adapted to the products of the farm, the growing of 
mutton can be made quite as profitable as the cultivation of wool only. In addition to the value of the carcase, the new American enterprise for manufacturing the combing wool of English sheep, has already materially advanced the value of their fleeces, as good combing wools are now commanding as high as thirty-seven cents per lb. ; and the average weight of fleece of the long-wooled breeds may safely be estimated it six lbs.

The prejudice entertained against the British breeds by American farmers originates in ignorance and mismanagement. In many instances they have been abandoned and unjustly condemned because they could not be supported on the same amount of feed which is requisite for smaller breeds. Now let the American breeder for one moment consider the fact that the expenditure of food is in the ratio of the size of the breed; and if the same amount of flesh and fat can be grown on three English sheep, that can on five or six grade Saxons, or Merinos, pray why are not the three as profitable as the six? The English breeds consune, we will suppose, double the quantity of an equal number of the ordinary American varieties, but when they are butchered the proportion of valuable parts to the offal is greatly the largest, and the weight of carcase is occasionally three times greater, and almost invariably more than double. All that it is necessary to do in order to test the truth of these remarks, is, to weigh accurately an equal number of English and Americian sheep, and also their daily rations till fit for the butcher. This is the only way for every farmer to do, who doubts.

The turnip system of feeding so universal in Great Britain for fattening sheep should be resorted to in this country wherever it is practicable, and conformity in all other respects to English practice. This we should not despise and reject simply because England is one thing and America another. English animals and agriculture are second to none in the world; and in whatever point we imitate these, when practicable, will result in the largest returns of profit. The following observations, by Mr. Spooner, are in keeping with the above remarks :

"The management and selection of any breed of sheep must, after all, become a matter of pounds, shillings, and pence. The question the farmer has to consider is, what description of sheep will in the long run return the most profit; and this question must be viewed in relation to the management.he 
will be able to adopt on the particular farm on which he may be located. It is not therefore a simple, but a compound question. It is not merely. which breed will make most flesh and fat, but which will make it in the shortest time and on the least food; which can bear the weather, or hard keep, or travelling, or a particular mode of management, with the greatest impunity. All these considerations must enter into the farmer's mind before he can come to a sound conclusion. From the want of making these considerations many fatal mistakes have been made, and a flock has been selected al together unsuitable to the soil, and incapable of bearing the severity of the weather."

\section{IN-AND-IN BREEDING.}

Nó point connected with breeding has elicited so much controversy, and much of it certainly of a random character, as the one we are about to consider. There are grounds, to a certain extent, both for an affirmative and negative of the question; and therefore, the writer, with due deference to divided opinion, will present some of the views and arguments entertained and advanced on either side, which will enable the reader to draw his own conclusions from the premises.

By breeding in and in is properly meant choosing individuals to breed from of the same family between which exist propinquity or relationship of blood. The objects sought to be accomplished by breeding in and $\imath n$, are to strengthen good qualities and get rid of bad ones as soon as possible; it is therefore very evident that it requires a master's skill in selection of individuals, for if any possess imperfections, these, however slight at first, become hereditary, and will go on assuming a worse and worse type till the breed become worthless. Mr. Cully, the eminent sheep breeder, entertained the opinion, that less risk was run by breeding in and in than is generally supposed; yet at the same time was slyly procuring his rams from Mr. Bakewell, and selling his own at high prices to others.

Blacklock contends that breeding in and in is as "destructive to flocks, as marriages of near relations to the human kind. We would not witness an every-day entailment of diseases, if people would forego their unnatural love of money, and cease their endeavors to keep it in 'the family, by forming matrimonial alliances with those whorare near of 
kin. The law of God forbids us to wed those who stand in certain degrees of propinquity ; but, if we and our descendants avail ourselves of the limits of this law, and marry on its verge a certain number of times, misery must infallibly be the lot even of the tenth generation; and instead of being fathers of a mighty people, few and full of sorrow will be the days of our children; while in place of retaining in their possession our darling wealth, it will, ere long, pass into the hand of the stranger."

In 1800, Mr. Ezra L'Hommedieu, Vice-President of the New York State Agricultural Society, collected very many observations and facts on the breeding of sheep, which went to show the degenerating tendency of breeding in and in. Mr. Dick, of Edinburgh, states, on information given him by many intelligent farmers, that cattle bred in and in are subject to clyers in the throat after-they have attained their first year. Blacklock says-"Clyers are enlarged lymphatic glands, which are a sure sign of what is termed a scrofulous habit, and a breaking up of the constitution."

Mr. Dickson asserts the following, which will be found in the Quarterly Journal of Agriculture, of Edinburgh :- "The evil of breeding in and in, or, in other words, producing too great refinement of tone, is manifested in the first place by a tenderness of constitution; the animals not being able to withstand the extremes of heat and cold, rain and drought. If the evil is prolonged through several generations, the forms of the animals become affected, the bone becomes very small, the neck droops, the skin of the head becomes tight and scantily covered with hair, the expression of the eye indicates extreme sensibility, the hair on the body becomes thin and short, and the skin as thin as paper; the points continue good, and predisposition to fatness increases, but the whole carcase becomes much diminished in size, though retaining its plumpness and beautiful symmetry. The evil, however, does not terminate in the production of these symptoms. Internal diseases ensue, such as disorganization of the liver, or rot, polypi in the trachea, clyers, and malformation of the neck and legs." A writer observes"It is from this cause that almost every Royal family contains a large proportion of idiots, or, at the best, persons of very weak intellect; and such will continue to occur till legislators fall on some plan of striking at the groundwork of the mischief. If the laws of God and man define to us so 
clearly the evils of intermarrying "with relatives,-and if, as all animals are constructed on one grand plan, we admit the proximity of the sheep to the human race, it follows, that what is destructive in this respect to the one, is destructive to the other, and that we should seek, by a nearly similar, if not wider range of rules, to obviate many of those diseases, of which, when under our protection, they are so frequently the subjects."

The above is deemed sufficient to show the ground on which the opponents of breeding in and in substantiate their arguments. The writer will now introduce the views of Mr. Spooner on the other side of the question, and from the great interest which every sheep-breeder, who aspires to complete success in his calling, should feel on the subject, no apology is necessary for the length of the extract.

"The subject of breeding in and in, or from near affinities, is one which has given rise to much discussion, and on which there still prevails much discordance of opinion. Its merits, however, can be best understood by carefully examining into its advantages and disadvantages. In the human subject, sexual intercourse between near relations is very properly forbidden by law, and appears, indeed, altogether foreign to our feelings; and even marriage between relatives of the second degree, such as cousins, is regarded by many persons as subject to great objection, and apt to entail disease on the offspring, and particularly disease of a mental character. Statistical facts bearing on this matter certainly support this opinion in a marked degree.

"With animals there is no reluctance to sexual intercourse between the nearest affinities, and the custom of breeding from sheep closely related has been for a long time practised by breeders of considerable eminence. In the human subject the objections to the practice are at once granted, but let us see whether they likewise obtain with animals. In the former, marriages are generally, entered into with little, if any regard to the health of the individuals concerned, the consequence of which is, that the diseases of the parents, or rather their predispositions, are entailed on their offspring. The result of this is, that most families have predisposition to some particular complaint; and thus if two members of the same family have sexual intercourse, the probability is, that if both parents had predispo. sition to a particular disease in an equal degree, this will be 
increased in their offspring in a double ratio. But on the contrary, if a man unites with a woman of a different family and a different predisposition, the idiosyncracy of the offspring to the diseases of either parent is likely to be prevented or retarded.

"With animals the case is different. If due attention be paid, a principal object will be to breed from healthy subjects, by which means one fertile cause of hereditary predisposition to disease is prevented. A healthy form and sound constitution are essential to successful breeding, and for the development of those points we seek to obtain. Thus the principal objection to breeding from near affinities which exists in the human subject, does not obtain amongst animals ; and even if, in the former, mental disease is more apt to occur when this practice is pursued, this also is an objection which does not apply to animals, though it has been urged by some that sheep bred in and in are more subject to diseases of the brain-a conclusion, however, which I am much disposed to doubt.

"Thus the objections to breeding in and in are not insuperable; what, however, are its advantages? The stronger resemblance there is in the qualities of both parents, supposing those qualities are good, the more likely is it that the offspring will be perfect. By breeding with a view to improvement, the greatest excellences are likely to be concentrated in one family; if, therefore, the members of this family were not coupled, they must probably be united to inferior animals of either sex, by which practice improvement will be materially retarded. It is, therefore, very frequently the surest method of arriving at the greatest degree of excellency, and thus it is a practice which has been followed by the most eminent breeders of sheep with the greatest success; yet it does not possess any advantages peculiar to itself and different from those we have stated, and if two rams were obtainable possessing precisely equal qualifications, I should not be disposed to select one because he was a near relation to the ewe, but the contrary.

"In-and-in breeding may thus be either productive of good or bad effects, but in neither case is the result to be attributed to the close affinity, but rather to the circumstances connected with it. If no care is employed either in selecting or culling the flock, unquestionably both disease and defect will arise; and two animals, each predisposed to the same 
bad quality, being allowed to connect, the predisposition to such defect will exist in their offspring in a twofold degree. If, on the other hand, proper care is employedif those animals only are allowed to breed that possess good forms and healthy constitutions, then undoubtedly the stock will be preserved pure, disease will be warded off, and the proper form and qualifications will be perpetuated."

It is proper to add, that Mr. Spooner in a subsequent page qualifies somewhat more the tendency of the above, leaving the reader to infer that breeding in and in is a very nice matter, of which the number is exceedingly small in whose hands it can be intrusted with safety, and to be pursued always within proper limits. His views are presented rather to show what can be said in its favor, and not because the writer thinks they should be acquiesced in. - In his humble opinion, in general, it is to this vile system of breeding that, quite as much as the miserable general management to which American flocks have been subjected, we see so many worthless specimens of sheep, both in form and fleece, throughout the length and breadth of the land. It has been the practice of thousands of sheep-farmers to confine themselves to a single tup in their flocks until age, perhaps, had nearly destroyed his procreative powers, putting him to his own progeny for successive years, which resulted in causing disease and premature death, which, however, was often ignorantly and unjustly attributed to imbecility of constitution of the breed: hence in numerous instances the violent prejudices engendered towards the Saxon race. Farmers in general of the North, from the vicissitudes of the climate, if for no other reason, must avoid the system of breeding in question, as they would a reptile. None need imagine for a moment that their sheep are so perfect in all respects, but others either far or near may be found among which can be obtained,individuals fully equal if not superior to their own. At all events, the effort should be made to find them, rather than iacur the risk of ultimately making worthless those in their possession. Every flock-master should beware of entering any flock to purchase from, if he knows that its proprietor has pursued for any length of time the breeding in-and-in system, and tespecially if the flock is small, and the range therefore has been limited for selection.

The evils incident to breeding in ard in have long since been discovered in England, and also among the celebrated 
German Saxon wool-growers, and consequently a system has been adopted of breeding from different families of the same race. This unquestionably is the best course, where the flocks are about perfect, as the males interchanged have shades of difference impressed by soil, herbage, and treatment, and the defects of each family have a good chance to be counteracted by the perfections of the other. By this means the bad points are gradually lessened, and of course are succeeded by other valuable properties.

\section{CROSSING.}

The next system adopted in breeding, is crossing an inferior race by another possessing properties desirable to acquire. This, it will at once be conceded, is the most proper course for us, as it will be the means of most speedily diminishing the imperfections which characterize the forms and fleeces of a large majority of American flocks. Where the contrast is so great as it is between the ordinary sheep of the country and the pure Merino and Saxon, years will be required of patience, steady perseverance, and nice discrimination in selecting from generation to generation, before the goal of perfection will be reached. Many sheep-farmers imagine that two or three crosses will accomplish their object, whereas nothing scarcely is more absurd to expect. The greater the contrast, or less homogeneousness of the breeds crossed, the greater length of time will be required, and skill necessary to employ. The proper steps to be taken in the process of crossing, the writer will endeavor familiarly to illustrate.

The object sought, we will suppose, is the improvement, for the most part, of the fleece, by changing its character from openness and coarseness to the opposites, fineness and compactness, or improvement in quantity as well as quality. The ewes we will imagine are the more ordinary grades and the ram of the Merino blood, the good pedigree of which there can be no question, and whose fleece comes fully up to the object of ounthishes.

The result of the first cross will exhibit a few, the wool of which about their shoulders approximates that of the sire, while of other parts there will be great discrepancies, and especially so in the region of the rumps and thighs. All will manifest a general improvement over the dams, and a few a marked likeness of form to the sire; taking the whole to- 
gether, however, the progeny of the first cross will present a queer melange; but they must undergo a rigid examination, and those whose fleeces conform nearest to the rams should be marked and retained, and those farthest from his excellencies, disposed of. The ram may be again put to the same ewes, but a similar result will follow, and selections should be made from the second batch in like manner as from the first. The question now presents itself, What should be done with the ewes of the first cross, which we will suppose old enough to receive the tup? Should they be put to their sire? This is certainly revolting, to say the least of it, and yet if it is done, is part and parcel of the in-and-in system. If it is permitted, however, there can be little doubt, that their progeny will approximate more nearly to the sire than if another ram equal in all respects had been substituted. This will arise from the first cross possessing much, in a general sense, of his nature, or, in the phraseology of breeders, a "strong dash of blood." Notwithstanding this, and however others may differ, the writer would prefer decidedly using a second ram, as, by so doing, he might correct some trifling defect the original one may have possessed, and which, if used, where the affinity is so extremely close, would exhibit itself in a much stronger type in the second progeny.

If the second ram has been used, which we will consider the most proper, it will make a second cross, and the progeny of this will exhibit also a curious variety of fleeces and forms, being neither one thing nor the other; indeed, on the whole, will operate to discourage much the breeder, and he will think his object almost unattainable. Some will be, as those of the first cross, pretty good about the shoulders, the fleeces, however, thin; others will show a dozen, more or less, qualities of wool in their respective fleeces, in short, everything but being right. . But the breeder must not be discouraged. Let another ram be procured of equal excellence with the first and second, and used for the third cross, and to his great delight, among the progeny he will discover a number which begin to resemble quite closely the object for which he is striving. After each successive-cross, he should pursue rigidly his course of selection, for his ultimate triumph will depend greatly on his skill and attention in this respect. The progeny of the fourth cross (at least a good majority of them) will come well up to the mark-not quite, however, as, by critical examination, he will discover some 
coarseness yet about the rump, belly, thighs, \&c.; and per haps the fleeces will not be compact enough; others there will be, although qualities generally good, whose fleeces will be too dry, not being sufficiently imbued with yolk.

Let the breeder pursue an undeviating track in selection, for he will discover individuals even after the seventh and eighth crosses comparatively indifferent, and if his motto is "onward," he will not breed from these. But what, perhaps, will surprise him greatly at this stage, notwithstanding a particular ewe may be almost as perfect in her fleece as either of the rams employed, yet she will bring forth an oflspring occasionally, which will represent the defects in a marked degree of some of those of the first and second cross! but were he an "old stager" this would not astonish him, as it is an ordinary occurrence for even ten or fifteen years after the commencement of improvement in instances where the blood on one side was of the ordinary stamp, and which would have been still more frequent, if the rams used had not been wholly pure. This is an item showing the great value to be attached to blood.

After the seventh or eighth cross, will it be proper to employ any males produced in the flock? As a general rule, no; it is safer to procure them from another family higher bred. Hitherto it has too frequently been the case that, after a flock has been pushed far on to perfoction, the breeder has resorted to his own rams, by which improvement has ceased, arising from the propensity of even high-grade animals to transmit some of the defects of the stock on one side from which they sprang, to their progeny. This rule, however, may sometimes be violated with impunity. For instance, after the third or fourth cross, some of the ewes may produce offspring uniformly alike, and very perfect, and such instances show that they have been very thoroughly infused with the pure blood of their sires; therefore in such cases it may be safe to employ their offspring as tups. But the breeder should be very sure of the circumstance stated, which can only be arrived at with certainty by attention in marking the lambs for several successive years.

In breeding for the fleece, other points must not be negected, such as form; and indications of sound constitution. The remarks which have appeared in reference to breeding he mutton sheep will apply in some measure to Merinos and Saxons. Small bone, and a compact square frame, but 
not too large, are always good points in any breed, and should never be lost sight of. It should be considered that, after we have shorn the fleece, the drovers have a right to step in to judge of the carcase, and they have a curious way of "coming over us," if our sheep are too small and slabsided.

The following observations on the subject in hand are by Blacklock, which the writer believes are worthy of much attention, and which he quotes for the reason that he feels they will have more weight than any he can offer himself, while they. also corroborate several points already set forth.

"The fact is; that, if you wish to have a particular kind of sheep, you must first of all be in possession of a pasture suitable for the new-comers. You must consider the influ ence of the individval parents on the progeny, the size of the animals, their habits and dispositions, and their peculiarities in regard to the time of their maturity, and fattening properties ; and, having anticipated these apparently trifling affairs, you must see that the surface of the farm, its degree of exposure, and the quantity and quality of its productions, are calculated for the profitable maintenance of the breed in view. Far too little attention is-bestowed, at the commencement of such an undertaking, on these all-swaying matters. Farmers enter upon this, the most arduous of all professions, with the settled conviction, that nothing is so simple as the engrafting of a race of animals on a particular part of a country. They have read, or heard, of others who have gained fame, and a fortune, by successful endeavors of the kind, and they think that nothing is easier than to follow their example; but they forget the thoughtful hours, and irksome duties, these men had to tolerate, before they could speak of anything like success. No animal yean be made to forego at once a long-used food, an ancient locality, a peculiarity of clime and season, and the instinctive habits that have been long nurtured by these, without both it and its progeny suffering from the change.*

"In crossing there are several important things to be attended to. Well-formed parents ought to be selected, and, if enlargement of the carcase be wanted, the issue should be better fed than its originators, which ought to be of a size rather under, than above what the pasture is capable of sup porting. The size of the parents should not be much dispro*

* The truth of this remark will strike the prairie flock-master 
portioned at first, as nature abhors sudden extremes, and does everything in the most gradual manner. We must not imagine that when, by dint of crossing, we have obtained the variety wanted, that it will remain in the condition we have brought it, without the slightest liability to alter. Many farmers believe they have done all that is required, if they subject their stock to three or four crossings with a breed of acknowledged excellence. They think that the improved animals they have obtained will support their acquired characters, uninfluenced by extraneous agency. Now nothing can be more faulty than this mode of management, as is proved by a comparison of stock so treated, with flocks which have uninterruptedly received that undeviating attention which can alone ensure a continuance of the properties desired. Such men forget that the climate is operating with as great certainty as on the rocks around; and that as the herbage is determined by the nature of the adjacent rocks, so are the peculiarities of the sheep influenced by the herbage; and that if they manage to change the characters of the breed, it can, in a majority of cases, be only for a time, unless the tendencies of the surrounding elements are counteracted by a constant recurrence to the originators of the flock.

"In crossing we must beware of the tendencies which nature, in numerous instances, displays to perpetuate diseases, dispositions, and aberrations of the normal structure. A predisposition to many diseases is engendered in the sheep, by too great refinement in breeding, which tends to diminish the size of the animal, prevents them feeding to perfection, destroys their fecundity, and imparts great tenderness of constitution. Accidental deviations from the natural type may, also, be hereditary, as is seen in those races of dogs which have a supernumerary toe on the hind foot, and tarsal benes to correspond. In the human race, also, several generations of a particular family have been distinguished by having six fingers and six toes on their hands and feet. It is in like manner to an accidental malformation, that the Americans are indebted for their Otter breed of sheep."

\section{BREEDING REGISTER.}

It is of the highest importance that every sheep-farmer who aspires to distinction and success in his profession, and more especially those who are strictly professional breeders, should properly classify their sheep, and keep a record of 
them. This particular, and, indeed, everything appertaining to the subject of breeding, is most rigidly attended to by German flock-masters, and is the means by which breeding from too close affinities is avoided, as also for affording a reference to the qualities of every individual of the flock.

The Germans are exceedingly particular in their examinations, beginning with the lamb when only a few months old, which receives at this time a mark denoting its qualities, and subsequently and before it has attained the age of one year, is subjected to two more inspections, and if the results correspond with the first examination, it receives a final mark of approval, and is retained as a permanent member of the flock. The first class is denominated "Super Elector ;" the second class "Elector;" the third class "Prima ;" the fourth class "Secunda;" the fifth class "Tertia." Few among the better flocks will range as low as the last, and if any individual is found to sink any farther, it is disposed of. The sheep are put upon a table and held, while the examiner with a small pair of scissors clips samples from the neck, shoulders, and thighs, which are at once enveloped in papers, and on the back of each is noted a number corresponding with the ear-marks. A clerk, with pen and ink, is in attendance, who notes down the texture of the staple, whether short or long, round, flat, or spiral, exterior appearance of the fleece, evenness, size, shape, \&c.

The following cut exemplifies the mode of numbering on the ears, by which the age of each individual is denoted, and its general qualities explained by reference to the Register.

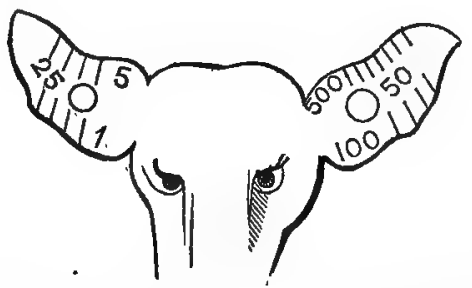

Each slit in the lower rim of the right ear represents, 1 upper do. 5 do. lower left 100 do. upper 500 
The central hole in the right ear,

do. left

In the above figure

7 slits in the upper rim of the left ear, 500 each

3500

4 do. lower do. do. 100 do.

400

The central hole in

do.

50

4 slits in the upper rim of the right ear, 5 do. 20

4 do. lower do. do. 1 do.

The central hole in do. 1 do.

Number of the sheep,

3999

The following is a form of a Breeding Register kept by the late Mr. H. D. Grove. His notes of explanation, together with some valuable remarks, are quoted from Colman's Fourth Mass. Agricultural Reports, and which are worthy of much attention, from his acknowledged experience and skill as a sheep-breeder.

BREEDING REGISTER, FROM JULY 1, 1838, TO JULY 1, 1839.

\begin{tabular}{|c|c|c|c|c|c|c|c|}
\hline \multirow{2}{*}{ No. } & \multirow{2}{*}{$\begin{array}{l}\text { Year in in } \\
\text { which } \\
\text { born. }\end{array}$} & \multirow{2}{*}{$\begin{array}{l}\text { Tup'd by } \\
\operatorname{Ram} \text { No. }\end{array}$} & \multirow{2}{*}{$\left|\begin{array}{c}\text { Date of } \\
\text { lambing }\end{array}\right|$} & \multicolumn{2}{|c|}{ No. of lambs. } & \multirow{2}{*}{$\begin{array}{l}\text { Classification of the } \\
\text { Lambs, etc. }\end{array}$} & \multirow{2}{*}{ General Remarka. } \\
\hline & & & & Rams & Exwes. & & \\
\hline 25 & 1833 & $27-4$ & $6-4$ & 1 & & $\begin{array}{l}1 \text { Cl. small, and } \\
\text { close curied. }\end{array}$ & $\begin{array}{l}\text { Thin lambs-one was } \\
\text { very feeble and died. }\end{array}$ \\
\hline 1 & 1834 & $26-4$ & $7-4$ & & 1 & $\begin{array}{l}2 \text { Cl. middle, } \\
\text { small.curls. }\end{array}$ & $\begin{array}{l}\text { The lambs had a fow } \\
\text { hairs under the belly, } \\
\text { \&cc. }\end{array}$ \\
\hline
\end{tabular}

"In the first column is the number of the ews ; in the second, his age, and instead of writing it out in full, I merely write $3,4,5$, and 6 , which means either $1833,{ }^{\prime} 34$, '35, and '36, \&c. In the third column is the number and age of the ram, thus $27-4,-27$ means the number, and 4 his age, namely, 1834, \&c. 'In the fourth column is the day and month when the lamb is yeaned, thus $6-4,-6$ means the 6 th day, and 4 , fourth month. In the 5 th and 6 th columns are the number of ram and ewe lambs. In the seventh is the classification of the lambs, when a few days old, and the last column is for general remarks.

"I am very particular in classifying my lambs with as much accuracy as possible, to enable me to decide upon the good or bad qualities of a progenitor as a breeder; if his progeny is not such as I desire, he is rejected at once from further service. I do not often use my rams after they are 
5 or 6 years old, for when they have attained that age, their progeny begins to fail in vigor and strength. Much, however, depends upon the treatment he receives. If a ram is carefully used, not over-worked; he will retain his vigor and elasticity much longer, and I have known rams 7,8 , or even 9 years of age, whose progeny was as vigorous as that from a ram of 3 years old.

"I select my stock rams with the greatest care, for I consider this the most important point in breeding; and here I find my records of great value in aiding me to make the best choice. If, for instance, I have a ram before me, who has, in every respect, the requisite qualities, and turning to my records, I find his ancestors occupy a high rank, that is, stand in the first class for a number of generations back, I then have no hesitation to appoint him a sire for my ewes, and in nine cases out of ten, he acquits himself to my entire satisfaction. Or, if I have two rams before me of equal quality, and hardly knowing to which one to give the preference, my records decide the question, for the one who has the best ancestry is preferred to the other.

"The experienced shepherd knows, that even in fullblood flocks, not all individuals are equal in quality of wool, size, form, \&c., but that some families arrive to much greater perfection than others. Here again my records are of great value, for with their aid I can designate every individual member of each family, and cross them with other families, and in such divisions as I think most beneficial. For eleven years have I thus managed my flock, and selected my stock rams from those of my own raising, and yet $I$ have no very near relationship, and I can go on eleven years more in the same manner and avoid that error, only taking a little more trouble, and some years use more rams, than to a superficial observer would seem necessary. Now if my sheep were not numbered and recorded, I could not go on without running the risk of injury to my flock by too close breeding. This is an important point in the breeding domestic animals of all kinds, and if once lost sight of, the injury will soon be perceived by the experienced and discerning eye, which injury is often irreparable. 'That it is lost sight of and is overlooked by too many of my brother shepherds, is but too true, and this is one reason why so many make but little progress in the improvement of their flocks."*

- Notwithstanding Mr. Grove undoubtedly was equal if not superior to 


\section{INFLUENCE OF SEX.}

This question, in former times, excited much discussion among breeders and physiologists, many contending that the influence of sire and dam were equal upon the progeny, taking general and not particular qualities into view. When thus considered, there is much of truth in this conclusion, although correct observation has very clearly established the fact, that the influence of the male greatly predominates relative to the color, as well as texture of the hair and wool. 'This opinion is sustained by Mr. Sanford Howard, associate ed itor of the Cultivator, in an able paper on the subject of breeding, published in that periodical of 1844 . On the point in question he speakes thus:

"It is, however, reasonable to suppose, that in some respects this influence of the parents cannot be equal; and that the theory is well founded that the constitutional qualities, nervous temperament, \&c., are more likely to resemble the dam, and the external qualities, such as outward form, color, hair, \&c., to resemble the sire. Many examples might be cited in support of this theory. Many farmers have noticed how much more likely their animals are to inherit the diseases of their dams, than their sires. When we consider that the animal is supported during the fœtal stage of its existence entirely from the blood of the mother, and that this blood, circulating through every part of the system, would, of course, be affected by the state of the animal's health, this consequence would seem to be perfectly natural.

"On the other hand, it has been noticed that the outward features of the sire, more frequently than those of the dam,

any other sheep-breeder of our country, and the great precautions he obBerved not to breed from those between whom there existed too near affinities of blood, yet the writer has every reason to believo that he encroached on the breeding in-and-in system to a greater extent than he was sensible of. Mr. G., as appears from his concluding remarks, deprecated the practice, for no one knew better than himself, theoretically at least, the certain evils attending it. The writer engaged a valuable ram of him previous to his decease, which, soon after getting home, he lost by one of those legitimate diseases (clyers) which follows the system of breeding in question. The loss of the valuable animal is certainly a matter of no consequence to the public, but the cause is, however, and which the writer has purposely delayed mentioning, that it might go forth appended to his late friend's remarks in allusion to the point in hand, and have its proper weight in connection with all that has hitherto been naid on the subject. 
are enstamped on the progeny. This has been attribufed to the nervous influence of the dam-or what is called the influence of the imagination of the dam on the fotus. Practical men believe there is something in this. Professional breeders avail themselves of the principle in giving to their animals some desired marks or qualities. It must have been something akin to this, by the influence of which, through the medium of peeled rods, Jacob caused the cattle to be born 'ringed, streaked, and speckled.' Breeders of horses sometimes take great pains to operate on the imagination of the mare, and thus produce in the foal certain characteristics. At the time of conception, or within the first month afterwards, the fotus seems to be particularly susceptible to this influence, and it is not difficult to produce the changes spoken of. Some striking instances of the effect of this sympathetic influence might be given. One of the most remarkable, perhaps, as showing the evidence of anterior excitement, is that of a mare, seven-eighths of Arabian blood, after having produced a foal by a stallion quagga, (a species of zebra,) continued, after a lapse of five years, to reproduce the markings of that animal, at three successive births, although the sire of all the subsequent progeny was a thorough bred, Arab horse. This is a well authenticated fact, and correct portraits of the mare, the hybrid, and the three foals which the mare afterwards had by the horse, the latter showing the stripes of the quagga, are preserved.

"The influence of one black sheep, though it may never have any progeny, is often noticed in causing black lambs, Shepherds who have kept black dogs with their sheep, have observed the same effect. The nervous influence of animals in a state of pregnancy, shows itself very conspicuously in the effects of fright on the offspring. Many cases of this kind might be cited in the human species, as well as in our domestic animals."

In immediate connection with his closing remarks, the writer will state, that he makes it a point never to breed from sires or dams that are otherwise than entirely white, yet a few years since one of his highest bred ewes produced a lamb whose head and tail were perfectly white, but everywhere else jetty black, and thus resembled a skunk. From this it is not unreasonable to suppose that, in the early stage of gestation, one of these disgusting animals crossed the path of the ewe, causing such a degree of fright as to impress the 
marks of the skunk upon the fotus. This is only an analo. gous instance, with results quite as singular, as observed in the offspring of the human species, produced by highly exciting circumstances during pregnancy.

The following will show that the male exercises a material influence also upon the form, indicated most strongly, however, in general, in the progeny of the first cross. Mr. Boswell, in his essay on the subject in question, published in the Quarterly Journal of Agriculture, says-_-"Being fully convinced of the power of the male on the offspring, I have always accounted it as a loss to put a bad male to a highbred female, and have never done so. I have, however, observed, where the country people have purchased highbred sheep at any sale' of mine, and bred from them with the ordinary rams, that the breed very quickly got bad; whereas, when a Bakewell ram had been purchased, I have seen a most remarkable change in the quality of the sheep; and, in several instances, where the ewes had been tolerable from which they had been bred, the cross was so nearly resembling a New Leicester, as to deceive any one who was not a thorough judge."

A. writer observes-" The progeny of most domesticated animals often bear a striking tesemblance to the grandmother or grandfather, and it is well known that the desired changes cannot be effected on a breed, or that the desired breed cannot be produced, till the third, fourth, or eyen the fifth crossing, so that the importance of having few defects in a. stock will readily be admitted, seeing their debasing consequences are carried through whole generations, and that, though absent in one remove, yet that they may appear in the next."

As an instance to show how these "debasing consequences" may be prolonged through defect of the male, the following is stated, having occurred with the writer's personal knowledge :- The father of the writer, nearly twenty years ago, purchased a high grade Saxon ram distinguished for good form and fineness of wool, but was objectionable on account of the openness of his fleece and shortness of its staple; he was used, however, for several years. The ram exhibited a peculiarity about his eyes, which protruded so far, as to give him a ludicrous aspect, and consequently he received the soubriquet of "bulge-eye ", in addition to this, his pate was entirely bare of wool, and nothing but the fineness of his fleece induced his usage in the flock. But after a fair 
trial he was abandoned, his stock in general exhibiting his ightness of fleece, and many his peculiarity of visage; and therefore the worst specimens were disposed of as soon as possible. But strange as it may appear, for more than twelve years after, a "straggler" would now and then appear, whose eyes and fleece were the very counterpart of the ram in question! and the novelty of the circumstance is, the dams of these were as perfect in all respects as the average of the flock, and entirely free from the peculiarities described in the ram! I. Stanley Carr, in a paper published in the Journal of the English Agricultural Society, on the agriculture and management of sheep in Northern Germany, says - "I know an instance where a large and valuable flock has been for years retrograding, in consequence of one unsuitable ram having been introduced into it 12 or 14 years ago."

The above strongly manifests the influence of the male, and affords a striking lesson to the flock-master, to beware of imperfections of every character, no matter however slight, in his stock rams, as irreparable injury may follow if it is neglected.

It is supposed by some that the sex of the progeny is determined by the relative ages of the parents; thus, issue from a young male and an old female will in general be feminine, while that from an old male and a young female will generally be masculine. The writer having little confidence in this theory, and from never having met with but one recorded instance of its being tested, he has never thought it worth the trouble of an experiment. "He has, however, repeatedly put rams of 18 months old to ewes which were from 4 to 7 in years, and as in other instances where older bucks were used to ewes of similar ages, the number of lambs as regards sex were nearly equal, rarely varying more than five in 100, which, as far as he is able now to recall, a majority would sometimes be masculine, and again, feminine. The point is noticed that others may make the experiment if they think proper.

\section{GOOD POINTS OF A MERINO AND SAXON.}

From the description of the Merino, as presented to the reader in the history of the race, it has been seen that there is an essential difference in conformation. between some of the varieties, and that all are deficient in that symmetry of outline so necessary in any animal to please the eye of the 
breeder of taste. Many of their ungainly points have been removed by the Germans ; and doubtless it would have been thus to some extent in this country, provided that, from their landing on our shores up to the present time, there had existed, without interruption, a remunerating price for their fleeces; but unfortunately this has not been so, and consequently the instances are rare where any improvement has been effected in either form or fleece. Nature, ever beneficent in her purposes, for centuries was at work moulding the Merino for a specific object, and that object consisted in producing a superabundant covering for its body, and incomparable in its general qualities for the manufacture of the softest and most beautiful fabrics; whereas, if its conformation had been essentially different, it would not be what it now is, but a mutton sheep. It has been seen that the improvement effected in the English breeds, was at the sacrifice of the quantity and quality of the wool of the old breeds, proving most conclusively, that in breeding the Merino, if we attempt to mould its form too much after the fashion of the improved English sheep, it will be at the hazard of a diminution of some of the admirable qualities of its fleece. $A$ wide chest and large abdominal organs are indispensable qualities in a mutton breed, as they afford the means of hastening maturity, by enabling the animal to take up much food, and more readily converting it into flesh and fat. But on the contrary, these qualities are not needed to the same degree for the production of a material for the finest fabrics, and in the largest quantity. Nature constantly battles for her rights in these matters, and evinced her obstinacy when the English breeder undertook to overtask her by endeavoring to make the Merino at once the producer of fine wool and fat mutton; but in the struggle she triumphed, showing, that the race and draft horse can never be so assimilated; that the product will exhibit the fleetness of the former with the strength and docility of the latter, nor the sheep both the bearer of much fat on its loins, and a fleece of the finest texture.

It has been observed that the Germans materially changed the form of the Merino, but it must be considered that in effecting this, they resorted to that extreme "refinement of tone" in breeding, which always results in producing effeminacy, and to this is to be ascribed the extreme fineness of the fleece of the Saxon Merino variety, at the sacrifice, how 
ever, of quantity, and much of its original hardiness of constitution. It is, therefore, for the reasons assigned, the writer is of the opinion that the form of the Merino cannot be essentially altered without perverting the object of nature, and at the hazard eventually of pecuniary loss. If we attempt to mould it after the fashion of the true mutton-sheep, there is danger that the assimilation of its food will be for the production of more flesh and fat, and a consequent deterioration of the fleece, and reduction of its weight. Again, if we breed for increase of size, we do not augment profits, as large animals consume proportionally; and if we adopt the German example, while we improve the appearance of the carcase, and texture of its covering, it will be at the expense of size, and hardiness. Therefore, in accordance with these views, the writer is bound in duty to say to the breeder of the Merino, Be not too anxious to rid the animal of those peculiarities with which nature has endowed it. We may relieve it in some measure, and can do so without sacrifice, by proper selections of a portion of the superfluons folds of skin about the neck; and by proper attentions in feeding, it will acquire that rotundity necessary to gratify the eye of taste. Wide chest and an expansive abdomen cannot be effected by mere breeding without also full measure of food. The horizontal springing out of the ribs from the spine in the improved English breeds, is quite as much from this cause as any other. Ill feed the famed Leicester for two successive generations, and think you that its beautifully-arched ribs, and capacious abdomen, would be present? Indeed, it would be the height of absurdity to expect it.

The best specimens of the Merino present forms well enough for all practical purposes, and it should be our duty to breed from such individuals as will best preserve and transmit the admirable properties of its fleece to the latest generations, and not hazard experiments simply because its form is not as perfect as our wishes would have it.

The qualities of a good Merino ram are as follows :Wool should appear from the forehead to the fetlocks, and - as compact as possible, with due regard to a good length of staple, which is now highly prized by manufacturers; the fibres spiral or much crimped; no jar or hairs intermingled with the fleece; little variation as possible in the qualities of the fleece, as in the genuine Spanish there are but four qualities, the lowest growing about the legs, and this, there 
fore, is one of the most essential points to observe. Mellowness of skin, which indicates a fine fleece, and that the mucous coat is filled with the unctuous substance, yolk, which confers so much softness and brilliancy to the wool, and protects its surface from the injurious action of the weather; hence in the male there can scarcely be too much yolk, for a deficiency in the ram will cause too little in the other classes of the flock, in which it is never present in too large quantities, however abundant in the sires; the eyes should be bright, prominent, with a placid expression, which indicates docility of disposition, a point always to be considered; the horns should be large, and the spirals not too short, and not too near the eyes; the frame compact, but not over large," neck thick where it sets on-to the body, and straight from the withers to the horns; back short and horizontal with the rump as possible, which is rare, however, with the breed; buttocks well protruded, and tail at its root, not too wide; the bones not too large, as they abstract nutriment, nor the legs too long.

We will now consider briefly the points of the Saxon variety of the Merino.

The artificial value attached to the finest fleece, induced the Germans to cultivate the Merino solely for this object; and so long as there are castes of society, and the highest of these fancy that a wardrobe only of the finest texture is necessary as a means in part to support that distinction, so long will the Saxon race be appreciated and profitably cultivated. But when this adventitious state of society ceases, the chief aliment of profit of the Saxon will cease with it. The reader, however, will probably coincide with the writer in the belief that that day is very remote, and therefore the race cannot become extinct; and in proportion to the increase of wealth in our country, in that ratio will increase the demand for the superlative material the breed produce.

The true Saxon is of beautiful symmetrical proportions, but not hardy ; a light fleece, but of such exquisite fineness of texture as in some instances to be only the $55^{1}$ th thart of an inch in diameter, while the Merino rarely is less than the. $7 \frac{1}{5} \pi$ th. That tenderness of constitution peculiar to the German Saxon is not present to the same degree in the American;"

* The writer has now in his possession a ewe 12 yeara old, from the flock of Major Grant of Walpole, descended from the Searl's importation, as lieshy and hardy as any individual of his flock. 
and is therefore successfully cultivated in the cold latitude of New Hampshire, and with equal profit to the Merino, when properly managed.

The essential points of a good Saxon ram conform to those of a Merino; in reference to the eyes and horns they are identical; the staple cannot be too fine, silky, long, and yet compact, - the objection to a very short staple is now very general; the spiral curls or crimp very minute or close,this is a prominent good point; the fleece should be imbued with yolk, which is indicated by the surface being somewhat dark, - a dry fleece is unprofitable, and the wool never so soft and strong; the wool should be very white below the surface,-if it has a bluish or pearly-grey cast, it denotes an unhealthy sheep or an indifferent constitution. The form should be square and compact, with a tolerable wide but deep chest, and full, round belly ; bones small, and legs not too long, with a good covering of wool; full about the hind quarters; the neck small and tapering near the head, without ruffles, and no droop from the withers to the poll; the back nearly straight, with tameness and docility of disposition.

TUPPING SEASON.

This important season we will suppose being near at hand, the rams should be rigidly examined, and those selected for use should be served in an aldermanly way for several weeks before they are put, by giving their "lordships" each a gill of oats daily, to which may be added, at intervals of two or three days, half a handful of wheat, which will increase more rapidly the supply of seminal fluid. If the duty to be performed is extra, high feeding should be continued till their services for the season have expired.

The number of rams apportioned to 100 ewes, depends much on the breed, the age, and vigor they possess. With the English breeds, the ram is put when 18 months old, and if he has been pushed forward by artificial means, will cover from 60 to 80 ewes; the latter is considered in England the maximum, with security to the health of the ram, and soundness of constitution to his progeny. Overtasking the male is always followed by a greater or less degree of effeminacy of his gettings, and therefore should be avoided. Nothing is gained either by allowing the ram to cover too many, as his vigor fails him proportionally, when he arrives at the age of six or seven; whereas, if prudently worked when young, will 
retain his generative powers in considerable strength till he is ten years old. The Saxon and Merino breeds being slower in attaining maturity than the British varieties, greater care should be observed with the young rams, by not permitting them to cover more than from 15 to 20 ewes, when only 18 months old. The writer uses five of this class to the hundred ewes, and from three to four when the rams are in their prime. This course is followed by hardier and earlier offspring, the lambs nearly all dropping within the space of a fortnight. They are put from the 5th to the 8th of December, and thus when the period of parturition arrives, the grass is somewhat abundant, and a flush of milk follows.

There is a diversity of opinion as to the best manner of putting the rams-a large majority turning in several at once, others keeping them confined in yards and bringing a certain number of ewes for each to serve daily, while many turn in only one buck at a time, to remain a day or two, when he is taken out and his place supplied by another. This is prob ably, where the flocks are large, the better and least troublesome way; and prevents contests which are unavoidable when several rams are together, which results in the master one performing a heavier duty than is compatible with retention of his vigor, and hardiness to his progeny.

Supposing the rams begin their services in the early part of the month of December, they should cease at the close of the month, and be withdrawn from the flock, as they lose their gallantry after the tupping season is over, and sometimes when feeding they are very unceremonious with their horns among the ewes, which cannot but cause momentary suffering, if nothing worse. In conclusion, the writer strongly protests against the use of one ram to over $50 \mathrm{ew}$, (and to do this he should be a very prime animal) not but what a larger number can be tupped, but because of its injurious tendency with the progeny, which may not manifest itself particularly when young, but is perceptible when grown, in some form or other, and limits materially longevity. If we reason from analogy on this point, it will quickly set us right.

From the earlier maturity of the British breeds, the ewes are ready for the tup when at 18 months old; but the Saxon and Merino never should be put until they have attained the age of two and a half years. If done before this, they will drop their lambs, and often wholly disregard them, which arises from their not being supplied with the necessary ali- 
ment to sustain thom. Nature teaches a lesson on this point which should not be disregarded, and supersedes all argu= ment.

Has the flock-master, before the tupping season has arrived, duly performed his duty in selecting those only that are right in all respects, for breeders? Does every ewe approximate or come fully up to the mark in form and fleece? Is the latter fine, close, and compact, staple long, and as even as possible from the neck to the thighs, and well wooled on the belly and legs? In short, do they possess those qualities which look to the goal for which the master is striving? If so, he has at least done his duty, and patience only is necessary to obtain his certain reward. But if he permits a solitary ewe to be tupped, whose general qualities are much below the average of the flock, his course of improvernent will be re tarded. Let him look to it. 


\title{
STRUCTURE .OF THE SHEEP.
}

\author{
- B Y W. C. S P O O E R, \\ VETERINARY GURGEON, LONDON.
}

\section{CHAPTER XV.}

GENERAL VIEW OF THE STRUCTURE OF THE SHEEP-SKELETON BONES OF THE HEAD-BONES OF THE BODY-BONES OF THE FORE EXTREMITIES-THE FOOT-BIFLEX CANAI-THE HIND EXTREMITLES-MUSCLES OR FLESH-BRAIN AND NERVES-ORGANS OF MASTICATION, \&c.-ORGANS OF DIGESTION-THE URINARY AND GENERATIVE ORGANS-CONTENTS OF THE CHEST-CIRCULATION OF THE BLOOD-RESPIRATION AND ITS EFFECTS.

UENERAL VIEW OF THE STRUCTURE OF THE SHEEP.

THE body of the sheep resembles, in most respects, that of the ox ; with a somewhat less degree of nervous energy, it possesses a greater capability of enduring the extremes of cold and heat, and still stronger digestive organs. Much of the nervous energy is, indeed, expended on these parts, and a diminished degree is possessed by the organs of locomotion and sensation, in which respect both the ox and the sheep differ considerably from the horse.

The body of the sheep, in common with other animals, is composed of solids and fluids, the latter exceeding the former in weight in the proportion of six or eight to one. To the solids, however, is owing the organization of the frame, for they surround and contain the fluids. Late anatomists consider that animals are composed of three forms of tissues, which they have derominated the fibrous, the lamellar, and the globular. The two former are exemplified in the structure of the cellular substance, which composes the greatest proportion of the animal fabric: the fibrous is characteristic at the muscular and ligamentous structures; the fibrous 
united with the granular is exhibited in the texture of the glands, and in the medullary substance of the nervous system; and the globular is showin in the composition of the chyle, the blood, and several of the secretions. These sereral textures being combined together in different proportions, we have the various organs of which the body is composed.

To give support to the animal frame, and afford fixed objects for the attachment of various parts, is the use of the skeleton, which is composed in the sheep of nearly two hundred bones of various sizes and shapes. "These bones, in order to admit of motion, are connected one to another by means of streng bands called ligaments, the ends of the bones being constructed in various ways so as to admit of motion; in many we have the form of a hinge, in others that of a ball and socket. The motion of the limbs is effected by means of the muscles or flesh, which, although to a casual observer appearing as a homogeneous mass, is readily separable into a greater number of distinct bodies of various forms and sizes. These muscles have commonly two separate attachments, which are usually bones, and by contracting in length, they. bring these points of attachment nearer to each other. Muscles are composed of a vast number of fibres, which, on being acted on by nervous influence, diminish in length and increase in bulk, and thereby approximate the different objects to which they are attached. They are usually fastened to bones by means of a strong white substance called tendon, which, however, possesses in itself no power of contraction, but merely communicates the contractile force to the object to be acted on. Where the two objects of attachment are distant from each other, the greater portion of the distance is occupied by the tendons, the advantage of which is owing to their diminished size in proportion to their strength ; thus we find the legs of sheep below the knee are light and slender, from the absence of muscular and the substitution of tendinous substance. The greater part of the muscles are voluntary, being under the control of the mind; but some are involuntary, such as the heart and the diaphragm.

Muscles are extensively supplied with vessels of various kinds, such as arteries for their nourishment, and veins for the return of the blood after this purpose is effected. They have likewise nerves, which not only furnish sensation, but also communicate to them the mandates of the will. 
These nerves proceed either from the brain or spinal cord, which, therefore, may be considered as the fountain of sensation and the residence of the mind. And thus sensation is first sent from the extremities to the brain by the nerves, and then by another set of nerves the will is conveyed to the muscles.

The brain is a soft pulpy substance contained within the head, and the spinal cord is somewhat similar in structure, and extends from the brain to the tail, through a hole in the bones which form the spinal column. The body is divided into two principal cavities, the chest and the abdomen, and separated by a muscular partition called the diaphragm. The former contains the heart and lungs, whose uses are principally to purify and distribute the blood by means of the respiration and the circulation; and the latter contains the stomach and bowels, in which the functions of digestion are carried on, besides several important glands, such as the liver, kidney, and pancreas, together with other supplementary parts. Both the small and large intestines are fastened to the spine by means of a strong membrane called the mesentery, which, besides veins and arteries, is furnished with a vast number of small vessels called lacteals. These lacteals open into the intestines, and there absorb the nutritious part of the food, which is a white milky fluid called the chyle, and convey it to a ressel running along the course of the spine, which empties itself near the heart into the circulating system. Thus by these means the blood becomes enriched with nutriment, and is thus enabled to supply the constant waste the system is continually undergoing.

The blood being furnished with nutriment, requires to be purified before it is fit for circulation; for this purpose it passes into the right side of the heart, by the muscular contraction of which it is sent to the lungs, where it becomes exposed to the action of the atmosphere, by which it is changed from a dark to a light red color, and being freed from impurities, it enters the left side of the heart, and from thence is sent, by means of the arteries, to all parts of the body, supplying every part with nourishment, and furnishing the various glands of the body, not only with their own proper nourishment, but with material for the secretion of their peculiar fluids. Thus the salivary glands separate the saliva from the blood ; the pancreas, a-juice somewhat similar; the testicles, the semen; and the kidneys, the urine. 
Each gland separates its, peculiar fluid and no other. The urine being secreted by the kidneys, is conveyed by means of two small but long tubes into the bladder, whence it is excreted from the body.

The liver is nourished by the arteries, but separates the bile from the dark impure blood, which is conveyed to it by a large vein. The contents of the bowels are passed onwards by the influence of their peculiar action, and having had the nutritious part extracted are excreted from the body, generally in a solid form.

The cellular membrane is a very elastic substance, and enters largely into the composition of the body: it connects the various glands together, forms frequently a covering for the muscles as well as for various vessels, and exists in the form of cells, which have communication with each other.

The adipose membrane is found in various parts of the .body, and, indeed, secretes the fat, which is deposited in a liquid form, and in small circumscribed bigs. The fat thus contained often performs the important office of affording a cushion for parts that would otherwise be exposed to injury; thus we find that the socket of the eye is abundantly furnished with this material.

There are two other important membranes which are extensively found in animal bodies : they are the serous and the mucous membranes. Whenever an internal part has an external opening, we find that it is furnished with a mucous membrane which secretes mucus for its protection; but . when the cavity has no external opening, then it is lined with a serous membrane which secretes a thin watery fluid to lubricate the parts, and preserve them from injury by friction. Thus from the entrance of the mouth and nostrils to the anus, throughout the whole internal surface of the bowels, a mucous membrane exists, by which the fluid is secreted, the nature of which gives a name to the membrane, and which protects it from injury either by the external air, or by the contents of the bowels. II like manner we find the bladder and urinary organs similarly lined.

On the other hand, the cavity of the chest and the abdomen, with their contents, as well as the internal surface of blood-vessels, are furnished with a-serous membrane, which secretes a watery vapor. These different membranes are very frequently the seat of disease, and are subject to severe and dangerous inflammation. The admirable manner in 
which the various organs are packed away in their proper cavities is worthy of particular notice. The lungs and the heart are so adapted to the shape of the chest, that there is at no time any vacant spot; and the more numeious contents of the abdomen are so disposed, that while each has sufficient freedom for the proper performance of its functions, yet the whole are packed away with the most economical. care : there is no void whatever to be found.

\section{SKELETON OR BONY STRUCTURE OF THE SHEEP.}

The skeleton of animal bodies is formed of bone, a substance possessing firmness and stability for the attachment of muscles, the protection of the vital organs, and the support of the softer parts. It is composed of animal matter and earthy salts; the former consisting of cartilage, gelatine, and fat or marrow, and the latter of phosphate of lime in considerable proportion, a lesser quantity of carbonate of lime, and a small portion of other salts. The cartilage of bones is formed before the earthy matter, and constitutes, in fact, the nidus in which the latter is deposited. Bones can be freed from their earthy portion by immersion in an acid, by which proess the gelatine is also dissolved, and pure cartilage is left, which is elastic, but retains the original figure of the bone. On the other hand, bones, by exposure to a great heat, are deprived of the animal substance, and the earthy part remains.

The use of the marrow is more particularly to prevent the too great dryness and brittleness of bones. To the animal portion of their composition they are, therefore, indebted for their shape and what degree of elasticity they possess, and from the earthy portion they derive the important purposes of strength and stability. Thus are these different elements combined together, and by an union of their different principles form a substance admirably adapted for affording full scope for the play of the various organs of life, protecting at the same time the vital parts from external injury, admitting and assisting the powers of locomotion, and, in fine, forming a secure fabric for the beautiful building of animal frames.

Every bone is covered by a membrane called the perios. teum, which also lines the internal cavities and secretes the marrow; its use is to circumscribe the form of bones and protect them by its tenseness, as well as to afford the medium 
whereby they are furnished with their vessels. The shape of particular bones intimately corresponds to the purpose for which they are intended; where for the office of protection we find them flat, and where for the purpose of motion, long and cylindrical, as in the extremities.

\section{THE BONES OF THE HEAD.}

In the construction of the skull the most perfect mechanism is displayed. The first object to be obtained is the protection of the brain from the accidents to which, from the peculiarities of animals, it is mostly exposed. For this purpose the skull consists of two tables or plates; the outer thick and tough, the inner hard and brittle: the former, by yielding in a measure to resistance, diminishes concussion, whilst the latter, by its hardness, prevents sharp bodies from penetrating to the brain. Now, if these two plates were reversed, the brittle would not only be in great danger of fracture, but would also vibrate considerably; and the injurious effect of this vibration may well be conceived when we are told that, even with the present wise precaution, it often occasions in the human subject greater mischief than the most serious fractures.

There is a remarkable difference in the appearance of the head in the horned and the polled sheep; the former have a more pugnacious, and it may be a more sensible appearance, owing to the elevation and projection of the upper part of the head. This, however, is in appearance only, for the prominence of the head is not formed by any increase in the brain, but is owing to the considerable space which exists between the two tables of the skull, the outer being half an inch or upwards from the inner. This separation accomplishes two purposes, one being the additional security it affords to the brain by the interposition of this vacant space, and the other the greater root or basis it affords to the horns. And when we consider that horned sheep are generally more pugnacious than others, and that they have not only the will, but the power, of butting each other with great force, the additional security is not without use. In fact the brain is seated so much beneath and behind the forehead, that very little of the shock can be communicated to it. This circumstance too operates in affording protection to the polled sheep as well. Between the skull and the brain are interposed several membranes, which also assist materially in preventing vibration, 
like a pitce of parchment on the inside of a rummer glass The skull in quadrupeds is composed of upwards of thirty bones, which are connected together by dove-tailed sutures. It used to be considered that the object of this extensive division of the bones was the convenience of ossification, which always commences at the centre; but a more extended view has discovered other wise purposes; for not only is the dovetailed suture the strongest mode of union, but it is also the best adapted for securing the brain from injury, as it yields considerably to the impression received, and thus wards off both concussion and vibration. There is an exception, however, to this usual connexion in the temporal bones which form the sides of the cranial cavity, and which are connected to the other bones by what is termed the squamous suture -one bone, in fact, simply overlaps another. This union is inferior in strength to the former; but nature has here another office to perform, and the reason of this exception will at once be comprehended on examining the skull. If a considerable blow be received on the upper portion of the arch, its sides are the parts most likely to give way; and to guard against this consequence, the under bone overlaps the upper, and thus acts like the tie-beam of an arch in keeping the parts together. This dove-tailed suture does not connect the bones of the inner table; for, though arcarpenter might find this mode of union serviceable in joining the sides of a wooden box, it would by no means be found applicable in connecting together brittle substances, as it would be extremely liable to chip off at the edges.

The cranial cavity, or that part which contains the brain, is not more than a third the size of the other parts of the skull, the remaining portions being devoted to mastication and smelling.

There are no less than nine bones which enter into the composition of the cranium. The two frontal bones form the anterior part usually called the forehead; but the internal plate of these bones separates and recedes from the external plate so as to form a cavity between them, which is called the frontal sinus, and is divided by a septum or ridge of bone between them. The internal plate forms a covering for the anterior lobe of the cerebrum. In horned sheep the separation of the plates of the frontal bones is considerably greater than in others. The horns proceed on each side from the frontal bone, and seem, as it were, prolongations of 
the bore; for although externally we find the structure of horn, internally we have bone, and between this horn and bone we find the vascular structure by which both are secreted. In many animals the age can be judged of by the horn, which each year presents an additional ring round its base. In the cow this is not an uncertain guide, and is owing to the irregular growth of the horn at different periods of the year, growing probably with greater force in the spring than in the winter; but in the sheep, although the same causes obtain, yet it cannot be depended on with accuracy. At the root of the horn we observe a cavity which communicates with the frontal sinus.

The two parietal bones are proportionately shorter than in the horse, and are situated at the upper and middle parts of the cranium, and cover the middle lobes of the cerebrum, to which their internal part closely corresponds.

The occipital, a single bone of great strength, is found at the back and base of the cranium. Its internal surface covers the cerebellum, and on a strong process at the base the medulla oblongata rests. The external surface of this bone is extremely irregular. At its lower and back part is the occipital hole, through which the spinal cord, as well as some nerves and an artery, make their exit from the brain. On each side of this hole the bone is smooth and rounded for the purpose of articulating with the atlas, the first bone of the neck; besides which there are several curious processes for the attachment of muscles.

The temporal bones forming the sides of the cranium are composed of two parts, the squamous and the petrous. Though in man these pieces are united, yet in the sheef they are distinct from each other. The squamous portion is externally a convex plate with a hooked projection arising from it; this process assists in forming the zygomatic arch. The squamous portion affords at the posterior part a shallow cavity for the articulation of the lower jaw-bone. This glenoid cavity, as it is termed, is much deeper in carnivorous animals, which require to open their jaws more extensively : and an inspection of this portion of the skeleton alone will enable the comparative anatomist to decide to what order the animal might have belonged. In herbivorous races a grinding lateral motion of the jaws only is required, and accordingly the articulation is wide and shallow. The zygomatic arch, too, is much more arched in the carnivora, in order 
to afford more room for the development of the temporal muscle, which governs the jaw, than is required for the more moderate exertions of herbivorous animals. The petrous portion of the temporal bone, so called from its rocky nature, is apparently a solid convex figure. It contains, however, the organ of hearing, and has on its internal surface orifices for the passage of the auditory nerve, and on the external we find a larger orifice for the passage of sound. The internal structure of this bone is as beautiful as it is curious, possessing vestibules and canals for the ramification of the nerve, and a singular cavity having a communication with the mouth, in which are discovered four diminutive bones, with their corresponding muscles, which serve the purpose of propagating and modifying the sound.

The inferior and middle parts of the cranium are formed principally by the sphenoid, a bone which somewhat resembles a bird in flight, having a body and four processes, two of which are called the wings and two the legs. This bone supports the middle lobes of the cerebrum, and presents holes and depressions for the passage of nerves. The cranial cavity is separated from the nasal by the ethmoid bone, which also somewhat resembles a bird in flight, but without legs, and is situated in front of the bone last described. It supports the anterior lobes of the cerebrum, and has holes for the exit of the olfactory nerves ; and on its internal and inferior surface it forms cavities called the ethmoidal sinuses, which are separated by a long septum from each other, and are perforated by a vast number of small holes for the passage of the olfactory nerves to the nasal cavities. It is this thin part of the bone which is penetrated in the operation of wiring giddy sheep. Such is a brief description of the various bones which form the cranium and envelop the brain, and which are connected together and arranged on principles more durable and economical than can be displayed by the noblest specimens of mechanical skill.

The face occupies a larger portion of the head than the cranium, but is less in proportion than the ox and the horse, and particularly the latter animal. Its upper part is formed by the lower portion of the frontal bones, which are considerably longer in the sheep than in the horse, descending much lower down, and in fact forming the roof of a great portion of the nasal cavity. Another peculiarity in these bones is, that whereas in the horse they $d$ sicend in a straight 
direction, in the sheep; just above the orbit, they form almost a right angle.

The nasal bones are much less developed in the sheep than in the horse.

The superior maxillary bones, though relatively smaller than in the horse, yet form a great portion of the face, extending the whole length of the molar teeth, for which these bones form suitable sockets, and laterally from the molar teeth to the frontal and nasal bones. Within the cavity of the mouth these bones form the roof of the palate, being united together by a suture. This portion of these bones is wider though shorter than in the horse, so that the molar teeth are farther apart, and the mouth thus gains in width what it loses in length. Thus situated, these bones have three surfaces-the facial, the nasal, and the palatine. At the superior part of their palatine surface we find what are called the palate bones, which, in the horse, chiefly consist of narrow curved bones, forming together the semi-oval border dividing the cavity of the mouth from that of the nostril, and serving for the attachment of the soft palate. In the sheep, however, these bones extend further down into the mouth, and form, indeed, a portion of the palate, which, in the horse, is formed of the maxillary. The border, too, instead of being nearly semi-circular, is almost conical, from being so very narrow. The consequence of this structure is, that the upper entrance to the cavity of the nostrils is much less in proportion than in the horse, and the soft palate is less developed, so as not to close the cavity of the mouth. The nature of the sheep corresponds with this structure: not being an animal of speed, it does not require to inhale so much atmospheric air; and the purposes of rumination require the food to ascend from the stomiach to the mouth, which it could not do if the soft palate were developed, as in the horse, where it closes the back part of the mouth, except when food is passing from the mouth towards the stomach.

The anterior or inferior maxillary bones, which are wanting in the human subject, are attached ab.ve to the superior maxillary bones, and thence descending and enlarging, in the horse form the sockets of the upper incisor teeth, but in the sheep and other ruminating animals not possessing these teeth, they become smaller instead of larger as they descend, merely forming the basis of the hard pad which meets the under incisor teeth. 
The molar bones, comparatively larger in the sheep thas in the horse, and irregular in shape, are situated on the sides of the face above the large maxillary, and partly within and partly without the orbit of which they form the lower part.

The lachrymal bones, so called because the lachrymal duct for the conveyance of the superfluous tears to the nostrils passes through them, is situated about half within and half without the orbit, the latter portion being between the molar and frontal bones-a different arrangement from that which obtains in the horse. The orbit or bony socket which contains the eye is thus composed of a variety of bones.

There is a long but very thin bone called the vomer, situated at the floor of the nostrils, and running throughout their length, and having a groove into which is imbedded the cartilaginous substance which divides the nostrils into two equal cavities.

The posterior maxillary or lower jaw bone is formed of two halves, united at the inferior part by cartilage in the young subject and by bone in the adult. This united portion forms the sockets for the eight incisor teeth, which sockets, however, are by no means so deep or so strong in proportion as in the horse, and thus it is common for sheep to lose or break these teeth soon after they are fully developed. From the place of junction the lower jaw bones separate and gradually recede from each other, becoming wider and deeper, and forming strong and secure sockets for the molar teeth, after which the bones become thinner, turn upwards, and terminate in two extremities, one rounded, which, with the temporal bone above, forms the maxillary joint, which is secured from displacement by a hook-like projection which is the other termination of the lower jaw bone.

The bones which we have mentioned as composing the face are none of them solid in their structure, but most. of them hollow, and thus various cavities or sinuses are formed which are called after the bones in which they appear. Ac. cordingly we have the frontal, the maxillary, the sphenoidal, the ethmoidal, and the palatine. The frontal are the largest and most important, particularly in the horned sheep, in which they are partly divided into cells and communicate with other sinuses immediately surrounding the horn. These singular cavities are not found in the young subject, but are gradnally formed as the size of the head increases. They 
thus serve the important purpose of increasing the size or the head without adding to its weight.

\section{THE BONES OF THE BODY.}

The neck is formed by seven bones, which, with the ex ception of the two first, are very much alike. The first is connected with the occipital, or bone of the skull, with which it forms a joint possessing much motion in a vertical direction. In the human subject it is termed the atlas, from its supporting the head. It forms a joint behind with the dentata, as the second bone is termed, from its having in the front part a process like a tooth, which, however, affords the head considerable lateral motion. A'll the bones of the neck are extremely irregular in shape; they all possess a large hole through the centre for the passage of the spinal marrow, and small ones at the sides for the exit of nerves and arteries. They have also projections on each side and above for the attachment of muscles, and each one forms a joint both bèfore and behind which affords that great flexibility to the neck which most animals possess.

The back or chine is composed of separate bones called vertebrx, of which there are thirteen belonging to the back alone. They all possess, like those of the neck, a hole through the centre for the passage of the spinal cord, as well as a small one at the side for the exit of the nerves. 'The superior projections or processes are much higher than those of the neck, but considerably shorter than we find in the horse; and thus we have high withers in this animal and low ones in the sheep, and they are also shorter in the improved breeds than in the wilder races of sheep, a channel between the shoulders and along the back being justly regarded as a sign of a disposition to fatten. These processes serve for the attachment of muscles, as well as of a strong elastic substance' which is attached to all the bones of the neck as well as to the occiput, and serves to support the head, and thus relieves the muscles to a great extent.

The ribs are attached to the vertebræ by means of a joint -one rib is joined to two vertebræ, and vice versâ, thus.af fording the ribs a certain extent of motion. There are thirteen ribs on each side, eight true and five false; the former are attached to the sternum or breast-bone, and the latter are merely joined to the former at their lower parts, which is formed of cartilage. The ribs should spring from the back 
bone as horizontally as possible, as thereby the rotundity of the frame is increased.

The loins are formed by five bones, which partly resemble the bones of the back; but instead of ribs springing from the sides there are fixed bony processes, several inches in length, which afford a protection or roof for the abdomen. These processes, in a well-formed sheep, should be long and horizontal.

After the loins the spine continues in the sacrum, which, in the lamb, is composed of separate pieces; but is consolidated into one bone in the sheep. This bone is perforated for the passage of the spinal cord, which, however, diminishes in size, and terminates at the end of the sacrum in several nerves which run to the tail. The bones of the tail are numerous, but are not perforated.

THE BONES OF THE FORE EXTREMITIES.

The joints or articulations of the extremities are the same in number as those of the horse, but the limbs, on reaching the fetlock joint, become divided, and the four bones situated below the fetlock are consequently double. The scapula or blade-bone is similar in shape to that of the horse, having a spine or ridge down its middle for the attachment of muscles, but in sheep the bone is not so long in proportion to its width. It is attached to the ribs by muscular substance, by means of which the body is suspended or hung like a carriage between the two fore-legs, and concussion is thereby materially diminished. From the more circular shape of the ribs the shoulder blades are attached to them with much less mechanical advantage as far as speed is concerned. They are placed wider apart, both above and below, but particularly at their lower parts, so that the limbs spread open, at a greater angle, much more like a pair of compasses than do those of the horse, and even the ox, thus giving the sheep that rolling walk so peculiar to the animal and so disadvantageous with regard to speed.

The humerus, or shoulder-bone, strong and cylindrical, forms with the blade above the shoulder-joint, the action of which, with that of the elbow-joint below, is more limited than that of the horse.

The radius or bone of the fore-arm is comparatively shorter than that of the horse, and we find that it is always 
long in animals of speed and short where speed is not required : this bone is also strong and cylindrical.

The ulna, or bone which forms the elbow, does not support the weight, but serves for the attachment of the powerful muscles so conspicuous in a shoulder of mutton and which are generally divided by the first cut. For this purpose it is attached to the radius, and rises above the elbowjoint, the back of which it forms, but does not reach the knee: This joint, the carpus, is composed of seven bones, arranged in two rows, the upper of which articulates with the radius, and the lower with the cannon or metacarpus.

The metacarpus or shank much resembles that of the horse, until it reaches the fetlock, where it is to some little extent cloven, so as to articulate with the double arrangement of the bones below. Instead of the two small metacarpal or splent-bones that we find in the horse, there is merely one, and that of small extent and use.

The small bones situated at the back of the fetlock, called the sesamoids, and which serve as levers for the attachment of ligaments and the action of the sinews, are double those of the horse, being four in number.

The bones below the fetlock, viz., the large pastern or os suffraginis, the small pastern or os corona, the os pedis or coffin-bone, and the navicular bone, are all double, and, like the same parts in the ox, somewhat resemble in shape the bones of the horse sawn in two.

All these joints have less extent of motion than we find in the horse, and the bones therefore present a more upright appearance. In the horse and in the ox an angle is formed at the fetlock with various degrees of obliquity, and the three bones below pass down in a straight line though in an oblique direction. In the sheep, however, there is a different conformation; the large pastern-bone passes down in an oblique forward course, as in the ox, but the small pastern descends in a perpendicular direction so as to form an angle with the bone above almost as great as, though precisely opposite to, that of the fetlock-joint. This it is which gives the more upright appearance to these parts in sheep, though the cause is not externally visible, and it throws the centre of gravity on the back part of the coffin-bone and on the horny heels of the foot: The small pastern bone is relatively longer than in the horse, and there is more motion in 26* 
the pastern-joint, though much less in the fetlock ; indeed the action of the former is quite as much as the latter.

Though not belonging to the skeleton, this will yet be the most convenient situation for noticing the structure of the other parts of

\section{THE FOOT.}

The bones dividing at the fetlock, the tendons likewise, both before and behind, become divisible, and there are consequently two flexor tendons or benders and two extensors to each division. The former, as in the horse, consists of a perforans and a perforatus, the latter forming a sheath for the perforans just above the fetlock, in which it continues to the small pastern-bone, into which the perforatus is inserted. The perforans then ghides over the back of the navicular bone, which forms a sort of pulley, and is inserted into the lower and back part of the coffin or foot-bone. Of the extensors one is inserted into the upper and front part of the small pastern, and the other is continued to the coffin-bone. These bones are connected together by capsular and other ligaments, and there is one very strong one in particular, which passes from the lower, inner, and anterior part of the large pastern in a perpendicular direction to the inner and back part of the coffin-bone. To the lower and back part of the coffinbone is attached an elastic pad of a fibrous and ligamentous nature, which receives the greater part of the superincumbent weight, and by yielding to it takes off the jar. It rests on the horny heels of the foot, which thus supports the principal part of the animal's weight, very little resting on the anterior portion of the foot. It is thus very evident that there is a considerable difference both in the structure and functions of the various parts of the foot in the sheep and in the horse. In the latter we find that the crust or wall of the foot is connected to the coffin-bone by means of a double arrangement of a vast number of horny and fibrous plates, the former connected with the inside of the crust, and the latter with the coffin-bone. These laminæ, as they are called, are dovetailed together, and thus the connection is rendered of great strength; and the vast extent of surface thus afforded, and the elasticity of the parts, obviate concussion, and afford, indeed, an admirable spring and a principal cause of the elastic tread of the animal. In the ox we observe an arrangement somewhat similar, though the laminæ are much 
less developed; but in the sheep, so little weight being supported by the crust and front part of the foot, such a complicated structure is not required, consequently we find no laminæ, but the crust is connected to the bone by a simple. vascular structure, which secretes the principal part of the crust, in the same manner as the sole or lower part of the foot is formed. The coronary substance which in the horse secretes the greater portion of the crust is wanting in the sheep. The sole of the foot is secreted as in the horse by the vascular membrane above, and there is a greater thickness of this dense substance interposed between the coffinbone and the sole of the foot.

We can thus understand from this description how it is that the horn of the foot is so speedily restored in sheep when the hoof is lost in foot-rot or the epidemic by the matter insinuating itself between the horn and the bone: it has not, as in the horse, to wait for the slow and tedious growth of the horn from the coronet downwards. The inside of the crust is considerably thinner and weaker than the outside, particularly towards the back part, where foot-rot most frequently commences.

The horny part of the foot may be considered to consist of the crust, or wall, and the sole. The former surrounds the outside of the foot and turns inwards at the toe, and passes in a straight direction to the heels. It is thickest at the toe and thinnest on the inside. The sole is situated at the bottom of the foot between the outer and inner part of the crust, but it is difficult to say where the crust ends or the sole begins, the structure of each being so much alike. The heels are formed both by the crust and the sole, though principally by the former, which turns inward and joins the inner crust, and it here becomes more elastic and spongy, resembling very much the frog-of the horse. This part supports the principal part of the weight, and suffers most when sheep are driven much on the hard road.

We have yet to notice a very singular peculiarity in the foot of the sheep, which is the

\section{BIFLEX CANAL.}

The large pastern-bones are connected together by ligamentous substance, and it is not till the pastern-joint that the foot becomes exteriorly disunited. At the situation of this joint in front we can detect a small opening sufficiently large 
to admit a small probe; this is the entrance of the canal just spoken of, which presently enlarges, and passes first downwards, and then winds round in a semicircular direction, ending in a sort of cul de sac. On cutting into this canal it appears to be a duplication of the skin; its internal sufface is lined with hair, and there is found a considerable quantity of detached hair mixed with a waxy secretion in the canal, secreted by various glands. This hair is no doubt excreted from the internal surface, and which, from the smallness of the opening, cannot escape, or rather is detained for a useful purpose: The use of this canal thus stuffed with hair is selfevident. We have mentioned the great motion possessed by this pastern-joint, which is so great as to threaten to chafe the skin by the friction of one side against the other. It is to prevent or ward off this friction that these biflex canals, or rather hair-stuffed cushions, are provided; and they act, indeed, precisely like the fenders which are lowered down the side of a vessel to prevent it coming into contact with another. The ox possesses little or no motion in this joint, and consequently requires no such provision to prevent friction. The benevolence of Nature is strikingly exemplified by this simple structure.

This part occasionally suffers from the insinuation of dirt and sand, and is subject to inflammation and ulceration, which sometimes prove very troublesome.

\section{THE HIND EXTREMITIES.}

The haunch is formed by three bones in the young subject, but these bones soon become consolidated into one, and is called the pelvis or basin, within which is situated the bladder and part of the organs of generation. Viewing this bone from below it appears pretty nearly circular within, but externally the circle is broken by various irregular processes, two of which project upwards on each side the spine which lies between; then two others extend backwards below the tail and are called the haunch bones, and two project laterally, and are termed the hips. These bones project but little in a wellformed sheep, being altogether clothed with flesh and fat.

The bones of the pelvis extend downwards and backwards from the spine, and towards the inferior part form on each side a deep cap or socket, into which fits the upper part of the thigh bone, which is formed like a ball so as to fit into the socket. The thigh bone, or formur, extends forward, and is relatively longer in the sheep than in the horse. It is the 
fiesh surrounding this bone which composes the bulk of a leg of mutton. Its lower part forms with the tibia below the stifle joint, which is singular from having two cartilaginous bodies within it; and is protected in front by a small bone called the patella or knee-pan, which bone becomes a sort of. pulley, receiving the insertions of the very strong muscles above, and is attached below to the tibia by strong ligaments.

The tibia or leg bone runs backwards from the stifle, and is not so long in proportion as in the horse; it corresponds to the radius in the fore extremity, and it forms the upper part of the hock joint.

This joint is composed of six bones arranged in rows so as to form three articulations, but motion is confined to that formed by the astragulus or knuckle bone and the tibia; the other bones serve as cushions to diminish concussion, with the exception of the os calcis, situated at the back, which acts as a lever receiving the insertions of the powerful muscles which straighten the liock. This bone is much shorter than it is in the horse, speed not being required. The bones below the hock correspond with those found below the knee in the fore extremity:

\section{THE MUSCLES OR FLESH.}

Although the shape of the body depends materially on that of the skeleton, so that if the latter is anywise faulty the former will not be perfect, yet there is a very great contrast between the appearance of the skeleton and that of the body itself, of which it forms a part. Whilst the former is angular and extremely irregular, the latter is round and smooth, so that though the good shape of the animal depends on the skeleton, yet it requires the eye of the anatomist to detect, in the conformation of the latter, the good points which in the body itself are readily observed.

The bulk of the body is formed of flesh or muscles; their principal use, when living; is to effect the movement of the limbs ; when dead; to afford nutriment to man. The motion of the body is occasioned by the contraction of the muscles, which, being fastened to different bones, draw these bones towards each other, and thus the limbs are bent whenever particular muscles shorten or contract. These muscles, which bend the limbs, are called the flexors, whilst an opposite set which straighten them again, are denominated tho extensors ; the latter, however, are mostly sm ller and weak- 
er than the former. The size and shape of muscles are very diversified, some being so minute as to be scarcely visible, as those within the ear; whilst others, namely, those of the loins and buttocks, are large enough to afford a feast for several persons; some muscles are thin and spread out like a fan, others are thick and bulky, and whilst some are extremely short, others are cylindrical and of great length. Muscles are furnished with nerves both of motion and sensation: the former convey the mandates of the will, and are thus the cause of motion ; the latter communicate the sense of feeling: and are the medium both of pleasure and pain ; but there is considerably less degree of feeling possessed by the flesh than by the skin. The muscles are composed of fibres, and are bound together by cellular membrane, and they are, in sheep, mostly clothed with fat, which also is deposited amongst the fibres. It is the capability of containing this fat, and the abundance and laxity of the membrane containing it, which distinguishes a sheep of a good from one of a bad breed, and gives to the former that softness and elasticity or resiliency which is felt on handling it, even when poor. 'The former sheep, too, possesses large muscles, particularly at those parts where the meat is most esteemed. Thus the loins of a good sheep are broad, and abundantly covered with flesh and fat, and so likewise are the buttocks and the shoulders, whilst the head and neck are small. The muscles that are in most constant use are more interlaced with tendinous fibre, and consequently are much less tender, as meat, than those which are less actively engaged. The muscles of the lower part of the legs between the knees and hocks and the joints above, as well as those of the neck and head, are instances of the former kind; whilst the muscles of the loins, and more particularly those within the pelvis, are examples of the latter, and afford the most tender meat in the body.

\section{THE BRAIN AND NERVES.}

The brain, the seat of the mind, and the fountain of sensation, is a soft body, situated in a cavity of the skull called the cranium. In man it occupies "by far the greater portion of the skull; but, in the sheep, from its much smaller size; and from the large space devoted to the face, its cavity, the cranium, is much the smaller part. It is closely invested by a membrane called the pia mater, whilst the cranium is lined by a firm, strong membrane called the dura mater. Between 
these there is another delicate membrane called the tunica arachnoides. The dura mater, by its duplications, forms several processes and sinuses; the former, by descending between its divisions, serve to secure the brain in its position, and the latter act as reservoirs for the venous blood, thus preventing the brain from being injured by any temporary impediment in its passage.

The pia mater closely embraces the brain, and dips into its convolutions. The brain consists of three parts-the cerebrum, the cerebellum, and the medulla oblongata.'

The cerebrum is considerably the largest, and is divided into two hemispheres, each of which closely corresponds. with its fellow.

On cutting into the cerebrum, we find that it consists of two portions - the medullary or white, and the grey or cortical part. The latter is mostly situated towards the surface, and the former towards the centre, but both appear to run into each other. Within the hemispheres there appear to be various cavities, canals, and membranes, which, in this work, it is unnecessary to describe.

The cerebellum, or little brain, is situated behind the cerebrum, than which it is considerably smaller. It appears to consist of medullary and cortical substance mingled together.

The medulla oblongata, the smallest division, is situated at the base of the brain. It is medullary in its structure, and gives origin to the greater part of the cranial nerves. It is by far the most sensible part of the brain, for whilst portions of the cerebrum have been cut away in some animals without giving any apparent pain, the least pressure on the medulla is productive of injury or death. The brain is largely supplied by means of the carotid arteries with blood, which is returned to the heart by the jugular veins.

The spinal marrow may be considered as the continuation of the brain, running from the medulla oblongata, throughout the spinal canal, to the tail. It is enveloped by the same membranes as the brain, and continues to the sacrum, where it ends in several nervous cords. Its form is cylindrical, and it has been found to consist of six bands, in the centre of which there is a sort of canal. The nerves arising from the brain and spinal cord, in sheep, are forty pair, ten of which proceed from the brain and the remainder from the cord, and are therefore called the spinal nerves. 
On examining a nerve, we find that it consists of a vast number of white filamients, each having its particular cover: ing, and yet compactly bound together and invested by membrane.

Of the cranial nerves the first pair is the olfactory, the nerve of smelling, pulpy in its structure, and the largest in the body. It rises from the cerebrum, passes out of the cranium, and is spread out on the membrane lining the nostrils.

The second pair, the optic, rise from the cerebrum, but, before they pass out of the skull, join together and decussate, the right nerve going to the left eye, and vice versâ. Each takes an oblique course, pierces the outer coats of the eye, art is spread out in the form of the retina, and thus conveys the impressions of objects to the brain. The sense of hearing is supplied by a soft nerve, the auditory, which enters an orifice in the temporal bone, where the seat of hearing is contained. The sense of taste is supplied by the fifth, which is a compound nerve, conveying both sensation and motion. The other cranial nerves convey sensation and motion to the various parts of the head; but there is one nerve which demands more particular notice. This is the par vagum, or pneumo-gastric of the French. It rises from the brain, passes down the neck close to the carotid artery, and distributes branches to the pharynx, larynx, and œsophagus, heart, lungs, stomach; and liver. If divided on both sides in the living animal, death immediately ensues. Its importance may thus be readily conceived; it is intimately connected with life itself, giving to the heart and stomach their power of motion, independent of the will. The spinal are.compound nerves; having a double function and a two fold origin, they convey both sensation and motion. They arise by numerous filaments from both the upper and under surface of the spinal cord. The filaments coalesce, and, before they emerge from the dura mater, join together, previous to which the upper nerve forms a sort of knot called a ganglion. This latter is the nerve of sensation, the other the nerve of motion; and thus, though united together, the filaments are yet distinct, and a part is endowed mostly. with sensation, or with motion, according as the filaments of the former or the latter predominate.

There is yet another nerve which requires to be noticed 
as being of great importance. It has been called the ganglial, from the nature of its apparent origin, and sympathetic, from its functions, but more properly the great organic nerve. It appears to arise from a small red ganglion or knot at the base of the brain, and just previous to the commencement of the spinal cord. It appears to have intimate communication with all the other nerves, and distributes branches to all the glands, arteries, and absorbents of the system-the heart, lungs, and digestive organs; it is the soul, as it were, of the organic system, influencing the functions of nutrition and secretion.

\section{$\therefore$}

We have before observed that the brain of the sheep is small as compared with the size of the body. In fact, the whole nervous system is, as it were, feebly developed, and this peculiarity has a considerable influence over the diseases of the animal, and accounts for the fact that in the greater number debility quickly supervenes, and in many the animal speedily sinks.

THE ORGANS OF MASTICATION, ETC.

The mouth of the sheep and its contents are admirably adapted for their natural functions. The sheep is intended by Nature to thrive on scanty pasture and to take a considerable bite, and much closer to the ground than the ox. The lips are therefore protected by hair, which defends them from injury from the ground; they approach somewhat to a point, and the upper lip is cleft, which suits it well for the purpose.

The incisor teeth or nippers; like those of the ox, are situated only on the lower jaw, the upper having instead a firm fibrous pad, sufficiently strong to retain the food between it and the teeth. The incisor teeth are eight in number in a perfect mouth, but the lamb, when dropped, has only two, and sometimes none visible, but in a few weeks the others make their appearance: these, however, are but temporary teeth, smaller than the permanent ones, and adapted to the size of the mouth. By two years old the central teeth drop out, and are succeeded by two larger and stronger teeth-the permanent. These teeth are formed within the sockets in the bone some time previous to their appearance, and pressing against the root of the temporary incisors, gradually induce their absorption. By three years old the two next teeth have undergone the same change, and are succeeded the 
following year by those adjoining, so that by five years the whole eight teeth are thus renewed, and the sheep is then said to be full-mouthed. Although the order and period of these changes are sufficiently regular to ensure them as a sufficient criterion for a general rule, yet it is not without exception, as sometimes the permanent teeth appear much earlier, and at others their appearance has been protracted to a later period.

After the sheep becomes full-mouthed, there is no method of judging of the age with accuracy, but the teeth rarely remain perfect long, particularly if fed on turnips; some of them are lost or become broken, and the sheep is then said to be broken-mouthed.

The incisor teeth are somewhat conical in shape, the point being inserted in deep sockets; the portion visible is covered by a very hard transparent material called the enamel, and it is brought to a sharp edge at the anterior part, so that it cuts very much like a chisel. Compared with those of the horse the incisor teeth appear somewhat loose, but this is rather an advantage than otherwise. The food, being embraced between the incisor teeth and the pad above, is torn asunder by the nodding action of the head, and the food is conveyed by the tongue to the molars or grinders. When turnips, however, form the diet, the food is scooped ont, as it were, by the teeth alone, and they are consequently sooner worn out and broken; but even otherwise, this effect generally follows a few years after the mouth becomes perfect. The molar teeth are six in number, on each side of each jaw ; they are firmly planted in deep sockets, and their faces are covered with enamel. These faces are very irregular, but admirably adapted for tearing and grinding the tough and unyielding grass ; and they are also secured in their positions by means of the gums, which, in common with the other parts of the mouth, are covered with a mucous membrane, and in some parts a firm dense material is interposed between the mucous membrane and the bone.

The sides of the mouth are formed by the cheeks, which are composed of skin and membrane sufficiently loose to admit the limited motion of the jaws; they are connected with the powerful masseter muscles, which form the greater part of the bulk of the face, and principally occasion the grinding motion of the jaws. In the skull we find the lower jaw considerably narrewer than the epper, but in the living 
animal this does not appear, the space being occupied by the masseter muscles.

The lips greatly assist in gathering together the food, and are largely furnished with the nerves of feeling; they are composed of skin, muscle, and membrane, and possess the powers of motion and sensation in a high degree.

The mouth is abundantly supplied with a watery fluid called saliva, particularly during mastication, when it is secreted and poured in in considerable quantities. This fluid is principally secreted by three pairs of glands, the largest of which are the parotid, situated at the root of each ear, and from which two ducts on each side convey the fluid and unite in one previous to entering the mouth. The submaxillary glands are situated under the jaws, and their ducts terminate in tubular eminences near the frænum or bridle of the tongue. The other salivary glands are the sublingual, situated under the tongue: its ducts terminate rather higher up than those last described. Besides these there are other small/glands connected with the cheek and the bottom of the mouth; and one peculiar to sheep situated behind the lower jaw, and extending towards the eye, and communicating with the mouth by means of a duct opening near the last molar tooth. There is thus from these various sources an abundant supply of saliva more copious than most animals possess, and which is rendered necessary by the hard and woody nature of the food consumed in a natural state. And it has been found that a large supply passes into the stomach independent of mastication, and is there required for softening and macerating the dry food; for, when deprived of this supply by an experiment, it has been found that the contents of the paunch remained dry.

The mouth is principally filled with the tongue, which is muscular in its structure and very flexible, being, indeed, a principal agent in mastication and swallowing. It is larger at the upper part than towards its tip, and is confined posteriorly to the muscles between the branches of the lower jaw, by a sort of fleshy bridle, and above to a singularly shaped bone called the os hyoides. It possesses both the power of feeling and tasting, and for this purpose is well supplied with two descriptions of nerves, and is covered by both cutis and cuticle.

There is a marked distinction in the back part of the mouth between the horse and the sheep and other rumina 
ting ani.nals. In the former the velum palati, or soft palate, a fleshy substance attached to the semicircular border of the palatine bones, is sufficiently long to fall down on the back of the tongue, and thus effectually to close the back part of the mouth, except when food is passing, and prevent either the air or food returning through the mouth. Thus a horse can breathe through his nostrils only, and whenever food is vomited it passes in the same direction. The sheep being a ruminating animal, such a structure would be inapplicable, as it would prevent the food being returned to the mouth; consequently the soft palate is considerably shorter and narrower. It does not reach the tongue, and the diminished extent of the palatine bones, to which it is attached, as before observed, also limits its action.

The larynx, the pharynx, and the tongue axe connected together and to the upper jaw-bone, or rather to the bones of the head, by means of the os hyoides, so called from its resemblance to a spur. The semicircular part of the spur embraces, in a manner, the larynx, whilst the shaft is intimately connected with the root of the tongue. The os hyoides has two long appendages, which articulate with the temporal bone. Thus situated and constituted, this bone gives great support to the soft parts connected with it, whilst, at the same time, it freely admits their extensive mobility. In the act of swallowing, therefore, this bone is greatly called into action.

Adjoining the pharynx are two large spaces called the Eustachian cavities, situated one on each side, and communicating by means of a tube with the internal ear.

THE ORGANS OF DIGESTION.

The digestive organs of the sheep; like those of graminivorous animals in general, are extensive and complicated, having a far more difficult and elaborate office to perform than those of carnivorous animals. The food of the latter is taken, as it were, ready prepared; its constituents closely resemble those of the blood itself, and, of course, it is exactly similar to the flesh it is intended to nourish. A small quantity of food only is required to be taken, and nearly the whole of this food is employed in nourishing the system or supplying its, waste, the faces being exceedingly scanty. The digestive organs of herbivorous animals have a much more onerous task to accomplish; the food is in a more 
crude or less prepared state; the nutritious portions bear a much smaller proportion to the whole mass, and, accordingly, the food taken is of very considerable bulk. 'To meet these peculiarities the digestive organs are.much more spacious and more complicated than those of the carnivora; means are afforded for detaining the food until the nutriment can be properly extracted, a larger amount of chemical and vital force is employed, and a more abundant supply of nervous energy afforded. The horse, in a state of nature, is almost continually feeding; he bites short and well triturates his food, but is almost constantly so engaged; and though, in a domesticated state, the food is not so abundant nor so frequently taken, it is in a much more nutritious form. Corresponding to these natural habits, we find that though the alimentary canal altogether is of enormous bulk, the stomach itself is single and of moderate size. Digestion is almost constantly going on; food is passing out of one orifice of the stomach as it comes in at the other, and the supply of bile is constant, there being no reservoir for it-no gallbladder. The smaltness of the stomach is compensated for by the prodigious bulk of the large intestines. Thus the horse, though an animal that requires a large quantity of food, is yet able to perform great physical exertions, and can make them after a full meal more readily than any other animal.

The ox, the sheep, and other ruminating animals, have, like the horse, very extensive digestive organs, but very differently arranged. The horse, in a state of nature, will rarely get fat; the ox and the sheep, in good pasture, will almost invariably do so, and will otherwise greatly increase in size; the digestive organs are, therefore, more bulky than in the horse, and much more complicated. The intestines are of greater length, though not so large, and instead of one stomach there are no less than four.

The natural food of the sheep is embraced by the joint apposition of the incisor teeth of the under jaw and the cartilaginous pad on the upper, and is separated mainly by the action of the muscles of the head and neck, giving the head an almost constant motion, which may be readily observed when the animal is feeding on pasture. The grass is torn off, not bitten; but when turnips form the food the teeth are more actively employed, and consequently are more worn and become sooner lost. The food being moderately chewed by the molar teeth or grinders, to which it is 
conveyed by the tongue, is by the same organ carried to the back of the mouth, and being softened by the saliva and thereby mixed with atmospheric air, enters a fleshy bag called the pharynx or gullet.

This pharynx is lined by the same membrane as the mouth, and is surrounded by, and, in fact, composed of various muscles, which contracting force the food forwards into a long tube called the osophagus, which leads to the stomach. The pharynx is situated immediately above the larynx or cartilaginous box which forms the entrance to the windpipe, and the food in entering the gullet passes over the entrance to the larynx, which it is prevented from entering by a triangular lid termed the epiglottis, which in the act of swallowing shuts down on the larynx, but otherwise leaves it open for the purpose of respiration. The food after leaving the gullet enters the osophagus, a very long tube lined internally by a white insensible membrane, and externally by muscular coats, which, by contracting, force the food onwards to the stomach. The csophagus passes down the neck towards its left side and somewhat above the windpipe, with which it enters the chest between the two first ribs; it then takes an upward or ascending course through the cavity of the chest over the base of the heart, passes the midriff or diaphragm, and then descending soon afterwards reaches the stomachs. On entering the chest it somewhat diminishes in size, but again expands in the abdomen. It does not actually terminate in either of the stomachs, but in what is called the cesophagean canal, which is about four inches and a half in extent, and is formed above by a continuation of the œsophagus, and below by a sort of muscular pillars -duplications of the upper portions of the first and second stomachs. Thus the osophagean canal is a sort of lobby or passage having entrances to the different stomachs, and which, with the exception of the second and fourth, are the only entrances these stomachs possess. By the annexed cut it will be seen that the food duct commences at the entrance to the rumen, and for the space of three inches its floor consists of muscular pillars or lips, formed by the upper part of the second stomach, the entrance to which is between these lips. The pillars then continue within the cavity of the third stomach for the space of an inch and a half to the entrance of the fourth stomach, the cavity of the third being principally situated above, forming the roof of 
the cesophagean canal. The entrance, however, to the third commences before the opening into the second stomach ceases. The entrance to the fourth stomach is two inches and a half in extent, and is formed by duplications of the mucous and muscular coats of this viscus, which meet so as to close the entrance when either the will of the animal or the necessity of nature requires.

The usual course of the food is into the rumen or first stomach, whose entrance is close to the termination of the cesophagus and the entrance of the canal. This stomach is of enormous extent, occupying, indeed, when full, nearly three-fourths of the abdomen. It lies towards the left side extending to the flank, and by a sort of muscular band it is partially divided into two principal compartments. It is lined externally by the peritoneal membrane, in common with the other contents of the abdomen, and internally by an insensible membrane, called the cuticular, between which there are two other coats-the mucous, which secretes the fluid found in the stomach, and external to this the muscular coat, which is formed of two orders of fibres running in opposite directions, Its interior aspect presents a number of pouches or compartments, which are formed by muscular bands thrown across from one part to another; and the surface presents an innumerable number of papillæ or eminences, not sharp, but blunt-pointed, which are formed by the mucous coat and merely covered by the cuticular. These papillæ are coarser in the lower compartment of the viscus thian in the upper. We havo said the rumen consists of two compartments, but with greater propriety it may be stated that there are three, a smaller one being situated immediately below the termination of the cesophagus and adjoining the second stomach. The use of these partial divisions is very evident. They relieve one portion of the stomach from sustaining the whole of the weight of the food, and they afford a sort of steps or resting-places for the food that has undergone maceration, the upper and smaller compartment being that into which the food is raised just previous to being ruminated. 'The rumen is partly attached to the second stomach, but only communicates with it through the common opening into the cesophagean canal.

The second stomach is called the reticulum; its size is considerably less than the rumen, bit it possesses much otrength in its coats, and its muscular fibres are more devel- 


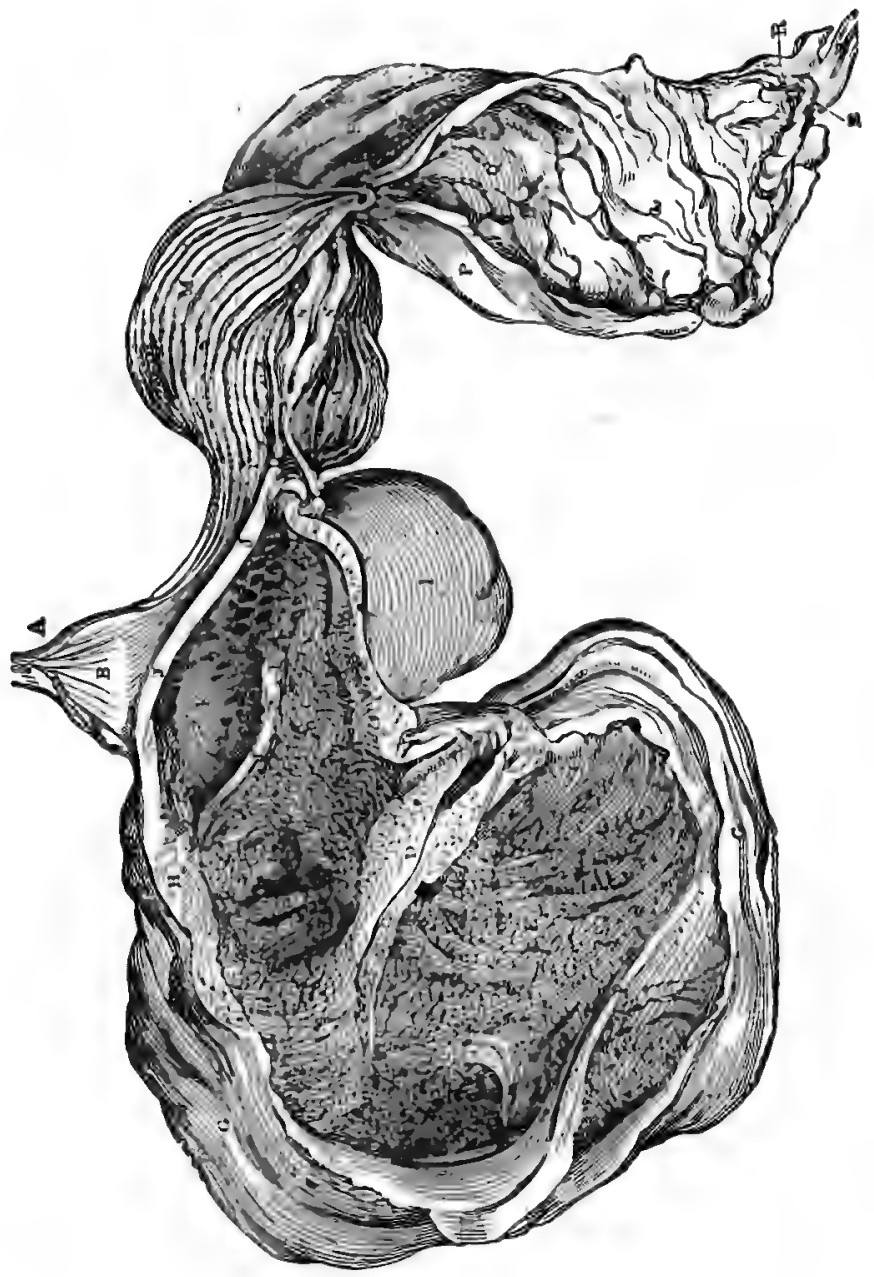

INTERNAT VIEW OF THE STOMACHS. 


\section{DESCRIPTION OF THE CUT.}

A. The lower part of the esophagus, showing its external coat.

B. Its internal coat at its termination.

C. The upjer compartment of the rumen, or first stomach, showing its internal coas.

D. The strong museular band which divides the lower from the upper compartment.

E. The lower compartment of the rumen.

F. Another muscular band.

G G. The external coat of the rumen.

H. The entrance to the rumen cut upen, and its opposite part reflected back, so as to exhibit an internal view of the second stomach.

I. The external coat of the reticulum, or second stomach.

J J J J. The muscular pillars forming the floor of the cesophagean canal when close, but now spread open to show the second stomach.

K K. An internal view of the reticulum, or second stomach, showing Jts peculiar honeycomb structure.

$L$ L. The continuation of the cesophagean canal at the entrance to the third stornach.

M M. An internal view of the maniplus, or third stomach, showing its peculiai folds or plaits.

N N. The fleshy lips, which act as valves to guard the entrance between them to the fourth stomach.

o. The termination of the cesophagean canal.

$P$ P. The external coat of the abomaswm, or fourth stomach.

$Q Q$. The internal coat of the abomasum, or fourth stomach, showing its folds. Both these coats are displayed by slitting open the stomach and then pinning the duplications together, at its upper part.

R R. The valve formed by puckerings of the internal coat, and guarding the entrance into the small intestines.

8. The internal coat of the small intestines.

oped. It is globular in shape and somewhat larger than the maniplus, and is familiar to us in tripe, not only from its cellular structure, but from its being thicker than the others. Its internal aspect is very singular, having a vast number, indeed several hundred, of shallow cells somewhat like a honeycomb. These cells are much smaller at the part of the viscus nearest the entrance, and gradually increase in size from this point. The sides of these cells consist of ridges formed by the mucous and cuticular coats, and smaller ridges are also observed running across within the cells. Most of them are pentagonal, but.many have six sides, and on their surface we observe an immense number of sharp-pointed papillæ much smaller in size though sharper than those of the rumen, and which secrete a mucous fluid. This viscus has the same coats as the rumen, but the muscular coat has two layers of strong fibres arranged both transversely and longitudinally. The opening into this stomach is of some extent compared to its size; the duplications or lips which form it are indeed the floor of the greater portion of the œsophagean canal. Though in the ordinary state the roof or upper part of the reticulum is the floor of the cesophagean canal, yet if air is pumped into the cesophagus so as to dis- 
tend the stomachs, the situation of the reticulum will beoome reversed, rising up towards the œsophagus; and thus if this viscus is distended in hoove, as from its free communication with the rumen it probably is, it must press upon the diaphragm with very considerable force, greater in proportion even that the rumen itself. The contents of this stomach are more liquid than those of the others.

Somewhat before the end of the entrance of the second, the canal terminates, as it were, in the third stomach, the maniplus or manifolds, so called from its curious internal structure, which is formed by a great number of plaits or folds arranged longitudinally in a direction from the entrance of the stomach; so that although it is not large, externally not exceeding the reticulum, its internal surface is increased in more than a tenfold degree. These plaits are very curiously arranged, being in the form of seven or eight groups of six leaves, each leaf dissimilar in length, the longest extending almost from the upper to the lower part of the stomach. These leaves are studded with numerous small papillæ, much harder than those of the reticulum, and some on the edges of the plaits of the shape of a bent cone, thus the point directed towards the entrance. It has been found in certain cows that would never retain their food, but were continually scouring, that these plaits were unusually short.

The maniplus has but one opening, but this opening is in direct communication with both the canal and the fourth stomach, as may be seen in the sketch, page 320 . The plaits are studded with numerous minute papillæ, somewhat similar to those found in the reticulum. The maniplus possesses four coats like the others, and its external appearance is globutlar. Its contents are generally found of a much harder consistence than those of the other stomachs.

This stomach, when full, is found above the cesophagean canal, forming, indeed, a portion of its roof, and its longest leaves fall down, as it were, almost into that canal.

The abomasum, as the fourth stomach is called, is, in fact, the true siomach, being that which secretes the gastric juice by which the food is converted into chyme. It is this peculiar acid which gives it the power of coagulating milk, and in calves it is particularly employed for this purpose in the manufacture of cheese, under the term rennet. 
Externally this organ is somewhat conical in shape, its apex being the part which joins the intestines. It possesses three coats, like the other stomachs; but its internal surface is very different, being smooth and shining, and of a pale red color. Its mucous membrane is, indeed, very vascular, and ihis secretes the gastric juice.- The internal surface is greatly increased, and exceeds the external, by being in the form of plaits, arranged longitudinally, but very different from those found in the maniplus. The entrance to this stomach (its ardiac opening) is close to the entrance to the maniplus ; it is arranged somewhat in a crescentic form, and is situated at one extremity of the base, whilst the pyloric opening, leading into the small intestines, is, as before observed, situated at the apex. Having thus described the situation and appearance of the stomachs, an external view of which may be seen at page 326 , we must return to the consideration of the course of the food through them.

- The situation, the structure; ; $_{2}$ and the size of the rumen point it out as the first and general receptacle for the food, which receives in the mouth only sufficient mastication to enable the animal to swallow it. It is then received by the rumen, and morsel after morsel is taken until this viscus is comparatively full. The animal then feels some repletion, and rumination usually takes place, the animal generally preferring a recumbent posture. It has been shown, however, that it is not the food just taken, but that which has been swallowed some twelve or sixteen hours previously, that undergoes the ruminating process. The food, indeed, is turned and shifted about the stomach by its muscular action, and well mixed with the fluid secreted by its internal surface : it, of course, enters at first the superior compartment, from which it passes to the inferior, and again enters the former division ere rumination takes place. A tolerably full stomach is necessary for the act ; for it has been found in sheep that had fasted for several days that a tolerable portion of food still remained in the rumen. Before rumination can take place it is evident that the food must rise to the upper part of the viscus and enter the œsophagean canal. What, then, is its direction? The liquid portion passes on in the course of the canal ; but it is contended by some physiologists that the second stomach, the reticulum, is the active agent in rumination, and that the food enters it previous to its being returned to the mouth, and they are supported in this opinion 
by the muscular strength possessed by this viscus. In op position to this opinion it may be urged that it requires but little more force to raise the food to the root of the cesophagus than to the entrance of the reticulum, and also, that the contents of the second stomach are of a more fluid nature than those of the first. It is not to be supposed that all the food taken is again ruminated; it is only the hard indigestible portion that undergoes the process. Rumination is assisted by the pressure of the abdominal muscles and the diaphragm, and the larger and more distended the stomachs the more likely they are to receive assistance from these aids. Keeping these facts in view, we are inclined to believe that both the first and second stomach may have equal power in the process of rumination. In accordance with this idea we must suppose that a mass of food is raised from the rumen into the cesophagean canal, that the hardest and driest portion is selected by the root of the cesophagus, and that the other part passes onwards, and whilst some portion may reach the third, the great part will fall, as it were, through the trap-door into the second stomach, there to undergo a further macerating or digesting process. When this viscus is moderately full it will contract on its contents, and first squeeze out the fluid portion, which will, of course, pass onwards into the third and fourth stomachs, whilst the solid part will be embraced by the csophagus and returned to the mouth.

It is evident that the functions of the cesophagus are much more onerous than in non-ruminating animals, and accordingly it is furnished with more muscular power; the lower portion particularly is surrounded with spiral muscles, by which the selected pellet is first sent upwards.

It is not unlikely that some portion of the food may be submitted two or more times to the process of rumination.

It is - probable that the most liquid portion of the food at once enters the fourth stomach, and that of a harder nature the maniplus. The singular construction of this viscus evidently shows that it must effect an important office, and it has been found that in animals which through life have never thriven well, notwithstanding that they have consumed a larger quantity of food than other beasts, the maniplus has been imperfectly formed, the plaits being short so as to afford considerably less surface than usual. The use of this stomach, therefore, is to detain the food, to press it between its fotds

3 to soften it by the secretion afforded by its extensive 
surface, and thus to prepare it for the action of the gastric juice in the fourth stomach, to which organ we now trace it.

In the young animal living entirely on its mother's milk, the fourth is the only stomach employed; it is, therefore, then fully developed, whilst the others are small and imperfectly formed. 'The milk contains the elements of cutrition in a much more perfect state than it exists in vegetable food. It requires but a little separation in order to fit it for nutrition. As the young animal gradually becomes inured to other food, the other stomachs become more developed. By the time the food reaches the abomasum it is in a macerated pulpy state, and fit to be exposed to the powerful solvent action of the gastric juice. This fluid is secreted in abundance by the mucous coat of the fourth stomach. It is a peculiar fluid, acid in its nature, and so powerful a solvent that it has been known after death to dissolve a portion of the coats of the stomach itself. It has in its composition hydrochloric acid, and its action on the food is of a chemical nature, converting it into chyme and rendering it into a fit ${ }^{\circ}$ state for the other digestive processes. The food being thus dissolved passes through the pyloric opening into the small intestines; this orifice has a valve-like construction (see p. $320)$, admitting the food to pass in one direction only, and then not until it has been sufficiently acted on by the gastric juice.

The small intestines are of considerable length in the sheep, being upwards of sixty feet. In the human subject it is customary to divide them into three portions, and they are called the duodenum, the jejunum, and the ileum. These distinctions are arbitrary even in man, but still more so in the sheep, and, in fact, cannot be properly applied The first portion of these intestines (the duodenum in man) differs much from the rest. It lies comparatively loose, and on opening it we observe a yellow substance, which is, in fact, the bile, which enters by a duct or very small tube some eighteen inches from the stomach, and at nearly the same place another fluid flows in from the pancreas or sweetbread. These fluids, it may be supposed, exercise an important office in the process of digestion, and the early portion of the small guts is the situation where the admixture takes place.

The liver is a bulky organ whose size, general appearance, and shape must be familiar to most people. Its weight 


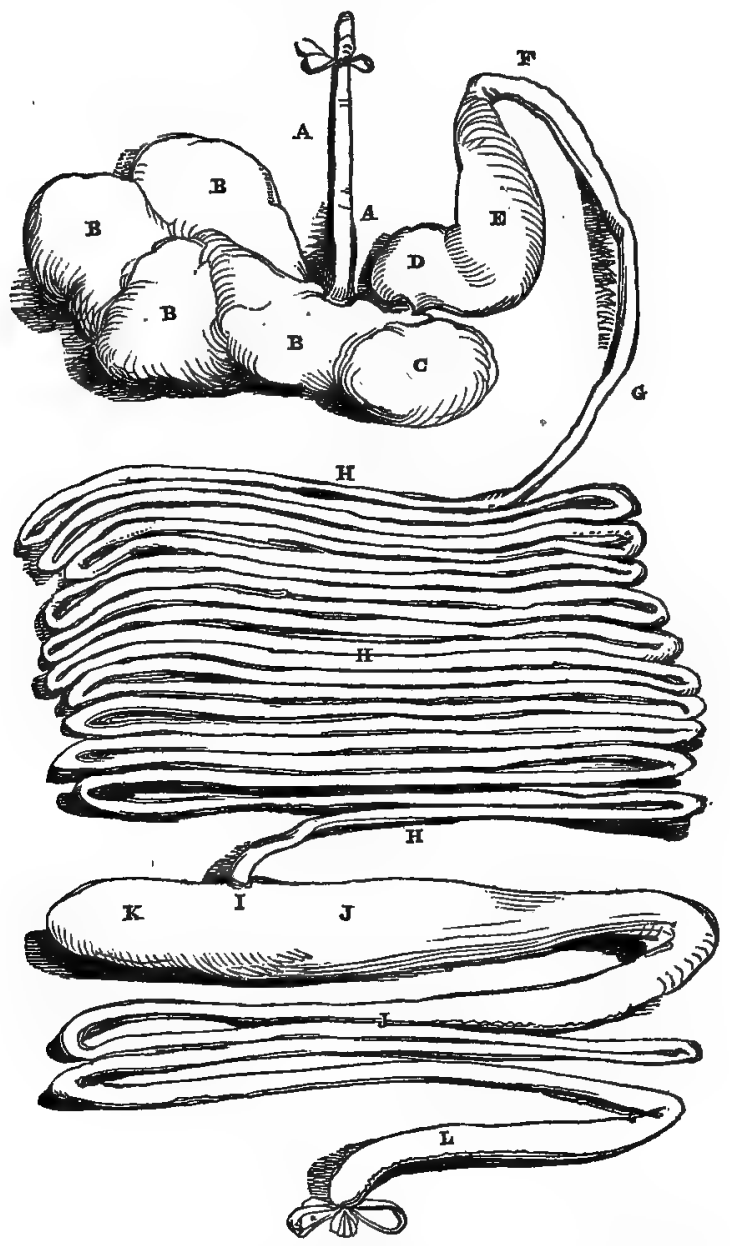

EXTERNAL VIEW OF THE STOMACH AND INTESTINES

Eread apart and arranged according to the following scale, so as to show theth actual and relative size.

1 foot. 


\section{DESCRIPTION OP THE CUT.}

A A. The esophagrus.

B B B B. The, rumen, or first stomach, showing its compartments.

C. The reticuium, or second stomach.

D. The maniplus, or third stomach.

E. The abomasum, or fourth or true stomach.

F. The commencement of the small intestines at the pyloric orifice of the stomacn.

G. The situation where the billary duct empties, its contents into the duodenum.

$\mathrm{H}$ H $\mathrm{H}$. The small intestines freed from the mesentery, and arranged evenly, so as to show their length. I. The termination of the sunall and beginning of the large intestines, guarded by a
valve.

J J. T'he colon, or first large intestine.

K. The blind extremity of the colon, by some termed the cacum.

L. The rectum, or straight gut.

in sheep is about one-fiftieth that of the carcase, and its specific gravity is somewhat greater than water. It is partially separated into: divisions or lobes, and is principally situated towards the right side. Its office is to separate the bile from the venous blood-that which has circulated through a. great portion of the body and is on its way to the lungs to be re-purified. It is called a gland, and is, in fact, a fine sieve or filter, having the power of separating a peculiar substance from the blood and no other. It is supplied with arterial blood for its own nourishment, but by means of a large vein called the vena porta it is furnished with venous blood for the exercise of its functions. The bile being thus separated, is then conveyed into a reservoir attached to the liver and called the gall-bladder, from which the gallduct rises, and enters the intestine about eighteen inches from the stomach. Ruminating animals, in common with man and the carnivora, are furnished with, a gall-bladder, whilst horses and the other solid ungulous animals do not possess them; the reason being that in the latter the digestive process is continually going on, and therefore a constant supply of bile is essential, while in the former the food is either taken in distinct meals, as in man and the carnivora, or otherwise the ruminating process is carried on and renewed at different periods, as in sheep and cattle-in either case requiring large and copious supplies of bile to complete the process of digestion. It must be evident from the existence of the gall-bladder in some species of animals and its absence in others that the bile must perform an important part in the digestive process. One of its functions is to neutralize the acidity which the food or chyme has acquired in the stomach by means of the gastric juice, and thusepre- 
pare it for-the separation of the chyle which may be soeu on the surface of the food. For this purpose it is largely supplied with an alkaline fluid, which unites chemically with the acid of the chyme. The quantity of bile secreted by the sheep in 24 hours is very considerable, probably from $3 \mathrm{lbs}$. to $5 \mathrm{lbs}$.; but we are not to suppose that its sole use is that above stated, for it has been proved that the bile does not pass away with the excrements, but is again taken into the system to perform an important office to be noticed when we speak of the circulation. Thus the liver separates that which would be detrimental to the blood, and it supplies what is wanted for digestion as well as for another important process in respiration.

Besides the bile the duodenum receives, a copious supply of fluid of a thin watery nature from the pancreas. This fiuid closely resembles the saliva, and its principal use appears to be to liquify the contents of the intestines.

The remaining part of the small intestines understood under the terms jejunum and ileum are confined to, and connected with, the spine by means of a thin transparent membrane called the mesentery, which not only supports the intestines, but prevents their entanglement, and serves as the vehicle by means of which the arteries, veins, nerves, and absorbent vessels are transmitted to and from the bowels. Amongst these there are some very minute, though very numerous vessels called the lacteals, whose office it is to convey the chyle, a white milky liquid resembling albumen, from the intestines to a duct termed the thoracic, which passes along the spine and terminates in a large vein just previous to its arrival at the heart.

The composition of the chyle is very similar to the blood, differing from it in little more than the absence of its coloring principles. The lacteals, of course, open into the inner coat of the intestines, and the greater portion of the chyle is taken from the food in the small intestines and in the earliest portion of them in the greatest degree. The small intestines are remarkably long in the sheep, exceeding, indeed, sixty feet, and this great length renders them capable of containing much more than the large guts.

In man, the large intestines are distinguished as the cocum, the colon, and the rectum; in the horse, these divisions likewise obtain, and with much more propriety than the artifi. cial distinctions of the small guts. The cæcum and the 
colon in the horse commence almost close to each other, but the former is a blind gut, having but one entrance. The sheep, however, can scarcely be said to possess a cæcum, unless we term the blind portion of the colon by that name; for the fact is, the small intestines terminate in the large at a right angle with them (see I. in cut p. 120), and the blind portion extends about a foot in one direction from this angle and maintains its size for the space of two feet.

The termination of the small intestines in the large deserves particular notice. The internal membrane of the former projects into the latter so as to form a sort of valve, which, admitting the fæces to pass forwards, effectually prevents their passing backwards, and thus, too, prevents the effects of clysters operating beyond the large intestines. The diameter of the colon is about treble that of the small intestines, but this increased size only reaches the extent of three feet, when the intestine-gradually diminishes to about the size of the small guts, and so continues for about nine feet, when it enlarges about a foot prior to its termination. This latter portion may be termed the rectum without impropriety. Soon after the large intestines become narrow, the fæces gradually become hard, and acquire the form of small black balls, in which state they are dropped.

The chyle, we have observed, is principally absorbed from that portion of the small intestines termed the ileum; there is little or none remaining by the time the fæces reach the large intestines, but the fluid absorbed from these guts is principally of a watery nature.

\section{THE URINARY AND GENERATIVE ORGANS.}

The urine is separated from the arterial blood by means of the kidneys, which are two large glands shaped like a bean, situated within the abdomen, but attached firmly to the Ioins. These glands are largely supplied with blood by im portant arteries; and the urine being separated as by a filter enters two long white ducts termed the ureters, one of which rises from the pelvis or central notch of each kidney, and passes on to the bladder, whose coats are pierced in an oblique direction (which, forming a sort of valve, prevents the urine rêturning) not very far from its extremity or fundus.*

- The urine of the sheep is much less copious than that of the cow. $28^{*}$ 
The bladder is situated partly in the pelvis and partly in the abdomen, the latter part being comparatively free, whilst the former is closely attached to the pelvis. The shape of the bladder is too well known to need description. It becomes smaller as it approaches its posterior part, where it contracts and forms the neck just prior to its opening into a canal called the urethra. The bladder, although apparently so thin, yet has three coats, the middle one of which is muscular and possesses the power of contracting so as to expel the whole of its contents when required, and the opening is usually kept closed by a sphincter or circular muscle, which relaxes when the bladder is being emptied. The urethra in the ewe is very short, a few inches only in length, and it is guarded by muscles which are employed both in expelling the urine and in the act of procreation.

In the ram the urethra is of considerably greater length, extending the whole length of the penis; it forms an acute angle at the perineum, just under the anus. 'The penis is a muscular organ, having a very curious structure, which enables it to receive at times a considerably increased quantity of blood, which causes the erection of the organ and fits it for the purpose of generation. Its usual state, however, is flaccid, when its use is confined to the ejection of the urine.

The vagina and uterus, or womb or lamb-bag, lies between the rectum above and the bladder below, and though much within the pelvis in their ordinary state, yet when pregnart they rise irito the abdomen to a great extent. The vagina, which commences a few inches within the body, is a cylin-

and, though less abounding in substances containing nitrogen, possesses a larger proportion of salts. The following is an analysis of 100.000 parts by weight:-

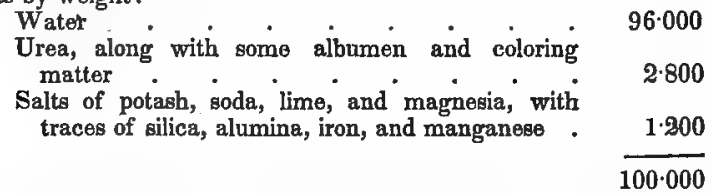

This gives 4 per cent. more water than the urine of cows, than which it is less fertilizing to the soil, if the latter is properly prepared; but the dung of sheep is much more nutritious than that of cows, and the urine likewise, when dropped on pasture land, is more serviceable, in consequence of the small quantity deposited at a time, and the less proportion of caustic ammonia contained, so that it does not render the herbage rank, as is the well-known effect of the freeh urine from cows. 
drical cavity several inches in length, and opens into the uterus by a round opening called the mouth of the womb, which is naturally open, but becomes closed after impregnation. Its shape corresponds with the extremity of the penis, and these parts come into contact in the act of coition. The womb consists of a body and two branches or horns. It has the same number of coats as the bladder, but they are much stouter and more so than those of the vagina. Attached to the extremity of each horn by a membranous substance are two red bodies called the ovaries, each of which consists of a number of ova or eggs, the germs of the offspring, one of which on being impregnated escapes into the uterus, and thus, in the course of time, becomes. a young animal ; sometimes, indeed, two or even three ova may be impregnated, and twins or triplets are produced.

The testicles, or stones, as they are commonly termed, are two oval glands situated in the scrotum, a sort of bag formed by the skin and two membranes within, which are so disposed as to form two separate cavities, each containing a testicle. The testicles are first formed in the abdomen of the fotus, and each possesses a covering closely attached to the gland. They escape from the abdomen through the openings called the abdominal rings and take with them portions of the peritoneum, the membrane which lines the abdomen and its contents; thus it is that they possess two coats besides the skin. The abdominal rings remain open afterwards, contrary to what takes place in the human subject, so that a fluid can be injected from the scrotum into the abdomen, and thus it is that sometimes after the operation of castration inflammation takes place and spreads upwards into the belly and destroys the lamb. In those cases where portions of the intestines are found in the scrotum they escape from the abdomen, together with the testicle, and the case is denominated congenital hernia. The testicles are also each connected with the belly by means of the spermatic cord, which consists of a long slender muscle, nerves, veins, arteries, and a strong hollow tube called the spermatic duct. It is the latter which conveys the seminal fluid secreted by the singular structure of the testicle into the urethra, where, after mixing with other secretions from some small glands, it is forcibly ejected by the muscles of the penis in the act of copulation.

The testicles are very large in proportion to the size of 
the animal, and are in keeping with the powerful seminal powers possessed by the ram, and which enable him when full grown to serve properly eighty ewes or upwards.

\section{THE CONTENTS OF THE CHEST.}

The mouth in the horse is almost entirely devoted to the office of mastication. It is separated from the cavity of the nostrils by a loose fleshy membrane called the velum palati, which is confined to the bone above by a semicircular border, and falls downwards and backwards so as to prevent, in a natural state, any communication between the windpipe and the mouth. The sheep likewise possesses this velum palati, but it is not so long, and therefore permits this animal to respire through the mouth as well as the nostrils. The importance of this construction is seen in the process of rumination, and also accounts for the horse vomiting through the nostrils, on those few occasions when this animal has been known to vomit. The nostrils, however, are the principal channel through which the air passes to and from the lungs. Their entrance is comparatively small and confined; the sheep does not require so extensive a supply of air as other animals that are called upon to make considerable exertions. The cavity of the nostrils is divided into two compartments by a thick cartilaginous substance, termed by anatomists the septum nasi, fixed to the nasal in front, and behind to the maxillary bones. This cartilage, as well as the other parts of the nostrils, is lined by a fine delicate membrane which secretes a mucus for its protection. It is indeed an inflammation of this membrane which constitutes a catarrh or cold, and an increase of its natural mucous secrétion is the discharge from the nose which is visible in this disease. This membrane is called the Schneiderian, from the name of its discoverer, as well as the pituitary, and it is endowed with a high degree of sensibility, which it derives from an abundant supply of sensitive nerves; it is also the principal seat of the sense of smelling, and for this purpose the nerve devoted to this function is spread out on its surface. This membrane also covers four curious bones, thin and gauze-like in their structure, and rolled up like a turban, so that they are termed turbinated, and attached to the chambers of the nostrils. These greatly extend the surface on which the nerve of smell is diffused, and consequently 
increases the function of this sense, which sheep enjoy in a very high degree. The nostrils at the upper and back part terminate in a cartilaginous box called the larynn, which is situated immediately beneath the pharynx or food-bag, so that food, in passing into the latter, traverses the entrance of the former, which, however, it is prevented from entering by a triangular lid called the epiglottis : this lid in its usual state is elevated from the glottis or entrance of the larynx, so as to admit the free entrance and exit of the air, but the passage of food forces it down so as to close the entrance of the windpipe. The larynx is formed by four separate cartilages besides the epiglottis just spoken of. One is shaped like a shield, and forms the front of the larynx and great portion of its sides. Another below this is circular, and two other smaller ones, shaped like an ewer, forms the rims on which the epiglottis shuts town. The larynx is lined throughout by a mucous membrane, which is endowed with a high degree of sensibility, particularly at its upper portion; and. thus when any foreign body accidentally enters, or the mucus is in undue quantity, it excites the membrane, and coughing is produced, by which it is expelled. The windpipe consists of a number of cartilaginous rings connected together by elastic membrane so as to form a continuous tube passing down the front part of the neck, and entering the chest between the two first ribs. The rings are not completely cartilaginous, but the circle is made up of membrane, the membranous part being on the upper portion of the tube. This structure permits the windpipe to be bent in any direction or compressed without injury, its elasticity quickly restoring it to its former shape, or position. The windpipe, on entering the chest, divides into two portions, going to each division of the lungs; and these subdivide into others, which again ramify into numerous small tubes, which ultimately terminate in very minute air-cells. The lungs, which receive these terminations, form by far the greater portion of the contents of the chest, which, however, it will be proper to describe first.

The chest of the sheep, in common with most quadrupeds, is unlike that of the human body, becoming narrow towards the lower part and terminating like the keel of a ship; a form more favorable to the flexion and extension of the forelegs, as well as of the shoulder-blades, than any other. This keel-like form is, however, much less developed in the 
sheep than in the horse and many other quadrupeds. The upper part of the chest is formed by the spine or back-bone, the sides by the ribs, and the lower and front part by the sternum or breast-bone. The number of ribs varies in different animals ; in man there are twelve, in the horse eighteen, but in the sheep there are only thirteen pair. Each rib possesses two heads or protuberances, each of which is connected by a joint with two vertebræ or bones of the back, and to the breast bone by means of cartilage. The sternum or breast-bone, in young animals, is chiefly cartilaginous, and may be separated into eight pieces; it afterwards becomes divisible into four only, and with age is consolidated into one. The ribs are externally convex, and are divided into the true and false; the former being situated anterior to the others, and immediately connected with the sternum, whilst the latter are implanted into each other at their cartilaginous extremities, and are only connected with the breast bone by means of the frue ribs. Their connexion with the spine, by means of a double joint, affords to the ribs a motion backwards and forwards, by which means the cavity of the chest is enlarged or diminished. This motion, however, is considerably less in quadrupeds than in man, for in the latter the rising and falling of the chest is seen in common respiration, whilst in the former it is not perceived, unless the breathing be embarrassed. The ribs are connected together by fleshy substance, termed the intercostal muscles, which are disposed in an oblique course, by which means their length considerably exceeds that of the space between one rib and another, so that a contraction of one-third their length will bring the ribs together, which could not be the case if the muscles took the shortest course from one rih to another.

The chest is separated from the abdomen or belly by a very singular and important muscle, called the diaphragm or midriff, which is convex towards the chest when in a state of rest. This muscle is shaped somewhat like a fan, and is attached to the inferior extremities of the ribs and the spine, by which means its position is rendered oblique, its development more extended, and its action greater than it would otherwise have been. The diaphragm, unlike every other muscle, is fleshy at its circumference and tendinous at its centre. The reason of this peculiar construction may bo thus explained :-the central part of the diaphragm is pierced 
with two holes, for the passage of the cesophagus (the tube which conveys food to the stomach) and the vein which conveys the blood to the liver for the secretion of bile. Now, if these important vessels were surrounded with muscular substance, they would be forcibly compressed every time the diaphragm contracted, and would in consequence be liable to considerable injury.; but being surrounded with tendinous substance, which possesses no such power of contraction, all danger of compression is at once removed, without any sacrifice of strength or power in the muscle. The diaphragm, when in a quiescent state, is convex towards the chest, and when in action it becomes flat, thus enlarging the cavity of the chest.

The thorax is everywhere lined internally by a thin serous membrane, which secretes a fluid by which the surface of the cavity is lubricated, and its contents are enabled to glide upon each other without occasioning any friction or inconvenience. This membrane is called the pleura, and the portion which lines the chest itself is designated the pleura costalis, while that which covers the lungs is distinguished as the pleura pulmonalis. This membrane divides the chest into three cavities, one on the right side containing the right lung, and the other two on the left side, the smaller of which contains the heart and the larger the left lung.

"The right lung is thus the largest, and consists of three lobes or divisions, whilst the left lung only contains two. These divisions of the chest do not communicate with each other, so that if one cavity is injured, or air is admitted into it, respiration can be carried on in the other.

The lungs are light spongy bodies, their specific gravity being one-half less than water. They are composed of the air-cells before spoken of, the bronchial tubes connected with them, and a vast number of arteries, veins, and absorbent vessels, the whole being connected together by cellular substance, or parenchyma as it is termed: thus constituted, the lungs are closely packed away in the cavity of the chest, filling every part of it, so as to leave no vacant space whatever.

THE BLOOD AND ITS CIRCULATION.

The blood is by far the most important fluid in the animal machine : it stimulates the heart to contract, secretes and nourishes the various organs of-the body, and supplies it 
with heat; and although it is the source whence other fluids are obtained, it is yet a fluid sui generis, differing from all others. Soon after it is drawn from the body it coagulates, and then separates into two parts: the serum, a watery, colorless fluid, which floats on the top, and the crassamentum, which appears of a firm consistency and a red color. 'The serum is a peculiar fluid, and may be separated into its constituent principles. If subjected to a temperature of $150^{\circ}$, a portion is converted into a substance resembling albumen or the white of an egg; the other portion remains fluid and is termed the serosity of the blood, and is that which constitutes the gravy in meat. 'The serum contains several salts in solution, the most abiundant of which is soda. The crassamentum is likewise divisible into two portions : the cruor, which gives to the blood its purple hue; and the lymph, which is more solid in its nature, and is considered the basis of the coagulum. The latter can be separated from the former by washing, and likewise separates when the blood is a long time congulating, in which case the red portion of the blood, being the heaviest, falls to the bottom of the vessel, leaving the lymph on the top. The cruor, or red portion of the blood, has been found, on being submitted to a microscope, to be composed of globules, which are supposed to be each about the three or four thousandth part of an inch in diameter. It is therefere to these globules that the blood owes its redness; but the intensity of the color is subject to great variation, being darker in animals that are poorly fed, or when exposed to carbonic acid, and becoming more florid in others that are well fed, and also when exposed to oxygen, or to atmospheric air.

The other part of the crassamentum, the lymph, which from its nature is also called the fibrine, is, in fact, the most important of all ; for it is that which mainly supplies the different parts of the body, particularly the muscles, with nutriment, and repairs wounds and fractures in an extraordinary manner. Unlitke the cruor, it exists in the blood of all animals, and in every part of the system. Some animals have entirely white blood, the cruor being absent; and in redblooded animals there are some portions of the body, such as the white of the eye, where the vessels are so small that they do not admit the red globules. The specific gravity of blood rather exceeds that of water; but venous blood is comewhat heavier than arterial. The temperature of the 
blood varies in different animals ; in man it is $90^{\circ}$, but in the sheep nearly $100^{\circ}$. It is rather warmer in the arteries than in the veins, and is liable to variation from disease, it having been found in severe inflammations to be raised $7^{\circ}$ in man, and in the cold fit of agues $4^{\circ}$ lower than in a state of health. It is, however, but slightly raised or depressed by external temperature. It was not till comparatively a recent date that the blood has been considered to possess vitality, which, however, is now generally acknowledged. The vitality and fluidity of the blood are intimately associated; in fact, its coagulation, when removed from the body, constitutes its death. The time in . which this is taking place is different in different animals, and is influenced. by various circumstances. In strong animals, such as the horse, it is longer than in such weak animals as the sheep: in the former it is often as long as fifteen minutes; and if the body be in a state of plethora, the vital power being 100 highly developed, the death of the blood is much longer resisted. In these cases coagulation is delayed, and, in consequence, the red portion of the blood, being the heaviest, falls to the bottom of the vessel, and the fibrine remains at the top, constituting the buffy coat of inflammation. This separation, when arising from the above cause, takes place long before the serum is developed. The coagulation of the blood has been endeavored to be accounted for without success ; it was held by some that it was produced by the cessation of its motion; but it has been found that if stirred in a vessel it will coagulate quicker than before. It was thought that exposure to the atmosphere was the cause ; but it has been known to coagulate in a vacuum, and likewiso in the body when a vein has been tied. It was next con ceived that it was caused by the low temperature to which it is exposed; but it has been ascertained that it will coagulate quicker if the temperature is either higher or lower than natural; but if so low as to freeze the blood, it will not coagulate when afterwards thawed. These :experiments show that the blood is analogous to no other fluid, and that coagulation cannot be owing to physical causes, but can be explained only by reference to its vitality.

Although the blood will coagulate in the body if obstructed, yet there is a considerable difference between this state and its coagulation out of the body. In the former instance co gulation is longer occurring, new vessels are thrown into 
its substance, and it becomes organized. So, likewise, if a part be wounded, the divided vessels throw out clots of blood, which adhere to the surface of the wound; the red particles become absorbed, the glutinous fibrine organized, and the breach is thus gradually restored. Thus we see how important it is that the blood should possess its peculiar properties, its state of fluidity, and its disposition to coagulate: if the former did not exist, the blood would. be obstructed in the capillary vessels, and the vital functions could not be carried on ; and if deprived of its coagulating property, no wounds could heal, or loss of substance be restored, but the most trifling cut would be the precursor of death.

The quantity of blood contained in the body is very difficult to ascertain; for if an animal be bled to death, a good deal will still remain in the blood-vessels. It has, however, been estimated to be about one-fifth the weight of the body; and of this, about three-fourths are contained in the veins, and one-fourth in the arteries. In young animals there is more than in old ones, as in them the body must not only be sustained, but increased in size. It is likewise more abundant in wild animals than in tame ones, and in proportion to the vigor of the animal.

The Heart is a strong hollow muscle, of a conical shape, with its base towards the spine, and its apex towards the left side, against which it is thrown at every contraction. It is double, having a right and left side, the former containing black, and the latter red blood; the right side is the thinnest and weakest, being devoted to the lesser office of the circulation of the lungs : the left the stoutest, having to govern the general circulation of the system. Each of these halves consists of two cavities, an auricle and a ventricle; the former, which derives its name from its resemblance to a dog's ear, is considerably thinner than the latter, and is situated towards the base. The heart is formed principally of fleshy fibres, connected together by cellular tissue, whence it obtains its elasticity ; and its surfaces, both internal and external, are lined by a transparent membrane. The blood is prevented from moving in a retrograde course by means of a number of valves: there are three in the left ventricle, the edges of which are connected by tendinous cords (corde tendine) to small fleshy eminences on the inside of the ventricle, called carnece columne, or fleshy 
coiumns. These tendinous cords are more numerous in the valves of the left ventricle than in the other parts, and being supposed, with the valves, to resemble a mitre, are named mitral valves. There are valves also in the right. ventricle for similar purposes, which are named tricuspid, or three pointed; also in the great artery, or aorta, and in the pulmonary artery, where, having no cords, and resembling, or supposed to do so, a half-moon, they are named semilunar. The heart is enclosed in a strong membranous bag, which is named pericardium, and this encloses also the trunks of the veins and arteries, as well as the appendages or auricles.

The heart is a muscle, but, unlike other muscles, it is involuntary, being altogether independent of the will, and is for this purpose supplied by a peculiar set of nerves. It is also furnished abundantly with blood for its support, by means of arteries which are the first that are given off; and these arteries are accompanied by veins for the return of the blood to its proper receptacle.

\section{THE CIRCULATION OF THE BLOOD}

is one of the most important processes in the animal economy : when suspended for a few moments, a state of insensibility is produced, and if this suspension continues a little longer, death quickly supervenes.

The heart, we have seen, consists of two halves or sides, the right being devoted to the pulmonary circulation. The right auricle receives from a large vein, called the vena cava, the blood which has travelled throughout the system; whence it passes, by the action of the heart, into the right ventricle, which by its contraction forces it into a large vessel called the pulmonary artery. Thence the blood is sent into the lungs and ramifies throughout its minute vessels, where it is exposed to the action of the inspired air, and becomes, by means we shall afterwards speak of, reddened and purified. This process being accomplished, the blood passes into minute vessels, which, coalescing, become the pulmonary veins, and through them the blood again returns to the heart; thus finishing the circuit of the pulmonary circulation.

The left auricle receives the purified blood from the pulmonary veins, forces it into the left ventricle, which, contracting, sends the vital fluid into a large strong vessel 
called the aorta, whence it enters smaller arteries, to be distributed throughout the whole system. The remote divisions of the arteries are called the capillary vessels, and in them the blood, after having accomplished its purposes and conveyed nourishment to all parts, becomes black and impure, and in this state enters the capillary veins, which, conjoining and increasing in size and diminishing in number, convey the bloôd again to the right auricle of the heart. Just before it enters the heart it receives a supply of chyle, which, as we have before observed, is extracted from the food, absorbed by certain small vessels called lacteals, and conveyed by a specific channel to the heart. Such, then, is the circle, or rather the double circle, which the blood takes, and by which so many important purposes are beautifully and correctly accomplished.

The circulation of the blood is accomplished by the joint action of the heart and arteries, but principally by that of the former. The contraction of the ventricles and of the quricles immediately succeed each other: as the one expands to receive the blood, the other contracts to force it forward, thus producing the unequal double action of the heart that we feel. These actions, however, of the different cavities could not be correctly performed unless some provision were made for preventing the blood, when the ventricles contract, from retrograding into the auricles. This, however, is effected by means of a valve, situated between these cavities, which is formed by a duplication of the inner membrane of the heart, thickened by fibrous substance. The floating edges of this valve in the right ventricle present three points and in the left two; whence the former is called the tricuspid, and the latter the mitral. The edges of each valve are joined by numerous short tendons to the fleshy columns of the heart; and whilst the blood is flowing into the ventricles the fleshy columns are passive; but when the ventricles act these columns also contract and draw the edges of the valve together, and thus close the cavity in that direction and prevent the blood re-entering the auricle.

There are also valves that guard the entrance of the aorta and pulmonary arteries, but they are of a different description, being of less strength, because they are not called upon to oppose the powerful action of the ventricles. Accordingly. we find that they consist of three folds of mem- 
brane, and are called, from their shape, semilunar. They are so situated that when the blood passes into the arteries they are thrown against their sides, and when the blood has passed they are thrown up so that their edges meet, and thus prevent the blood returning to the heart.

In fishes the heart is single, and only serves the office of the pulmonary circulation, that of the system being accomplished by the arteries alone. In the sheep, though the heart is the principal power, yet the arteries greatly assist The aorta, which receives the blood from the left ventricle, -divides into two branches, called the anterior and posterior aorta; the former conveying the blood to the head and neck, and the latter to the lower parts of the body. These arteries are strong and thick, and consist of three coats; the outer, the strongest and thickest, gives the vessels the remarkable elasticity which they possess ; the middle coat is the fibrous, which seems to be a modification of muscular power, and enables the arteries to contract on their contents; the third coat is the serous, which lubricates the interior of the-vessel and facilitates the passage of the blood. Thus to these several coats, but particularly to the two former, do the arteries owe the remarkable property they possess of contracting when distended with blood, and almost immediately afterwards expanding to receive a fresh supply, and which, assisted by the action of the heart, constitutes the pulse; and may be felt in every part of the body where an artery is sufficiently near the surface to be perceptible.

The arteries, however, do not all possess an equal thickness and power; for instance, the pulmonary artery, though quite as large as the aorta, is neither so thick nor so strong; and the reason is, that the same power is not required to send the blood over the smaller circuit of the lungs as over the larger one of the whole system; and, for the same reason, the right side of the heart is weaker than the left. The arteries, as they divide and subdivide in their course, become weaker in their coats in proportion to the diminution of their size, till at length they terminate in the minute branches called the capillary vessels, which do not possess any pulsating power, and many of which do not contain red blood. Diminutive, however, as these branches may be, yet it is by them that the most important offices are performed; by them the different parts of the body are nourished, whether bone, flesh, nerve, or skin; by them the various 
fluids are secreted, however different in appearance they' may be ; by them the most ghastly wounds are healed, and often in a remarkably short space of time; and all these various offices are performed not only by the same class of vessels, but by the same fluid, the blood. Having accomplished these important purposes, the capillary arteries terminate in equally minute vessels, called the capillary veins; and so abundant are these diminutive vessels that the finest point of the finest needle cannôt be plunged into the body without penetrating some of them. By the time the blood reaches the veins it becomes dark and impure, and loaded with carbon: the office of the veins, therefore, is to return it to the heart to be again purified. "The circulation; however, becomes much slower as it is further removed from the impulsive power of the heart, and the veins, which are , supposed to contain two-thirds of the whole blood circulating in the system, are consequently much more numerous than the arteries: they do not, however, possess the same strength in their coats as the arteries, nor have they any pulsating power. They have, however, the assistance of other agents in propelling the blood to its destination. The greater number of them possess valves, which admit the blood to pass in one direction, but effectually prevent its passing in any other. It was, indeed, from reflecting on the structure and necessary office of these valves that led the immortal Harvey to discover the circulation of the blood. Another circumstance peculiar to the veins is their situation, being mostly near the surface of the body, whilst the arteries are generally deep seated. The wisdom of this provision is evident : it is well known that in wounds it is readily ascertained if an artery be wounded by the jet of blood that ensues, and which even from an artery of small size is very considerable, and the danger of death from bleeding is often great in consequence of the force with which the blood is thrown into these vessels. Now such being the danger attending the division of arteries, it was necessary to remore them as much as possible from the risk of injury, and accordingly they are almost invariably deep seated, and when they do approach the surface it is in parts least likely to be injured. Thus round these important vessels nature throws a thick muscular covering, and protects the whole by a mantle so sensitive as to give warning to the least attack. The veins, however, do not require this care 
in them the circulation is languid, and their wounds are comparatively unimportant and unattended with danger, for the blood generally stops, without assistance, from its coagulating quality. It is also of importance that the greater portion of the veins should be situated near the surface, in order to receive the influence of the atmospheric pressure, which greatly assists the motion of the blood; and it has also been found that veins possess a power of absorption in common with a particular order of vessels called the absorbents; thus these various purposes are effected by the relative position of the veins and arteries. The structure of the veins is very different from that of the arteries; for, whilst the latter are thick, elastic, and composed of three coats, the former are thin, inelastic, and composed only of two coverings. But although thin they are yet capable of affording great resistance to pressure.

We have seen that the blood is sent to all parts of the body by the action of the heart and arteries, but what is the cause of its return? First in importance is the law of hydrostatics, "that all fluids support their level." Thus the same law by which springs arise, and streams are produced, and rivers flow towards the sea, is brought to bear in the living system, and enables the blood in the arteries to support that in the veins. This effect is greatly assisted by the action of the valves in supporting the column of blood. The blood thus supported and propelled by the arteries, assisted by atmospheric pressure, must go somewhere, as the valves prevent return; it goes, therefore, where alone a vacancy is afforded, and that is in the right auricle of the heart, which has just propelled its contents into the ventricle. To these several forces may be added a power of suc tion the heart possesses whenever the chest is enlarged in respiration.

The manner in which the chyle is mixed up with the blood, so that its color quickly disappears, is worthy of particular notice. It is owing, indeed, to the great agitation the blood : receives, and to the irregularity of the heart's -internal surface. When the auricles contract, their contents are, in a great measure, discharged into the ventricles, but a portion is thrown back into the veins, which constitutes what is called the venous pulse, and may sometimes be seen in the jugular veins. In like manner, when the ventricles contract a portion of their contents is thrown back into the 
auricles, at any rate that part of it situated behind the valves. By these means an agitation is produced which effectually mixes these different fluids together.

It has been ascertained that the veins possess a power of absorption in common with a numerous class of vessels called the absorbents, or lymphatics. These vessels are very minute, and are distributed throughout the whole body; they generally accompany the veins, and, like them, are furnished with valves.

\section{ON RESPIRATION AND ITS EFFECTS.}

The phenomenon of respiration, which is carried on from the first minute after birth to the last of exis tence, consists of two acts, inspiration and expiration. The former, that of inhaling the atmosphere; is accomplished mostly by the diaphragm, which, in its relaxed state, is convex towards the chest. As its fibres contract, the muscle flattens, and thus enlarges in a considerable degree the cavity of the thorax. A vacuum is thus produced, or rather a tendency towards it; for the air rushes into the lungs, and the blood into the heart; and, as the lungs are elastic and spongy in their nature, they become closely adapted to the enlargement of the chest, and prevent any vacuum from taking place between them and the sides of the thorax. The diaphragm is thus the chief agent in the act of inspiration, although in some degree assisted by the intercostal muscles, which raise the chest, and also, when the breathing is violently excited, by those muscles that in quadrupeds attach the fore extremities to the body. The air thus drawn into the lungs traverses throughout its internal surface, and, having fulfilled its office, is forced out by the act of expiration. This part of the process is effected chiefly by means of the elasticity of the lungs, which acts as soon as the diaphragm becomes passive, assisted, however, in some degree by the elastic cartilages of the chest, and occasionally by the abdominal muscles.

Atmospheric air consists of unequal parts of two aëriform fluids, viz., four-fifths of nitrogen or azote, and one-fifth of oxygen in each 100 parts; besides which it contains other heterogeneous matters, such as odorous effluvia, aqueous exhalations, electric matter, and carbonic acid gas. It every where surrounds and embraces the globe, extending, in the opinion of some, a distance of forty-five miles, and in that of others a much greater height. Its gravity differs very 
much at different times and in different places, being heavier, on a clear than on a close day, and also in low places than in lofty ones. 'The small portion of carbonic acid gas which the atmosphere contains is not chemically, but mechanically mixed with it. This gas is evolved by the fermentation of beer, and the decomposition of vegetables, and is often found in wells and deep places. It is much heavier than the atmosphere, and thus remains in these low places by its gravity. A lighted candle placed in this gas is immediately extinguished; so that it is used as a safeguard in descending into these low and foul places; for whatever will not support combustion will not support life. It is not a simple gas, like oxygen, but is formed by the union of carbon and oxygen.

Nitrogen or azote is a simple gas, but its use in the atmosphere seems to be principally of a passive nature, being. for the purpose of diluting the oxygen and rendering it less stimulating: it will not alone support life or combustion, but is chemically mixed with the oxygen. Oxygen is essential for the support of life and combustion; for if air be deprived of it no animal can live, nor will a candle remain lighted It is abundantly furnished by plants and shrubs, which thus restore the loss of it occasioned by animals. When a flame is exposed to this gas it greatly increases in brilliancy ; and when venous blood is submitted to it, it quickly becomes florid.

We have before shown that all the blood in the body was in its turn carried from the heart to the lungs by means of the pulmonary artery, which divides and subdivides into the smallest branches, and terminates in small capillary veins, which, coalescing, become larger, and convey the blood again to the heart by the pulmonary veins. Before it reaches these veins, however, an important change takes place: the blood proceeds from the heart in a black and impure state; it returns reddened and purified; it is submitted in its course to the action of the air in the air-cells, not by actual contact, but through the membrane which forms these cells : and by this means the important change is effected.

There is, we well know; a considerable difference between the expired and the inspired air; the former is hot, the latter cold ; this is healthy, that injurious ; one will support combustion and life, the other is unfit for breathing, and will extinguish a flame. There is but little difference in quantity between the air in its different states, but the oxy 
gen in expired air has nearly disappeared and carbonic acid gas is found in its stead; it also contains much aqueous rapor, which is condensed in a visible form, at a temperature of $60^{\circ}$. Thus, although the carbonic acid gas is much heavier than common air, yet, partly from the aqueous vapor which the expired air contains being much lighter, but principally from its own increased temperature, the expired air, notwithstanding its carbonic acid, is yet specifically lighter than the atmosphere; and consequently rises upwards, and thus, in great measure, is prevented from being respired a second time. It has been found by experiment with a portion of atmospheric air, containing 80 parts of nitrogen, 18 of oxygen, and 2 of carbonic acid, that, on being respired, the nitrogen continued the same, but the carbonic acid was increased to 13 parts, and the oxygen reduced to 5 ; whence it appeared that 11 parts of carbonic acid were substituted for 13 of oxygen, 2 parts having entirely disappeared. Thus the disappearance of the greater portion of the oxygen was accounted for by its being converted into carbonic acid; but there remained a small portion, whose absence could not be thus explained, more particularly as Sir H. Davy calculated that about 32 ounces of oxygen were necessary for 24 hours' expenditure in a man; but only $26 \frac{1}{2}$ ounces are requisite for the formation of even 37 ounces of carbonic acid gas, giving us an unexplained surplus of $5 \frac{x}{4}$ ounces of oxygen, during the above period. By some it was supposed that this surplus oxygen united with the hydrogen thrown off by the blood, and is thus converted into watery vapor : by others it is held, that this oxygen is absorbed by the blood, and enters the circulation: Carbonic acid gas is exhaled from the lungs in different quantities during different periods of the day, being generated in the greatest quantity about noon, decreasing in the afternoon and night, and again increasing in the morning. It also in- creases in man by taking animal food.

Sir H. Davy contended that a small portion of nitrogen is absorbed by the blood; but this has been denied by others. The chief use of nitrogen, however, is to dilute the oxygen; for if the latter is inspired pure a sense of warmth is felt in the chest, the heat of the skin is raised, the pulse quickened, and other symptoms of excitement are produced. A given quantity of oxygen will, however, support life longer than the same quantity of atmospheric air. It has been computed 
that, in the course of twenty-four hours, about 2 lbs. 8 ozs. of oxygen is consumed by a man. After an ordinary respiration a considerable quantity of air still remains-perhaps four-fifths, one-fifth having been expired.

Having mentioned the changes that take place in the atmosphere, we must next consider in what manner the blood becomes so altered by its passage through the lungs.

The blood, as it traverses through the body, gradually becomes darker; it is loaded with carbon, and is rendered unfit for the circulation, and in this state it is called venous blood. If venous blood, taken out of the body, be exposed to oxygen, it quickly becomes red; and so it does if exposed to the atmosphere, but not so rapidly. So, likewise, if arterial blood be exposed to carbonic acid, it quickly acquires the color and character of venous blood. In the same manner is the color of the blood changed in the lungs; thus- the principal use of respiration appears to be to free the blood from its impurities; and this is effected although the air and the blood do not actually come in contact. It was found, that if blood in a common bladder were exposed to the atmosphere for some time, it acquired a coating of florid blood; and thus, as the membrane lining the air-cells is by no means so thick as that of the bladder, there is no longer any difficulty in accounting for the change taking place. It has been the subject of some dispute as to when the change, or rather exchange, takes place, some contending that the carbon unites with the oxygen in the air-cells, whilst others maintain that the oxygen enters the blood, and there unites with the carbon, forming carbonic acid gas, which is then exhaled into the air-cells. It was found, however, that if venous blood were put within the exhausted receiver of an air-pump a quantity of carbonic acid escapes; thus proving the presence of this gas in the blood, and supporting the second theory. And as there appears to be a greater quantity of oxygen abstracted from the atmosphere than can be accounted for by the formation of carbonic acid, we must conclude that a portion mingles with the blood and enters the circulation; which theory agrees with the fact, that it has recently been discovered, by correct analyses, that both venous and arterial blood contains carbonic acid, nitrogen, and oxygen; but that the latter gas is most abundant in ar terial and the former in venous blood.

Although the action of the heart is much more frequen 
than that of the chest in respiration, yet there is a most intimate connexion between the one and the other; for, besides the changes which we have spoken of in the blood, if rushes into the heart when the chest is expanded, and when, from any cause, respiration is delayed, the pulse becomes less frequent and more languid in consequence of the obstruction in the current of the blood. Thus, in violent fits of coughing, the chest collapses, the air is expelled, and the blood not being purified, is unfit for circulation, and the consequence is the veins of the head become distended, and, in man, the person becomes red or black in the face, and sometimes a blood-vessel has ruptured and death supervened. 


\section{CHAPTER XVI.}

\section{DISEASES OF THE SHEEP.}

INTRODUCTORY OBSERVATIONS-DISEASES OF THE BRAIN AND SPINAL MARROW-STURDY OR DIZZY-HYDROCEPHALUS-'[REM BLING-APOPLEXY. THE AIR PASSAGES-CESTRIS OVIS OR GAD FLY, CAUSING WORMS IN THE HEAD-CORYZA OR COLDS. DIS EASES OF THE STOMACH AND INTESTLNES-HOOVE-BRAXYSTRETCHES-DIARRHCEA OR SCOURS-ACUTE DROPSY OR RED WA TER-DYSENTERY-POISON. DISFASES OF THE LUNGS-ANATOMY OF THE LIVER-ROT-INFLAMMATION OF THE LUNGS - DROPSY. DISEASES OF PARTURITION-ABORTION-INVERSION OF THE UTERUS-GARGET. THE INTEGUMENT OR SKIN-DISEASES OF THE SKIN-SCAB OR ITCH-ERYSIPELAS-JOHNSWORT-SCAB-PELT-ROT -SORE MOU'H-MAGGOTS. FOOT-ROT-FOULS.

\section{INTRODUCTORY REMARKS.}

ThERE is no department in the management of sheep so little understood as the nature and treatment of their diseases. Happily, however, for the American shepherd, many of the diseases which prove so destructive in Great Britain, are here of rare occurrence. From this circumstance, the compiler of the following treatise has been compelled to rely on Messrs. Youatt and Blacklock, both distinguished veterinary surgeons, for much information concerning those diseases, which, with us, are but partially known. It is proper therefore to affirm, that this treatise has been compiled from the most approved authorities-from personal knowledge of the writer of some diseases which are most common to the country, as well from careful comparison of the opinions and experience of some of the most distinguished breeders of sheep in this and the Eastern States; and hence, he has every reason for believing that the pre monitory symptoms, preventives, and treatment of every dis ease, which will be noticed, are entitled to the implicit con fidence of the American shepherd. 
But, should the several remedies proposed, in every case prove inadequate to perform a cure, let the reader, before he condemns, remember that diseases of the human family are sometimes fatal from their extraordinary virulence, and at other times from neglect of timely treatment. This remark is applicable to sheep, as well as, all other domestic animals. Again : diseases are often fatal from want of the necessary knowledge of their origin and locality, confounding those peculiar to the brain and spinal marrow with those of the air passages, or the stomach and intestines. Therefore, with a view to avoid mistakes of this character, the various diseases have been properly classified under appropriate heads, as will hereafter be noticed.

The following remarks of $\mathrm{Mr}$. Blacklock, inculcating " caution in prescribing," are very just :- " Great reliance is in general placed upon prescriptions, which profess to suit diseases in every stage and eircumstance. Than this, however, scarcely anything can be more absurd. It is an opinion engendered not so much by ignorance as by laziness, a determination not to be put about by thinking of a remedy for the evils which surround us, but, while we continue to soothe ourselves by doing. something, to leave everything to the hit-or-miss practice of charlatans.* There are many who, on being informed of the presence of disease in a neighbor's flock, confidently advise the employment of a favorite nostrum, on the empirical supposition that because it cured, or was thought to cure, one flock; it will cure another. Nothing is taken into account, saving that, in both cases the affected animals are sheep; and it is at once concluded, that what benefited one will benefit another. 'The many niceties in prescribing are never thought of: oh, no, that would be of no use! Of course it can be of no importance to give a moment's attention to age or sex, pasture and situation, or to leanness or fatness, or to the presence of pregnancy! These are of trifling moment, and only to be despised by a person armed with a recipe, which some one has shown to be capable of walking like a constable through the body, and bearing off the intruder ! : But enough of this : sufficient has, I think, been said to prove the utter folly of confiding in things of the above nature or intention, and to

* Whenever we hear a person recommending a medicine of univereal virtues, we may safely set him down either for a fool or an impostor. Things which are good for everything are good for nothing. 
show that such confidence can lead to nothing but a waste of life and capital. Even though the remedy is a harmless one, it ought (unless calculated from known powers to arrest disease) to be received with distrust, as incurring a loss of time, during which other and better measures-might have been resorted to."

\section{DISEASES OF THE BRAIN AND SPINAL MARROW.}

The Diseases of the Brain are Sturdy; or Dizzy, caused by Hydatids or Blobs; Hydrocephalus, or Water in the Head; Trembling, or Leaping-ill; Apoplexy.

\section{STURDY, OR STAGGERS.}

This disease is not of frequent occurrence in the United States, but very common in Great Britain. It is caused by Hydatids or Blobs. "These are animals, generally pearshaped, found in various animals where they are parasitic, and resembling a vesicle or bladder filled with water. It was for a long time doubted whether they had an independent existence ; but as they have evidently a voluntary motion, and as they have the property of acting on matter in such a way as to convert it into a substance like that which constitutes the agent, (which, according to Roget, demonstrates a vital power) there is no reason to doubt it has a distinct animal existence. Hydatids occur sometimes in man, but more frequently in animals. In hogs, it causes the measles; in sheep, in the brain, they cause the staggers, and in the liver, the rot."

In England, according to Mr. Youatt, this disease is nearly always confined to sheep from six to twelve months old; after that period sheep seem to have acquired an immunity from the attack of the hydatid.

The symptoms are as follows:- "The sheep cease to gambol with their companions-they are dull--they. scarcely graze, they ruminate in the most languid and listless manner - they separate themselves from the rest of the flock-they walk in a peculiar staggering, vacillating way-they seem at imes to be unconscious where they are, or they seek some litch or brook, and there stand until they appear to be com.

* Dic. of Terms ; Cultivator. 
pletely giddy, and suddenly tumble in. In the midst of their grazing they stop all at once, look wildly around as if they were frightened by some imaginary object, and start away and gallop at full speed over the field. They lose flesh; the countenance becomes haggard; the eye wanders and assumes a singular blue color. 'This last circumstance, although not observed so carefully as it ought to be, is perfectly characteristic of the disease; and a good shepherd would select every sturdied sheep from the flock, guided simply by the color of the eyes.

By and bye the sturdied sheep commences a rotatory motion, even while grazing, and always in one way, and with the head on the same side. When this occurs, he almost ceases to eat or to ruminate (chew the cud), partly because the disease, from its debilitating character, destroys the appetite altogether; and also because he cannot restrain those circular motions, during which it is almost impossible to graze; but principally because he is rapidly becoming blind. He begins to be unconscious of surrounding objects. The habit of turning round increases; he continues to form these concentric circles for an hour at a time, or until he falls ; and then scrambles up again, and commences the same strange motion. At length he dies emaciated and exhausted."

The remedy sometimes for hydatids, as soon as discovered, is by removal from all wet, low land, to dry pasturage. The disease, however, is rarely cured. In some desperate cases it has been effected by trepanning, and the extrication of the hydatids.

James Hogg, the Ettrick Shepherd, says-" The sturdy more commonly attacks sheep if exposed to a windy and sleety winter. It "is always most destructive on farms that are ill-sheltered, and on which the sheep are most exposed to blasts and showers."

\section{HYDROCEPHALUS, OR WATER IN THE HEAD,}

This disease, it appears, is more general with young lambs, than with the adult sheep. "It is not confined within a cyst-it is not a portion or part of a living animal, as in the disease just treated of-but it accumulates between the two inverting membranes of the brain,- - the pia mater and the arachnoid coat; or it is found within the latter; or, and 
more frequently, it occupies and distends the ventricle of the brain."*

An English writer remarks-"Young lambs oftener die of water in the head than the shepherd or the sheep-master suspects." The symptoms are-a short time after birth the appetite sometimes fails, but frequently is voracious-the bowels become relaxed, but oftener constipated; the lamb is dull and disinclined to move-staggering a little, pining gradually away almost- to a skeleton-and dying, occasionally before it is a month old. The disease is generally incurable. Epsom salts, with ginger and gentian, have sometimes proved efficacious. Diseases of the brain in animals are unmanageable, and baffle the most skilful efforts for their removal.

TREMBLING, OR LEAPING-ILL.

Blacklock says, "Several affections are included under the name of trembling, or leaping-ill, all having, in common, more or less of the symptoms which these names denote. They may be considered as arising from exposure to cold and damp, especially on long, fatiguing journeys. Injuries of the loins, either inflicted by themselves in jumping and running, or by others from rough usage in the fold, are common causes of the disease; but in this veriety the hind quarters only are powerless. Another species is owing to oppression of the brain from congestion, in this way resembling incipient sturdy, and occurring only in very fat sheep.

"The treatment of the-first variety is by rest, shelter, and a supply of nutritious food. In the second kind, no cure can be accomplished, and the animal should be immediately slaughtered. Copious blood-letting, and doses of Epsom salts, will be found of most advantage in the third species; but if the sheep can be disposed of, so much the better, as this kind of trembling is almost certain, unless combated by energetic depletion, to end in sturdy."

\section{APOPLEXY.}

This disease is peculiar only to sheep when they are very fat; it is their plethoric situation which is the inducing cause. But the fit rarely occurs, if the animal is kept quiet; but hurried journeys, worry, and over-fatigue will often do it. Sheep, therefore, in high condition, should be driven with

* Youatt. 
great care. If the symptoms are aggravated, a small quantity of blood should be drawn from the jugular vein, and four oz. of Epsom salts immediately administered, and one oz. every six hours, until the bowels are open. The sheep should then be very sparingly fed for a few days.

\section{THE AIR PASSAGES.}

\section{GETRIS OVIS, OR GRUB IN THE HEAD-CORYZA.}

Blacklock says, "Much annoyance is caused to the sheep by the presence of animals in the air passages. The OEstris ovis (Gad-fly) deposites its eggs on the margin of the nostril in autumn; these are soon hatched, and the larvæ immediately find their way up the interior of the nose, till they arrive at the frontal sinus, a cavity situated between the layers of the frontal bone, and of considerable size in the sheep. Here they remain until the following spring, when they quit, burrow in the earth for a short season, then become winged insects, and ready to enter upon the career of torment so ably gone through by their predecessors."

'To prevent the attacks of this mischievous insect, it will be found necessary about the beginning of July, and again about the first of August, to assemble the flock, and thoroughly tar the parts adjacent to the nostrils. Others have tried, with success, smearing the bottoms of troughs, and sprinkling salt occasionally over it. The effluvia of tar is abhorrent to all winged insects ; and hence the philosophy of this treatment.

Few sheep are exempt from grubs in the head, and when the number does not exceed two or three, will not cause much annoyance. It feeds on the mucus secreted by the sinus membrane.

When the number of grubs is larger than common, they produce much irritation, and the sheep will sneeze violently. Blacklock says, "Tobacco smoke is the only available remedy, and a very good one, being easily brought in contact with the worms, and, when properly administered, certain in its effects. One person secures the sheep, holding the head in a convenient position, while another, having half-filled a pipe with tobacco, and kindled it in the usual manner, places one or two folds of a handkerchief over the 
opening of the bowl, then passes the tube a good way up the nostril, applies his mouth to the covered bowl, and blows vigorously through the handkerchief. When this has continued for a few seconds; the pipe is withdrawn, and the operation repeated on the other nostril."

\section{CORYZA.}

During the winter season this disease is very common with sheep that are wholly, exposed, or when shelters are imperfectly constructed. The chief annoyance is occasioned by an excess of mucus, which clogs the nasal passages, and causes great difficulty of breathing. When a sheep is in this situation, it is said to have a "bad cold." In some cases, unless relieved, the sheep will sometimes die from suffocation. At other times the inflammation will extend to the bronchial tubes, and pulmonary consumption (rot) will ensue.

Treatment.-Removal to a warm shelter, and a dose or purgative medicine, is all that will be required. The efforts of nature, however, are sufficient to remove the disease, when the attack is slight.

The preventive, which is always worth the pound of cure. are good shelters, and wholesome food.

\section{DISEASES OF THE STOMACH AND INTESTINES.}

\section{HOOVE, OR DISTENSION OF THE STOMACH BY GAS.}

This cannot be considered a disease, but an impediment of respiration and circulation. It is occasioned by the sheep being changed from a poor pasture to a luxuriant one, and gorging itself to an immoderate degree. The gullet is obstructed, and the gases in the paunch cause remarkable distension, with no passage for their escape, except into the chest, which ends in suffocation of the animal.

Treatment.-An aperture is sometimes made. with a sharp instrument in the side to permit the passage of the gas ; but this Blacklock explicitly condemns. . The remedy is the probang, a flexible rod, with a small ball of wood or ivory at the end, which, being forced to the lower extremity of the gullet, removes the obstruction, and the gas or wind is readily voided. 
Prevention.-Change the flock often, and neither a poor pasture nor too rich a one will follow. But peradventure it happens that sheep must be put suddenly on too high keep, salt them freely before it takes place, and this should be repeated for several successive days.

\section{BRAXY.}

This disease is not unusual to sheep kept in the latitude of ours. It originates from several causes; and first-a sudden change from green to dry food; second-when the animal partakes of some irritating weed to which it is wholly a stranger; third-frozen grass is an exciting cause, rapidly producing inflammation by lowering the temperatare of the stomachs so as to arrest digestion; fourth-when, being worried, forced to plunge into a stream of cold water. It is 'constipation of the bowels, followed by a high degree of inflammation.

- Symptoms.-The sheep is seen to frequently lie down and get up, loathing its food, and drinking often; the mouth is parched, the eyes red, partly closed and watery. The head is down, the back drawn up, and belly swollen; there is scarcely any passage through the bowels, the urine is small in quantity, high colored, and sometimes bloody. Death occurs not unfrequently after a lapse of a few hours, and again, not till nearly the expiration of a week.

Treatment.-Bleeding must be resorted to at as early a stage of the disease as possible; but previous to this the sheep must be placed in a tub of warm water, and there kept for half an hour; then administer two ounces of Glauber salts, dissolved in water. An injection of tobacco decoction will be also of great benefit. The animal must then be kept warm by throwing a blanket about it, and given laxative provender for a week or more.

\section{STRETCHES.}

This disease very commonly occurs in flocks which are kept exclusively on hay, or other dry food, and is fatal very often, unless an early application of medicine follows the attack

Symptoms.-The sheep will alternately lie down and rise at brief intervals, frequently stretching, and refuses every kind of food. It is now generally admitted that it proceeds 
from costrveness, by being deprived wholly of green food. The disease is unknown in Great Britain, where succulent provender is so bountifully fed.

Treatment.-Two table-spoonfuls of castor oil, or one ounce of Epsom salts, will be effectual. A small quantity. of hog's lard has also been used with success. A neighbor administers a large quid of tobacco; and he recently informed the writer that he had never lost a sheep by the stretches after administering this nauseous potion.

Preventive.-Give the flock green food once a week or oftener-such as apples, potatoes, or turnips. Pine or hemlock boughs are also excellent.

\section{DIARRHEA, OR SCOURS.}

This being so common and fatal a disease with the junior portions of the flock, in our own country, requires an extended notice. The following are Mr. Youatt's remarks, and mode of treatment :-

"If the affections of the external coats of the intestines do not frequently occur, inflammation of the inner coat or mucous membrane is the very pest of sheep. When it is confined principally to the mucous membrane of the small intestines, and is not attended by much fever, it is termed diarrhea; when there is inflammation of the large intestines, attended by fever, and considerable discharge of mucus, and occasionally of blood, it is dysentery. These diseases are seldom perfectly separate, and diarrhoa is too apt to degenerate into dysentery. The diarrhoa of lambs is a dreadfully fatal disease. If they are incautiously exposed to the cold, or the mother's milk is not good, or if ihey are suckled by a foster-mother that had yeaned too long before, a violent purging will suddenly come on, and destroy them in less than twenty-four hours.

"When the lamb begins to crop the grass at his mother's side he is liable to occasional disturbance of the bowels; but as he gains strength, the danger attendant on the disease diminishes. At weaning-time care must sometimes be taken of him. Let not, however, the farmer be in haste to stop every little looseness of the bowels. It is in these young animals the almost necessary accompaniment or consequence of every change of diet, and almost of situation; and it is frequently a sanative process; but if it continues longer than twenty-four hours-if it is attended with pain-if much mu- 
cus is discharged-if the appetite of the animal is failing him in the slightest degree, it will be necessary to attend to the case. Then use the following remedy:-Take of prepared, chalk an ounce, powdered catechu half an ounce, powdered ginger two drachms, and powdered opium half a drachm; mix them with half a pint of peppermint water. The dose is from one to two table-spoonfuls morning and night.

"The diarrhca of lambs is, in a majority of cases, attributable to the carelessness or mismanagement of the farmer, either referrible to deficient or improper food, or the want of shelter at an early age; as the animal grows up he is better able to struggle with the disease.

"Diarrhoa occasionally attacks the full-grown sheep, and is too often fatal, especially when it has degenerated into dysentery. It is very common in the spring and particularly in the early part of the season, when the new grass begins rapidly to sprout. Here, still more decidedly than with the lamb, the sheep proprietor is urged not too suddenly to interfere with a natural or perhaps beneficial discharge; and after which the animal often rapidly gains condition. Four and twenty hours should pass before any decisive step is taken; but if the looseness then continues the sheep should be removed to shorter and dryer pasture, and hay should be offered to them, if, after having tasted of the fresh grass of spring, they can be induced to touch it. If the looseness does not abate, then adopt the treatment recommended."

With the writer's flock, diarrhcea rarely occurs with lambs when suckling the ewes; it is at an after age, generally during their first winter, and early in the following spring, when they commence nipping the young grass.

The disease originates under the following circumstances:

First: Too sudden a change from dry to green food. Therefore, as has already been remarked in a previous part of this work, when the foddering season is about to expire, the flock should not be allowed to go wholly to grass, but permitted to eat only a little each day for a week or more; then the sheep may be placed on their pastures permanently, with impunity.

Second: Salting freely too early in the spring, while the grass is young and flashy.

Third: When beginning to feed grain, giving it in too 
large quantities. It should be fed moderately at first, and the quantity gradually increased.

Fourth: Feeding unripe hay. This is not generally. known as an inducing cause of scours; but the compiler knows it to be so from sad experience, and the fact has been repeatedly confirmed by the experience of farmers living in the vicinity of his residence. In this country, it is probably the most prominent cause of the disease.

Fifth: Exposure to sudden transitions of weather; shel ters are therefore needed as a preventive.

Sixth : Eating of irritating weeds ; the flock in this case cannot be removed too quickly to another field, and salted.

Diarrhcea can be easily arrested, by mixing a small quan. tity of pulverized alum in wheat bran, and fed for a day or two. If this should, not succeed, there is a tendency to dysentery, and a purgative of castor oil (a table-spocnful) should be administered, accompanied with dry food, and little drink. .. The reader is also referred to Mr. Youatt's recipe, already stated. A decoction of hemlock bark, after boiling, is a powerful astringent, and has been used with success.

\section{ACUTE DROPSY, OR RED WATER.}

Red water is a common disease in American flocks. Sheep that are destroyed by it present no premonitory symptoms of any disease whatever; the shepherd leaves his flock at night after a minute examination, and on his return in the morning, a sheep will be found dead, lying nearly in the usual posture, the legs bent under them, and the head protruded. Apparently there has not been any severe struggle, and on examination the belly contains a greater or less quantity of bloody fluid. Often a change of pasture, especially from a dry to a cold one, and especially if accompanied with white frost, will induce the disease, which originates in excessive inflammation of the enveloping membrane of the intestines. The animal becomes chilled by this sudden change of situation. The belly, coming most in contact with the damp and cold ground, is first affected; the peritoneal coat of the intestines becomes chilled-reaction, inflammation, soon follows-its natural function, the secretion of a fluid to lubricate the cavity of the belly, is morbidly and strangely increased-the fluid accumulates, and it is red and bloody from the rupture of the small vessels of the periton 
eum distended by inflammation. The inflammation pursues. its course with almost incredible rapidity, and the animal soon dies.

\section{DYSENTERY。*}

The careless observer would not always mark the difference between diarrhcea and dysentery; they are, however, perfectly distinct in their seat, their nature, and their consequences. Diarrhoea is often an effort of nature to expel from the intestinal canal something that offends. It may be only increased peristaltic action of the bowels, increased secretion from the mucous glands, and accompanied by little inflammation and less danger. It is, at first, an affection ot the small intestines alone; but it may extend through the whole alimentary canal, and inflammation, which is not a necessary part of it, appearing and increasing, general fever may be excited, attended by considerable danger. Dysentery is essentially inflammation of the large intestines-the result of neglected or obstinate diarrhœa, or altogether distinct from it-the consequence of unwholesome food-of being pastured on wet or ill-drained meadows-and of being half starved even there. Fever. is a constant attendant on it in its early stages, and wasting and debility rapidly follow.

The discharge of dysentery is different from that of diarrhcea. It is thinner, and yet more adhesive. A great deal of mucus mingles with it, which causes it to cling to the tail and the thighs; and there it accumulates, layer after layer -a nuisance to the animal, a warning to the owner of mucb danger, and that near at hand. When this kind of evacuation has been established but a little while, the next warning will be a loss of flesh, and that to an extent that would scarcely be deemed credible. Sometimes the animal eats as heartily as ever; at other times the appetite utterly fails. Dysentery occasionally earries off its victim in a few days; but frequently will live five or six weeks.

It is only lately that the proper treatment of this malady has been recognized. In every case of acute dysentery, and whenever fever is present, bleeding is indispensably requisite; for this is a disease of inflammation. Physic should likewise be administered, however profuse the discharge may be ; for it may carry away some of that perilous stuff which has accumulated in the large intestines, and is a

- By Youatt. 
source of fearful irritation there, and it will lessen the general fever which accompanies this stage of the malady. The sheep must be removed, and its food changed. Mashes, gruel, and a small quantity of hay, must be given.

Two doses of physic must be administered, and then re. course must be had to astringents.

The purging medicines must not be discontinued, until there is a perceptible alteration in the stools; the dọses, as a general rule, should be small, and given for several days.

The sheep must not be turned on the same pasture from which it was taken; let it be a dryer one.

\section{POISON.}

Sheep and calves will often, in the winter or spring of the year, eat greedily of the low Laurel (Kalmia Angustifolia). The animal appears to be dull and stupid; swells a little, and is constantly gulping up a greenish fluid which it swallows down; a part of it will trickle out of its mouth, and discolor its lips.

The plant probably brings on a fermentation in the stomach, and Nature endeavors to throw off the poison herb by retching or vomiting.

Treatment.-In the early stages, if the greenish fluid be suffered to escape from the stomach, the animal most generally recovers. To effect this, gag the sheep, which may be done in this manner. Take a stick of the size of your wrist and six inches long,-place it in the animal's mouth; tie a string to one end of it, pass it over the head and down to the other end, and there make it fast. The fluid will then run from the mouth as fast as thrown up from the stomach. In addition to this, give roasted onions and sweetened milk freely.*

130

DISEASES OF THE LUNGS, LIVER, AND KIDNEY.

\section{ANATOMY OF THE LIVER. $\dagger$}

It seems to be a law of comparative anatomy that the bulk of the liver shall be in an inverse proportion to that of the lungs. In the horse the lungs are necessarily capacious. He needs a large supply of arterial blood in order to answer

- Northern Shepherd.

+ By Youat 
to its rapid expenditure when the utmost exertion of strength and speed are required from him. In the ox the lungs are less developed; yet this animal is used in some countries as a beast of burden, and employed in Great Britain in agricultural labor; the lungs, therefore, are of considerable size, and the liver, although much larger than in the horse, is restricted in its growth. In sheep little exertion of strength or speed is required; and the lungs are smaller compared with the size of the animal. The liver is proportionally larger: it is about one twentieth part of the whole weight of the animal, or nearly double the proportionate size which it is in the human being.

The liver of the sheep differs little in form and situation from that of the ox. It is placed in the anterior part of the abdomen, between the maniplus and the diaphragm. It has but two principal lobes, separated by a triangular scissure, through which, in the pregnant ewe, the umbilical vein of the foetus passes. Its office is to receive the blood that is returned from the intestines; to separate from the blood, or to secrete by means of it, a fluid termed bile, and to transmit the remaining part to the lungs, there to undergo the usual process of purifaction, and be changed to arterial blood. The ressel to which the bile is first conveyed is the gallbladder; where it is stored up for future use, and perhaps undergoes some change. From the gall-bladder it is conveyed to the first intestine, the duodenum, either in a constant but slow stream, or probably in a larger stream while the work of digestion is going on; the supply from the gall bladder, and probably the secretion from the liver, being stopped at other times. A little before this duct reaches the intestine, it is joined and perforated by the duct from the pancreas. The fluid from the pancreas is mixed with that from the liver, and the compound flows on to the duodenum."

\section{ROT.}

This disease is classed among those of the liver, because, except when the animal dies perfectly worn out by the malady, the most striking and the supposed characteristic mischief is found in this organ.

Happily for the American farmers, this destructive malady is, comparatively, of unfrequent occurrence in their flocks ; but in Great Britain, on the authority of Mr. Youat, 
more than a million of sheep and lambs die every year by this disease. "In the wirter of 1830-31 this number was more than doubled; and had the pestilence committed the same ravages throughout the kingdom which it did in a few of the middle, eastern, and southern counties, the breed of sheep would have been, in a manner, extirpated." Many of the farmers lost their entire flocks, not an individual sheep escaping.

It appears, however, the disease is not peculiar to England. Many sheep are destroyed by it in Germany. In the north of France they are frequently swept away by it; and in the winter of 1809 the ravages were terrific throughout the kingdom. It has prevailed at some periods nearly over all Europe, as far north as Norway.

The compiler has no personal knowledge of this destructive malady, and is therefore compelled to rely on the account presented by Mr. Youatt, all of which that is of interest is subjoined.

"The early symptoms of this disease are exceedingly obscure; this is much to be deplored, because in the first stage of it alone does it often admit of cure. The animal is dull, lagging behind his companions-he does not feed so well as usual. If suspicion has been a little excited by this, the truth of the matter may easily be put to the test, for if the wool is parted, and especially about the brisket, the skin will have a pale yellow hue.

"The eye of the sheep beginning to sicken with the rot can never be mistaken; it is injected, but pale; the small veins at the corner of the eye are turgid, but they are filled with yellow serous fluid, and not with blood. Farmers very properly pay great attention to this in their examination or purchase of sheep. If the caruncle is red, they have a proof which never fails them that the animal is healthy. There is no loss of condition, but quite the contrary, for the sheep in the early stage of the rot has a great propensity to fatten. Mr. Bakewell was aware of this, for he used to overflow certain of his pastures, and when the water was run off turn those of his sheep there which he wanted to prepare for the market. They speedily became rotted, and in the early stage of the rot they accumulated flesh and fat with wonderful rapidity. By this manceuvre he used to gain five or six weeks on his neighbors.

"As the disease becomes confirmed the yellow tinge be- 
gins to spread-the muzzle and the tongue are stained-the animal is more dull and dispirited-his false condition rapidly disappears-the membrane of the nose becomes lividthe tongue gradually assumes the same character-the eyes are dull, and their vessels charged with a yellow-brown fluid. The breath now becomes fetid-the bowels variable - sometimes costive, and at other times loose to a degree that defies the power of medicine. The skin often becomes - spotted with yellow or black-the emaciation is more and more rapid-the general fever increases-the vessels of the eye are more distended and red-the skin becomes loose and flabby, and if it is pressed upon, a peculiar crackling sound is heard-the wool comes off when pulled with the slightest force-the appetite entirely fails-the belly begins to enlarge-on pressure fluid is easily recognized within it, and hence one of its names 'the hydropic' or dropsical rot. The animal is weak in every limb-a violent purging is now very frequently present-the sheep wastes away to a mere skeleton, and at length he dies-the duration of the disease being from two to four or six months.

"When a rotted sheep is examined after death, the whole cellular tissue is found to be infiltrated, and a yellow serous fluid everywhere follows the knife. The muscles are soft and flabby; they have the appearance of being macerated. The kidneys are pale, flaccid, and infiltrated. The belly is frequently filled with water, or purulent matter; the peritoneum is everywhere thickened; and the bowels adhere together by means of an unnatural growth. The heart is enlarged and softened, and the lungs are filled with tubercles. The principal alterations of structure are in the liver. It is pale, livid, and broken down with the slightest pressure; and on being boiled it will almost dissolve away. When the liver is not pale, it is often curiously spotted. In some cases it is speckled like the back of a toad. Nevertheless, some parts of it are hard and scirrhous; others are ulcerated, and the biliary ducts are filled with flukes. Here is the decided seat of the disease, and it is here that the nature of the malady may be learned. It is inflammation of the liver. In consequence of this the secretion from the liver is increased-at first scarcely vitiated, and the digestive powers are rendered more energetic; but soon the bile flows so abundantly that it is taken into the system, and the eye, the brisket, the mouth, become yellow. As the disease 
proceeds, the liver becomes disorganized, and its secretion more vitiated, and even poisonous; and then foliows a total derangement of the digestive powers.

The liver attracts the principal attention of the examiner; it displays the evident effects of acute and destructive inflammation; and still more plainly the ravages of the parasites with which its ducts are crowded. Here is plainly the original seat of the disease; the centre whence a destructive influence spreads on every side. Whatever else is found, it is the consequence of previous mischief existing here. Then the first inquiry is a very limited one-the nature of this hepatic affection, and the agency of the parasites that inhabit the liver. Are they the cause or consequence of disease?

The Fluke-the Fasciola of Linnæus-the Distoma hepaticum of Rodolphi-is found in the biliary ducts of the sheep, the goat, the deer, the ox, the horse, the ass, the hog, the dog, the rabbit, and various other animals, and even in the human being. It is from three-quarters of an inch to an inch and a quarter in length, and from one-third to half an inch in greatest breadth. The head is of a pointed form, round above, and flat beneath ; and the mouth opens laterally instead of vertically. There are no barbs or tenacula, as described by some authors. The eyes are placed on the most prominent part of the head. No difference of sex has yet been discovered in the fluke-worm, and it is believed to be an hermaphrodite.

Then, is the fluke-worm the cause or the effect of the rot? To a certain degree both. They aggravate the disease ; they perpetuate a state of irritability and disorganization, which must necessarily undermine the strength of any animal; they unnaturally distend, and consequently weaken the passages in which they are found; they force themselves into the smaller passages, and, always swimming against the stream, they obstruct the flow of the bile, and produce inflammation by its accumulation; they consume the nutritive juices by which the neighboring parts should be fed; and they impede the flow of the bile into the intestines, by clogging up the ducts with their excrement and their spawn. Notwithstanding all this, however, if the fluke follows the analogy of other entozoa and parasites, it is the effect and not the cause of the rot. The ova are continually swallowed by the sound animals and the dis- 
eased; but it is only when the fluids are altered, and sometimes essentially changed, and the condition of the digestive organs is materially impaired, that their appearance is favored, or their multiplication encouraged.

WHAT, THEN, IS THE CAUSE OF THE ROT IN SHEEP?

The knowledge of the cause can alone guide us to a cure, or at best to the prevention of it. It does not arise from deficiency of food; a sheep may be reduced to the lowest state of condition-he may be starved outright, but the liver would not be necessarily as often in a diseased state. It is not to be traced to the effects of sudden flush of grass. The determination of blood to the head, diarrhoea, dysentery, might be thus produced, but not one symptom resembling rot. Some persons, led away by a favorite theory, have traced it to defective ventilation; but in the closest keeping to which the British sheep is usually committed there is no foul air to be got rid of, and defective ventilation would be words without meaning.

The rot in sheep is evidently connected with the soil or state of the pasture. It is confined to wet seasons, or to the feeding on ground moist and marshy at all seasons. It has reference to the evaporation of water, and to the presence and decomposition of moist vegetable matter. It is rarely or almost never seen on dry or sandy soils and in dry seasons. In the same farm there are certain fields on which no sheep can be turned with impunity. There are others that seldom or never give the rot.

Some seasons are far more favorable to the development of the rot than others, and there is no manner of doubt as to the character of the seasons. After a rainy summer, or a moist autumn, or during a wet winter, the rot destroys like a pestilence. A return and a continuance of dry weather materially arrests its murderous progress. It is, therefore, sufficiently plain that the rot depends upon, or is caused by the existence of moisture. A rainy season, and a tenacious soil, are fruitful or inevitable sources of it.

But there is something more than moisture necessary for the production of rot. The ground must be wet, and its surface exposed to the air ; and then the plants, previously weakened or destroyed by the moisture, will be decomposed; and, in that decomposition, certain gases or miasmata will 
be developed, that cannot long be breathed, or scarcely breathed at all, by the sheep without producing the rot.

Chemistry, even in its present advanced state, will afford no means of analyzing these deleterious gases; and it is a matter of little practical consequence to be acquainted with their constituent principles. ***** Then the mode of prevention consists in altering the character of as much of the dangerous ground as he can, and keeping his sheep from those pastures which defy all his attempts to improve them.

Treatment.-In the early stage of the disease, bleed. Abstract, according to the circumstances of the case, eight, ten, or twelve ounces of blood. There is no disease of an inflammatory character, at its commencement, which is not benefited by an early bleeding. To this let a dose of physic succeed-two or three ounces of Epsom salts; and to these means let a change of diet be immediately added-good hay in the field, and hay, straw, or chaff in the straw-yard.

To this should be added-a simple and a cheap medicine, but that which is the sheet anchor of the practitioner herecommon salt. **** 红矛 The farmer is beginning to be aware of the valuable properties of salt in promoting the condition, and relieving and preventing many of the diseases of all the domesticated animals. In the first place, it is a purgative, inferior to few, when given in a full dose; and it is a tonic as well as purgative. Its first power is exerted on the digestive organs - on the stomach and intestinesaugmenting the secretions and quickening the energies of each. It is the stimulus which Nature herself points out, for, in moderate quantities and mingled with the food, men and beasts are fond of it. The sheep, having a little recovered from the disease, should still continue on the best and dryest pasture on the farm, and should always have salt within their reach. It should be rock salt.

\section{INFLAMMATION OF THE LUNGS.}

This is by no means an unfrequent disease among sheep. It is caused by cold and wet pasture-chills after hard driving-washing before shearing, when the water is at too low a temperature-shearing when the weather is too chilly and wet, and other circumstances of a similar description. Its first indication is that of fever-hard and quick pulse-disinclination for food-ceasing to chew the cud-unwillingness to move-slight heaving of the flanks, and a frequent 
and painful cough. The lisease soon assumes a more aggravaited form, but further description will be useless: it is sufficient for the farmer to know the first stages of the mala$\mathrm{dy}$, and then pursue that course of treatment which experience determines as best.

Treatment.-Bleed and purge freely, and secure the sheep in some comfortable place, free from all exposure to the vicissitudes of the weather. Let no irritating food be given. Mashes of wheat bran will be found excellent, with a little salt occasionally.

DROPSY.

This disease is induced by long exposure to cold and wet weather. Tapping is condemned by Blacklock, unless performed by a skilful veterinary. The best plan is to bleed freely, and give two or three doses of Epsom salts. It is better, however, in general, to kill the sheep at once, as. rarely a permanent cure can be effected.

\section{DISEASES OF PARTURITION.}

\section{ABORTION.}

This disease is not so common as in cows, but sometimes occurs very extensively in flocks of sheep. Ewes are liable to it through every stage of pregnancy ; but generally it occurs when they are about half-gone. The causes are variious :- sudden fright, jumping over ditches and whatnot, worried by dogs, and the too free use of salt; but the prominent cause is the unlimited use of turnips and succulent food.

The symptoms, according to Spooner, first manifested, are dulness and refusal to feed; the ewe will be seen moping at a corner of the fold, and will be heard to bleat more than usual. To these succeed restlessness, and often trembling: with slight labor pains; and in the course of twelve hours abortion will have taken place. Sometimes the parts will be so relaxed, that the uterus or vagina will become inverted, and the expulsion of the Flacenta will precede that of the foetus.

Mr. Spooner recommends placing the ewe in a dry situa- 
tion, as soon as her situation is discovered, and the follow ing medicine may be given with some nourishing gruel:

$$
\begin{aligned}
& \text { Epsom salts - - - - - - } \frac{1}{2} \text { ounce. } \\
& \text { Tincture of opium - - - } 1 \text { drachm. } \\
& \text { Powdered camphor - - - } \frac{1}{2} \text { do. }
\end{aligned}
$$

The two latter medicines may be repeated the following day, but not the salts, unless the bowels are confined.

\section{INVERSION OF THE UTERUS.}

Though this occasionally takes place in the ewe at any period, from sudden severe exertion or straining hard, yet it is most frequent immediately or very shortly after parturition. In this case it arises from the violent spasmodic action of the womb, which turns inside out, and protrudes out of the sheep.

No time should be lost in replacing it. The ewe must be placed on her back, with her hind feet elevated; and the hands being lubricated with oil or lard, the uterus should be gently forced back into its natural situation. Twenty to thirty drops of the tincture of opium should be given in a pint of gruel, and the ewe kept perfectly quiet.

\section{GARGET.}

This is inflammatory affection of the ủdder, caused sometimes by constitutional derangement, but generally by the death of the lamb, and the milk of the udder becoming coagulated.

An ounce or two of Epsom salts, with a drachm of ginger, should be given the ewe, dissolved in warm water; let the udder be fomented with water as hot as it can be borne. The fomentation, if necessary, should be repeated, and then camphor ointment rubbed upon it twice a day. If the swelling continues, and matter forms, it, should at once be opened by an incision, and the puss pressed out. If the smell is very offensive, it should be syringed with a weak solution of chloride of lime for several days.

\section{THE INTEGUMENT, OR SKIN.*}

The skin of the sheep, although composed, like that of other animals, of the cuticle, the subjacent mucous tissue and the true skin, differs materially from that of most of them in 
some of its functions. It is exceedingly deficient both in the powers of secretion and absorption; or rather there are circumstances about it which materially limit the action of these functions ; and, as it were, confine the office of the skin to the production and the support of the fleece. It is surrounded by a peculiar secretion, adhesive and impenetrable to moisture-the yolk-destined chiefly to preserve the wool in a soft, pliable, and healthy state.

There can be little cutaneous perspiration going forward from the skin of the sheep, and there are consequently few diseases that are referrible to change in this excretion; and, on the other hand, little or no advantage can be derived from an increase of it, as indicating a salutary direction of the fluids, or relieving other and dangerously-congested parts. There is likewise less expenditure or radiation of animal heat, both on account of the interposition of the yolk, and the non-conducting power of the wool. The caloric disengaged from the sheep is about the seventh part of that of a man. This is a wise and kind provision of nature, well explaining the means by which the animal is enabled to endure many hardships from vicissitudes of weather.

\section{DISEASES OF THE SKIN.}

\section{Scab, Erysipelas, Johnswort-scab, Pelt-rot, Sore Mouth, Maggots.}

SCAB, OR ITCH.

This disease of the skin is exceedingly common among sheep almost all over the civilized world. According to Mr. Youatt, there are several varieties of it. "A sheep is occasionally observed to scratch himself in the most furious manner, and with scarcely a moment's intermission. He rubs timself against every projection of the fence, and of every post, and the wool comes off from him in considerable flakes. When he is caught there is no appearance whatever of cutaneous disease." Mr. Young says, that "the sheep rub themselves in all attitudes-they have clear skins without the least sign of scab-never observed that it was catching-and the better the food the worse they become."

Treatment.-The sheep should be caught and housed, shorn as closely as possible, washed all over, and most care 
fully, with soap and water; and after that, on the second day, with a wash of lime-water and tobacco decoction, of equal parts.

The ordinary scab in sheep is much akin to the mange in other animals. It is most common in the spring and early part of the summer. It may be produced by a variety of causes, such as bad keep, and exposure to cold and wet weather; thus producing suppression of the perspiration. The pre vailing cause, however, is contagion.

Symptoms.-The sheep is restless-scratching and nibbling itself, and tearing off the wool. When closely examined, the skin will be found to be red and rough. Numerous pustules have broken and run together, and form small or large patches of crust or $s c a b$-hence the name of the disease. The shoulders and the back, most frequently, earliest exhibit these pustules. The general health of the animal is affected according to the extent and virulemce of the eruption ; sometimes he pines away and dies, exhausted by continued irritation and suffering. It is a most contagious disease. If it is once introduced into a flock, the farmer may be assured that, unless the diseased sheep are immediately removed, the whole of his flock will become infected.

It seems to spread among the sheep, not so much by direct contact as by means of the rubbing-places; for it has happened, that when a farmer has got rid of his tainted flock, and covered his pastures with a new one, the disease has broken out again; and this has arisen from contact of the sheep with the old scratching places of fences, trees, and so forth.

"After it was found that the itch in the human race was caused by an insect, a species of Acarus, it was supposed that similar cutaneous diseases in animals might arise from the same source. . M. Walz, a German, was the first to establish this point and fully investigate its character, and numerous subsequent examinations have proved the correctness of his opinions. He found that the scab, like the itch, mange, \&c., is caused by animalcula; that the irritation caused by his burrowing in the skin, forms the pustule, and that when this breaks, the acarus leaves his habitation and travels to another part of the skin, and thus extends the disease. When one of these acari is placed on the wool of a sound animal, they quickly travel to its roots, where the place of burying themselves is shown by a minute red point. About the sixteenth day the pimple or pustule breaks, and if the acari is 
a female it appears with a multitude of young. These immediately set to work on the skin, bury themselves and propagate until the poor animal is irritated to death, or becomes incrusted with scab. M. Walz satisfactorily traced the parasite through all its changes, and by experiment discovered its mode of action, and method of infection. He found that when the male acari was placed on a sheep it burrowed, the pustule was formed, but the itching and scab soon disappeared without the employment of any remedy. Such was not the case where the female acari was placed on the sound skin ; as with the breaking of the pustule from eight to fifteen little ones made their appearance. M. Walz found that the young acari kept in a dry place, dried and crumbled to dust; but when old, that it would retain its life through the whole winter; thus proving the necessity of not relying on the season for their destruction, but on preparations of active medicine when the disease shows itself. Of the origin of these insects, we of course can know nothing; it is enough that we are certain when they make their appearance they can be met and destroyed."-(Cultivator.)
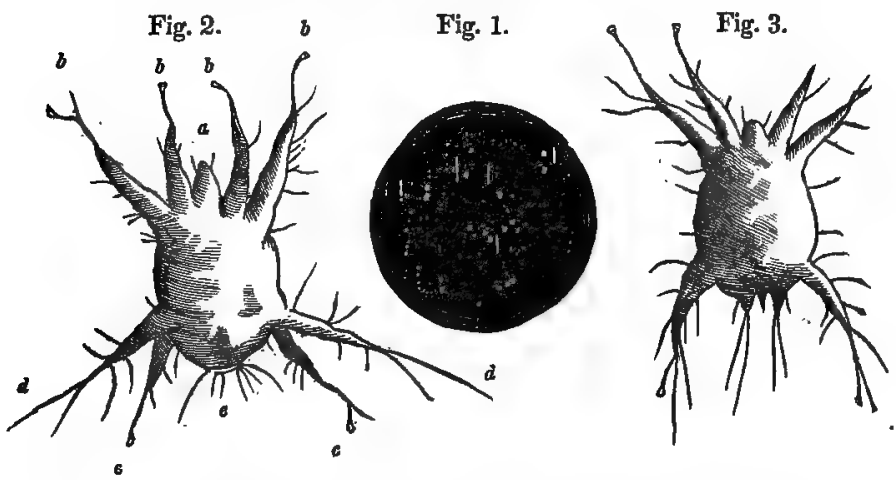

Fig 1. The insects of their natural size on a dark ground.

Fig. 2. The female, of 366 times the natural size, larger than the male, of an oval form, and provided with eight feet, four before and four behind.

a. The sucker.

b. b. b. b. The four anterior feet with their trampet-like àppendices.

c. c. The two interior hind-feet.

c. c. The two interior hind-feet. long hairs, and on other parts of the legs are shorter hairs. To these hairs the young ones adhere when they first appear from the pustale.

e. The tail, containing the anus and valva, garnished by some short halrs.

Fig. 3. The male on his back, and seen by the same magnifying power. 
Treatment.-Shear off the wool about the pustules, then let the scab be removed with knife or comb: after which the diseased parts must be washed with soap and water; then apply the following mixture :-One $\mathrm{lb}$. of plug tobacco to four gallons of water, which should be thoroughly boiled; then add the same quantity of lime-water with one pint of spirits of turpentine.

Another recipe. A decoction of hellebore, mixed with vinegar, sulphur, and spirits of turpentine.

The "Mountain Shepherd's Manual" recommends the following :

Corrosive sublimate -
White hellebore in powder

The sublimate is to be reduced to a fine powder, and mixed with a portion of oil, and also the hellebore. The rosin, tallow, and remainder of the oil are to be melted together, and the other ingredients then added and well mix. ed. Should the ointment appear too thin, the proportion o oil may be reduced, and that of the tallow increased."

Many years ago the first recipe was used in the writer's flock, with entire success. The best recipe, however, is in the shape of a preventive, namely, warm shelters for the flock during winter, and wholesome and nutritious food the year round. A poor sheep will always be the first to suffer from this loathsome disease.

\section{ERYSIPELAS.}

The appearance of this disorder is that of a red inflammatory thickening of the skin breaking out into a fine eruption frequently watery, attended with fever and heat. It attacks most generally those sheep which are in the best condition, and has sometimes proved very fatal, it being a disease which does not run long before it kills the animal.

Examination after death generally shows an inflammation of the stomach, kidneys, intestines, or the neck of the bladder, which may be brought on by feeding on too succulent foud.

Treatment.-A change of diet is recommended, and cool. ing purgative medicines administered freely. The follow 
ing prescription has been used with success :-Epsom salts, six ounces ; nitre, four ounces; boiling water, three pints: pour the water upon the salts, and when about blood warm, add four ounces of spirits of turpentine-give from three to four table-spoonfuls at a dose, once or twice per day, according to the severity of the disease.*

\section{JOHNSWORT SCAB, OR ITCH.}

That pestiferous weed, called Johnswort, if growing abunlantly where sheep are pastured, will cause an irritation of the skin, often over the whole body and legs of the sheep; but generally it is confined to the neighborhood of the mouth. If eaten in too large quantities, it produces violent inflammation of the bowels, and is frequently fatal to lambs, and sometimes to adults. Its effects when inflammation is produced internally are very singular. The writer has witnessed the most fantastic capers of sheep in this situation, and once a lamb, while running, described a circle with all the precision of a circus horse : this was continued until it fell from exhaustion.

Treatment.-Anoint the irritated parts with hog's lard and sulphur. If there are symptoms of inflammation of the stomach, administer tar-putting it into the mouth of the sheep with a flattened stick. Simply hog's lard is used frequently with success. Remove the flock to pasture free from the.weed, and salt freely. It is said that salt, if given often to sheep, is an effectual guard against the poisonous properties of the weed.

\section{PELT-ROT.}

This is a disease of the skin, as the name implies. It causes a premature falling off of the fleece in the spring of the year.

It is produced by exposure during the winter, and low condition-the latter principally.

Preventive.-Grood shelters and good keep. Let the wool fluids be kept healthy and abundant, and there will be no danger of any attack from this disease.

SORE MOUTH.

This is supposed by some to be caused by sheep eating, in the winter season, noxious weeds, for it is that period of 
the year generally that they are most subject to it. A correspondent of the Cultivator thus speaks concerning it: "It generally commenced in one corner of the mouth and spread over both lips, and the lips swelled to the thickness of a man's hand. My flock consisted of about 300, and in the space of three weeks, about forty died of the distemper, and not one had recovered. By this time at least one half of the remainder of the flock were attacked. It occurred to me that tar would be as likely as anything to give relief. I accordingly had my sheep all brought together; and filled their mouths, and daubed on to their lips all that could be made to stick; and, to my surprise, it effected an immediate cure. I lost but two or three after this, and these were nearly dead when I made the application. In a few days, every sheep was well."

The writer, a few years since, had a few of his sheep affected in a similar way, and inasmuch as it was confinel to but one flock, he attributed it to irritating weeds cut with the hay. The application of tar to their mouths was made, as described above, which effected an immediate cure Hog's lard and sulphur will also cure the disorder.

MAGGOTS.

Sheep in the spring are subject to scours or diarrhœa, which causes an accumulation of filth about the tail and attracts the maggot-fly ; and again-rams by fighting will often lacerate the skin around the forehead, which will also invite the approach of the fly. If maggots are at work about the tail, the sheep will be seen biting it, and rubbing against fences and whatnot; and the ram to shake his head almost constantly, and also rubbing against every object that presents itself.

Treatment.-Dislodge the worms with a knife, and apply spirits of turpentine. If they have penetrated far into the skin, hold the sheep in such a position as to retain the liquid for a minute or more in the affected part. By so doing the maggot will crawl out and perish instantly. Sheep cannot be too closely watched before they are shorn, otherwise some will be destroyed from the above cause.

Sheep Louse (Hippobosca ovina) and the Tick (Acarus reduvius) are destroyed by tobacco decoction. For particulars, see "Summer Manägement of Sheep." 


\section{DISEASES OF THE HOOF.}

\section{FOOT-ROT.}

This common scourge of the sheep, through all parts of the United States, requires an extended notice of the causes, and the most approved treatment. The compiler has had no personal observation of this loathsome malady, other than from seeing it in flocks away from his home, not a sheep of his own ever having been attacked with it. For this reason, he is compelled to rely on the scientific accounts of Mr. Youatt, and of Professor Dick of Edinburgh, as to the causes, and to intelligent sheep-breeders of our own country, for its treatment.

Mr. Youatt proceeds to say,- "Foot-rot is a disease at first, and usually throughout its whole course, confined to the foot. 'The first indication of foot-rot is a certain degree of lameness in the animal. If he is caught and examined, the foot will be found hot and tender, the horn softer than usual, and there will be enlargement about the coronet, and slight separation of the hoof from it, with portions of the horn torn away, and ulcers formed below, and a discharge of thin fetid matter. The ulcers, if neglected, continue to increase; they throw out fungous granulations, they separate the hoof more and more from the parts beneath, until at length it drops off. All this is the consequence of soft and marshy pasture. The mountain or the Down sheep-the sheep in whose walk there is no poachy ground, if he is not actually exposed to infection by means of the virus, knows nothing at all about it; it is in the yielding soil of the low country that all the mischief is done."

The following is from the pen of Professor Dick :-

"The foot presents a structure and arrangement of parts well adapted to the natural habits of the animial. It is divided into two digits or toes, which are shod with a hoof composed of different parts, similar in many respects to the noof of the horse. Each hoof is principally composed of the crust, or wall, and the sole. 'The crust, extending along the outside of the foot, round the toe, and turning inwards, is continued about half way back between each toe on the inside. The sole fills the space on the inferior surface of the hoof between these parts of the crust, and being contin: ued backwards becomes softer as it proceeds, assuming 
somewhat the structure of the substance of the frog in the foot of the horse, and performing, at the same time, analogous functions. ' The. whole hoof, too, is secreted from the vascular tissue underneath.

"Now this diversity of structure is for particular purposes. The crust, like that in the hoof of the horse, being harder and tougher than the sole, keeps up a sharp edge on the outer margin, and is mainly intended to resist the wear-andtear to which the foot of the animal is exposed. The soft - pasturage on which the. sheep is occasionally put presents little, if any, of that rough friction to which the feet of the animal is naturally intended to be exposed. The crust, therefore, grows unrestrained, until it either laps over the sole, Jike the loose sole of an old shoe, and serves to retain and accumulate the earth and filth, or is broken off in detached parts ; in some cases exposing the quick, or opening new pores, into which particles of earth or sand force their way, until, reaching the quick, an inflammation is set up, which, in its progress, alters or destroys the whole foot.

"The finest and richest old pastures and lawns are particularly liable to this disease, and so are soft, marshy, and luxuriant meadows. It exists to a greater or less extent in every situation that has a tendency to increase the growth of the hoofs without wearing them away.

"Sheep that are brought from an upland range of pasture are more particularly subject to it. This is very easily accounted for. By means of the exercise which the animal was compelled to take on account of the scantier production of the upland pasture, and also in consequence of the greater hardness of the ground, the hoof was worn down as.fast as it grew; but on its new and moist habitation, the hoofs not only continued to grow, but the rapidity of that growth was much increased, while the salutary friction which kept the extension of the foot within bounds was altogether removed. When the nails of the fingers or toes of the human being exceed their proper length, they give him so much uneasiness as to induce him to pare them, or if he neglects this operation they break. He can pare them after they have been broken, and the inconvenience soon ceases, and the wound heals. When, however, the hoof of the sheep exceeds, its natural length and thickness, that animal has no power to pare them down, but there long continues a wound, jrritated and induced to spread, by the exposure of its sur$32^{*}$ 
face, and the introduction of foreign and annoying matters into it.

"The different parts of the hoof, likewise, deprived of their natural wear, grow out of their proper proportions. The crust, especially, grows too long; and the overgrown parts either break off in irregular rents, or by overshooting the sole allow particles of sand and dirt to enter into the pores of the hoof: These particles soon reach the quick, and set up the inflammation already described, and followed by all
its destructive effects.

"The ulceration of foot-rot will not long exist without the additional annoyance of the fly. Maggots will multiply on every part of the surface and burrow in all directions. To this, as may be readily supposed, will be added a great deal of constitutional disturbance. A degree of inflammatory fever is produced. The animal for a while shifts about on its knees ; but at length the powers of nature fail, and it dies from irritation and want."

Treatment.-The following is Mr. Youatt's mode of curing the disease; and it will be well to remember that this gentleman is highly distinguished in England for his eminent skill and knowledge as a veterinary surgeon.

"The foot must be carefully examined, and every portion of loose and detached horn pared off, even though the greater part, or almost the whole of the hoof, may be taken away. The horn once separated from the parts beneath will never again unite with them, but become a foreign body, and a source of pain, inflammation, and fungous sproutings. This, then, is the first and fundamental thing-every portion of horn that is in the slightest degree separated from the parts beneath must be cut away. A small, sharp, curved-pointed knife, or a small d drawing knife, will be the best instrument to effect this.

"If there are any fungous granulations they must be cut down with the knife or a pair of sharp curved scissors, unless they are exceedingly minute, and then the caustic about to be mentioned will destroy them. The whole hoof raust be thoroughly cleaned, although it may occupy no little time, and inflict considerable pain on the animal. 'The after expenditure of time, and the suffering of the patient, will be materially diminished by this decisive measure.

"The foot should then be washed with a solution of chloride of lime, in the proportion of one pound of the powder to 
a gallon of water. This will remove the fetor, and tendency to sloughing and mortification, which are the too frequent attendants on foot-rot. The muriate or butyr of antimony must then be resorted to, and by means of a swab, applied to every denuded part; lightly where the surface has a healthy appearance, and more severely where fungous granulations have been cut off, or there are small granulations springing up. There is no application comparable to this. It is effectual as a superficial caustic ; and it so readily combines with the fluids belonging to the parts to which it is applied, that it quickly becomes diluted, and comparatively powerless, and is incapable of producing any deep or corroding mischief. The change of color in the part will accurately show to what portions it has been applied, and what effect has been produced.

"If the foot has been in a manner stripped of its horn, and especially, if a considerable portion of the sole has been removed, it may be expedient to wrap a little clean tow round the foot, and to bind it tightly down with tape, the sheep being removed to a straw yard, or some enclosed place, or to a dryer pasture. This last provision is absolutely necessary when the sheep is again turned out; for if the foot is exposed to the original cause of disease; the evil will return under an aggravated form.

"The foot should be dressed every day ; each new separation of horn removed; and every portion of fungous submitted to the action of the caustic, with a degree of severity proportioned to the necessity of the case. The new horn should likewise be examined. If it appears to be healthy and tolerably firm, nothing should be done to it; but if it is soft and spongy, the caustic must be lightly applied. The sooner the bandage can be removed, and the sheep turned into some upland or thoroughly dry pasture, the better it will be for the foot, and the health of the animal generally.

"The sheep that has been attacked by foot-rot should not be suffered to rejoin his companions while there is the slightest discharge from any part of the hoof, inasmuch as the disease is highly infectious."

The following recipes for foot-rot have been used successfully by American sheep-breeders:

By Major Grant, of Walpole, N. H. :-4 oz. blue vitriol, 2 oz. verdigris to a junk bottle of urine. The same has been adopted by others with success. 


\section{Another :-Spirits turpentine, tar, and verdigris, in equal parts. \\ Another, by Leonard D. Clift, Esq., of Carmel, Putnam Co.,} N. Y. :-3 quarts of alcohol, 1 pint spirits of turpentine, 1 pint strong vinegar, $1 \mathrm{lb}$. blue vitriol, $1 \mathrm{lb}$. copperas, $1 \frac{\mathrm{l}}{2} \mathrm{lbs}$. verdigris, $1 \mathrm{lb}$. alum, $1 \mathrm{lb}$. saltpetre, pounded fine : $\operatorname{mix}$ in close bottle, shake every day, and let it stand six or eight days before using: also mix 2 lbs. honey and two quarts of tar, which must be applied after the previous compound. Two applications will entirely remove the disease. A correspondent of the Cultivator says, that he used the above with perfect success, while almost every other recipe that he ever heard of, failed.

There are an abundance of other mixtures or compounds which are asserted to be "infallible cures ;" but the question naturally arises, Is not the prevention better than all ? and if so, what is it? A friend of the writer, after having become acquainted with the true cause of the malady, made known by Professor Dick, and which has been fully presented to the reąder, immediately after his sheep are tagged, which is done in April, he pares the horn or crust of the hoof down to a level with the sule, and then applies a mixture of tar-say four quarts, half a pint of spirits of turpentine, and the same quantity of oil of vitriol, using it almost boiling hot. The two latter ingredients are not mixed with the tar all at once, but a little poured in at a time, inasmuch as they are, in a heated state, very evanescent. A small brush is used, and not only the bottom of the hoofs, but the sides and clefts are thoroughly coated. If the season is a wet one, he goes through the same process late in the fall-but not otherwise. By this precaution, although in the district of his residence. foot-rot is common, his sheep know nothing of the disease. This is at least worthy of a trial by all.

One remark more. Foot-rot is contagious beyond all question: and hence necessary care is requisite not to put sound sheep on grounds where infected ones have run; no, not during the spring, summer, or fall-not until' the frosts of winter have utterly destroyed the poison virus which has been left by diseased flocks. The following instance will show this precaution to be indispensably necessary : A farmer of the writer's acquaintance having been sorely plagued with foot-rot in his flock, frequently renewing itself after repeated cures, resolved to slaughter the whole, which was according- 
ly done. Several months afterwards he possessed himself of another flock, which were known never to have been in. fected, nor was the disease known in the vicinity where their purchase was made; and lo! in less than a month after they were brought to their new home, the sheep became diseased like their ill-fated predecessors. Every farmer should deduce a lesson from this not uncommon instance.

Fouxs.

Blacklock says-" Another variety of foot-rot is produced by the friction of long grass between the hoofs.' The rubbing of the grass frets the skin in the cleft of the hoof, the gland in that situatlion swells, becomes enlarged, and suppurates. 'This complaint is, however, more readily remedied than the other, and does not cause nearly so much suffering to the sheep. An application of tar, warmed to a liquid, and a small quantity of spirits of turpentine, will heal the irritation." It is not contagious. 


\section{CHAPTER XVII.}

\section{SURGICAL OBSERVATIONS.*}

WOUNDS-TO STOP BLEEDING-REMOVAL OF EXTRANEOUS MATTER -CLOSURE OF A WOUND-BANDAGING-CLEAN CUTS-PUNCTURED WOUNDS-BRUISES AND SPRAINS-WOUNDS OF JOINTB-FRAC TURES-BLOOD-LETTING.

WOUNDS.

All the wounds which can be inflicted may be classed un der the heads of incised, punctured, and lacerated.

An incised wound is one made by a cutting instrument, such as a knife or piece of glass.

Punctured wounds are those produced by sharp-pointed bodies, such as pins or thorns.

Lacerated wounds are those occasioned by blunt bodies, as the teeth of a dog, tearing rather than cutting the flesh.

Ist. Arrest the bleeding, if profuse, and likely to endanger life.

2d. Clip away the wool for a few inches around the injured part.

3d. Remove dirt or other foreign body from the wound.

\section{TO STOP BLEEDING.}

Bleeding will, if no large arteries are divided, cease on the free exposure of the surface for a few minutes to the air; but when a large vessel has been cut, more determined means must be had recourse to. Pressure on the bleeding surface and its neighborhood will in many cases succeed, but this or any other similar method is far inferior to that of securing the open vessel by a thread. To accomplish this,

* By Blacklock. 
the mouth of the vein or artery must be slightly drawn out from the contiguous surface, by means of a small hook, call. ed by surgeons a tenaculum, and easily procured from any blacksmith. While the mouth of the vessel is thus held exposed, an assistant must surround it with a noose of thread, which, on being secured with a double knot, will effectually close it. The thread ought to be of white silk, though any undyed thread, which is firm, round, and capable of standing a pull, will answer the purpose. Care must be taken to place the thread, before tying it, fairly behind the point of the tenaculum, so as to avoid including the instrument within the ligature-a circumstance which would lead to the slipping of the noose and failure of the operation. The hook is now to be withdrawn, and one end of the ligature cut off by scissors a short distance from the noose. The remaining threads are allowed to hang out of the wound, so as to admit of their removal when they become loose, which does not, however, take place till the termination of the first four days, and they are frequently retained for a longer period. At each time the wound is dressed, after the fourth day, the ligatures should be gently pulled, or, which is preferable, twisted, to disengage them, if at all loose, so that the wound may be more speedily closed. Before proceeding to any operation where bleeding is expected, the operator should provide himself with a few well-waxed threads, each twelve inches long, so that no delay may ensue on a division of large vessels.

\section{REMOVAL OF EXTRANEOUS MATTER.}

Dirt is best removed by washing with a sponge or old linen rag and warm water. Other foreign bodies may in general be extracted by the finger and thumb. In some cases, however, it may be necessary to enlarge the wound with a fine-edged knife, in order to facilitate the removal of substances which, from their shape or situation, cannot be otherwise displaced.

\section{ClOSURE OF A WOUND.}

The last thing to be done is to bring the edges of the wound into as accurate contact as the state of the parts will at the moment permit, without, however, using any force. This, with a little care, is readily accomplished, the only 
difficulty being to retain them in the desired position. They may be held in contact either by stitches, plasters, or bandages, or by a union of the three. Stitches are only required when the wound gapes to a considerable degree, as $i^{\circ}$ will always do when running across a muscle. They may be applied in the following manner. Transfix one side of the wound with a curved needle with a well-waxed thread, forcing the needle from without obliquely toward's the bottom of the wound, then carry it through the opposite side from within, taking care to bring it out about the same distance from the edge as that at which it entered on the other margin. The needle must now be removed, by cutting the threads close to its eye, and while the ends are allowed to hang loose. Your assistant will now bring the sides of the wound together as accurately as possible, and retain them there till you have tied the corresponding ends of the threads in a double knot.

\section{BANDAGING.}

Adhesive plaster is in some instances of service, but upon the whole ought rather to be dispensed with, being of difficult application, and moreover tending to the accumulation of filth and the discomfort of the animal. Nothing will be found to serve the purpose of supporting the parts so well as a properly adjusted bandage, which is useful in every instance, and sure to stay on if sewed here and there to the fleece. The bandage should never be omitted where the wound has any tendency to gape, as too great a strain upon the stitches cannot but lead to delay in the healing process. In bandaging a limb or part of a limb, commence always at the foot, and proceed upwards; in other parts of the body, begin where you find it most convenient. Before applying a bandage to a wounded surface, a couple of pieces of old linen or cotton rag should be folded into pads or compresses, and laid one on each side of the cut, and over these the bandage should be rolled, evenly and with moderate and uniform firmness. By this plan the separated surfaces are supported and preserved in close juxtaposition, especially at tho bottom of the wound, a thing of some importance where the cavity is deep. Transverse cuts of the limbs of sheep require more careful and more complicated treatment than cuts in other parts, as there is a constant tendency of the edges to retract. 'This retraction of the edges may be in some de. 
gree obviated by the application of a splint, which may be made of a slip of stiff leather well wetted, so as to be easily adapted to the form of the limb. It is intended to impede the motion of the leg, which occasions the gaping of the wound, and must therefore be made to pass over one or more joints as circumstances may require. A bandage must be placed over to make everything secure,

\section{CLEAN CUTS.}

Clean cuts, as every one knows, heal readily in a healthy animal, seldom demanding above three dressings; lacerations, on the other hand, require a longer period for their reparation, inasmuch as the process which nature goes through is more complicated. In the former, the parts are speedily glued together, so soon almost as in contact, and the union is generally complete within the firgt thirty-six hours. Not so, however, with the latter. Here the parts are bruised, torn, and perhaps to a considerable extent wanting. Some of the bruised portions may die, and are of course to be renewed. This is a process requiring a great effort on the part of the vital powers, which are often inadequate to the task, and on this account we ought, when the injury is severe, to sacrifice the animal rather than run the risk of its dying during the process of the attempted cure. To replace the lost part, suppuration or the formation of matter commences; while under cover of this, a crop of fleshy particles. (granulations) rise to fill the vacancy. Granulations are best promoted by warm emollient applications, such as poultices of oatmeal, linseed meal, or barley. flour, which ought to be frequently renewed to prevent their becoming cold or dry. When the granulations become too luxuriant, and rise, as they are apt to do, above the level of the skin, the poultices must be laid aside, the sore washed once or twice a day with a solution of sulphate of copper; (made by dissolving two or three drachms of blue vitriol in a pint of soft water), and covered carefully over with a little fine tow, spread with lard, or any simple ointment, by which means, conjoined with cleanliness, a cure will easily be accomplished.

\section{PUNCTURED WOUNDS.}

The orifice being small in these, and the depth consider able, the sides are apt to adhere irregularly, and prevent the 
free escape of matter, which is certain to collect at the bot tom. To avoid such occurrences, it is in many cases proper to convert a punctured into an incised wound. When, from neglecting this, the matter is denied, an outlet, an incision must be made to allow it to escape, otherwise much harm will ensue from its burrowing between the different textures. Fomentations will also here be serviceable, and should be preferred to poultices. To apply them, place well-boiled hay, when very hot and moist, within a fold of old blanket or woollen cloth, and lay it on the injured parts, taking care to renew the heat frequently, by dipping the bundle in the hot decoction.

\section{BRUISES AND SPRAINS.}

These, unless severe, need not be interfered with. When the shepherd, however, considers it necessary to make an application, he cannot do better than foment the part for an hour or so with meadow hay, in the same manner as recommended for punctured wounds.

\section{WOUNDS OF JOINTS.}

Such wounds are highly dangerous, and apt to baffle the most experienced. If the injury be extensive, the best thing the farmer can do is to slaughter the animal.

\section{FRACTURES.}

If there be no wound of the soft parts, the bone being simply broken, the treatment is extremely easy. Apply a piece of wet leather, taking care to ease the limb when swelling superrenes. When the swelling is considerable, and fever present, you can do no better than open a vein of the head or neck, allowing a quantity of blood to escape, proportioned to the size and condition of the animal and the urgency of the symptoms. Purgatives in such cases should never be neglected. Epsom salts in ounce doses, given either as a gruel or a drench, will be found to answer the purpose well. If the broken bones are kept steady, the cure will be complete in from three to four weeks, the process of reunion always proceeding faster in a young than in an old sheep. Should the soft parts be injured to any extent, or the ends of the bone protruding, recovery is very uncertain, and it will become a question whether it would not be better at once to convert the animal into mutton. 
BLOOD-LETTING.

In describing this operation, too much stress is always laid on the importance of opening particular veins, or divisions of a vein, in certain diseases. Such directions are altogether unnecessary, as it matters not from what part of the animal the blood be drawn, provided it be taken quickly. Nothing tends so much to the recovery of an animal from a disease in which bleeding is required, as the rapid flow of the blood from a large orifice. Little impression can be made on an acute disease by the slow removal of even a large quantity of blood, as the organs have time to accommodate themselves to the loss, which might, for any good it will do, as well be dispensed with. Either bleed rapidly, or bleed not at all. The nearer the commencement of an ailment, in which you employ bleeding, the operation is resorted to, the greater the chance of doing good; no time ought, therefore, to be lost in using the lancet, when once it is known to be required. Bleeding and nicking the under surface of the tail, does very well where no great deal of blood is required, but it is not to be thought of if the veins of the face or neck can possibly be opened. These are to be taken in preference to a vein on the leg, as they are much more readily got at. The facial vein commences by small branches on the side of the face, and runs downwards and backwards to the base of the jaw, where it may be felt within two inches of the angle, or opposite the middle grinding tooth. It is here that the orifice must be made; the thumb of the left hand being held against the vein, so as to prevent the flow of blood towards the heart, will make it rise. Some prefer opening the jugular vein, which commences behind the eye and runs down the side of the neck. This vessel is, however, more difficult to open than the former, being more covered with wool, and not so easily exposed or made to swell. To effect this, a cord is drawn tightly round the neck, close to the shoulder, so as to stop the circulation through the vein, and render it perceptible to the finger. A lancet is the instrument generally used in bleeding, though a sharp-pointed penknife will do at a pinch. The opening must always be made obliquely; but before attempting this the animal must be secured, by placing it between the operator's legs, with its croup against a wall. The selected vein is then fixed by the fingers of the opera- 
tor's left hand, so as to prevent it rolling or slipping before the lancet. Having fairly entered the vein, the point of the instrument must be elevated, at the same time that it is pushed a little forward, by which motion it will be lifted from, or cut its way out of the vein. A prescribed quan tity of blood should never be drawn, for the simple reason, that this can never be precisely stated. If the symptoms are urgent, as in all likelihood they will, your best plan is not to stop the flow of blood till the animal fall or is about to fall. When this occurs, run a pin through the edges of the orifice, and finish by twisting round it a lock of wool. 


\section{A P P E N D IX.}

\section{LETTERS FROM DISTINGUISHED WOOL-GROWERS ON THE MANAGEMENT OF THEIR FLOCKS.}

\section{LETTER FROM HON. WM. JARVIS, WEATHERSFIELD, VERMONT.}

Dear Sir,-I received your favor of the 28th ultimo, making inquiries respecting Merino Sheep, and putting several questions to me regarding those invaluable animals, which $I$ cheerfully answer; and the more so, because at some futrure period, when the wool-growing business may be a primary object of agriculture with the farmers of the Northern and Western States, much confusion may arise from the conflicting pretensions and accounts of many persons who are more disposed to puff up their flocks, than to give the public correct information.

[Mr. Jarvis here alludes to the importation of Chancellor Livingston.]

The" next importation was by Genl. Humphreys when he was about leaving the Court of Spain, in 1801, to give place to the Hon. Charles Pinckney, of South Carolina. It has been stated by some late writer, that Genl. Humphreys married a Spanish lady and obtained a part of his flock by means of her father. This is not correct. Genl. Humphreys married the second daughter of John Buckley, a wealthy British merchant of Lisbon, when he was Chargé at the Court of Portugal, and took her with him to Madrid on his appointment, in 1797, Minister at that Court. The story of his obtaining these sheep is this. It was a custom of the' Spanish Court, when a Foreign Minister was recalled, on taking leave to make him a present of five to ten bars of gold; each bar, if I recollect right, was of one pound weight; but as the law of this country forbids any Minister taking any present from a foreign coutt, Mr. Humphreys declined it, but suggested to the Minister that he should be much gratified with a royal li cense to take out of the kingdom two hundred Merino sheep. This the Minister stated could not be granted, but intimated that if he wished to take them out no obstruction should be thrown in his way. These were purchased in Lower Leon, or Upper Estremdura, and driven down the valley of the Mondego to Figueira, where they were embarked for the United States. I never could 
learn out of what flock these sheep were obtained, but they unquestionably were pure blood Transhumantes, which is the only fact of importance worth knowing. Still, I thought it worth while to go into the above detail, as some late writer has undertaken to give an account of Genl. Humphreys' marriage and the manner of obtaining some of these sheep, very different from the above.* In 1831 and 1832, I made inquiries of some Cannecticut gentlemen about Genl. Humphreys' flock, and they told me that, at his death, they had been sold in small parcels, and distributed about. Many now make a parade of having Paular sheep, and those who have the bump of credulity largely developed on the cranium, may believe it, but I am persuaded that no one in the United States can trace back any Merinos they may have had for the last twenty years to that cabanna or flock. As I have mentioned elsewhere, I bred my Paulars, Aiguerras, Negrettis, Escurials, and Montarcos separately, that is, each kind by itself, from 1811 to 1816 , but in that year I began by mixing all together, and have ever since bred so without discrimination. Although at that early day I had a very extensive intercourse with our breeders, I did not know of another breeder who purchased Merinos of the different flocks imported, that ever took any pains to separate the different kands. So far from it, there was a general opinion pervading the country that crossing the different kinds would improve the wool. Doubtless the reason why we have latterly heard so much puffiing about Paulars is owing to its having been understood that the Paulars carried rather the heaviest fleeces.

From 1811 to 1826, when I began to cross with the Saxonies, my average weight of wool was 3 lbs. $14 \mathrm{oz}$. to $4 \mathrm{lbs}$. $2 \mathrm{oz}$., varying according to the keep. The weight of the bucks was from 5 t lbs. to $6 \frac{1}{2}$ lbs. in good stock case, all washed on the sheeps' backs. My flock now consists of 160 pure blood Merino ewes, bucks, and lambs, 100 pure blood Saxonies, and about 750 crossed between pure blood Merinos and pure blood Saxonies. My flock has always been composed of the descendants of the Merinos I exported in 1809 and '10, and the Saxonies imported in 1826, and the crosses between the two, never having bred from any other kind. The present average weight of my flock as above is about $3 \mathrm{lbs} .4 \mathrm{oz}$. per head, but the pure blood Merino part of it will not vary materially from the original weight.

In reply to your question, whether I consider the Escurial, Montarco, Negretti, Paular, or Gaudaloupe most profitable to the American wool-grower, I reply, that as none of these varieties are now distinct in our country, we cannot have a choice; but when I had a control of the five flocks, namely, the Paular, the

\footnotetext{
* The author of this treatise is personally acquainied with the wool-grower who put forth the statement Mr. Jarvis alludes to, and he has not a doubt but that it was innocently done. It should serve as a caution, however, to others, to beware of going before the public with statements of which they have not proper testmony to sustain. The public is indebted to Mr. Jarvis for the exposure of several errors relative to Merinos.
} 
Aiguerras, the Escurial, the Negretti and Montarco, I thought there was so little difference that I concluded to mix them all together. It is true the Paular was rather the handsomest and carried the heaviest fleece, and the Escurial was a shade the finest; but the wool of all was soft and silky to the touch, and all possessed the felting or fulling properties so essential for superfine broadcloths.

I take up my sheep from the 15th to the 25th of November, according to the weather, and put them in separate yards of a hundred to two hundred in a yard, having a trough supplied by running water from an aqueduct in each yard. I give about a pound and a quarter of hay in the morning, and the same quantity in the afternoon to each sheep, fed in racks. If my hay runs short, and I have a plenty of grain, I lessen my hay and give a gill of corn or a half pint of oats per head, at noon. By feeding in racks in yards, as we have no trouble in driving our sheep to water, one man will feed a thousand sheep, and take care of four to six horses in a stable besides. To every yard there is attached a shed for the sheep to run under whenever they will, and when the shed gets foul it is lightly strawed over. A part of a sill is slightly boxed up and salt kept in it. Potatoes contain much mucilage or starch, and are a good article of food. The sugar beet or mangel wurtzel possesses much saccharine matter, and is likewise nutritious. When hay is scarce, about half may be saved by giving an equal weight of either sliced up in a cutting machine. Rutabaga is also good food, but I think it does not contain more than half the nutriment of either of the foregoing.

My usual yeaning season has been about the first of May, but 1 have sometimes purposely had the lambs come ten days later, sometimes ten days sooner, and the success of either has much depended on the state of the weather. In a lot near to my house where a man has looked after them three or four times a day, and in rainy and stormy weather they have been put under cover at night, I have raised nine lambs from ten ewes; but when turned to pasture without any special care, we generally do not raise more than a lamb to two ewes. But I am satisfied it would amply pay breeders if their pastures were within convenient distances to erect slight shanties in them, and in stormy weather to put their ewes in during the yeaning season. My rule has been to put a buck to twenty-five to thirty-five ewes, according to his strength ; the Spanish rule was one to twenty-five.

Sheep prefer high dry grounds for pasture, but any dry lands will answer well. They are not so healthy when fed on cold, wet, or swampy land, and the foot-rot is undoubtedly occasioned by swampy grounds. As sheep are somewhat nice in the choice of their food, if put in pastures where they can select a sufficiency, I am not aware that the coarse or finer grasses would be likely to have much influence on the quality of their wool. There was a general opinion prevalent amongst the shepherds of Spain, that to 
retain the soft, flexible, and felting properties of the wool, the Merinos must be pastured the year round. But the experience of the Saxons, and of all those countries where the Merinos have been bred, has proved this opinion to be erroneous. If one wac to reason from analogy, we should conclude that the wool grown in a cold climate would be softer than that raised in a warm one, as it is a well known fact that the beaver and all other furred animals, found in high northern latitudes, have longer, softer, and thicker fur than the same species have in southern latitudes, Spain, however, has a mild climate, the thermometer being seldom or never lower than forty degrees in the plains of Estremadura or Leon during the winter, but the excessive heat of those plains in the summer is avoided by pesturing the sheep in the mountainous region. I think this breed of sheep would thrive in the Alleghany range as far south as Georgia, and everywhere north of forty degwes of latitude. But I am inclined to believe, from what little I know of our Western Prairies, that the Leicester or some other of the large, strong, long-wooled breeds of sheep would do better on the tall, coarse grasses common to them.

As connected with sheep management, it will not be improper to point out the remedies for some of the most common diseases. Foot-rot was totally unknown among the Spanish Merinos. It was brought into this country in 1826 with the sheep imported from Saxony. The best remedy for this disease is Roman or blue vitriol, pulverized very fine, three parts, and one part of white lead mixed into a thin paste with linseed oil. Slightly cut the horn of the hoof to come at the part affected, and if put on in season one or two dressings will almost invariably cure them. The foul substances ought to be cleaned out with a knife or thin stick from between the hoof before it is put on. An excellent preventive against the foot-rot is to wash the hoofs clean in strong soap suds made of ordinary soft soap, directly after shearing, as duiring this process their feet get very foul.* The scab, however, was a disorder to which the Spanish Merinos were very subject, if not taken great care of. Sulphur mixed with hog's lard, well rubbed into the part affected, directly after shearing, will cure the disease. Another remedy is boiling tobacco in water till the liquor is pretty strong, put into a hogshead tub, take the fore legs in one hand and the two hind legs in the other, and immerse the sheep except its head for about two minutes, then take a very hard brush or a very fine curry-comb and scrub the hard scab off from the part affected till it appears raw-pour on some tobacco liquor and let the sheep run. One or two dressings will almost invariably cure them; the best time likewise is directly after shearing. If the lambs are immersed, it must be in a much weaker liquor, as, if too strong, it is very pernicious to them. Lambs are often infested with ticks, which are easily destroyed

* This will be avoided by littering the pounds often with straw.-Author Am shepherd. 
by immersing them, about ten days or a fortnight after shearing the ewes, in weak tobacco water. Sheep are sometimes subject. to be blown or bloated, which I believe to be a kind of colic. The remedy is two great spoonfuls of castor oil mixed with a tea-spoonful of pulverized rhubarb, to which add two or three great. spoonfuls of hot water to make it more fluid; open the mouth and put down a spoonful at a time as fast as they can swallow it. It never fails to cure them if given before the sheep has fallen. About half as much more is required for a stout buck, and half the quantity for a lamb. If pulverized rhubarb is not at hand, ground ginger will do, but it is not so certain.

$I$ believe $I$ have now answered all your questions, and shall leave you at liberty to make what use you pleasè of this lețter, or that some time since published in the Cultivator, which I the more readily do, as it affords me great pleasure to aid, in any way, the advancement of this very important branch of American agriculture.

\section{LETTER FROM WM. BROWNLEE, OF WASHINGTON, PENNSYLVANIA}

Dear Sir, -I received your letter informing me of your inten tion of publishing a work on Sheep Husbandry, and desiring my views on the subject. I have been engaged in that business for nearly thitty years, and have at this time a flock numbering about three thousand and five hundred, one half of which is in this county, and the remainder in Lee County, Iowa. I commenced my flock with the full-blooded Merinos, and after some time crossed them with the long-wooled Saxons, which I received from Dutchess County, N. York. My flock at present is chiefly Saxon-blood, and average about three lbs. to the fleece of clean washed wool. I give the preferrence to the Saxonies, as their wool is rather the softest, and free of yolk or eke. The length of time we feed our sheep, and the amount of hay they consume, I cannot well decide, as it greatly depends on the winter, and the quantity of winter pasture that we may have; but generally we have to feed more or less about five months, in which time the sheep eat from six to eight tons of hay to the hundred; but I believe in a close winter, and without much winter pasture, that number will require ten tons. I prefer good clover hay to any other, as they will improve upon it more than other descriptions. I feed but little grain until towards spring, and then make use of oats and com, which I think equally good. But if there are any dousy or poor sheep, I feed them some grain through the whole of the winter. It has not been my practice to feed any roots, although I think them very good.

I have been in the habit of housing my sheep in the winter. The dimensions of my shelters are about sixty or seventy feet in 
length, ard sixteen in width, which are closed on the west side - and open at the east; some are covered with boards, and others with straw.

[The kind of rack Mr. Brownlee uses is the box rack.]

As for pasture, I prefer the prairie grass to any other until towards fall, when it becomes dry, and sheep will not do so well on it as other kinds. The blue grass I think ranks next, but timothy and clover do very well. The prairie grass is not good for hay, in my opinion, it being too binding, and therefore sheep do not thrive upon it so well.

I generally keep from 150 to 200 together summer and winter, unless on the prairies, where I keep one thousand together in the summer, if they have a large district to range over. When we keep our sheep in the fields, I generally change them once a week, and keep salt and ashes (about equal portions) in a trough under some shelter constantly by them summer and winter; they can then take it as often as they please, and the ashes will prevent them from eating too much salt. The effect of the ashes is to keep them more healthy. I think sheep should not be without water every day during the winter when confined to dry food. My bucks are put with the ewes from the 15th to the 20th of November, and usually raise from 80 to 90 lambs to the hundred ewes.

As to diseases, I am happy to say that I have very little experimental knowledge of them, as our sheep have not been exposed to them, until last summer, when the foot-rot visited us, which is a very stubborn disease to cure. I had it in one of my flocks, but I think I have eradicated it after much trouble, and will here give you a recipe for the cure of it:-

One $1 \mathrm{~b}$. of Blue Vitriol finely pulverized.

One ounce of Alum.

Honey and hog's lard enough to make a stiff salve. The feet nust be closely pared, cleaned, and anointed with the salve, and the sheep should be kept on dry ground on all occasions of this kind.

I am glad to hear that you are undertaking a work of the description you name, and the few lines of broken remarks I send you are at your service. I wish you much success in your project.

\section{LETTER FROM CHARLES B. SMPTH, OF WOLCOTTVILLE, CONN.}

Dear Sir,-Your favor of the 12th inst. is at hand. It gives me great pleasure to learn that the public is so soon to be in possession of a work on Sheep Husbandry, the need of which I have no doubt every wool-grower feels. I am aware that I can give you no new ideas on sheep management, yet I willingly comply with your request in giving you my experience in the matter. 
During the summer season my sheep receive but little attention. As soon as they are shorn, which is about the 1st of June, I immerse all of them in a decoction of tobacco of sufficient strength to kill the ticks, if there are any. I then divide them into flucks, paying regard only to sex and condition, put them into pastures, and when it can be done conveniently, change them every week. They are regularly salted once a week. About the Ist November, or when the wool is of sufficient length to judge of its quality, I examine each one of them myself and select for sale such as I consider of the least value. I do not sell my best ewes, although I am not unfrequently offered prices for them which might be considered exorbitant. I let my rams remain with the ewes from the 25th of November till ist of January. During the winter. season, if the ground is not covered with snow, I keep them in yards, always providing for them good shelters, and of course plenty of water-feed them in the common racks or boxes, placed in the open yard, on hay of good quality, and give them as much as they, will eat. I do not feed grain or roots of any kind. I find by this treatment that my flock go out in the spring in as good condition as they were at the commence ment of winter, with their wool more perfect and more rich in appearance.* If sheep in good condition at the beginning of winter do not receive sufficient attention during the winter to keep them so, of course, the wool will show it, besides it very much lessens its value. I have been engaged for several years past in the purchase of wool, and almost daily have come in contact with wool of this description, which has been essentially injured by the bad management of the flocks during the winter season.

I have at this time something over 300 sheep, most of which are pure-blooded Saxonies (i. e., if the importations of Saxons were pure), having been bred from imported sheep. I have long been of the opinion that the pure Saxony sheep, well managed, would be hardy, and my object in the commencement of my flock was to produce a strong, healthy animal, with a fleece of superfine quality, and gond weight; in this I have perhaps succeeded tolerably well-certainly beyond my expectations, although I am far from being satisfied yet. Notwithstanding there is quite a family resemblance throughout the flock, yet I have some sheep which are so different from any I have seen that I shall not be satisfied until my entire flock more nearly resemble them than they now do.

I had much rather show my sheep than describe them, but as you wish to know the quantity of wool they yield, \&c., I will give you the weight of the fleeces of 104 ewes, which were kept in the same flock last winter, and which raised 101 lambs; their fleeces (104) weighed 341 lbs.; and although the quality of it was

* Mr. Smith seems to be well aware of the impolicy of high feeding, simplr to make heavy fleeces, and causing harsh and wiry wool. 
considered better than the average of my clip, yet it was sold with my entire lot for 70 cents per $l b$, to Messrs. Samuel Slater \& Sons, of Providence, R. I. To give you some idea of the constitution of my sheep, I will say that during the last eighteen months I have lost but four sheep, one of which was an imported ram injured by fighting. I had forgotten to mention that I imported from Germany two years since two rams and one ewe; I think my flock will be improved by this cross.

\section{LETTER FROM JOHN JOHNSTON, OF GENEVA, NEW TORR.}

Dear Sir,-I have before me your favor of the 24th inst., and take great pleasure in stating to you my experience and practice in sheep farming.

It is now twenty-three years that I have kept sheep in this (Seneca) county, and for the last 16 years my flock has varied in number from 600 to 1000 ; at this time it amounts to 974 , all Merinos, and which originated from the flock of the late Hon. $R$. S. Rose, before he crossed with the Saxon breed.

In relation to feeding sheep, my early custom was to feed with hay alone during winter, excepting the lambs, to which I gave in addition a little oats or corn, and to my wethers, which were stallfed, corn, oats, brckwheat or peas, feeding at the rate of one bushel of corn, or its equivalent in other grain, per day to the hundred, allowing also as much hay as they would eat. I think buckwheat quite equal to corn as feed for sheep.

Since the year 1840 I have adopted a different system of keeping my sheep, at least so long as my straw holds out, which is generally until the middle of Feb. or 1st of March. In 1840 I entered the winter with 1050 sheep, allowing them as much straw in their racks as they would eat, and some to waste. In addition to the straw I fed one bushel of oats, or one bushel of corncob meal, (oats also mixed in grinding), to every 100 sheep per day, except my lambs, which were fed on hay. Under this treatment my sheep wintered well, full as well as when fed hay alone. I threshed every week, and consequently the straw was always sweet.

During the winter of 1843-44, I tried an experiment successfully, as follows:-I selected 100 ewes and 10 wethers of one year old past; to this flock I fed wheat straw only, with one bushel oil-cake meal per day; this was continued until the 22d March, when my straw was exhausted. I then fed them on hay, and discontinued the oil meal. This flock did exceedingly well, being fat in the spring. I also fed a flock of lambs (134) in the same way until the 1st March, and then fed them on hay, discontinuing the oil-cake; they likewise did remarkably well, and were the bost yearlings of the breed I ever saw. The ewes yielded 
precisely $3 \frac{3}{\mathrm{lbs}}$ of clean washed wool per head, and the yearlings lacked only one pound in the aggregate quantity from them, of averaging 3 s lbs.

The present season I am feeding the whole of my flock, except the lambs, straw and oil meal, at the rate of one bushel to the hundred per day; 318 lambs are fed with hay and an allowance of two bushels of oil meal per day. I may as well say here that, in my opinion, the oil meal causes the wool to be finer than the grain; it is more economical also than hay-and therefore think it the best feeding for sheep. Clover hay will certainly fatten sheep, if well cured, but they eat very large quantities of it, and we know that it costs more to cut and cure than herds grass; while oil meal costs at the mill $\$ 11$ per ton; now a ton contains 40 bushels, which gives $27 \frac{1}{1}$ cents cost per bushel. If I then feed 150 days, as we generally do, then each sheep would consume 41 cents worth of oil meal, and no more.

The quantity of hay consumed by sheep depends much on the winter, and also on the condition of the lands. If the fields are left rough in the autumn, with the pasture old, and the winter like the last, and mild as the present so far, sheep would not require so much hay. But where the pastures are close fed by the end of November, and where sheep are on hay for 150 days, I believe that each sheep will in that period consume $500 \mathrm{lbs}$. of hay, if fed nothing else. In making this estimate, I of course suppose that the sheep are to be shorn in as good condition as they were in the previous November; such is almost always the case with mine, for I have no opinion of putting on flesh in summer to be wasted in winter.

In respect to the keeping of sheep through the summer, I would remark that I hare large fallows, and I change my sheep from pastures to these ; after harvest they have a range on the stubbles. I never turn from winter keep until the pastures are good; these I sow with plaster, which causes a great increase of feed.

[Mr. Johnston states that his ewes raise 90 per cent. of lambs.]

In relation to my Bucks, I would say that I have been tempted recently to purchase some from gentlemen who have from time to time boasted of their large average weight of fleeces, as published in the Cultivator and other papers; but unfortunately thus far none of them have produced anything near the average weight of wool claimed for them, which I cannot account for, unless the gentlemen do not wash as clean as we do- in this quarter. Certainly the sheep are never in worse condition than when they came into my hands. For several yeaw past my flock has yielded an average of from 3 to $3 \frac{1}{\mathrm{l}} \mathrm{lbs}$; the last clip averaged $3 \mathrm{lbs}$. $10 \mathrm{oz}$., and this year I hope for more.

Since I commenced purchasing high-priced bucks, it has been my practice to put only one to the 100 ewes; but he is permitted to retnain among them only about 30 days, preferring rather a dry 
ewe to a late lamb. I have rarely, however, more than five bar ren ewes to the 100 , and that would be the case if 10 bucks had been permitted to run with them. The time when I turn in my bucks is from the 20th to the 25th of Nov.; the ewes therefore begin yeaning about the 20th of April.

[Mr. Johnston thinks, and very rightly too, that it is bad policy to put ewes, of the Saxon and Merino blood, to buck before they are two and a half years old.]

I always tag my sheep thoroughly before I turn them to pasture, and wash them well about twelve days before shearing them. I salt regularly once a week during the season of pasturage ; salt is mixed with the oil meal when fed, as often as once a week, or else a brine is made and sprinkled over the straw.

The protection of sheep from severe weather, I deem very important. My sheds are 24 feet wide, 16 feet posts, with girts $5 \frac{1}{2}$ feet from the foot of the posts, with poles laid on them to support the hay, leaving the clear space under for sheep to go in at pleasure.

[Mr. Johnston makes use of the box rack, and his feeding troughs are of triangular shape and made of boards.]

During some winters I have confined my sheep to their yards, while other seasons I have allowed them to go in and out at will; but the former management I deem altogether preferable, though it is attended with much additional trouble in pumping water for them. More manure is made by confining them wholly, an object of much importance to the farmer; in addition to all, quietness is promoted by it, and more flesh will be acquired from the same amount of feed.

[Mr. Johnston adopts the old Scotch system of castrationmaking an incision on each side of the scrotum, and then drawing out the testicles with the teeth; he thinks highly of this method.]

In conclusion, I will add that land in this neighborhood is worth fifty dollars per acre, and will pay as good an interest, or perhaps better, by raising sheep, than by tillage. Yet sheep and wheat do well together, for the sheep manure the land, and better crops of wheat and grass follow.

\section{LETTER FROM JOSEPH BARNARD, OF HOPKINTON, NEW HAMI SHIRE.}

Dear Sir,-Your letter of 12 th inst. was duly recelved, and by its contents I am informed that you are preparing a work for publication on sheep-husbandry, which I think is very much called for in this country.

You wished me to give you a history of my flock of sheeptheir pedigree, \&c. The fillowing are the answers to your inouiries:-The number of my flock is between three and fomr 
mundred, and the breed, Saxony, and mostly from the Searls importation. I also obtained a buck which arrived at Boston in 1826, from the Burendorf flock, one of the most esteemed in Saxony, for which we paid $\$ 128$. The full-grown sheep of my flock shear from 2 to $2 \frac{1}{2}$ lbs. per head, when in good condition. The sheep are washed very clean, tagged close, by cutting off all the wool that is in the least dirty. We are very fastidious in doing up our wool and preparing it for market. I received in 1838 from the American Institute (New York) a medal for the finest wool, and in 1839 my wool was sorted at the Middlesex Manufactory, Lowell, which stood thus :-

[It having been stated in a former part of this work that there were American Saxon flocks which rivalled the German, the following sorts of Mr. Barnard's wool will confirm the statement.]

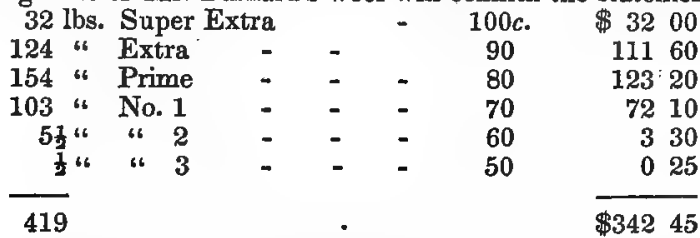

[Average per lb. nearly 82 cents.]

When my flock comes to the barn for the winter, it is separated into lots of from 50 to 60 each, and their apartments well ventilated and littered; in a word, I aim to keep the flock comfortable. The principal provender given them is, from the first coming to the barn until February, mowed oats, cut when about half ripe. From the latter period and for the remainder of the foddering season, they receive boiled potatoes, oat and corn-cob meal, mixed together, and strewed on good hay, and put into crib boxes, which are placed in the sheep stalls.

[As far as could be comprehended from the description of the crib-boxes they are similar to the cut, Figure 2.]

I browse my sheep occasionally during the winter season, by driving them into the pastures, or woods, where they can crop sweet-fern, hemlock, pine and cheekberry, and whatever else they please. 'This contributes to their health; if browse cannot be obtained (owing to the depth of snow), roots of all kinds are substituted. Raw potátoes are very good, if given regularly and in small quantities. Sheep, to do well; should have plenty of good water provided for them through the foddering season.

My ewes yean their lambs in the month of May; I raise generally 90 lambs from 100 ewes. My loss has not exceeded 2 per cent. during the winter season.

[Mr. Barnard states that his sheep were affected with footrot about 20 years since; his remety for the disease is omitted.] 
Dear Sir,-Your communication came duly to hand, and with the greatest pleasure I embrace the opportunity of communicating to you, as far as conveniently may be, the information desired.

My flock at present numbers about 900 - of the Merino breedoriginally from the stock of Dickinson of Ohio, and Marvin of this State.

$2 d$. The flock yields from $3 \frac{1}{4}$ to $3 \frac{1}{2}$ lbs. per head.

$3 \mathrm{~d}$. The blood is considered valuable, and my sales annually have been large.

4th. I never allow my sheep to herd in greater numbers than 50 to 100 , either summer or winter.

5th. For the last two years, I have folded from 100 to 150 at the commencement of winter, within a small yard containing water, without removing them until shearing. These were for slaughtering, and fed accordingly.

We generally feed clover and timothy hay three times per day when the weather is severe, and when otherwise, twice a day. We do not feed grain or roots till in January or February, except to such portions of the flock as appear in a declining condition. These are put by themselves, and fed on wheat bran, oats, potatoes, and such articles as the nature of the case requires. To our breeding ewes we generally feed from a bushel and a half to two bushels of potatoes, finely cut, with the addition of half a bushel of bran mixed per day to the 100. The sheep for slaughtering alluded to, receive the same treatment as the ewes, except, that instead of the bran, 1 peck of oats or buckwheat was mixed with a peck of bran, and the whole mixed with the potatoes, and fed in the latter part of the season twice a day. We generally feed our corn fodder at noon.

6th. We shelter our sheep during the whole winter season.

7th. In our climate we are obliged to fodder five months of the year.

8th. Blue grass and white clover mixed, and timothy are, for sheep pasture, the best we have here.

9 th. We salt our flock once a week, but think twice would be better.

10th. When we think our hay has not been sufficiently cured, or has been damaged by bad weather, we add 1 quart of salt to the ton; but when well cured, we do not salt it at all.

11 th. We put our bucks during the two last weeks in Nov., and wean our lambs in the latter part of August. It is destructive to put lambs upon luxuriant clover immediately after wean. ing.

12th. There is always a ready cash market for wool in this quarter. 
13th. The average price of land in Beaver county is about 15 dollars per acre.

14th. The foot-rot is a disease unknown to the sheep of Beaver county.

JOINT IETTER FROM CHAS. W. HULL AND M. $Y$. TILDEN, OF NEW LEBANON, NEW YORK.

The flock was accidentally commenced, in the year 1810, by 'the late Elam Tilden. He was in New York waiting the sloof to sail, when he met the late Chancellor Livingston, who invited him to go to a sale of Merino sheep, and while there he purchased a full-blooded ewe, and shortly after purchased of other importations.

From this stock sprang quite a flock of full-blooded Merinos In $1822 \mathrm{Mr}$. Hull became associated with him, and as soon as the Saxons were introduced, they commenced crossing with them. In 1827 they purchased one of the best rams ever imported (at a sale in Brighton); in 1828 they purchased largely of both bucks and ewes at the large sale in New York. From this stock, preserved pure, have sprung our present flocks. We have been very particular to breed from the best Saxon bucks we could procure. The flock on the farm of the late Elam Tilden numbers about 800 ; Mr. Hull's about 300.

Formerly our aim was short staple and light wool; then our fleeces averaged from $2 \mathrm{lbs} .6 \mathrm{oz}$. to $2 \mathrm{lbs} .9 \mathrm{oz}$; ; since the manufacturers have discovered that length of staple is not incompatible with fine wool, we have, by increasing its length, increased its weight to $2 \frac{3}{4}$ lbs., and we hope, by judicious breeding, to bring them to $3 \mathrm{lbs}$., and still preserve the fineness of the fleece.

We winter in herds, ranging from 50 to 100 , and in herding aim to keep those of an age, size, and sex together. We shelter all principally in cellar barns, and feed all under cover, in boxes, being particular to keep fresh water and salt by them constantly. We consider both as essential for them as for neat cattle or horses, for by having both water and salt by them, they never eat or drunk inordinately. To one who has never practised this system, it would be quite a curiosity to see them rumning from the hay to the water.

Our feed is well-cured hay, three times a day, of which we feed them all they will eat, which is about 15 tons to the 100, except, about four weeks before the dropping of the lambs, when we feed the ewes about a peck of corn-cob meal, mixed with one bushel potatoes, or Rutabaga, grated, to the 100 . Occasionally we feed oat and barley straw, corn stalks, \&c., as we have them to spare." We make no difference in the feed of our lambs.

* Messrs. Hall \& Tilden, it seems, adopt the German system of variely of foed -for which they are to be commended for their sagacity. 
We have pursued this system for many years, and would like to compare cur flocks, of over 1100 , with any like number of finewooled to be found, which are not furnished with a warm shelter, let their feed be what it may. Our losses have also been very small, not averaging one per cent. We aim to bring them into the fold in fine order, which we consider very essential to their wintering well. . Under the old system of short pastures, feeding at stacks without shelter, you may estimate the per centage of loss, as high as you please, and not overstretch the bounds of probability. Are there not many farmers of the present day, who still pursue this system, and wonder why they lose so many sheep, and finally ascribe their "bad luck" to disease rather than the true cause? Experience should have taught them ere this, that a large portion of hay stacked is injured by storms, which, at the very time the sheep should eat plentifully, they almost refuse it, particularly if it becomes wet by a drizzling rain or a snow storm; as a consequence the loss of hay and sheep is large-the flock comes out "spring-poor"-cuts less wool, and that more or lese injured for manufasturing.

We tried this system long enough to see its utter want of econ-. omy, and then adopted barns with basements or cellars underneath, taking care to have them well ventilated; and each succeeding year has found us more and more satisfied with our experiment. So firm is our faith, that we have no hesitation in recommending to every farmer who has none, to lose no time in providing them for all his stock, or at least for his sheep. The increased value of the manure will alone pay a good interest upon the investment.

In breeding we are "careful to avoid the "in-and-in system." We turn out from the 1st to the 15th Nov., and put from 50 to 100 with a buck, depending on his age and constitution. The buck should be well fed. In large flocks, from 80 to 85 lambs to the 100 is the usual average raised; small flocks the average will range higher. Nights, and cold, unpleasant days, we are careful to keep them housed. Warm days we tum them out to graze, and find when the ewes can get a good bite of grass, that the lambs are stronger, and that they require less feed and care. We wean about the 20th of August. The sheep should be tagged early in the spring, and when well tagged will yield from 15 to 20 lbs. to the hundred.

From several causes, Saxon wool is not now cultivated so eagerly as formerly, and the demand for Merino has largely increased. The heavier the fleece, the larger the price, even though much of the weight consists of gum, \&c. This is a lamentable fact, but how can it be expected otherwise, when so little discrimination is made between Saxon and Merino wool? Some large flocks have been broken up, and sheep shearing from $3 \frac{1}{2}$ to $4 \mathrm{lbs}$. substituted, and we predict, if this system of buying without making a suitable discrimination is to be continued, it will result eventually in the destruction of nearly all the fine-wooled sheep in 
the conntry. Pride will doubtless cause some of us to continue growing fine wool, for a time, but when we see our neighbors getting about as much by the pound, and more by the fleece, interest will prompt us to adopt the course which pays best.

The supply of wool having been larger than the demand for the past three years, has, in our opinion, led the manufacturers to suppose that no such change was going on. When the old stock. is worked off and a fair competition springs up, they will find it difficult' to obtain a supply of as 'good wool as under the. same demand three years ago.

If this should be the result they may attribute it to the want of their usual sagacity. We trust they will look to this subject before it is too late. All the wool-grower needs to induce him to grow fine wool is a proper system of discrimination; let this be done, and there will be no difficulty in procuring a supply.

We believe that a proper emulation in the growing of fine wool, tends to make better farmers, for if they once acquire a taste for superior flocks, it will extend to other branches of farming, which is a result to be desired by every one who has the interest of the farming community at heart.

\section{LETTER FROM YOSEPH BARNUM, OF SHOREHAM, VERMONT.}

Dear Sir,-According to your request, I herewith send you a statement of my management of sheep, and the breed. My flock consists of about 700, and is of the pure Merino blood; for their pedigree I refer you to Mr. Randall's statement in the Albany Cultivator of December last. My flock was bought of Mr. A. Cock, of Long Island, by Leonard Bedell, and said to be of the Paular breed. I now own the flock and farm of the said Bedell, and the sheep have been kept pure to this day. Last year I sheared 610 , which yielded to me $2441 \mathrm{lbs}$. of wool, being a fraction over four pounds per head. I tag my sheep immediately before turning them to pasture, and take from each about 3 ounces of wool.

I think it very necessary that sheep should be sheltered in win ter. Feeding roots is preferable to grain; oats, however, I think as good a grain as any.' Turnips and carrots are very acceptable to sheep, especially the last. One bushel of carrots to the hundred will keep them thriving; half a bushel of oats to an hundred lambs daily will result greatly to their benefit. Four weeks before lambing it is very necessary that ewes should be fed from 8 to 16 quarts of corn or peas daily, as it will contribute to their strength, increase their milk, and give less trouble in raising the lambs. I raise from 85 to 95 lambs from 100 ewes. They are usually dropped in the field, during the month of May. One buck to a hundred ewes is sufficient, if put up nights, and grained high. I do not allow more than nne buck to go with a flock of ewes at the 
same time. I prefer ridge land for pasture; an acre of our land will pasture from 4 to 10 sheep. An hundred will consume from 10 to 15 tons of hay, if fed nothing else.

\section{LETTER FROM CHARLES COLT, OF GENESEO, NEW YORK.}

Dear Sir,-Your esteemed favor was duly received, and I hasten to comply with the request therein contained. I have not that experience to give you, which you will be able to obtain from many of your correspondents, but such information as I am possessed of will be cheerfully rendered.

Four years ago, I commenced my present flock of sheep by purchasing of S. C. Scoville, of Litchfield county, Connecticut, twenty-five yearling ewes and one yearling buck. This is all I know concerning their pedigree; $I$, however, believe them to be full-blooded Saxons. My flock at present numbers two hundred and fifty-six. Wishing to increase it as fast as possible, I have never as yet been able to cull my flock. I have always sold my buck lambs in the fall after they were one year old.

The average weight of wool per head the present season was 2 lbs. 14 ounces. I am fully persuaded that by pursuing the course I have marked out for myself, I can realize at least $3 \mathrm{lbs}$. per head, of as fine quality of wool as I now get. I tag my ewes in the fall and all my sheep in the spring, before turning them out to pasture, clipping about $\frac{1}{2}$ a pound from each sheep.

At shearing $I$ do not put into the fleece any tags, or any of the wool that falls upon the floor during the process of clipping. My practice is to wash in a clean running stream, if possible, soon after a hard shower. I then torn my sheep into a hard turf pasture, shearing from six to ten days thereafter, as the weather will permit. There has been much complaint made on account of the impossibility of shearing Saxons without the fleeces breaking. This is owing to the want of proper benches for shearing. I use benches about four feet long, two being connected by a piece of tow cloth, about one yard wide and four feet long. The fleece falling upon the cloth is kept clean, and is prevented from breaking.

I protect my sheep during winter, and here insert a ground plan of my barn and sheds.

[Mr. Colt's plan is meritorious, but of necessity is omitted.]

My feeding fixtures are racks of different kinds. The best kind is upon the following plan:-The bottom is a two inch oak plank a foot wide and sixteen feet long, legs four and a half feet long. crossed and halved together, and the bottom plank framed into them, twenty inches from the ground, by a two inch round tenon. The rack is filled with inch rounds, three inches apart. The top pieces and legs are made of oak scantling, four by two 
inches; and the top pieces are connected to the legs in the same manner as the bottom plank is, the tenon running through the legs sufficiently to put in a small wooden pin. The rick is made flaring, so that it is two feet wide at top. The cost of each is about two dollars.

I have never had my attention called particularly to the amount of hay Saxon sheep will consume, but should judge I had kept well one hundred during the winter on seven tons, together with the straw and chaff I fed them.

I feed neither roots nor grain, believing it to be neither profitable nor economical so to do, for the following reasons :- It is much more expensive to feed grain;-grain I corrceive to be an unnatural food for sheep;-it causes an undue degree of heat, and as it produces a greater quantity of wool, it is of coarser texture.

I think it is of great importance that a sheep should be, as nearly as possible, in the same condition, as regards flesh, at all seasons of the year, particularly a flock of sheep you intend to keep and breed from. This you cannot do and feed grain a portion of the year.

I think variety of food is beneficial during the winter. I should prefer feeding clover hay about one-third of the time and timothy the remainder; clover has an effect upon the bowels of sheep similar to that produced by grass. I also feed straw and chaff, believing that there is no animal to which they can be fed with as much profit.

Never having fed any grain, I cannot say what kind will produce the greatest quantity of wool.

The supposition that sheep cannot besufficiently well kept upon hay during the winter is, in my opinion, erroneous. Much depends upon the time at which, and the manner in which, it is cured. I am satisfied from my experience, that timothy for sheep should be cut at least two weeks before you would cut it for cattle; before the seed gets fully ripe, and clover while in the blow. My practice in curing timothy is to turn out the swarths immediately after the mower in the morning, turning over again after dinner, and cocking up the grass before night. The next day (if fine) turning out from cock as soon as the dew is off, turning over twice, and getting it into the barn before night. Hay should be thoroughly cured, and still be as fresh as possible. Clover requires a different process-I turn out as in timotby, cure as much as possible the first day, cock it up at night in tall, elim cocks, and let it remain so two or three days till it is nearly cured, then open it to the air and gèt it in. This process of curing preserves all the heads, leaves, and most of the juice of the hay.

$\therefore$ There is no difficulty in keeping sheep well upon such hay, nroperly fed out. I feed my sheep. three times a day with hay and twice with straw and chaff, watering twice daily. 
I put my bucks about the 1st of December. Yearlings with 25 ewes, older ones with about 40 . I make it a practice not to put a ewe until she is two years old past. In this way a larger and hardier race of sheep are produced. I have generally been very successful in the raising of lambs; coming as they do about the first of May, few die. Nine-tenths I think would be a fair estimate of the per centage of lambs I raise. Coming late in the season, they generally drop in the field.

It is difficult to say how many Saxons can be supported on an acre of land during the year, depending as it does on the quality of the soil, the manner in which the land is stocked, the care taken of the sheep, and various other circumstances. I stock my lands with one bushel of timothy seed to every 8 acres in the fall, and with the like quantity of clover, on the same ground, in the spring. Herd grass pasture is peferable for sheep, but clover is best to plough under for wheat. During the summer past I kept 250 sheep on 36 acres of pasture ground; 10 acres of meadow would yield sufficient hay to support them through the winter. This would seem to indicate that about five sheep can be kept the year round upon an acre of my land.

Good improved farms in this section are worth $\$ 35$ per acre.

The diseases most prevalent are the foot-rot, the scab, and the grub in the head, but never having had any diseases in my flock, 1 can give no opinion as to the best mode of treating them. Since I commenced my present tlock, I have lost but three sheep.

\section{LETTER FROM C. N. BEMENT, OF ALBANY, NEW YORK.}

Dear Sir,-Your favor came duly to hand, and in compliance with your request offer you the following replies to your queries :-

In regard to the management of sheep, I fear I cannot render you such information as you may wish, as I have never kept an exact account of the food consumed by them, neither can I impart much information on the subject of feeding sheep for slaughtering.

You are aware, I presume, that my little flock consists of the South Down variety, which are so highly esteemed in England and beginning to be appreciated in this country for the quality of their fiesh, hardihood, and great aptitude to take on fat.'

The stock from which my flock originated, was imported by Sidney Hawes, in 1823, of whom I obtained them, consisting of 36 ewes, 2 bucks, and 10 two-year old wethers. ' The ewes, in consequence of the carelessiess of the person who had them in charge, the winter and spring previous to my purchase, lost nearly all the lambs; and at the time they came into my possession, which was in July, they were most all afflicted with foot-rot. This I soon cured by paring the hoofs and washing with a preparation of blue vitriol,spirita of turpentine, and vinegar. Some of 
them were so lame as to stand on their knees to feed. After two or three applications they entirely recovered, and became very fat, so much so, that I feared they. would not breed. On the 20th of Nov. I commenced feeding the ten wethers a few rutabagas, and continued to increase the quantity until they consumed about three bushels per day. They were fed as much hay as they would eat. I sold them to one of our butchers, early in February, for ten dollars per head. : After dressing, their carcases weighed from 80 to $100 \mathrm{lbs}$. each; and the mutton was greatly admired, and extolled for its high flavor, juicy and tender quality, by all who partook of it. Their fat, unlike the Bakewell breed, lying on the outside, like pork, was firmly mixed with the lean, or marbled, as some term it. It is estimated by those who have cooked the South Down mutton, that there is as much edible meat on a saddle weighing $30 \mathrm{lbs}$., as there is on a saddle of Bakewell weighing $40 \mathrm{lbs}$., as a great proportion of the latter finds its way into the dripping-pan.

I winter my sheep in yards with tight fences, and open sheds, facing the east; feed hay in board racks, under cover, and no grain. I put the bucks with the ewes about the 25th of October, so that the lambs will come the latter part of March, and first of April. About the first of March we begin to feed the ewes, say one bushel of rutabagas to fifteen head, to induce a flow of milk. I have a warm stable, where the ewes which are expected to lamb are confined nights. The lambs are confined with their mothers until three or four days old, when they are turned into the yard, and seem to stand the cold as well as their mothers.

This method, I am aware, could not be adopted where large flocks of sheep are kept. Formerly; I allowed the lambs to come in May, and used to lose some from the cold storms which usually oceur in that month. Lambs will stand severe. cold, if dry, much better than wet. Besides, we have more time to look after them in March, than we have in May, when work in the field is pressing. Young ewes will not always own their lambs; by having them in yards they are more at our command. Another advantage I found in having lambs come early was, that when first turned to pasture the young lambs will feed on the young grass, by which means their growth was much accelerated, and by the first of July were fit to wean.

The South Down sheep are very prolific, often producing twins, and sometimes three lambs at a birth, and being good nurses, will bring them up as well, if not better, than some other breeds will one. A neighbor has ten half-blood South Down ewes, that produced läst spring twenty-one lambs, all of which he succeeded in raising.

My flock has generally consisted of breeding ewes, and when 1 have weighed their fleeces, they have averaged $3 \frac{1}{\mathrm{l}}$ lbs. per head. I had one buck, which at two years old gave me $6 \frac{3}{3} \mathrm{lbs}$. I have cold my wool from 25 to 35 conts per pound; but latterly had it 
manufactured into flannel, which I have sold at 50 to 58 cents per yard.

South Down sheep, according to my experience, are better adapted for those farmers living near market, where carcase as well as wool is an object. They are also well adapted to cross with our native sheep, imparting to them a better quality of mutton, as well as wool, stronger constitution, and greater aptitude to fatten. Butchers will pay from 75 cents to $\$ 1.00$ per head for early lambs of this cross, and the mutton will always sell more readily, and command the highest price in market, for, as the outchers term it, they always " die well."

There is another good quality of the South Down: they have not a roaming disposition, but are quiet and orderly, seldom leaving their pasture, even when the fence is partly down; whereas, the native sheep can hardly be restrained when the fences are upin fact, I have had some long-legged sheep, that would silear, at one leap, a six rail fence. After nine years experience, I have found the South Down sheep as they have been represented, a tough, hardy race, defying the severest storms.

\section{LETTER FROM SAMUEL WHITMAN, OF WEST HARTFORD, CONN.}

Dear Sir,-My flock at present consists of 275 , some of which are superfine full-blood Saxons, raised from sheep which I purchased at auction, at Brighton, Mass, and imported by George and Thomas Searle, of Boston, in the years 1824, '25, '26, and '28. In 1826, I bought a buck without horns, which I think laid the foundation for all the wool in this region, which may be said to be absolutely superfine. A majority of my present flock are Saxony and Merino mixed, with a few half-blood South Downs, and a few mixed blood Leicesters for experiment. I have come to the conclusion that the Saxon, after it has attained its growth, is as hardy a sheep as any with which I have been acquainted. Our country in general, I think well adapted to sheep. Our land, however, I think too valuable for. sheep husbaindry, being yorth about 50 dollars per acre. Such of our land as is devoted to sheep pastures are those in which clover abounds. In winter I feed under cover entirely; my shelters are in my barn under hay-lofts. I allow from 50 to 100 sheep to herd together in winter. I do not think water indispensable for sheep when they can get plenty of clean snow ; but think they do better where they have access to water. I have seldom made use of grain; when I have, it has been for that class of sheep which I have thought needed better keeping than barely hay, whether old or young. ' White beans are excellent; sometimes I have made use of oil meal, and in quantity it has been from half to one gill per head daily. I generally succeed in raising 95 per cent. of my lambs; in my first stock of half- 
blood Saxons, I raised 126 lambs from 127 ewุes. They com. mence dropping about the first of April, and I wean themi by the first of September. When my flock was mostly. Saxons, it sheared $2 \frac{1}{2}$ lbs. per head, and a mixture of Merino has increased it to 23. 'lbs. I wash them in brisk running water, at the mill tail, and shear from 7 to 10 days after. I have lost 5 per cent. yearly, from disease, age, and accident. The only disease from which they have suffered has been the rot; in two instances within 25 years, I have lost 20 per cent. from this cause. Sometimes, too, they have suffered from worm in the head. As yet I am ignorant of any cure for these complaints. I feed both in boxes and in racks.

[The former are like cut No. 1, and, as near as comprehended, the latter conform to No. 2. See plate-racks.]

Within 8 or 10 years past, I have several times sold the principal part of my flock, always reserving, however, some of the very best, from which I might reproduce another flock of superior excellence. At the present time I have only a small number of pureblood Saxons, the principal part consisting of the aforementioned mixtures. As the result of my own observation and experience with regard to the health and thrift of a flock, I may state that, in this section of country, at least, more disease is induced by scanty and bad keeping, than from any other cause whatever.

\section{LETTER FROM MARK R. COCKRIIL, OF NASHVILLE, TENNESSEE.}

Dear Sir,-Your favor duly reached me, and I am much pleased to give you any information my experience has taught me upon the important subject of wool-growing. You ask many questions which I will endeavor to answer in part, in my plain way of writing. I have about a thousand head of fine sheep, and from 400 to 500 long-wooled or mutton sheep. My Saxon sheep were imported in 1824 or '26, I cannot say which, and I find as yet no falling off in quantity or quality of their fleeces; on the contrary, I believe a little improvement on both points and a little more yolk, when well provided for, which you know does not abound much in the Saxon breed. In addition, the fleeces are a little more compact than formerly-hence more weight, and, from our mild climate, the staple has become longer. In Tennessee we do not fodder more than 80 or 100 days, and from the little snow, our sheep pasture upon the grain fields, which soon grow again, and thus we are provided with an excellent substitute for roots. But both may' be made use of to good advantage, as all very well know that succulent food for sheep the year round, the better they thrive. I assert it to be a fact that the cotton region I am now in (Mr. Cockrill dates from Madison county, Mississippi, where a part of his sheep are kept), in about latitude 32 degrees 
north, is better than any country north of it to grow wool, as the sheep can be kept all the time grazing, by sowing small grain, for if grazed off; it quickly grows again in a few days; and the wool of fine Saxon sheep in this climate is softer and more cotton-like than any I have ever seen, although I have samples from all parts of the world. I have travelled from this very place to Boston sampling all the sheep of note on the way, and I found nothing on my journey or at Boston as good as the wool I had grown, and so said all the wool-staplers whom I met with, and they were not a few. I presumed, in reality, that the blood of my sheep was no better than many I saw, but the superiority of my wool I ascribed to our climate, and the provision for the sheep of succulent food the year round. The weight of my fleeces is fair -say from 3 to $5 \frac{1}{1} \mathrm{lbs}$. each.

At my residence, near Nashville, in latitude $36 \mathrm{deg}$. north, the best lands, if well set in blue and orchard grass, will graze from 5 to 8 sheep per acre during the grazing season, when we have the usual rains through the summer. With proper care of our grown ewes, we may calculate on raising 80 lambs from one hun dred.

The long-wooled or Bakewell sheep are rather short lived in Tennessee, from getting too fat in summer, as they cannot lose that great body of fat without deranging their health; hence, compared to the Saxon or Merino, they are short-lived. My finewooled lambs commence dropping on the 10th of March. Our meadows yield from $1 \frac{1}{2}$ to $2 \frac{1}{2}$ tons per acre. Tennessee is not the true grass climate; about $28 \mathrm{deg}$. north is the most congenial for grass ; notwithstanding, our State is fair for pasture; blue and orchard grass, white and red clover, prosper pretty well. We feed cunsiderable millet, which yields from 4 to 6 tons to the acre; this and Irish potatoes, which thrive reasonably well here, will keep sheep in good health and condition.

There is much country in Tennessee and other Southern States not fit for the plough, and would do admirably well for fine-wooled sheep, and can be profitably so employed. A small capital thus appropriated here in Mississippi would do better than cotton-growing, at present prices.

[Mr. Cockrill states that sheep are exposed to liver-rot and grubs in the head.]

LetTer From T. C. PETERs, OF DARIEN, GENESEE COUNTT, NEW YORK.

Dear Sir,-Your favor covering certain queries in relation to sheep husbandry is before me. I shall give you an account of our management withouf a formal answer to the various question 
which your letter contains, giving you full liberty to use so much of it as you may deem important.

We have been engaged in the business fifteen years, and for ten years our flock has averaged about 600, mostly Meriros, or a cross of Merino and Saxony. The average yield in that time exceeds $37 \mathrm{lbs}$, probably not far from $3 \mathrm{lbs} .6 \mathrm{oz}$. of washed wool. The sheep are usually tagged before. they are turned out to grass. We never wash our sheep until the water is warm, nor shear until the weather has become warm and dry. Hundreds of valuable sheep are lost every year by too early washing and shearing. If a rain-storm comes on soon after shearing we give them shelter.

The bucks are let among the ewes about the 5th of December, and we think eight to an hundred not too many, but have frequently used but five. The lambs begin to drop in May, and generally continue through the month. In April we usually feed the ewes with a little Indian corn daily, less than a wine-glassful, to each one. This makes them strong, and the lambs are much more active than when the dam has not been so fed. About the 1st of September we take the lambs from the ewes and put them into a field by themselves with a few dry ewes or wethers. They are wintered in a separate flock.

Shelter we consider indispensable, not so much against cold, as wet and storms. Around our barns we have sheds; but, as we prefer wintering a portion in the meadows, we make our stacks so that sheds can be constructed there with little trouble. Two stacks are built about 60 feet apart, perhaps further, depending upon the number intended to be fed there. As our prevailing wind is from the west, the stacks are on the north and south side of the shed, and it is open to the east. The shed is usually made of boards kept for the purpose, and is four feet high in the rear and six in front. It is also very important that these shelters be often littered with dry straw, or when that is not at hand, dry muck or swamp earth will answer if put in often. We usually put a stack of straw to each shed. One hundred and fifty are as many as it is prudent to keep in a flock during the winter, though we have kept as many as two hundred. We have used moveable mangers or board racks some, but generally feed upon the ground, and fodder often.

We have fed peas, oats, and corn; peas we consider the cheapest food [and Mr. Peters might have added, without fear of controversy, the best to promote the growth of a soft and long filament]. Like many others, we have never kept any account of the quantity of grain fed.

Twelve tons of hay is considered a fair allowance for 100 sheep during the winter. We never make any account of straw except as litter. Sheep do best when they have free access to water in winter; although I have seen sheep winter well in fields where they could not get it; if shut up in yards water is indispensable. 
The pastarage which seems to do best for sheep is in old fielde which have been long in grass. They prefer dry, rolling land. Old pastures, however, should be slose fed early in the season, so that the grass will come up alike over the whole field; otherwise, it will be spotted. We usually calculate that thirty acres should carry 100 sheep through summer and winter, pasture, hay, and grain. The longer a field has been used for a sheep-pasture the more it will support. Farms which will carry through four to the acre, summer and winter, with tolerable buildings, can be bought for from nine to fifteen dollars the acre. Lands with us are valued according to their productiveness of wheat. Good wheat farms are worth from twenty-five to fifty dollars per acre. The most profitable farming with us is sheep and wheat, as the sheep do much the best with us when they have the free range of a summer fallow.

Clover hay, if well cured, makes excellent fodder for them. We, when stocking for hay, put one-third timothy with the clover seed, and mow when the clover is in blossom, and cure in cocks. There can be no better hay for sheep than is made in this manner. Hence there is no stock that goes so well with wheat raising as sheep. Many persons have lost sheep by turning them too soon into wheat stubble. They should not be allowed to go in until the hogs have had time to glean the field thoroughly.

We usually allow fifteen per cent. for loss of lambs, depending, however, very much upon the season. Our loss rarely comes up to ten per cent. Stall feeding has not been much practised by us, the fall market generally paying the best.

'The only disease among us is the foot-rot, and that has been confined to the two flocks in which it appeared; and hopes are entertained by our flock-masters that it will be eradicated. The disease was brought into the country by sheep from the southeast. We have seen nothing of it yet among our own, and haye maintained a rigorous quarantine against our neighbors. If vigilantly watched, I hope we shall be able to prevent its spreading.

LETTER FROM DANIEL B. HAIGHT, OF WASHINGTON, DUTCHESS COUNTY, NEW YORK.

Dear Sir,-I received a letter from you, in which you wished me to inform you of my mode of keeping sheep, which I will do - vith pleasure, although I have not had very much experience in keeping South Downs, having, until recently, kept Saxons only; therefore I am not able to answer all of your interrogatories.

I have a small but valuable flock of South Downs, which I intend to increase as fast as practicable, as I consider them the most 
profitable, being more hardy and better adapted to our climate than any other breed of sheep.

I have had a few of the Cotswold breed, but was glad to get rid of them as soon as possible, on account of their being very tender, and the wool of little value; also, their requiring more food for the same quantity of mutton than the South Downs,

- You wished to know my practice of wintering sheep. I endeavor to have them in good condition at the commencement of winter, which I do by feeding them with grain when the pasture begins to fail, as I think there is much lost by neglecting them at this season of the year. [Mr. Haight never uttered a truer thing.] It canno be too firmly impressed on the mind of every farmer that it is more easy to keep an animal in good condition, and requires less food to do it, by not allowing it to fall away, than to restore it after once becoming poor. [Here is another important truth.]

It is of great importance to protect them from the cold winds and storms, particularly rain. I keep them in flocks not exceeding fifty, and a less number is preferable. I give them free access to water, and feed them morning and night with hay, which was lightly salted when put up, and some kind of vegetables in the middle of the day. Potatoes, in my opinion, are preferable to any other. I salt them frequently in the pasturing season, and keep their noses thoroughly tarred from the first of July to the first of October.

You wished to know how large a flock I keep. I have only about thirty South Downs, and two hundred and fifty Saxons; the former will yield from three and a half to four pounds of wool a head, and the last clip was worth thirty-seven and a half cents per pound.

You also wished me to inform you of my mode of fattening them, and at what age I turn them off to the butcher. I am not able to answer, these inquiries, having kept them so short a time, but I think they will do to turn off at two years old.

I weighed some of my lambs at three months and a half old; the twins weighed from seventy to eighty pounds each, and one single lamb one hundred and one.

I have my ewes to lamb about the middle of April, and generally raise two lambs from each ewe. They are excellent nursers, and produce very fine lambs for market.

I feed my ewes a little grain for three or four weeks before lambing, so as to have them in good condition for yeaning, and afterward commence feeding them with regetables and with oat meal and wheat bran mixed with a little water, which' I increase as the lambs increase-in size. 
LETTER FROM JOHN H. WWING, OF WASHINGTON, PENN.

Dear Sir,-Your favor was duly received, from which I was pleased to learn that you were engaged in the preparation of a work on sheep husbandry; one much needed by the wool-grower, and of great importance to the country generally, as comparatively litile is known on the subject. Wool-growing must, in time, become the great business of this country, possessing as we do all the facilities to produce an article as cheap in time as any other country, our climate, soil, and mountains being favorable for the business ; nothing, therefore, but a home market is wanud to induce our people to engage largely in it, and shortly not only supply home demand, but furnish large quantities for exportation

But I must return to your inquiries, and endeavor to impart, as far as experience will warrant, my knowledge of wool-growing:

I have been engaged in the business about twenty years, and have given it my personal attention. My flock exceeds two thousand, and partake more of the Saxon than Merino character, as well the most of the flocks in this section of country ; and yet 1 am inclined to think the most of the original stock was of Merino blood. But many of the flocks have been formed by crossing with the native sheep, and by close attention for a series of years have become very good, and will generally pass for full-blood Merino. Shortly after the introduction of the Merino sheep in this country, a few enterprising individuals, namely, the late William Hoge, James Gilmore, and others, commenced the business, which was afterwards much improved by Wm. Brownlee, and the late Alexander Reed, and some others. But of those most distinguished for their efforts, Messrs. Wells and Dickinson of Steubenville, Ohio, are entitled to the greatest credit; they made great progress in wool improvement, and spent a fortune to accomplish their purpose, and establishing its manufacture. After a series of reverses, they finally failed, to the great regret of all who knew them. Upon the sale of their flock, I became the purchaser of a thousand, from which my stock has been formed; and notwithstanding they were originally from the best imported stock, and the greatest care and attention given-to their improvement for many years, and since by myself, there is still much to be done. Nothing, indeed, is more difficult than the making of proper selections of such as produce wool desirable to the manufacturer, and at the same time profitable to the wool-grower. Again, in the selection of breeders, the peculiar character of the stock will be carried down for generations; hence the selection of good bucks is all-important. There ought, in all casts, to be three bucks to the hundred ewes, otherwise the bucks will be more or less injured.

It is desirable that the lambs should not drop before the middle of April, and on until the middle of May, at which time the grass 
will begin to spring, and enable the ewes to furnish an abundant supply of milk. The time here mentioned is applicable to this section of country ; the most suitable period in other places must depend on the climate in some measure. Whenever the ewes can have a flush of grass they will do well; the deficiency of pasture, however, may be supplied with a good rye-field, which will be rather earlier, and no danger need be apprehended in turning ewes upon rye, as they will not scour as other sheep; the nourishment appears to be secreted in milk.

Our foddering season here lasts from five to six months; but not. more than three or four of bad weather, during which time we feed on hay, oats, corn and corn fodder. Sheep should have just what hay they will eat up clean; and the ewes and weaker ones be provided with.a bushel of oats per hundred daily; or half that quantity of corn; in bad weather it is best to fodder three times a day. The less grain, however, they have the better, provided they can be kept in good order, which alone can be done by the use of roots, or an extensive range, which has been permitted to grow up during the summer, which of all others is the best mode of keeping (if the owner has extensive lands); under these circumstances, sheep will require but little care. Those who adopt this course should have fields of blue grass, as it is less liable to be affected with frost than any other, and one of the best for pasturage.

Those who feed during the winter on dry food, should be careful to see that their stock has plenty of water ; the idea that sheep will do without it is absurd, except when upon soft grass in the summer. Potatoes are excellent to counteract the binding effect of dry food, but are troublesome to feed where the flocks are large; when given, they should be washed and cut up in small pieces.

As to the use of salt, my plan is to salt two or three times a week in the summer, more frequently in wet weather than in dry, and generally on the ground. I do not salt my hay, though some of our wool-growers speak well of it; my stock is supplied with it regularly during winter, and salt is very essential to health.

You ask, what kind of pasturage is best? My experience has led me to believe that wood-land range is best. For many years, I have been accustomed to graze my flock on the mountains, where it is all covered with timber and underbrush, and whenever they have had sufficient scope, have done well; and my opinion is, that it has greatly contributed to their health. [This is to be attributed to the variety of herbage they obtained.] Nothing more conduces to the health of sheep than frequent change of pasture; without it they will not thrive.

[Mr. Ewing remarks that sheep are little subject to disease in his section.]

Another and important matter with the wool-grower, is the preparation of wool for market. The mode I have adopted in washing, is to drive the sheep across some water that will swim 
them, two or three hours before commencing to wash, so as to let the wool become thoroughly soaked; it will then wash easily, and all the ink will come out, leaving the wool perfectly white; those, however, who wish to make the manufacturer pay for dirt, will not adopt this course.

There is one of your inquiries which I have omitted to refer to, viz., the effect of climate and herbage upon the quality of the wool. Upon this subject there can be but little doubt-a northern climate is far preferable for fine wool, and I am of opinion from my present experience that very fine wool cannot be raised in the South. In all cases that I have known it tried, the wool has deteriorated, and the health of the sheep failed. Much also. in my opinion, depends on the soil; high poor lands will produco better wool than rich low lands. I sent a flock a few years since to Warren county, Illinois, of about our latitude, and after three years' experience, I scarcely knew my own wool; the quantity of wool and size of the sheep have increased, but the wool has not retained its fineness. This no doubt arises from the pasturage; the sheep become very fat in the summer, which increases the harshness of the wool, and destroys that delicate texture it has in the more eastern and high lands. The business of woolgrowing must ultimately settle down in the hilly and mountainous countries where lands are cheap, and climate adapted to the nature of sheep. Lands in this section are worth on an average from 20 to 25 dollars per acre, and at present the growing of wool is considered better than the raising of grain; this, however, will not continue long, as the prices of grain must advance, and wool decline.

But I must close this communication, having extended it beyond your inquiries; but it being a subject of much interest to me, and one of importance to the country, I could wish our people to know more on the subject. My ardent wishes are for the success of your undertaking.

\section{LETTER FROM LEONARD D. CLIFT, OF CARMEL, PUTNAM COUNTY,} NEW YORK.

Dear Sir,-Your favor of ——was duly received, but I have not found time before this, to bestow that care in my answer, which its importance demands. And even now, I know not whether I shall be able to do the subject on which you request me to write, viz., "my experience in the cultivation of the long-wooled sheep," that justice, which will give satisfaction, and prove worthy of a place in your contemplated treatise on American - sheep husbandry. I very much appreciate, sir, your motive, and the object you have in view. It is high time that we have something American on this, as well as many other subjects that 
relate to our agricultural pursuits. I have been long convinced, that to follow implicitly any foreign system of agriculture, will, and has already, led us into many fatal errors.

My experience has been considerable with almost all of the different breeds of sheep which have been common among us; and more especially for the last ten or twelve years my attention has been given, in a great degree, to a flock of English, or longwooled sheep. During this time I have imported several on my own account, and have bought quite a number of others that were imported, and have spared no pains nor expense to establish a sample flock of English mutton sheep, fit or suitable to propagate their species, or turn over to the shambles.

You propose a number of questions, relative to the habits and qualities of my flock as a distinct breed-viz., the Lincolnshire. I have, as is well known, written several articles in respect to them, as published in the Albany Cultivator and American Agriculturist, of recent dates. This, I think, supersedes the necessity of repeating what I have already said about them, only further to say, however, that taking the Lincolnshire sheep such as I have bred, of this species of sheep, I have never yet had any, in all respects, their equal. They have a compact. wellformed carcase, and covered with a thick, long, and fine-stapled fleece of wool, including the belly, neck, and legs. No sheep will prove as hardy in our Northern climate, as those well covered with wool; and by the same rule, vice versa, in the Southern. The fleece is the protection from heat as well as cold, and more than anything else, in my opinion, secures the good and hardy constitution of the sheep. The Lincolns are good feeders, and from close observation $I$ have noticed, that they would consume much that other sheep would pass over and leave. They are quiet, and easy of restraint, and excellent nurses; but at the same time have more agility and spirit of countenance, than any other of the long-wooled breeds with which I am acquainted.

My flock of Lincolns have usually given me from -5 to $6 \frac{1}{2}$ lbs. of wool per head, on the average, and many individuals from 8 to $10 \mathrm{lbs}$., clean washed, and free from all tags, \&c. In years gone by, I have sold much of my wool at 37 cents per lb., and the last clip brought 30 cents per $1 \mathrm{~b}$. This kind of wool is now beginning to be much sought for, and in quick demand for purposes of worsted fabrics, \&c. And now that machinery is being put into operation for the manufacture of our long wools, these sheep, and others of the like class, must be the most profitable to cultivate for the fleece alone, aside from their great value for mutton. I have sold numbers of my wethers in the New York market, according to age, \&c., from 10 to 20 dollars per head. My lot this winter, marketed about the 1st of February, brought me 12 dollars per head, on the average. Two of this lot was sold at 15 dollars each, and the weight of the carcases dressed, was 150 and 133 lbs. These wethers were two years old past. I fed 
them last winter with good hay, and a moderate feed of chopped turnips, mixed with a little meal, once per day ; and the present winter, until marketed, their feed was about one pint of corn and oats to each sheep per day, for about eight weeks only.

As respects my general mode of management of these kind of sheep, it may be asserted, that what is essential to the proper management of one, or any particular breed of sheep, is essential to all, less or more. A few things I can only name; and first, I regard protection from storms in winter, and the right sort of hay, secured under cover, as lying at the foundation of all good sheep husbandry. It is a well known fact, that of all domestic animals, the sheep is the most harmless, and the most delicate in the choice of its food; hence, we have only to be guided by these principles of their nature, in all our management of them, to ensure success.

[Mr. Clift here enters into minute details of his process of curing hay, which is very meritorious, and worthy of imitation by every farmer, but of necessity is omitted.]

It will be expected that I should say something of the management of my ewes and lambs ; first, in regard to the ewes. In the fall, about the first of September, I overhaul my whole flock, selecting such of them as I design to keep over, and have lambs the following spring, selecting none but those I feel assured will remain hardy through the winter, and bring a good larab or lambs. The remainder, or those I have condemned for purposes of breeding, I fat, and sell to the drover or butcher, as soon as possible. $T^{t} \mathrm{t}$ is important that ewes should be in a thriving condition, previous, and at the time of taking the bucks, which, with me, is about the middle of October, or first of November. I endeavor to have my ewes come into the winter strong in flesh, and in order to this, I am careful not to keep them out upon the fall pastures too late. Many sheep are permitted to fall off in this way, when of 'all other times it is most important to keep up thrift, and this I do by giving them daily, at first, a bite of my choicest hay. I am not in the habit of feeding grain, or roots of any kind, to my stock ewes during winter. This I do, however, when the time draws nigh for them to bring forth their young, by drawing off from time to time those coming forward. Ten days previous feeding at this time is none too soon, and is of more importance than twenty after the ewes have lambed, if you could do but the one or the other. But my practice is to continue the grain or roots, more or less, until they are turned off to pasture for the season. Tagging at this time is highly necessary, and should be performed with a good pair of shears, and in as tasteful a manner as a jockey would trim his horse; 'and also at all other times, when any dung is seen adhering to the wool about the tail.

Small ranges, with a few sheep together, and shifted often, sheep will thrive the best when at pasture.

Lambs should be weaned at the age of three or four months. J do this as soon as my early mown meadows get a good coat of 
grass, say from the middle of July to the first of August. There are s€veral important advantages to your flock, by weaning lambs at those ages. At the time mentioned, the grass of the pastures begins to be too wiry and tough for the lambs to thrive upon it, and the ewes fail in tlesh on the same account. Both, therefore, will do better to be separated.

I might yet speak of many things connected with the management of sheep, such as the necessity of water for them in winter, keeping them free from ticks, shelters, barns, racks, \&c. All these things I attend to. And I would just observe, that while I have been penning this article, we have had here an unusually severe snow-storm, which has continued some forty-eight hours; and I can assure you, sir, next to the health and comfort of my family, has been the pleasure and satisfaction of having every animal on my premises comfortably housed and sheltered from the howling storm of snow and wind that has raged without and around us. With one exception, and this was a Tom turkey, that would, in spite of me, keep himself perched high up into the top of an apple tree.. I was somewhat vexed at the foolish bird, but let him have his own way. Why, sir, motives of mercy and humanity, as well as interest, ought to influence every man that has a beast or bird, to give them comfortable protection, and food sufficient to supply their natures.

I regret that my connmunication is not more acceptable in matter as well as manner; such as it is, however, it is at your disposal.

\section{LETTER FROM TALBOTT HAMMOND, OF BROOKE COUNTY, VA.}

Dear Sir,-Your letter was duly received, and you have my best wishes for the success of your worthy undertaking.

The number of my flock at present exceeds one thousand. My sheep are principally of the Spanish Merino blood. My first adventure was in the fall of 1822, when I purchased seven ewes and a buck of my brother, Charles Hammond, of Belmont county, Ohio. His flock was bred directly from the flocks of Messrs. Wells and Dickinson, of Steubenville. The buck that I obtained of my brother was an imported one, for which he paid $\mathrm{Mr}$. Dickinson eighty dollars; he was quite old at the time I procured him. I have since then crossed my sheep with Saxony bucks from Dutchess county, New York, but the result was not very favorable; therefore, on the whole, I preferred the Merino.

The average weight of my clips is from 23 to $3 \mathrm{lbs}$. per head. Our foddering season in this country is not less than four months, and sometimes longer. I shelter all my sheep in the winter season. I have two shed barns, one of which will accommodate 500 , the other 300 , and for the balance of the flock we make tom- 
porary sheds. - I think there is no stock needs to be sheltered from the storm more than sheep, as we are subject to very sudden changes of weather in this climate during the winter months.

Of grain, we feed principally corn and sheaf oats; corn-cub meal makes a very hearty feed. I have no doubt but sugar-beets and other roots might be raised and fed to great advantage here, but we have not got into the way of it yet,

I think the best flocks of sheep in the State are of the Spanish Merino, though some of them have been crossed more or less with the Saxony. In my opinion, the northwestern part of the State is best adapted to sheep, the land being hilly, and a rich limestone soil, well suited to the production of grass.

A half bushel of corn to the hundred, or a dozen sheaves of oats once a day, is about our rule of feeding grain..

On the subject of housing sheep, I am decidedly in favor of good dry sheds for them; my experience is, that sheep should not be suffered to get wet in the winter season. Last winter, I had comfortable shelters for all my sheep, except one flock of about 200 , which were exposed to the weather; and I have no hesitation in saying that they ate one-fourth more feed than any other flock of the same number on the farm; and the consequence of this exposure was, that in the spring, when grass came, they were all very poor, while the rest of my sheep were in good condition, with full coats of wool on them. By feeding under sheds we save all the manure, which is a very desirable object.

LETTER FROM ASAHEL B. HODSKINS, OF WALPOLE, N. HAMPSHIRE.

Dear Sir,-Your favor was duly received, in which you propound a series of questions, which I now proceed to answer to the best of my ability.

My stock of sheep amounts to over 400 ; about one half of which are pure Saxonies, bred from the importations of $\mathrm{G}$. and $\mathrm{T}$. Searls, of Boston; the residue were bred from pure Merinos, and which have been crossed with Saxon bucks since 1825 .

My sheep average $3 \mathrm{lbs} .2 \mathrm{oz}$. per head of clean washed wool, which shrinks, in cleansing, from 22 to 25 per cent. I shelter my sheep in winter. My shelter is formed by digging sufficiently deep on a warm dry side hill, sloping to the south, and building a smooth-faced stone wall, well pointed with lime mortar, below the frost on the rear side, and across the ends and the middle, to support my barns, and rising $2 \frac{1}{2}$ feet above the ground on the rear side, so as to fill against it to turn off water, and admit of a glass window of $186 \times 8$ glass. 'There are six divisions of my principal establishment, and one of these windows in each division, hung to the sill of the barn, and turns upwards, to admit a fresh current of air, which I think is indispensable to the health of sheep. On 
these walls are placed my barns, 126 feet long, with additional supports between the divisions of a sill and posts, the whole facing the south, with 12 feet doorway to each, and closed by four doors, $;$. so as to shut the two bottom, and leave the top ones open, if necessary.

[Mr. Hodskin's racks conform to cut No. 2. (See racks.)]

I do not give my sheep grain when I have good hay, except wethers, which I fatten; and to these I give 8 quarts of corm per day, and one bushel of potatoes, cut fine. To my lambs I give four bundles of oats per day to the one hundred. For some years past I have given to my breeding ewes 5 pecks of potatoes every other day, to the 100 , from the time they were put in winter quarters till turned to grass. Three weeks before my ewes drop their lambs they are provided with 8 quarts of corn, and the same quantity of oats, which is fed between potato days.

I think sheep do better with a variety of food; mine receive hay three times per day, and once oat straw, the latter being fed at night. I think they do much better thus fed than on hay only.

My lambs begin to drop about the 12th of April. I shut my ewes under cover nights, while dropping their lambs, but when grass begins to appear, I turn them out in fair weather, near by, where I can see to them often. I do not lose on an average two in 100; I reared this year 139 lambs from 140 ewes, and gave three others away, which were twin lambs.

I think I have as hardy a flock of Saxonies as I ever saw of Merinos, and are well formed; but there are other flocks in this town as hardy as my own. I seldom lose a sheep except by dogs. I do not know of a Merino flock, that produces so much money per head as mine and some other Saxon flocks in this place.

I do not believe that there is a flock of pure Merinos in New Hampshire; as to Saxons, there is one small flock in this place which are all pure, and several, a part only. A mixture of $\mathrm{Me}$ ring native, and Saxon abound the most in this section.

I should have said, I never shut my sheep under cover in winter, unless in some driving snow-storm, and never close my back windows except when the weather is very severe. I think when sheep are provided with a comfortable shelter, kept clean and well littered, they will seek it, when needed.

I think salting another essential point of good management. My practice is to keep salt by them in troughs, and intermixed with a little flour of sulphur; at other times, a little tar. Both of these substances have a tendency to ward off scab, and other distempers.

I also practise immersing my lambs in a decoction of tobaccowater, say $7 \mathrm{lbs}$. of tobacco to the 100 , to destroy ticks; besides, it keeps the skin healthy. 
LETTER FROM MESSR. PERKINS AND BROWN, OF AKRON, SUHMIT COUNTY, OHIO.

Dear Sir,-Your favor was received, and our reply will be as brief as possible, and our remarks practical, so far as we are able to make them.

We have about 1300 sheep, Saron, and mixed-blooded, of Saxon and Merino. We have nev ,r taken more than 59 lbs. of wool from 20 head of our fine sheep; but our flock is principally ewes and lambs. We are so well aware of the great difference in the manner of fitting wool for market, that we deem the reports of wool-growers in this particular as of very little value. We suppose that kind of sheep (to the wool-grower) which not only pays the most cash per head, but pay most per acre for the land they occupy, to be the best breed. These remarks we do not intend for those who can sell fat sheep and lambs to good account.

We take this opportunity to propose to those who keep fine sheep, that, in order to determine where the best fine sheep may be found, each man concerned furnish yearly a certain number of fleeces-say not less than five bucks, 20 lambs, and 25 ewesto be cleansed by some manufacturer in the best manner, and the cash value of each parcel to be determined by a committee of three of the best manufacturers in the United States; and further, that each individual deposit with his wool from one to five dollars towards the expense of cleansing, and publishing a full statement, and the balanoe to be paid as a premium to him who shall furnish 50 fleeces worth most in cash when cleansed; or, in other words, to him who shall furnish the greatest weight of the most valuable pure wool per head from each of the kinds of sheep mentioned. We would like to go into something of that kind the present season. Who will join us?

Our pure-blooded Saxons were from the flocks of Samuel Whitman, of West Hartford, Conn. ; Col. Jenison, of Walpole, New Hampshire; and of Frederick Brandt, of Kilgore, Carroll county, Ohio, who brought over his sheep in company with the late $H$. D. Grove's, of Hoosic, New York. Our mixed-blonded sheep were selected from some of the best tlocks in the counties of Washington and Beaver, in Pennsylvania, and from the counties of Brooke and Ohio in Virginia, and from Columbiana and Stark counties in this State.

We keep more or less in a flock in summer and winter, according to circumstances. We think the health of flocks depends, in summer, more upon frequent change of pasture, than the number of the flock; but we have no doubt that the smaller the flock at any season the better. We generally salt twice a week with about three quarts to 100 . We salt our hay when it is gathered. What kind of pasture is best for sheep, we cannot well determine; with us they appear to be most fond of timothy or herds 
grass. The amount of sheep per acre that our lands will keep, varies much; some of them will support five to the acre through the year. Lands will average about 25 dollars per acre here; and we think wool-growing, if the whole business was properly managed, and the sales of wool made understandingly, might be made equal to any other farming business.

We put in our bucks from the 20th of Nov. to the 1st of Dec. We probably raise 80 per cent. of lambs to the 100 ewes. For the two last winters our -flock suffered severely from worms in the head; before that our loss. was merely nominal. We shelter our sheep. Any kind of shelter that will keep off the storms and break the winds, and yet be airy, we use.

[Messrs. Perkins and Brown use box racks.]

We have as yet had no experience in the use of roots. We. feed the value of half a bushel of oats, or some kind of grain, per day, to the hundred, unless we have them in as good condition as we wish them, without it; or unless we have plenty of fall feed on the ground, when the winter sets in ; in that case, we want neither roots nor grain, except in extreme cases. We stallfeed no sheep.

The most fatal of all diseases of which we have any experience. is that occasioned by the fly (OEstris Ovis), causing the worm in - the head. There is also a disorder of the feet, the fouls, to which our sheep are very subject in summer. It is very easily cured with tar only, and indeed will go off of itself, and is not in the least contagious. Our horned cattle have the very same. We suppose it to be entirely different from foot-rot, but are not certain, as we have no experience personally with that disease. [Messrs. Perkins and Brown are right in their conjectures; see Diseases of Sheep.] We generally get along with as good common care of our flock as we can, with but very little in the way of medicine.

We think that most shepherds do not examine and compare flocks enough to know what constitutes a good sheep; and that an animal combining constitution, quality of wool, as well as quantity, would not be preferred by thousands, at least of those who think they understand the matter well. The last remark we suppose to be the most valuable we can make. Our success must mainly depend on our first learning what is a thoroughly good animal, and in the next place, how to take good common care of him, and finally, how to make the peculiar traits of a good sheep as general in our flock as possible. We suppose, if our flock is not what it should be, that we need a variety to make it so ; say very fine sheep, very long-wooled sheep, and very thick-wooled sheep; each kind of good constitution, and given very much to wool, (i. e.) woolly all over, in order to breed successfully. We believe any traits may be imparted to a-flock, and would like to see our brother wool-growers getting clear, among other things, of that worse than aseless appendage, the horns. We think it best to class our ewes for breeding, giving to our most perfect class our most perfect 
bucks, keeping a distinction afterwards in all iambs from that class. For those ewes that are defective in any trait, we use bucks that excel as much as possible in those traits; but avoid breeding in-and-in. We doubt not that Americans are capable of as nice breeding as any other men on the globe, if they will but apply in earnest to the matter, and not be governed by foolish prejudice and short-sighted selfishness. [The sentence would have been complete, if the gentlemen had added criminal laziness.] One great hindrance to improvement is the strong relish many have for the extravagant accounts that some give of the proceeds of their business, and the marvellous fine puffing they give when they want others to bay of them. Sober realities will, we believe, wear the best.

LETTER FROM E. KIREY, OF BROWNVILLE, JEFFERSON CO., N. T.

Dear Sir,-I am pleased to learn from your favor that you are progressing with your treatise on sheep. I am necessarily so much absent from home, that I have not been able to bestow such careful attention upon all the details of sheep husbandry, as to authorize me to set up for a teacher. I will confine myself, therefore, to a few general remarks, bearing on such points of the inquiries contained in your letter as I can speak to with some confidence.

I have about 1500 sheep. I formed my flock nineteen years ago, by the purchase of 500 high-grade Merinos, and by subsequent additions, which I endeavored to improve, after the fashion of the time, by an infusion of Saxon blood, for which purpose I, from time to time, purchased imported Saxon bucks. Having become satisfied that the wool-buyers do not make a just discrimination in price between fine wool and that of inferior grade, and that the Spanish Merino, by reason of its heavier fleece, is a more profitable sheep for the farmer, in this climate, than the Saxon, I am endeavoring to get back to the Merino platform, or rather to medium ground between it and the Saxon, which shall combine the advantages of the fine staple of the Saxon wool with the heavier fleeces, and more rugged constitution, of the Merino. This may unquestionably be attained by proper care in breeding these rival branches of the family together.

To this end, in 1842, I purchased a Rambouillet buck of D. C. Collins, of Hartford, Conn. His stock promises to realize my wishes. My yearlings of his getting are greatly admired; one buck, in especial, is a noble fellow. I lost my Rambouillet buck in the spring of $1843 ; \mathrm{Mr}$. Collins kindly sent me another, which I value highly. At the cattle show at Poughkeepsie, in September last, I purchased one of the Merino bucks exhibited by J. $\mathbf{N}$. Blakeslee, of Litchfield County, Conn., said to be of uncontamina. 
sed descent from the importations of Gen. Humphreys and others. I also, at the same time, purchased of S. W. Jevwett, of Vermont, one of the Merino bucks exhibited by him. $\mathrm{He}$ is a fine animal, of fair pretensions to purity of blood, as set forth in the certificates recently published by $\mathbf{H}$. S. Randall. In addition to these, I procured, in October last, two bucks and six ewes from Vermont. I I intended to gét them from Consul Jarvis' well-known flock, but they came from his neighborhood, with a warranty of purity of blood; but the warrant is not so reliable as if signed by Mr. Jarvis, who is well understood to have pure Merinos:

You have asked me to describe my flock; I have done so fully, - and you can judge of its character. I will now say something of its treatment. Commencing the business of farming with more zeal than experience, I fell into the common error, that sheep require no shelter in winter. The consequence was, that from this cause, and perhaps allowing too great numbers to herd together, I lost many every winter for several years. From exposure to the weather they became diseased, discharged mucus from the nostrils, and numbers perished miserably. The survivors came through the winter greatly emaciated-ewes, from want of nourishment for their lambs, would abandon them as soon as dropped, and many "of them perished also.

I soon became conscious of the improvidence, as well as cruelty, of exposing these valuable animals to the pelting storms of our severe winters, and set about providing shelter for them. I contented myself at first with sheds open, or nearly so, at the sides, which turned the rain and descending snow, but left the sheep exposed to the cutting winds that prevail so frequently in the winter months. I continued to improve upon these structures, till now my sheds are carefully enclosed on all sides, with an opening near each end, for free ingress and egress, and made comfortable by frequent litterings of straw.

Instead of the severe losses I used to sustain, I now have the satisfaction of wintering my sheep with very little loss at all, and that confined to the old and infirm. I am as well persuaded of the importance of providing shelter for sheep, in this rigorous climate, from the storms of winter, as of any other ascertained fact. Its necessity is indieated, as well by the instinct which invariably leads them in bad weather to seek the shelter of fences, thickets, or the lee of barns, as by the fatal effects of exposure. The advantages of this sort of protection may be summed up in the preservation of health, consumption of less food, better fleeces, and more lambs.

My sheep are usually divided into lots of about 100 each for winter quarters, though sometimes as many as 150 are allowed to run together; but the smaller the divisions the better. They are fed on hay, corn-stalks, straw, peas, oats, corn, oil-meal or shorts, according to circumstances. Sometimes portions of them rough it through the winter on hay alone. I have never fed them 
with rutabaga or other roots, except to a small extent, with potatoes. I am not so systematic and careful in feeding grain as to make it worth while to go into details. This winter I am feeding two flocks of 100 each with hay at morning and evening and five half pints each of still-slops at noon. The slops cost me $17 \frac{1}{t}$ cents for 100 gallons, and the expense of hauling them from the distillery, distant about 60 rods. The sheep are thriving under this treatment, but I am not clear that it is more economical than feeding grain. I feed out much less grain now than I did in former years, when my sheep were exposed to the weather without shelter, and the sheep do much better now without it than they did with it.

[Mr. Kirby's racks are of the box kind.] In wet weather it is of great advantage to be able to fodder under shelter. I have abandoned the practice of salting my hay, except when compelled, by stress of weather, to house it before it is thoroughly cured. My sheep are salted about once a week the year round, and instead of giving them tar as recommended by some persons, I occasionally strew the yards with pine boughs, which they are fond of.

I regard the fall management of lambs one of the most important branches of sheep husbandry. Having paid for my experience on this point as well as that of winter shelter, I can speak with confidence. They should be separated from their dams about the first of September, and with a few old sheep, that require nursing, turned to the best pasture. Care should be taken that they are not stinted till removed to winter quarters, when they should have a small allowance of grain or oil-meal in addition to a plentiful supply of gond hay. As soon as the pasture begins to fail the ration of grain should be supplied. By neglecting to provide suitable pasture for a lot of upwards of 100 very superior lambs one season, I lost the greater part of them the ensuing winter. My utmost efforts, after I discovered the error, were of no avail. I gave them a comfortable shed, plenty of litter, good hay, a regular allowance of meal, and free access to water; but they never recovered, and the greater. part died before spring:

My bucks and ewes are put together about the first of December. The flock which I keep at my home barn, under my own eye, and from which I raise bucks for the supply of my own, and many of my neighbors' flocks, is managed in this way. The ewes in lots of 20 to 35 are placed in separate pens, and a select buck is turned into each pen, where they are kept together 15 or 20 days. The ewes in each pen are marked with a letter in tar and lampblack, to indicate what buck they were served by: At shearing time, the best buck lambs are selected, and receive a mark to denote their origin.

In my judgment, water is as essential to sheep as it is to any other animal. They will go through the winter on snow instead of water, and so would a man or a horse, if compelled by neces- 
gity to do so ; but either would prefer to have it thawed before using it, rather than perform that office in his bowels.

When my sheep run in large flocks without shelter, they were occasionally affected with the scab, but since I have provided comfortable sheds for them, they have been troubled with no serious disease. This climate is well suited to sheep.

IETTER FROM STEPHEN ATWOOD, OF WOODBURY, CONNECTICUT.

Dear Sir,-I have made, agreeably to your request, diligent inquiries respecting the varieties of Merinos imported by General Humphreys, but can learn nothing definite on the subject. I was 17 years old at the time of their arrival in this country, and think Gen. H. called them Paulars; but of this I cannot be positive. I purchased a ewe from his flock, for which I paid him 120 dollars, and put her to bucks sold by him into my immediate neighborhood, and her descendants to bucks raised from his ewes, until about 15 years ago; since then $I$ have used bucks of my own raising. I have now a small flock of Merinos, in number about 150, about half of which are ewes, and the other half bucks and wethers. They will consume through the winter'about 18 tons of hay: I feed the ewes, once a day, half a gill of corn and oats mixed, from the first of December until the first of May. I feed the lambs the above given time with half the quantity mentioned; the rest of the flock hay only. I wash my sheep as clean as I can in the river, and let them run 6 or 8 days, and then shear them; we generally shear from 10 to 15 per day; indeed, I never hired a man that sheared as many as 20 in one day. My ewres will shear yearly 5 lbs. of wool per head, my lambs 5 lbs. each, asd wethers 6 lbs.; my bucks will - shear from 7 to 9 lbs. per head. The heaviest ewe fleece last spring was 6 lbs. 6 oz., and the heaviest buck fleece $12 \mathrm{lbs} .4 \mathrm{oz}$. I tag my sheep in the spring, but not so thoroughly as you do. The buck I sold you was finer than my others would average. You will confess, doubtless, that he is a noble animal. Since I began my fullblood flock, I have had three important properties in view to combine, viz., constitution, quantity, and quality ; my success has at least been satisfactory to myself.

LETTER FROM ABNER BROWN, OF NORTHEAST, DUTCHESS COUNTY, NEW YORK.

Dear Sir,-Yours I have duly received, and now with pleasure proceed to answer some of your interrogatories.

My flock of fine-wooled sheep is small, averaging for the last 
10 years probably 160 . I usually shear about 3 lbs. of wool per head, and in the spring clip about 14 lbs. of tags from 100 sheep. I much prefer washing in a stream of running water; I think this mode is easier for the washer, and there is less risk of injuring the animal. Experienced and skilful shearers will sometimes shear 30 per day, and do their work well; but those workmen who manifest carelessness, or recklessness in regard to the comfort of sheep, should be immediately discharged. I think that from seventy-five to one hundred is as many as should herd together in the winter season. The building for shelter should be enclosed, with doors to open and shut, as circumstances may require, on the south side. I deem it of vital importance, that sheep have easy access to water, during the winter season. If the water is not convenient to the sheep-barn, and cannot be brought there, then carry the barn to the water. Some assert that sheep will live in winter if they can get snow ; this is true, and it is equally true, more or less will die too. Many diseases are induced by depriving sheep of water.

After haying, I scrape my sheep-yards, and carry the manure on to my meadows, before the rowen starts much; in that way I often double the quantity of hay, besides improving the quality. [Mr. Brown made an experiment, which satisfied him that nothing is gained by feeding fine-wooled sheep grain, provided they are well cared for during the whole year, and fed enough of the best quality of hay.]

I think the Saxon sufficiently hardy to endure our hard winters with that care and attention which may easily be given to all dumb beasts in the domestic line, intrusted to reasonable and rational man. It is true that farmers sometimes, either by breeding in-and-in, or by making an injudicious cross, will obtain an unsightly, ill-shapen, narrow-chested animal, with weak vitals, that will lie down and die at almosit any time. But I have not lost over one per cent. annually, for the last ten years, and with large flocks, properly managed, no greater loss will accrue. Success must ever depend on good judgment and skill in management. [Nothing more true.]

My lambs usually drop in the field in pleasant weather; but if the weather is stormy or cold, the ewes are placed in the sheepfold. We usually raise 95 per cent. of lambs from mature ewes.

The fine-wooled sheep are generally cultivated in this county now; but there are some Bakewells, Lincolns,. Cotswolds, and a few of the beautiful South Downs; there seems to be a prevailing desire among farmers in this vicinity to get the pure Saxons. [Mr. B. uses a tobacco decoction to destroy ticks; his locality is well adapted to sheep, diseases being very rare; cures the stretches by the use of castor oil; land is worth, in his town, from 45 to 50 dollars per acre.] 


\section{LET TER FROM JESSE EDINGTON, OF HOLLDAY's COVE, VIRGINIA.}

Dear Sir,- [Mr. Edington states, that his flock was formed by the purchase, in 1821, of 200 superior ewes, descended, from Gen. Humphreys' importation, and subsequently. by a portion of the celebrated flock of Messrs. Wells and Dickinson, of Ohio.] These flocks form the basis of my present flock of 3000 , and they also form the basis of nearly all the fine sheep in this region of country.

My sheep are kept in flocks of about 200 each. They are fed on hay and corn; say 5 tons to the 100, and at the rate of 50 bushels of corn for that number, which is fed in troughs, and half a bushel per day. Housing I think is necessary to protect the animal from drenching rains in winter, as frequent wetting of the wool renders the tops stiff and rotten, and the whole fleece harsh and apparently coarse; moreover, injures the health of the sheep, and requires more provender to sustain them. In severely cold weather, they should be kept closely housed, and exposed only for the purpose of obtaining water. [Mr. E. is located near the Ohin river, and raises considerable corn, the stalks of which he feeds his sheep during winter.] I raised a considerable crop of sugar-beet, which is excellent food for sheep, but expensive, compared with corn. Hay and corn I think, upon the whole, the cheapest, best, and most convenient feed for large flocks, with some oats occasionally.

My average yield for the last 5 years does not exceed $2 \frac{1}{2}$ lbs. per head, having 700 lambs, 800 to 1000 ewes, and the greater part of the flock not full grown. I raise about 75 lambs from the 100 ewes.

I wash in the Ohio river, which is generally very clear and soft, with a pretty strong current. We put about 150 in a ferry boat, anchored a short distance in the stream, where three or four hands wash over the sides of the boat. In this way, $a^{-}$sheep can be washed pretty clean in about two minutes, and then they are permitted to swim ashore, which removes all remaining dirt and grease from the wool. They are then put on a clean sward from 4 to 8 days before shearing. The wool, washed in that way, will be some 20 per cent. lighter than if washed in cold, limestone water. [Mr. Edington's barns are spacious and convenient, but his description is omitted.] - I put my rams to the ewes the first week in November, and permit two or three to the 100 ewes. The rams remain with them about four weeks, and during this time they are fed 2 gills of corn a day, or twice that quantity of oats, which is continued for a month- after their separation from the ewes.

Our best pasture is spear grass (poa pratensis), which grows epontaneously on our rich lands, and will last the year round; for early and late grazing, white clover is uncertain. We are obliged to fodder some five months of the year. I sold my crop of wool 
of 1830 to Messrs. Bullock and Davis, at 75 cents per $\mathrm{lb}$., which amounted to 6,400 dollars. I raised that year $900 \mathrm{lambs}$, and sold 800 sheep for 2,500 dollars. [If Mr. Edington's success has been in proportion to this statement since the period he mentions, is it not highly encouraging to our Southern bretbren to undertoke his vocation, of growing fine wool?]

\section{LETTER FROM SAMUEL GRANT, OF WALPOLE, N. HAMPSHIRE.}

Dear Sir,-Your esteemed favor of the 16th came to hand a few days since. I am gratified to learn that a work of the nature you mention, so much needed by wool-growers, is about to be published.

My flock at present numbers between 800 and 900, Saxony, Merino, and half-bloods, the Saxons, perhaps, predominating. My Saxons are pure-blooded, bred from the flocks imported by Searle and Kratzman, in 1829. For the last three or four years, I have crossed part of my flock with Jarvis Merinos. My fleeces averaged last season 3 lbs. $6 \mathrm{oz}$. well-washed wool, which, considering the number of Saxony fleeces, is a fair average. My sheep (and this will apply to every lot in town) are closely sheltered in winter, and all have pure water in abundance at all times. This I consider absolutely necessary. I feed in racks, under the hay-lofts, with corresponding openings above, where hay is carefully shaken down, at least three times a day. Hay is the principal article of food. I have sometimes fed straw alone, with a bushel of potatoes, (cut by machine) to 100 ewes, with good success. The smallest, poorest lambs are selected at the beginning of the winter season, and usually fed with the better kinds of hay, rowen, \&c., together with perhaps half a pint oats each per day. I feed either potatoes or oats liberally to ewes, four to six weeks before they commence having lambs; litter the folds well with straw, at all times, to make them comfortable, and to increase the quantity of manure. I fatten generally with corn - dislike potatoes for this purpose. We are careful to waste no hay, every particle is eaten, when the quality is good; feeding without racks I consider slovenly and wasteful. We tend our bucks when put to ewes, permitting them to serve 6 or 8 per day, and are careful to feed their lordships $h i g h$; they seldom exceed 100 ewes, going but once to the same ewe. We are partial to, and take good care of our bucks throughout the year: I have used this fall a Merino buck which sheared the past season 13t lbs. washed wool.

The Saxons are not considered too tender for this region. We are obliged to treat them carefully, but find no difficulty at all in rearing them. Our ewes seldom foal out of doors, except perhaps during the day, at which time they have the limits of the 
yard. We oftentimes raise 94 to 98 lambs frum an hundred ewees. The price of pure Saxony ewes varies from two to four dollars. There are no diseases among sheep at present in this quarter, except perhaps some cases of foot-rot. 'The best remedy for this disease is, first, paring the hoofs clusely, and then apply a wash composed of the following ingredients: say, $4 \mathrm{oz}$. blue vitriol, 2 oz. verdigris to a junk bottle of urine. This is " sure fire."

I have no means of ascertaining accurately the amount of hay necessary for 100 sheep during the winter; I should think at least 12 or 13 tons. We are in the habit of dipping our sheep in a strong.decoction of tobacco, immediately after shearing, for the purpose of destroying ticks. We give salt weekly, but never feed tar.

[The feeding-racks of Mr. Grant conform to the cut Fig. 2, to whom, with Mr. Hodskins, the writer is indebted for the design.]

At the time Searle and Kratzman imported their sheep, something like 1000 of the very best grades were selected in Germany, and from this lot about 150 again selected and reserved for themselves, being the cream of the entire flock. This last very superior lot were given into my hands to keep, and eventually became mine.

\section{LETTER FROM JACOB N. BLAKESLEE, OF WATERTOWN, LITCF- FIELD COUNTY, CONN.}

Dear Sir,-Your favor has been received, in which you express a wish to know the pedigree of my flock of Merinos, and some particulars as to my mode of management. In reference to pedigree, I must refer you to a statement of mine on the subject, and published in the Nov: number of the Albany Cultivator of 1844. [The following is an extract:] "My pure bloods are the offspring of some of the first that ever came into the United States, brought into the country by David Humphreys in 1802, which were a present to his wife by her father. After a few years, two pairs of them were purchased by Daniel Bacon, of Woodbury, Litchfield county. They were kept in their pure state till 1811. There was then an importation of the Guadaloupe sheep by a company formed in Litchfield county ; John De Forest, superrcargo. They arrived at New Haven, and were sold at anction, Jan. 17, 1811. There was one full-blooded Escurial buck, which was purchased by Daniel Bacon at $\$ 275$, and was crossed upon those sheep that came by the way of Mrs. Humphreys. He continued this cross till 1816 or 1817, when he sold his Escurial buck to William $\mathbf{K}$. Lampson for $\$ 1,130$. He kept his sheep pure till the introduction of Saxony sheep. He then sold the remainder of his flock to Daniel Martin. I began a flock of sheep in 1815, that were im. 
ported by. Peck \& Atwater, New Haven. A part of them were the Negretti and a part Montarco. I let them run together till 1823. I then procured the use of a buck for three seasons, bred by Daniel Bacon from his Escurial buck. The average weight of the fleeces of the stock from this buck was four pounds, and the wool brought me ten cents a pound more than the original stock. In 1828 I purchased a buck that was raised by Daniel Bacon.' From that time down to the present, I have kept that blood pure; this flock is now a cross of three sorts of Spanish sheep, and perfectly clear from native or Saxony blood. My farm is not a healthy farm for sheep, and of course they are a little under size. 'They are a full, round, handsome-bodied sheep, with shortish legs and a very round neck. They have very heavy fleeces for their size. Their wool is a long staple, a great deal of crimp, and very compact at the outer end. They have generally wool about their face and on their legs down to their feet. After taking great pains to wash them, the average weight of their fleeces this season was three pounds and a half, and there are very few flocks of Saxony sheep any finer. Mr. Samuel Lawrence, of Lowell, who has had this wool for four seasons past, has given his opinion that there is no Merino wool that compares with it. This improvement has been made by a cross of the different breeds. I am decidedly of the opinion that there is no full-blood animal equal to a cross ; the reason I give is, that there is no perfect animal on the face of this earth: where an animal is imperfect, you can never remedy the defect by the use of an animal that has the same defect."

I have for the last ten years kept from four to six hundred sheep, but they were not all of the breed of which $I$ have given the pedigree. My last clip from my pure bloods averaged just $3 \frac{1}{2}$ lbs. per head, exclusive of tag-wool. I raise from 90 to 95 lambs to the 100 ewes. My lambs are dropped in the month of March, and of course during that time the ewes are protected. My best buck went to 160 ewes the present season, and was fed high during service; 50 ewes are enough for one buck, if he is permitted to run altogether with them. My sheep generally are fed in the open field in the winter season, having sheds, however, to run under when it suits them. My practice is to confine them to hay mostly, except my ewes, before and during their yeaning, when they are grained. I feed grain also to my feeble sheep. I think a change of food very conducive to the health of a flock, and I conform to this opinion as far as possible. In regard to other particulars of management, I probably differ so little from the practice of many other wool-growers, that it is needless, perhaps, to enter into further details. My attention is not confined to raising of sheep, but for years past have bred many cattle and horses; the former is of the Devon blood. 


\section{LETTER FROM ETEPHEN. SIBLEX, OF HOPKINTON, NEW HAMP-} SHIRE.

Dear Sir,-In answer to yours of the 14 th inst., I will say that my flock of sheep is of the Saxon breed, and at this time numbers three hundred; before my sales' in the fall, it usually reaches from three hundred seventy-five to four hundred. I began my flock in the fall of eighteen hundred and twenty-one, with a few Merinos which originated from a flock imported into this country from Spain, and kept in the neighborhood of Newburyport, Mass.. by a gentleman of the name of Gorham Parsons.' I bred in the same flock several years, and then procured and put to my sheep an imported Merino buck. In the summer of 1826 a cargo of very fine Saxony sheep was imported into Boston, and sold at Brighton, Mass. A friend of mine in Hillsborough county in this State attended the sale and bought two bucks, one of which I purchased immediately after his return. In $1828 \mathrm{I}$ introduced into my flock a few Saxony ewes. The principal importers of Saxony sheep into New England were two gentlemen of Boston by the name of Searle. They purchased in Saxony, for their own use, one hundred ewes and four bucks, without regard to price. That flock was taken to Walpole, N. H., by Samuel Grant, who eventually became the owner of it, and from that stock I drew my miale breeders from 1832 to 1839 . I likewise bought of the same gentleman a few of his most approved ewes. In the fall of 1839 , I visited the celebrated flock of Electoral Saxony sheep of the late Henry D. Grove, of Hoosic, New York, and bought of that gentleman forty-seven ewes and three bucks. Since my purchase of Mr. Grove, I have introduced no sheep from abroad into my flock, for I am satisfied it cannot be done from any flock in this country, without producing a retrograde. I am an equal owner with another person of a silver medal, awarded for the finest American wool by the American Institute at the city of New York in 1838. The Massachusetts Charitable Mechanic Association also awarded to me a splendid gold medal for the finest American wool in 1841.

My sheep are small, beautifully proportioned, and perfectly bealthy. I shear per head on an average, after tagging three ounces from each, about two pounds of wool. I dispose of all my wethers as young as possible to give place to breeders, which are more profitable. Were I to keep a usual proportion of fullgrown males it would bring up my average to about two and a half pounds. I have made it a rule for about twenty years to cull from my flock every coarse and ordinary ewe, and breed from the finest only, with the utmost care as to male parentage. İ make the month of May my yeaning month, for I have never known a delicately fine-wooled sheep that came in the winter. Climate has an effect, and a very great one, on our flocks, as regarda 
the quality of wool. All agree that a cold climate is calculatud to produce a finer, softer, and more abundant covering for the animal creation, than a hot one, and for that reason a lamb that is dropped in May, or the fore part of June, will produce more, and better, wool than one that comes in the fall or fore part of winter. By allowing the male to go to the female in December, we have the whole of the winter for the formation of the animal, and with all the other parts every fibre of wool is formed, and the lamb is fitted for a cold climate, with a fleece of the finest and warmest kind. After the perfect formation and production of the animal, the heat of our summers produces no change in the quality of the wool, or, if any, it is so slight as to be wholly unperceived. Sheep that are at all times kept in a perfectly healthy condition, continue to produce wool equally fine, soft, and beautiful, year after year, till visited by old age, and then, like the hair of an aged person, it becomes in some degree more harsh and rigid. Were we to provide for the birth of lambs in December, gestation would be going on during the heat of summer, and nature, true to her work, would prepare the lamb with a hairy, coarse covering, suited to a warm climate. The broken surface, the dry summers, and steadily cold winters of New England, New York, Peninsylvania, seem admirably adapted to the perfect development of all the valuable properties of the sheep; and it is certainly true that the offspring of the Spanish and Saxony sheep that have been judiciously managed, and bred in this section of country, now produce wool more open and free, and more elastic and delicately fine, than the imported original stock. It is not known that any person in this country has gone into a minute calculation of the greater or less increase of wool arising from different kinds of food; nor is it necessary, for Providence itself attends to this business, and it will not lead the husbandman astray if he furnishes his flock with a variety of food such as their appetites crave. The disposition of sheep prompts them to range over a precipitous country, where herbage is various and territory extensive. No domestic animal feeds upon so many kinds of plants as the sheep, ner does any so quickly pine by confinement to any one" kind. Peculiarity of pasture may have some effect upon the fleece, making it finer or coarser, so far as it affects the general health of the sheep, and no farther. The most perfect and valuable wool that can be produced is from sheep that are neither over-fat nor miserably lean, but in a perfectly healthy condition. The nuin and almost entire reliance for the improvement of the wool of our flocks is in judicious selection, season of breeding, patience, and the shepherd's unceasing attention. By a long and undeviating course in these practices, our best flocks may be made to yield fleeces that will not suffer by a comparison with the finest the world produces; and thus the avaricious may gratify his desire, and the patriotic be prouder of his country.

During the inclemency of our winters sheep should be well 
sheltered, but the stalls at all times well ventilated and made to accommodate not more than one hundred. The wethers ought not to be allowed to go in the stalls with the ewes in winter, nor the lambs the first season of foddering with either. The cribs should be swept daily and replenished with hay, cut in proper season and perfectly dried, and made from all the usual kinds of our grasses-the more kinds the better, not excluding the sour ones that grow upon our low lands; and weeds and vines may also be included to advantage. ' In addition to hay, about 12 quarts of Indian corn or an equivalent of smaller grain ought to be fed daily to a hundred ewes, during three or four weeks in the rutting, and four or five weeks in yeaning season-beginning the latter term three weeks before yeaning. Lambs ought to be fed during the whole of the first winter with about six quarts of corn or its equivalent, daily, to the hundred. Wethers full grown and healthy will pass the winter very well without grain.

That management may be perfect, it is very essential that exercise, fresh air, and green food, should be given our flocks through all the winter, and as often as four or five times each week. This can best be done by driving them to the woods where they can browse from the bushes, or boughs pendant from large trees. If the browse is beyond their reach, it ought to be cut for them and placed in rows from which they can conveniently feed without the privilege of running over it. No snow is so deep as to prevent this being done, for, led by the shepherd, they make their own paths and use them when needed. If browsing sheep is not practicable with all wool-growers, they certainly can give their flocks exercise in some other way, and green food also, by dealing out to them potatoes, or some kind of turnips, which will be better than nothing green; turnips, however, are not regarded in this place conducive to the growth of wool.

In the season of shearing, sheep ought to be washed as clean as possible in soft running water, and their fleeces suffered to dry on them, and then become a very little moist with the oil of the animal before shearing. No definite time can be fixed between washing and shearing, for that depends on the weather. The honest wool-grower will readily decide on the proper time to shear, and be careful that his sheep do not wallow in the sand-bank or upon ploughed ground, after the disappearance of snow in the spring, and before shearing.

Sheep of the Merino and Saxon family are smaller than most other kinds, but they produce the finest wool known in this or any other country. The size and quantity of wool per head has been an objection to these sheep by some. It is calculated that if the cash income of a large; coarse; individual sheep is greater than that of a small, fine one, the coarse sheep are most profitable to the wool-grower. These partial calculations are delusive; for it requires the same, or nearly the same quantity and quality of food 
to produce a pound of wool or a pound of mutton, whether it be given to a large or a small sheep. The rational and safe basis on which a profit is to be calculated and derived, is upon the quantity and cost of food and the greater value of wool and mutton produced therefrom. Fine sheep, ever since their introduction into New England, have been duly valued by some, and they are now coming into more general favor-the demand and price steadily increasing.

The American who shall publish a work on Sheep Husbandry, such as is needed and shall be approved, will do a greater service to his country than all the furious politicians in it, and secure to himself a name as durable as our gxanite, while theirs pass from the world like shadows. I heartily wish you all the success due to your laudable undertaking.

LETTER FROM SAMUEL IAWRENCE, OF LOWELL, MASSACHUSETTS.

Dear Sir, _ * * * * That the properties of wool are affected by herbage and soil, I have not a doubt, and were it not invidious, I would name some sections where wool-growers are greatly favored by nature. One thing is certain, whatever may be the character of the soil, where there are good shepherds there is sure to be found good wool. By judicious selections and crossing, I believe a breed may be reared which will give 4 lbs. of exquisitely fire wool to the fleece.

We can make a fine cloth from a long staple, if the felting property is right.

As a geveral remark, the wool of this country is badly put up, the sheep are not properly washed, then they are allowed to run too long after washing before being sheared; and what is worse, the "tags and stuff" are rolled up inside the fleece, and tied with tow yarn, or heavy twine in enormous quantities. There are honorable exceptions to this usage, and the names of the parties I should like to show up as models for their inferiors to imitate. Manufacturers are quite as much to blame in this business as wool-growers; they have seldom made sufficient difference in prices between wool in good and bad condition.

The woollen manufacture of this country is on a more permanent base than at any former period of its history, as there are engaged in it more men of character and property, and the amount of skill employed is very great. Should anything be done to injure the present excellent tariff, the wool-grower will receive the blow. Our works are in full operation as usual, and if we have no accidents, shall wòrk over a million of pounds this year. We are preparing to extend our works by the addition of 
a new mill, which will require from three to four hundred thousand pounds more per annum; this will not be completed till the fall of 1846.

If the wool-growers of this country will carry on their business with as much heart and spirit as the Middlesex Company, the time is not distant when we shall export woollens to foreign sonuntries. 












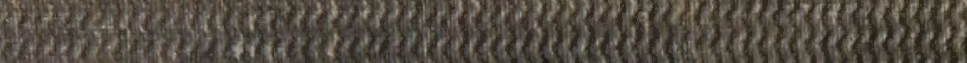

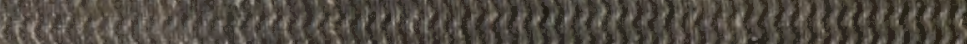

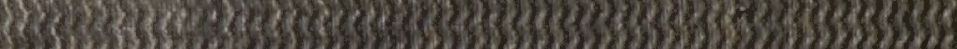

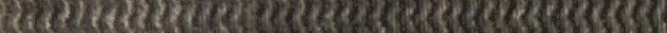

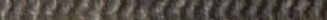
ariater? ingespes

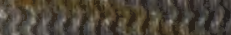

S1:32. 1) 17 . (2) 128 1)

and: xif? ted 1)

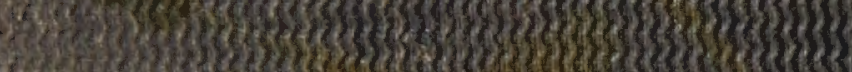

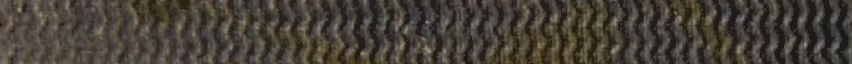

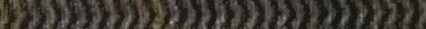

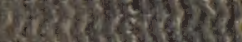

in:

tist 7)

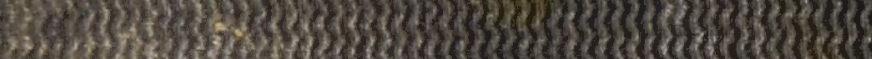

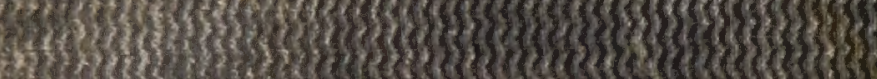

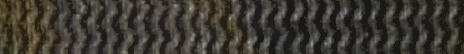

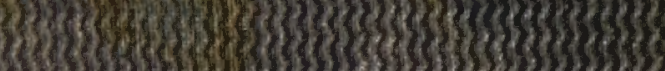

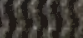
celer

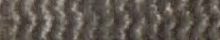

ation:

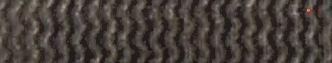

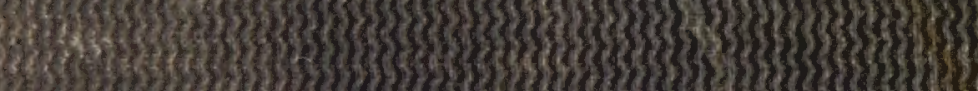
35
3

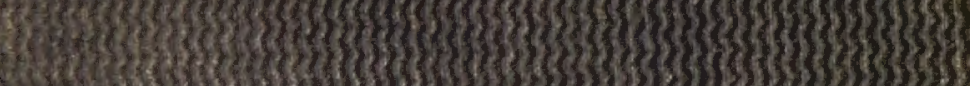

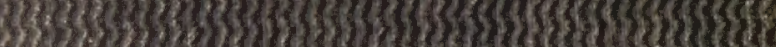

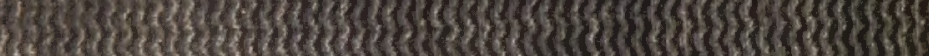
2.0.

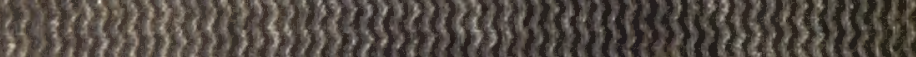

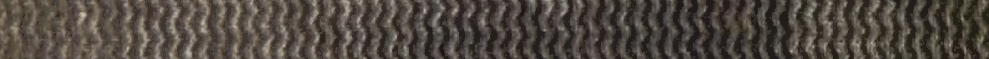

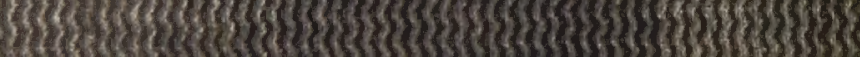
3.

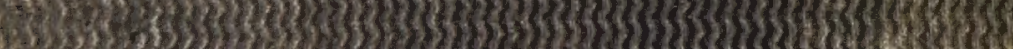

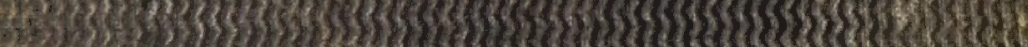

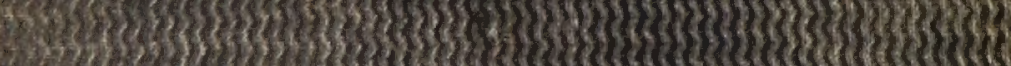

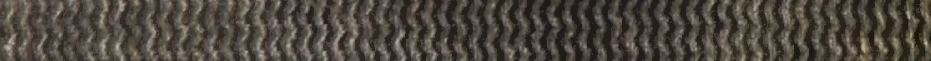

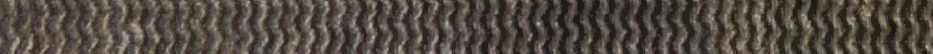

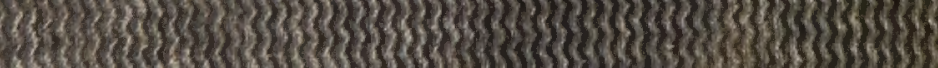

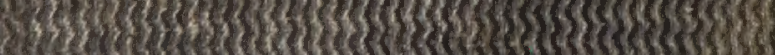
ats

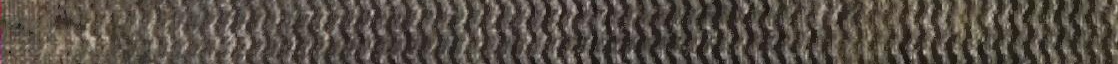
1.2.

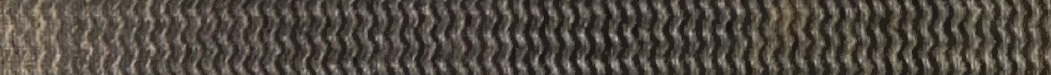
Wh 